Aus dem Institut für Humangenetik

(Prof. Dr. med. B. Wollnik)

der Medizinischen Fakultät der Universität Göttingen

\title{
Identifizierung von Patientinnen und Patienten mit der hereditären Form des Mamma- und Ovarialkarzinoms mittels Next-Generation- Sequencing-(NGS)-Technologie
}

\author{
INAUGURAL - DISSERTATION \\ zur Erlangung des Doktorgrades \\ der Medizinischen Fakultät der \\ Georg-August-Universität zu Göttingen
}

\author{
vorgelegt von \\ Mateja Smogavec \\ aus \\ Maribor, Slowenien
}

Göttingen 2018 
Dekan: Prof. Dr. rer. nat. H. K. Kroemer

Referent: Prof. Dr. P. Burfeind Ko-Referent/in: Prof. Dr. P. Ströbel

Drittreferent/in: Prof. Dr. M. Schön

Datum der mündlichen Prüfung: 26.06.2019 
Hiermit erkläre ich, die Dissertation mit dem Titel "Identifizierung von Patientinnen und Patienten mit der hereditären Form des Mamma- und Ovarialkarzinoms mittels Next-GenerationSequencing-(NGS)-Technologie"eigenständig angefertigt und keine anderen als die von mir angegebenen Quellen und Hilfsmittel verwendet zu haben.

Göttingen, den 17.10.2018

(Unterschrift) 


\section{Inhaltsverzeichnis}

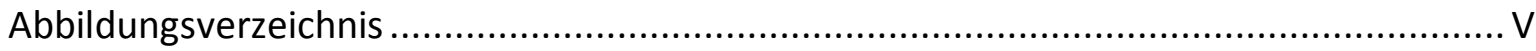

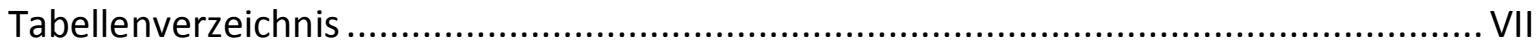

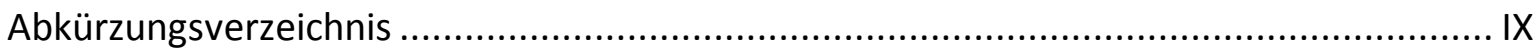

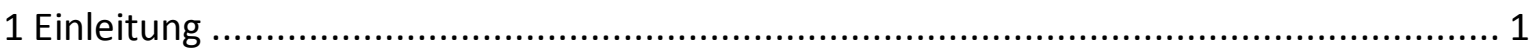

1.1 Definition und Epidemiologie des sporadischen und hereditären Mamma- und

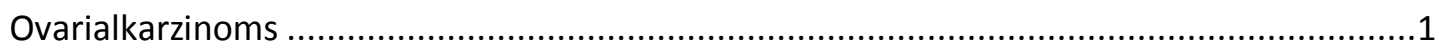

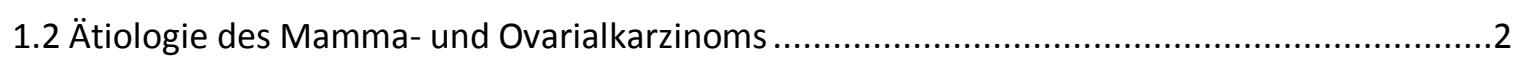

1.3. Risikogene des hereditären Mamma- und Ovarialkarzinom-Syndroms ................................2

1.3.1 Hochpenetrante Gene des hereditären Mamma- und Ovarialkarzinoms .......................2

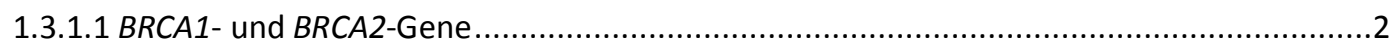

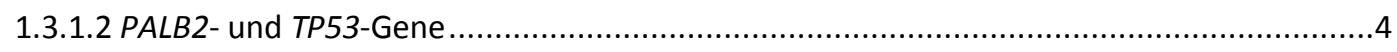

1.3.2 Moderat penetrante Gene des hereditären Mamma- und Ovarialkarzinoms...................4

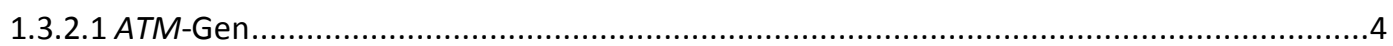

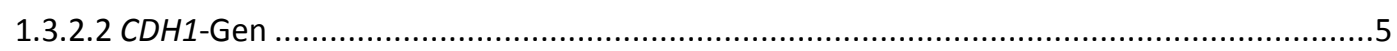

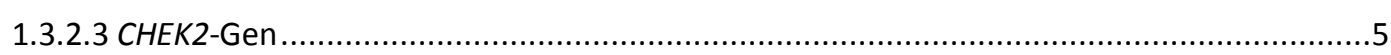

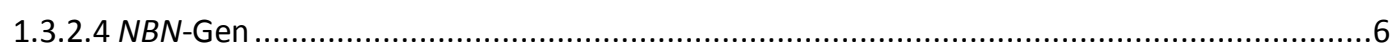

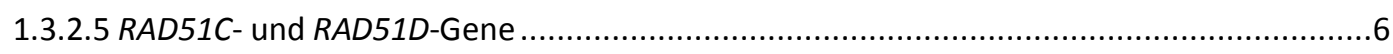

1.4 Diagnosestellung, histologische Typen, Rezeptorstatus und medikamentöse Therapie der

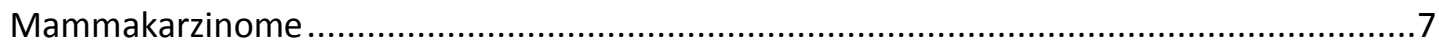

1.5 Vererbungsmodus und Kriterien für eine molekulargenetische Untersuchung bei Verdacht auf ein hereditäres Mamma- und Ovarialkarzinom-Syndrom ........................................10

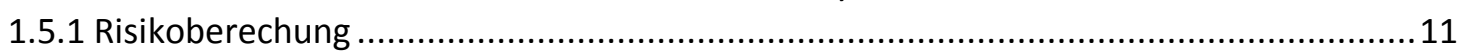

1.6 Deutsches Konsortium Familiärer Brust- und Eierstockkrebs............................................12

1.7 Ablauf der genetischen Versorgung und Beratung der Patienten mit Verdacht auf ein

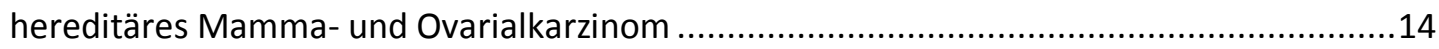

1.8 Klinische Bedeutung des hereditären Mamma- und Ovarialkarzinoms ...............................15

1.9 Molekulargenetische Diagnostik des hereditären Mamma- und Ovarialkarzinoms ................18

1.9.1 Detektionsmöglichkeiten der verschiedenen Methoden .............................................. 18

1.9.2 Möglichkeiten der Next-Generation-Sequencing (NGS) in der molekulargenetischen

Diagnostik.

1.9.3 Bedeutung der Multi-Gen-Panel-(NGS)-Analyse in der Diagnostik des hereditären

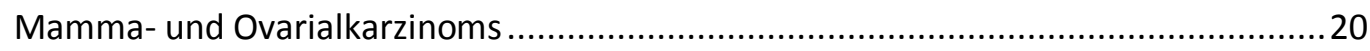

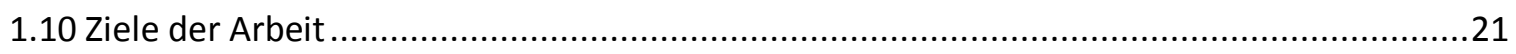

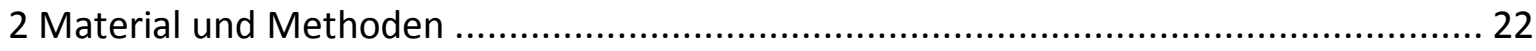

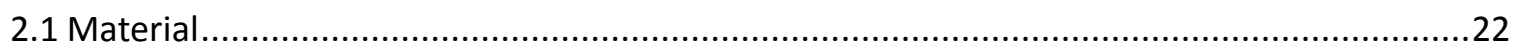

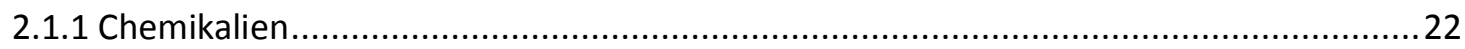

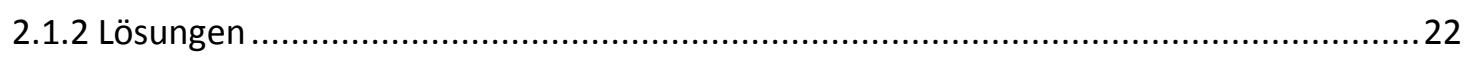

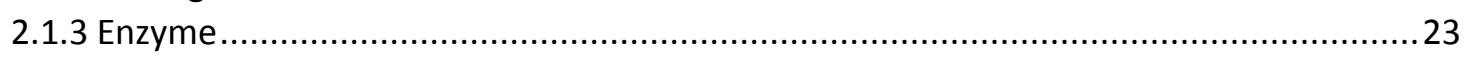

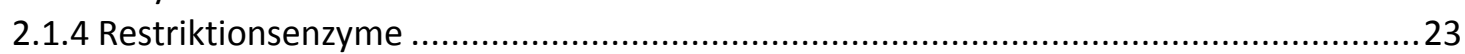

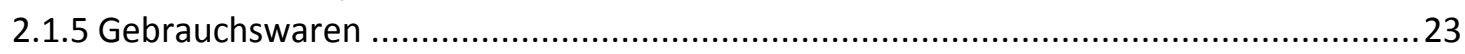

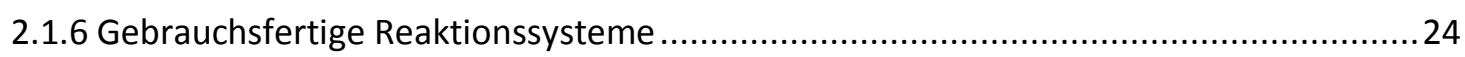

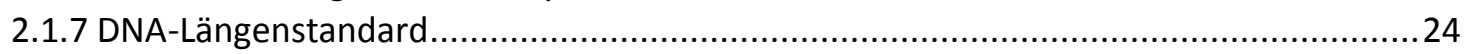

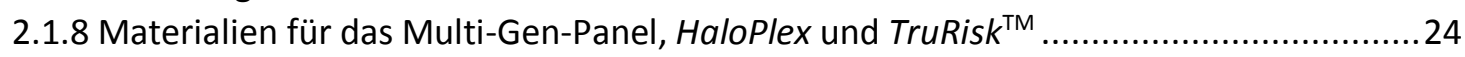

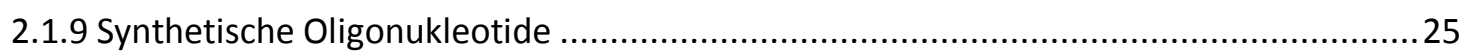

2.1.9.1 Sequenzprimer für die Nachsequenzierung der Sequenzvarianten der ACMG-Klasse 3, 4 oder 5 in den Core-Genen................................................................................. 25

2.1.9.2 Primer für die Real-Time PCR-Analyse des MSH6-Gens.................................................30 


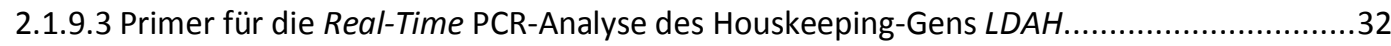

2.1.9.4 Primer für die Expressionsanalyse des MSH6-Gens in Lymphozyten ..............................32

2.1.9.5 Primer für die Methylierungsanalyse des distalen und proximalen $M L H 1$ -

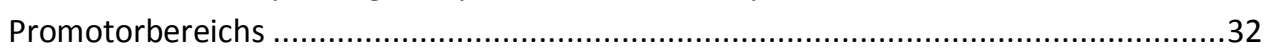

2.1.9.6 Primer für die Amplifikation und Sequenzanalyse der RAD51D-cDNA ............................33

2.1.9.7 Primer für die Expressionsanalyse des RAD51D-Gens in Lymphozyten............................33

2.1.9.8 Primer für die Long-Range-PCR des CHEK2-Gens an genomischer DNA aus Lymphozyten 33

2.1.9.9 Primer für die Nested-PCR des CHEK2-Gens an genomischer DNA aus Lymphozyten ........33

2.1.10 Datenbanken und Analyse-Software ................................................... 34

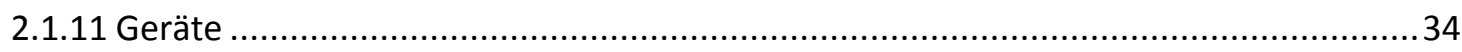

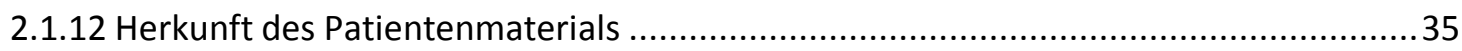

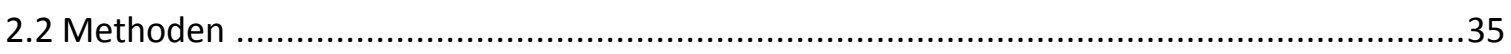

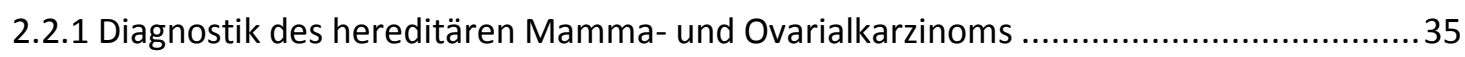

2.2.2 Isolierung und Aufreinigung von Nukleinsäuren ............................................... 36

2.2.2.1 Isolierung von genomischer DNA aus EDTA-Blut.....................................................36

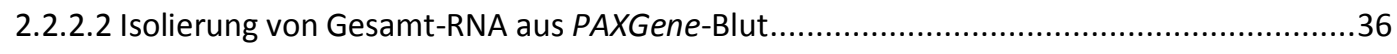

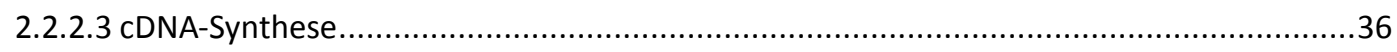

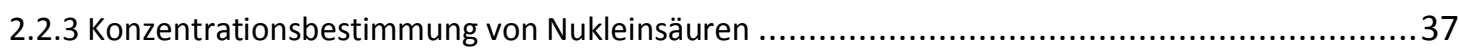

2.2.4 Amplifikation der DNA mit Hilfe der Polymerase-Kettenreaktion (PCR)............................. 37

2.2.4.1 Quantitative Real-Time PCR an genomischer DNA und an cDNA ..................................37

2.2.5 Multiplex Ligation-dependent Probe Amplification (MLPA)-Analyse ....................................39

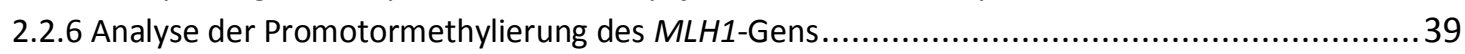

2.2.7 Histologische Beurteilung und Rezeptorstatus der Mammakarzinome ...............................40

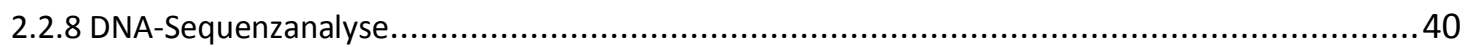

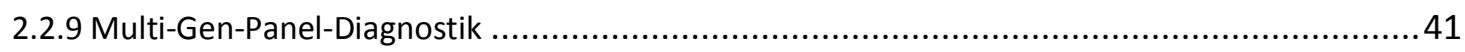

2.2.9.1 Das Prinzip des HaloPlex Target Enrichment Systems ....................................................42

2.2.9.1.1 Konzentrationsbestimmungen der genomischen DNA (gDNA) ................................. 43

2.2.9.1.2 Fragmentierung der genomischen DNA............................................................. 43

2.2.9.1.3 Hybridisierung der Sonden und Index-Sequenzen (Target Enrichment und Sample

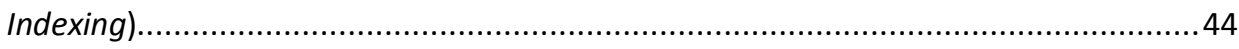

2.2.9.1.4 Capturing der Patienten-DNA....................................................................... 44

2.2.9.1.5 Herstellen der Sequenzierbibliotheken (Libraries) ............................................... 45

2.2.9.1.6 Aufreinigung der Sequenzierbibliothek mit Reinigungs-Beads (AMPure Beads)............46

2.2.9.2 Prinzip des SureSelect ${ }^{\text {QXT }}$ Target Enrichment Systems ....................................................47

2.2.9.2.1 Konzentrationsbestimmungen der genomischen DNA ............................................ 47

2.2.9.2.2 Fragmentierung der genomischen DNA und Ligation der Adaptoren (Adapter-Tagging)47

2.2.9.2.3 Aufreinigung der Adaptor-ligierten Bibliothek mit Reinigungs-Beads (AMPure Beads) .. 48

2.2.9.2.4 Amplifikation der mit den Adaptoren ligierten Sequenzierbibliothek (Library) ............. 48

2.2.9.2.5 Aufreinigung der amplifizierten Sequenzierbibliothek mit AMPure XP Beads ...............49

2.2.9.2.6 Quantifizierung der Libraries................................................................................49

2.2.9.1.7 Hybridisierung der Sonden und der Index-Sequenzen (Indices)..................................50

2.2.9.2.8 Amplifikation der Libraries, Anhängen der Indices (Indexing) und Reinigung der

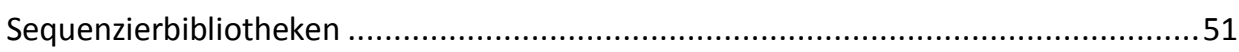

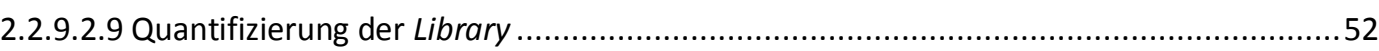

2.2.9.2.10 Pooling der Proben für die Multiplex-Sequenzierung und Vorbereitung der Libraries für die Sequenzierung mit dem MiSeq-System.......................................................53

2.2.9.3 Sequenzierung mit dem MiSeq Sequencing Reagent Kit ..............................................53

2.2.9.3.1 Vorbereitung für die Sequenzierung mit dem MiSeq-System ....................................54

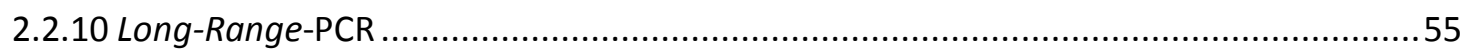

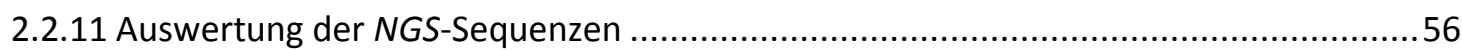




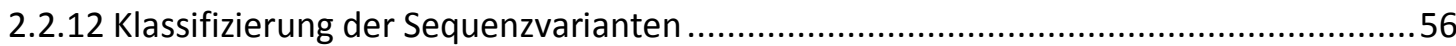

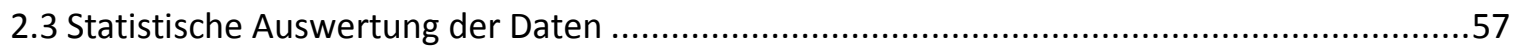

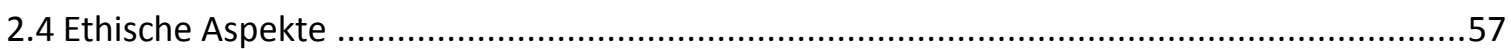

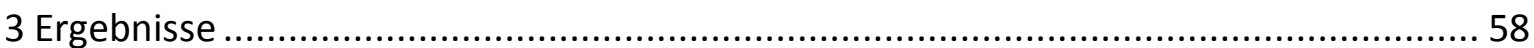

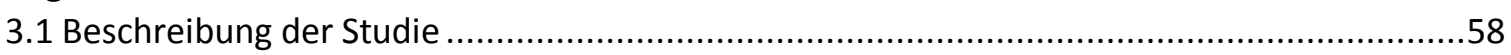

3.2 Klinische Charakteristika der analysierten Patienten-Kohorte .........................................58

3.2.1 Alterserfassung der Patienten bei Erstdiagnose eines Mamma- oder Ovarialkarzinoms59

3.2.2 Einteilung der untersuchten Patienten in Bezug auf die erfüllten Kriterien für eine molekulargenetische Analyse der 10 Core-Gene ....................................................5 59

3.2.3 Risikoberechnung der Patienten-Kohorte mit Hilfe des Risikokalkulations-Programms Cyrillic 2.13.

3.2.4 Heterozygoten-Risiko für eine autosomal-dominant vererbte Mutation in einem der 10 Core-Gene in Abhängigkeit vom erfüllten Kriterium ...............................................61

3.2.5 Histologische Formen und Rezeptorstatus der Mammakarzinome ................................62

3.2.6 Weitere Tumorerkrankungen in den Familien über drei Generationen ..........................63

3.3 Molekulargenetische Daten der untersuchten Patienten-Kohorte......................................63

3.3.1 Allgemeine Informationen zu den molekulargenetischen Untersuchungen ..................63

3.3.2 Allgemeine Informationen zur Klassifizierung der identifizierten Sequenzvarianten .....64

3.3.3 Verteilung der Sequenzvarianten in den analysierten 10 Core-Genen ..........................65

3.3.4 Vergleich der identifizierten Sequenzvarianten der ACMG-Klasse 3, 4 oder 5 in

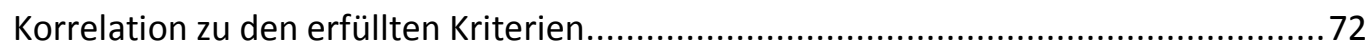

3.3.5 Patientenalter bei Erstdiagnose des Mammakarzinoms in Abhängigkeit zur Detektionsrate der Sequenzvarianten der ACMG-Klasse 3, 4 oder 5 in den 10 Core-

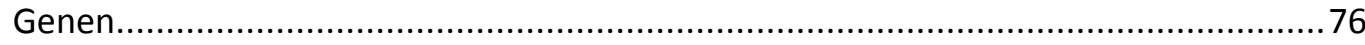

3.3.6 Berechnung des Heterozygoten-Risikos in Assoziation mit identifizierten

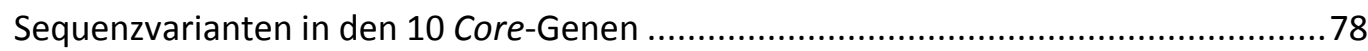

3.3.7 Berechnung des Lebenszeitrisikos in Assoziation mit identifizierten Sequenzvarianten in

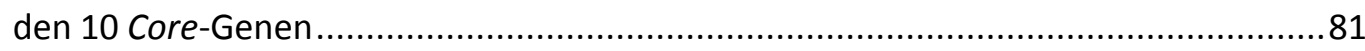

3.3.8 Histologische Subtypen der Mammakarzinome in Abhängigkeit von der identifizierten

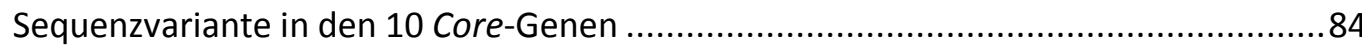

3.3.9 Rezeptorstatus der Mammakarzinome in Korrelation zu identifizierten

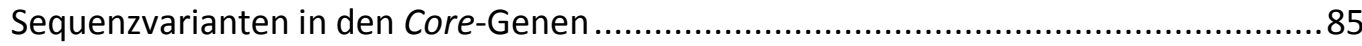

3.3.10 Detektionsraten der Sequenzvarianten in den BRCA1- und BRCA2-Genen im Vergleich

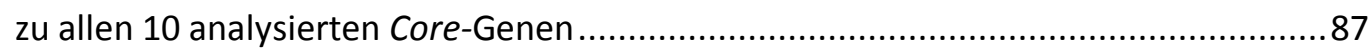

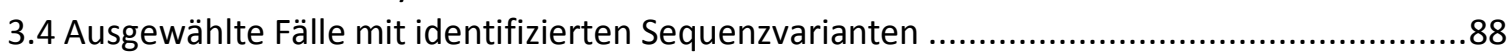

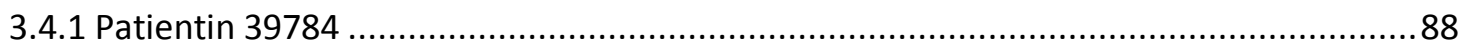

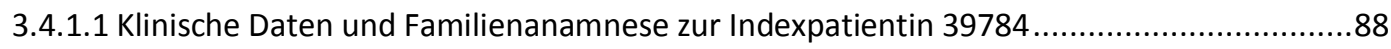

3.4.1.2 Ergebnisse der molekulargenetischen Analyse der Indexpatientin 39784 .....................89

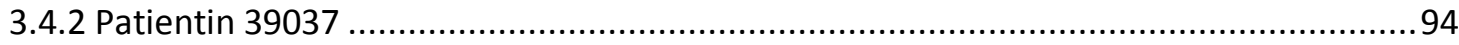

3.4.2.1 Klinische Daten und Familienanamnese zur Indexpatientin 39037 ..............................94

3.4.2.2 Ergebnisse der molekulargenetischen Analyse der 10 Core-Gene der Indexpatientin 39037

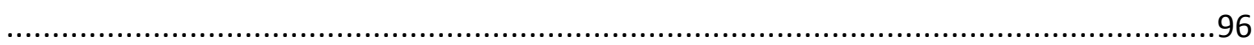

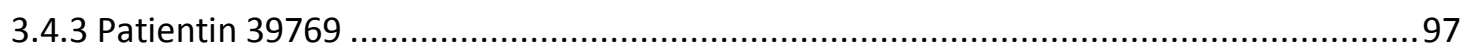

3.4.3.1 Klinische Daten und Familienanamnese zur Patientin 39769 ......................................97

3.4.3.2 Ergebnisse der molekulargenetischen Analyse der 10 Core-Gene der Patientin 39769.....98

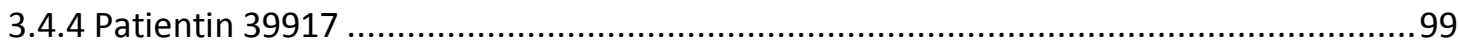

3.4.4.1 Klinische Daten und Familienanamnese zur Indexpatientin 39917 ................................99

3.4.4.2 Ergebnisse der molekulargenetischen Analyse der 10 Core-Gene der Patientin 39917...100

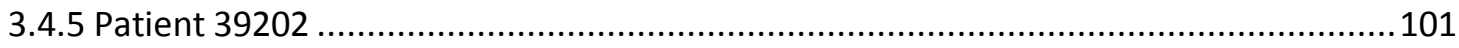

3.4.5.1 Klinische Daten und Familienanamnese zum Indexpatienten 39202 .............................101 
4 Diskussion 109

4.1 Zusammenfassung der klinischen Charakteristika der Patienten-Kohorte und der Multi-Gen-

Panel-(NGS)-Analyse ..... 109

4.2 Auswertungen der Daten der Multi-Gen-Panel-Analyse (NGS) . 110

4.2.1 Vergleich der Daten aus NGS-Analysen bei Verdacht auf ein hereditäres Mamma- und

Ovarialkarzinom

4.2.2 Detektionsraten der Mutationen der ACMG-Klasse 4 oder 5 in einzelnen Core-Genen117

4.2.3 Typen der identifizierten Sequenzvarianten. 118

4.2.4 Tumortypen und Rezeptorstatus der Mammakarzinome ........................................119

4.2.5 Weitere Tumorerkrankungen in den Familien 122

4.3 Vergleich der Detektionsraten der Sequenzvarianten der ACMG-Klasse 3, 4 oder 5 der NGS-

Technologie mit der Sanger-Sequenzierungstechnologie. 123

4.4 Beurteilungen der Sanger-Technologie und der Next-Generation-Sequencing (NGS) 125

4.5 Multi-Gen-Panel-Analysen (NGS) bei Patienten mit Verdacht auf ein hereditäres Mammaund Ovarialkarzinom 125

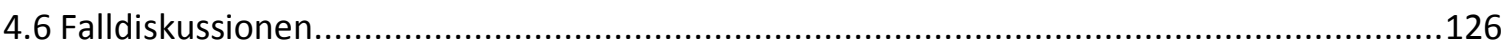

4.6.1 Heterozygote Sequenzvariante c.346G>A im RAD51D-Gen (Indexpatientin 39784) ....127

4.6.2 Heterozygote wahrscheinlich pathogene Mutation c.6336C >A im ATM-Gen (Indexpatientin 39037) 128

4.6.3 Heterozygote pathogene Mutation c.706-1G>A im RAD51C-Gen (Patientin 39769) ...130

4.6.4 Heterozygote wahrscheinlich pathogene Mutation c.1587delT im CDH1-Gen (Indexpatientin 39917) 131

4.6.5 Große genomische Deletion des MSH6-Gens (Indexpatient 39202) ….....................133

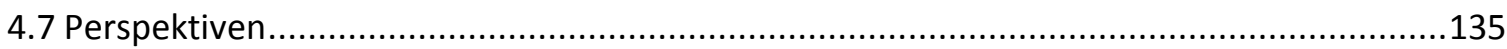

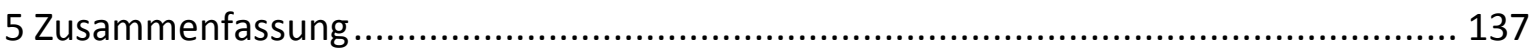

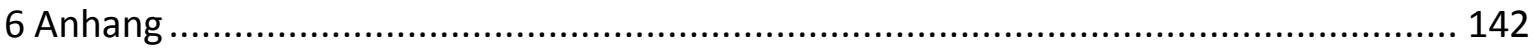

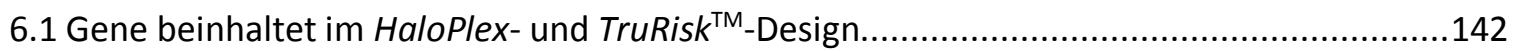

6.2. Liste der Patienten ohne eine detektierte Sequenzvariante der ACMG-Klasse 3, 4 oder 5 in

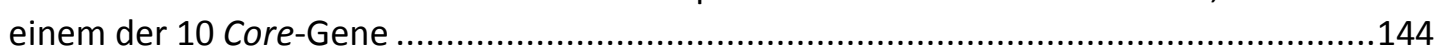

6.3 Rezeptorstatus der Mammkarzinome in Assoziation mit identifizierten Sequenzvarianten in

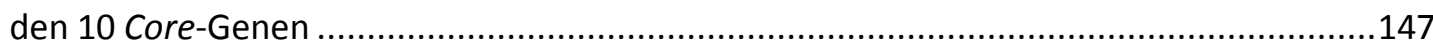

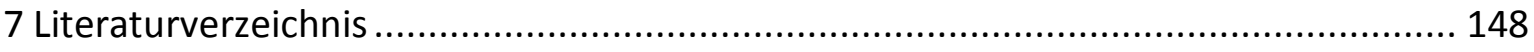

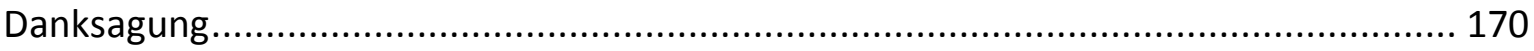




\section{Abbildungsverzeichnis}

Abb. 1.1: Mitglieder des Deutschen Konsortiums Familiärer Brust- und Eierstockkrebs .13

Abb. 1.2: Vorgehensweise und klinische Empfehlungen bei Frauen mit nachgewiesener wahrscheinlich pathogener (ACMG-Klasse 4) und pathogener Mutation (ACMG-Klasse

5) in einem der 10 Core-Gene 16

Abb. 2.1: Wesentliche Schritte im Prozessfluss des HaloPlex Target Enrichment Systems

Abb. 2.2: Aliquotierung des Restriktions-Master-Mixes in eine 96-Well-Platte und Zugabe der genomischen DNA (gDNA) der Patienten

Abb. 2.3: Profil der PCR-Reaktion.

Abb. 2.4: Repräsentatives Elektropherogramm der prä-capture-Analyse der ampifizierten DNALibraries mit dem 2100 BioAnalyzer

Abb. 2.5: Repräsentatives Elektropherogramm der post-capture-Analyse der ampifizierten DNALibraries mit dem 2100 BioAnalyzer

Abb. 2.6: Amplifizierung der Libraries auf der Illumina-Plattform MiSeq und Vorbereitung auf die Sequenzierung

Abb. 2.7: Sequenzierung der Libraries mit der MiSeq-Plattform der Firma Illumina .54

Abb. 2.8: Schematische Darstellung der Primer für die Amplifikation des genomischen Fragments von Exon 10 bis 15 des CHEK2-Gens . .56

Abb. 3.1: Einteilung der untersuchten Patienten nach der Häufigkeit der erfüllten Kriterien .60

Abb. 3.2: Darstellung des Heterozygoten-Risikos der Patienten-Kohorte in Korrelation zum erfüllten Kriterium

Abb. 3.3: Darstellung der 106 identifizierten Sequenzvarianten in den 10 Core-Genen . .70

Abb. 3.4: Verteilung der molekulargenetischen Typen der Sequenzvarianten in den BRCA1- und BRCA2-Genen (BRCA1/2) im Vergleich zu den anderen acht Core-Genen (nicht BRCA1/2)

Abb. 3.5: Einteilung der Sequenzvarianten der ACMG-Klasse 3, 4 oder 5 zum Core-Gen in Assoziation mit dem erfüllten Kriterium

Abb. 3.6: Verteilung der Patienten mit den Mutationen der ACMG-Klasse 4 oder 5 über die CoreGene in Assoziation mit den definierten Kriterien

Abb. 3.7: Medianes Erkrankungsalter bei der Erstdiagnose des Mammakarzinoms bei Patienten mit Sequenzvarianten bzw. Mutationen in den BRCA1- und BRCA2-Genen im Vergleich zu den anderen acht Core-Genen

Abb. 3.8: Berechnung des medianen Heterozygoten-Risikos in Korrelation zu identifizierten Sequenzvarianten in den 10 Core-Genen

Abb. 3.9: Berechnung des medianen Heterozygoten-Risikos in Korrelation zu identifizierten Sequenzvarianten in den einzelnen Core-Genen

Abb. 3.10: Berechnung des medianen Lebenszeitrisikos in Korrelation zu identifizierten Sequenzvarianten in den 10 Core-Genen

Abb. 3.11: Berechnung des medianen Lebenszeitrisikos in Korrelation zu identifizierten Sequenzvarianten in den einzelnen Core-Genen 
Abb. 3.12: Histologischer Subtyp des Mammakarzinoms in Abhängigkeit von einer Mutation der ACMG-Klasse 4 oder 5 in den 10 Core-Genen

Abb. 3.13: Rezeptorstatus der untersuchten Mammakarzinome in Korrelation zu den identifizierten Sequenzvarianten in den Genen BRCA1 und BRCA2 (BRCA1/2) und in

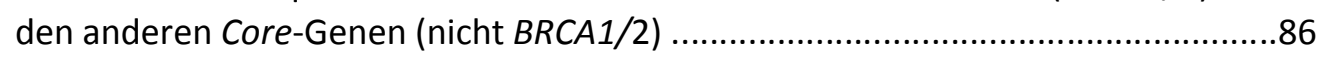

Abb. 3.14: Stammbaum der Indexpatientin 39784 (III.11) über drei Generationen 89

Abb. 3.15: Nachweis der heterozygoten Sequenzvariante c.346G>A im RAD51D-Gen bei der Indexpatientin 39784 .90

Abb. 3.16: Schematische Darstellung der Lokalisation der RAD51D-Gen-spezifischen Primer zur Amplifikation der Patienten-cDNA .91

Abb. 3.17: Gelelektrophoretische Auftrennung der PCR-Produkte nach Amplifikation der RAD51DCDNA und Ergebnisse der Sequenzanalyse des RAD51D-PCR-Produkts der Indexpatientin 39784

Abb. 3.18: Ergebnisse der quantitativen Real-Time-PCR (qRT PCR)-Analyse der RAD51DTranskripte der Indexpatientin 39784 und einer Wildtyp-Kontrolle

Abb. 3.19: Stammbaum der Indexpatientin 39037 (III.12) über vier Generationen . .95

Abb. 3.20: Nachweis der heterozygoten Mutation c.6336C >A im ATM-Gen an genomischer DNA der Indexpatientin 39037

Abb. 3.21: Stammbaum der Patientin 39769 (III.5) über vier Generationen 98

Abb. 3.22: Nachweis der heterozygoten Mutation c.706-1G>A im RAD51C-Gen an genomischer DNA der Patientin 39769 99

Abb. 3.23: Stammbaum der Indexpatientin 39917 (III.5) über vier Generationen 100

Abb. 3.24: Nachweis der heterozygoten Mutation c.1587delT im CDH1-Gen an genomischer DNA der Indexpatientin 39917 101

Abb. 3.25: Stammbaum mit Tumorerkrankungen in der Familie des Indexpatienten 39202 102

Abb. 3.26: Methylierungsanalyse des distalen und proximalen MLH1-Promotorbereichs im gesunden kolorektalen Gewebe sowie im Tumorgewebe des kolorektalen Karzinoms

Abb. 3.27: Schematische Darstellung der Lokalisation der MSH6-Gen-spezifischen Sonden von Exon 1 und flankierender Bereiche des Exons 1 enthalten im MLPA-Kit P072-C ......104

Abb. 3.28: Nachweis einer heterozygoten Deletion von Exon 1 und flankierender Bereiche des MSH6-Gens beim Indexpatienten 39202 mittels CNV- und MLPA-Analyse .105

Abb. 3.29: Nachweis der Deletion im MSH6-Gen mittels qPCR-Analyse an genomischer DNA des Indexpatienten 39202 106

Abb. 3.30: Nachweis der verringerten Expression des MSH6-Gens in den Lymphozyten des Indexpatienten 39202

Abb. 4.1: Schematischer Vergleich der bei dem Indexpatienten 39202 identifizierten genomischen Deletion im MSH6-Gen mit den publizierten Fällen .... 134 


\section{Tabellenverzeichnis}

Tab. 1.1: Genetische Risikofaktoren für das hereditäre Mamma- und Ovarialkarzinom bei den definierten 10 Core-Genen

Tab. 1.2: Graduierung des Tumors

Tab. 1.3: Kriterien zur molekulargenetischen Untersuchung bei Verdacht auf ein hereditäres Mamma- und Ovarialkarzinom (Deutsches Konsortium Familiärer Brust- und Eierstockkrebs).

Tab. 1.4: Abteilungen, Institutionen und Selbsthilfegruppe beteiligt im Brustkrebszentrum der UMG

Tab. 1.5: Klinische Konsequenzen und Therapie bei Mutationen in den Core-Genen entsprechend den Vorschlägen des Deutschen Konsortiums Familiärer Brust- und Eierstockkrebs

Tab. 2.1: Verwendete MLPA-Kits zur Detektion von genomischen Deletionen und Duplikationen

Tab. 2.2: Master-Mix für die Restriktionsanalyse .43

Tab. 2.3: Herstellung des Hybridisierungs-Master-Mixes .44

Tab. 2.4: Zusammensetzung des Ligations-Master-Mixes .45

Tab. 2.5: Zusammensetzung des PCR-Master-Mixes .45

Tab. 2.6: Reaktions-Master-Mix für die DNA-Fragmentierung ..... . .47

Tab. 2.7: Master-Mix für die prä-PCR 48

Tab. 2.8: Einstellung des Thermocyclers für die prä-capture-PCR .48

Tab. 2.9: Hybridisierungsvorgang der Sonden und der Index-Sequenzen . .50

Tab. 2.10: Ansetzung des Hybridisierungsmixes . .50

Tab. 2.11: Vorbereitung der RNase-Blockierungslösung . .50

Tab. 2.12: PCR-Master-Mix .51

Tab. 2.13: Das PCR-Profil 52

Tab. 2.14: Core-Gene mit entsprechenden Nummern der Referenzsequenzen .56

Tab. 2.15: Datenbanken für die Einschätzung der Pathogenität der detektierten Sequenzvarianten 56

Tab. 2.16: Vorhersageprogramme für die Einschätzung der Pathogenität der Sequenzvarianten .57

Tab. 3.1: Erkrankungsalter der analysierten Patienten bei Erstdiagnose eines Mamma- oder Ovarialkarzinoms

Tab. 3.2: Einteilung der Sequenzvarianten in fünf Klassen nach den Richtlinien des $A C M G$ und Empfehlungen des IARC

Tab. 3.3: Identifizierte Sequenzvarianten der ACMG-Klasse 3, 4 oder 5 bei 88 der analysierten Patienten

Tab. 3.4: Verteilung der identifizierten Sequenzvarianten der ACMG-Klasse 3, 4 oder 5 nach NGSAnalyse der 10 Core-Gene und der MLPA-Analyse 
Tab. 3.5: Verteilung der Sequenzvariantentypen der ACMG-Klasse 3, 4 oder 5 über die 10 CoreGene ...

Tab. 3.6: Typen der Sequenzvarianten der ACMG-Klasse 3, 4 oder 5 unterteilt in die ACMG-Klasse 3 sowie in die $A C M G$-Klasse 4 oder 5

Tab. 3.7: Verteilung der Sequenzvarianten der ACMG-Klasse 3, 4 oder 5 in den Core-Genen nach dem erfüllten Kriterium .....

Tab. 3.8: Mittleres Erkrankungsalter bei der Erstdiagnose des Mammakarzinoms bei Patienten mit den Sequenzvarianten der ACMG-Klasse 3 sowie Mutationen der ACMG-Klasse 4 oder 5 in den 10 Core-Genen .76

Tab. 3.9: Frequenz der detektierten Sequenzvarianten der ACMG-Klasse 3 und Mutationen der ACMG-Klasse 4 oder 5 in Korrelation zum Erkrankungsalter bei der Erstdiagnose eines Mamma- oder Ovarialkarzinoms

Tab. 3.10: Histologischer Subtyp des Mammakarzinoms in Abhängigkeit von identifizierten Sequenzvarianten der ACMG-Klasse 3, 4 oder 5 in den 10 Core-Genen

Tab. 3.11: Triple-negative Mammakarzinome in Abhängigkeit von identifizierten Sequenzvarianten der ACMG-Klasse 3, 4 oder 5 in den 10 Core-Genen

Tab. 4.1: Empirische und berechnete Wahrscheinlichkeiten für Mutationen in den Genen BRCA1 und BRCA2 .

Tab. 4.2: Übersicht der Detektionsraten der Mutationen und Varianten unklarer Signifikanz in den 10 Core-Genen 116

Tab. 4.3: Detektionsraten der Mutationen der ACMG-Klasse 4 oder 5 bei Patienten mit triplenegativen Mammakarzinomen .121

Tab. 4.4: Weitere Tumorerkrankungen bei Indexpatienten (außer Mammakarzinomen und Ovarialkarzinomen)

Tab. 4.5: Detektionsraten der identifizierten Sequenzvarianten der ACMG-Klasse 3, 4 oder 5 in den Genen BRCA1 und BRCA2 mittels Sanger-Sequenzierung und NGS-Technologie 123

Tab. 4.6: Detektionsraten der Mutationen der ACMG-Klasse 4 oder 5 in den Genen BRCA1 und BRCA2 mittels Sanger-Sequenzierung und NGS-Technologie 124

Tab. 4.7: Detektionsraten der identifizierten Sequenzvarianten der ACMG-Klasse 3, 4 oder 5 pro Patient mittels Sanger-Sequenzierung und NGS-Technologie ....

Tab. 4.8: Vergleich der Detektionsraten der identifizierten Mutationen der ACMG-Klasse 4 oder 5 pro Patient mittels Sanger-Sequenzierung und NGS-Technologie

Tab. 6.1: Gene im HaloPlex-Panel-Design .142

Tab. 6.2: Gene im TruRisk ${ }^{\mathrm{TM}}$-Panel-Design ...

Tab. 6.3 Analysierte Patienten ohne eine identifizierte Sequenzvariante der ACMG-Klasse 3, 4 oder 5 . 144

Tab. 6.4: Rezeptorstatus der Mammakarzinome in Abhängigkeit von identifizierten Sequenzvarianten in den 10 Core-Genen 147 


\section{Abkürzungsverzeichnis}

5'-UTR

Abb.

ACMG

ACR1

$B I C$

bds.

BOADICEA

$\mathrm{bp}$

BRIDGES

BSA

$\mathrm{C}$

CDNA

ChIP-Seq

CMMC

CNV

CRC

Cy

DCIS

ddNTP

del

DK

DNA

dNTP

dsDNA

DTT

dup

dUTP

$\mathrm{E}$

$E C D$

ED

EDTA

EGFR

ENST

$E R \alpha$

E/Ex/ex

EXAC

for

fs

g

G

GC-HBOC

gDNA

GWAS

HBOC

HGMD

HGVS

HNPCC

IARC 5'-untranslatierte Region

Abbildung

American College of Medical Genetics and Genomics

ACR-Dichteindex 1

Breast Cancer Information Core

beidseits

Breast and Ovarian Analysis of Disease Incidence and Carrier Estimation

Algorithm

Basenpaar

Breast Cancer Risk after Diagnostic Gene Sequencing

bovine serum albumine

Konzentration

kodierende DNA

Chromatin ImmunoPrecipitation DNA-Sequencing

Center for molecular medicine Cologne

Kopienzahlvariation (copy number variation)

kolorektales Karzinom

Cyanine

duktales Carcinoma in situ

Didesoxynukleotiden

Deletion

Deutsches Konsortium

Desoxyribonukleinsäure

Desoxynukleotiden

doppelsträngige DNA

Dithiothreitol

Duplikation

Deoxyuridin-Triphosphat

PCR-Effizienz

Enrichment Control DNA

Erstdiagnose

Ethylendiamintetraessigsäure

Epidermal Growth Factor Receptors

Ensembl genome browser

Östrogenrezeptor $\alpha$

Exon

Exome Aggregation Consortium

forward

frame shift

Gramm

Graduierungsgrad

German Consortium for Hereditary Breast and Ovarian Cancer

genomische DNA

Genome-Wide Association Study

Hereditary Breast and Ovarial Cancer

Human Gene Mutation Database

Human Genome Variation Society

Hereditäres Nicht Polyposes kolorektales Karzinom

International Agency for Research on Cancer 


\begin{tabular}{|c|c|}
\hline IFNP & Intensiviertes Früherkennungs- bzw. Nachsorgeprogramm \\
\hline IHC & immunhistologische Untersuchung \\
\hline IMISE & Institut für Medizinische Information, Statistik und Epidemiologie \\
\hline K & Cluster \\
\hline $\mathrm{kb}$ & Kilobasenpaare \\
\hline$\bigsqcup$ & Lebensjahr \\
\hline $\mathrm{LOH}$ & loss of heterozygosity \\
\hline LOVD & Leiden Open Variation Database \\
\hline $\mathrm{m}$ & milli $=10^{-3}$ \\
\hline M & Molar \\
\hline M & Metastase (TNM-Klassifikation) \\
\hline $\max$. & maximal \\
\hline $\mathrm{Mb}$ & Megabasenpaare \\
\hline $\mathrm{MCa}$ & Mammakarzinom \\
\hline $\min$. & minimal \\
\hline $\mathrm{ml}$ & Mililiter \\
\hline$M L P A$ & Multiplex Ligation-dependent Probe Amplification \\
\hline MMR & Mismatch-Reparatur \\
\hline mol & Stoffmenge \\
\hline MoM & multiple of the median \\
\hline MRT & Magnetresonanztomographie \\
\hline MVZ & Medizinisches Versorgungszentrum \\
\hline $\mathrm{n}$ & nano \\
\hline $\mathrm{N}$ & Nodus (Lymphknoten; TNM-Klassifikation) \\
\hline NA & keine Angaben \\
\hline$N C B I$ & The National Center of Biotechnology Information \\
\hline ng & Nanogramm \\
\hline NGS & Next-Generation-Sequencing \\
\hline NierenCa & Nierenkarzinom \\
\hline $\mathrm{nM}$ & Nanomolar \\
\hline ÖGD & Ösophago-Gastro-Duodenoskopie \\
\hline OMIM & Online Mendelian Inheritance in Man \\
\hline$O R$ & Odds Ratio \\
\hline OvCa & Ovarialkarzinom \\
\hline $\mathrm{p}$ & piko $=\left(10^{-12}\right)$ \\
\hline PARP & Poly-ADP-Ribose-Polymerase \\
\hline PCR & Polymerasekettenreation (Polymerase Chain Reaction) \\
\hline $\mathrm{pH}$ & negative dekadischer Logarithmus der $\mathrm{H}^{+}$-Ionenkonzentration \\
\hline $\mathrm{pM}$ & Picomolar \\
\hline PR & Progesteron-Rezeptor \\
\hline PRA & Progesteron-Rezeptor A \\
\hline PRB & Progesteron-Rezeptor B \\
\hline ProstataCa & Prostatakarzinom \\
\hline PRS & Polygenic Risk Score \\
\hline$\mu$ & Mikro $=10^{-6}$ \\
\hline$\mu l$ & Mikroliter \\
\hline RE-Puffer & Puffer mit Restriktionsenzym \\
\hline rev & reverse \\
\hline ROI & Region of Interest \\
\hline RSB & Resuspensionspuffer \\
\hline
\end{tabular}


RTK

qPCR

$S$

SNP

SSC

$T$

Tab.

TE

UICC

UMG

$\mathrm{V}$

VDEK

VUS

wahrschl.

WES

WGS
Rezeptor-Tyrosinkinasen

quantitative PCR

Sekunde

Single Nucleotide Polymorphism

saline-sodium citrate

Tumor, Tumorgröße (INM-Klassifikation)

Tabelle

Tris-EDTA

Internationale Vereinigung gegen Krebs (Union internationale contre le cancer)

Universitätsmedizin Göttingen

Volumen

Verband der Ersatzkassen

Variante unklarer Signifikanz

wahrscheinlich

Whole-Exome-Sequencing

Whole-Genome-Sequencing

\section{Code der Nukleinsäuren}
A, a
Adenin
$C, C$
Cytosin
G, $\mathrm{g}$
Guanin
$\mathrm{T}, \mathrm{t}$
Thymin 


\section{Einleitung}

\subsection{Definition und Epidemiologie des sporadischen und hereditären Mamma- und Ovarialkarzinoms}

Das Mammakarzinom stellt eine maligne Erkrankung der Mammae dar (Netters 2006). Hierbei handelt es sich um die häufigste maligne Erkrankung der Frau in Deutschland mit ca. 69.220 Neuerkrankungen im Jahr (Krebsregister, Stand 2014). Das mittlere Erkrankungsalter der betroffenen Frauen lag bei 64,0 Jahren. Etwa $1 \%$ aller Mammakarzinome traten bei Männern auf (Kiechle 2010). Im Jahr 2014 wurden in Deutschland 650 Mammakarzinome bei Männern mit einem mittleren Erkrankungsalter von 71 Jahren registriert (Krebsregister, Stand 2014). Die Zahlen der registrierten Mamma- und Ovarialkarzinome im Krebsregister unterscheiden jedoch nicht zwischen sporadischen und hereditären Formen. Die Zahlen in weiteren westlichen Ländern ähneln den deutschen Daten, z. B. in den USA und in England ist das Mammakarzinom die häufigste maligne Erkrankung der Frau mit 252.170 (15,0 \% aller Tumorerkrankungen) (USA National Cancer Institute, Stand 2017) bzw. 55.200 Neuerkrankungen im Jahr (Cancer Research UK, Stand 2014). Weltweit betrachtet ist das Mammakarzinom die zweithäufigste maligne Erkrankung des Menschen (World Cancer Research Fund International, Stand 2012).

Die Mehrzahl der Mammakarzinome (ca. 70 \%) entsteht spontan. Diese Tumoren werden als sporadische Mammakarzinome bezeichnet (Kiechle 2010). Bei etwa $10 \%$ - $30 \%$ der betroffenen Patienten zeigt sich eine familiäre Häufung von Mammakarzinomen. Bei einem diagnostizierten Mammakarzinom (ca. 5 \% - 10\%) konnte in seltenen Fällen eine Keimbahnmutation in einem mit dem Mammakarzinom assoziierten Gen identifiziert werden. In einem solchen Fall wird von einer hereditären Form des Mammakarzinoms gesprochen (Gage et al. 2012).

Das Ovarialkarzinom ist nach dem Mammakarzinom der dritthäufigste gynäkologische maligne Tumor in Deutschland (Kiechle 2010). Im Jahr 2014 wurden 7.250 neu aufgetretene Ovarialkarzinome im deutschen Krebsregister verzeichnet (Krebsregister; Stand 2014). Für die USA werden für das Jahr 2017 etwa 22.440 neu aufgetretene Ovarialkarzinome erwartet 1 1,3\% aller Tumorerkrankungen) (USA National Cancer Institute, Stand 2017). Dabei traten ca. $90 \%$ der Ovarialkarzinome sporadisch auf. Im Gegensatz dazu basierten ca. 5,0 \% - 10,0 \% der Tumoren auf Keimbahnmutationen und wiesen somit eine hereditäre Genese auf (Prat et al. 2005; Kiechle 2010).

Klinisch unterscheiden sich die hereditären Formen der Mamma- und Ovarialkarzinome von den sporadischen Karzinomen durch ein früheres Erkrankungsalter (häufig vor dem 50. Lebensjahr), eine familiäre Häufung von Karzinomen, die Häufung assoziierter Tumorerkrankungen, wie z. B. das Prostata- (Leongamornlert et al. 2012; Kote-Jarai et al. 2011) und das Pankreaskarzinom (Thompson et al. 2002; Risch et al. 2006) und ein höheres kumulatives Risiko für ein kontralaterales Mammakarzinom von etwa 47 \% für Patienten mit Mutationen in den Genen BRCA1 und BRCA2 (Graeser et al. 2009).

Die hereditäre Form des Mamma- und Ovarialkarzinoms bezieht sich auf Keimbahnmutationen. Der Begriff Mutation in dieser Dissertation bezieht sich ausschließlich auf den Nachweis von Keimbahnmutationen. In den Tumoren identifizierte Mutationen werden nachfolgend explizit als somatische Mutationen bezeichnet.

Die Begriffe Patient und Patienten beziehen sich in dieser Disseration auf weibliche und männliche Patienten (geschlechtsneutral), außer die Begriffe beschreiben explizit die männlichen Patienten. 


\section{2 Ätiologie des Mamma- und Ovarialkarzinoms}

Die genaue Ätiologie des Mammakarzinoms ist unbekannt. Es wird von einem multifaktoriellen Geschehen ausgegangen (Kiechle 2010). In mehreren Studien wurde belegt, dass der Lebensstil das Risiko für das Auftreten eines sporadischen Mammakarzinoms beeinflusst. Bewegungsmangel, Alkoholkonsum (Cloud et al. 2015), Nikotinabusus, hochkalorische und fettreiche Ernährung, Adipositas, die Einnahme oraler Kontrazeptiva sowie eine postmenopausale Hormonersatztherapie (Key et al. 2003; Rosner et al. 2017) erhöhen das Risiko, an einem sporadischen Mammakarzinom zu erkranken. Schwangerschaft sowie Geburt erhöhen zunächst das Risiko, ein Mammakarzinom zu entwickeln, wirken aber langfristig protektiv (Chie et al. 2000). Langes Stillen (Collaborative Group 2002) und physische Aktivität (Kruk 2007) wirken protektiv auf die Entwicklung des Mammakarzinoms. Mehrere Studien ergaben Hinweise, dass sportliche Betätigung im jungen Lebensalter und Vermeidung von Übergewicht bei Trägerinnen von BRCA1oder BRCA2-Mutationen protektiv auf die Entwicklung des Mammakarzinomrisikos wirken können (King et al. 2003; Manders et al. 2011).

Die Mamma- und Ovarialkarzinome können im Rahmen von unterschiedlichen hereditären Tumorsyndromen vorkommen. Am häufigsten treten diese im Rahmen eines hereditären Mamma- und Ovarialkarzinom-Syndroms auf. Sie können aber auch in Assoziation mit weiteren hereditären Tumorsyndromen, wie z. B. dem Cowden-Syndrom (OMIM 158350), dem PeutzJeghers-Syndrom (OMIM 175200) sowie dem Li-Fraumeni-Syndrom (OMIM 151623) beobachtet werden (Schaaf 2013). Bei den genannten Tumorsyndromen sind andere Karzinome und Tumoren, wie z. B. Sarkome, Leukämien, dem Mamma- und Ovarialkarzinom übergeordnet.

\subsection{Risikogene des hereditären Mamma- und Ovarialkarzinom-Syndroms}

Als Risikogene für ein hereditäres Mamma- und Ovarialkarzinom wurden im Jahr 1996 ausschließlich die Gene BRCA1 und BRCA2 definiert. Jedoch hat sich das molekulargenetische Angebotsspektrum in den letzten Jahren durch den Informationsgewinn durch verschiedene Studien und die Entwicklung neuartiger diagnostischer Technologien auf insgesamt 10 sogenannte Core-Gene ausgeweitet. Die molekulargenetische Untersuchung dieser 10 Core-Gene wird dem Patienten bei mindestens einem erfüllten Kriterium angeboten. Als Core-Gene wurden die Gene ATM, BRCA1, BRCA2, CDH1, CHEK2, NBN, PALB2, RAD51C, RAD51D und TP53 durch das Deutsche Konsortium Familiärer Brust- und Eierstockkrebs definiert.

\subsubsection{Hochpenetrante Gene des hereditären Mamma- und Ovarialkarzinoms 1.3.1.1 BRCA1- und BRCA2-Gene}

Die ersten hochpenetranten Mutationen im BRCA1-(Breast cancer 1; OMIM 113705)-Gen wurden im Jahr 1994 (Miki et al. 1994) identifiziert. Nachfolgend konnten Mutationen im BRCA2-(Breast cancer 2; OMIM 600185)-Gen im Jahr 1995 (Wooster et al. 1995) detektiert werden. Das BRCA1Gen ist auf Chromosom 17q21.31 lokalisiert und enthält 23 Exons, davon sind 22 kodierend. Das BRCA2-Gen ist auf Chromosom 13q13.1 lokalisiert und besteht aus 28 Exons, davon sind 26 kodierend. Die Gene BRCA1 und BRCA2 stellen Tumorsupressorgene dar, die eine wichtige Funktion in der zellulären Antwort auf DNA-Schäden ausüben. BRCA1 ist über zahlreiche Interaktionspartner an mehreren Signalwegen beteiligt. BRCA1 übt weitere Funktionen in der Zellzykluskontrolle, in der Chromatinremodelierung, in der Regulation der Transkription, in der XChromosomeninaktivierung und in der Ubiquitinierung von Proteinen aus (Bochar et al. 2000; Narod und Foulkes 2004). Die bisher wichtigste Funktion von BRCA2 scheint die Regulation von RAD51 zu sein, dem wichtigsten Enzym bei der fehlerfreien Reparatur mittels homologer Rekombination (Narod und Foulkes 2004). Mehrere Studien zeigten, dass in BRCA1- und BRCA2assoziierten Tumoren gemäß der Zwei-Treffer-Hypothese nach Knudson (Knudson 1971) eine Inaktivierung des zweiten Allels bzw. Wildtyp-Allels durch einen Verlust der Heterozygotie (loss of 
heterozygosity, LOH) stattfindet (Neuhausen et al. 1994; Collins et al. 1995; O'Donovan et al. 2010). Allerdings handelt es sich bei dem second hit nicht immer um ein reines LOH. Das zweite Allel kann auch durch andere Mechanismen, wie z. B. Promotormethylierung, abgeschaltet werden (Maxwell et al. 2017). Die Studie von Maxwell et al. (2017) zeigte keinen Verlust des LOH in der DNA von Mammakarzinomen bei $10 \%$ der Trägerinnen einer BRCA1-Mutation und bei $46 \%$ der Trägerinnen einer BRCA2-Mutation sowie in der DNA von Ovarialkarzinomen bei $7 \%$ der Trägerinnen einer BRCA1-Mutation und bei $16 \%$ der Trägerinnen einer BRCA2-Mutation. Somatische BRCA1- und BRCA2-Mutationen in sporadischen Mammakarzinomen wurden in der Studie von Winter et al. (2016) in ca. 3 \% der Fälle beobachtet. Somatische BRCA1-Mutationen wurden bei $5 \%$ - $9 \%$ und somatische BRCA2-Mutationen bei $3 \%-4 \%$ der sporadischen Ovarialkarzinome identifiziert (Merajver et al. 1995, Berchuck et al. 1998, Hennessy et al. 2010, Chao et al. 2016).

Keimbahnmutationen in den Genen BRCA1 und BRCA2 konnten in etwa $3 \%$ - $5 \%$ der an einem Mammakarzinom erkrankten Frauen nachgewiesen werden und in 22,5\% der Patienten in den Familien, welche die Einschlusskriterien des Deutschen Konsortiums Familiärer Brust- und Eierstockkrebs erfüllten (Engel et al. 2015).

Die Gene $B R C A 1$ und $B R C A 2$ werden den sog. Hochrisikogenen zugeordnet. Für Träger einer Keimbahnmutation in den Genen BRCA1 und BRCA2 ergaben verschiedene Studien ein sehr breites kumulatives Risiko an einem Mamma- und an einem Ovarialkarzinom bis zum 70. Lebensjahr zu erkranken. Das Risiko für BRCA1-Mutationsträgerinnen an einem Mammakarzinom zu erkranken weist eine Spanne von 46,0 \% - 86,0 \% auf, während das Risiko an einem Ovarialkarzinom zu erkranken bei 39,0 \% - 63,0 \% liegt. Dieses Risiko ist für Trägerinnen einer Keimbahnmutation im BRCA2-Gen etwas geringer und zwar wurden für das Mammakarzinom Risikowerte von 38,0 \% - 84,0 \% ermittelt und für das Ovarialkarzinom wurden Risikozahlen von $16,5 \%-27,0 \%$ erhoben. Für männliche Träger einer Keimbahnmutation im BRCA1-Gen besteht ein Risiko von $1,2 \%$ an einem Mammakarzinom zu erkranken. Für männliche Träger einer Keimbahnmutation im BRCA2-Gen liegt das Risiko bei bis zu 8,9 \% (s. auch Tab. 1.1). Keimbahnmutationen im BRCA2-Gen steigern bei Männern zusätzlich das Risiko an einem Prostatakarzinom (bis zu $20 \%$ ) zu erkranken, während sowohl BRCA1- als auch BRCA2Mutationen das Pankreaskarzinomrisiko ( $1 \%-3 \%$ bzw. 2 \% - 7 \%) erhöhen (NCBI Bookshelf, BRCA1- and BRCA2-Associated Hereditary Breast and Ovarian Cancer; Letzte Aktualisierung am 15. Dezember 2016).

Für ein rezidivierendes, high-grade seröses und Platin-sensitives Ovarialkarzinom wurde bei Trägerinnen einer Keimbahn- oder somatischen BRCA1- oder BRCA2-Mutation die Therapie mit dem PARP-(Poly-ADP-Ribose-Polymerase)-Inhibitor Olaparib eingeführt. Die Poly-ADP-RibosePolymerase ist an DNA-Reparaturmechanismen der Zelle beteiligt. Der PARP-Inhibitor inhibiert über die Bindung an PARP1- und PARP2-DNA-Komplexe bei Patientinnen mit Ovarialkarzinom und einer nachgewiesenen Mutation in den Genen BRCA1 oder BRCA2 die DNA-Reparatur in den Tumorzellen (Kaufman et al. 2015). Die Studie von Murai et al. 2012 zeigte, dass diese Inhibition die Zellproliferation inhibiert und somit eine antitumorigene Aktivität aufweist.

Biallelische Mutationen im BRCA2-Gen können die autosomal-rezessiv vererbte Fanconi-Anämie Typ D1 (OMIM 605724) verursachen. Bei dieser Erkrankung können ein Kleinwuchs, Fehlbildungen des Daumens, eine Mikrozephalie, faziale Dysmorphien, kongenitale Herzfehler, gastrointestinale Fehlbildungen und Cafe-au-Lait-Flecken auftreten. Es besteht ebenso ein kumulatives Risiko von 97 \% für das Auftreten von verschiedenen Malignomen (Leukämien und solide Tumoren) (Alter et al. 2007). 


\subsubsection{PALB2- und TP53-Gene}

Das PALB2-(Partner and localizer of BRCA2; OMIM 610355)-Gen ist auf Chromosom 16p12.2 lokalisiert und besteht aus 13 kodierenden Exons. Das PALB2-Gen stellt ein Tumorsupressorgen dar und vermitelt die Integrität der genomischen Stabilität der Zelle. PALB2 spielt eine wichtige Rolle in verschiedenen Interaktionen in der zellulären Antwort auf Brüche der Doppelstrang-DNA, fördert die DNA-Reparatur mittels homologer Rekombination, interagiert in der Regulation des Chromatins und in der Regulation des oxidativen Stresses (Park et al. 2014). Für das PALB2-Gen wurde lange Zeit angenommen, dass Keimbahnmutationen in diesem Gen das Erkrankungsrisiko für ein Mammakarzinom um etwa 2,3-fach bis zu 5-fach (Casadei et al. 2011, Rahman et al. 2007) erhöhen. Eine weitere Studie zeigte jedoch, dass PALB2-Keimbahnmutationen das Risiko für das Auftreten eines Mammakarzinoms altersabhängig bis zu 8-fach erhöhen können und dass das PALB2-Gen somit als hochpenetrantes Gen betrachtet werden muss (Antoniou et al. 2014). Mutationen im PALB2-Gen konnten in etwa $1 \%$ der untersuchten Fälle mit familiären Mammakarzinomen nachgewiesen werden. Ein LOH ist jedoch nicht typisch für die Entstehung des Mammakarzinoms bei Patienten mit einer PALB2-Keimbahnmutation (Tischkowitz et al. 2007; Foo et al. 2017). Zusätzlich wurde eine Assoziation von PALB2-Mutationen und einem 10- bis 32fach erhöhten Erkrankungsrisiko im Vergleich zur Allgemeinbevölkerung für ein Pankreaskarzinom bereits durch mehrere Studien belegt (Jones et al. 2009; Slater et al. 2010; Tischkowitz et al. 2009) (s. Tab. 1.1). Biallelische Mutationen im PALB2-Gen führen zur Fanconi-Anämie Typ N (OMIM 610832). Betroffene Patienten zeigen eine Entwicklungsstörung, eine Knochenmarkaplasie und ein erhöhtes Risiko für pädiatrische Tumore (Pauty et al. 2014).

Das TP53-(Tumor protein p53; OMIM 191170)-Gen ist auf Chromosom 17p13.1 lokalisiert und besteht aus 11 Exons, davon sind 10 kodierend. Das TP53-Gen ist ein Tumorsupressorgen und spielt eine essentielle Rolle in der Kontrolle des Zellzyklus, die entweder in einer Inhibierung der Progression des Zellzyklus oder in einer Apoptose resultiert (Lalloo und Evans 2012). Keimbahnmutationen im TP53-Gen wurden als ursächlich für die seltene, autosomal-dominant vererbte Tumordispositionserkrankung Li-Fraumeni-Syndrom (OMIM 151623) beschrieben. Zudem sind Keimnahmutationen im TP53-Gen mit einem erhöhten Erkrankungsrisiko für ein Mammakarzinom assoziiert. De novo TP53-Mutationen wurden einerseits in singulären Fällen mit Mammakarzinom und multiplen weiteren malignen Erkrankungen (u.a Liposarkom, malignes Histiozytom) nachgewiesen (Speiser et al. 1996; Salmon et al. 2007; Ferrarini et al. 2011), andererseits wurden Keimbahnmutationen im TP53-Gen in Familien mit einem sehr frühen Auftreten von Mammakarzinomen zwischen dem 20. und 30. Lebensjahr identifiziert (Fostira et al. 2015). Mutationen im TP53-Gen verursachen ein 18- bis 60-fach erhöhtes Risiko für die Entwicklung eines Mammakarzinoms vor dem 45. Lebensjahr (Lalloo und Evans 2012). Keimbahnmutationen im TP53-Gen zeichnen sich durch eine extreme phänotypische Heterogenität aus (s. Tab. 1.1). In der Studie von Silwal-Pandit et al. (2014) war ein LOH in etwa 80 $\%$ der Mammakarzinome zu beobachten.

\subsubsection{Moderat penetrante Gene des hereditären Mamma- und Ovarialkarzinoms 1.3.2.1 ATM-Gen}

Das ATM-(Ataxia-telangiectasia mutated gene; OMIM 607585)-Gen ist ein Tumorsupressorgen, welches auf Chromosom 11q22.3 lokalisiert ist. Es besteht aus 63 Exons, davon sind 62 kodierend. ATM ist eine Proteinkinase, die als Antwort auf DNA-Schäden, vor allem der Doppelstrangbrüche, aktiviert wird und den G1-Kontrollpunkt sowie den Kontrollpunkt der S-Phase reguliert (Tichý et al. 2010). Diese Regulation erfolgt über einen Signalweg zusammen mit TP53, BRCA1 und CHEK2 (Lalloo und Evans 2012). Homozygote oder compound-heterozygote Mutationen im ATM-Gen verursachen eine Ataxia telangiectasia (OMIM 208900). Bei dieser autosomal-rezessiv vererbten Erkrankung können sich bei den Patienten die ersten Symptome wie eine zerebelläre Ataxie mit 
Kleinhirnatrophie, Athetose, Störungen der Augenbewegungen, ein Entwicklungsrückstand, Immundefekte, Teleangiektasien, eine Hypersensibilität für ionisierende Bestrahlung und eine Demenz bereits im Kindesalter äußern (Sandoval et al. 1999). Zudem besteht bereits im Kindesalter eine Tumorprädisposition. Heterozygote Trägerinnen einer trunkierenden Mutation im ATM-Gen zeigen ein etwa 2,3-fach erhöhtes Mammakarzinomrisiko gegenüber der Allgemeinbevölkerung (Ahmed und Rahman 2006, Thompson et al. 2005) (s. Tab. 1.1).

\subsubsection{CDH1-Gen}

Das Tumorsupressorgen CDH1 (Cadherin 1; OMIM 192090) ist auf Chromosom 16q22.1 lokalisiert und besteht aus 16 kodierenden Exons. Das CDH1-Gen kodiert für E-Cadherin, welches der Gruppe der Cadherine angehört. E-Cadherin ist ein Calcium-abhängiges Zell-ZellAdhäsionsmolekül mit einer wichtigen Rolle in der epithelialen Architektur, zellulären Polarität und Differenzierung (van Roy und Berx 2008; Liu und Chu 2014). Eine Dysregulation des ECadherins fördert die Dysfunktion verschiedener Signalwege (u. a. den Wnt-Signalweg), beeinflusst die zelluläre Polarisation, zelluläres Überleben, Invasion und Migration und ist somit ein wichtiger Schritt in der Tumorigenese (Pećina-Slaus 2003; van Roy und Berx 2008). Keimbahnmutationen im CDH1-Gen können ursächlich für das diffuse hereditäre Magenkarzinom (OMIM 137215) sein. CDH1-Mutationen sind vor allem in Familien mit einem gehäuften Auftreten des histologischen Subtyps des lobulären Mammakarzinoms beschrieben worden (Oliveira et al. 2013). Pathogene $C D H 1$-Mutationen finden sich in Familien mit einem gleichzeitigen Auftreten eines diffusen Magen- und eines lobulären Mammakarzinoms (Pharoah et al. 2001; Kaurah et al. 2007). Bei Vorhandensein isolierter lobulärer Mammakarzinome in der Familie wurden pathogene Mutationen im CDH1-Gen in 1,3 \% der Fälle detektiert (Schrader et al. 2011) (s. Tab. 1.1). Die Studie von van Roy und Berx (2008) zeigte, dass die Inaktivierung des zweiten Allels bei Trägern einer Keimbahnmutation im CDH1-Gen durch somatische Mutationen des zweiten Allels oder durch Hypermethylierung des Promotors entsteht.

\subsubsection{CHEK2-Gen}

Das Tumorsupressorgen CHEK2 (Checkpoint kinase 2, OMIM 604373) ist ein auf Chromosom 22q12.1 lokalisiertes Gen und besteht aus 15 Exons, davon sind 14 für eine Serin-Threonin-Kinase kodierend. CHEK2 spielt eine wichtige Rolle in der zellulären Antwort auf DNA-Schäden im gemeinsamen Signalweg mit TP53 und BRCA1 (Lalloo und Evans 2012) und ermöglicht so die genomische Integrität der Zelle (Bartek et al. 2001). Keimbahnmutationen im CHEK2-Gen führen zu einer 2- bis 3-fachen Erhöhung des Mammakarzinomrisikos (Nevanlinna und Bartek 2006). Die Penetranz ist jedoch stark von der familiären Risikokonstellation abhängig (Cybulski et al. 2011). Die Inzidenz der heterozygoten Anlageträgerschaft für die häufigste Punktmutation (c.1100delC) im CHEK2-Gen in der nordwestlichen europäischen Population wird auf 1,5 \% geschätzt. Im Vergleich zur Allgemeinbevölkerung weisen Frauen mit einer nachgewiesenen heterozygoten c.1100delC Keimbahnmutation im CHEK2-Gen ein 4,8-fach erhöhtes Risiko auf, ein Mammakarzinom zu entwickeln (Huijts et al. 2014) (s. Tab. 1.1). Weiterhin besteht für Männer mit einer pathogenen Mutation im CHEK2-Gen ein moderat erhöhtes Risiko, ein Prostatakarzinom zu entwickeln (Cybulski et al. 2004; Ta et al. 2015). Weiterhin zeigte die Studie von Cybulski et al. (2004) für Träger einer pathogenen CHEK2-Keimbahnmutation ein erhöhtes Risiko für ein kolorektales Karzinom (Odds Ratio $(\mathrm{OR})=2,0)$, ein Nierenkarzinom $(\mathrm{OR}=2,1$ ) und ein Schilddrüsenkarzinom $(O R=1,9)$. Unabhängige Studien zeigten, dass ein LOH im Tumor bei Patienten mit einer CHEK2-Keimbahnmutation nicht stattfand (Sodha et al. 2002; Cybulski et al. 2004) oder zu einem niedrigen Prozentsatz von etwa 17 \% nachzuweisen war (Suspitsin et al. 2014). 


\subsubsection{NBN-Gen}

Das Tumorsupressorgen NBN (Nibrin; OMIM 602667) liegt auf Chromosom 8q21.3 und besteht aus 16 kodierenden Exons. Das NBN-Genprodukt Nibrin ist als Teil des hMre11/Rad50/NibrinMultikomplexes unter anderem am DNA-Reparaturmechanismus beteiligt (Carney et al. 1998; Kobayashi 2004). Biallelische Mutationen im NBN-Gen verursachen das Nijmegen-BreakageSyndrom (OMIM 251260), das u. a. durch Kleinwuchs, Mikrozephalie, faziale Dysmorphien, wiederkehrende respiratorische Infekte, ein erhöhtes Tumorrisiko und eine mentale Retardierung gekennzeichnet ist (Chrzanowska et al. 2012). Für Trägerinnen einer heterozygoten NBNKeimbahnmutation besteht ein ca. 2,4-fach erhöhtes Mammakarzinomrisiko gegenüber der Allgemeinbevölkerung. Für Mutationen im NBN-Gen existieren aktuell keine Daten für ein erhöhtes Risiko bezüglich der Entwicklung eines Ovarialkarzinoms (Gao et al. 2013) (s. Tab. 1.1). Verschiedene Studien demonstrierten, dass ein LOH im Tumor bei Patienten mit einer NBNKeimbahnmutation nicht charakteristisch war und zu einem niedrigen Prozentsatz von etwa $25 \%$ identifiziert wurde (Buslov et al. 2005; Suspitsin et al. 2014).

\subsubsection{RAD51C- und RAD51D-Gene}

Das RAD51C-Gen (RAD51, S. cerevisiae, homolog of, C; OMIM 602774), welches in Familien mit einem hereditären Mamma- und Ovarialkarzinom mutiert vorliegt, wurde im Jahr 2010 identifiziert (Meindl et al. 2010). Das RAD51C-Gen liegt auf Chromosom 17q22 und besteht aus 9 kodierenden Exons. Als Tumorsuppressorgen spielt es eine zentrale Rolle bei der DNADoppelstrangreparatur (Chun et al. 2013). Pathogene Mutationen in diesem Gen wurden in 1,0 \% - 1,5 \% der Risikofamilien mit einem Mamma- und Ovarialkarzinom nachgewiesen (s. Tab. 1.1). Einige weitere Arbeiten konnten dies für andere Populationen weltweit belegen, teilweise mit höheren Mutationsfrequenzen, aber auch mit einer Verschiebung des Tumorspektrums in Richtung eines häufigen Auftretens von Ovarialkarzinomen (Osorio et al. 2012; Coulet et al. 2013). Biallelische Mutationen im RAD51C-Gen führen zur Fanconi-Anämie Typ O (OMIM 613390). Bei dieser autosomal-rezessiv vererbten Erkrankung können bei den Patienten Extremitätenfehlbildungen, ein Kleinwuchs, kongenitale Herzfehler, gastrointestinale Fehlbildungen und Nierenanomalien auftreten (Vaz et al. 2010).

Das Tumorsupressorgen RAD51D (RAD51, S. cerevisiae, homolog of, D; OMIM 602954) wurde kurze Zeit später als ein weiteres Risikogen identifiziert (Loveday et al. 2011). Das RAD51D-Gen liegt auf Chromosom 17q12 und besteht aus 10 kodierenden Exons. RAD51D ist eines von fünf RAD51-Paralogen mit einer DNA-Rekombinasefunktion und spielt eine wichtige Rolle in der homologen Rekombination bei Eukaryonten (Masson et al. 2001). Keimbahnmutationen im RAD51D-Gen weisen eine Frequenz von etwa $1 \%$ in den Risikofamilien mit einem Mamma- und Ovarialkarzinom auf.

In reinen Mammakarzinomfamilien lagen die Mutationsfrequenzen für die beiden o. g. Gene jedoch deutlich niedriger. Mutationen in den Genen RAD51C und RAD51D führen zu einem etwa 6-fach erhöhten Risiko für das Auftreten eines Ovarialkarzinoms (Meindl et al. 2010; Loveday et al. 2011). Eine Mutation in einem der beiden o. g. Gene ist mit einem lebenslangen Risiko für die Entwicklung eines Mammakarzinoms von $\geq 20$ \% assoziiert (Meindl et al. 2015) (s. Tab. 1.1). 
Tabelle 1.1: Genetische Risikofaktoren für das hereditäre Mamma- und Ovarialkarzinom bei den definierten 10 Core-Genen

\begin{tabular}{|c|c|}
\hline \multicolumn{2}{|c|}{ Hochpenetrante Gene (Risikomodifikation etwa 5- bis 20-fach) } \\
\hline Gen (Mutationshäufigkeiten) & Lebenszeitrisiken für $\mathrm{MCa} / \mathrm{OvCa} / \mathrm{Ca}$ \\
\hline BRCA1 (ca. $17 \%^{\mathrm{a}}$ ) & MCa $(60,0 \%-85,0 \%)$, MCa bil $(30,0 \%-60,0 \%)$, OvCa $(45,0 \%)$ \\
\hline$B R C A 2\left(\right.$ ca. $\left.8 \%{ }^{a}\right)$ & MCa $(40,0 \%-85,0 \%$, MCa bil $(15,0 \%-40,0 \%)$, OvCa $(15,0 \%-20,0 \%)$ \\
\hline PALB2 (ca. $1 \%$ ) & MCa $(35,0 \%-65,0 \%)$ \\
\hline TP53 (са. $1 \%)$ & Ca (w: > 90,0 \%; m: >70,0 \%) \\
\hline \multicolumn{2}{|c|}{ Moderat penetrante Gene (Risikomodifikation 1,5- bis 5-fach) } \\
\hline Gen (Mutationshäufigkeiten) & Lebenszeitrisiken für $\mathrm{MCa} / \mathrm{OvCa}$ \\
\hline $\mathrm{CDH} 1$ (са. $<1 \%)$ & $\begin{array}{c}\text { MCa: lebenslang 40,0 \%, in reinen MCa-Familien unbekannt, } \\
\text { Altersabhängigkeit in Familien mit MagenCa }\end{array}$ \\
\hline CHEK2 $\left(2,0 \%-4,0 \%{ }^{a}\right)$ & MCa $(25,0 \%-45,0 \%)$ \\
\hline $\operatorname{ATM}($ ca. $1 \%)$ & MCa $(25,0 \%-45,0 \%)$ \\
\hline$N B N(<1,0 \%)$ & MCa $(25,0 \%-50,0 \%)$ \\
\hline $\operatorname{RAD51C}\left(1,0 \%-1,5 \%{ }^{\mathrm{a}, \mathrm{b}}\right)$ & MCa $(15,0 \%-25,0 \%)$, OvCa $(10,0 \%-20,0 \%)$ \\
\hline RAD51D (ca. $1 \%{ }^{\mathrm{a}, \mathrm{b}}$ ) & MCa $(15,0 \%-20,0 \%)$, OvCa $(10,0 \%-20,0 \%)$ \\
\hline
\end{tabular}

$\mathrm{Ca}=$ Karzinom (u. a. Weichteilsarkom, Osteosarkom, Astrozytom, Plexuskarzinom, Mammakarzinom, adrenokortikales Karzinom, Leukämie, Lymphom, Bronchialkarzinom, Magenkarzinom, kolorektales Karzinom, Ovarialkarzinom (Tinat et al. 2009; McCuaig et al. 2012); MCa = Mammakarzinom; MCa bil = bilaterales Mammakarzinom; MagenCa = Magenkarzinom; OvCa = Ovarialkarzinom, $\mathrm{w}=$ weiblich; $\mathrm{m}=$ männlich. aMutationsfrequenzen innerhalb des Deutschen Konsortiums Familiärer Brust- und Eierstockkrebs. ${ }^{b}$ Mutationsfrequenzen beziehen sich auf Familien mit einem Mamma- und Ovarialkarzinom; modifiziert nach Meindl et al. 2015.

\subsection{Diagnosestellung, histologische Typen, Rezeptorstatus und medikamentöse Therapie der Mammakarzinome}

Die gängigen klinischen Untersuchungen zur Diagnosestellung eines Mammakarzinoms beinhalten Palpationen der Mammae, die Mammasonographie, die Mammographie und die Magnetresonanztomographie-(MRT) sowie Biopsien der Mammae (McDonald et al. 2016).

Die pathologische Stadieneinteilung des Mamma- und Ovarialkarzinoms wird nach der TNMKlassifikation vorgenommen (Kiechle 2010). Diese definiert die Größe des Karzinoms (T), die Metastasierung in regionale Lymphknoten (N) und die Metastasierung in Fernorgane (M). Sie wird von der UICC (Union internationale contre le cancer; Internationale Vereinigung gegen Krebs 2002) bestimmt. Die Graduierung des Tumors ist die Bewertung des histologischen Übereinstimmungsgrades eines Tumors mit seinem Ursprungsgewebe und seiner Zellaplasie (Riede et al. 2009). Es sind vier Graduierungsgrade bekannt (Riede et al. 2009) (s. Tab. 1.2).

Tabelle 1.2. Graduierung des Tumors

\begin{tabular}{|c|c|}
\hline Grad der Differenzierung des Tumors & Beschreibung \\
\hline G1 & $\begin{array}{r}\text { gut differenzierter Tumor bzw. hohe Übereinstimmung mit } \\
\text { Ursprungsgewebe }\end{array}$ \\
\hline G2 & mäßig differenziertes malignes Gewebe \\
\hline G3 & schlecht/niedrig differenziertes malignes Gewebe \\
\hline G4 & $\begin{array}{c}\text { keine Differenzierung bzw. sehr hohe Malignität, } \\
\text { Entdifferenzierung (anaplastischer Tumor) }\end{array}$ \\
\hline
\end{tabular}

G = Grading (Differenzierungsgrad des Tumorgewebes). Modifiziert nach Riede et al. 2009. 
Das Mammakarzinom stellt histologisch gesehen eine sehr heterogene Erkrankung dar. Die zwei wichtigsten histologischen Subtypen sind das invasiv duktale Mammakarzinom (ca. 70 \% - 80 \%) und das invasiv lobuläre Mammakarzinom (ca. $10 \%$ ). Seltenere Subtypen sind u. a. das medulläre (ca. $5 \%$ ), das tubuläre (ca. $2 \%$ ), das muzinöse (ca. $2 \%$ ) und das papilläre (ca. $1 \%$ ) Mammakarzinom (Netters 2006; Kiechle 2010).

Um zu ermitteln, ob ein Mammakarzinom hormonabhängig proliferiert, wird postoperativ eine immunhistochemische Bestimmung der Expression des Östrogenrezeptors $\alpha$ (ER $\alpha)$ und des Progesteron-Rezeptors (PR) ermittelt. Eine positive Expression wird als $>10 \%$ der Tumorzellen mit nukleärer Expression des entsprechenden Hormonrezeptors definiert (Badowska-Kozakiewicz et al. 2015). In ca. 55 \% - $60 \%$ der Mammakarzinome wird eine Expression der beiden genannten Hormonrezeptoren detektiert (Nadji et al. 2005; Francis et al. 2009).

Aus der Literatur ist bekannt, dass Östrogene (v. a. Östradiol) zur Entwicklung des Mammakarzinoms beitragen können und Antiöstrogene dagegen protektiv wirken (Clemons et al. 2001; Yue et al. 2010). Eine erhöhte lebenslange Exposition von Östrogenen, bedingt $u$. a. durch eine frühe Menarche, eine späte Menopause, eine langzeitige menopausale Therapie mit Östrogenen und Adipositas, sind mit einer erhöhten Inzidenz von Mammakarzinomen assoziiert (Kaaks et al. 2005; Chen et al. 2006). Die exakten molekularen Mechanismen des ÖstradiolEinflusses auf die Entwicklung des Mammakarzinoms sind bisher nicht ausreichend verstanden (Yue et al. 2010). Östradiol zählt zu den Steroidhormonen, ist lipophil und bindet seinen Rezeptor im Zytosol der Zelle. Dieser Komplex wird in den Nukleus transportiert. Es existieren zwei Rezeptoren für Östradiol, der Östrogenrezeptor $\alpha$ (ER $\alpha)$ und der Östrogenrezeptor $\beta$ (ERß). Beide Rezeptoren stellen ligandenaktivierte nukleäre Transkriptionsfaktoren dar, weisen homologe DNA-Bindungsstellen und steroide Bindungsdomänen auf. Das humane ESR2-Gen (OMIM 601663) ist auf Chromosom 14q23.2-q23.3 lokalisiert und kodiert für den ERß mit einer Größe von 59kDa. Das humane ESR1-Gen (OMIM 133430) kodiert für den ER $\alpha$ und ist auf Chromosom 6q25.1-q25.2 lokalisiert (Kumar et al. 1987; Khan et al. 1994). Die weitverbreiteste Theorie zur Funktion bezieht sich auf die Einwirkung des Östradiols auf den ER $\alpha$, welcher die Zellproliferation stimuliert und so die Entstehung von Mutationen während der DNA-Replikation initiiert. Weiterhin beeinflusst Östradiol das Wachstum der Zellen mit vorhandenen Mutationen, welche sich bis zur Tumorentwicklung weiter akkumulieren (Preston-Martin et al. 1990; Preston-Martin et al. 1993). Es wurde ebenso gezeigt, dass die Metaboliten des Östrogens genotoxische Effekte aufweisen und somit zur Entwicklung eines Mammakarzinoms beitragen (Cavalieri et al. 2006; Yager und Davidson 2006).

Der Progesteron-Rezeptor (PR) vermitelt die Aktion des ovariellen Progesterons, welches zusammen mit Östradiol die Sekretion der Gonadotropine reguliert, das Endometrium für die Implantation vorbereitet, die Schwangerschaft bewahrt und die Differenzierung des Mammagewebes fördert (Kim et al. 2013). Progesteron zählt ebenfalls zu den Steroidhormonen und besitzt zwei Rezeptoren, nämlich den Progesteron-Rezeptor A (PRA) und den ProgesteronRezeptor B (PRB). Beide Rezeptoren werden vom humanen PGR-Gen (OMIM 607311) durch einen alternativen Promotor reguliert und transkribiert. Der PRB besitzt eine Größe von 116 kDa und der PRA eine Größe von 94 kDa. Der PRB weist im Gegensatz zum PRA am N-Terminus einen Zusatz von 164 Aminosäuren auf (Clarke und Southerland 1990). Die Isoform B des PR ist für die normale Entwicklung und Funktion der Mammadrüse erforderlich (Mulac-Jericevic et al. 2000; Mulac-Jericevic et al. 2003). Einige Studien ergaben Hinweise darauf, dass Progesteron und der PR die Entwicklung und das Wachstum des Mammakarzinoms fördern können (Poole et al. 2006; Chlebowski et al. 2009). Weiterhin wurde gezeigt, dass das Risiko bei postmenopausalen Frauen, ein Mammakarzinom zu entwickeln, durch die gleichzeitige Einnahme von Östrogen und Progestine höher liegt im Vergleich zu Frauen, die nur Östrogenpräparate einnehmen (Beral et al. 2003). Bei gesunden erwachsenen Frauen konnten in nur etwa $7 \%-10 \%$ der epithelialen Zellen 
der Mammae eine Expression des PR nachgewiesen werden (Woolcott et al. 2008; Oh et al. 2016). Im Gegensatz dazu konnte in etwa $50 \%-70 \%$ der Mammakarzinomzellen eine Expression des PR nachgewiesen werden (Badowska-Kozakiewicz et al. 2015, Ono et al. 2017, Truin et al. 2017). Es wird vermutet, dass die Proliferation durch parakrine Mechanismen reguliert ist (Silberstein et al. 1996; Ismail et al. 2002; Shyamala et al. 2002). Die neoplastisch transformierten epithelialen Zellen der Mammadrüse haben einen höheren Anteil von exprimierten ER $\alpha / P R$ bzw. auch die Zellen des Normalgewebes der Mammae und die hyperplastischen Zellen bei Patienten mit einem Mammakarzinom haben einen höheren Anteil der exprimierten PR. Dieses ist mit einer autokrinen Regulation der neoplastischen Transformation der Zellen verbunden (Anderson 2002). Weiterhin wurde gezeigt, dass die nicht-genomische Aktion des PR zu der Zellproliferation beitragen kann (Kim et al. 2013). Es wurde gezeigt, dass der PR direkt den MAPK-Signalweg sowie die Src/p21Ras/Erk-, PI3K/Akt- und JAK/STAT-Signalwege aktivieren kann und somit zu den proliferativen Effekten in der Tumorentstehung des Mammakarzinoms beitragen kann (Boonyaratanakornkit et al. 2001; Boonyaratanakornkit et al. 2007; Carnevale et al. 2007; Obr und Edwards 2012).

Patienten mit exprimierten ER $\alpha$ und PR haben die höchste Wahrscheinlichkeit einer guten Ansprache auf eine endokrine Therapie und eine bessere Prognose als Patienten mit Mammakarzinomen ohne exprimierten ER $\alpha$ und PR (Anderson 2002; Badowska-Kozakiewicz et al. 2015). Die Expression des ER $\alpha$ wird daher als Therapieansatz für Mammakarzinome verwendet. Nach der Bindung eines Liganden (z. B. Östradiol) auf den nukleär positionierten ER kommt es zu einer Dimerisierung des ER und einer Interaktion mit einem Östrogen-Response-Element der spezifischen DNA-Sequenz, was zu einer Gentranskription führt (Gruber et al. 2009). Es ist bekannt, dass ER $\alpha$ immer als ein Aktivator wirkt. Der ER $\beta$ formiert einen Heterodimer nach der Bindung an ER $\alpha$ und kann die Aktion des ER $\alpha$ inhibieren (Lindberg et al. 2003). Die selektiven Östrogenrezeptormodulatoren übermitteln ihre Wirkung über den ER und können sowohl als Agonisten als auch als Antagonisten wirken (Riggs und Hartmann 2003). Tamoxifen wirkt z. B. zytostatisch und verlangsamt die Proliferation der Mammakarzinomzellen durch die inhibierte Progression aus der G1-Phase im Zellzyklus. Auf Mammazellen wirkt Tamoxifen als ÖstrogenAntagonist (Osborne 2009). Auf der anderen Seite werden zur Therapie des Mammakarzinoms Aromatase-Inhibitoren verwendet. Diese hemmen das Enzym Aromatase, welches die Konversion von Androgenen in Östrogene reguliert (Asten et al. 2014). Eine Metaanalyse zeigte, dass der Einsatz von Aromatase-Inhibitoren bei Patientinnen mit Mammakarzinomen die Wahrscheinlichkeit eines Rezidivs um ca. $30 \%$ mehr verringerte als vergleichsweise Tamoxifen in der Phase der Einnahme. Jedoch weisen Aromatase-Inhibitoren keine verbesserte Langzeitwirkung bzgl. des Auftretens von Rezidiven auf (Early Breast Cancer Trialists 2015).

Zusätzlich wird in der pathologischen Routineanalyse der Mammakarzinome die Überexpression des ERBB2-Rezeptors sowie in einigen grenzwertigen Fällen die genomische Amplifikation des ERBB2-Gens ermittelt. Der ERBB2-Rezeptor liegt in etwa $15 \%-25 \%$ der Mammakarzinome überexprimiert vor (Francis et al. 2009; Bilous et al. 2012). Das humane ERBB2-Gen (OMIM 164870) ist auf Chromosom 17q12 lokalisiert und kodiert für den ERBB2-Rezeptor, dieser wird der Klasse der Rezeptor-Tyrosinkinasen (RTK) zugeordnet und gehört zur Familie des Epidermal Growth Factor Receptors (EGFR). Die Überexpression des ERBB2-Rezeptors oder ein mutierter ERBB2-Rezeptor können zu einer Dimerisierung der ERBB2-Rezeptoren führen. Der ERBB2Signalweg fördert die zelluläre Proliferation durch Aktivierung des RAS-MAPK-Signalwegs und inhibiert die Apoptose durch den Phosphatidylinositol 3'-Kinase-AKT-(mTOR)-Signalweg (Sliwkowski und Yarden 2001). Eine Überexpression des ERBB2-Rezeptors führt zur spontanen Dimerisierung des Rezeptors ohne Liganden und somit zu einer konstitutiven Aktivierung (Hynes et al. 1994). Eine Überexpression des ERBB2-Rezeptors ist mit einem aggressiveren klinischen Verlauf des Mammakarzinoms und mit einer schlechteren Prognose von Mammakarzinom- 
Patienten assoziiert (Wolf et al. 2007). Der therapeutische Ansatz bei Patienten mit nachgewiesener Überexpression des ERBB2-Rezeptors beruht daher auf dem Einsatz humanisierter monoklonaler Antikörper (u. a. Trastuzumab, Pertuzumab), die die extrazelluläre Domäne des ERBB2-Rezeptors binden, eine Dimerisierung des Rezeptors blockieren und somit die intrazelluläre Aktivierung der Tyrosinkinase verhindern (Hudis 2007; Baselga und Swain 2009). Weiterhin werden zur Therapie Tyrosinkinase-Inhibitoren eingesetzt, die die intrazelluläre Domäne der ERBB1- und ERBB2-Rezeptoren blockieren (Burris 2004; Nelson und Dolder 2006).

Hereditäre Mammakarzinome mit einer nachgewiesenen BRCA1-Keimbahnmutation unterscheiden sich von den sporadischen Mammakarzinomen in morphologischer und immunphänotypischer Hinsicht sowie in ihren molekularen Charakteristika. Beim Vorliegen einer Keimbahnmutation im BRCA1-Gen finden sich häufiger histopathologische Eigenschaften eines medullären Mammakarzinoms (11\%) als bei Keimbahnmutationen im BRCA2-Gen (2\%) oder in sporadischen Mammakarzinomen (1\%) (Lakhani et al. 2000). Verschiedene Studien zeigten, dass Mammakarzinome bei Trägerinnen einer pathogenen Keimbahnmutation im BRCA1-Gen in > $70 \%$ der Fälle eine G3-Morphologie des Karzinoms aufweisen. Im Vergleich dazu wurde in nur ca. 35 \% der Fälle mit einem sporadischen Mammakarzinom eine G3-Morphologie beobachtet (Stratton et al. 1997; Lakhani et al. 2000; Quenneville et al. 2002). Es konnte demonstriert werden, dass Mamakarzinome bei Vorliegen einer Keimbahnmutation im BRCA2-Gen in ca. $60 \%-90 \%$ der Fälle eine Expression des ER $\alpha$ zeigten und in etwa $40 \%$ - $80 \%$ der Fälle eine Expression des PR aufwiesen. Dahingegen zeigten Mamakarzinome mit nachgewiesener BRCA1-Keimbahnmutation nur in etwa $35 \%$ der Fälle eine Expression des ER $\alpha$ und in etwa $20 \%$ eine Expression des PR (Lakhani et al. 2002; Palacios et al. 2003). Zusätzlich konnte bei hereditären Mammakarzinomen mit identifizierten Mutationen in den Genen BRCA1 und BRCA2 eine verminderte Frequenz der ERBB2-Überexpression (13\%) im Vergleich zu den sporadischen Mammakarzinomen (18\%) beobachtet werden (Honrado et al. 2005).

\subsection{Vererbungsmodus und Kriterien für eine molekulargenetische Untersuchung bei Verdacht auf ein hereditäres Mamma- und Ovarialkarzinom-Syndrom}

Das Tumorsyndrom des hereditären Mamma- und Ovarialkarzinoms (Hereditary Breast and Ovarial Cancer; $H B O C$ ) wird autosomal-dominant mit einer reduzierten Penetranz und variabler Expressivität vererbt (Aretz 2014). Eine reduzierte Penetranz bedeutet, dass sich trotz des vorhandenen Genotyps die Merkmale des zugehörigen Phänotyps nicht immer manifestieren werden. Auch die Expressivität, d. h. der Schweregrad der klinischen Ausprägung (Allen 1952; Shawky 2014), zeigt sich sowohl intra- als auch interfamiliär variabel.

Beim hereditären Mamma- und Ovarialkarzinom-Syndrom mit einer Mutation in einem der 10 Core-Gene (s. Abschnitte 1.3.1 und 1.3.2) besteht zusätzlich zu den deutlich erhöhten Erkrankungsrisiken für Mamma- und Ovarialkarzinome noch (abhängig vom mutierten Gen) ein erhöhtes Risiko für weitere Tumorerkrankungen, wie z. B. für ein Tubenkarzinom, ein primäres Peritonealkarzinom, ein Pankreaskarzinom sowie ein Prostatakarzinom (Pharoah et al. 2001; Kaurah et al. 2007; Tischkowitz et al. 2009; NCBI Bookshelf, BRCA1- and BRCA2-Associated Hereditary Breast and Ovarian Cancer; letzte Aktualisierung am 15. Dezember 2016;).

Zur Einschätzung einer genetischen Disposition für die interdisziplinäre Beratung und Mutationssuche bei Verdacht auf ein hereditäres Mamma- und Ovarialkarzinom wurden deshalb spezielle diagnostische Kriterien entwickelt (Schumtzler et al. 2008). Das Deutsche Konsortium Familiärer Brust- und Eierstockkrebs definierte bestimmte Familienkonstellationen bzw. übernahm einige Kriterien aus den S3-Leitlinien bei Verdacht auf ein hereditäres Mamma- und Ovarialkarzinom für Fälle mit einer Mutationswahrscheinlichkeit von $\geq 10$ \% (s. Tab. 1.3). 
Tabelle 1.3: Kriterien zur molekulargenetischen Untersuchung bei Verdacht auf ein hereditäres Mammaund Ovarialkarzinom (Deutsches Konsortium Familiärer Brust- und Eierstockkrebs)

\begin{tabular}{|c|}
\hline \\
\hline $\begin{array}{l}\text { Kriterium A: Mindestens drei Frauen aus der gleichen Linie einer Familie sind an einem Mammakarzinom } \\
\text { erkrankt (unabhängig vom Alter bei der Erstdiagnose). }{ }^{1}\end{array}$ \\
\hline $\begin{array}{l}\text { Kriterium G: Mindestens zwei Frauen aus der gleichen Linie einer Familie sind an einem } \\
\text { Mammakarzinom erkrankt, davon eine vor dem 51. Lebensjahr. }{ }^{1}\end{array}$ \\
\hline $\begin{array}{l}\text { Kriterium J: Mindestens eine Frau ist an einem Mammakarzinom und mindestens eine Frau an einem } \\
\text { Ovarialkarzinom erkrankt. }{ }^{1}\end{array}$ \\
\hline Kriterium N: Mindestens eine Frau ist an einem Mamma- und einem Ovarialkarzinom erkrankt. ${ }^{1}$ \\
\hline Kriterium Q: Mindestens eine Frau ist vor dem 36. Lebensjahr an einem Mammakarzinom erkrankt. ${ }^{1}$ \\
\hline $\begin{array}{l}\text { Kriterium R: Mindestens eine Frau ist an einem bilateralen Mammakarzinom erkrankt, wobei das erste } \\
\text { Mammakarzinom vor dem 51. Lebensjahr aufgetreten ist. }{ }^{1}\end{array}$ \\
\hline $\begin{array}{l}\text { Kriterium U: Mindestens ein Mann ist an einem Mammakarzinom und mindestens eine Frau ist an einem } \\
\text { Mamma- oder Ovarialkarzinom erkrankt. }{ }^{1}\end{array}$ \\
\hline $\begin{array}{l}\text { Kriterium Z: Mindestens zwei Frauen aus der gleichen Linie einer Familie sind an einem Ovarialkarzinom } \\
\text { erkrankt. }{ }^{1}\end{array}$ \\
\hline $\begin{array}{l}\text { Kriterium Y: Keine Indexpatientin vorhanden, das Heterozygoten-Risiko für die Anlageträgerschaft einer } \\
\text { autosomal-dominant vererbten Mutation berechnet mittels des Risikokalkulationsprogramms Cyrillic } \\
2.13 \text { beträgt } \geq 20 \%{ }^{2}\end{array}$ \\
\hline $\begin{array}{l}\text { Mindestens eine Frau ist an einem triple-negativen Mammakarzinom bis zum vollendeten } 49 . \text { Lebensjahr } \\
\text { erkrankt (am 01.10.2016 in Kraft getreten und vom Konsortium validiert). }{ }^{3}\end{array}$ \\
\hline $\begin{array}{l}\text { Mindestens eine Frau ist an einem Ovarialkarzinom bis zum vollendeten } 79 . \text { Lebensjahr } \\
01.10 .2016 \text { in Kraft getreten und vom Konsortium validiert). }{ }^{3}\end{array}$ \\
\hline
\end{tabular}

${ }^{1}$ Schmutzler et al. 2008 und modifiziert nach http://www.konsortium-familiaerer-brustkrebs.de, Zugriff im November 2017. In dieser Dissertation wurden die Kriterien zur besseren Übersicht mit Buchstaben gekennzeichnet: A, G, J, N, Q, R, U, Y und Z. ${ }^{2}$ Dieser Punkt ist nicht direkt als eines der vom Deutschen Konsortium Familiärer Brust- und Eierstockkrebs definierten Kriterien bezeichnet, sondern wird als ein Zusatzpunkt gewertet. Dieser Punkt kommt zur Anwendung, wenn kein Indexpatient zur Verfügung steht. Zur besseren Übersicht wird in dieser Dissertation dieser Zusatzpunkt als ein Kriterium bezeichnet. ${ }^{3}$ Diese Einschlusskriterien gelten nur in den spezialisierten Zentren und nur für Patientinnen, die den VDEKKrankenkassen angehören. Die Betreuung der Familien erfolgt im Rahmen der „besonderen Versorgung“ nach SGBV, §140a.

Bei Verdacht auf eine hereditäre Form des Mamma- und Ovarialkarzinoms muss mindestens eines der oben genannten Kriterien erfüllt sein. In diesem Fall kann eine molekulargenetische Untersuchung der vom Deutschen Konsortium Familiärer Brust- und Eierstock definierten 10 Core-Gene (s. Abschnitte 1.3.1 und 1.3.2) angeboten werden.

Eine weitere Möglichkeit zur Risikoerhebung einer Anlageträgerschaft einer heterozygoten Mutation in einem der 10 Core-Gene bzw. zur Ermittlung des Lebenszeitrisikos für das Auftreten eines Mammakarzinoms besteht in der detaillierten Stammbaumanalyse über mindestens drei Generationen unter Berücksichtigung der mütterlichen und der väterlichen Linie. Die Richtlinien für diese rechnerische Erhebung wurden vom Deutschen Konsortium Familiärer Brust- und Eierstockkrebs definiert und die Risiken müssen mit Hilfe des Risikokalkulationsprogramms Cyrillic 2.13 ermittelt werden.

\subsubsection{Risikoberechung}

Der Risikoberechnung mittels des Programms Cyrillic 2.13 liegt ein genetisches Ein-Gen-Modell für die Erkrankung zugrunde. Hierfür wird für die Krankheitsentstehung durch ein monogenes Mendelsches-Modell (autosomal-dominant vererbte Erkrankung) eine altersabhängige Penetranz 
angenommen (Fischer und Bickelböller 2007). Bei den genetischen Modellen werden (im Gegensatz zu den empirischen Modellen) nicht-genetische Risikofaktoren meist nicht berücksichtigt. Die Berechnungen erfolgen im Hintergrund mit MLINK vom LINKAGE-Paket (Grimm 2014). Das Risikokalkulationsprogramm Cyrillic 2.13 berücksichtigt dabei ein ein- und ein beidseitiges Mammakarzinom, ein männliches Mammakarzinom und mehr als zwei an einem Mamma - und/oder einem Ovarialkarzinom erkrankte Personen.

Den Ratsuchenden ohne verfügbaren Indexpatienten in der Familie und einer Mutationswahrscheinlichkeit (Heterozygoten-Risiko) von $\geq 20 \%$ und/oder einem Lebenszeitrisiko von $\geq 30 \%$ kann eine molekulargenetische Diagnostik der 10 Core-Gene ermöglicht werden. Den Patienten ohne nachgewiesene wahrscheinlich pathogene oder pathogene Mutation in einem der 10 Core-Gene und einem Lebensalter < 50 Jahre mit einem postanalytisch berechneten Lebenszeitrisiko von $\geq 30 \%$ und/oder einem Heterozygoten-Risiko von $\geq 20 \%$ kann ein intensiviertes Früherkennungs- und Nachsorgeprogramm (IFNP) angeboten werden (Fischer und Bickeböller 2007).

\subsection{Deutsches Konsortium Familiärer Brust- und Eierstockkrebs}

Das Deutsche Konsortium Familiärer Brust- und Eierstockkrebs ("German Consortium for Hereditary Breast and $\underline{\text { Ovarian }}$ Cancer", GC-HBOC) ist ein Zusammenschluss von 17 universitären Zentren (s. Abb. 1.1). Das Institut für Humangenetik der Universitätsmedizin Göttingen (UMG) ist seit November 2011 Mitglied dieses Konsortiums. Das Ziel des Konsortiums ist, die bundesweite Versorgung der Familien mit Verdacht auf ein familiäres und hereditäres Mamma- und Ovarialkarzinom zu gewährleisten und die neuesten wissenschaftlichen Erkenntnisse in die Praxis umzusetzen. Das Konsortium wird seit dem Jahr 1996 durch die Deutsche Krebshilfe gefördert. In diesem Verbund arbeiten Humangenetiker, Gynäkologen, Onkologen, Pyschoonkologen, Radiologen, Pathologen und Naturwissenschaftler eng zusammen. In den Zentren des Konsortiums wird eine interdisziplinäre, intensive Kooperation mit den Kollegen aus Brustzentren, gynäkologischen Krebszentren sowie niedergelassenen Kolleginnen und Kollegen angestrebt. Es bestehen wissenschaftliche sowie klinische Kooperationen sowohl auf nationaler als auch auf internationaler Ebene (u. a. BRIDGES-Studie, Perspektive-Studie, Libre-Studie) (Internetseite des Konsortiums, Stand 24.11.2017). 


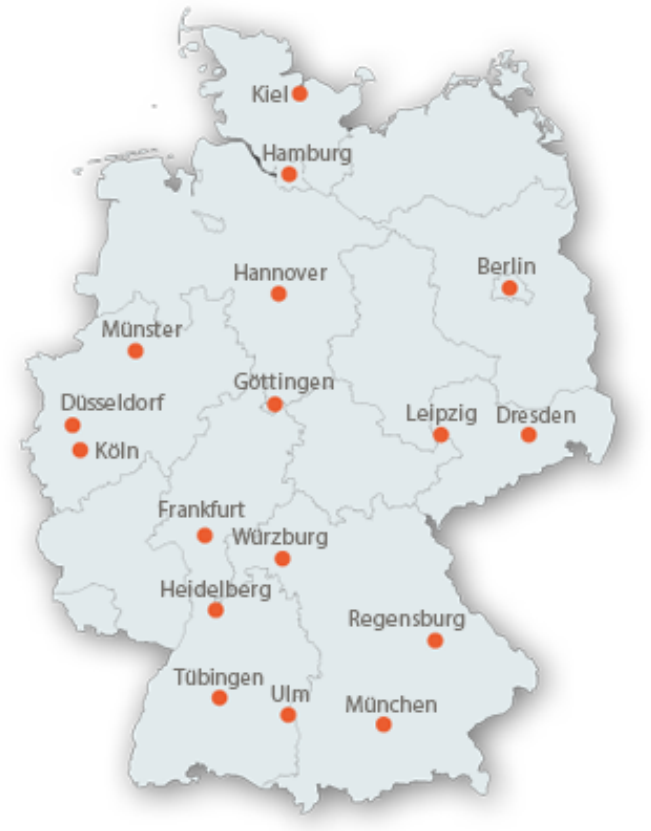

Abbildung 1.1: Mitglieder des Deutschen Konsortiums Familiärer Brust- und Eierstockkrebs (übernommen aus der offiziellen Seite des Deutschen Konsortiums Familiärer Brust- und Eierstockkrebs http://www.konsortium-familiaerer-brustkrebs.de). Alle 17 universitären Zentren des Deutschen Konsortiums Familiärenr Brust- und Eierstockkrebs sind mit roten Punkten auf der Karte gekennzeichnet.

Durch das Konsortium wurde weiterhin die zentrale Datenbank BRCA2006 in Leipzig etabliert. Diese Datenbank wird vom Institut für Medizinische Information, Statistik und Epidemiologie (IMISE) der Universität Leipzig betreut. In diese Datenbank werden seit dem Jahr 2006 alle Familien eingegeben, die in den Zentren des Konsortiums beraten wurden. Es werden klinische, radiologische, pathologische und genetische Informationen zum Mamma- und Ovarialkarzinom des Indexpatienten sowie in der Familie erhoben. Es werden ebenso alle identifizierten Varianten unklarer Signifikanz (VUS) sowie wahrscheinlich pathogene und pathogene Mutationen und einige Polymorphismen eingetragen. Diese Datenbank ermöglicht daher eine ausführliche anonymisierte Übersicht der Patienten mit Verdacht auf ein hereditäres Mamma- und Ovarialkarzinom. Weiterhin können diese Daten statistisch bearbeitet und ausgewertet werden.

Das Deutsche Konsortium Familiärer Brust- und Eierstockkrebs etablierte ebenfalls eine sogenannte TaskForce. Die TaskForce stellt ein Team aus Naturwissenschaftlern, Humangenetikern und Gynäkologen innerhalb des Konsortiums dar, welches sich mit der Neubewertung bzw. Reklassifizierung der in die Datenbank eingetragenen Sequenzvarianten beschäftigt. In diesem Zusammenhang wurde ein Recall-System eingeführt. Dieses Recall-System informiert die Mitglieder des Konsortiums über die Reklassifizierung der in die Datenbank eingetragenen Sequenzvarianten. Die jeweiligen Zentren des Konsortiums sind im Anschluss an diese Mitteilung verpflichtet, entsprechende Patienten über die Neuklassifizierung der Sequenzvarianten zu informieren und die Patienten über die daraus resultierenden Folgen aufzuklären.

Weiterhin wurde im Rahmen des Konsortiums eine Biobank aufgebaut. Die DNA-Proben werden im CMMC (Center for Molecular Medicine Cologne) gelagert. In der Biobank werden DNA-Proben von etwa 21.650 Patienten (Stand Oktober 2017) von allen Zentrumsmitgliedern gelagert und stehen den Mitgliedern des Konsortiums für verschiedene wissenschaftliche Projekte zur Verfügung.

Das Deutsche Konsortium Familiärer Brust- und Eierstockkrebs definierte bestimmte Familienkonstellationen bzw. Kriterien für eine molekulargenetische Untersuchung auf 
Veränderungen in den Risikogenen (s. Tab. 1.3) bei Verdacht auf ein hereditäres Mamma- und Ovarialkarzinom.

\subsection{Ablauf der genetischen Versorgung und Beratung der Patienten mit Verdacht auf ein hereditäres Mamma- und Ovarialkarzinom}

In der Mehrzahl der Fälle erfolgten die humangenetischen Beratungen bei Patienten mit Verdacht auf ein hereditäres Mamma- und Ovarialkarzinom in der Universitätsmedizin Göttingen (UMG) in der Interdisziplinären Brustkrebsrisikosprechstunde des Brustzentrums der Klinik für Gynäkologie und Geburtshilfe. Im Brustkrebszentrum sind mehrere Abteilungen der Universitätsmedizin Göttingen und des Evangelischen Krankenhauses Weende sowie der Selbsthilfegruppe Horizonte vereint und durch eine zentrale Koordinatorin organisiert (s. Tab. 1.4).

Tabelle 1.4: Abteilungen, Institutionen und Selbsthilfegruppe beteiligt im Brustkrebszentrum der UMG

\begin{tabular}{|l|}
\hline Abteilungen und Organisationen beteiligt im Brustkrebszentrum der UMG \\
\hline Abteilung Gynäkologie und Geburtshilfe \\
\hline Abteilung diagnostische Radiologie \\
\hline Abteilung für Pathologie \\
\hline Abteilung Hämatologie und Onkologie \\
\hline Abteilung Strahlentherapie und Radioonkologie \\
\hline Abteilung Plastische Chirurgie (Evangelisches Krankenhaus Weende) \\
\hline Abteilung Nuklearmedizin \\
\hline Institut für Humangenetik \\
\hline Tumorzentrum \\
\hline Selbsthilfegruppe Horizonte \\
\hline
\end{tabular}

UMG = Universitätsmedizin Göttingen.

Einige Patienten, die im Rahmen dieser Dissertation analysiert wurden, nahmen an der genetischen Sprechstunde des Medizinischen Versorgungszentrums (MVZ) im Institut für Humangenetik der UMG teil.

Patienten, die sich in der Interdisziplinären Brustkrebsrisikosprechstunde des Brustkrebszentrums der Klinik für Gynäkologie und Geburtshilfe zur genetischen Beratung angemeldet hatten, wurden zunächst telefonisch durch eine ausgewiesene study nurse über die Einschlusskriterien für eine hereditäre Form des Mamma- und Ovarialkarzinoms befragt. Wurde hierdurch eine Familienkonstellation mit Verdacht auf ein hereditäres Mamma- und Ovarialkarzinom ermittelt, erfolgte eine Einladung zum humangenetischen Beratungsgespräch. Bei der humangenetischen Beratung wurde u. a. ein Stammbaum des Patienten über mindestens drei Generationen erstellt. Wenn sich in der humangenetischen Beratung die Ermittlungen der study nurse bestätigten, wurde dem Indexpatienten nachfolgend eine molekulargenetische Diagnostik der 10 Core-Gene angeboten. Der Indexpatient stellt i. d. R. eine lebende erkrankte Person dar, die für eine molekulargenetische Diagnostik erreichbar/verfügbar ist. Alternativ konnte einer nicht-erkrankten ratsuchenden Person anhand der Familienanamnese eine molekulargenetische Diagnostik der 10 Core-Gene bei genügend hohem Heterozyogten- ( $\geq 20 \%$ ) bzw. Lebenszeitrisiko ( $\geq 30 \%$ ) angeboten werden. Diese Risiken wurden mit Hilfe des Risikokalkulationsprogramms Cyrillic 2.13 ermittelt. Diese Vorgehensweise wurde angewendet, wenn die erkrankten Familienmitglieder bereits verstorben waren bzw. einer molekulargenetischen Testung nicht zugestimmt hatten.

Bei vorliegender Einwilligung des Patienten in die molekulargenetische Untersuchung erfolgte anschließend eine Multi-Gen-Panel-Analyse mittles Next-Generation-Sequencing (NGS) der 10 Core-Gene und eine entsprechende Multiplex Ligation-dependent Probe Amplification-(MLPA)Analyse zur Detektion von Deletionen und Duplikationen innerhalb der angeforderten Gene. Nach 
Vorliegen des molekulargenetischen Ergebnisses wurde dieser Befund dem Patienten im Rahmen eines Zweitgesprächs erläutert. Mitgeteilt wurden in den diagnostisch angeforderten Genen die Sequenzvarianten, die nach den Standards des American College of Medical Genetics and Genomics (ACMG; Richards et al. 2015) in die ACMG-Klasse 3 (Variante unklarer Signifikanz), ACMG-Klasse 4 (wahrscheinlich pathogene Mutation) und ACMG-Klasse 5 (pathogene Mutation) eingestuft wurden. Es wurde im Zweitgespräch den Patienten die klinische Bedeutung des erhobenen Befundes erläutert. Weiterhin wurde dem Patienten eine Bestätigung des erhobenen Befundes bei Mutationen der ACMG-Klasse 4 und 5 als Qualitätskontrolle an einer zweiten Blutprobe mittels Sanger-Sequenzierung bzw. MLPA-Analyse angeboten. Für die Patienten mit einem Alter von < 50 Jahren ohne identifizierte wahrscheinlich pathogene bzw. pathogene Mutation stand eine Risikoberechnung mit Hilfe des Risikokalkulationsprogramms Cyrillic 2.13 zur Verfügung. Frauen mit einem rechnerischen Heterozygoten-Risiko von $\geq 20 \%$ oder einem Lebenszeitrisiko von $\geq 30 \%$ konnte trotz unauffälligem molekulargenetischem Befund ein intensiviertes Früherkennungs- und Nachsorgeprogramm (IFNP; s. Abschnitt 1.8) bis zum 50. Lebensjahr angeboten werden.

Für Frauen mit einer identifizierten Keimbahnmutation im BRCA1- oder BRCA2-Gen, die bisher nicht an einem Mamma- oder Ovarialkarzinom erkrankt waren, wurde eine Risikoberechnung mittels des Risikokalkulationsprogramms BOADICEA ( Breast and $\underline{\text { Ovarian }}$ Analysis of Disease

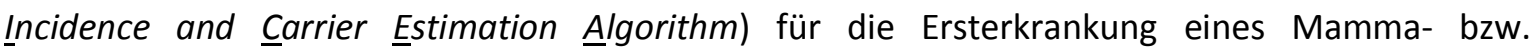
Ovarialkarzinoms durchgeführt. Für bereits an einem einseitigen Mammakarzinom erkrankte Frauen erfolgte diese Risikoermittlung für ein kontralaterales Mammakarzinom und ein Ovarialkarzinom (Deutsches Konsortium Familiärer Brust- und Eierstockkrebs 2017).

Für Patienten, die im Rahmen der Sprechstunde des MVZs im Institut für Humangenetik der UMG genetisch beraten worden waren, wurden die Einschlusskriterien des Deutschen Konsortiums Familiärer Brust- und Eierstockkrebs für eine hereditäre Form des Mamma- und Ovarialkarzinoms direkt bei der humangenetischen Beratung geprüft. Ein erhobener molekulargenetischer Befund wurde dem Patienten im Rahmen eines Zweitgesprächs erläutert, falls eine Sequenzvariante der ACMG-Klasse 3, 4 oder 5 identifiziert wurde. Bei einem unauffälligen molekulargenetischen Befund wurde dieser dem Patienten schriftlich in Form eines Beratungsbriefs mitgeteilt. Alle weiteren Schritte der genetischen Versorgung unterschieden sich nicht voneinander.

\subsection{Klinische Bedeutung des hereditären Mamma- und Ovarialkarzinoms}

Frauen mit einem hereditären Mamma- und Ovarialkarzinom haben ein erhöhtes Risiko vor allem an einem Mamma- und Ovarialkarzinom zu erkranken. Die wichtigste Aufgabe einer humangenetischen Beratung liegt darin die Patienten mit den erfüllten Kriterien bei Verdacht auf ein hereditäres Mamma- und Ovarialkarzinom zu identifizieren und deren Risiko für die Tumorerkrankungen zu bestimmen. Das Erkrankungsrisiko kann durch eine Familienanamnese mit der Erstellung eines Stammbaumes über mindestens drei Generationen und die erforderliche spezielle molekulargenetische Untersuchung der 10 Core-Gene konkretisiert werden. Aufgrund des hohen Erkrankungsrisikos benötigen Frauen mit einer hereditären Form des Mamma- und Ovarialkarzinoms umfangreiche Maßnahmen der Früherkennung bzw. der Krebsnachsorge. Diese Maßnahmen werden im Rahmen eines intensivierten Früherkennungs- und Nachsorgeprogramms (IFNP) angeboten. Für Männer wurde bisher kein IFNP definiert (s. Abb. 1.2; s. Tab. 1.5). 


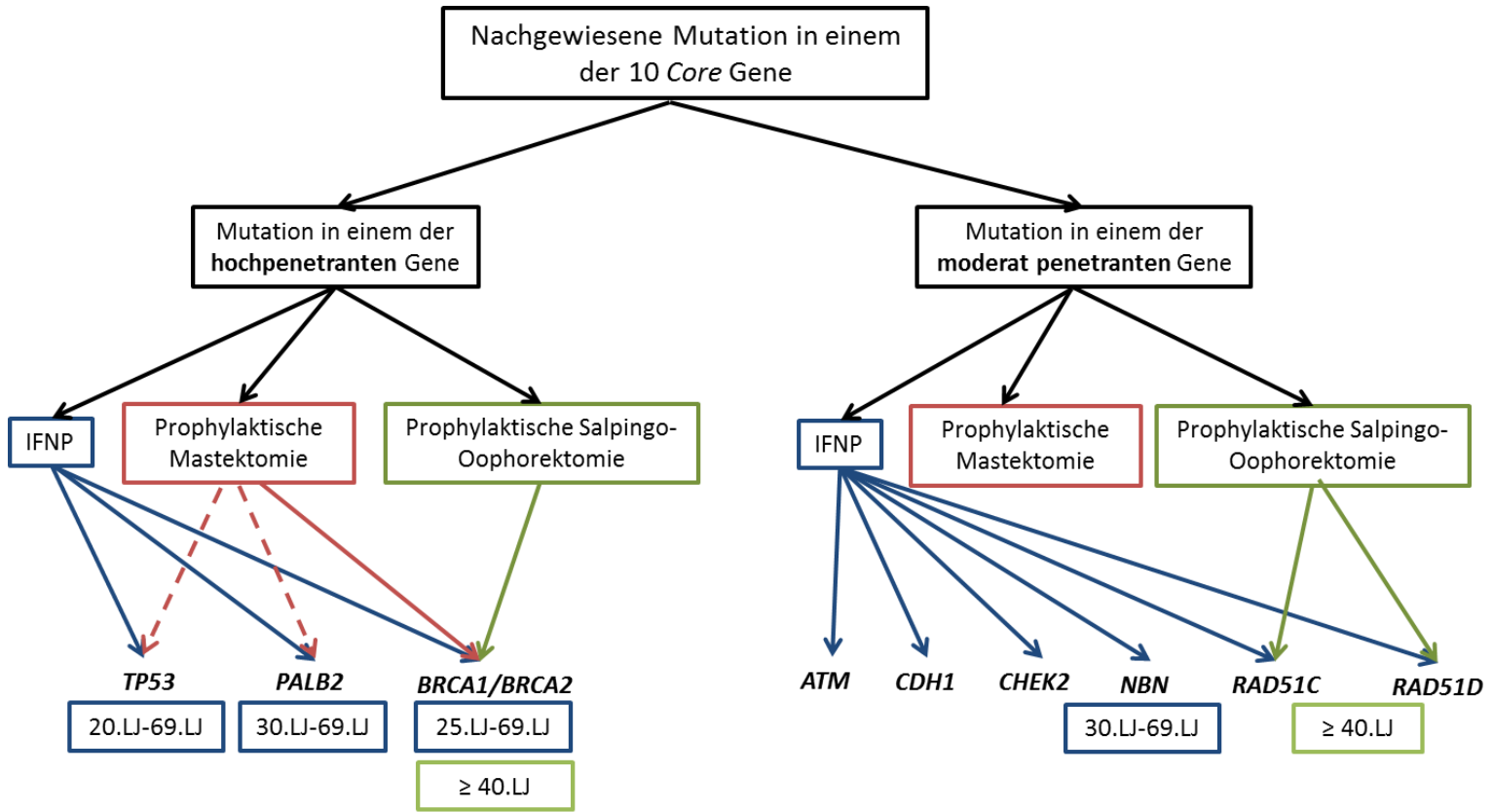

Abbildung 1.2: Vorgehensweise und klinische Empfehlungen bei Frauen mit nachgewiesener wahrscheinlich pathogener (ACMG-Klasse 4) und pathogener Mutation (ACMG-Klasse 5) in einem der 10 Core-Gene. Bei einer nachgewiesenen Mutation in einem der Core-Gene ist die Vorgehensweise abhängig davon, ob eine Mutation in einem hochpenetranten Gen oder einem moderat penetranten Gen vorliegt. Die blaue Farbmarkierung repräsentiert das INFP, die rote Farbmarkierung die prophylaktische Mastektomie und die grüne Farbmarkierung die prophylaktische Salpingo-Oophorektomie. Bei Nachweis von Mutationen im PALB2- und TP53-Gen ist eine prophylaktische Mastektomie ggf. eine Einzelfallentscheidung (durchtrennter roter Pfeil). Die in blau bzw. grün markierten Jahresangaben beziehen sich auf die Altersspanne, in der das IFNP bzw. die Salpingo-Oopherektomie durchgeführt werden können. Alle Maßnahmen können auch fünf Jahre vor dem frühesten Auftreten eines Mammakarzinoms in der Familie angeboten werden. IFNP = Intensiviertes Früherkennungs- und Nachsorgeprogramm.

Für gesunde Frauen mit einer nachgewiesenen pathogenen Keimbahnmutation in den Hochrisikogenen BRCA1, BRCA2, PALB2 und TP53 beginnt das IFNP entweder im Alter von 20 Jahren (TP53-Gen) oder im Alter von 25 Jahren (BRCA1- und BRCA2-Gen) oder im Alter von 30 Jahren (PALB2-Gen) oder 5 Jahre vor dem frühesten Auftreten eines Mammakarzinoms in der Familie. Bereits an einem Mammakarzinom erkrankte Frauen mit einer Mutation in einem Hochrisikogen können ab dem Erkrankungsalter in das Programm aufgenommen werden. Das IFNP umfasst ein jährliches MRT der Mammae, eine halbjährliche Ultraschalldiagnostik der Mammae und alle zwei Jahre eine Mammographiediagnostik (s. Abb. 1.2; s. Tab. 1.5, 1A).

Gesunden Frauen mit nachgewiesener Keimbahnmutation in einem der moderat-penetranten Risikogene ATM, CDH1, CHEK2, NBN, RAD51C und RAD51D wird das IFNP im Alter von 30 Jahren oder 5 Jahre vor dem frühesten Auftreten eines Mammakarzinoms in der Familie angeboten. An einem Mammakarzinom erkrankte Frauen mit Keimbahnmutationen in einem der moderatpenetranten Risikogene können ab dem Ersterkrankungsalter in das IFNP aufgenommen werden. Das IFNP umfasst auch hier ein jährliches MRT der Mammae, eine halbjährliche Ultraschalldiagnostik der Mammae und alle zwei Jahre eine Mammographiediagnostik (s. Abb. 1.2; s. Tab. 1.5, 1B).

Die Voraussetzung für eine indizierte prophylaktische Mastektomie ist eine nachgewiesene Keimbahnmutation im BRCA1- oder BRCA2-Gen. Bei dem Nachweis von Mutationen im PALB2und TP53-Gen ist eine prophylaktische Mastektomie ggf. als Einzelfallentscheidung der behandelnden Ärzte in Kooperation mit dem Deutschen Konsortium Familiärer Brust- und Eierstockkrebs möglich. Die prophylaktische beidseitige Mastektomie bei Frauen mit einer 
Mutation im BRCA1- oder BRCA2-Gen senkt das Risiko für ein Mammakarzinom um etwa $90 \%$ und in Kombination mit einer prophylaktischen Salpingo-Oophorektomie um etwa 95 \% (Rebbeck et al. 2004). Bei einer Mastektomie kommen entweder eine komplette Mastektomie mit der höchsten Risikoreduktion inklusive Entfernung des Mamillen-Areola-Komplexes oder eine vollständige Entfernung des Mammadrüsengewebes durch eine subkutane oder Mamillensparende Mastektomie in Frage. Das letzte Verfahren ermöglicht eine hohe Risikoreduktion (s. Tab. 1.5, 2A). Für Keimbahnmutationen in den moderat penetranten Risikogenen ATM, CDH1, CHEK2, NBN, RAD51C und RAD51D gibt es bisher generell keine Empfehlungen zur prophylaktischen Mastektomie (s. Abb. 1.2; s. Tab. 1.5, 2A).

Eine prophylaktische Salpingo-Oophorektomie wird bei einer nachgewiesenen Mutation in den Genen BRCA1, BRCA2, RAD51C und RAD51D bei einer Trägerin einer Keimbahnmutation nach abgeschlossenem Kinderwunsch im Alter von $\geq 40$ Jahren oder 5 Jahre vor dem frühesten Erkrankungsalter an einem Ovarialkarzinom in der Familie empfohlen (s. Tab. 1.5, 3A; s. Abb. 1.2). Die prophylaktische beidseitige Salpingo-Oophorektomie reduziert das Ovarialkarzinomrisiko um 97 \% (Kauff et al. 2002; Rebbeck et al. 2002). Zusätzlich wird durch diesen prophylaktischen Eingriff das Risiko für ein Mammakarzinom um 50 \% (Rebbeck et al. 2005) und das Risiko für ein kontralaterales Zweitkarzinom um 30 \% - 50 \% gesenkt (Heemskerk-Gerritsen et al. 2009). Bei dieser Operation wird eine vollständige Exstirpation der Ovarien und Tubae uterinae mit Probenentnahme des Peritoneums u. a. im Bereich der beidseitig parakolischen Rinnen und im Douglasraum sowie eine Peritonelalavage vorgenommen (Verfahrensanweisung des Deutschen Konsortiums. 2016).

Tabelle 1.5 Klinische Konsequenzen und Therapie bei Mutationen in den Core-Genen entsprechend den Vorschlägen des Deutschen Konsortiums Familiärer Brust- und Eierstockkrebs

\begin{tabular}{|l|}
\hline 1. Intensiviertes Früherkennungsprogramm (IFNP) \\
\hline A. Mutationen in den Hochrisikogenen BRCA1, BRCA2, TP53, PALB2 \\
\hline $\begin{array}{l}\text { Beginn: im Alter von } 20 \text { Jahren (TP53), } 25 \text { Jahren (BRCA1/2) und } 30 \text { Jahren (PALB2) oder } 5 \text { Jahre vor dem } \\
\text { frühesten Erkrankungsalter an einem MCa in der Familie. }\end{array}$ \\
\hline Jährliches MRT bis ACR1 bzw. max. 69. L \\
\hline Halbjährlicher Ultraschall bis 69. L \\
\hline Ab 40.-45. U evtl. alle zwei Jahre Mammographie \\
\hline B. Mutationen in den Risikogenen ATM, CDH1, CHEK2, NBN, RAD51C, RAD51D \\
\hline Jährliches MRT ab dem 30. L bis ACR1 bzw. max. 69. LJ \\
\hline Jährlicher Ultraschall bis zum 69. $\amalg$ \\
\hline Ab dem 40.-45. LJ evtl. alle zwei Jahre Mammographie \\
\hline 2. Prophylaktische Mastektomie \\
\hline A. Mutationen in den Risikogenen BRCA1, BRCA2, (PALB2), (TP53) \\
\hline Evtl. kontralaterale Mastektomie bei junger Ersterkrankung \\
\hline Evtl. beidseitige Mastektomie bei entsprechender Familienanamnese \\
\hline B. Mutationen in den Risikogenen ATM, CDH1, CHEK2, NBN, RAD51C, RAD51D \\
\hline Generell keine Empfehlung \\
\hline 3. Prophylaktische Salpingo-Oophorektomie \\
\hline A. Mutationen in den Hochrisikogenen BRCA1 und BRCA2 \\
\hline Salpingo-Oophorektomie ab dem/zwischen dem 40. $\sqcup$ und 45. LJ \\
\hline B. Mutationen in den Risikogenen RAD51C und RAD51D \\
\hline Zeitpunkt der Salpingo-Oophorektomie abhängig vom Erkrankungsalter in der Familie \\
\hline
\end{tabular}

Modifiziert aus: Meindl et al. (2015) und aus der Verfahrensanweisung des Deutschen Konsortiums Familiärer Brust- und Eierstockkrebs für die Konsortialzentren im Rahmen der integrativen Versorgung; 
Stand 28.07.2016; ACR1 = ACR-Dichteindex 1 (sehr gute mammographische Beurteilbarkeit); $L=$ Lebensjahr; $\mathrm{MCa}=$ Mammakarzinom; $\mathrm{OvCa}=$ Ovarialkarzinom .

Wird eine verantwortliche Keimbahnmutation bei der untersuchten Person in einem der 10 CoreGene identifiziert, kann nachfolgend eine Aussage über das Wiederholungsrisiko bei den Kindern und weiteren Familienmitgliedern getroffen werden. Den Verwandten kann im Rahmen einer humangenetischen Beratung eine prädiktive Diagnostik auf die familiär bekannte Mutation angeboten werden.

\subsection{Molekulargenetische Diagnostik des hereditären Mamma- und Ovarialkarzinoms}

\subsubsection{Detektionsmöglichkeiten der verschiedenen Methoden}

Bei Verdacht auf ein hereditäres Mamma- und Ovarialkarzinom wurden lange Zeit nur eine Sanger-Sequenzierung (Sanger et al. 1977) und eine MLPA-Analyse (Schouten et al. 2002) der BRCA1- und BRCA2-Gene durchgeführt. Die Sanger-Sequenzierung ermöglicht die Identifizierung von Punktmutationen, kleinen Deletionen und Duplikationen in den untersuchten kodierenden und angrenzenden intronischen Bereichen der einzelnen ausgewählten Gene. Mit Hilfe der MLPAAnalyse können größere Deletionen und Duplikationen einzelner Exone des Gens, des gesamten Gens oder mehrerer Gene identifiziert werden. Innerhalb des Deutschen Konsortiums Familiärer Brust- und Eierstockkrebs wurde in den Familien mit den erfüllten Einschlusskriterien eine Detektionsrate der Mutationen der ACMG-Klasse 4 und 5 in den Genen BRCA1 und BRCA2 von 22,5 \% festgestellt (Engel et al. 2015). Da die Einzelgenanalyse per Sanger-Technologie eine zeitund kostenintensive Methode darstellt und bei der Mehrzahl der Patienten mit Verdacht auf ein hereditäres Mamma- und Ovarialkarzinom keine Mutationen in den BRCA1- und BRCA2-Genen identifiziert werden konnten, wurde die Multi-Gen-Panel-Untersuchung mittels Next Generation Sequencing (NGS) als Routinemethode in die molekulargenetische Diagnostik eingeführt.

Die NGS-Untersuchung ist eine Methode der massiven parallelen Sequenzierung (gleichzeitige Analyse mehrerer Gene), die einen höheren Probendurchsatz (gleichzeitige Analyse mehrerer DNA-Proben verschiedener Patienten), kürzere Bearbeitungszeiten und niedrigere Kosten im Vergleich zu den bisherigen Verfahren ermöglicht (Auber et al. 2014).

Verschiedene NGS-Studien bei Verdacht auf ein hereditäres Mamma- und Ovarialkarzinom zeigten eine erhöhte Detektionsrate von Mutationen, wenn zusätzlich zu den BRCA1- und BRCA2Genen weitere assoziierte Gene analysiert wurden. Kurian et al. (2014) ermittelten eine zusätzliche Detektionsrate von $11,4 \%$ von pathogenen Mutationen in den nicht BRCA-Genen (ATM, BLM, CDH1, CDKN2A, MLH1, MUTYH, NBN, PRSS1 und SLX4). Cybulski et al. (2015a) zeigten eine Detektionsrate von trunkierenden Mutationen und das Spleißen beeinträchtigender pathogener Mutationen von $11,8 \%$ in den Genen BRCA1 und BRCA2 und zusätzlich eine Detektionsrate von $7,0 \%$ in den weiteren analysierten Genen (ATM, BARD1, BRIP1, CHEK2, PALB2 und XRCC2). LaDuca et al. (2014) detektierten 7,4 \% von wahrscheinlich pathogenen bzw. pathogenen Mutationen bei Patienten mit Verdacht auf ein hereditäres Mammakarzinom in den nicht BRCA-Genen. Tung et al. (2015) identifizierten pathogene Mutationen bei 9,1 \% der Patienten in den Genen BRCA1 und BRCA2 und bei weiteren 4,3\% der Patienten mindestens eine Mutation in den restlichen 23 untersuchten Genen. Schroeder et al. (2015) identifizierten Mutationen bei 75 Patienten (12,1\%) in den 10 Core-Genen, davon 9,2 \% in den BRCA1- und BRCA2-Genen und 2,9\% in den restlichen acht Core-Genen. Buys et al. (2017) zeigten bei 3.305 von 35.074 (9,3 \%) untersuchten Patientinnen mindestens eine pathogene Mutation in den analysierten Genen. Etwa die Hälfte aller Mutationen wurde dabei in den Genen BRCA1 und BRCA2 detektiert. 


\subsubsection{Möglichkeiten der Next-Generation-Sequencing (NGS) in der molekulargenetischen Diagnostik}

Next-Generation-Sequencing (NGS) ist eine Bezeichnung für eine molekulargenetische Hochdurchsatzsequenzierungsmethode. Im Gegensatz zur klassischen Sanger-Sequenzierung, die die Sequenzanalysen aller DNA-Moleküle zu einer Sequenz zusammenführt, können mit Hilfe der NGS-Technologie Tausende bis Millionen DNA-Fragmente parallel analysiert werden. Die Anwendung der NGS-Methode ermöglicht eine schnellere Untersuchung als die bisherige Praxis der schrittweisen Einzelgenanalysen mittels konventioneller Sanger-Sequenzierung. Diese Methode ermöglicht auch die Detektion der Sequenzvarianten weit unter der Nachweisgrenze der klassischen Sanger-Sequenzierung und somit auch eine Identifizierung von niedriggradigen Mosaiken. Es besteht die Möglichkeit, kleine oder große Multi-Gen-Panels bis hin zur genomweiten Analyse der Exome (Whole-Exome-Sequencing, WES) oder des gesamten Genoms (Whole-Genome-Sequencing, WGS) parallel zu sequenzieren, bioinformatisch zu bearbeiten und auszuwerten.

Ein weiterer Anwendungsbereich der NGS-Technologie ist die Liquid-Biopsie-Diagnostik (engl. liquid biopsy). Hierunter versteht man vor allem die molekulare Analyse zellfreier zirkulierender Tumor-DNA (ct-DNA) im Blut des Patienten (Bettegowda et al. 2014). Die NGS-Methode wird vorzugsweise für den Nachweis der zellfreien zirkulierenden Tumor-DNA verwendet und kann zur Früherkennung von Tumoren und dem Monitoring einer möglichen Resttumor-Aktivität dienen (Heitzer et al. 2015). Diese Methode wird für die Detektion spezifischer Mutationen im Tumor verwendet, was eine gezielte Therapie sowie das Monitoring der Entwicklung der therapieresistenten Mutationen in den Tumoren ermöglichen kann (Bettegowda et al. 2014).

Ein weiterer Anwendungsbereich der NGS-Technologie ist die nicht-invasive pränatale Testung (NIPT), bei der im mütterlichen Plasma gezielt die zellfreien DNA-Fragmente des Fetus auf eine Chromosomenfehlverteilung der Chromosomen 21, 18, 13 oder der Geschlechtschromosome oder Mikrodeletionen hin analysiert werden (Gil et al. 2015; Maxwell et al. 2015). Diese Untersuchung wird schwangeren Frauen in Deutschland diagnostisch angeboten.

Des Weiteren kann mit Hilfe der NGS-Technologie das gesamte Transkriptom, d. h. alle Transkripte einer Zelle in einem spezifischen Entwicklungszustand, vor allem der mRNA, der nichtkodierenden RNAs und kleiner RNAs analysiert werden (Wang et al. 2009).

Mittels der ChIP-Seq-(Chromatin ImmunoPrecipitation DNA-Sequencing)-Methode können Interaktionen zwischen Proteinen und der DNA analysiert werden. Die Chip-Seq-Methode stellt eine Kombination aus Chromatin-Immunpräzipitation und der NGS-Sequenzierung dar (Pareek et al. 2011; Furey 2012).

Die Multi-Gen-Panel-Diagnostik ermöglicht die gleichzeitige Untersuchung mehrerer für die jeweilige Erkrankung relevanter Gene. Dieses Verfahren eignet sich besonders für genetisch heterogene Erkrankungen, wie z. B. hereditäre Tumorsyndrome, syndromale kindliche Erkrankungen, neurodegenerative Erkrankungen, Epilepsien, u. a., d. h. bei Patienten bei denen Mutationen in verschiedenen Genen für eine definierte Erkrankung ursächlich sein können.

Je mehr Gene parallel mittels NGS pro Patient sequenziert werden, desto mehr Sequenzvarianten werden identifiziert. Für die Auswertung dieser Sequenzvarianten werden verschiedene Gendatenbanken (u. a. Datenbank des Deutschen Konsortiums Familiärer Brust- und Eierstockkrebs (BRCA2006), die BIC-(Breast Cancer Information Core)-Datenbank, die HGMD(Human Gene Mutation Database)-Professional)-Datenbank, Publikationen, computergesteuerte Vorhersageprogramme (u. a. MutationTaster, PolyPhen-2, SIFT, Human Splicing Finder Version 3.0), funktionelle Analysen der Sequenzvarianten sowie Segregationsanalysen der Varianten unklarer Signifikanz bei betroffenen und nichtbetroffenen Familienmitgliedern in den Familien benötigt. Somit kann beurteilt werden, ob es sich um eine pathogene Mutation, eine wahrscheinlich pathogene Mutation, eine Variante unklarer Signifikanz (VUS) oder einen Polymorphismus handelt. Abgesehen von der molekulargenetischen Beurteilung der Pathogenität 
einer Sequenzvariante gestaltet sich die klinische, fallbezogene Interpretation oft noch schwieriger. Die Erläuterung zahlreicher Sequenzvarianten unklarer Signifikanz erschwert die humangenetische Beratung.

\subsubsection{Bedeutung der Multi-Gen-Panel-(NGS)-Analyse in der Diagnostik des hereditären Mamma- und Ovarialkarzinoms}

Bei dem hereditären Mamma- und Ovarialkarzinom-Syndrom handelt es sich um eine genetisch heterogene Erkrankungsgruppe mit Mutationen in verschiedenen Genen. Anhand der klinischen Parameter (z. B. Erkrankungsalter, Tumorspektrum in der Familie, etc.), der histologischen Beurteilung des Tumors sowie des Rezeptorstatus des Mammakarzinoms kann das hereditäre Mamma- und Ovarialkarzinom sehr begrenzt einem Einzelgen bzw. einem der 10 Core-Gene zugeordnet werden. Auf der anderen Seite handelt es sich um eine relativ häufige monogene Erkrankung mit einem hohen Durchsatz im humangenetischen Alltag.

Aufgrund dieser Eigenschaften ist die Multi-Gen-Panel-Untersuchung als eine diagnostische Methode optimal für die Identifizierung von Sequenzvarianten bei Verdacht auf ein hereditäres Mamma- und Ovarialkarzinom geeignet.

Bisherige Untersuchungen durch Multi-Gen-Panel-Analysen bei Verdacht auf ein hereditäres Mamma- und Ovarialkarzinom führten zur zusätzlichen Aufklärung der molekulargenetischen Ursache der Tumorerkrankung durch Mutationen der ACMG-Klasse 4 und 5 in den weiteren (außer BRCA1- und BRCA2-Genen) analysierten Genen (die Auswahl der analysierten Gene variiert von Studie zu Studie) in 0,7 \% - 38 \% der Fälle (Chong et al. 2014; Castéra et al. 2014; LaDuca et al. 2014; Kurian et al. 2014; Cybulski et al. 2015a; Maxwell et al. 2015; Lincoln et al. 2015; Tung et al. 2015; Desmond et al. 2015; Schroeder et al. 2015; Susswein et al. 2016; Thompson et al. 2016; Mannan et al. 2016; Kwong et al. 2016; Buys et al. 2017; Crawford et al. 2017; Eliade et al. 2017). Mit einer nachgewiesenen pathogenen Keimbahnmutation in einem der 10 Core-Gene können dem Patienten entsprechende intensivierte Früherkennungsmaßnahmen und Nachsorgeuntersuchungen sowie entsprechende prophylaktische Operationen angeboten werden. Ebenfalls kann das Risiko eines kontralateralen Mammakarzinoms und eines Ovarialkarzinoms bzw. evtl. weiterer Tumorerkrankungen besser eingegrenzt werden. Weiterhin eröffnet sich die Möglichkeit einer gezielten prädiktiven Untersuchung weiterer Familienmitglieder im Rahmen einer humangenetischen Beratung. Die prädiktive Untersuchung ist nur für wahrscheinlich pathogene Mutationen der ACMG-Klasse 4 sowie pathogene Mutationen der ACMG-Klasse 5 möglich. Zusätzlich zu dem Tumorrisiko können Mutationen in den Genen ATM, BRCA2, NBN, PALB2 und RAD51C bei einem bestehenden Kinderwunsch für die Kinderplanung des Paares von großer klinischer Relevanz sein. Homozygote bzw. compound heterozygote Mutationen in diesen Genen können schwerwiegende autosomal-rezessiv vererbte Erkrankungen auslösen, wie z. B. die Fanconi-Anämie, die Ataxia telangiectasia und das Nijmegen-Breakage-Syndrom. 


\subsection{Ziele der Arbeit}

Im Rahmen der vorliegenden Dissertation erfolgte eine nähere Analyse der Bedeutung der MultiGen-Panel-Diagnostik mit Hilfe der Next-Generation-Sequencing-(NGS)-Technologie bei Verdacht auf ein hereditäres Mamma- und Ovarialkarzinom. Die hierzu gewählten Ansätze lassen sich in folgende Unterpunkte gliedern:

- Etablierung und Validierung der Multi-Gen-Panel-Diagnostik für die hereditäre Form des Mamma- und Ovarialkarzinoms im Institut für Humangenetik der Universitätsmedizin Göttingen.

- Molekulargenetische Analyse der 10 Core-Gene von 200 Patienten mit erfüllten Kriterien für die hereditäre Form des Mamma- und Ovarialkarzinoms mittels Multi-Gen-Panel-(NGS)-Untersuchung und der Auswertung der Datensätze mit Hilfe der Software Sequence Pilot, Modul SeqNext.

- Bestätigung jeder identifizierten Sequenzvariante der ACMG-Klasse 3, 4 und 5 in einem der CoreGene mit Hilfe der Sanger-Sequenzierung und Auswertung der Sequenzen mittels der Software Sequence Pilot, Modul SeqPatient.

- MLPA-Analyse der Gene BRCA1, BRCA2, CHEK2, PALB2, RAD51C, RAD51D und Auswertung der Daten mittels der Software Sequence Pilot, Modul MLPA.

- Bewertung einzelner identifizierter Sequenzvarianten mit Hilfe der verfügbaren Datenbanken, Literatur und Vorhersageprogramme und deren Klassifizierung.

- Erhebung der Detektionsrate der Sequenzvarianten der ACMG-Klasse 3, 4 und 5 in den 10 CoreGenen.

- Analyse des Zusammenhangs der klinischen Eigenschaften, wie z. B. des Erkrankungsalters, des erfüllten Kriteriums für eine molekulargenetische Untersuchung, histologischer Tumoreigenschaften und des Rezeptorstatus der Mammakarzinome mit den detektierten Sequenzvarianten der ACMG-Klasse 3, 4 oder 5.

- Es wurden fünf analysierte Fälle ausgewählt und einer intensivierten molekulargenetischen Diagnostik unterzogen. Bei diesen Fällen war entweder die detektierte Sequenzvariante in der Literatur und in den Datenbanken nicht beschrieben oder die Pathogenität der identifizierten Sequenzvariante musste mittels funktioneller Analysen weiter klassifiziert werden oder die Segregationsanalyse der identifizierten Sequenzvariante bzw. der Mutation in der Familie erbrachte unerwartete Ergebnisse. Neben der NGS-Analyse wurden weitere Methoden zur Abklärung der Sequenzvarianten verwendet. Um die identifizierte Sequenzavariante im RAD51DGen bei der Indexpatientin 39784 weiter abklären zu können, wurden eine Amplifikation der RAD51D-cDNA mit gelelektrophoretischer Auftrennung und eine Real-Time PCR-Analyse der RAD51D-Transkripte durchgeführt. Die bei der Indexpatientin 39037 identifizierte wahrscheinlich pathogene Mutation im ATM-Gen, wurde einer Segregationsanalyse in der Familie unterzogen. Bei dem Indexpatieten 39202 wurden für die weitere Abklärung der genomischen Deletion im MSH6-Gen eine Analyse zur MLH1-Promothormethylirung, eine Real-Time PCR-Analyse des MSH6-Gen an genomischer DNA und an der cDNA durchgeführt.

- Vergleich der ermittelten Detektionsraten der mittels NGS-Untersuchung identifizierten Sequenzvarianten bei 200 Patienten mit den retrospektiven Daten der 124 mit der SangerSequenzierung untersuchten Patienten aus dem Jahr 2014. 
2 Material und Methoden

2.1 Material

\subsubsection{Chemikalien}

\begin{tabular}{|c|c|}
\hline Chemikalien & Hersteller \\
\hline 3130 POP-7TM Polymer & Applied Biosystems, Darmstadt \\
\hline Agarose & Bio-Budget Technologies, Krefeld \\
\hline AMPure Beads XP (Cat.Nr. A63881) & Beckman Coulter, Krefeld \\
\hline Ampuwa & Fresenius AG, Bad Homburg \\
\hline Anode Puffer Container 3500 Dx Series & Thermo Fisher Scientific, Darmstadt \\
\hline BigDye $^{\circledR}$ Terminator v3.1 Cycle Sequencing Kit & Thermo Fisher Scientific, Darmstadt \\
\hline Box1 (Cat.Nr.5190-5972) & Agilent Technologies, Böblingen \\
\hline DNeasy ${ }^{\circledR}$ Blood \&Tissue Kit & Qiagen, Hilden \\
\hline dNTP's & Invitrogen, Karlsruhe \\
\hline Essigsäure & Carl Roth \& Co., Karlsruhe \\
\hline Ethanol & Carl Roth \& Co., Karlsruhe \\
\hline Gene Scan ${ }^{\mathrm{TM}}$ - 500 LIZÒ Size Standard & Thermo Fisher Scientific, Darmstadt \\
\hline Hi-Di ${ }^{\mathrm{TM}}$ Formamide & Thermo Fisher Scientific, Darmstadt \\
\hline Human DNA male, Art\#360486 & Applied Biosystems, Darmstadt \\
\hline IllustraTM SephadexTM G-50, Fine DNA Grade & GE Healthcare, München \\
\hline $\mathrm{MgCl}_{2}$ & Bioline, Luckenwalde \\
\hline $\mathrm{NaOH}$ Stocklösung & Merck, Darmstadt \\
\hline Oligonukleotidprimer & Operon Biotechnologies $\mathrm{GmbH}$, Köln \\
\hline PAXgene Blood RNA Tubes & PreAnalytix/Qiagen, Hilden \\
\hline PAXgene ${ }^{\circledR}$ Blood RNA Kit & PreAnalytix/Qiagen, Hilden \\
\hline Random Hexamere & Roche, Grenzach-Wyhlen \\
\hline Oligo-dT & Invitrogen, Karlsruhe \\
\hline Superscript II Reverse Transcriptase Kit & Invitrogen, Karlsruhe \\
\hline SYBR Green I & Qiagen, Hilden \\
\hline TE-Puffer & AppliChem, Darmstadt \\
\hline Tris HCl Puffer & Carl Roth \& Co., Karlsruhe \\
\hline
\end{tabular}

\subsubsection{Lösungen}

\begin{tabular}{|l|l|}
\hline Lösungen / Puffer & Hersteller bzw. Zusammensetzung \\
\hline BigDye Terminator v3.1 5x Sequencing-Puffer & Thermo Fisher Scientific, Darmstadt \\
\hline 10x 3130TM Puffer & Thermo Fisher Scientific, Darmstadt \\
\hline Humane Cot-1 DNA & Invitrogen, Karlsruhe \\
\hline
\end{tabular}




\begin{tabular}{|l|l|}
\hline Lösungen / Puffer & Hersteller bzw. Zusammensetzung \\
\hline dNTP-Mix & $10 \mathrm{mM} \mathrm{dCTP}$ \\
\hline Stopp-Mix & $15 \%$ Ficoll 400 \\
\hline TE - Puffer (Tris-EDTA-Puffer) pH 8,0 & EDTA-Na $2 \mathrm{H}_{2} \mathrm{O} 0,1 \mathrm{M}$ und Tris $1 \mathrm{M}$ \\
\hline
\end{tabular}

\subsubsection{Enzyme}

\begin{tabular}{|l|l|}
\hline Enzym & Hersteller \\
\hline Immolase & Bioline, Luckenwalde \\
\hline Platinum-Taq-DNA Polymerase & Invitrogen, Karlsruhe \\
\hline Proteinase K & Roth, Karlsruhe \\
\hline
\end{tabular}

\subsubsection{Restriktionsenzyme}

\begin{tabular}{|c|c|c|}
\hline Restriktionsenzym & Erkennungssequenz & Schnittposition \\
\hline Hin6I & $\begin{array}{l}5^{\prime} \ldots \text { CGCG ....3' } \\
3^{\prime} \ldots \text { GCGC .... } 5^{\prime}\end{array}$ & $\begin{array}{l}5^{\prime} \ldots C \quad \text { GCG....3' } \\
3^{\prime} \ldots \text { GCG } \quad \text { C.... } 5^{\prime}\end{array}$ \\
\hline$X b a l$ & $\begin{array}{l}5^{\prime} \ldots \text { TCTAGA } \ldots 3^{\prime} \\
3^{\prime} \ldots \text { AGATCT ...5 }\end{array}$ & $\begin{array}{l}5^{\prime} \ldots \text { CTAGA...3' } \\
3^{\prime} \ldots \text { AGATC T... } 5^{\prime}\end{array}$ \\
\hline Dral & 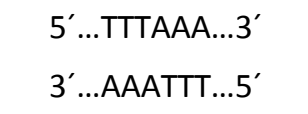 & $\begin{array}{ll}5^{\prime} \ldots \text { TTT } & \text { АAА...3' } \\
3^{\prime} \ldots \text { AAA } & \text { TTT...5 }\end{array}$ \\
\hline
\end{tabular}

\subsubsection{Gebrauchswaren}

\begin{tabular}{|l|l|}
\hline Gebrauchsware & Hersteller \\
\hline 4er Reaktiongefäß-Streifen & Sarstedt, Nümbrecht \\
\hline 96-Well PCR Plate (mit und ohne Rand) & ABgene, Hamburg \\
\hline 96-Well Filtration System & Millipore, Schwalbach \\
\hline Abdeckfolien für 96-Well-Platten & 4titude, Berlin \\
\hline Falcon Röhrchen 50 ml & Sarstedt, Nümbrecht \\
\hline Gel Loder Tips extra lang (Page Gel) & Sarstedt, Nümbrecht \\
\hline MicroAmpTM Optica 96-Well Reaction Plate & Thermo Fisher Scientific, Darmstadt \\
\hline MSB HTS PCRapace & Stratec biomedical, Berlin \\
\hline MSB Spin PCRapace & Stratec biomedical, Berlin \\
\hline MultiScreen Aufreinigungsplatten & Millipore, Schwalbach \\
\hline Multyply $\mu$ Strip Pro 4er Kette & Sarstedt, Nümbrecht \\
\hline Multyply-Pro Gefäß 0,2 ml Cup & Sarstedt, Nümbrecht \\
\hline $\begin{array}{l}\text { Nucleo Spin gDNA Clean up (Cat.-No. REF } \\
\text { 740230.250) }\end{array}$ & Macherey-Nagel, Düren \\
\hline
\end{tabular}




\begin{tabular}{|l|l|}
\hline Gebrauchsware & Hersteller \\
\hline Nucleo-Spin Clean up-Kit & Macherey-Nagel, Düren \\
\hline Pipettenspitzen (mit und ohne Filter) & Sarstedt, Nümbrecht \\
\hline Reaktionsgefäße $(0,2 \mathrm{ml}, 0,5 \mathrm{ml}, 1,5 \mathrm{ml}, 2 \mathrm{ml})$ & Eppendorf, Hamburg \\
\hline Röhrchen $13 \mathrm{ml}$ & Sarstedt, Nümbrecht \\
\hline
\end{tabular}

\subsubsection{Gebrauchsfertige Reaktionssysteme}

\begin{tabular}{|l|l|}
\hline Reaktionssystem & Hersteller \\
\hline Genomic DNA Labeling Kit PLUS & Agilent, USA \\
\hline Montage PCR Säulen & Millipore, Schwalbach \\
\hline MultiScreen-HV Platten & Millipore, Schwalbach \\
\hline
\end{tabular}

\subsubsection{DNA-Längenstandard}

Um die Größe von DNA-Fragmenten im Zuge einer Gelelektrophorese zu bestimmen, wurde folgender DNA-Längenstandard parallel mitgeführt:

\begin{tabular}{|l|l|}
\hline Längenstandard & Hersteller \\
\hline 1 kb plus DNA Leiter & Invitrogen, Karsruhe \\
\hline
\end{tabular}

\subsubsection{Materialien für das Multi-Gen-Panel, HaloPlex und TruRisk ${ }^{\mathrm{TM}}$}

\begin{tabular}{|c|c|}
\hline Bezeichnung & Firma \\
\hline 0,2 ml PCR Reaktionsgefäße & Sarstedt, Nümbrecht \\
\hline 1,5 ml Reaktionsgefäße & Ochs, Bovenden \\
\hline $10 \mathrm{M} \mathrm{NaOH}$ Stocksolution (50mM NaOH) & Merck, Darmstadt \\
\hline 10 mM Tris HCL-Puffer $(\mathrm{pH} 8,0)$ & Agilent Technologies, Böblingen \\
\hline 13 ml Röhrchen & Sarstedt, Nümbrecht \\
\hline 2 M Essigsäure & Carl Roth \& Co., Karlsruhe \\
\hline 2100 Bioanalyzer (Fa. Agilent Technologies) & Agilent Technologies, Böblingen \\
\hline 50 ml Falcon Röhrchen & Sarstedt, Nümbrecht \\
\hline $70 \%$ Ethanol & Carl Roth \& Co., Karlsruhe \\
\hline 96-Well-Platten & 4titude, Berlin \\
\hline AMPure Beads XP (Cat.Nr. A63881) & Beckman Coulter, Krefeld \\
\hline Box1 (Cat.Nr. 5190-5972) & Agilent Technologies, Böblingen \\
\hline Filterspitzen & Sarstedt, Nümbrecht \\
\hline Gelloader Tips extra lang & Sarstedt, Nümbrecht \\
\hline
\end{tabular}




\begin{tabular}{|c|c|}
\hline Bezeichnung & Firma \\
\hline $\begin{array}{l}\text { HaloPlex Enrichment System Kits, Magnetic Beads Box } \\
2 \text { (Cat. Nr. 5190-5976) }\end{array}$ & Agilent Technologies, Böblingen \\
\hline $\begin{array}{l}\text { HaloPlex Target Enrichment System Reagent Kits } \\
\text { HaloPlex 1-500Kb ILMFST }\end{array}$ & Agilent Technologies, Böblingen \\
\hline $\begin{array}{l}\text { Herculase II Fusion Enzym with dNTP Combo } 200 \text { Rxn } \\
\text { Kit (Cat. Nr. 600677) }\end{array}$ & Agilent Technologies, Böblingen \\
\hline Magnetständer DynaMag ${ }^{\mathrm{TM}}-2$ & Invitrogen, Karlsruhe \\
\hline Magnetständer für 1,5ml Reaktionsgefäße & Promega, Mannheim \\
\hline Nanodrop ND 8000 & Peqlab, Helmholtz Zentrum München \\
\hline Nucleo Spin gDNA Clean up (Cat.-No. REF 740230.250) & Macherey-Nagel, Düren \\
\hline PCR-Cycler p/n 951010006 & Eppendorf, Wesseling-Berzdorf \\
\hline PCR Foil Seal & 4titude, Berlin \\
\hline PCR-Plattenschweißgerät & 4titude, Berlin \\
\hline Plattenzentrifuge und Tischzentrifuge & Eppendorf, Wesseling-Berzdorf \\
\hline Protean II Gelkammer & Biorad, München \\
\hline Qubit 2.0 Fluorometer & Invitrogen, Karlsruhe \\
\hline $\begin{array}{l}\text { Sure SelectQXT Reagent Kit for } 96 \text { Sample } \\
\text { (Artikelnummer 1046009) }\end{array}$ & Agilent Technologies, Böblingen \\
\hline $\begin{array}{l}\text { Sure SelectXT Curstom } 1 \mathrm{~Kb}-499 \mathrm{~Kb} \text { Library } \\
\text { (Artikelnummer 1046102) }\end{array}$ & Agilent Technologies, Böblingen \\
\hline
\end{tabular}

Sowie puderfreie Handschuhe, Stoppuhr und Vortex-Mixer.

\subsubsection{Synthetische Oligonukleotide}

Das Design der Primer erfolgte mit Hilfe des Programms PRIMER3 (Whitehead Institute for Biomedical Research, http://frodo.wi.mit.edu/primer3/). Die Spezifität und Dimer- bzw. Sekundärstrukturbildung der Primerpaare wurde mittels NCBI-BLAST (http://blast.ncbi.nlm.nih.gov/Blast.cgi) überprüft. Die verwendeten Oligonukleotide wurden von der Firma Operon Biotechnologies $\mathrm{GmbH}$ (Köln) bezogen, mit destilliertem Wasser auf eine Konzentration von $100 \mu \mathrm{M}(100 \mathrm{pmol} / \mu \mathrm{l})$ eingestellt und als Stocklösung bei $-20^{\circ} \mathrm{C}$ gelagert.

Für den Gebrauch der Sequenzierungsprimer wurden diese mit einer Linkersequenz versehen. Forward Primer erhielten die Linkersequenz 5'-ggtcagctctcccagcgat-3' und reverse Primer die Linkersequenz 5'-cagctctcccacaggcga-3'.

2.1.9.1 Sequenzprimer für die Nachsequenzierung der Sequenzvarianten der ACMGKlasse 3, 4 oder 5 in den Core-Genen

\begin{tabular}{|l|l|l|}
\hline Gen/Transkript & Exon/Bezeichnung & Sequenz \\
\hline ATM & Ex5-Fw & $5^{\prime}$-cattccaagtgtcttatttt-3' \\
\hline & Ex5-Rw & $5^{\prime}$-tgttaaactgtcaggtcact-3' \\
\hline
\end{tabular}




\begin{tabular}{|c|c|c|}
\hline Gen/Transkript & Exon/Bezeichnung & Sequenz \\
\hline \multirow[t]{2}{*}{ ATM } & Ex9-FwN & $5^{\prime}$-caacaacagcgaaactctgg-3' \\
\hline & Ex9-RwN & $5^{\prime}$-tgtcatggcaatcacatatcc-3' \\
\hline \multirow[t]{2}{*}{ ATM } & Ex13-Fw & $5^{\prime}$-aggtctcaaagtccgaagaaga-3' \\
\hline & Ex13-Rw & $5^{\prime}$-tttcctgcccctatttctcct- $3^{\prime}$ \\
\hline \multirow[t]{2}{*}{ ATM } & Ex14-F2 & $5^{\prime}$-aactcttgtccggtgttcac-3' \\
\hline & Ex14-R2 & $5^{\prime}$-acaaacctgcatgctctaca-3' \\
\hline \multirow[t]{2}{*}{ ATM } & Ex15-F & $5^{\prime}$-actgtatgactacgtggaacttct-3' \\
\hline & Ex15-R & $5^{\prime}$-gtgacaatcccactgcactc- $3^{\prime}$ \\
\hline \multirow[t]{2}{*}{ ATM } & Ex24-FwN2 & $5^{\prime}$-agttcagttgggattttata-3' \\
\hline & Ex24-RwN2 & $5^{\prime}$-acctaaggaagcttctaata-3' \\
\hline \multirow[t]{2}{*}{ ATM } & Ex26-F & $5^{\prime}$-tcttctaacagactgctttcca-3' \\
\hline & Ex26-R & $5^{\prime}$-attcatgggttggctatgct-3' \\
\hline \multirow[t]{2}{*}{ ATM } & Ex29A-Fw & $5^{\prime}$-tgagaacagaatcttgtgacactt-3' \\
\hline & Ex29A-Rw & 5'-tcgaagaacaaaggcccaag-3' \\
\hline \multirow[t]{2}{*}{ ATM } & Ex35-Fw & $5^{\prime}$-cagtggaggttaacattcatcaag-3' \\
\hline & Ex35-Rw & 5'-acagtcatgacccacagcaa-3' \\
\hline \multirow[t]{2}{*}{ ATM } & Ex37-Fw & 5 -gcagtatgttgagtttatggcaga-3' \\
\hline & Ex37-Rw & $5^{\prime}$-gtgggattccatcttaaatccat-3' \\
\hline \multirow[t]{2}{*}{ ATM } & Ex40-Fw & $5^{\prime}$-tgtttgccaccttcattagttt-3' \\
\hline & Ex40-Rw & 5'-ctcaagaagtggcagagtcagt-3' \\
\hline \multirow[t]{2}{*}{ ATM } & Ex41-F & $5^{\prime}$-caaactcgtgttgtttgaactgt- $3^{\prime}$ \\
\hline & Ex41-R & $5^{\prime}$-ccacattgcttcgtgttcat-3' \\
\hline \multirow[t]{2}{*}{ ATM } & Ex43-Fw & $5^{\prime}$-ctcctgggctcaagtgatcc- $3^{\prime}$ \\
\hline & Ex43-Rw & 5'-tgtttagaatgaggagagaggcaa-3' \\
\hline \multirow[t]{2}{*}{ ATM } & Ex51-Fw & $5^{\prime}$-tgtgctaatagaggagcactgtct-3 \\
\hline & Ex51-Rw & 5'-gcagaggcctatgaggaattag-3' \\
\hline
\end{tabular}




\begin{tabular}{|c|c|c|}
\hline Gen/Transkript & Exon/Bezeichnung & Sequenz \\
\hline \multirow[t]{2}{*}{ ATM } & Ex52-FwN & $5^{\prime}$-tttctctctctaattcctca-3' \\
\hline & Ex52-RwN & $5^{\prime}$-ggaaagactgaatatcacac-3' \\
\hline \multirow[t]{2}{*}{$B R C A 1$} & ex2F.1 & $5^{\prime}$-cgttgtcattagttctttggtttg-3' \\
\hline & ex2R.1 & $5^{\prime}$-ctgttcatttgcataggagataatc- $3^{\prime}$ \\
\hline \multirow[t]{2}{*}{$B R C A 1$} & ex3F.1 & $5^{\prime}$-cagttcctgacacagcagaca-3' \\
\hline & ex3R.1 & 5'-ttcctgggttatgaaggacaaa-3' \\
\hline \multirow[t]{2}{*}{$B R C A 1$} & ex11F.5 & $5^{\prime}$-ggttcttcagagaaaatagact-3' \\
\hline & ex11R.5 & $5^{\prime}$-tgccaaatctgctttcttgata-3' \\
\hline \multirow[t]{2}{*}{$B R C A 1$} & ex11F.6 & $5^{\prime}$-agcgtaaaaggagacctaca-3' \\
\hline & ex11R.6 & $5^{\prime}$-aattcgagttccatattgctt-3' \\
\hline \multirow[t]{2}{*}{$B R C A 1$} & ex11F.7 & $5^{\prime}$-ctttcaaaacgaaagctgaa-3' \\
\hline & ex11R.7 & $5^{\prime}$-ccagttgcaggttctttacc-3' \\
\hline \multirow[t]{2}{*}{ BRCA1 } & ex11F.14 & 5'-tgaaataggttccagtgatga-3' \\
\hline & ex11R.14 & $5^{\prime}$-acaggtcatcaggtgtctca-3' \\
\hline \multirow[t]{2}{*}{ BRCA1 } & ex11F.15 & $5^{\prime}$-gtcagataacttagaacagcct-3' \\
\hline & ex11R.15 & $5^{\prime}$-ttggaagcagggaagctctt- $3^{\prime}$ \\
\hline \multirow[t]{2}{*}{$B R C A 1$} & ex11F.16 & 5 '-atacacatttggctcagggtta-3' \\
\hline & ex11R.16 & 5'-agcagaacattttgtttcctca-3' \\
\hline \multirow[t]{2}{*}{$B R C A 1$} & ex17F.1 & 5'-tgagctgtgtgctagaggtaac-3' \\
\hline & ex17R.1 & 5'-tcccaaagtgctgcgattaca-3' \\
\hline \multirow[t]{2}{*}{$B R C A 1$} & ex19F.1 & $5^{\prime}$-ggcagttctagaagaatgaaaactc-3' \\
\hline & ex19R.1 & $5^{\prime}$-gcaagagaccgaaactccat-3' \\
\hline \multirow[t]{2}{*}{ BRCA1 } & ex20F.1 & $5^{\prime}$-tgtctgctccacttccattg-3' \\
\hline & ex20R.1 & 5'-tgcaaaggggagtggaatac-3' \\
\hline \multirow[t]{2}{*}{$B R C A 1$} & ex24F.1 & $5^{\prime}$-ttgattagagcctagtccag-3' \\
\hline & ex24R.1 & $5^{\prime}$-ctgaagagtgagaggagctcc- $3^{\prime}$ \\
\hline
\end{tabular}




\begin{tabular}{|c|c|c|}
\hline Gen/Transkript & Exon/Bezeichnung & Sequenz \\
\hline \multirow[t]{2}{*}{$B R C A 2$} & ex2F.1 & $5^{\prime}$-aatgcatccctgtgtaagtgc- $3^{\prime}$ \\
\hline & ex2R.1 & $5^{\prime}$-cgtactgggtttttagcaagc- $3^{\prime}$ \\
\hline \multirow[t]{2}{*}{$B R C A 2$} & ex3F.1 & $5^{\prime}$-tggttaaaactaaggtgggatttt-3' \\
\hline & ex3R.1 & $5^{\prime}$-gagactgatttgcccagcat-3' \\
\hline \multirow[t]{2}{*}{$B R C A 2$} & ex10F.1 & $5^{\prime}$-tgtttctatgagaaaggttgtgaga-3' \\
\hline & ex10R.1 & $5^{\prime}$-tggatcagtatcatttggttcc-3' \\
\hline \multirow[t]{2}{*}{$B R C A 2$} & ex10F.5 & $5^{\prime}$-aaaaagaaactgaagcctctgaaa-3' \\
\hline & ex10R.5 & $5^{\prime}$-gcttcaaactgggctgaaca-3' \\
\hline \multirow[t]{2}{*}{$B R C A 2$} & ex10F.6 & 5'-tccactttgaaaaagaaaacaaa-3' \\
\hline & ex10R.6 & 5'-tcatgtatacagatgatgcctaaga-3' \\
\hline \multirow[t]{2}{*}{$B R C A 2$} & ex11_F.1 & $5^{\prime}$-tttagtgaatgtgattgatggtactt-3' \\
\hline & ex11_R.1 & 5'-gcaggcatgacagagaatca-3' \\
\hline \multirow[t]{2}{*}{ BRCA2 } & ex11F.9 & $5^{\prime}$-tgaagtgcctgaaaaccaga-3' \\
\hline & ex11R.9 & $5^{\prime}$-ttcacagctttttgcagagc- $3^{\prime}$ \\
\hline \multirow[t]{2}{*}{$B R C A 2$} & Ex $11 \mathrm{~F} .18$ & $5^{\prime}$-gcatgtctaacagctattcctacc-3' \\
\hline & Ex 11R.18 & $5^{\prime}$-tggctgcatttttatttttgc- $3^{\prime}$ \\
\hline \multirow[t]{2}{*}{$B R C A 2$} & ex13F.1 & 5'-tttttgtgtatttacagtaacatggat-3 \\
\hline & ex13R.1 & 5'-tcatttataaaaacgagacttttctca-3' \\
\hline \multirow[t]{2}{*}{$B R C A 2$} & ex16F.1 & $5^{\prime}$-tttggtaaattcagttttggtttg-3' \\
\hline & ex16R.1 & $5^{\prime}$-gaagaaagagggatgagggaat-3' \\
\hline \multirow[t]{2}{*}{$B R C A 2$} & ex17F.1 & $5^{\prime}$-ttgaattcagtatcatcctatgtgg- $3^{\prime}$ \\
\hline & ex17R.1 & $5^{\prime}$-cacagaaaccttaaccatactgc-3' \\
\hline \multirow[t]{2}{*}{$B R C A 2$} & ex19F.1 & $5^{\prime}$-ggcagttctagaagaatgaaaactc-3' \\
\hline & ex19R.1 & 5'-gcaagagaccgaaactccat-3' \\
\hline \multirow[t]{2}{*}{$B R C A 2$} & ex27F.2 & 5 ' - tca gcc cag atg act tca aa - '3 \\
\hline & ex27R.2 & $5^{\prime}$-cgtcagctattgaattactttcca-3' \\
\hline
\end{tabular}




\begin{tabular}{|c|c|c|}
\hline Gen/Transkript & Exon/Bezeichnung & Sequenz \\
\hline \multirow[t]{2}{*}{$C D H 1$} & ex2-F.1 & $5^{\prime}$-ctgttggtttcggtgagcagga-3' \\
\hline & ex2-R.1 & $5^{\prime}$-tgtcgtttgagccaaggaggga-3' \\
\hline \multirow[t]{2}{*}{$\mathrm{CDH} 1$} & ex11-F.2 & $5^{\prime}$-cgaccggcctattgttggttttcaa-3' \\
\hline & ex11-R.2 & 5'-caaaagaagggaggggcaagga- $3^{\prime}$ \\
\hline \multirow[t]{2}{*}{ CHEK2 } & Ex2A-Fw & $5^{\prime}$-agagcatgtttgccctgttt-3' \\
\hline & Ex2A-Rw & $5^{\prime}$-aaggagctcagtgtcccaga-3' \\
\hline \multirow[t]{2}{*}{ CHEK2 } & Ex4-F1 & $5^{\prime}$-aggagagctggtaatttggtca-3' \\
\hline & Ex4-R1 & $5^{\prime}$-acgcccagcaacttactcat-3' \\
\hline \multirow[t]{2}{*}{ CHEK2 } & Ex10-F1 & $5^{\prime}$-cccagctgtgagatgtgtgt- $3^{\prime}$ \\
\hline & Ex10-R1 & $5^{\prime}$-ggtaacagtgaaagggtcaga-3' \\
\hline \multirow[t]{2}{*}{ CHEK2 } & Ex11-F1 & $5^{\prime}$-agcctacgtgtcttcttgga- $3^{\prime}$ \\
\hline & Ex11-R1 & $5^{\prime}$-ccagtctgtgcagcaatgaa--3' \\
\hline \multirow[t]{2}{*}{ CHEK2 } & Ex13-F1 & $5^{\prime}$-ctttctgaatggtggcctgt- $3^{\prime}$ \\
\hline & Ex13-R1 & $5^{\prime}$-tcatgtctctcaggcagcag-3' \\
\hline \multirow[t]{2}{*}{ NBN } & Ex1-Fw & $5^{\prime}$-cactcccgcctcatccaagg-3' \\
\hline & Ex1-Rw & $5^{\prime}$-cgtgctgcccgggaagaata-3' \\
\hline \multirow[t]{2}{*}{ NBN } & Ex5-Fw & $5^{\prime}$-ggatgtaaacagcctctttgt-3' \\
\hline & Ex5-Rw & $5^{\prime}$-catcctgaaacaagcattaaaga-3' \\
\hline \multirow[t]{2}{*}{ NBN } & Ex6-F1 & $5^{\prime}$-gccttttgagtgtcagatagtca-3' \\
\hline & Ex6-R1 & 5'-aaccccgtaatcacagccat-3' \\
\hline \multirow[t]{2}{*}{ NBN } & Ex11B-FwN & $5^{\prime}$-cacaaactcagacaataactt-3' \\
\hline & Ex11B-RwN & $5^{\prime}$-agcattctaagcttctatgt-3' \\
\hline \multirow[t]{2}{*}{ NBN } & E14-Fw & $5^{\prime}$-ggcacttatgcatgatttacca-3' \\
\hline & E14-Rw & $5^{\prime}$-gccaccataatggaccaaag-3' \\
\hline \multirow[t]{2}{*}{ PALB2 } & Ex3-Fw & $5^{\prime}$-ctctagcgtgcccaaagag-3' \\
\hline & Ex3-Rw & $5^{\prime}$-aaagcaggcataagtgaatgg-3' \\
\hline
\end{tabular}




\begin{tabular}{|c|c|c|}
\hline Gen/Transkript & Exon/Bezeichnung & Sequenz \\
\hline \multirow[t]{2}{*}{ PALB2 } & Ex4F-Fw & $5^{\prime}$-aagtgaaattaggatgtctg-3 \\
\hline & Ex4F-Rw & $5^{\prime}$-caggcaaatagtaattgtta-3' \\
\hline \multirow[t]{2}{*}{ PALB2 } & Ex7-Fw & $5^{\prime}$-agaactgttgccattgtgtca-3' \\
\hline & Ex7-Rw & $5^{\prime}$-gccttgcatggtcatagctc- $3^{\prime}$ \\
\hline \multirow[t]{2}{*}{ PALB2 } & Ex8-Fw & $5^{\prime}$-tctgagccttcaaatgatgaaa- $3^{\prime}$ \\
\hline & Ex8-Rw & $5^{\prime}$-ccagctgacagagacaaagatg-3' \\
\hline \multirow[t]{2}{*}{$P A L B 2$} & Ex12-FwN & $5^{\prime}$-tggatacttcagagcctatc- $3^{\prime}$ \\
\hline & Ex12-RwN & $5^{\prime}$-ttccattcttctaagtgacac- $3^{\prime}$ \\
\hline \multirow[t]{2}{*}{ RAD51C } & Ex4F & $5^{\prime}$ - tgccaatacatccaaacagg-3' \\
\hline & Ex4R & $5^{\prime}$-tcatgcttatcaaacacctcaaa-3' \\
\hline \multirow[t]{2}{*}{ RAD51C } & ex5F.1 & $5^{\prime}$-tcttggagagagagagcattttt-3' \\
\hline & ex5R.1 & $5^{\prime}$-caggcaaacgctattttgac- $3^{\prime}$ \\
\hline \multirow[t]{2}{*}{ RAD51D } & Ex5-Fw & $5^{\prime}$-gagagaagatgggtaataag-3 \\
\hline & Ex5-Rw & $5^{\prime}$-tacaatgttaagggataatg-3' \\
\hline \multirow[t]{2}{*}{ RAD51D } & E8-Fw & $5^{\prime}$-cagtggaatgtgacctcgc- $3^{\prime}$ \\
\hline & E8-Rw & $5^{\prime}$-aagggaaataaagagctcgcaa-3' \\
\hline \multirow[t]{2}{*}{ RAD51D } & Ex10-Fw & $5^{\prime}$-taactccactgactccttac- $3^{\prime}$ \\
\hline & Ex10-Rw & $5^{\prime}$-tgtggtttatatgcttacag-3' \\
\hline \multirow[t]{2}{*}{ TP53 } & Ex4-Fw & $5^{\prime}$-cctggtcctctgactgctct- $3^{\prime}$ \\
\hline & Ex4-Rw & $5^{\prime}$-caggcattgaagtctcatgg-3' \\
\hline
\end{tabular}

Ex/ex = Exon; F/Fw =Forward Primer; R/Rw =Reverse Primer.

\subsubsection{Primer für die Real-Time PCR-Analyse des MSH6-Gens}

\begin{tabular}{|l|l|l|}
\hline Gen/Transkript & Bezeichnung & Sequenz \\
\hline MSH6 & $202-2 p M S H 6-U-F(1)$ & 5'-ttaggatcagggagatggctgctct-3' \\
\hline MSH6 & $202-2 p M S H 6-U-R(1)$ & $5^{\prime}$-tgacactcaagctctcgctgttctg-3' \\
\hline
\end{tabular}




\begin{tabular}{|c|c|c|}
\hline Gen/Transkript & Bezeichnung & Sequenz \\
\hline & 202-2pMSH6-T-R (2) & 5'-tcttctcaccagaggcaggagacac-3' \\
\hline \multirow[t]{2}{*}{ MSH6 } & 202-2pMSH6-S-F (3) & $5^{\prime}$-gaggggctgcaaacacgagaatagt-3' \\
\hline & 202-2pMSH6-S-R (3) & $5^{\prime}$-ctgccagacctttgctctccttttc- $3^{\prime}$ \\
\hline \multirow[t]{2}{*}{ MSH6 } & 202-2pMSH6-R-F (4) & $5^{\prime}$-taagctgtagccctcccatcctttg-3' \\
\hline & 202-2pMSH6-R-R (4) & $5^{\prime}$-gcctctgcttatttcttcccaccac-3' \\
\hline \multirow[t]{2}{*}{ MSH6 } & 202-2pMSH6-P-F (5) & $5^{\prime}$-cagggcccatctctttggttctcta-3' \\
\hline & 202-2pMSH6-P-R (5) & $5^{\prime}$-tcactctcaaaggggccttgtcttc-3' \\
\hline \multirow{2}{*}{ MSH6 } & 202-2pMSH6-K-F (6) & $5^{\prime}$-gctctctaggtgacttccgtgtcca-3' \\
\hline & 202-2pMSH6-K-R (6) & $5^{\prime}$-gctctctaggtgacttccgtgtcca-3' \\
\hline \multirow[t]{2}{*}{ MSH6 } & 202-2pMSH6-L-F (7) & $5^{\prime}$-agatggtttaggctcgcactcacac-3' \\
\hline & 202-2pMSH6-L-R (7) & $5^{\prime}$-ccagcctggttgtggactttagaga-3' \\
\hline \multirow[t]{2}{*}{ MSH6 } & 202-2pMSH6-M-F (8) & 5'-gacaggacaagttcagagccacctg-3' \\
\hline & 202-2pMSH6-M-R (8) & 5'-gcgagaggtttgaggaagagcagat-3' \\
\hline \multirow[t]{2}{*}{ MSH6 } & 202-2pMSH6-A-FN (9) & 5'-agggagaggaggtatcaagtct-3' \\
\hline & 202-2pMSH6-A-RN (9) & $5^{\prime}$-atctcccctcctctaatctgtc- $3^{\prime}$ \\
\hline \multirow[t]{2}{*}{ MSH6 } & 202-2pMSH6-B-F (10) & $5^{\prime}$-ttccacctaggatggctttggagag-3' \\
\hline & 202-2pMSH6-B-R (10) & $5^{\prime}$-gacatgagccacctcgactaactgg-3' \\
\hline \multirow[t]{2}{*}{ MSH6 } & 202-2pMSH6-C-F (11) & 5'-ggttgggcactgcagactaaagaca-3' \\
\hline & 202-2pMSH6-C-R (11) & $5^{\prime}$-gtgtgcgtcctcacaccctgataat-3' \\
\hline \multirow[t]{2}{*}{ MSH6 } & 202-2pMSH6-D-F (12) & 5'-caacatagggctccagaaccagctt-3' \\
\hline & 202-2pMSH6-D-R (12) & 5'-gctgaggcacagttgggtcaagtaa-3' \\
\hline \multirow[t]{2}{*}{ MSH6 } & 202-2pMSH6-F-F (13) & $5^{\prime}$-acagctgcaggctttcaccatacac-3' \\
\hline & 202-2pMSH6-F-R (13) & $5^{\prime}$-cgtgacctcctgccgttagagc- $3^{\prime}$ \\
\hline \multirow[t]{2}{*}{ MSH6 } & 202-2pMSH6-N-F (14) & $5^{\prime}$-accctcgacctattcggctcaagt-3' \\
\hline & 202-2pMSH6-N-R (14) & 5'-gaatgccaaaataggccaggtgtg-3' \\
\hline MSH6 & 202-2pMSH6-H-F (15) & 5'-cttaatcgggcgctggacaaagat-3' \\
\hline
\end{tabular}




\begin{tabular}{|l|l|l|}
\hline Gen/Transkript & Bezeichnung & Sequenz \\
\hline & $202-2 p M S H 6-H-R(15)$ & $5^{\prime}$-cagcctggacttgagcgaaactctc-3' \\
\hline MSH6 & $202-2 p M S H 6-N-F(16)$ & $5^{\prime}$-accctcgacctattcggctcaagt-3' \\
\hline MSH6 & $202-2 p M S H 6-N-R(16)$ & $5^{\prime}$-gaatgccaaaataggccaggtgtg-3' \\
\hline & $202-2 p M S H 6-O-F(17)$ & $5^{\prime}$-cccatcttgaagggtccaagagaa-3' \\
\hline
\end{tabular}

Ex $=$ Exon; $\mathrm{F}=$ Forward Primer $; \mathrm{R}=$ Reverse Primer.

\subsubsection{Primer für die Real-Time PCR-Analyse des Houskeeping-Gens LDAH}

\begin{tabular}{|l|l|l|}
\hline Gen & Bezeichnung & Sequenz \\
\hline$L D A H$ & Q1-Fw & $5^{\prime}$-ggagatccatcatctctccc-3' \\
\hline & Q2-Rev & $5^{\prime}$-ggcctgtgccatcagtatct-3' \\
\hline
\end{tabular}

$\mathrm{Fw}=$ Forward Primer; Rev = Reverse Primer .

\subsubsection{Primer für die Expressionsanalyse des MSH6-Gens in Lymphozyten}

\begin{tabular}{|l|l|l|}
\hline Gen & Bezeichnung & Sequenz \\
\hline MSH6 & P1F & $5^{\prime}$-tggcagttgtgatgagcctc-3' \\
\hline MSH6 & P1R & $5^{\prime}$-gcgacacataggaccatcaccc-3' \\
\hline MSH6 & P2F & $5^{\prime}$-gcgaagaacctcaacggag-3' \\
\hline P2R & $5^{\prime}$-caggggtaacctccatctt-3' \\
\hline MSH6 & P3F & $5^{\prime}$-cgctgagtgatgccaacaaggc-3' \\
\hline & P3R & $5^{\prime}$-tggccaaaccaaatctcctgg-3' \\
\hline & P4F & $5^{\prime}$-ttacgtcctgctgaagtgtgc-3' \\
\hline
\end{tabular}

$\mathrm{F}=$ Forward Primer; $\mathrm{R}=$ Reverse Primer.

2.1.9.5 Primer für die Methylierungsanalyse des distalen und proximalen MLH1Promotorbereichs

\begin{tabular}{|l|l|l|}
\hline Gen/Transkript & Bezeichnung & Sequenz \\
\hline$M L H 1$ & PROXF & $5^{\prime}$-cggcatctctgctcctattg-3' \\
\hline & PROXR & $5^{\prime}$-tgcccgctacctagaaggat-3' \\
\hline$M L H 1$ & DISTF & $5^{\prime}$-'aagtcgcctgacgcagac-3' \\
\hline
\end{tabular}




\begin{tabular}{|l|l|l|}
\hline Gen/Transkript & Bezeichnung & Sequenz \\
\hline & DISTR & 5'-actacgaggctgagcacgaa-3' \\
\hline
\end{tabular}

$\mathrm{F}=$ Forward Primer $\mathrm{R}=$ Reverse Primer.

2.1.9.6 Primer für die Amplifikation und Sequenzanalyse der RAD51D-cDNA

\begin{tabular}{|l|l|l|}
\hline Gen/Transkript & Exon/Bezeichnung & Sequenz \\
\hline RAD51D & Ex4_7Fc & 5'-gactgaaattgtaggaggcccaggta-3' \\
\hline & Ex4_7Rc & 5'-cacagttcctgaagaaccagtcacct-3' \\
\hline
\end{tabular}

$\mathrm{F}=$ Forward Primer $\mathrm{R}=$ Reverse Primer.

2.1.9.7 Primer für die Expressionsanalyse des RAD51D-Gens in Lymphozyten

\begin{tabular}{|l|l|l|}
\hline Gen/Transkript & Exon/Bezeichnung & Sequenz \\
\hline RAD51D & E4_6F_cDNA & 5'-gcccaggtagcggcaaaact-3' \\
\hline & E4_6R_cDNAa & 5'-cacagtgcctcggagctcct-3' \\
\hline
\end{tabular}

2.1.9.8 Primer für die Long-Range-PCR des CHEK2-Gens an genomischer DNA aus Lymphozyten

\begin{tabular}{|l|l|l|}
\hline Gen/Transkript & Bezeichnung & Sequenz \\
\hline CHEK2 & LRPC_F1 & 5'-ggttgtgtgtatcacggcttacgg-3' \\
\hline & LRPC_R1 & 5'-atctaatcacctcctaccagtctg-3' \\
\hline
\end{tabular}

2.1.9.9 Primer für die Nested-PCR des CHEK2-Gens an genomischer DNA aus Lymphozyten

\begin{tabular}{|l|l|l|l|}
\hline Gen/Transkript & Exon/Bezeichnung & Sequenz & \\
\hline CHEK2 & Ex11F & 5'-agcctacgtgtcttcttgga-3' $^{\prime}$ & \\
\hline CHEK2 & Ex11R & $5^{\prime}$-ccagtctgtgcagcaatgaa-3' & \\
\hline & Ex12F & $5^{\prime}$-aatgccactgagaatgccac-3' & \\
\hline CHEK2 & Ex12R & $5^{\prime}$-aactcccaccacagcacata-3' & \\
\hline & Ex13F & $5^{\prime}$-ctttctgaatggtggcctgt-3' & \\
\hline CHEK2 & Ex13R & $5^{\prime}$-tcatgtctctcaggcagcag-3' & \\
\hline & Ex14F & $5^{\prime}$-cacataatggcttcgctgtg-3' & \\
\hline CHEK2 & Ex14R & $5^{\prime}$-gtgctggagcgaatcaagtt-3' & \\
\hline & Ex15F & $5^{\prime}$-agaatttcacatcaaatgcccc-3' & \\
\hline
\end{tabular}

$\mathrm{F}=$ Forward Primer; $\mathrm{R}=$ Reverse Primer. 


\subsubsection{Datenbanken und Analyse-Software}

\begin{tabular}{|c|c|}
\hline Programm/Datenbank & Anwendung \\
\hline BIC-(Breast Cancer Information Core)-Datenbank & https://research.nhgri.nih.gov/bic \\
\hline ClinVar von NCBI & http://www.ncbi.nlm.nih.gov/clinvar \\
\hline Chromas Lite 2.1 .1 & Sequenzanalyse, Technelysium Pty Ltd, Australien \\
\hline $\begin{array}{l}\text { Datenbank des Deutschen Konsortiums Familiärer } \\
\text { Brust- und Eierstockkrebs (BRCA2006) }\end{array}$ & $\begin{array}{l}\text { Nur für Mitglieder des Deutschen Konsortiums } \\
\text { Familiärer Brust- und Eierstockkrebs verfügbar }\end{array}$ \\
\hline ExAC - Exome Aggregation Consortium & http://www.exac.broadinstitute.org \\
\hline $\begin{array}{l}\text { HGMD (Human Gene Mutation Database)- } \\
\text { Professional }\end{array}$ & https://portal.biobase-international.com/hgmd \\
\hline Human Splicing Finder Version 3.0 & http://www.umd.be/HSF3/ \\
\hline LOVD v.3.0 (Leiden Open Variation Database) & http://www.lovd.nl/3.0/home \\
\hline MutationTaster & http://www.mutationtaster.org/ \\
\hline NCBI-BLAST & $\begin{array}{l}\text { Überprüfung der Spezifität der Primer } \\
\text { http://blast.ncbi.nlm.nih.gov/Blast.cgi }\end{array}$ \\
\hline PolyPhen-2 & http://genetics.bwh.harvard.edu/pph2/ \\
\hline Primer3, http://frodo.wi.mit.edu/ & Primer Design für PCR \\
\hline SDS Version 2.3 & $\begin{array}{l}\text { qPCR Auswertung, Sequence-Detection-System, PE } \\
\text { Applied Biosystem }\end{array}$ \\
\hline Sequence Pilot, Modul MLPA & MLPA-Analyse, JSI Medical Systems GmbH \\
\hline Sequence Pilot, Modul SeqNext & $\begin{array}{l}\text { DNA-Multi-Gen-Panel-Sequenzanalyse, } \\
\text { JSI Medical Systems GmbH }\end{array}$ \\
\hline Sequence Pilot, Modul SeqPilot & $\begin{array}{l}\text { DNA-Sanger-Sequenzanalyse, JSI Medical Systems } \\
\text { GmbH }\end{array}$ \\
\hline SIFT & http://sift.jcvi.org/ \\
\hline
\end{tabular}

\subsubsection{Geräte}

\begin{tabular}{|l|l|}
\hline Bezeichnung & Firma \\
\hline 2100 Bioanalyzer & Agilent Technologies, Böblingen \\
\hline ABI PRISM ${ }^{\text {TM }} 3130$ Genetic Analyzer & Applied Biosystems, Darmstadt \\
\hline ABI PRISM ${ }^{\text {TM }} 3500 x$ I Genetic Analyzer & Applied Biosystems, Darmstadt \\
\hline Etikettendrucker LabXpert & Brady, Egelsbach \\
\hline Kamera Canon EOS 600D & Canon \\
\hline $\begin{array}{l}\text { Kühlzentrifuge (mit Rotor und Einsätzen für } 50 \mathrm{ml} \\
\text { Reaktionsgefäße), Sigma 4K15 }\end{array}$ & Sigma, Osterode am Harz \\
\hline Magnetständer DynaMag & Invitrogen, Karlsruhe \\
\hline Magnetständer für PCR-Reaktionsgefäße & Promega, Mannheim \\
\hline MultiScreen TM_HTS Vacuum Manifold & Millipore, Schwalbach \\
\hline Nanodrop ND 8000 Spectrometer & PeqLab, Darmstadt \\
\hline
\end{tabular}




\begin{tabular}{|l|l|}
\hline Bezeichnung & Firma \\
\hline PCR Cycler (C1000 Thermal Cycler) & Biorad, München \\
\hline PCR-Plattenschweißgerät & 4titude, Berlin \\
\hline Protean II Gelkammer & Biorad, München \\
\hline Qubit 2.0 Fluorometer & Invitrogen, Karlsruhe \\
\hline UV-Transilluminator & Biostep, Burkhardtsdorf \\
\hline Vakuumpumpe & Millipore, Schwalbach \\
\hline Vortex Mixer 4basic & IKA, Staufen \\
\hline Zentrifuge & Biozym, Hessisch Oldendorf \\
\hline
\end{tabular}

\subsubsection{Herkunft des Patientenmaterials}

Im Rahmen dieser Arbeit wurden molekulargenetische Untersuchungen der 10 Core-Gene an den DNA-Proben aus peripheren Lymphozyten von insgesamt 200 Patienten mit Verdacht auf ein hereditäres Mamma- und Ovarialkarzinom und den vom Deutschen Konsortium Familiärer Brustund Eierstockkrebs definierten und erfüllten Kriterien durchgeführt. Bei allen Patienten erfolgte vor der Untersuchung eine humangenetische Beratung durch einen Facharzt für Humangenetik oder einen Arzt in der Weiterbildung zum Facharzt für Humangenetik. Die Blutproben der Patienten wurden zum Zweck der molekulargenetischen Multi-Gen-Panel-Diagnostik im Institut für Humangenetik der Universitätsmedizin Göttingen (UMG) entnommen oder von auswärtigen Kliniken bzw. niedergelassenen Ärzten zugesandt. Im ersten Schritt wurde möglichst ein Indexpatient auf Keimbahnmutationen in den 10 Core-Genen hin untersucht (Indexpatient = eine erkrankte noch lebende Person) mit den erfüllten Kriterien für eine molekulargenetische Untersuchung. Wenn kein Indexpatient verfügbar war, wurde das rechnerische Risiko des Patienten für eine Anlageträgerschaft einer autosomal-dominant vererbten Mutation mittels des Risikokalkulationsprogramms Cyrillic 2.13 berechnet. Ratsuchende, die das rechnerische Risiko für eine heterozygote autosomal-dominant vererbte Mutation in einem der 10 Core-Gene von $\geq 20$ $\%$ erreicht hatten, wurde ebenfalls eine molekulargenetische Untersuchung der 10 Core-Gene angeboten. Bei Zustimmung des Patienten wurde diese Analyse durchgeführt. Als Untersuchungsmaterial wurde aus den erhaltenen EDTA-Blutproben die genomische DNA aus peripheren Blutlymphozyten isoliert und bis zur molekulargenetischen Analyse bei $4{ }^{\circ} \mathrm{C}$ asserviert.

\subsection{Methoden}

\subsubsection{Diagnostik des hereditären Mamma- und Ovarialkarzinoms}

Aus der Literatur ist bekannt, dass bei 22,5\% der betroffenen Patienten mit Verdacht auf ein hereditäres Mamma- und Ovarialkarzinom Mutationen in den Genen BRCA1 oder BRCA2 identifiziert werden (Engel et al. 2015). Mutationen können aber auch in weiteren Genen (außer den BRCA1- und BRCA2-Genen) auftreten.

Das Institut für Humangenetik der UMG ist Mitglied des Deutschen Konsortiums Familiärer Brustund Eierstockkrebs. Die Mitglieder des o. g. Konsortiums definieren diagnostisch zu untersuchende Gene und therapeutische Konsequenzen bei den nachgewiesenen Mutationen. Weiterhin wurde durch das Konsortium das TruRisk ${ }^{T M}$-Genpanel konzipiert, welches neben den 10 Core-Genen noch weitere 24 Kandidatengene umfasst (s. Tab. $6.2 \mathrm{im}$ Anhang). Innerhalb des Konsortiums wurde festgelegt, dass zunächst die Untersuchung und die Mitteilung der identifizierten Sequenzvarianten der ACMG-Klasse 3, 4 und 5 für die 10 Core-Gene verpflichtend ist. Unter den weiteren 24 Kandidatengenen befinden sich ebenfalls die Gene MLH1, MSH2, MSH6 
und PMS2, die mit dem Hereditären Nicht-Polyposen kolorektalen Karzinom (HNPCC, LynchSyndrom) assoziiert sind, da in mehr als 10 \% der Familien mit Verdacht auf ein hereditäres Mamma- und Ovarialkarzinom, mindestens ein Fall eines kolorektalen Karzinoms auftritt (Meindl et al. 2015).

Diesbezüglich wurde im Institut für Humangenetik die Multi-Gen-Panel-Diagnostik bei Verdacht auf ein hereditäres Mamma- und Ovarialkarzinom etabliert und validiert. Mit Hilfe der NextGeneration-Sequencing (NGS) ist es möglich einen zusätzlichen Anteil der Patienten mit einer hereditären Form des Mamma- und Ovarialkarzinoms zu identifizieren.

Die genomische DNA der Patienten wurde teilweise mit Hilfe des HaloPlex-Panels (umfasst 44 Gene) oder mittels der SureSelect-Technologie im Rahmen des TruRisk ${ }^{\mathrm{TM}}$-Panels (umfasst 34 Gene) angereichert, amplifiziert und nachfolgend mit der NGS-Technologie auf dem Illumina MiSeqSystem sequenziert. Zur Untersuchung von Punktmutationen sowie kleinerer Insertionen, Deletionen und Duplikationen wurden die kodierenden Bereiche einschließlich der Intron-ExonÜbergänge (bis intronische Nukleotidposition - 20 und bis intronische Nukleotidposition +20 ) der 10 Core-Gene analysiert.

Bei spezifischen klinischen Zusatzsymptomen bzw. zusätzlichen Krebserkrankungen beim Indexpatienten selbst oder in der Familie des Indexpatienten konnte über die Analyse der CoreGene hinaus die Auswertung einzelner weiterer Gene selektiv angefordert werden. Die Sequenzen der o. g. Abschnitte dieser Gene wurden ebenfalls vollständig analysiert und ausgewertet.

Weiterhin wurden im Rahmen dieser Studie mit Hilfe der MLPA-Analyse größere Rearrangements (Deletionen/Duplikationen) in den Genen BRCA1, BRCA2, CHEK2, PALB2, RAD51C und RAD51Danalysiert.

\subsubsection{Isolierung und Aufreinigung von Nukleinsäuren}

\subsubsection{Isolierung von genomischer DNA aus EDTA-Blut}

Die genomische DNA wurde automatisiert mit dem Gerät Chemagen MSM I isoliert. Der Chemagen MSM I stellt eine automatisierte Präparationsplattform mit einem Stangenkopf für 12 Proben dar, das der Isolierung von genomischer DNA im Bereich der molekulargenetischen Diagnostik dient. Dazu wurden $50 \mathrm{ml}$ Reaktionsgefäße mit $7 \mathrm{ml}$ EDTA-Blut und $25 \mu \mathrm{l}$ Protease abgefüllt. Die DNA-isolierung erfolgte mit Hilfe von Magnetic Beads. Alle weiteren Schritte erfolgten nach Angaben des Herstellers. Die extrahierte genomische DNA wurde im geschlossenen Eppendorf-Cup bei $4{ }^{\circ} \mathrm{C}$ gelagert.

\subsubsection{Isolierung von Gesamt-RNA aus PAXGene-Blut}

Nach der Blutentnahme musste zunächst eine Lyse für 2 Stunden in den PAXgene-Monovetten bei Raumtemperatur stattfinden. Die Gesamt-RNA wurde aus $2,5 \mathrm{ml}$ Vollblut mit dem PAXgene ${ }^{\circledR}$ Blood RNA-Kit (PreAnalytix) entsprechend den Herstellerangaben extrahiert. Nachdem die Gesamt-RNA extrahiert war, konnte sie bis zur weiteren Verwendung bei $-80^{\circ} \mathrm{C}$ gelagert werden.

\subsubsection{3 cDNA-Synthese}

Für die cDNA-Synthese wurden $11 \mu \mathrm{L}$ der Gesamt-RNA (1 $\mu \mathrm{g}$ RNA) in ein 1,5 mL EppendorfReaktionsgefäß aliqoutiert und $2 \mu$ l der Oligo-dT- oder der Random Hexamer-Primer (jeweils 10 $\mathrm{mM}$ ) und $2 \mu \mathrm{l}$ der $10 \mathrm{mM}$ dNTPs zugegeben. Dieser Reaktionsansatz wurde für 5 Minuten bei 65 ${ }^{\circ} \mathrm{C}$ inkubiert und danach sofort auf Eis gestellt. Es wurden $4 \mu \mathrm{l} 5 \mathrm{x}$,First Strand“ Puffer und $2 \mu \mathrm{l}$ DTT (Dithiothreitol) hinzugegeben. Die Reaktionsansätze wurden durch Auf- und Abpipettieren gemischt und für 2 Minuten bei $42{ }^{\circ} \mathrm{C}$ inkubiert. Es wurde $1 \mu \mathrm{l}$ der "SuperScript"-Reverse Transkriptase dazugegeben und erneut durch Auf- und Abpipettieren gemischt. Dieser Reaktionsansatz wurde für 50 Minuten bei $42^{\circ} \mathrm{C}$ inkubiert. Um das Enzym durch Hitze inaktivieren zu können, erfolgte eine Inkubation für 2 Minuten bei $70^{\circ} \mathrm{C}$. Die Qualität der synthetisierten cDNA 
wurde mittels Amplifikation des Houskeeping Gens GAPDH und anschließender gelelektrophoretischer Trennung der PCR-Produkte qualitativ beurteilt. Die synthetisierte cDNA konnte bei $-20^{\circ} \mathrm{C}$ bis zum Gebrauch gelagert werden.

\subsubsection{Konzentrationsbestimmung von Nukleinsäuren}

Die Konzentration von Nukleinsäuren wurde mit einem Spektralphotometer (BioPhotometer 6131) bestimmt. Zunächst wurden die Nukleinsäuren entsprechend verdünnt. Dazu wurden $3 \mu \mathrm{l}$ Nukleinsäure (genomische DNA bzw. RNA) mit $297 \mu \mathrm{l} \mathrm{H}_{2} \mathrm{O}$ auf ein Gesamtvolumen von $300 \mu \mathrm{l}$ gebracht. Die Bestimmung der Konzentration der genomischen DNA-Probe erfolgte mit der Messung der Absorption der Nukleinsäurelösung bei $260 \mathrm{~nm}$ jeder einzelnen genomischen DNAProbe bzw. jeder einzelnen RNA-Probe. Das BioPhotometer verfügt über eine integrierte Software, die eine Berechnung der Konzentration auf Basis der gewählten Methode (dsDNA, RNA) sowie der Verdünnung automatisch ermöglicht. Die Nukleinsäurekonzentration wurde nach folgender Formel berechnet:

$$
\begin{aligned}
& C[\mu \mathrm{g} / \mu \mathrm{l}]=\mathrm{E}_{260} \times \mathrm{f} \times \mathrm{C} \\
& C=\text { Nukleinsäurekonzentration der Ausgangslösung } \\
& \mathrm{E}=\text { Extinktion } \\
& f=\text { Verdünnungsfaktor } \\
& c=\text { nukleinsäurespezifischer Koeffizient in } \mu \mathrm{g} / \mu \mathrm{l} \\
& \text { für doppelsträngige DNA: } \\
& \text { für RNA: } \\
& c=0,05 \\
& c=0,04
\end{aligned}
$$

\subsubsection{Amplifikation der DNA mit Hilfe der Polymerase-Kettenreaktion (PCR)}

Die Technik der Polymerasen-Kettenreatkion (PCR) ist eine enzymatische Methode für die in-vitroAmplifikation spezifischer DNA-Fragmente (Saiki et al. 1988). Die Spezifität dieser Amplifikation basiert auf einem Oligonukleotidprimerpaar, das das zu amplifizierende DNA-Segment flankiert und nach einer Hitzedenaturierung an den komplementären Strängen bindet. Die hitzestabile DNA-Polymerase synthetisiert bei ihrer optimalen Temperatur die DNA entlang der Region zwischen den Primern. In der PCR dienen die neu synthetisierten DNA-Stränge ebenso wie die eingesetzte gDNA als Matrize und tragen so dazu bei, dass in jedem Synthesezyklus (mit Ausnahme der beiden ersten Zyklen) die Menge an PCR Produkt theoretisch verdoppelt wird. Durch sich wiederholende Zyklen von Denaturierung der DNA-Stränge, die als Annealing

\begin{tabular}{|c|c|c|c|}
\hline $94^{\circ} \mathrm{C}$ & $5 \mathrm{~min}$ & Vordenaturierung & \\
\hline $94^{\circ} \mathrm{C}$ & $30 \mathrm{~s}$ & Denaturierung & \\
\hline $55-65^{\circ} \mathrm{C}$ & $45 \mathrm{~s}$ & Annealing & 30 - 35 Zyklen \\
\hline $72^{\circ} \mathrm{C}$ & $1 \mathrm{~min} / \mathrm{kb}$ & Elongation & \\
\hline $72^{\circ} \mathrm{C}$ & $7 \mathrm{~min}$ & Abschlusselongation & \\
\hline
\end{tabular}
bezeichnete Anlagerung der Primer und die Elongation des DNA-Stranges wird eine exponentielle Vermehrung des jeweiligen DNA-Fragments erreicht. Der Bereich der exponentiellen Produktzunahme ist nicht beliebig groß. Das Prozessieren und die Effizienz der DNA-Polymerase nimmt mit zunehmender Zyklenzahl ab, da das Enzym sowohl durch die hohen Temperaturen im Zuge der Denaturierungsphasen als auch durch die im Reaktionsverlauf zunehmende Ansäuerung des Milieus (DNA besitzt saure Eigenschaften) geschädigt wird.

Die Ansätze wurden in einem Thermocycler mit folgendem PCR-Programm für 30 - 35 Zyklen inkubiert.

\subsubsection{Quantitative Real-Time PCR an genomischer DNA und an CDNA}

Die Real-Time PCR bezeichnet ein Verfahren, bei dem während der PCR die Menge der entstandenen Produkte in Echtzeit gemessen wird. Wie bei der klassischen PCR kommt es bei der 
quantitativen Real-Time PCR (qRT PCR) zu einer gezielten Vervielfältigung eines DNA-Bereichs invitro. Bei der qRT PCR wird die Zunahme der Produktmenge während jedes einzelnen Zyklusses der PCR gemessen, sodass man dem Reaktionsverlauf in Echtzeit folgen kann. Diese Technik wurde benutzt um die Ausweitung der Deletionen bzw. Duplikationen in den zu analysierenden Genen genauer bestimmen zu können, falls dies mit einer anderen Methode wie z. B. der CNVAnalyse (Kopienzahlanalyse mittels NGS) oder mittels der MLPA-Analyse nicht abschließend beurteilt werden konnte.

Die Technik der qRT PCR basiert auf dem grundlegenden Prinzip des Fabrstoffes SYBR ${ }^{\circledR}$ Green. Der Fluoreszenzfarbstoff SYBR $^{\circledast}$ Green ist ein asymmetrischer Cyanin-Farbstoff, der mit doppelsträngiger DNA interkaliert. Während bei der PCR Amplifikationsprodukte entstehen, interkaliert das im Reaktionsansatz enthaltene $\mathrm{SYBR}^{\circledR}$ Green mit diesen Produkten. Die Fluoreszenz kann nach Anregung des Farbstoffes mit einem Laser gemessen werden. Die Zunahme der Fluoreszenz ist dabei proportional zu der entstandenen Produktmenge. In der exponentiellen Phase der Reaktion, in der die volle Aktivität der Polymerase vorherrscht und genügend Materialien (Primer, $\mathrm{MgCl}_{2}$ ) vorliegen, wird der Threshold-Wert bestimmt und anhand des PCR-Zyklus, in dem dieser erreicht wird, werden die anschließenden Berechnungen zur Quantifizierung vorgenommen (Ct-Wert $=$ engl. cycle threshold für Schwellenwert-Zyklus).

Vor dem Ansetzen der Reaktionsansätze wurde von den zu analysierenden Patientenproben die Konzentration der präparierten DNA photometrisch mit dem Eppendorf BioPhotometer 6131 ermittelt. Parallel zu den Patientenproben wurden eine Standard-DNA (männlich; Human DNA male, Art\#360486, $10 \mathrm{ng} / \mu \mathrm{l}$ ) sowie eine Positiv-(soweit verfügbar)- und eine Negativkontrolle („Wildtyp“) entsprechend vermessen. Ausgehend von der ermittelten Konzentration der jeweiligen Nukleinsäure wurden die Patientenproben und die Positivkontrolle mit Ampuwa Wasser jeweils auf eine Konzentration von $1,25 \mathrm{ng} / \mu$ l verdünnt.

Um die Primer verdünnen zu können, wurde ein Gemisch der einzusetzenden Primer (forward und reverse) mit Ampuwa-Wasser mit einer Endkonzentration von 1 pmol $/ \mu \mathrm{l} \mathrm{je} \mathrm{Primer} \mathrm{im} \mathrm{Primer-}$ Mix angesetzt.

Zunächst wurden alle benötigten Komponenten bereitgestellt und im Prä-PCR-Labor aufgetaut. Das SYBR ${ }^{\circledast}$ Green Mix wurde auf einem Kühlblock im Prä-PCR Labor bereitgestellt. Nachdem alle Komponenten vollständig aufgetaut waren und durch kurzes Vortexen gemischt wurden, wurde je 2,5 $\mu \mathrm{l}$ des Primer-Mixes pro Reaktion in die 384-Loch-Platte verteilt. Die Platte wurde danach für 2 Minuten bei 1.500 rpm zentrifugiert.

Anschließend wurde ein Master-Mix entsprechend der Anzahl der zu untersuchenden Proben einschließlich der Leerkontrolle und Positivkontrolle in einem Reaktionsgefäß vorbereitet, der aus der genomischen DNA und dem SYBR ${ }^{\circledR}$ Green Mix besteht. Die Komponenten der vorbereiteten Master-Mixe wurden durch kurzes Vortexen vollständig gemischt und dann entsprechend der Belegung der 384-Loch-Platte mit einer Pipette je 7,5 $\mu$ l pro Reaktion verteilt.

Die Platte wurde sorgfältig verschlossen. Um die Luftblasen zu eliminieren wurde die Platte noch einmal für 10 Minuten bei $3.000 \mathrm{rpm}$ abzentrifugiert und schließlich für die Ermittlung der Daten in den ABI PRISM ${ }^{T M} 7900 H T$ Fast Real-Time PCR-System geladen. Die ermittelten Rohdaten wurden mit dem Programm SDS Software (Version 2.3) ausgewertet und in Excel (Microsoft) für weitere Berechnungen exportiert.

Die quantitative Real-Time PCR ( $q R T$ PCR) an der cDNA erfolgte im Prinzip nach dem Protokoll der qRT PCR an der genomischen DNA. Die zuvor eingesetzte Menge der Kontroll-RNA und der Patienten-RNA (von Fall zu Fall unterschiedlich) wurde für den jeweiligen Versuchsansatz in die cDNA umgeschrieben. Somit wurde davon ausgegangen, dass in jedem Versuch die identische Menge an cDNA entsteht. In jedem Versuchsansatz für die cDNA-Synthese wurde $1 \mu \mathrm{gg}$ der Gesamt-RNA eingesetzt. Die aus der RNA gewonnene cDNA wurde anschließend 1:20 mit $\mathrm{H}_{2} \mathrm{O}$ verdünnt. Der Versuchsansatz für die qRT PCR-Analyse beinhaltete 2,5 $\mu \mathrm{l}$ cDNA, 2,5 $\mu \mathrm{l}$ 
genspezifische Primer (forward und reverse, jeweils $1 \mathrm{pmol} / \mu \mathrm{l}$ ) und 5,0 $\mu \mathrm{l} \mathrm{SYBR}{ }^{\circ} \mathrm{Green}$. Als Kontrolle wurden spezifische Primer für das Houskeeping-Gen LDAH (s.Tab. 2.1.9.3) verwendet. Nach der qRT PCR-Analyse wurden die erhaltenen Daten mittels des Programms SDS Software (Version 2.3) ausgewertet und in Excel (Microsoft) für weitere Berechnungen exportiert.

\subsubsection{Multiplex Ligation-dependent Probe Amplification (MLPA)-Analyse}

Die Multiplex Ligation-dependent Probe Amplification (MLPA)-Analyse ist eine Methode zur relativen quantitativen Darstellung der Kopienzahl in bis zu 50 unterschiedlichen genomischen DNA bzw. RNA Proben in einem Versuchsansatz. Die MLPA-Methode ermöglicht anhand von Dosisunterschieden Rückschlüsse auf Duplikationen und Deletionen in definierten Regionen im Genom (Schouten et al. 2002). Die MLPA-Analyse basiert auf einer indirekten Amplifikation einer Zielsequenz, d. h. auf der Amplifikation einer Sonde, die komplementär zu der Zielsequenz ist. Hierzu wird ein Sondenpaar an die Proben-DNA hybridisiert. Eine MLPA-Reaktion lässt sich grundsätzlich in fünf Reaktionsschritte unterteilen: die DNA-Denaturierung und die Hybridisierung der Sonden, die Ligationsreaktion, die PCR-Reaktion, die elektrophoretische Trennung der PCRProdukte auf dem ABI PRISM ${ }^{T M} 3130$ Genetic Analyser und die Detektion der Fluoreszenzsignale sowie die Datenauswertung. Die Sequenzen des Sondenpaares sind so gewählt, dass sie im Genom nebeneinander positioniert sind und daher von einer thermostabilen Ligase verknüpft werden können. In einem zweiten Schritt werden die ligierten Sondenpaare per PCR amplifiziert. Wenn die Zielsequenz der Sondenpaare im Genom mutiert vorliegt, können die Sondenpaare $u$. $U$. nicht binden bzw. sich zusammenlagern und es entsteht kein PCR-Produkt. Liegt eine untersuchte Region dupliziert bzw. deletiert vor, schlägt sich dies in einem signifikanten Dosisunterschied der PCR-Produkte nieder. Die durchschnittliche Größe der PCR Produkte beträgt in den kommerziell erhältlichen Kits von MRC Holland ca. 130 bp - 480 bp. Die einzelnen eingesetzten Sonden unterscheiden sich durch eine unterschiedlich lange Stuffer-Sequenz, sodass die PCR Produkte anschließend elektrophoretisch auf dem ABI PRISM ${ }^{T M} 3130$ Genetic Analyser getrennt werden können. Durch den quantitativen Vergleich der PCR-Produkte im Versuchsansatz der DNA-Probe mit einer Kontrollprobe werden die Abweichungen detektiert. Durch eine Fluoreszenzmarkierung eines der beiden eingesetzten universellen Primer wurden die ermittelten Daten schließlich in einem automatisierten Verfahren durch herkömmliche Fragmentanalyse mit dem Programm SequencePilot im Modul MLPA ausgewertet.

In dieser Dissertation wurden fünf verschiedene MLPA-Kits mit den entsprechenden Genen von MRC-Holland verwendet (s. Tab. 2.1).

Tabelle 2.1: Verwendete MLPA-Kits zur Detektion von genomischen Deletionen und Duplikationen

\begin{tabular}{|c|l|}
\hline MLPA-Kit & Gene \\
\hline P002-D1 & BRCA1 \\
\hline P045-B3 & BRCA2 \\
\hline P190-C1 & CHEK2, ATM (Exons 1, 4, 22, 27, 44, 49, 56), PTEN-(Exons 3, 5, 6, 7, 9), TP53-(Exons 3, 11) \\
\hline P260-B1 & PALB2, RAD51C, RAD51D, RAD50 (Exons 1, 2, 4,10, 14, 21, 23 und 25) \\
\hline P072-C1 & $\begin{array}{l}\text { EPCAM (Exon 3, } 8 \text { und 9), KCNK12 (Exon 2), MLH1 (Exon 1), MSH2 (Exon 1), MSH6, } \\
\text { MUTYH (Exon 4, 5, 18) }\end{array}$ \\
\hline
\end{tabular}

\subsubsection{Analyse der Promotormethylierung des MLH1-Gens}

Methylierungen des MLH1-Gens im Promotorbereich führen zum Verlust der Expression von MLH1 und PMS2 im Tumorgewebe des kolorektalen Karzinoms und sind charakteristisch für sporadische kolorektale Karzinome (Bettstetter et al. 2008). Menigatti et al. (2001) zeigten zwei Promotorbereiche mit der höchsten CpG-Dichte im Promotor von MLH1 (proximaler Bereich: intronische Position - 294 bis - 157 vor dem Startcodon ATG des MLH1-Gens und distaler Bereich: intronische Position - 716 bis - 563 vor dem Startcodon ATG des MLH1-Gens). Eine 
Hypermethylierung dieser Promotorbereiche führt zum Verlust der Expression von MLH1 und PMS2. Dabei wird ein Schwellenwert von etwa $\geq 20 \%$ Methylierung im Tumor angenommen. Für die Analyse der Promotormethylierung wurde die DNA aus dem FFPE-Gewebe (Formalin-fixiertes Paraffin-eingebettetes Gewebe) mit dem DNeasy ${ }^{\circledR}$ Blood \& Tissue-Kit nach dem Protokol des Herstellers in der Abteilung Pathologie der UMG isoliert. Die Methylierungsanalyse basiert auf der methylierungssensitiven Digestion mit der Endonuklease Hin6l und den nichtmethylierungsspezifischen Endonukleasen Xbal/Dral und der nachfolgenden Quantifizierung der Methylierung mittels Real-Time PCR. Für jede Probe wurden zwei Restriktionsanalysen vorbereitet (eine Quantifizierungsrestriktion mit dem Enzym Hin6I und eine Kalibrierungsrestriktion mit den Enzymen Xbal/Dral). Das Restriktionsenzym Hin6I schneidet dabei nur die nichtmethylierte Erkennungssequenz 5'-GCGC-3'. Wenn die Erkennungssequenz methyliert vorliegt, ist die Restriktion blockiert. Die Primer der folgenden Real-time PCR-Analyse enthalten Hin6ISchnittstellen, d. h. nur der hypermethylierte MLH1-Promotor bleibt nach der Restriktionsanalyse mit Hin6l als Template erhalten. Schnittstellen für Xbal und Dral sind in diesen Promotorfragmenten nicht enthalten. Diese dienen der Fragmentierung der genomischen DNA, damit identische PCR-Effizienzen gelten (Bettstetter et al. 2008).

Die restringierten DNA-Proben werden als Templates in die Real-time PCR eingesetzt und deren Ct-Werte (engl. cycle threshold für Schwellenwert-Zyklus) bestimmt. Der Anteil der methylierten Templates wird aus der Differenz aus Kalibrator-Real-time PCR und Quantifizierungs-Real-time $\mathrm{PCR}$ als $\triangle \mathrm{Ct}$-Wert berechnet. Die Formel $\mathrm{E}^{\Delta \mathrm{Ct}} \mathrm{x} 100$ ergibt den Anteil der methylierten DNAMoleküle (\%) der Probe (E = PCR-Effizienz) (Bettstetter et al. 2008). Als Kontrolle diente DNA aus dem korrespondierenden normalen kolorektalen Gewebe der zu untersuchenden Tumorprobe. Das Ausbleiben der Amplifikation bei der nachfolgenden quantitativen Real-time PCR mit der Hin61-restringierten DNA zeigte eine $0 \%$-ige Methylierung des MLH1-Promotors an.

\subsubsection{Histologische Beurteilung und Rezeptorstatus der Mammakarzinome}

83,5 \% der Mammakarzinome wurden histologisch untersucht und somit der histologische Subtyp des Mammakrzinoms bestimmt. Ebenso wurde die Expression der Östrogen- $\alpha$ - $(E R \alpha)$ - und Progesteron-(PR)-Rezeptoren sowie die Überexpression des ERBB2-Rezeptors im Tumorgewebe analysiert. Diese Untersuchungen erfolgten in der Mehrzahl der Fälle durch Kollegen aus der Abteilung Pathologie der UMG, oder wurden von auswärtigen Kollegen der Pathologie vorgenommen.

Die o. g. Untersuchungen wurden nach den internen Protokollen der jeweiligen Abteilungen für Pathologie durchgeführt. In den pathologischen Befunden der Abteilung für Pathologie der UMG oder in den Befunden von externen Kollegen der Pathologie wurde die histologische Klassifizierung der Mammakarzinome mitgeteilt. Zusätzlich wurde in diesen Befunden nur darüber berichtet, ob eine Expression der ER $\alpha$ - und PR-Rezeptoren im Tumor vorlag oder ob diese Rezeptoren nicht exprimiert wurden (Angabe im Befund: „positiv“ oder "negativ") und ob der ERBB2-Rezeptor überexprimiert vorlag (Angabe im Befund: „positiv“ oder „negativ“).

\subsubsection{DNA-Sequenzanalyse}

Bei der DNA-Sequenzierung nach Sanger (auch als Dideoxymethode, Kettenabbruchmethode oder Sanger-Sequenzierung bezeichnet) handelt es sich grundsätzlich um die Analyse der primären, linearen Basenzusammensetzung von DNA (Sanger et al. 1977). Ausgehend von einem kurzen DNA-Stück bekannter Sequenz (Primer) wird durch eine DNA-Polymerase einer der beiden komplementären DNA-Stränge in einer zyklischen Reaktion aus der Denaturierung, der PrimerAnlagerung und der Elongation verlängert. In dem Reaktionsansatz sind neben den vier Deoxynukleotidtriphosphate (dNTPs) auch die vier modifizierten Dideoxynukleotidtriphosphate (ddNTPs) vorhanden. Da bei den ddNTPs am 3-C-Atom die Hydroxylgruppe fehlt, kann ein nukleophiler Angriff des O-Atoms auf das $\alpha$-P-Atom des neu hinzukommenden dNTPs (oder 
ddNTPs) nicht erfolgen. Der DNA-Strang kann nicht weiter verlängert werden, wenn als 3'terminales Nukleotid ein ddNTP eingebaut worden ist. Die wachsende Kette wird abgebrochen. Da die dNTPs und ddNTPs mit nahezu der gleichen Wahrscheinlichkeit in den wachsenden DNAStrang eingebaut werden können, wird diese wachsende Kette statistisch an jeder Stelle wenigstens einmal abgebrochen. Als Folge enthält das Reaktionsgemisch Sequenzprodukte unterschiedlicher Länge. In dem Reaktionsgemisch sind üblicherweise alle vier ddNTPs vorhanden. Jedes ddNTP trägt einen für die jeweilige Base spezifischen terminalen Fluoreszenzfarbstoff. Werden die Fluoreszenzfarbstoffe angeregt (z. B. durch einen Argon-Laser), emittiert jedes ddNTP eine Fluoreszenz spezifischer Wellenlänge, sodass zwischen den vier Bausteinen (ddATP, ddCTP, ddGTP und ddTTP) unterschieden werden kann. Das Reaktionsgemisch enthält i. d. R. nur einen Primer, sodass die Verlängerung der DNA einem linearen Profil folgt. Die unterschiedlich langen Sequenzprodukte können elektrophoretisch in einer hochauflösenden Matrix getrennt, die terminal gekoppelten Fluoreszenzfarbstoffe angeregt und mit Hilfe eines komplexen optischen Systems detektiert werden.

Ausgangsmaterial für die Sequenzierung nach Sanger sind PCR-Produkte der zu analysierenden DNA-Abschnitte.

Für die Sequenzierung wurden alle benötigten Komponenten des Reaktionsansatzes bereitgestellt und aufgetaut. Die benötigten Primer Mixes wurden aufgetaut und eine entsprechende Arbeitslösung mit einer Konzentration von $10 \mu \mathrm{M}$ vorbereitet. Entsprechend der Anzahl der Reaktionen inklusive Leerwert und berechnet für ein Endvolumen von $10 \mu \mathrm{l}$ pro Reaktion wurde ein Master-Mix vorbereitet, der allgemein Big Dye ${ }^{\circledR}$ Terminator v3.1 Cycle Sequencing Kit, 5x Sequencing Puffer, Primer (forward oder reverse, jeweils $10 \mu \mathrm{M}$ ) und $\mathrm{H}_{2} \mathrm{O}$ (Ampuwa-Wasser oder Wasser vergleichbarer Qualität und Reinheit) enthielt.

Der Master-Mix wurde entsprechend der vorbereiteten Liste bzw. des Plattenbelegungsplanes auf die einzelnen Reaktionsgefäße aufgeteilt. Anschließend wurde das gereinigte PCR-Produkt zugegeben. Die Sequenzansätze wurden nach der Zugabe des PCR Produkts sorgfältig verschlossen, in ein PCR-Gerät gestellt und das entsprechende PCR-Programm gestartet. Die Kettenabbruchreaktion wurde als PCR in einem Thermocycler mit dem folgenden PCR-Programm durchgeführt:

\begin{tabular}{|c|c|c|}
\hline $95^{\circ} \mathrm{C}$ & $1 \mathrm{~min}$ & Vordenaturierung \\
\hline $95^{\circ} \mathrm{C}$ & $20 s$ & Denaturierung \\
\hline $60^{\circ} \mathrm{C}$ & $30 s$ & Annealing \\
\hline $72{ }^{\circ} \mathrm{C}$ & $3 \mathrm{~min}$ & Elongation \\
\hline $72{ }^{\circ} \mathrm{C}$ & $7 \mathrm{~min}$ & Abschlusselongation \\
\hline
\end{tabular}

Anschließend wurde der Ansatz mit $10 \mu \mathrm{l} \mathrm{H}_{2} \mathrm{O}$ aufgefüllt und über eine Sephadex ${ }^{T M} \mathrm{G}-50$ Multiscreen-HTS Platte aufgereinigt.

Nachdem die Sequenzprodukte durch Zentrifugation bei 910xg für 5 Minuten eluiert wurden, wurden die Produkte entweder gleich zur Ermittlung der Sequenzdaten weiter auf den ABI PRISM $^{\mathrm{TM}}$ 3500x Genetic Analyzer bzw. den ABI PRISM ${ }^{\mathrm{TM}} 3130$ Genetic Analyzer gebracht oder bis zur weiteren Verarbeitung bei $-20^{\circ} \mathrm{C}$ gelagert. Die Auswertung der Sequenzen erfolgte mit der Software Sequence Pilot im Modul SeqPatient.

Diese Methode wurde zur Bestätigung der bei der Multi-Gen-Analyse (NGS; s. Abschnitt 2.2.9) identifizierten Sequenzvarianten der ACMG-Klasse 3, 4 oder 5 und zur Nachsequenzierung der mittels NGS nicht ausreichend abgedeckten Bereiche (s. auch Ergebnisse, Abschnitt 3.3.1) angewandt.

\subsubsection{Multi-Gen-Panel-Diagnostik}

Im Institut für Humangenetik der UMG wurde im ersten Schritt das HaloPlex Target Enrichment System Multi-Gen-Panel der Firma Agilent etabliert und validiert. Die ersten 28 analysierten 
Patienten in dieser Dissertation wurden daher mit diesem System untersucht (für die Liste der Gene auf dem HaloPlex-Panel s. Anhang Tab. 6.1). Da die Abdeckung der Sequenzen dieser Methode in vielen Genabschnitten nicht ausreichend war und viele Nachsequenzierungen mit Hilfe der Sanger-Methode notwendig waren, wurde im nächsten Schritt das TruRisk ${ }^{T M}$-Multi-GenPanel vom Deutschen Konsortium Familiärer Brust- und Eierstockkrebs eingeführt bzw. etabliert und validiert.

\subsubsection{Das Prinzip des HaloPlex Target Enrichment Systems}

Das HaloPlex Target Enrichment System der Firma Agilent Technologies ermöglicht eine parallele Anreicherung und Analyse einer großen Anzahl von Genen (Multi-Gen-Panel-Diagnostik), die in einem Design mit der Software SureSelect definiert wurden. Für die Untersuchung wurde das „HaloPlex Target Enrichment System von Agilent Technologies" Protokoll Version F1, Juli 2015 zugrunde gelegt.

Der Prozessfluss zur Anreicherung der in einem Panel festgelegten Genregionen umfasst vier wesentliche Schritte:

A) Enzymatische Fragmentierung der genomischen DNA mit acht unterschiedlichen Restriktionsendonukleasen (s. Abb. 2.1 A).

B) Hybridisierung der biotinylierten HaloPlex-Sonden für die Anreicherung der Zielregionen (die HaloPlex-Sonden binden an beide Enden der Zielregion, wodurch - über diese Sonden vermittelt - eine Zirkularisierung der Zielregionen erreicht wird. In diesem Schritt wird auch die Index-Sequenz zur Unterscheidung der einzelnen Proben eingebracht) (s. Abb. 2.1 B).

C) Reinigung der durch die Sonden gebundenen DNA-Fragmente und Ligation (die durch die Sonden gebundenen Fragmente wurden über magnetische Streptavidin-Beads gereinigt und ligiert) (s. Abb. 2.1 C).

D) Amplifikation der gereinigten Zielregionen (s. Abb. 2.1 D).

A) Enzymatische Fragmentierung der genomischen DNA.

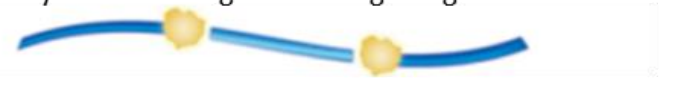

B) Hybridisierung der biotinylierten HaloPlex-Sonden für die Anreicherung der Zielregionen.

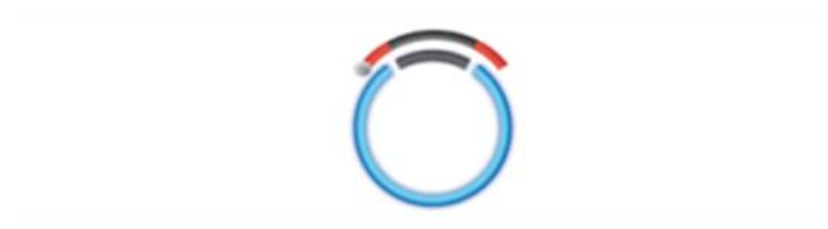

C) Reinigung der durch die Sonden gebundenen DNA-Fragmente und Ligation.

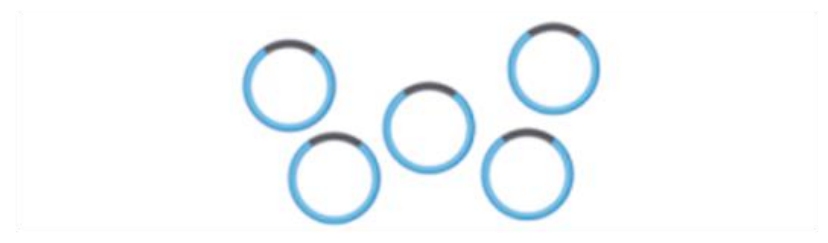

D) Amplifikation der gereinigten Zielregionen.

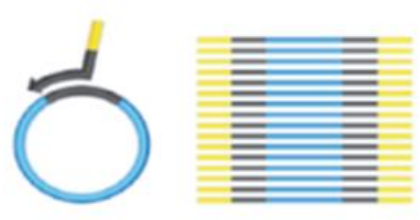

Abbildung 2.1: Wesentliche Schritte im Prozessfluss des HaloPlex Target Enrichment Systems (modifiziert nach dem Protokoll HaloPlex Target Enrichment System Agilent Technologies; Protokoll Version F1, Juli 2015). 


\subsection{Konzentrationsbestimmungen der genomischen DNA (gDNA)}

Die genomischen DNA-Proben wurden zunächst mit Hilfe des Nucleo Spin gDNA Clean up Kits nach Angaben des Herstellers aufgereinigt. Die gereinigten Proben wurden parallel sowohl mit dem QuBit v2.0 als auch mit dem Nanodrop ND 8000 gemessen. Die mit dem QuBit 2.0 ermittelte Konzentrationsdoppelbestimmung diente direkt als Grundlage zur Berechnung der einzusetzenden Konzentration der Proben in die HaloPlex-Anreicherung. Die Qualitäts- und Konzentrationsbestimmung der gereinigten Proben erfolgte mittels Nanodrop ND 8000. Diese Daten dienten der qualitativen Überprüfung der Proben (Anwesenheit niedermolekularer Salze, etc.). Aus der Doppelbestimmung wurde eine $5 \mathrm{ng} / \mu \mathrm{l}$ Arbeitskonzentration hergestellt. Für die qualitative Überprüfung der DNA mittels Agarosegelelektrophorese wurden die gereinigte gDNA, die $50 \mathrm{ng} / \mu \mathrm{l}$ - und die $5 \mathrm{ng} / \mu \mathrm{l}$-Verdünnung nebeneinander aufgetragen.

\subsection{Fragmentierung der genomischen DNA}

Ausgehend von den mit dem Qubit 2.0 ermittelten Konzentrationswerten wurde die DNAKonzentration von $225 \mathrm{ng}$ in $45 \mu \mathrm{l}$ hergestellt $(\hat{=} 5 \mathrm{ng} / \mu \mathrm{l}) .45 \mu \mathrm{l}$ der Kontroll-DNA (Enrichment Control DNA; ECD) wurde in ein PCR-Cup überführt. Für die DNA-Fragmentierung wurde der Restriktions-Master-Mix angesetzt (s. Tab. 2.2).

Tabelle 2.2: Master-Mix für die Restriktionsanalyse

\begin{tabular}{|c|c|c|}
\hline Komponenten & Volumen pro Reaktion in $\mu \mathrm{l}$ & Volumen für 7 Reaktionen in $\mu \mathrm{l}$ \\
\hline RE-Puffer & 34,00 & 238,00 \\
\hline BSA-Lösung & 0,85 & 5,95 \\
\hline Gesamtvolumen & 34,85 & 243,95 \\
\hline
\end{tabular}

RE-Puffer = Puffer mit Restriktionsenzym; BSA = Bovine Serum Albumine.

Der Restriktions-Master-Mix wurde auf 8er-Strip Reaktionsgefäße verteilt. Pro Restriktionsansatz (Well) wurden mindestens $4 \mu \mathrm{l}$ benötigt. In die vorbereiteten Reaktionsgefäße wurden aus den 8er-Strips HaloPlex Kit mit einer 8-Kanal-Pipette Restriktionsenzyme markiert mit grün $(0,5 \mu \mathrm{l}$ pro Reaktion) und markiert mit rot $(0,5 \mu$ l pro Reaktion) dazugegeben, kurz auf dem Vortex gemischt und abzentrifugiert. Jeweils $5 \mu$ des fertigen Restriktions-Master-Mixes wurden mit einer 8-KanalPipette in eine 96-Well-Platte aliquotiert (s. Abb. 2.2). Pro Well wurden $5 \mu$ DNA $(5 \mathrm{ng} / \mu \mathrm{l})$ dazugegeben (s. Abb. 2.2).

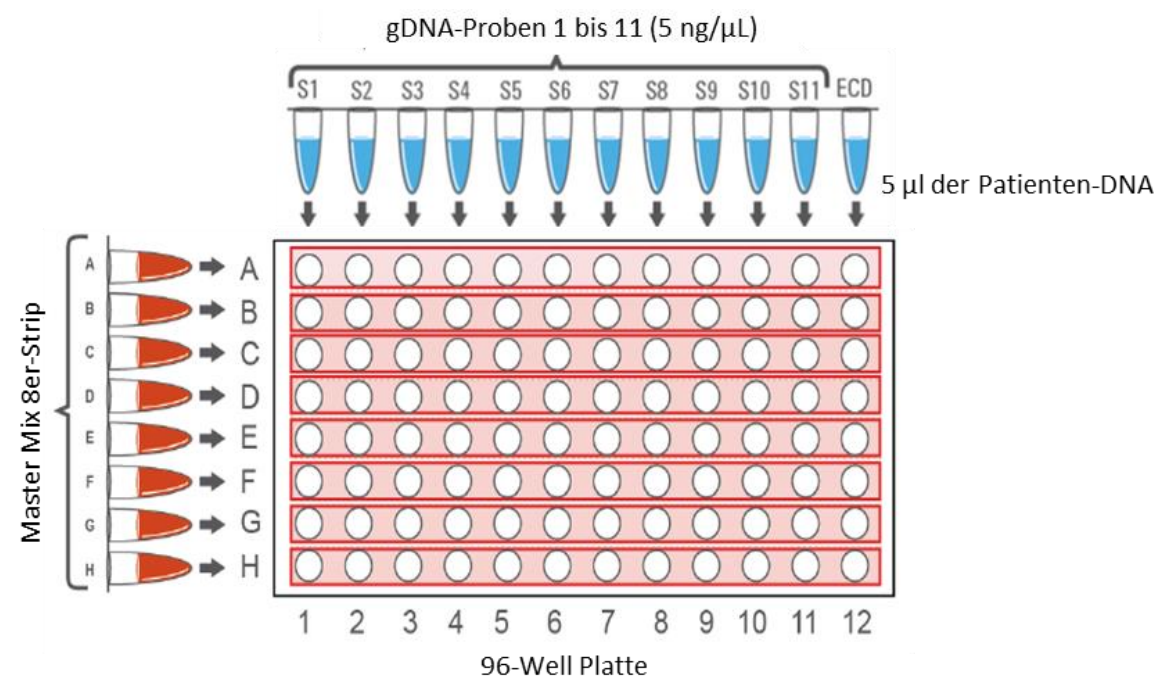

Abbildung 2.2: Aliquotierung des Restriktions-Master-Mixes in eine 96-Well-Platte und Zugabe der genomischen DNA (gDNA) der Patienten (modifiziert nach HaloPlex Target Enrichment System; Protokoll Version F1, Juli 2015). Jeweils $5 \mu$ l des fertigen Restriktions-Master-Mixes wurden mit einer 8-Kanal-Pipette 
in eine 96-Well-Platte aliquotiert (links in rot). Pro Well wurden $5 \mu$ l DNA $(5 \mathrm{ng} / \mu \mathrm{l})$ dazugegeben (oben in blau). S1 bis S11 = DNA-Proben (Samples) der Patienten. ECD = Enrichment Control DNA (Kontroll-DNA).

Die 96-Well-Platte wurde mit einer Folie auf dem Schweißgerät verschlossen, kurz abzentrifugiert und in ein PCR-Gerät bei $37{ }^{\circ} \mathrm{C}$ für 30 Minuten gesetzt. Das Abkühlen erfolgte bei $8{ }^{\circ} \mathrm{C}$. Die Restriktions-Reaktionsansätze konnten danach bis zu ihrer Weiterverarbeitung bei $-20{ }^{\circ} \mathrm{C}$ eingefroren werden.

Die Restriktionsreaktion wurde anhand der ECD mittels BioAnalyzer qualitativ überprüft. Es wurden jeweils $4 \mu \mathrm{l}$ der $E C D$ Kontrolle pro Restriktion entnommen und mit dem ECD-KontrollEnzym für 5 Minuten auf $80{ }^{\circ} \mathrm{C}$ inaktiviert. Zu je $4 \mu \mathrm{l}$ Restriktions-Reaktionsansatz wurden $5 \mu \mathrm{l}$ Stop Mix und $10 \mu \mathrm{l} \mathrm{H}_{2} \mathrm{O}$ dazugegeben. Die Fragmente wurden bei $220 \mathrm{~V}$ für ca. 3 1 $2 / 2$ Stunden auf dem Gel getrennt.

\subsection{Hybridisierung der Sonden und Index-Sequenzen (Target Enrichment und Sample Indexing)}

Dieses Vorgehen erfolgte am zweiten Tag nach dem Beginn der Bearbeitung der Proben. In diesem Schritt wurden die fragmentierte genomische DNA mit den HaloPlex-Sonden für die sog. Sequenzierbibliothek oder Library hybridisiert. Die HaloPlex-Sonden wurden für die selektive Hybridisierung mit den zu sequenzierenden Regionen bzw. Genen (Region of Interest, ROI) definiert und um eine Zirkularisation der Ziel-DNA-Fragmente zu bewirken.

Der angesetzte Hybridisierungs-Master-Mix (s. Tab. 2.3) wurde kurz auf dem Vortex gemischt und abzentrifugiert. Je $70 \mu \mathrm{l}$ des Hybridisierungs-Master-Mixes wurden in neue 0,2 $\mathrm{ml}-$ Reaktionsgefäße verteilt.

Tabelle 2.3 Herstellung des Hybridisierungs-Master-Mixes

\begin{tabular}{|c|c|c|}
\hline Komponenten & Volumen pro Reaktion in $\mu \mathrm{l}$ & Volumen für 7 Reaktionen in $\mu \mathrm{l}$ \\
\hline Hybridisierungslösung & 50 & 350 \\
\hline HaloPlex-Probe & 20 & 140 \\
\hline Gesamtvolumen & 70 & 490 \\
\hline
\end{tabular}

Für jede Probe wurde ein neuer Index (Markierung) verwendet, damit die Proben der AusgangsDNA zugeordnet werden konnten. Dafür wurden $10 \mu \mathrm{l}$ des jeweiligen Index-Primers dazugegeben. Die einzelnen Restriktions-Reaktionsansätze wurden pro Patienten in die entsprechende $0,2 \mathrm{ml}$ Reaktionsgefäße mit der Hybridisierungslösung überführt. Somit entstand ein Gesamtvolumen von $160 \mu \mathrm{l}(70 \mu \mathrm{l}$ Master-Mix $+10 \mu \mathrm{l}$ Index $+80 \mu \mathrm{l}$ Restriktions-Reaktionsansatz). Für die ECDKontrolle wurde $32 \mu \mathrm{l} \mathrm{H}_{2} \mathrm{O}$ verwendet. Die Reaktionsansätze wurden kurz auf dem Vortex gemischt und abzentrifugiert. Die Hybridisierungsansätze wurden anschließend in ein PCR-Gerät überführt und inkubiert (1. Denaturierungsschritt für 10 Minuten bei $95^{\circ} \mathrm{C}, 2$. Hybridisierungsschritt für 3 Stunden bei $\left.54^{\circ} \mathrm{C}\right)$.

\subsection{Capturing der Patienten-DNA}

In diesem Schritt wurden die zirkulierenden Ziel-DNA-HaloPlex-Hybride, welche Biotin enthalten, mit den Streptavidin Beads ausgefiltert. Es wurden weitere Lösungen aus dem HaloPlex-Kit aufgetaut und auf Raumtemperatur gebracht. Diese waren: Capture-Lösung, Wash-Lösung, Ligations-Lösung, SSC-(saline-sodium citrate)-Puffer und HaloPlex Magnetic Beads. Zusätzlich wurden $2 \mathrm{M}$ Essigsäure und $50 \mathrm{mM} \mathrm{NaOH}$ frisch angesetzt. Kurz vor dem Ablauf der Hybridisierung wurden die Magnetic Beads vorbereitet.

Nach der vollendeten Hybridisierung wurden die Ansätze aus dem Thermocycler herausgenommen. Es folgte die Zugabe von $40 \mu \mathrm{l}$ der vorbereiteten Beads zur jeder Probe. Die Reaktionsansätze wurden gemischt und für 15 Minuten bei Raumtemperatur inkubiert. Danach 
wurden die Reaktionsgefäße mindestens 5 Minuten auf dem Magneten gehalten, um die Beads zu pelletieren. Die Lösung musste dabei klar werden. Der klare Überstand wurde abgenommen und verworfen. Die Reaktionsgefäße wurden vom Magneten entfernt. Es wurden $100 \mu$ Wash-Lösung zu jedem Reaktionsansatz dazugegeben und mit der Pipette kräftig gemischt. Die Reaktionsansätze wurden im PCR-Cycler bei $46{ }^{\circ} \mathrm{C}$ für 10 Minuten inkubiert und danach kurz abzentrifugiert. Die Reaktionsansätze wurden erneut auf dem Magnetständer für mindestens 5 Minuten inkubiert, bis die Lösung komplett klar war. Der klare Überstand wurde erneut abgenommen und verworfen. Die im Pellet enthaltene genomische DNA der Patienten wurde weiter verarbeitet.

\subsection{Herstellen der Sequenzierbibliotheken (Libraries)}

In diesem Schritt wurden zu der Patienten-DNA Primer für die zu sequenzierende Regionen bzw. Gene (Region of Interest, ROI) dazugegeben um somit eine Library zu generieren. Eine Ligase wurde zu der Reaktion dazugegeben um nicks in den zirkulären HaloPlex-Hybriden zu schließen.

Für die Ligation wurde ein Ligations-Master-Mix hergestellt (s. Tab. 2.4). Jeweils $50 \mu l$ des Ligations-Master-Mixes pro Reaktion wurden zu den pelletierten Beads gegeben und kräftig gemischt. Es erfolgte eine Inkubation bei $55^{\circ} \mathrm{C}$ für 10 Minuten im PCR-Gerät.

Tabelle 2.4: Zusammensetzung des Ligations-Master-Mixes

\begin{tabular}{|c|c|c|}
\hline Komponente & Volumen pro Reaktion in $\mu \mathrm{l}$ & Volumen für 7 Reaktionen in $\mu \mathrm{l}$ \\
\hline Ligations Lösung (HaloPlex-Kit) & 47,5 & 332,5 \\
\hline DNA Ligase (HaloPlex-Kit) & 2,5 & 17,5 \\
\hline Gesamtvolumen & 50 & 350 \\
\hline
\end{tabular}

Während der Ligation wurde der PCR-Master-Mix hergestellt (s. Tab. 2.5)

Tabelle 2.5: Zusammensetzung des PCR-Master-Mixes

\begin{tabular}{|c|c|c|}
\hline Komponente & Volumen pro Reaktion in $\mu \mathrm{l}$ & Volumen für 7 Reaktionen in $\mu \mathrm{l}$ \\
\hline DNA & 20 & je 20 \\
\hline 5x Herculase Reaktion-Puffer II & 10 & je 7 \\
\hline Primer for/rev & $1+1$ & 2,8 \\
\hline dNTP's & 0,4 & 3,5 \\
\hline 2 M Essigsäure & 0,5 & 7 \\
\hline Herculase II Fusion & 1 & 112,7 \\
\hline DNA Polymerase & 16,1 & 350 \\
\hline $\mathrm{H}_{2} \mathrm{O}$ & 50 & \\
\hline Gesamtvolumen & & \\
\hline
\end{tabular}

$\mathrm{dNTP}=$ Desoxynukleotide; for = forward $;$ rev = reverse .

Der PCR-Master-Mix wurde kurz gemischt und abzentrifugiert. Pro Ansatz wurden jeweils $30 \mu \mathrm{l}$ des PCR-Master-Mixes in jeweils ein frisches 0,2 ml-Reaktionsgefäß verteilt und auf Eis gelagert. Die Ligationsansätze wurden nach der Inkubation kurz abzentrifugiert und auf den Magnetständer überführt. Die Beads wurden erneut pelletiert, bis die Lösung vollständig klar geworden war. Der klare Überstand wurde abgenommen und verworfen. Die Reaktionsgefäße wurden vom Magneten genommen, zu jedem Bead-Pellet wurden $100 \mu \mathrm{l}$ SSC-Puffer gegeben, kräftig durchgemischt und abzentrifugiert. Diese wurden erneut auf den Magnetständer überführt, die Beads pelletiert, der klare Überstand möglichst komplett abgenommen und verworfen. Zu jedem Reaktionsansatz wurden $25 \mu \mathrm{l}$ der frisch hergestellten $50 \mathrm{mM} \mathrm{NaOH}$ zugegeben und kräftig durchgemischt. Die Reaktionsgefäße wurden für 1 Minute bei Raumtemperatur inkubiert und danach kurz abzentrifugiert, auf den Magnetständer gebracht und die Beads pelletiert. 
Nach diesem Schritt war die DNA durch die $\mathrm{NaOH}-$ Behandlung in dem klaren Überstand vorhanden, und $20 \mu \mathrm{l}$ des Überstands wurden in den $30 \mu \mathrm{l}$-PCR-Master-Mix überführt, gemischt und kurz abzentrifugiert. Der PCR-Ansatz wurde in den PCR-Cycler gestellt. Die DNA wurde bei 98 ${ }^{\circ} \mathrm{C}$ denaturiert. Im zweiten Schritt wurden die Primer bei $60{ }^{\circ} \mathrm{C}$ für die Herstellung der Library an die DNA hybridisiert (Annealing). Es folgte eine Synthese (Elongation) der Library bei $72{ }^{\circ} \mathrm{C}$. Die PCR-Reaktion erfolgte nach einem speziellen PCR-Profil (s. Abb. 2.3).

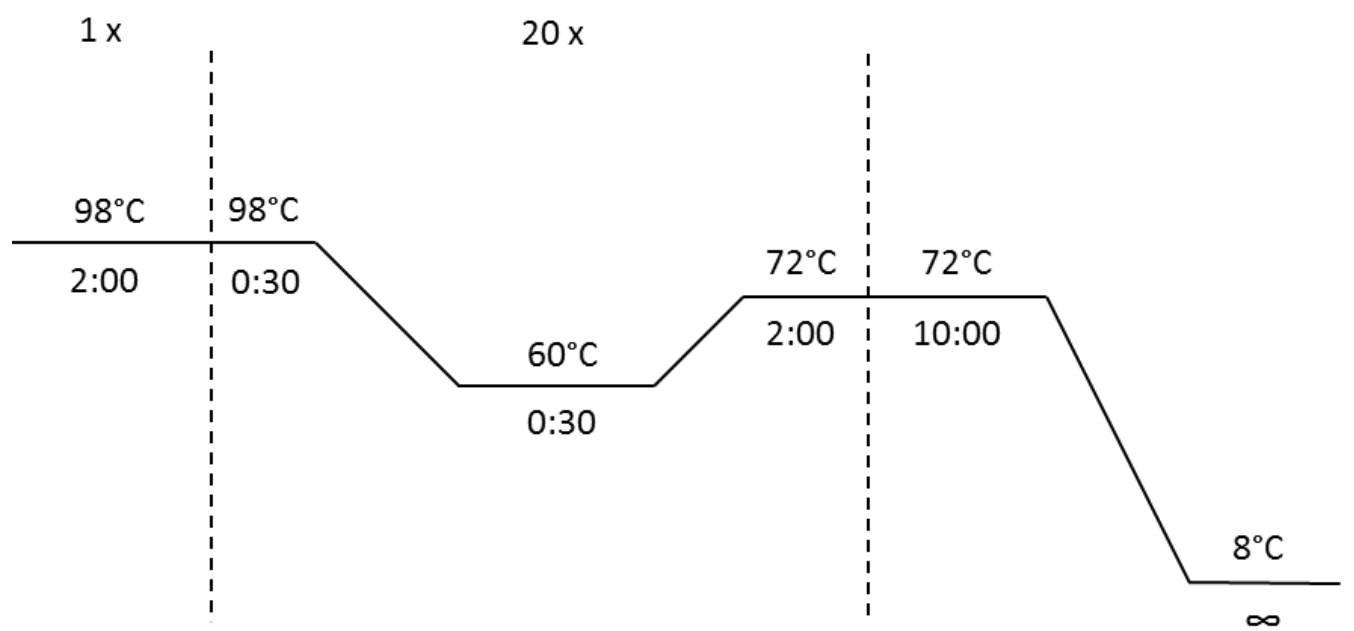

Abbildung 2.3: Profil der PCR-Reaktion. Die DNA wurde bei $98{ }^{\circ} \mathrm{C}$ denaturiert. Im zweiten Schritt wurden die Primer bei $60^{\circ} \mathrm{C}$ für die Herstellung der Library an die DNA hybridisiert (Annealing). Es folgte eine Synthese (Elongation) der Library bei $72^{\circ} \mathrm{C}$ für 2 Minuten (Zyklenzahl 20x).

Die PCR-Produkte konnten nach diesem Schritt bei $-20^{\circ} \mathrm{C}$ eingefroren oder bei $8{ }^{\circ} \mathrm{C}$ über Nacht gelagert werden.

\subsection{Aufreinigung der Sequenzierbibliothek mit Reinigungs-Beads (AMPure Beads)}

Am dritten Tag erfolgte die Aufreinigung der hergestellten Libraries. In diesem Schritt war es sehr wichtig besonders darauf zu achten, dass keine Reinigungs-Beads am Ende der Aufreinigung in den Proben verblieben, da diese die Sequenzierung der Proben stark stören könnten.

Die Reinigungs-Beads wurden für 30 Minuten bei Raumtemperatur inkubiert. Pro Probe wurden $400 \mu \mathrm{l}$ des $70 \%$-igen Ethanols hergestellt. Jeweils $40 \mu \mathrm{l}$ der PCR-Reaktion wurden in frische 1,5 ml Reaktionsgefäße überführt. Der Rest der Produkte konnte bei $-20{ }^{\circ} \mathrm{C}$ aufbewahrt werden. Die Reinigungs-Beads wurden kräftig auf dem Vortex gemischt. Es wurde ein Master-Mix aus $40 \mu \mathrm{l}$ $\mathrm{H}_{2} \mathrm{O}$ und $100 \mu \mathrm{l}$ Reinigungs-Beads pro Reaktion hergestellt. 140 $\mu$ l des Master-Mixes wurden zu jeder Probe gegeben, auf dem Vortex gemischt, für etwa 5 Minuten bei Raumtemperatur inkubiert, abzentrifugiert und 5 Minuten auf dem Magnetständer inkubiert. Der Überstand wurde vorsichtig abgenommen und verworfen. Zu dem Pellet wurden $200 \mu \mathrm{l}$ des 70 \%-igen-Ethanols gegeben und 30 Sekunden auf dem Magnetständer inkubiert. Der klare Überstand wurde vorsichtig abgenommen und verworfen. Die Zugabe des Ethanols wurde wiederholt und der Überstand verworfen. Das Pellet wurde bei Raumtemperatur ca. 30 Minuten getrocknet, bis der Ethanol vollständig verdunstet war und das Pellet Risse aufwies. Die Reaktionsgefäße wurden vom Magneten genommen und die Libraries durch Zugabe von $40 \mu \mathrm{l} 10 \mathrm{mM}$ TRIS- $\mathrm{HCl}(\mathrm{pH} 8.0)$ eluiert. Die Reaktionsansätze wurden durchgemischt und für 2 - 5 Minuten bei Raumtemperatur auf dem Magneten inkubiert. Danach wurden die Reaktionsansätze auf dem Magneten für weitere 2 Minuten belassen, bis die Lösung vollständig klar war. Der klare Überstand mit den Libraries wurde vollständig abgenommen und in ein neues $0,2 \mathrm{ml}$ Reaktionsgefäß überführt. Die Libraries wurden mit dem 2100 BioAnalyzer quantifiziert und konnten bei $-20{ }^{\circ} \mathrm{C}$ bis zur Sequenzierung gelagert werden. 
Die Libraries wurden mit dem MiSeq Sequencing Reagent Kit auf dem MiSeq-Sequenzierer der Firma Illumina sequenziert. Die ermittelten Sequenzdaten wurden anschließend mit der Software Sequence Pilot (JSI medical systems $\mathrm{GmbH}$ ) im Modul SeqNext ausgewertet und zur Identifizierung von Sequenzvarianten mit der jeweiligen Referenzsequenz des zu analysierenden Gens abgeglichen.

\subsubsection{Prinzip des SureSelect ${ }^{\text {QxT }}$ Target Enrichment Systems}

Das SureSelect ${ }^{Q X T}$ Target Enrichment System der Firma Agilent Technologies ermöglicht ebenfalls eine parallele Anreicherung und Analyse einer großen Anzahl von Genen (Multi-Gen-Panel-(NGS)Diagnostik), die zuvor in einem Design mit der Software SureDesign der Firma Agilent Technologies definiert wurden. Für die Untersuchung wurde das "SureSelect ${ }^{Q X T}$ Target Enrichment for Illumina Multiplexed Sequencing "Protokoll Version D0, November 2015, zugrunde gelegt.

Der Prozessfluss zur Anreicherung der in einem Panel festgelegten Regionen umfasst die folgenden wesentlichen Schritte:

A) Enzymatische Fragmentierung der genomischen DNA mit dem Enzym Transposase (statistische Fragmentierung).

B) Anhängen der Adaptersequenzen an die erzeugten DNA-Fragmente.

C) Hybridisierung der SureSelect Capture-Library.

D) Reinigung der durch die Sonden gebundenen DNA-Fragmente mit Streptavidin-Beads.

E) Amplifikation der gereinigten Zielregionen.

\subsection{Konzentrationsbestimmungen der genomischen DNA}

Es wurde eine DNA-Konzentration von $46 \mathrm{ng}$ (ausgehend von den mit dem QuBit 2.0 ermittelten Konzentrationswerten) in $2 \mu \mathrm{l}$ hergestellt $(\hat{=} 23 \mathrm{ng} / \mu \mathrm{l})$.

\subsection{Fragmentierung der genomischen DNA und Ligation der Adaptoren (Adapter-Tagging)} In diesem Schritt wurde die genomische DNA (gDNA) enzymatisch fragmentiert und die Adaptoren für die PCR am Ende der Fragmente angelagert (Adapter-Tagging). Für jede DNA-Probe wurde eine Library vorbereitet.

Der Thermocycler wurde auf $37{ }^{\circ} \mathrm{C}$ eingestellt und die AMPure XP Beads bei Raumtemperatur für mindestens 30 Minuten inkubiert. Pro Probe wurden $800 \mu \mathrm{l}$ des $70 \%$-igen-Ethanols hergestellt. Die Reagenzien für die Fragmentierung wurden auf dem Vortex gemischt und auf einen Kühlblock gestellt. Die SureSelect ${ }^{Q x T}$ Stop Lösung wurde bereitgestellt.

Die Reagenzien wurden in 4er PCR-Cups angesetzt (s. Tab. 2.6). Der Reaktions-Master-Mix wurde für 20 Sekunden auf dem Vortex gemischt und kurz abzentrifugiert.

Tabelle 2.6: Reaktions-Master-Mix für die DNA-Fragmentierung

\begin{tabular}{|c|c|}
\hline Komponente & Volumen pro Reaktion in $\mu \mathrm{l}$ \\
\hline SureSelect ${ }^{\text {OXT }}$-Puffer & 17,0 \\
\hline SureSelect Enzyme Mix ILM & 2,0 \\
\hline gDNA 23 ng/ $\mu \mathrm{l}$ & 2,0 \\
\hline Gesamtvolumen & 21,0 \\
\hline
\end{tabular}

gDNA = genomische DNA.

Nach dieser Vorbereitung wurde die gDNA im Thermocycler für 10 Minuten bei $45{ }^{\circ} \mathrm{C}$ fragmentiert. Nach Ablauf der Fragmentierung wurden die Proben zentrifugiert. Zu jeder Reaktion wurden $32 \mu \mathrm{l}$ der $1 x$ SureSelect ${ }^{Q \times T}$ Stop Lösung gegeben, kurz auf dem Vortex gemischt und zentrifugiert. Es folgte eine Inkubation der Proben für 1 Minute bei Raumtemperatur. 


\subsection{Aufreinigung der Adaptor-ligierten Bibliothek mit Reinigungs-Beads (AMPure Beads)} In diesem Schritt wurden mit Hilfe der Reinigungs-Beads (AMPure Beads) die mit dem Adaptor ligierten Fragmente aufgereinigt. Dafür wurden $52 \mu \mathrm{l}$ AMPure Beads in frische $1,5 \mathrm{ml}$ Reaktionsgefäße gefüllt. Zu den AMPure Beads wurden $53 \mu \mathrm{l}$ der fragmentierten Proben gegeben. Das Gemisch wurde vorsichtig auf- und abpipettiert und zentrifugiert. Die Proben wurden für fünf Minuten bei Raumtemperatur inkubiert und danach für 3-5 Minuten in den Magneten gestellt. Der flüssige Überstand wurde vorsichtig abgenommen und verworfen. $200 \mu \mathrm{l}$ des $70 \%$-igenEthanols wurden seitlich am Reaktionsgefäß einlaufen gelassen. Nach einer einminütigen Einwirkung wurde das Ethanol vorsichtig abgenommen. Die Waschschritte von der Inkubation auf dem Magneten bis zur Abnahme des Ethanols wurden einmal wiederholt. Die Pellets wurden bei $37^{\circ} \mathrm{C}$ im PCR-Cycler für 1-3 Minuten getrocknet. Um die DNA zu eluieren, erfolgte die Zugabe von $11 \mu \mathrm{l}$ Nuklease-freiem $\mathrm{H}_{2} \mathrm{O}$ (Ampuwa). Nachdem das $\mathrm{H}_{2} \mathrm{O}$ über die Pellets eingelaufen lassen wurde, wurden die Pellets vorsichtig abgelöst. Dieser Vorgang wurde wiederholt bis das Pellet vollständig abgelöst war. Die Proben wurden kurz zentrifugiert ohne die Beads zu pelletieren. Bei Raumtemperatur erfolgte für zwei Minuten die Inkubation der Proben. Die Proben wurden danach für zwei Minuten in den Magneten gestellt, bis der Überstand klar erschien. $10 \mu \mathrm{l}$ des klaren Überstands wurden vorsichtig in frische PCR-Reaktionsgefäße überführt. Die Proben wurden zur Weiterverarbeitung auf Eis gestellt.

\subsection{Amplifikation der mit den Adaptoren ligierten Sequenzierbibliothek (Library)}

In diesem Schritt wurden die DNA-Enden der Adaptor-ligierten-Library repariert und die DNALibrary mittels PCR-Reaktion amplifiziert. Für diesen Schritt wurde der Master-Mix für die präcapture-PCR (prä-PCR) benötigt (s. Tab. 2.7).

Tabelle 2.7: Master-Mix für die prä-PCR

\begin{tabular}{|c|c|c|}
\hline Komponente & Volumen pro Reaktion in $\mu \mathrm{l}$ & $\begin{array}{c}\text { Volumen für 8 Reaktionen } \\
\text { in } \mu \text { (inkl. Überschuss) }\end{array}$ \\
\hline Nuklease-freies Wasser & 25 & 212,5 \\
\hline Herculase II 5x Reaktions-Puffer & 10 & 85 \\
\hline 100 mM dNTP Mix (25 mM jedes dNTP) & 0,5 & 4,25 \\
\hline Dimethylsulfoxid (DMSO) & 2,5 & 21,25 \\
\hline SureSelect ${ }^{\text {QXT Primer Mix }}$ & 1 & 8,5 \\
\hline Herculase II Fusion DNA Polymerase & 1 & 8,5 \\
\hline Gesamtvolumen & 40,0 & 340 \\
\hline
\end{tabular}

Zu jeder $10 \mu \mathrm{l}$ Probe wurden $40 \mu \mathrm{l}$ des prä-capture-PCR-Master-Mixes dazugegeben. Die Gefäße wurden verschlossen, auf dem Vortex für 5 Sekunden gemischt und kurz zentrifugiert, im Thermocycler inkubiert und die prä-capture-PCR (s. Tab. 2.8) gestartet.

Tabelle 2.8: Einstellung des Thermocyclers für die prä-capture-PCR

\begin{tabular}{|c|c|c|c|}
\hline Schritt & Anzahl der Zyklen & Temperatur in ${ }^{\circ} \mathrm{C}$ & Zeit \\
\hline 1 & 1 & 68 & 2 Minuten \\
\hline 2 & 1 & 98 & 2 Minuten \\
\hline 3 & 8 & 98 & 30 Sekunden \\
& & 57 & 30 Sekunden \\
& 1 & 72 & 1 Minute \\
\hline 4 & 1 & 72 & 5 Minuten \\
\hline 5 & & 4 & unendlich \\
\hline
\end{tabular}




\subsection{Aufreinigung der amplifizierten Sequenzierbibliothek mit AMPure XP Beads}

Die amplifizierten Proben wurden zu $50 \mu \mathrm{l}$ der AMPure Beads in frische 1,5 ml-Reaktionsgefäße überführt. Die Proben wurden durch vorsichtiges Auf- und Abpipettieren gemischt, zentrifugiert und für fünf Minuten bei Raumtemperatur inkubiert. Es folgten mehrere Waschschritte. Die Proben wurden für 3 - 5 Minuten in den Magneten gestellt, der flüssige Überstand wurde vorsichtig abgenommen und verworfen. Zu den Proben wurden $200 \mu \mathrm{l}$ des 70 \%-igen Ethanols seitlich am Reaktionsgefäß einlaufen gelassen, ohne die Beads aufzuwirbeln, und für eine Minute auf den Beads belassen. Anschließend wurde das Ethanol vorsichtig abgenommen. Alle Waschschritte wurden einmal wiederholt. Nachdem der Rest-Ethanol mit einer Pipette vollständig abgenommen wurde, wurden die Pellets für 1-3 Minuten bei $37{ }^{\circ} \mathrm{C}$ im Cycler getrocknet. Die Pellets wurden vorsichtig abgelöst, indem das $13 \mu \mathrm{l}$ Nuklease-freie $\mathrm{H}_{2} \mathrm{O}$ (Ampuwa) über das Pellet einlief. Die Proben wurden kurz zentrifugiert ohne die Beads zu pelletieren und für zwei Minuten bei Raumtemperatur inkubiert. Der klare Überstand wurde vorsichtig in neue PCRReaktionsgefäße überführt, die bis zur Weiterverarbeitung auf Eis aufbewahrt wurden.

\subsection{Quantifizierung der Libraries}

Die Proben wurden mit dem 2100 BioAnalyzer mittels des DNA 1000-Assays quantifiziert. Die Proben wurden jeweils auf 750 ng DNA in einem Volumen von $12 \mu$ verdünnt.

Die Berechnung war wie folgt:

$\frac{750 \mathrm{ng}}{\mathrm{X}(\text { Konzentration der Probe)ng/ } \mu \mathrm{l}}=$ Probenmenge $\mu \mathrm{l}$

Probenmenge $(\mu \mathrm{l})+\mathrm{X} \mu \mathrm{l} \mathrm{H}_{2} \mathrm{O}=12 \mu \mathrm{l}$

Nach der Amplifikation der prä-capture-Library-DNA sollten die optimalen Längen der Fragmente zwischen 245 bp bis 325 bp liegen (s. Abb. 2.4).

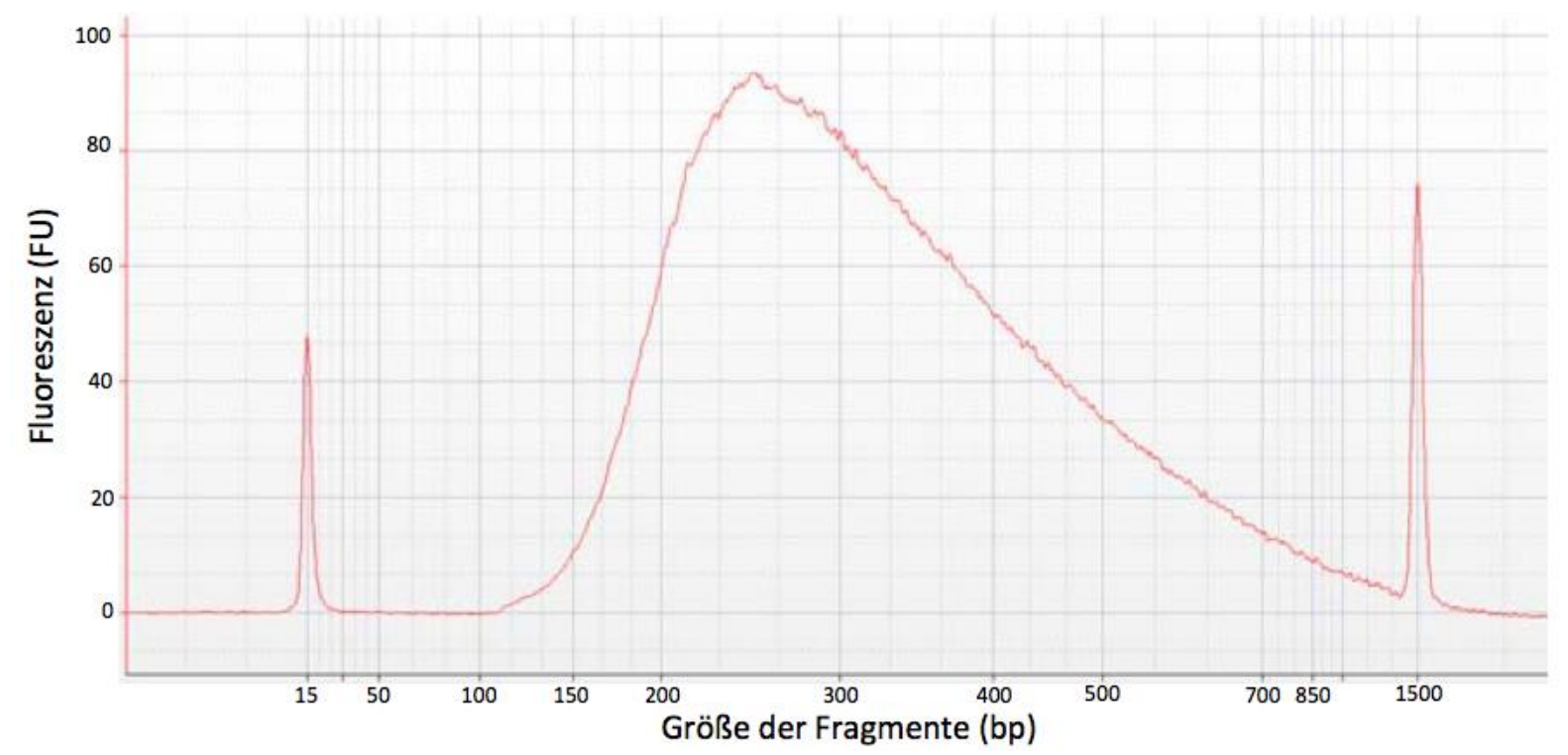

Abbildung 2.4: Repräsentatives Elektropherogramm der prä-capture-Analyse der ampifizierten DNALibrary mit dem 2100 BioAnalyzer (übernommen aus "SureSelectQXT Target Enrichment for Illumina Multiplexed Sequencing "Protokoll Version D0, November 2015). bp = Basenpaar. Die Peaks bei 15 bp und 1500 bp repräsentieren entsprechend den unteren und oberen Längenmarker. Diese dienten der Bestimmung der Fragmentenlänge. 


\subsection{Hybridisierung der Sonden und der Index-Sequenzen (Indices)}

In diesen Schritten hat die Hybridisierung der vorbereiteten genomischen DNA-Library mit der ziel-spezifischen capture-Library stattgefunden. Nach der Hybridisierung wurden die Zielmoleküle mit Streptavidin-Beads gefangen (captured).

$\mathrm{Zu}$ den verdünnten Proben wurden $5 \mu \mathrm{l}$ des SureSelect Fast Blocker Mixes gegeben, auf dem Vortex gemischt, zentrifugiert und die Hybridisierung durchgeführt (s. Tab. 2.9). In den ersten zwei Schritten wurden die Adaptoren blockiert, die an den Fragmenten gebunden waren. Nachdem die Hybridisierungslösung (s. Tab. 2.10 und Tab. 2.11) dazugegeben wurde, hybridisierten die Primer auf die Target-Regionen (Regions of Interest; ROI).

Tabelle 2.9: Hybridisierungsvorgang der Sonden und der Index-Sequenzen

\begin{tabular}{|c|c|c|c|}
\hline Schritt & Anzahl der Zyklen & Temperatur in ${ }^{\circ} \mathrm{C}$ & Zeit \\
\hline 1 & 1 & 95 & 5 Minuten \\
\hline 2 & 1 & 65 & 10 Minuten \\
\hline 3 & 1 & 65 & 1 Minute \\
& 60 & 65 & (Pause; Zugabe der Hybridisierungslösung) \\
\hline 4 & 1 & 37 & 3 Sekunden \\
\hline 5 & & 65 & unendlich \\
\hline
\end{tabular}

Tabelle 2.10: Ansetzung des Hybridisierungsmixes

\begin{tabular}{|c|c|c|}
\hline Komponente & $\begin{array}{l}\text { Volumen pro Reaktion } \\
\text { in } \mu l\end{array}$ & $\begin{array}{l}\text { Volumen für } 8 \text { Reaktionen } \\
\text { in } \mu \mathrm{l} \text { (inkl. Überschuss) }\end{array}$ \\
\hline $\begin{array}{c}25 \% \text {-RNase-Blockierungslösung } \\
\text { (s. Tab. 2.11) }\end{array}$ & 2 & 17 \\
\hline $\begin{array}{c}\text { SureSelect }{ }^{Q X T} \text { Custom Capture-Library } \\
<3 \mathrm{Mb}\end{array}$ & 2 & 17 \\
\hline SureSelect ${ }^{Q X T}$ Fast Hybridisierungs-Puffer & 6 & 51 \\
\hline Nuklease-freies Wasser & 3 & 25 \\
\hline Gesamtvolumen & 13 & 110 \\
\hline
\end{tabular}

$\mathrm{Mb}=$ Megabasenpaare.

Für den Hybridisierungsmix wurde eine 25 \%-ige-RNase-Blockierungslösung hergestellt (s. Tab. 2.11).

Tabelle 2.11: Vorbereitung der RNase-Blockierungslösung

\begin{tabular}{|c|c|c|}
\hline Komponente & Volumen pro Reaktion in $\mu \mathrm{l}$ & $\begin{array}{c}\text { Volumen für } 8 \text { Reaktionen } \\
\text { in } \mu \mathrm{l} \text { (inkl. Überschuss) }\end{array}$ \\
\hline SureSelect RNase-Block & 0,5 & 5 \\
\hline Nuklease-freies Wasser & 1,5 & 15 \\
\hline Gesamtvolumen & 2 & 20 \\
\hline
\end{tabular}

Etwa 40 Minuten vor dem Ablauf des Programms wurden die streptavidin-coated magnetic Beads vorbereitet. In zwei 1,5 ml Reaktionsgefäße für jeweils 4 Proben wurden je $200 \mu \mathrm{l}$ Beads mit 800 $\mu \mathrm{l}$ Binding-Puffer durch Auf- und Abpipettieren gemischt und kurz zentrifugiert. Nachdem die Beads 5 Minuten in den Magneten belassen waren, wurde der Überstand abgenommen und nochmals $800 \mu$ l Binding-Puffer dazugeben und gemischt. Der Waschvorgang wurde noch zweimal wiederholt. Die Beads wurden in $800 \mu$ l Binding-Puffer aufbewahrt. 
Nach der Hybridisierung wurden die Proben auf Raumtemperatur gebracht. Das Gesamtvolumen von $30 \mu \mathrm{l}$ des Hybridisierungsansatzes wurde zu den $200 \mu$ l gewaschenen Streptividin Beads in ein $1,5 \mathrm{ml}$ Reaktionsgefäß dazugegeben, gut gemischt und kurz zentrifugiert. Die Proben wurden für 30 Minuten in einen Thermomixer bei Raumtemperatur gestellt und bei $1800 \mathrm{rpm}$ geschüttelt.

Während der Inkubationsphase der Hybridisierungsansätze wurden $3 \times 200 \mu \mathrm{l}$ "Wasch-Puffer 2" pro Probe in 4er Strips abgefüllt und bei $65^{\circ} \mathrm{C}$ für 30 Minuten im PCR-Gerät inkubiert.

Anschließend wurden die Proben kurz abzentrifugiert ohne die Beads zu pelletieren und für eine Minute in einen Magneten gestellt. Der Überstand wurde verworfen und die Proben aus dem Magneten genommen. Es wurden $200 \mu \mathrm{l}$ „Wasch-Puffer 1" dazugeben und durch Auf- und Abpipettieren gemischt. Danach wurden die Proben in frische 0,2 $\mathrm{ml}$ 4er Strips überführt, acht Sekunden auf dem Vortex gemischt, zentrifugiert und für eine Minute in den Magneten gestellt. Danach wurde der Überstand der Proben verworfen. Es wurden $2 \times 100 \mu \mathrm{l}$ des aufgewärmten Puffers zu den Proben gegeben und gemischt. Die Proben wurden auf den PCR-Ständer zurückgestellt und mit dem Ständer mit dem Vortex gemischt und kurz zentrifugiert ohne die Beads zu pelletieren. Im PCR-Gerät wurden die Proben bei $65^{\circ} \mathrm{C}$ für 10 Minuten inkubiert. Im Anschluss wurden die Proben für eine Minute in den Magneten gestellt. Der Überstand wurde verworfen. Der Waschvorgang wurde noch zweimal wiederholt.

Nach dem zweiten Waschvorgang wurden die Komponenten für die zweite PCR vorbereitet (Herculase II 5x Puffer, 100 mM dNTP Mix, SureSelect ${ }^{Q X T}$ P7 und P5 Index Primer und Herculase II Polymerase).

Nach dem Ablauf des dritten Waschvorgangs wurden die Proben kurz zentrifugiert und nochmals in den Magneten gestellt, um alle Pufferreste abnehmen zu können. Anschließend wurden die Proben aus dem Magneten genommen. Das Pellet wurde in $23 \mu \mathrm{l}$ Nuklease-freiem Wasser gelöst und die Proben bis zur Weiterverarbeitung auf Eis gelagert.

\subsection{Amplifikation der Libraries, Anhängen der Indices (Indexing) und Reinigung der Sequenzierbibliotheken}

In diesem Schritt wurde die mit dem SureSelect-Kit angereicherte DNA-Library unter Verwendung des spezifischen Paares von dualen Index-Primern amplifiziert. Es wurde ein PCR-Master-Mix vorbereitet (s. Tab. 2.12), auf dem Vortex gemischt und zentrifugiert.

Tabelle 2.12: PCR-Master-Mix

\begin{tabular}{|c|c|c|}
\hline Komponente & $\begin{array}{c}\text { Volumen pro Reaktion } \\
\text { in } \mu l\end{array}$ & $\begin{array}{c}\text { Volumen für 8 Reaktionen } \\
\text { in } \mu \text { l (inkl. Überschuss) }\end{array}$ \\
\hline Herculase II 5x Reaktions-Puffer & 10 & 85 \\
\hline 100 mM dNTP Mix (25 mM pro dNTP) & 0,5 & 4,25 \\
\hline Herculase II Fusion DNA-Polymerase & 1 & 8 \\
\hline Nuklease-freies Wasser & 13,5 & 114,75 \\
\hline Gesamtvolumen & 25 & 212,0 \\
\hline
\end{tabular}

dNTP = Desoxynukleotide.

Es wurden $25 \mu \mathrm{l}$ des PCR-Master-Mixes zu jeder Probe mit Beads gegeben, auf dem Vortex gemischt und zentrifugiert.

Für jede Probe wurde eine Index-Primer-Kombination aus vorhandenen Primern festgelegt. Zu jeder Probe wurde $1 \mu \mathrm{l}$ des gleichen P7-Primers (von den zwölf möglichen Primern; P7 i1 bis P7 i12) und je $1 \mu \mathrm{l}$ eines unterschiedlichen P5-Primers (von P5 i13 bis P5 i20) gegeben. Die Proben wurden sorgfältig auf dem Vortex gemischt und kurz zentrifugiert ohne die Beads zu pelletieren. Danach die post-capture-PCR durchgeführt (s. Tab. 2.13). 
Tabelle 2.13: Das PCR-Profil

\begin{tabular}{|c|c|c|c|}
\hline Schritt & Anzahl der Zyklen & Temperatur in ${ }^{\circ} \mathrm{C}$ & Zeit \\
\hline 1 & 1 & 98 & 2 Minuten \\
\hline 2 & 14 & 98 & 30 Sekunden \\
& & 58 & 30 Sekunden \\
& 1 & 72 & 1 Minuten \\
\hline 3 & 1 & 72 & 5 Minuten \\
\hline 4 & & 4 & unendlich \\
\hline
\end{tabular}

Nach Beendigung der PCR-Reaktion wurden die Proben (mit Beads) kurz zentrifugiert und bei Raumtemperatur für 2 Minuten in den Magneten gestellt.

$50 \mu \mathrm{l}$ des Überstandes jeder Probe wurden jeweils zu den $60 \mu \mathrm{l}$ der AMPure Beads in frischen 1,5 $\mathrm{ml}$ Reaktionsgefäße dazugegeben. Die Proben wurden gemischt, zentrifugiert und für 5 Minuten bei Raumtemperatur inkubiert. Nachfolgend wurden die Proben für 3 - 5 Minuten in den Magneten gestellt, der flüssige Überstand wurde vorsichtig abgenommen und verworfen. Zu den Proben, die weiterhin in dem Magneten verblieben waren, wurden $200 \mu \mathrm{l}$ des 70 \%-igen Ethanols dazugegeben und für eine Minute inkubiert. Das Ethanol wurde danach vorsichtig abgenommen. Diese Schritte wurden nochmals wiederholt.

Ethanolreste wurden mit einer Pipette vollständig abgenommen. Die Pellets wurden bei $37^{\circ} \mathrm{C} \mathrm{im}$ PCR-Cycler für ca. 1-3 Minuten getrocknet. Nachfolgend wurden $25 \mu \mathrm{l}$ Nuklease-freies $\mathrm{H}_{2} \mathrm{O}$ dazugegeben und das Pellet wurde vorsichtig abgelöst. Die Proben wurden kurz zentrifugiert, für 2 Minuten bei Raumtemperatur inkubiert und für 2 Minuten in den Magneten gestellt.

Der klare Überstand wurde vorsichtig abgenommen und in neue PCR-Reaktionsgefäße überführt. Die Proben wurden zur Weiterverarbeitung auf Eis gestellt.

\subsection{Quantifizierung der Library}

Die generierte Library wurde mit Hilfe des 2100 BioAnalyzers gemessen. Die optimale Fragmentenlänge nach der Amplifizierung der post-capture-Library-DNA sollte zwischen 325 bp bis 450 bp liegen (s. Abb. 2.5).

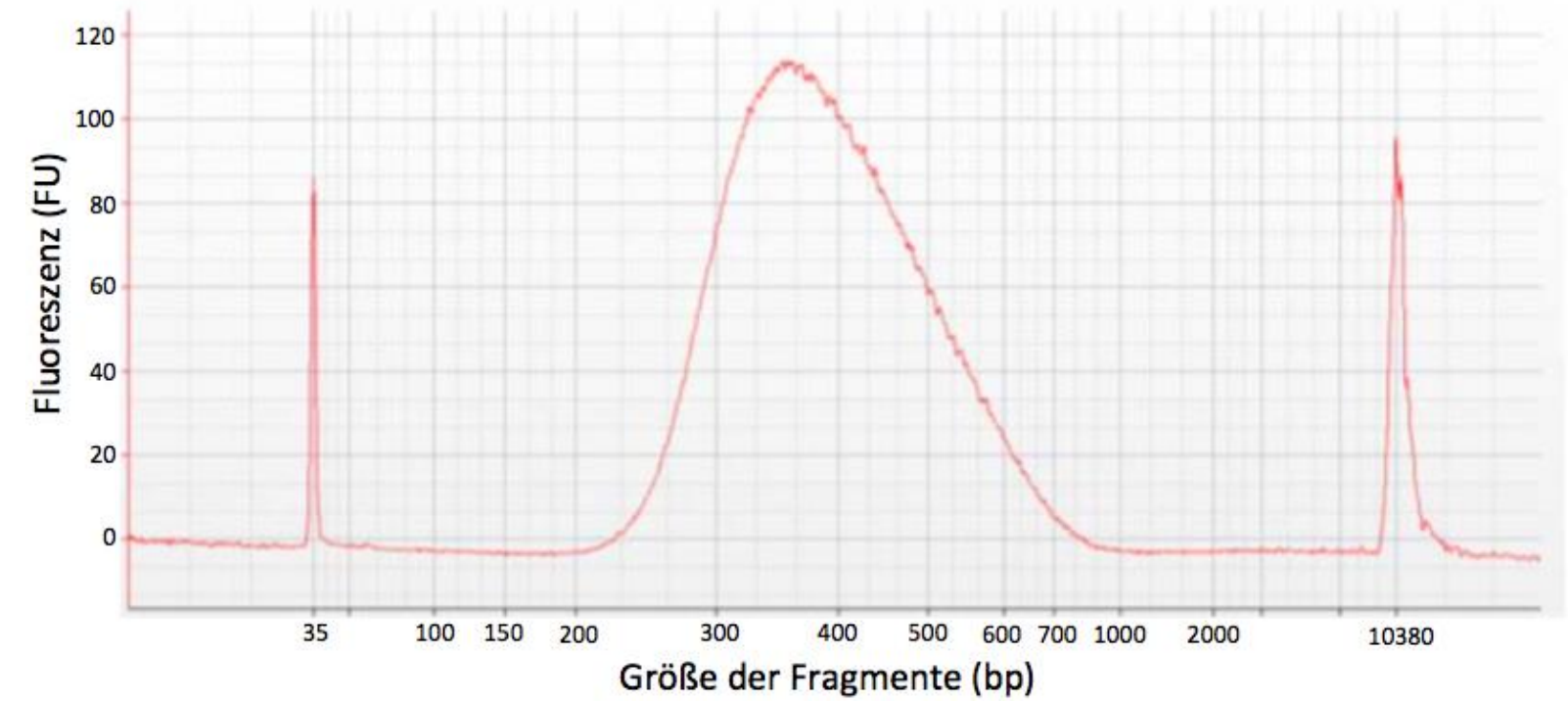

Abbildung 2.5: Repräsentatives Elektropherogramm der post-capture-Analyse der ampifizierten DNALibraries mit dem 2100 BioAnalyzer (übernommen aus "SureSelectQXT Target Enrichment for Illumina Multiplexed Sequencing" Protokoll Version D0, November 2015). Die Peaks bei 35 bp und 10380 bp repräsentieren den unteren und oberen Längenmarker. Diese beiden Marker dienten der Bestimmung der Fragmentlänge. 
Nach diesem Schritt konnten die Restriktions-Reaktionsansätze bis zu ihrer Weiterverarbeitung bei $-20^{\circ} \mathrm{C}$ gelagert werden.

2.2.9.2.10 Pooling der Proben für die Multiplex-Sequenzierung und Vorbereitung der Libraries für die Sequenzierung mit dem MiSeq-System

Die Anzahl der Libraries die parallel sequenziert werden können, ist von den OutputEigenschaften der Sequenzier-Plattform (im unserem Fall des MiSeq-Systems der Firma llumina) und der Menge der Sequenzierdaten abhängig.

Alle mit Index markierten Proben mussten ein identisches äquimolares Volumen im Pool aufweisen. Für jede Library wurde dazu die genaue Menge der Probe bestimmt:

Volumen der Probe $=\frac{V(f) \times C(f)}{\# \times C(i)}$

$V(f)=$ gewünschtes Gesamtvolumen des Pools

$C(f)=$ gewünschte Gesamtkonzentration aller DNAs im Pool

\# = Anzahl der Proben

$C(i)=$ initiale Konzentration der Probe

Das Gesamtvolumen der gepoolten Library musste mit dem 10 mM Tris-EDTA-Puffer (TE-Puffer, $\mathrm{pH}=7,5)$ auf das gewünschte Gesamtvolumen angepasst werden.

\subsubsection{Sequenzierung mit dem MiSeq Sequencing Reagent Kit}

Das MiSeq Sequencing System stellt eine automatisierte Sequenzierplattform der Gerätegeneration des Next Generation Sequencing (NGS) dar. Das Gerät dient der Ermittlung von Sequenzdaten im Bereich der molekulargenetischen Diagnostik. Dabei handelt es sich um eine Sequenziertechnologie, die einen hohen Probendurchsatz ermöglicht und dementsprechend für die Multi-Gen-Panel-Diagnostik eingesetzt werden kann. Die Amplifizierung der Libraries erfolgt auf der Durchflusszelle (engl. flow cell) mittels der Bridge-Amplifizierung (engl. bridgeamplification), d. h. das einzelne DNA-Moleküle mit beiden Enden an die Oberfläche der Durchflusszelle binden und somit klonal amplifiziert werden. Es enstehen etwa 1000-1400 Klone pro Cluster (Quail et al. 2008; Voelkerding et al. 2009) (s. Abb. 2.6).

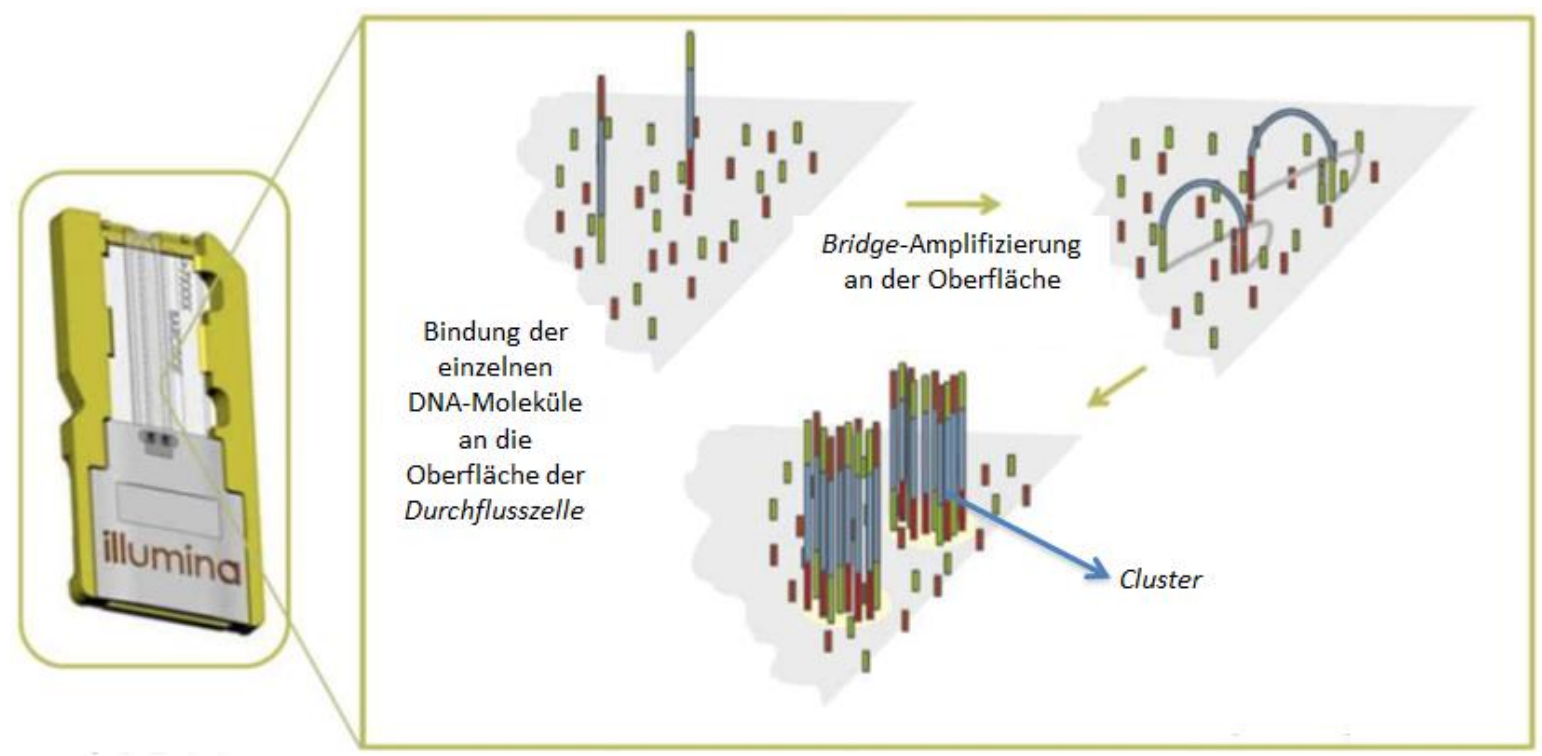

Abbildung 2.6: Amplifizierung der Libraries auf der Illumina-Plattform MiSeq und Vorbereitung auf die Sequenzierung. Die Adaptoren einzelner DNA-Moleküle binden an die komplementäre Sequenz der 
Oligonukleotide an der Oberfläche der Durchflusszelle (engl. flow cell). Diese bilden Brücken (engl. bridge) mit dem Adaptor an dem anderen Ende des Fragments, der an ein weiteres Oligonukleotid an der Oberfläche der Durchflusszelle bindet. Die Polymerase synthetisiert den komplementären DNA-Strang. Dieser bildet weitere Brücken und neue Stränge werden mittels der Bridge-Amplifizierung synthetisiert. Somit entstehen etwa 1000 bis 1400 Klone in einem Cluster (modifiziert nach Illumina www.illumina.com).

Für die Sequenzierung werden die Cluster denaturiert. Nach der chemischen Reaktion und dem Waschvorgang werden nur die Forward-Stränge belassen. Für die Sequenzierung sind eine Polymerase und Zugabe von allen vier mit jeweils einem unterschiedlichen Fluoreszenz-Farbstoff (fluorescent reversible dye terminators) markierten Basen notwendig. Die Terminatoren werden anhand der komplementären DNA-Sequenz inkorporiert. Der Überschus wird abgewaschen. Die Farbstoffe werden optisch angeregt, sodass die Fluoreszenz ermittelt werden kann. Dieser Vorgang wird mehrmals wiederholt (s. Abb. 2.7). Wenn die Forward-Stänge komplett sequenziert sind, wird der Vorgang für die Reverse-Stränge wiederholt. Die Sequenzen einzelner Fragmente sind im Durchschnitt 151 Basenpaare lang (Quail et al. 2008; Voelkerding et al. 2009; Metzker 2010).
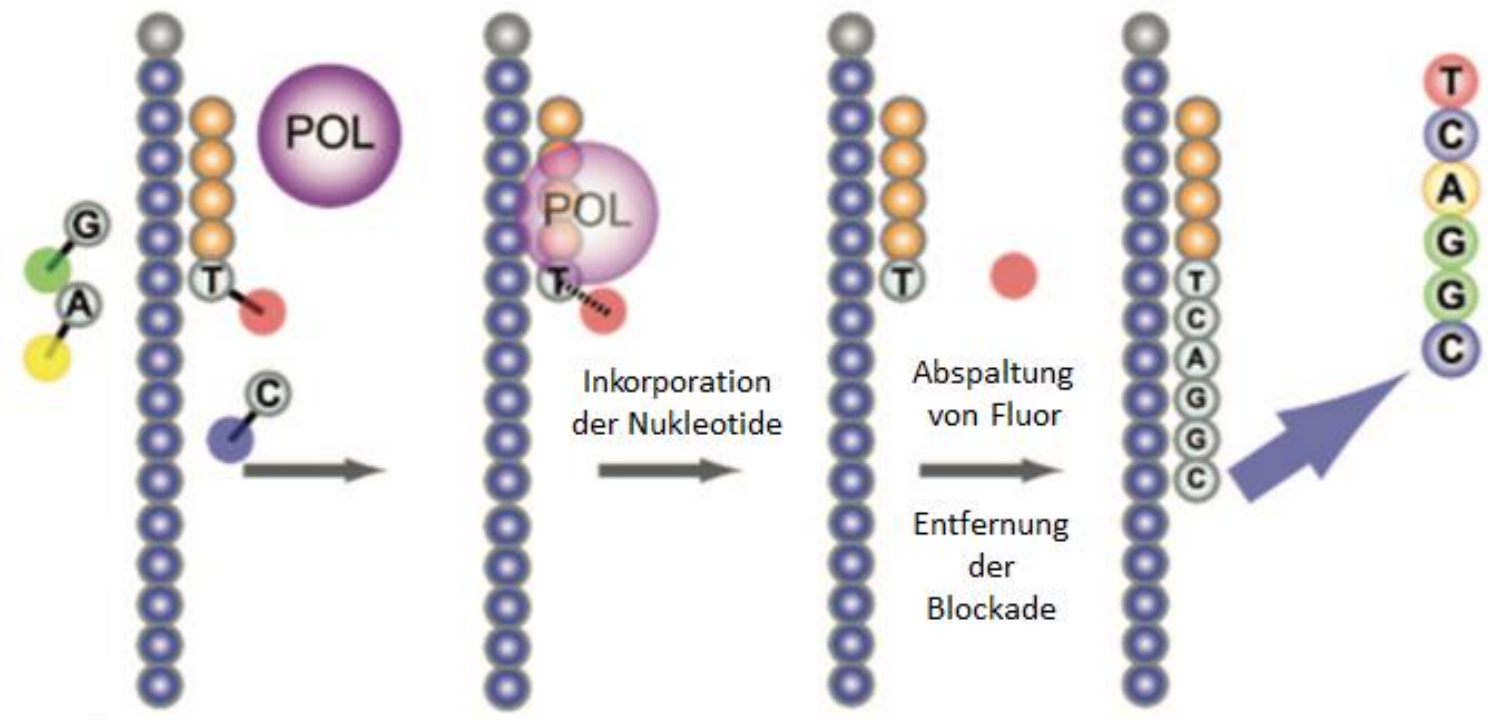

Matrizenstrang

Abbildung 2.7. Sequenzierung der Libraries mit der MiSeq-Plattform der Firma Illumina. Für die Sequenzierung sind eine Polymerase und die Inkorporation von allen vier mit jeweils einem FluoreszenzFarbstoff (fluorescent reversible dye terminators) markierte Basen notwendig. Der Überschus wird abgewaschen. Die Farbstoffe werden optisch angeregt, sodass die Fluoreszenz ermittelt werden kann. Dieser Vorgang wird mehrmals wiederholt. Wenn die Forward-Stränge komplett sequenziert sind, wird der Vorgang für die Reverse-Stränge wiederholt (modifiziert nach Voelkerding et al. 2009; Metzker 2010).

\subsection{Vorbereitung für die Sequenzierung mit dem MiSeq-System}

Die optimale Konzentration für die SureSelect ${ }^{Q X T}$ Target-enriched Library liegt bei 8 pM bis 12 pM für den MiSeq-Sequenzierer. Für die Sequenzierung der TruRisk ${ }^{T M}$-Library wurden $12 \mathrm{pM}$ der Library eingesetzt.

Die mittels Bioanalyzer 2100 quantifizierten Proben wurden auf $4 \mathrm{nM}$ in einem Volumen von $20 \mu \mathrm{l}$ oder mehr verdünnt.

Pro Probe wurden $5 \mu \mathrm{l}$ der verdünnten Library in ein 1,5 ml-Eppendorf-Reaktionsgefäß gegeben. Aufgrund der unterschiedlichen Index-Primer ist eine Unterscheidung der Proben weiterhin möglich. $5 \mu \mathrm{l}$ einer 0,2 M NaOH-Lösung wurden dazugegeben. Der Ansatz wurde auf dem Vortex für eine Minute gemischt und für 5 Minuten bei Raumtemperatur inkubiert (Denaturierung der 
DNA in Einzelstränge). Anschließend wurden $990 \mu \mathrm{l}$ des HT1-Puffers zu den $10 \mu \mathrm{l}$ der denaturierten DNA dazugegeben. Es resultiert eine $20 \mathrm{pM}$ Library in $1 \mathrm{mM} \mathrm{NaOH}$. Die denaturierte DNA musste noch auf eine gewünschte Konzentration von $12 \mathrm{pM}$ dilutiert werden, $d$. h. zu $360 \mu$ der 20 pM denaturierten DNA wurden $240 \mu$ ler HT1-Puffer dazugegeben, gemischt und zentrifugiert. Die denaturierte und dilutierte DNA konnte dann bis zur weiteren Verarbeitung auf Eis gelagert werden.

Im nächsten Schritt wurde die Kontroll-DNA (PhiX Control) vorbereitet, die als Positivkontrolle mitsequenziert wurde. Die $2 \mu \mathrm{l}$ der $10 \mathrm{nM}$ Kontroll-DNA wurden denaturiert. $20 \mathrm{pM}$ der denaturierten Kontroll-DNA $(375 \mu \mathrm{l})$ wurden mit $225 \mu \mathrm{l}$ des Hybridisierungs-Puffers dilutiert. Somit wurde eine Cluster-Dichte von $1000-1200 \mathrm{~K} / \mathrm{mm}^{2}$ erzielt.

Zu jeder der fertig verdünnten Libraries wurde ein 5 \%-iger Anteil an Kontroll-DNA gegeben, d. h. $70 \mu \mathrm{l}$ der fertig verdünnten Library $+30 \mu \mathrm{l}$ der denaturierten Kontroll-DNA (Arbeitslösung $=12,5$ pM).

Für das SureSelect ${ }^{Q x T}$ Enrichment-System wurde die Sequenzierchemie MiSeq Sequencing Reagent Kit v3 Chemie verwendet. Bei dem Target-Enrichment mit SureSelectQXT musste die Cartridge (Sequenzier-Kassette) speziell vorbereitet werden. Aus den Positionen 12, 13 und 14 der Catridge musste das gesamte vorhandene Volumen auspipettiert werden und mit jeweils $3 \mu \mathrm{l}$ der QXTPrimer vermischt werden. Diese Mischungen mussten in eine neue Position in der Catridge einpipettiert werden (Gemisch aus der Position 12 in die Position 18 (Read Primer 1), aus der Position 14 in die Position 20 (Index Read Primer) und aus der Position 13 in die Position 19 (Read Primer 2)). $600 \mu \mathrm{l}$ der fertigen Libraries wurden direkt in die Catridge gegeben.

Die mit dem MiSeq-Sequenzierer ermittelten Sequenzen wurden in das Programm Sequence Pilot hochgeladen. Die ermittelten Sequenzdaten wurden mit der Software Sequence Pilot (JSI medical systems $\mathrm{GmbH}$ ) im Modul SeqNext ausgewertet und zur Identifizierung von Sequenzvarianten mit der jeweiligen Referenzsequenz des zu analysierenden Gens abgeglichen.

Das TruRisk ${ }^{T M}$-Panel umfasst die folgenden 34 Gene: ATM, BARD1, BRCA1, BRCA2, BRIP1, CDH1, CHEK2, ERCC2, FAM175A, FANCA, FANCL, FANCM, GPRC5A, MAP3K1, MLH1, MRE11A, MSH2, MSH6, MUTYH, MYCT1, NBN, PALB2, PIK3CA, PMS2, PPM1D, PTEN, RAD50, RAD51C, RAD51D, RINT1, SMARCA4, STK11, TP53, XRCC2 (s. auch Anhang Tab. 6.2). Fett gekennzeichnet sind die vom Deutschen Konsortium Familiärer Brust- und Eierstockkrebs definierten 10 Core-Gene, die ebenfalls in der Routinediagnostik angeboten wurden und in dieser Dissertation analysiert und ausgewertet wurden.

\subsubsection{Long-Range-PCR}

Die Exons 11 bis 15 des CHEK2-Gens besitzen untereinander eine 95,0 \% - 98,0 \%-ige Homologie mit den CHEK2-Pseudogenen auf den Chromosomen 7, 10, 15, 16, 22 und X (Sodha et al. 2000). Die Sequenzen dieser Exone des CHEK2-Gens konnten nach der Erstellung der Library mittels der HaloPlex-Technologie und in der Anfangsphase der Verwendung der SureSelect ${ }^{\text {OXT }}$-Technologie nicht ausgewertet werden. Wegen der Pseudogene konnten die Exone 11 bis 15 des CHEK2-Gens ebenfalls nicht mittels einer normalen PCR amplifiziert werden, da die Pseudogene mitamplifiziert würden. Daher wurde eine Long-Range-PCR eingesetzt. Die genomische DNA des gewünschten Abschnitts (Exon 11 bis 15) wurde mittels Long-Range-PCR (Forward (for) Primer ist im Intron 9 und der Reverse (rev) Primer in der 3'UTR des CHEK2-Gens (NM_007194) lokalisiert) amplifiziert (s. Abb. 2.8). Diese Primer amplifizieren spezifisch ein etwa $10 \mathrm{~kb}$ großes genomisches Fragment des CHEK2-Gens (Shaag et al. 2005). 


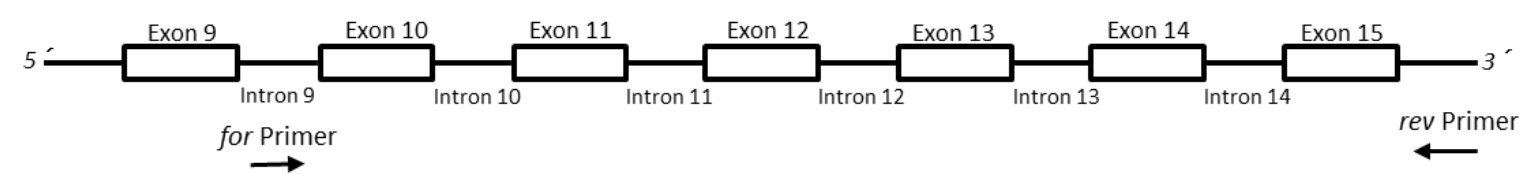

Abbildung 2.8: Schematische Darstellung der Primerlokalisation für die Amplifikation des genomischen Fragments von Exon 10 bis 15 des CHEK2-Gens. Schematische Darstellung eines Abschnittes des CHEK2Gens. Sieben Exons und sechs Introns der genomischen DNA des CHEK2-Gens mit deren Nummerierungen sind angegeben. Die Lokalisation des forward (for) Primers im Intron 9 und des reverse (rev) Primers in der 3'UTR sind jeweils mit einem Pfeil markiert. Diese Primer liegen in den Bereichen von nicht-homologen Sequenzen zu den CHEK2-Pseudogenen. Mit einer anschließenden Nested-PCR mit Primern für die jeweiligen Exone 11 bis 15 wurden diese Exone des CHEK2-Gens amplifiziert und anschließend mittels Sanger-Technologie sequenziert.

Um die Produkte zu visualisieren, wurden $10 \mu \mathrm{l}$ des PCR-Produkts auf ein $0.8 \%$-iges Agarose-Gel aufgetragen. Anschließend wurden die Exons 11 bis 15 direkt amplifiziert (Nested-PCR) und mit Hilfe der Sanger-Methode sequenziert. Die ermittelten Sequenzdaten wurden mit der Software Sequence Pilot Modul SeqPilot (JSI medical systems GmbH) im Modul SeqPatient ausgewertet und zur Identifizierung von Sequenzveränderungen mit der Referenzsequenz abgeglichen.

\subsubsection{Auswertung der NGS-Sequenzen}

Die Gen-Sequenzen ermittelt nach Sequenzierung auf der MiSeq-Plattform von Illumina wurden mit dem Auswerteprogramm SequencePilot (JSI medical systems Gmbh) im Modul SeqNext ausgewertet.

\subsubsection{Klassifizierung der Sequenzvarianten}

Um die Gensequenzen der Patienten mit der korrekten Referenzsequenz der Core-Gene vergleichen zu können, wurden den analysierten Genen entsprechende Referenzsequenzen nach der ENST- (Ensembl genome browser 88) bzw. der NM-Nomenklatur (aus NCBI-National Center for Biotechnology Information) zugeordnet (s. Tab. 2.14).

Tabelle 2.14: Core-Gene mit entsprechenden Nummern der Referenzsequenzen

\begin{tabular}{|c|c|c|}
\hline Gen & NM_Nummer"\# & ENST_Nummer"11 \\
\hline ATM & NM_000051 & ENST00000278616 \\
\hline BRCA1 & NM_007294 & ENST00000357654 \\
\hline BRCA2 & NM_000059 & ENST00000544455 \\
\hline CDH1 & NM_004360 & ENST00000261769 \\
\hline CHEK2 & NM_007194 & ENST00000328354 \\
\hline NBN & NM_002485 & ENST00000265433 \\
\hline PALB2 & NM_024675 & ENST00000261584 \\
\hline RAD51C & NM_058216 & ENST00000337432 \\
\hline RAD51D & NM_002878 & ENST00000345365 \\
\hline$T P 53$ & NM_000546 & ENST00000269305 \\
\hline
\end{tabular}

\# NM_Nummer übernommen aus NCBI (https://www.ncbi.nlm.nih.gov/guide/howto/find-transcript-gene/).

\#1ENST_Nummer übernommen aus Ensemb/ genome browser 88 (www.ensembl.org).

Um die Klassifizierung der Pathogenität der identifizierten Sequenzvarianten in den Core-Genen definieren zu können, wurden die Datenbank des Deutschen Konsortiums Familiärer Brust- und Eierstockkrebs, die nur für Mitglieder des Konsortiums zugängig ist, sowie andere frei verfügbare oder lizenzierte Datenbanken verwendet (s. Tab. 2.15). 
Tabelle 2.15: Datenbanken für die Einschätzung der Pathogenität der detektierten Sequenzvarianten

\begin{tabular}{|l|l|}
\hline Datenbank & Homepage \\
\hline $\begin{array}{l}\text { Datenbank des Deutschen Konsortiums Familiärer } \\
\text { Brust- und Eierstockkrebs (BRCA2006) }\end{array}$ & $\begin{array}{l}\text { Nur für Mitglieder des Deutschen Konsortiums } \\
\text { Familiärer Brust- und Eierstockkrebs verfügbar }\end{array}$ \\
\hline BIC-(Breast Cancer Information Core)-Datenbank & https://research.nhgri.nih.gov/bic \\
\hline $\begin{array}{l}\text { HGMD (Human Gene Mutation Database)- } \\
\text { Professional }\end{array}$ & https://portal.biobase-international.com/hgmd \\
\hline ClinVar (NCBI) & http://www.ncbi.nlm.nih.gov/clinvar \\
\hline LOVD v.3.0 (Leiden Open Variation Database) & http://www.lovd.nl/3.0/home \\
\hline ExAC-Exome Aggregation Consortium & http://www.exac.broadinstitute.org \\
\hline
\end{tabular}

Wenn eine identifizierte Sequenzvariante nicht in einer der oben genannten Datenbanken gelistet war, wurden für die mögliche Einschätzung der Pathogenität frei im Internet verfügbare computergesteuerte Vorhersageprogramme verwendet (s. Tab. 2.16). Mit diesen Programmen wurde anhand der unterschiedlichen Algorithmen die Pathogenität der Sequenzvarianten eingeschätzt. Vom Deutschen Konsortium Familiärer Brust- und Eierstockkrebs wurde definiert, dass eine nicht beschriebene Sequenzvariante, die mit mindestens drei Vorhersageprogrammen als pathogene Mutation eingestuft wird, höchstens als eine Variante unklarer Signifikanz (VUS) eingeschätzt werden darf.

Tabelle 2.16: Vorhersageprogramme für die Einschätzung der Pathogenität der Sequenzvarianten

\begin{tabular}{|l|l|}
\hline Vorhersageprogramm & Homepage \\
\hline SIFT & http://sift.jcvi.org/ \\
\hline MutationTaster & http://www.mutationtaster.org/ \\
\hline PolyPhen-2 & http://genetics.bwh.harvard.edu/pph2/ \\
\hline Human Splicing Finder Version 3.0 & http://www.umd.be/HSF3/ \\
\hline
\end{tabular}

\subsection{Statistische Auswertung der Daten}

Alle statistischen Auswertungen wurden mit Hilfe von Herrn Dr. rer. nat. Andreas Leha aus der Abteilung Medizinische Biometrie und Statistische Bioinformatik der UMG durchgeführt. Der Einfluss der Co-Faktoren auf die Detektionsrate der Mutationen wurde mit dem logistischen Regressionsmodell berechnet. Die Auswertungen wurden mit dem statistischen Programm „statistic software R" (Version 3.3.1, www.r-project.org) mit dem R-Paket Ime4 für das logistische Regressionsmodell vorgenommen. Die Grenze für die statistische Signifikanz wurde bei $5 \%$ gesetzt.

\subsection{Ethische Aspekte}

Die vorliegende Dissertation ist im Rahmen der humangenetischen Betreuung von Patienten mit Verdacht auf ein hereditäres Mamma- und Ovarialkarzinom entstanden. Die Ethikkommission der Georg-August-Universität Göttingen hat mit Schreiben vom 02.06.2015 unter der Antragsnummer DOK_227_2015 keine ethischen oder rechtlichen Bedenken gegenüber dieser Studie mit dem Titel „Identifizierung von Patientinnen und Patienten mit der hereditären Form des Mamma- und Ovarialkarzinoms mittels Next-Generation-Sequencing-(NGS)-Technologie" geäußert. 


\section{Ergebnisse}

\subsection{Beschreibung der Studie}

Im Rahmen dieser Arbeit wurde im Zeitraum von Mai 2015 bis September 2016 ein Kollektiv von 200 Patienten mit den erfüllten klinischen Kriterien für eine molekulargenetische Untersuchung bei Verdacht auf eine hereditäre Form des Mamma- und Ovarialkarzinoms molekulargenetisch analysiert. Bei allen 200 Patienten wurden im Rahmen einer genetischen Beratung die Eigen- und Familienanamnese sowie ein Stammbaum der Familie über mindestens drei Generationen erhoben. Die genetischen Beratungen erfolgten bei 160 Patienten (80,0 \%) im Rahmen der Interdisziplinären Brustkrebsrisikosprechstunde des Brustkrebszentrums der Klinik für Gynäkologie und Geburtshilfe der Universitätsmedizin Göttingen (UMG) durch eine Fachärztin für Humangenetik und bei 40 Patienten (20,0 \%) im Rahmen der humangenetischen Sprechstunde des medizinischen Versorgungszentrums (MVZ) im Institut für Humangenetik der UMG. Bei der humangenetischen Beratung wurde anhand des erhobenen Stammbaums entschieden, ob die vom Deutschen Konsortium Familiärer Brust- und Eierstockkrebs definierten Kriterien für eine molekulargenetische Untersuchung bei $V$. a. eine hereditäre Form des Mamma- und Ovarialkarzinoms bei dem jeweiligen Patienten erfüllt waren. In einem solchen Fall wurde dem Patienten eine molekulargenetische Analyse der sogenannten 10 Core-Gene (ATM, BRCA1, BRCA2, CDH1, CHEK2, NBN, PALB2, RAD51C, RAD51D und TP53) angeboten. Im Fall, dass die Kriterien nicht erfüllt waren bzw. kein Indexpatient verfügbar war, wurde für den ratsuchenden Patienten eine Risikoberechnung mit Hilfe des Risikokalkulationsprogramms Cyrillic 2.13 vorgenommen. Wenn dadurch das Heterozygoten-Risiko für eine autosomal-dominant vererbte Mutation in einem der 10 Core-Gene des Patienten die definierte Grenze von $\geq 20 \%$ überschritten hatte, wurde dem Patienten eine molekulargenetische Untersuchung dieser Gene angeboten.

Die DNA-Proben aller 200 Patienten wurden aus EDTA-Blutproben extrahiert und nachfolgend mit Hilfe eines Multi-Gen-Panels und Next-Generation-Sequencing (NGS) analysiert. Es wurden die vom Deutschen Konsortium Familiärer Brust- und Eierstockkrebs definierten o. g. 10 Core-Gene auf das Vorliegen von Keimbahnmutationen hin analysiert. Weiterhin wurde bei allen 200 Patienten zur Erfassung von größeren genomischen Rearrangements (Deletionen oder Duplikationen) eine MLPA-Analyse der Gene BRCA1, BRCA2 und CHEK2 durchgeführt. Bei 181 Patienten (90,5 \%) wurde zusätzlich die MLPA-Analyse der Gene PALB2, RAD51C und RAD51D durchgeführt. Diese Untersuchung erfolgte nicht bei allen Patienten, da bei diesen Patienten die MLPA-Analyse der Gene PALB2, RAD51C und RAD51C diagnostisch nicht angefordert war und die

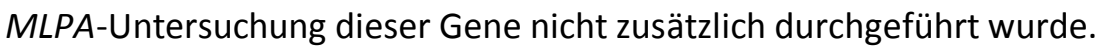

\subsection{Klinische Charakteristika der analysierten Patienten-Kohorte}

Es wurden genomische DNA-Proben von insgesamt 196 weiblichen $(98,0 \%)$ und vier männlichen $(2,0 \%)$ Patienten analysiert. Bei 173 Patienten $(86,5 \%)$ der untersuchten Kohorte wurde präanalytisch ein Mammakarzinom diagnostiziert. Bei 22 Patienten (12,7 \%) mit der Diagnose Mammakarzinom wurde weiterhin ein kontralaterales Mammakarzinom identifiziert. Bei vier der an Mammakarzinom erkrankten Patienten wurde zusätzlich ein Ovarialkarzinom diagnostiziert. Ein Patient war an einem Mamma- und einem kolorektalen Karzinom erkrankt. Bei 10 Patienten $(5,0 \%)$ lag ausschließlich die Diagnose eines Ovarialkarzinoms vor. Bei 17 der untersuchten Patienten $(8,5 \%)$ konnten klinisch kein Mamma- oder Ovarialkarzinom diagnostiziert werden. Aufgrund des mit Hilfe des Risikokalkulationsprogramms Cyrillic 2.13 berechneten HeterozygotenRisikos von $\geq 20 \%$ wurden diese Patienten molekulargenetisch auf Sequenzvarianten in den o. g. 10 Core-Genen hin analysiert.

Bei allen 200 untersuchten Patienten dieser Kohorte wurden die klinischen Daten zu den Mammaund Ovarialkarzinomen erfasst. So wurden das Erkrankungsalter der Patienten bei der Erstdiagnose des Mamma- und/oder Ovarialkarzinoms und das Vorhandensein eines ein- oder 
beidseitigen Mammakarzinoms festgehalten. Weiterhin wurde ermittelt, ob die vom Deutschen Konsortium Familiärer Brust- und Eierstockkrebs definierten Kriterien erfüllt wurden. Zusätzlich wurden das Heterozygoten-Risiko für eine autosomal-dominant vererbte Mutation (Anlageträgerschaft) für ein hereditäres Mamma- und Ovarialkarzinom und das Risiko bis zum 85. Lebensjahr an einem Mammakarzinom zu erkranken mit dem Risikokalkulationsprogramm Cyrillic 2.13 berechnet. Ebenso wurden der histologische Tumortyp und der jeweilige Rezeptorstatus (Östrogenrezeptor $\alpha=E R \alpha$, Progesteron-Rezeptor $=$ PR und ERRB2-Rezeptor) des Mammakarzinoms und das Vorhandensein weiterer Tumoren (außer Mamma- und Ovarialkarzinomen) über drei Generationen der Verwandtschaft aufgenommen.

\subsubsection{Alterserfassung der Patienten bei Erstdiagnose eines Mamma- oder Ovarialkarzinoms}

Um einen Überblick über die Verteilung des Erkrankungsalters bei der Erstdiagnose des Mammaoder Ovarialkarzinoms zu erhalten, wurden die Patienten in sieben Altersgruppen anhand des Erkrankungsalters bei der Erstdiagnose des Mamma- oder Ovarialkarzinoms eingeteilt. Das durchschnittliche Alter der Patienten bei der Erstdiagnose des Mamma- oder Ovarialkarzinoms im untersuchten Kollektiv betrug 41,9 Jahre. 68 der untersuchten Patienten $(34,0 \%)$ erkrankten zwischen dem 40. und 49. Lebensjahr an einem Mamma- oder Ovarialkarzinom, die zweitgrößte Altersgruppe mit 43 Patienten (21,5\%) erkrankte zwischen dem 50. und 59. Lebensjahr. Die drittgrößte Gruppe mit 32 Patienten, die an einem Mamma- oder Ovarialkarzinom erkrankten $(16,0 \%)$ war die Altersgruppe zwischen dem 30 . und 39. Lebensjahr, gefolgt von 10 Patienten $(5,0$ $\%)$, die vor dem 29. Lebensjahr erkrankt waren, sieben Patienten (3,5\%), die zwischen dem 70. und 79. Lebensjahr und vier Patienten $(2,0 \%)$, die zwischen dem 80 . und 89 . Lebensjahr erkrankten. 17 der molekulargenetisch untersuchten Patienten (8,5\%) waren nicht an einem Mamma- oder Ovarialkarzinom erkrankt (s. Tab. 3.1).

Weibliche Patienten erkrankten mit einem mittleren Erkrankungsalter von 47,4 Jahren an einem Mammakarzinom, bei den männlichen Patienten wurde ein mittleres Erkrankungsalter für ein Mammakarzinom von 54,0 Jahren ermittelt. Das mittlere Erkrankungsalter weiblicher Patienten für ein Ovarialkarzinom betrug in diesem Patentenkollektiv 60,4 Jahre.

Tabelle 3.1: Erkrankungsalter der analysierten Patienten bei Erstdiagnose eines Mamma- oder Ovarialkarzinoms

\begin{tabular}{|c|c|}
\hline Altersgruppen bei der Ersterkrankung eines MCa oder OvCa (in Jahren) & Anzahl der Patienten \\
\hline $0-29$ & 10 \\
\hline $30-39$ & 32 \\
\hline $40-49$ & 68 \\
\hline $50-59$ & 43 \\
\hline $60-69$ & 19 \\
\hline $70-79$ & 7 \\
\hline $80-89$ & 4 \\
\hline kein MCa/OvCa & 17 \\
\hline
\end{tabular}

$\mathrm{MCa}=$ Mammakarzinom; OvCa = Ovarialkarzinom.

\subsubsection{Einteilung der untersuchten Patienten in Bezug auf die erfüllten Kriterien für eine molekulargenetische Analyse der 10 Core-Gene}

Das Deutsche Konsortium Familiärer Brust- und Eierstockkrebs hat spezifische Kriterien für die Durchführung einer molekulargenetischen Analyse bei Verdacht auf ein hereditäres Mamma- und Ovarialkarzinom definiert (s. Einleitung, Tab. 1.3). Jeder der 200 in dieser Arbeit untersuchten Patienten erfüllte eines der definierten Kriterien. Um zu ermitteln, wie diese Kriterien in der 
untersuchten Kohorte verteilt waren und wie sich die Häufigkeit der erfüllten Kriterien darstellte, wurde die Verteilung dieser Kriterien analysiert.

72 der untersuchten Patienten (36,0 \%) erfüllten das Kriterium A, gefolgt von 44 Patienten $(22,0$ $\%)$, die das Kriterium G erfüllten. Die drittgrößte Gruppe waren 27 Patienten (13,5\%), die das Kriterium J erfüllten. Es folgten jeweils 17 Patienten (8,5\%), die das Kriterium $\mathrm{R}$ und $\mathrm{Y}$ erfüllten. Die kleinsten Gruppen waren vier Patienten (2,0\%), die das Kriterium N, drei Patienten (1,5\%), die das Kriterium $U$ und zwei Patienten (1,0 \%), die das Kriterium Z erfüllten (s. Abb. 3.1).

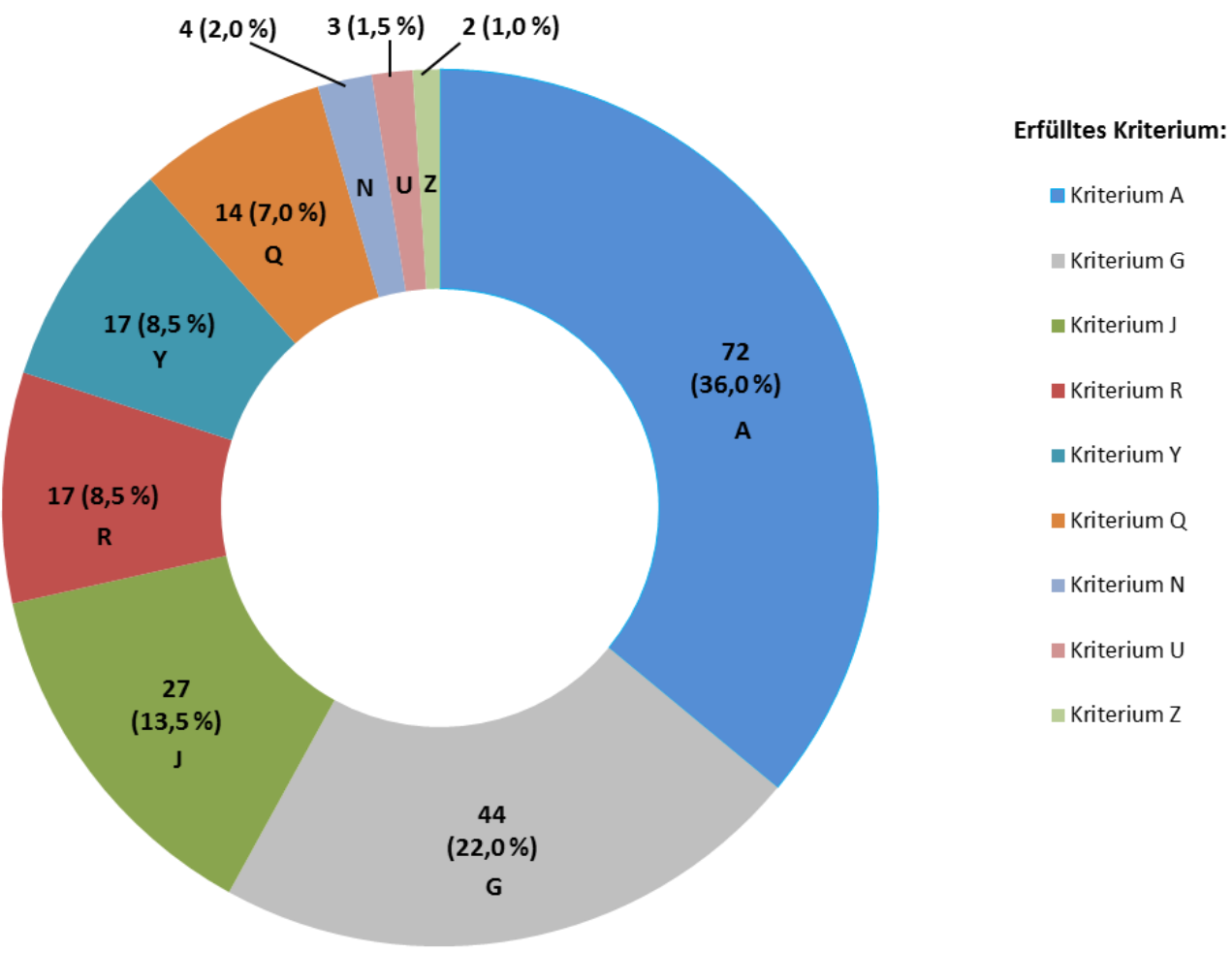

Abbildung 3.1: Einteilung der untersuchten Patienten nach der Häufigkeit der erfüllten Kriterien. Die Patienten der untersuchten Kohorte wurden nach den erfüllten Kriterien, definiert vom Deutschen Konsortium Familiärer Brust- und Eierstockkrebs, eingeteilt. Jede Farbe des Kreises repräsentiert eines der erfüllten Kriterien. Die Kriterien sind mit Buchstaben durchnummeriert ( $A, G, J, N, Q, R, U, Y$ und Z). Die Zahl im Kreis repräsentiert die Anzahl der Patienten, die ein bestimmtes Kriterium erfüllten. In Klammern ist die entsprechende Prozentzahl aufgeführt. Es wurde eine Wichtung nach der Häufigkeit der erfüllten Kriterien vorgenommen.

\subsubsection{Risikoberechnung der Patienten-Kohorte mit Hilfe des Risikokalkulations- Programms Cyrillic 2.13}

Das Risikokalkulationsprogramm Cyrillic 2.13 wurde für die Berechnungen des HeterozygotenRisikos der Anlageträgerschaft einer Mutation in einem der Core-Gene und des Lebenszeitrisikos bis zum 85. Lebensjahr an einem Mammakarzinom zu erkranken verwendet. Dazu wurde ein Stammbaum des Patienten über mindestens drei Generationen in das Risikokalkulationsprogramm eingegeben. Das Risikokalkulationsprogramm Cyrillic 2.13 betrachtet allerdings nur Mamma- und Ovarialkarzinome in seiner Berechnung, jedoch keine weiteren Tumorerkrankungen.

Aus diagnostischer Sicht sowie nach den Richtlinien des Deutschen Konsortiums Familiärer Brustund Eierstockkrebs müssen die o. g. Risiken präanalytisch für Patienten mit dem Verdacht auf das hereditäre Mamma- und Ovarialkarzinom berechnet werden, bei denen in der Familie kein lebender bzw. verfügbarer Indexpatient vorhanden ist. Ebenfalls gilt diese Regelung 
postanalytisch für Patienten $<50$ Jahre ohne eine identifizierte wahrscheinlich pathogene oder pathogene Mutation in einem der 10 Core-Gene. Im Rahmen dieser Dissertation wurden die Risiken für alle 200 Patienten unabhängig von der diagnostischen Indikation berechnet. Somit können die Risiken des jeweiligen Patienten mit der Detektionsrate der Sequenzvarianten der ACMG-Klasse 3, 4 oder 5 in den 10 Core-Genen sowie mit den klinischen Angaben der Patienten und der Tumore verglichen werden.

Wird bei nicht an einem Mammakarzinom erkrankten Patienten ein Heterozygoten-Risiko von $\geq$ $20 \%$ oder ein Lebenszeitrisiko von $\geq 30 \%$ ermittelt, so kann diesen Patienten eine molekulargenetische Untersuchung der 10 Core-Gene angeboten werden. Frauen mit aktuellem Alter $<50$ Jahre mit den o. g. berechneten Risiken, aber ohne Detektion einer wahrscheinlich pathogenen oder pathogenen Mutation bzw. nach Identifizierung einer Sequenzvariante der ACMG-Klasse 3 in einem der 10 Core-Gene steht ein intensiviertes Früherkennungs- bzw. Nachsorgeprogramm (IFNP) zur Verfügung.

Das mittlere berechnete Heterozygoten-Risiko der gesamten Patienten-Kohorte lag bei $38 \pm 30 \%$. Das Lebenszeitrisiko an einem Mammakarzinom bis zum 85. Lebensjahr zu erkranken betrug in der gesamten untersuchten Patienten-Kohorte $27 \pm 21 \%$.

\subsubsection{Heterozygoten-Risiko für eine autosomal-dominant vererbte Mutation in einem der 10 Core-Gene in Abhängigkeit vom erfüllten Kriterium}

Das Heterozygoten-Risiko wurde für jeden Patienten der Kohorte in Abhängigkeit vom Stammbaum über mindestens drei Generationen mittels des Risikokalkulationsprogramms Cyrillic 2.13 berechnet. Das Heterozygoten-Risiko wurde berechnet um es mit den jeweiligen empirischen Risiken, generiert vom Deutschen Konsortium Familiärer Brust- und Eierstockkrebs (Meindl et al. 2011), vergleichen zu können. Somit konnte die Stringenz des jeweiligen erfüllten Kriteriums mit dem vom Deutschen Konsortium Familiärer Brust- und Eierstockkrebs definierten empirischen Risiken verglichen werden.

Für die Patienten mit dem erfüllten Kriterium R wurde der höchste Mittelwert des Risikos für die Anlageträgerschaft einer Mutation in einem der 10 Core-Gene $(61,6 \%)$ berechnet, gefolgt von den Patienten mit dem erfüllten Kriterium N (56,5 \%) (s. Abb. 3.2). Das dritthöchste Heterozygoten-Risiko (46,2 \%) wiesen Patienten auf, die das Kriterium U erfüllten. Es folgte die Gruppe der Patienten mit dem erfüllten Kriterium A mit einem Heterozygoten-Risiko von 44,1\%. Mit einem Heterozygoten-Risiko von 40,2 \% folgt anschließend die Gruppe der Patienten mit dem erfüllten Kriterium J. Bei Patienten mit dem erfüllten Kriterium Z konnte ein Heterozygoten-Risiko von $37,2 \%$ ermittelt werden, gefolgt von Patienten mit dem erfüllten Kriterium Y (33,2\%). Die niedrigsten Mittelwerte der Heterozygoten-Risiken von 23,7 \% bzw. von 17,5\% wurden für die Patienten mit dem erfüllten Kriterium $G$ bzw. Kriterium $Q$ berechnet (s. Abb. 3.2). 


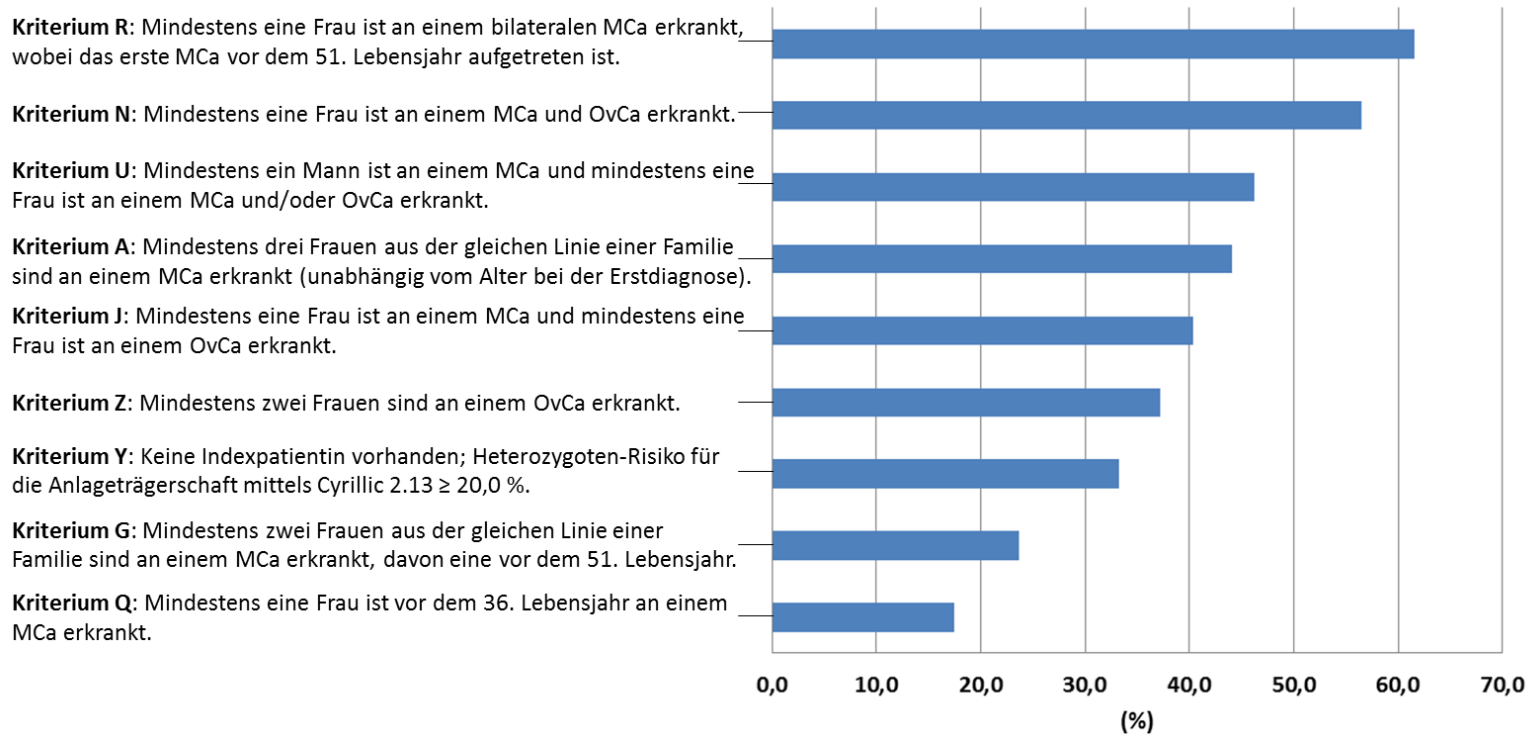

Abbildung 3.2: Darstellung des Heterozygoten-Risikos der Patienten-Kohorte in Korrelation zum erfüllten Kriterium. Für jeden untersuchten Patienten wurde entweder prä- oder postanalytisch das HeterozygotenRisiko für eine Anlageträgerschaft einer autosomal-dominant vererbten Mutation in einem der 10 CoreGene mittels des Risikokalkulationsprogramms Cyrillic 2.13 berechnet. Der Mittelwert dieses Heterozygoten-Risikos wurde für die jeweilige Patientengruppe mit dem entsprechenden erfüllten Kriterium dargestellt. $\mathrm{MCa}=$ Mammakarzinom; OvCa = Ovarialkarzinom.

\subsubsection{Histologische Formen und Rezeptorstatus der Mammakarzinome}

Der histologische Typ und der jeweilige Rezeptorstatus der Mammakarzinome wurden in der Mehrzahl der Fälle von Mitarbeitern des Instituts für Pathologie der UMG oder von Mitarbeitern des Instituts für Pathologie Nordhessen in Kassel erfasst. Aus der Literatur ist bekannt, dass bestimmte histologische Subtypen der Mammakarzinome mit Mutationen vor allem im BRCA1Gen assoziiert sind (Lee et al. 2011). Um diese Assoziation sowie weitere Korrelationen in dieser Patienten-Kohorte aufzuzeigen, wurden die histologischen Subtypen der Mammakarzinome bei den erkrankten Patienten ermittelt. Bei 105 der untersuchten Patienten (52,5\%) konnte ein invasiv duktales Mammakarzinom nachgewiesen werden. Bei der nächstgrößten Gruppe konnte bei 32 Patienten (16,0 \%) ein DCIS (duktales Carcinoma in situ) identifiziert werden, gefolgt von 16 Patienten (8,0 \%) mit einem invasiv lobulären Mammakarzinom. Nur zwei Mammakarzinome $(1,0$ \%) wiesen eine medulläre Histologie auf. Die Angaben zum histologischen Subtyp des Mammakarzinoms fehlten bei insgesamt 33 Patienten (16,5\%).

Bei der Analyse des jeweiligen Rezeptorstatus der Mammakarzinome wird die Expression des $E R \alpha$, des PR und die Überexpression des ERBB2-Rezeptors im Tumorgewebe bestimmt. Der Rezeptorstatus der o. g. Rezeptoren im Mammakarzinom kann in Assoziation mit dem Stammbaum Hinweise auf einen hereditären Ursprung der Tumore liefern (Honrado et al. 2005, Lee et al. 2011).

Die Information über das Expressionsmuster aller drei o. g. Rezeptoren im Tumorgewebe war für 138 der Mammakarzinome erhältlich. Bei den untersuchten Patienten wurden unterschiedliche Expressionsmuster dieser drei Rezeptoren im Gewebe des Mammakarzinoms beobachtet. Das weitverbreiteste Expressionsmuster war eine Expression des ER $\alpha$ und des PR und keine Überexpression des ERBB2-Rezeptors bei 63 der untersuchten Mammakarzinome (45,7 \%). Das zweithäufigste Expressionsmuster waren die triple-negativen Mammakarzinome (kein Nachweis der Expression des ER $\alpha$ und des PR und ohne Überexpression des ERBB2-Rezeptors im Tumorgewebe) bei 32 Mammakarzinomen (23,2 \%). Die dritthäufigste Gruppe waren die Mammakarzinome mit exprimierten ER $\alpha$ und PR mit Überexpression des ERBB2-Rezeptors im 
Tumor bei 21 Mammakarzinomen (15,2 \%). Andere Kombinationen der Expression/ Überexpression dieser drei Rezeptoren in den Mammakarzinomen wurden deutlich seltener beobachtet. Es wurden sechs Fälle (4,3\%) mit nicht nachgewiesener Expression von ER $\alpha$ und PR und Überexpression des ERBB2-Rezeptors identifiziert. Bei fünf Fällen (3,6 \%) konnte die Expression des ER $\alpha$ nachgewiesen werden sowie eine Überexpression des ERBB2-Rezeptors ohne Nachweis der Expression des PR. Bei weiteren fünf Fällen (3,6 \%) konnte die Expression des ER $\alpha$ detektiert werden. Es konnte kein Nachweis der Expression der PR und der Überepression des ERBB2-Rezeptors beobachtet werden. Die kleinsten Gruppen waren drei Fälle $(2,2 \%)$ mit der Expression des PR und nicht nachgewiesener Expression der ER $\alpha$ und der Überexpression des ERBB2-Rezeptors sowie zwei Fälle (1,4 \%) mit der Expression des PR und der Überexpression von ERBB2-Rezeptor und nicht nachgewiesener Expression des ER $\alpha$. Bei allen anderen Mammakarzinomen war entweder die Information zur Expression/Überexpression der o. g. Rezeptoren unvollständig oder fehlte vollkommen.

\subsubsection{Weitere Tumorerkrankungen in den Familien über drei Generationen}

Neben den Mamma- und Ovarialkarzinomen wurden in den Stammbäumen der untersuchten Patienten über mindestens drei Generationen weitere Tumorerkrankungen beobachtet. Diese Information wurde ermittelt, um das gesamte Tumorspektrum in den Familien mit Verdacht auf ein hereditäres Mamma- und Ovarialkarzinom abzudecken.

Weitere Tumorerkrankungen lagen in 102 Familien $(51,0 \%)$ der untersuchten Patienten vor. Am häufigsten wurde in 54 Fällen $(52,9 \%)$ ein kolorektales Karzinom beobachtet, gefolgt von 25 Fällen (24,5 \%) mit einem Prostatakarzinom, an dritter Stelle wurden Magen- und Pankreaskarzinome in jeweils 16 Fällen $(15,7 \%)$ nachgewiesen, gefolgt von Lungenkarzinomen in 14 Fällen (13,7 \%). Weiterhin wurden Leukämien sowie Lymphome bei jeweils 10 Fällen (9,8 \%) beobachtet. Seltener wurden Leber-, Blasen-, Nieren-, Hoden- und Endometriumkarzinome sowie Sarkome und Hauttumore detektiert. Als letzte Gruppe sind die Patienten zu benennen bei denen unbekannte Formen der Krebserkrankungen in der Verwandtschaft über drei Generationen beobachtet wurden.

\subsection{Molekulargenetische Daten der untersuchten Patienten-Kohorte}

\subsubsection{Allgemeine Informationen zu den molekulargenetischen Untersuchungen}

Zur Untersuchung von Punktmutationen sowie kleinerer Insertionen und Deletionen wurden die kodierenden Bereiche einschließlich der Intron-Exon-Übergänge (bis intronische Nukleotidposition - 20 und bis intronische Nukleotidposition +20$)$ der 10 Core-Gene als Bestandteil eines Multi-Gen-Panels mittels der HaloPlex-Technologie oder als Bestandteil eines Multi-Gen-TruRisk 1.2 $2^{\mathrm{TM}}$-Panels mit dem SureSelect ${ }^{\mathrm{QXT}}$-Verfahren angereichert, amplifiziert und mit der Next-Generation-Sequencing-(NGS)-Technologie mit dem Illumina MiSeq-System sequenziert (s. Material und Methoden Abschnitt 2.2.9.1 und 2.2.9.2).

Die unterschiedlichen verwendeten Technologien entstanden dadurch, dass das Institut für Humangenetik der UMG im ersten Schritt das Multi-Gen-Panel mit der HaloPlex-Technologie eingeführt hatte. Mit diesem Panel wurden 28 Patienten (14,0 \%) dieser Kohorte untersucht. Wegen der ungleichmäßigen bis unzureichenden Abdeckung einzelner Bereiche der analysierten Gene, wurde die HaloPlex-Technologie durch das Multi-Gen-TruRisk 1.2 ${ }^{\text {TM}}$-Panel ersetzt. Dieses Panel wurde vom Deutschen Konsortium Familiärer Brust- und Eierstockkrebs entworfen und wird allen Brustkrebszentren innerhalb des Konsortiums zur Verfügung gestellt. Mit diesem Multi-GenPanel wurden die 10 Core-Gene von insgesamt 172 Patienten (86,0\%) dieser Kohorte analysiert. Eine nicht ausreichend abgedeckte Gensequenz der entsprechenden Core-Gene wurde mit der Sanger-Technologie nachsequenziert. Eine ausreichende Abdeckung wird mit den Reads pro Base 
definiert. Nach den internen Regularien des Instituts für Humangenetik der UMG wird eine ausreichende Abdeckung wie folgt definiert:

- Wenn Gensequenzen für beide Leserichtungen (forward und reverse Sequenz) vorhanden sind, ist eine Abdeckung von mindestens 20 Reads pro Base für die jeweilige Leserichtung notwendig.

- Wenn die Gensequenz nur für eine Leserichtung (forward oder reverse Sequenz) vorhanden ist, muss eine Abdeckung von mindestens 50 Reads pro Base vorhanden sein.

Die ermittelten Sequenzdaten der 10 Core-Gene ATM, BRCA1, BRCA2, CDH1, CHEK2, NBN, PALB2, RAD51C, RAD51D und TP53 wurden mit der Software Sequence Pilot (SeqNext-Modul, JSI medical systems $\mathrm{GmbH}$ ) ausgewertet und zur Identifizierung von Sequenzvarianten mit den jeweiligen Referenzsequenzen abgeglichen (Referenzdatenbanken: www.ncbi.nlm.nih.gov; www.ensembl. org). Zusätzlich wurde eine MLPA-Untersuchung der Gene BRCA1, BRCA2 und CHEK2 durchgeführt sowie bei der Mehrzahl der Patienten eine MLPA-Analyse der Gene PALB2, RAD51C und RAD51D vorgenommen (s. Abschnitt 3.1).

\subsubsection{Allgemeine Informationen zur Klassifizierung der identifizierten Sequenzvarianten}

Die nachgewiesenen Sequenzvarianten in den o. g. 10 Core-Genen wurden nach den Standards des ACMG und den Empfehlungen des International Agency for Research on Cancer (IARC; Plon et al. 2008) in fünf Klassen eingestuft (s. Tab. 3.2).

Tabelle 3.2: Einteilung der Sequenzvarianten in fünf Klassen nach den Richtlinien des ACMG und Empfehlungen des IARC

\begin{tabular}{|c|c|}
\hline $\begin{array}{c}\text { Klasse der } \\
\text { Sequenzvariante }\end{array}$ & Beschreibung der Sequenzvariante \\
\hline 1 & benigne Sequenzvariante \\
\hline 2 & wahrscheinlich benigne Sequenzvariante \\
\hline 3 & Variante unklarer Signifikanz (VUS) \\
\hline $\mathbf{4}$ & wahrscheinlich pathogene Sequenzvariante \\
\hline $\mathbf{5}$ & pathogene Sequenzvariante \\
\hline
\end{tabular}

Die identifizierten Sequenzvarianten wurden mittels der unten gelisteten Datenbanken und Berechnungen anhand der computergesteuerten Vorhersageprogramme sowie der Literaturrecherche in die o. g. Klassifikation eingestuft.

Es wurden die Datenbank des Deutschen Konsortiums Familiärer Brust- und Eierstockkrebs (die Datenbank ist nur für Brustzentren des Konsortiums Familiärer Brust- und Eierstockkrebs verfügbar), die Breast Cancer Information Core-(BIC)-Datenbank, die Human Gene Mutation Database-(HGMD $\left.{ }^{\circledR}\right)$-Professional 2016.4-Datenbank, die ClinVar-Datenbank von NCBI und die Leiden Open Variation Database v.3.0-(LOVD)-Datenbank verwendet (s. Tab. 2.15).

Bei einer identifizierten Sequenzvariante, welche zuvor nicht in den Datenbanken und/oder in der Literatur beschrieben worden war, wurden für die Einschätzung der Pathogenität dieser Sequenzvariante die folgenden computerunterstützten, online verfügbaren Vorhersageprogramme wie z. B. SIFT (www.jgvi.sift), MutationTaster (www.mutationtaster.org), PolyPhen-2 (www.genetics.bwh.harvard.edu/pph2) und Human Splicing Finder Version 3.0 (http://www.umd.be/HSF3/) verwendet (s. Tab. 2.16).

In dieser Dissertation sind die nachgewiesenen Sequenzvarianten der ACMG-Klassen 3, 4 oder 5 in den 10 Core-Genen angegeben. Die Sequenzvarianten der ACMG-Klasse 4 oder 5 werden im folgenden Text als Mutationen bezeichnet (s. Tab. 3.2). 
Bei einer detektierten Sequenzvariante der ACMG-Klasse 3, 4 oder 5 in einem der 10 Core-Gene erfolgte immer eine Bestätigung dieser Sequenzvariante mittels einer unabhängigen Sequenziermethode, d. h. der entsprechende Genabschnitt wurde mit Hilfe der SangerSequenzierungstechnologie nachanalysiert. Bei einer nachgewiesenen Mutation der ACMG-Klasse 4 oder 5 wurde immer eine Bestätigung dieser Mutation an einer zweiten, unabhängigen Blutprobe des Patienten empfohlen. Die Bestätigung der Mutation an einer zweiten Blutprobe erfolgte bei 27 von 35 Patienten (60,0\%) mit einer identifizierten Mutation.

Alle Sequenzvarianten wurden nach der Nomenklatur der Human Genome Variation Society (HGVS) (den Dunnen et al. 2016) benannt.

\subsubsection{Verteilung der Sequenzvarianten in den analysierten 10 Core-Genen}

Die Verteilung der Sequenzvarianten der ACMG-Klasse 3, 4 oder 5 in den 10 Core-Genen wurde analysiert um das Spektrum der identifizierten Sequenzvarianten der ACMG-Klasse 3, 4 oder 5 in den Core-Genen zu erfassen und um eine Korrelation dieser Sequenzvarianten mit den Typen der Sequenzvarianten und den klinischen Daten der Patienten und der Tumore herzustellen.

Insgesamt wurden 106 Sequenzvarianten (44,0\%) der ACMG-Klasse 3, 4 oder 5 bei 88 der untersuchten Patienten nachgewiesen (s. Tab. 3.3; s. Abb. 3.3A), davon wurden bei 15 Patienten gleichzeitig zwei Sequenzvarianten in zwei unterschiedlichen Genen detektiert, nämlich in den Genen ATM und BRCA2, BRCA2 und CHEK2, PALB2 und RAD51D, ATM und CHEK2, BRCA1 und RAD51C, BRCA2 und CHEK2, BRCA1 und BRCA2, BRCA1 und PALB2, BRCA2 und RAD51D, BRCA1 und NBN, ATM und NBN, ATM und CHEK2, PALB2 und RAD51D, BRCA1 und ATM sowie BRCA1 und RAD51C. Zusätzlich wurden bei einem Patienten zwei Sequenzvarianten jeweils der ACMG-Klasse 3 im BRCA2-Gen identifiziert. Bei einem weiteren Patienten wurden drei Sequenzvarianten in drei unterschiedlichen Genen, d. h. eine Mutation der ACMG-Klasse 5 im BRCA1-Gen sowie jeweils eine Sequenzvariante der $A C M G$-Klasse 3 in den Genen CHEK2 und RAD51D identifiziert. In den Genen NBN, RAD51D und TP53 wurden keine wahrscheinlich pathogenen bzw. pathogenen Mutationen detektiert. Bei 122 Patienten (66,0 \%) wurden in allen 10 untersuchten Core-Genen keine Sequenzvarianten der ACMG-Klasse 3, 4 oder 5 nachgewiesen (s. Tab. 6.3 im Anhang). Die Detektionsrate der Sequenzvarianten der ACMG-Klasse 3, 4 oder 5 in den 10 Core-Genen beträgt somit 44,0 \%, die Nachweisrate von Mutationen der ACMG-Klasse 4 oder 5 liegt dagegen bei 18,0 $\%$.

Tabelle 3.3: Identifizierte Sequenzvarianten der ACMG-Klasse 3, 4 oder 5 bei 88 der analysierten Patienten. In der Tabelle sind 88 Patienten mit nachgewiesenen Sequenzvarianten der ACMG-Klasse 3, 4 oder 5 in den 10 analysierten Core-Genen aufgeführt, die entweder mittels der NGS-Technologie oder mit Hilfe der MLPA-Untersuchung identifiziert wurden. Fett markiert sind in der Tabelle alle 35 Patienten mit einer wahrscheinlich pathogenen Mutation der ACMG-Klasse 4 oder einer pathogenen Mutation der ACMGKlasse 5 in einem der Core-Gene. Alle gelisteten Sequenzvarianten liegen heterozygot vor.

\begin{tabular}{|c|c|c|c|c|c|c|c|}
\hline & $\begin{array}{l}\text { Patienten- } \\
\text { Nummer }\end{array}$ & MCa & OvCa & Geschlecht & $\begin{array}{c}\text { Gen mit } \\
\text { Sequenzvariante } \\
\end{array}$ & $\begin{array}{c}\text { Sequenzvariante } \\
\text { (HGVS Nomenklatur) }\end{array}$ & ACMG-Klasse/Pathogenität \\
\hline 1 & 38560 & ja & nein & w & $\begin{array}{l}\text { ATM } \\
\text { BRCA2 }\end{array}$ & $\begin{array}{c}\text { c.2347T>A (p.(Cys783Ser)) } \\
\text { c.8181_8189delTGTTAAGGC } \\
\text { (p.(Val2728_Ala2730del)) }\end{array}$ & $\begin{array}{l}\text { Klasse 3/VUS } \\
\text { Klasse 3/VUS }\end{array}$ \\
\hline 2 & 38564 & ja & nein & w & $\begin{array}{l}\text { BRCA1 } \\
\text { CHEK2 } \\
\text { RAD51D }\end{array}$ & $\begin{array}{c}\text { c.3700_3704delGTAAA } \\
\text { (p.(Val1234GInfs*8)) } \\
\text { c.132C>T (p.(Ser44=)) } \\
\text { c.796C>T (p.(Arg266Cys)) }\end{array}$ & $\begin{array}{l}\text { Klasse 5/pathogen } \\
\text { Klasse 3/VUS } \\
\text { Klasse 3/VUS }\end{array}$ \\
\hline 3 & 37966 & nein & nein & w & CHEK2 & c.470T>C (p.(Ile157Thr)) & Klasse 3/VUS \\
\hline 4 & 38585 & ja & nein & w & $B R C A 2$ & c.3499A>G (p.(Ile1167Val)) & Klasse 3/VUS \\
\hline
\end{tabular}




\begin{tabular}{|c|c|c|c|c|c|c|c|}
\hline & $\begin{array}{l}\text { Patienten- } \\
\text { Nummer }\end{array}$ & MCa & OvCa & Geschlecht & $\begin{array}{c}\text { Gen mit } \\
\text { Sequenzvariante } \\
\end{array}$ & $\begin{array}{c}\text { Sequenzvariante } \\
\text { (HGVS Nomenklatur) }\end{array}$ & ACMG-Klasse/Pathogenität \\
\hline & & & & & CHEK2 & c.470T>C (p.(Ile157Thr)) & Klasse 3/VUS \\
\hline 5 & 38573 & ja & nein & w & CHEK2 & c.470T>C (p.(Ile157Thr)) & Klasse 3/VUS \\
\hline 6 & 38559 & ja & nein & $\mathbf{w}$ & BRCA2 & c.1813delA (p.(Ile605Tyrfs*9)) & Klasse 5/pathogen \\
\hline 7 & 39009 & ja & nein & w & $\begin{array}{c}\text { PALB2 } \\
\text { RAD51D }\end{array}$ & $\begin{array}{c}\text { c. } 2794 G>A \text { (p.(Val932Met)) } \\
\text { c.868c>T (p.(Arg290Trp)) }\end{array}$ & $\begin{array}{l}\text { Klasse 3/VUS } \\
\text { Klasse 3/VUS }\end{array}$ \\
\hline 8 & 39003 & ja & nein & w & $\begin{array}{c}\text { ATM } \\
\text { CHEK2 }\end{array}$ & $\begin{array}{c}\text { c.2250G>A (p. (Lys750=)) } \\
\text { c.1100delC (p.(Thr367Metfs*15)) }\end{array}$ & $\begin{array}{c}\text { Klasse 3/VUS } \\
\text { Klasse 5/pathogen }\end{array}$ \\
\hline 9 & 39040 & ja & nein & w & BRCA2 & c.9976A>T (p. (Lys3326*)) & Klasse 3/VUS \\
\hline 10 & 39029 & ja & nein & $\mathbf{w}$ & BRCA1 & $\begin{array}{c}\text { c.5266dupC } \\
\text { (p.(GIn1756Profs*74)) }\end{array}$ & Klasse 5/pathogen \\
\hline 11 & 38943 & ja & nein & $\mathbf{w}$ & BRCA1 & c.4386delA (p.(Glu1462Aspfs*4)) & Klasse 5/pathogen \\
\hline 12 & 39012 & ja & nein & w & PALB2 & c.1470C $>T(p .($ Pro490=)) & Klasse 3/VUS \\
\hline 13 & 38579 & ja & nein & w & CHEK2 & c.470T>C (p.(Ile157Thr)) & Klasse 3/VUS \\
\hline 14 & 39032 & ja & nein & w & $N B N$ & c.643C>T (p. (Arg215Trp)) & Klasse 3/VUS \\
\hline 15 & 39035 & ja & nein & w & ATM & c.1986T>C (p. (Phe662=)) & Klasse 3/VUS \\
\hline 16 & 39036 & ja & nein & $\mathbf{w}$ & CHEK2 & $\begin{array}{c}\text { Deletion von Exon } 9 \\
\text { und Exon } 10\end{array}$ & $\begin{array}{c}\text { Klasse 4/ } \\
\text { wahrschl. pathogen }\end{array}$ \\
\hline 17 & $39037^{\#}$ & ja & nein & $\mathbf{w}$ & ATM & c.6336C>A (p. $($ Cys2112*)) & $\begin{array}{c}\text { Klasse 4/ wahr. } \\
\text { pathogen }\end{array}$ \\
\hline 18 & 39038 & ja & nein & w & ATM & c.415G>A (p.(Ala139Thr)) & Klasse 3/VUS \\
\hline 19 & 39042 & ja & nein & w & ATM & c.5286C $>T($ p. $($ Ala1762=)) & Klasse 3/VUS \\
\hline 20 & 39050 & ja & nein & $\mathbf{w}$ & PALB2 & $\begin{array}{l}\text { c.172_175delTTGT } \\
\text { (p.(GIn60Argfs*7)) }\end{array}$ & Klasse 5/pathogen \\
\hline 21 & $26937 C$ & ja & nein & w & TP53 & c. $336 C>A(p .($ Gly112=)) & Klasse 3/VUS \\
\hline 22 & 39060 & ja & nein & w & $N B N$ & c.511A>G (p.(Ile171Val)) & Klasse 3/VUS \\
\hline 23 & 38566 & ja & nein & w & CHEK2 & c.1036C >A (p.(Arg346Cys)) & Klasse 3/VUS \\
\hline 24 & 39061 & ja & nein & w & BRCA2 & c. $8479 C>G$ (p.(Pro2827Ala)) & Klasse 3/VUS \\
\hline 25 & 39065 & ja & nein & w & ATM & c.4324T>C (p.(Tyr1442His)) & Klasse 3/VUS \\
\hline 26 & 39051 & ja & nein & $\mathbf{w}$ & BRCA1 & $c .5503 C>T\left(p .\left(\operatorname{Arg} 1835^{*}\right)\right)$ & Klasse 5/pathogen \\
\hline 27 & 39074 & ja & nein & $\mathbf{w}$ & CHEK2 & c.1100delC (p.(Thr367Metfs*15)) & Klasse 5/pathogen \\
\hline 28 & 39066 & ja & nein & $\mathbf{w}$ & BRCA1 & $\begin{array}{c}\text { c.68_69delAG } \\
\text { (p.(Glu23Valfs*17)) }\end{array}$ & Klasse 5/pathogen \\
\hline 29 & 37369 & ja & nein & w & ATM & c.5497-2A $>C$ & Klasse 5/pathogen \\
\hline 30 & 39072 & nein & nein & $\mathbf{w}$ & BRCA1 & c.1999C $>T\left(p .\left(G \ln 667^{*}\right)\right)$ & Klasse 5/pathogen \\
\hline 31 & 39082 & ja & nein & $\mathbf{w}$ & $\begin{array}{l}\text { BRCA1 } \\
\text { RAD51C }\end{array}$ & $\begin{array}{c}\text { c.1953_1956delGAAA } \\
\text { (p.(Lys653Serfs*47)) } \\
\text { c.572-17G>T }\end{array}$ & $\begin{array}{c}\text { Klasse 5/pathogen } \\
\text { Klasse 3/VUS }\end{array}$ \\
\hline 32 & 39084 & ja & nein & w & $\mathrm{CDH} 1$ & c. $88 \mathrm{C}>\mathrm{A}$ (p.(Pro30Thr)) & Klasse 3/VUS \\
\hline 33 & 39090 & ja & nein & w & BRCA2 & c.9976A>T (p. (Lys3326*)) & Klasse 3/VUS \\
\hline 34 & 39081 & ja & nein & w & PALB2 & c.194C>T (p.(Pro65Leu)) & Klasse 3/VUS \\
\hline 35 & 39086 & ja & nein & w & ATM & c. $7788+8 \mathrm{G}>\mathrm{T}$ & Klasse 3/VUS \\
\hline 36 & 39097 & ja & nein & $\mathbf{w}$ & BRCA1 & $\begin{array}{c}\text { c.3397dupA } \\
\text { (p.(Pro1133Thrfs*11)) }\end{array}$ & Klasse 5/pathogen \\
\hline 37 & 39703 & ja & nein & w & BRCA2 & c.9976A>T (p. (Lys3326*)) & Klasse 3/VUS \\
\hline 38 & 39070 & ja & nein & w & ATM & c.6067G>A (p.(Gly2023Arg)) & Klasse 3/VUS \\
\hline
\end{tabular}




\begin{tabular}{|c|c|c|c|c|c|c|c|}
\hline & $\begin{array}{l}\text { Patienten- } \\
\text { Nummer } \\
\end{array}$ & MCa & OvCa & Geschlecht & $\begin{array}{c}\text { Gen mit } \\
\text { Sequenzvariante } \\
\end{array}$ & $\begin{array}{c}\text { Sequenzvariante } \\
\text { (HGVS Nomenklatur) }\end{array}$ & ACMG-Klasse/Pathogenität \\
\hline 39 & 39077 & ja & nein & $\mathbf{w}$ & CHEK2 & c.1100delC (p.(Thr367Metfs*15)) & Klasse 5/pathogen \\
\hline 40 & 39717 & ja & nein & w & RAD51C & c.790G >A (p.(Gly264Ser)) & Klasse 3/VUS \\
\hline 41 & 39720 & ja & nein & w & $\begin{array}{l}\text { BRCA2 } \\
\text { CHEK2 }\end{array}$ & $\begin{array}{c}\text { c.794-11T>C } \\
\text { c.479T>C (p.(Ile160The)) }\end{array}$ & $\begin{array}{l}\text { Klasse 3/VUS } \\
\text { Klasse 3/VUS }\end{array}$ \\
\hline 42 & 39722 & nein & ja & $\mathbf{w}$ & $\begin{array}{l}\text { BRCA1 } \\
\text { BRCA2 } \\
\end{array}$ & $\begin{array}{c}\text { c.5266dupC } \\
\text { (p.(GIn1756Profs*74)) } \\
\text { c.9976A>T (p.(Lys3326*)) }\end{array}$ & $\begin{array}{c}\text { Klasse 5/pathogen } \\
\text { Klasse 3/VUS }\end{array}$ \\
\hline 43 & 39719 & nein & nein & w & RAD51C & c.790G >A (p.(Gly264Ser)) & Klasse 3/VUS \\
\hline 44 & 39728 & nein & nein & w & BRCA2 & c.1964delC (p.(Pro655GInfs*5)) & Klasse 5/pathogen \\
\hline 45 & 39055 & ja & ja & $\mathbf{w}$ & $\begin{array}{l}\text { BRCA1 } \\
\text { PALB2 } \\
\end{array}$ & $\begin{array}{c}\text { c.5030_5033delCTAA } \\
\text { (p.(Thr1677llefs*2)) } \\
\text { c.2794G>A (p.(Val932Met)) }\end{array}$ & $\begin{array}{c}\text { Klasse 5/pathogen } \\
\text { Klasse 3/VUS }\end{array}$ \\
\hline 46 & 39732 & ja & nein & $\mathbf{w}$ & BRCA2 & c.133G>T (p. (Glu45*)) & Klasse 5/pathogen \\
\hline 47 & 26928B & ja & nein & w & PALB2 & c. $2590 \mathrm{C}>\mathrm{T}$ (p.(Pro864Ser)) & Klasse 3/VUS \\
\hline 48 & 39734 & ja & nein & w & $N B N$ & c.643C>T (p.(Arg215Trp)) & Klasse 3/VUS \\
\hline 49 & 39741 & ja & nein & $\mathbf{w}$ & CHEK2 & c.1427C>T (p.(Thr476Met)) & $\begin{array}{c}\text { Klasse 4/ } \\
\text { wahrschl. pathogen }\end{array}$ \\
\hline 50 & 39743 & ja & nein & w & $B R C A 2$ & c.7874G>T (p.(Arg2625lle)) & Klasse 3/VUS \\
\hline 51 & 39746 & ja & nein & w & RAD51C & c.790G >A (p.(Gly264Ser) & Klasse 3/VUS \\
\hline 52 & 38554 & ja & nein & w & ATM & c.342G>A (p. (Arg114=)) & Klasse 3/VUS \\
\hline 53 & 39760 & ja & nein & w & $\begin{array}{c}B R C A 2 \\
R A D 51 D \\
\end{array}$ & $\begin{array}{l}\text { c.9976A>T (p.(Lys3326*)) } \\
\text { c.698A>G (p.(Glu233Gly)) }\end{array}$ & $\begin{array}{l}\text { Klasse 3/VUS } \\
\text { Klasse 3/VUS }\end{array}$ \\
\hline 54 & 39766 & ja & nein & w & $\begin{array}{c}\text { BRCA1 } \\
\text { NBN }\end{array}$ & $\begin{array}{c}\text { c.81-13C }>A \\
\text { c.1787A }>\text { T (p. (Asp896Val)) }\end{array}$ & $\begin{array}{l}\text { Klasse 3/VUS } \\
\text { Klasse 3/VUS }\end{array}$ \\
\hline 55 & $39784^{\#}$ & ja & nein & w & RAD51D & c.346G>A (p.(Val116lle)) & Klasse 3/VUS \\
\hline 56 & 39791 & ja & nein & w & $R A D 51 D$ & c.698A>G (p.(Glu233Gly)) & Klasse 3/VUS \\
\hline 57 & 39769" & ja & nein & $\mathbf{w}$ & RAD51C & c.706-1G>A & Klasse 5/pathogen \\
\hline 58 & 39773 & ja & nein & $\mathbf{w}$ & ATM & c.6004C>T (p. $(G \ln 2002 *))$ & Klasse 5/pathogen \\
\hline 59 & $34486 \mathrm{~B}$ & ja & nein & $w$ & $N B N$ & c. $37+5 G>A$ & Klasse 3/VUS \\
\hline 60 & 39775 & ja & nein & w & PALB2 & c. $2794 G>A$ (p.(Val932Met)) & Klasse 3/VUS \\
\hline 61 & 39780 & ja & nein & w & PALB2 & c.2752C>T (p.(Pro918Ser)) & Klasse 3/VUS \\
\hline 62 & 39794 & ja & nein & w & $\begin{array}{l}B R C A 2 \\
B R C A 2\end{array}$ & $\begin{array}{c}\text { c. } 7759 \mathrm{C}>\mathrm{T} \text { (p. (Leu2587Phe)) } \\
\text { c.927A }>\mathrm{G}(\mathrm{p} .(\text { Ser309=)) }\end{array}$ & $\begin{array}{l}\text { Klasse 3/VUS } \\
\text { Klasse 3/VUS }\end{array}$ \\
\hline 63 & 39795 & ja & nein & w & $N B N$ & c. $-16 C>T$ & Klasse 3/VUS \\
\hline 64 & 39797 & ja & nein & w & $\begin{array}{l}\text { ATM } \\
\text { NBN }\end{array}$ & $\begin{array}{c}\text { c.7568T>G (p.(Leu2523Trp)) } \\
\text { c.511A>G (p.(Ile171Val)) }\end{array}$ & $\begin{array}{l}\text { Klasse 3/VUS } \\
\text { Klasse 3/VUS }\end{array}$ \\
\hline 65 & 39799 & ja & nein & w & PALB2 & c.3251C>T (p.(Ser1084Leu)) & Klasse 3/VUS \\
\hline 66 & 39909 & ja & nein & w & BRCA1 & c.5194-12G>A & Klasse 5/pathogen \\
\hline 67 & 39902 & ja & nein & $w$ & $N B N$ & c.20741G >A (p.(Val691lle)) & Klasse 3/VUS \\
\hline 68 & 39792 & ja & nein & w & $N B N$ & c.664T>C (p. (Phe222Leu $))$ & Klasse 3/VUS \\
\hline 69 & 39904 & ja & nein & w & $B R C A 2$ & c.1744A>C (p.(Thr582Pro)) & Klasse 3/VUS \\
\hline 70 & 39907 & ja & nein & w & ATM & c.1986T>C (p. $($ Phe662=)) & Klasse 3/VUS \\
\hline 71 & 39912 & nein & ja & w & CHEK2 & c.538C >T (p.(Arg180Cys)) & Klasse 3/VUS \\
\hline 72 & 39916 & ja & nein & w & $B R C A 2$ & c.67G>T (p.(Asp23Tyr)) & Klasse 3/VUS \\
\hline
\end{tabular}




\begin{tabular}{|c|c|c|c|c|c|c|c|}
\hline & $\begin{array}{l}\text { Patienten- } \\
\text { Nummer }\end{array}$ & MCa & OvCa & Geschlecht & $\begin{array}{c}\text { Gen mit } \\
\text { Sequenzvariante }\end{array}$ & $\begin{array}{c}\text { Sequenzvariante } \\
\text { (HGVS Nomenklatur) }\end{array}$ & ACMG-Klasse/Pathogenität \\
\hline 73 & $39917^{\#}$ & ja & nein & $\mathbf{w}$ & $\mathrm{CDH1}$ & c.1587delT (p.(Ala530Profs*27)) & $\begin{array}{c}\text { Klasse 4/ } \\
\text { wahrschl. pathogen }\end{array}$ \\
\hline \multirow[t]{2}{*}{74} & 39920 & nein & nein & w & ATM & c.3925G>A (p.(Ala1309Thr)) & Klasse 3/VUS \\
\hline & & & & & CHEK2 & c.1376C>T (p.(Ala459Val)) & Klasse 3/VUS \\
\hline 75 & 39922 & ja & nein & w & $\mathrm{CDH} 1$ & c.1610C>T (p.(Pro537Leu)) & Klasse 3/VUS \\
\hline 76 & 39924 & ja & nein & w & ATM & c.1229T>C (p.(Val410Ala)) & Klasse 3/VUS \\
\hline 77 & 39927 & ja & nein & $\mathbf{w}$ & BRCA1 & $\begin{array}{c}\text { c.3485delA } \\
\text { (p.(Asp1162Valfs*48)) }\end{array}$ & Klasse 5/pathogen \\
\hline \multirow[t]{2}{*}{78} & 39930 & ja & nein & w & PALB2 & c.1194G>A (p.(Val398=)) & Klasse 3/VUS \\
\hline & & & & & RAD51D & c.698A>G (p.(Glu233Gly)) & Klasse 3/VUS \\
\hline 79 & 39934 & ja & nein & $\mathbf{w}$ & ATM & $\begin{array}{l}\text { c.7417_7520delGAGA } \\
\text { (p.(Arg2506Thrfs*3)) }\end{array}$ & Klasse 5/pathogen \\
\hline 80 & 39943 & nein & ja & $\mathbf{w}$ & BRCA1 & $\begin{array}{c}\text { c.68_69delAG } \\
\text { (p.(Glu23Valfs*17)) }\end{array}$ & Klasse 5/pathogen \\
\hline \multirow[t]{2}{*}{81} & 39945 & ja & ja & $\mathbf{w}$ & & $\begin{array}{c}\text { c.68_69delAG } \\
\text { (p.(Glu23Valfs*17)) }\end{array}$ & \\
\hline & & & & & ATM & c.1986T>C (p. (Phe662=)) & Klasse 3/VUS \\
\hline 82 & 39946 & ja & nein & $\mathbf{w}$ & BRCA2 & c.7007G>A (p.(Arg2336His)) & Klasse 5/pathogen \\
\hline 83 & 39951 & ja & nein & $\mathbf{w}$ & CHEK2 & c.1100delC (p.(Thr367Metfs*15)) & Klasse 5/pathogen \\
\hline 84 & 39952 & ja & nein & $\mathbf{w}$ & BRCA1 & c.1612C $>T\left(p .\left(G \ln 538^{*}\right)\right)$ & Klasse 5/pathogen \\
\hline 85 & 39940 & nein & nein & w & ATM & c.3406C>G (p.(His1136Asp)) & Klasse 3/VUS \\
\hline 86 & 39944 & ja & nein & $\mathbf{w}$ & BRCA1 & $\begin{array}{l}\text { c.3770_3772delAG } \\
\text { (p.(Glu1257Glyfs*9)) }\end{array}$ & Klasse 5/pathogen \\
\hline 87 & 39963 & ja & nein & $\mathbf{w}$ & BRCA1 & $\begin{array}{c}\text { Deletion von Exons 13, } 14 \\
\text { und } 15\end{array}$ & Klasse 5/pathogen \\
\hline 88 & 39961 & ja & nein & w & BRCA1 & c.181T>G (p.(Cys61Gly)) & Klasse 5/pathogen \\
\hline & & & & & RAD51C & c.790G >A (p.(Gly264Ser)) & Klasse 3/VUS \\
\hline
\end{tabular}

$\mathrm{MCa}=$ Mammakarzinom; OvCa = Ovarialkarzinom; VUS = Variante unklarer Signifikanz; HGVS = Human Genome Variation Society; $\mathrm{w}=$ weiblich; $\mathrm{m}$ = männlich; wahrschl. pathogen = wahrscheinlich pathogen;

\# Der jeweilige Patient ist ausführlich bei den ausgewählten Fällen in Abschnitt 3.5 beschrieben.

Bei den untersuchten Patienten wurden in den Genen ATM sowie BRCA1 jeweils 19 Sequenzvarianten der ACMG-Klasse 3, 4 oder 5 identifiziert. Im ATM-Gen wurden 15 Varianten unklarer Signifikanz (VUS; ACMG-Klasse 3) und vier wahrscheinlich pathogene bzw. pathogene Mutationen gefunden. Im BRCA1-Gen wurde eine Variante unklarer Signifikanz (VUS; ACMGKlasse 3) und 18 wahrscheinlich pathogene bzw. pathogene Mutationen identifiziert. Im BRCA2Gen wurden insgesamt 18 Sequenzvarianten der ACMG-Klasse 3, 4 oder 5 nachgewiesen, davon 14 Varianten unklarer Signifikanz (VUS; ACMG-Klasse 3) und vier wahrscheinlich pathogene bzw. pathogene Mutationen (ACMG-Klasse 4 bzw. 5). Im CHEK2-Gen wurden insgesamt 15 Sequenzvarianten detektiert, neun davon wurden als ACMG-Klasse 3 definiert und sechs als wahrscheinlich pathogene bzw. pathogene Mutationen. Im PALB2-Gen wurden 10 Sequenzvarianten identifiziert, d. h. neun Sequenzvarianten der ACMG-Klasse 3 und eine pathogene Mutation der ACMG-Klasse 5. Im NBN-Gen wurden insgesamt neun Sequenzvarianten nachgewiesen und alle Varianten konnten der ACMG-Klasse 3 zugeordnet werden. Im RAD51CGen wurden insgesamt sechs Sequenzvarianten detektiert, fünf davon wurden als Varianten unklarer Signifikanz eingestuft und eine Variante stellte sich als pathogene Mutation der ACMG- 
Klasse 5 heraus. Im RAD51D-Gen wurden sechs Sequenzvarianten identifiziert, alle sechs wurden der ACMG-Klasse 3 (VUS) zugeteilt. Im CDH1-Gen wurden insgesamt 3 Sequenzvarianten der ACMG-Klasse 3, 4 oder 5 identifiziert, davon zwei Varianten der ACMG-Klasse 3 und eine Mutation der ACMG-Klasse 4. Im TP53-Gen wurde insgesamt nur eine Variante unklarer Signifikanz (VUS; ACMG-Klasse 3) identifiziert (s. Tab. 3.4; s. Abb. 3.3B).

Tabelle 3.4: Verteilung der identifizierten Sequenzvarianten der ACMG-Klasse 3, 4 oder 5 nach NGSAnalyse der 10 Core-Gene und der MLPA-Analyse

\begin{tabular}{|c|c|c|c|}
\hline \multirow{2}{*}{ Gen } & \multicolumn{2}{|c|}{ Sequenzvarianten } \\
\cline { 2 - 4 } & $\begin{array}{c}\text { Sequenzvarianten der } \\
\text { ACMG-Klasse 3, 4, 5 }\end{array}$ & $\begin{array}{c}\text { Varianten unklarer } \\
\text { Signifikanz } \\
\text { (ACMG-Klasse 3) }\end{array}$ & $\begin{array}{c}\text { Wahrscheinlich pathogene/ } \\
\text { pathogene Mutationen } \\
\text { (ACMG-Klasse 4, 5) }\end{array}$ \\
\hline ATM & 19 & 15 & 4 \\
\hline BRCA1 & 19 & 1 & 18 \\
\hline BRCA2 & 18 & 14 & 4 \\
\hline CHEK2 & 15 & 9 & 6 \\
\hline PALB2 & 10 & 9 & 1 \\
\hline NBN & 9 & 9 & 0 \\
\hline RAD51C & 6 & 5 & 1 \\
\hline RAD51D & 6 & 6 & 0 \\
\hline CDH1 & 3 & 2 & 1 \\
\hline TP53 & 1 & 1 & 0 \\
\hline Gesamt & 106 & 71 & 35 \\
\hline
\end{tabular}

Bei der Unterteilung aller 106 Sequenzvarianten nach dem molekulargenetischen Typ der Sequenzvariante wurden insgesamt 52 missense-Sequenzvarianten identifiziert (49,1\%). Missense-Sequenzvarianten wurden in allen 10 Core-Genen, mit Ausnahme des TP53-Gens, detektiert. Die zweitgrößte Gruppe mit 21 Sequenzvarianten $(19,8 \%)$ waren die frame-shiftSequenzvarianten. Mit 12 Sequenzvarianten (57,1 \%) wurde die Mehrzahl dieser Sequenzvarianten im BRCA1-Gen detektiert. Die drittgrößte Gruppe mit 11 Sequenzvarianten $(10,4 \%)$ waren die nonsense-Sequenzvarianten. Diese wurden in den Genen ATM, BRCA1 und BRCA2 nachgewiesen. Insgesamt wurden 10 synonyme-Sequenzvarianten $(9,4 \%)$ detektiert. Sechs dieser Sequenzvarianten wurden im ATM-Gen identifiziert und jeweils eine in den Genen BRCA2, CHEK2, PALB2 und TP53. Die fünftgrößte Gruppe mit neun Sequenzvarianten (8,5\%) waren die splicing-Sequenzvarianten bzw. die potentiellen splicing-Sequenzvarianten, die in den Genen ATM, BRCA1, BRCA2, NBN und RAD51C detektiert wurden. Große Deletionen wurden zweimal nachgewiesen (1,9\%) und diese Deletionen wurden in den BRCA1- und CHEK2-Genen beobachtet. Weiterhin wurde eine in-frame-Sequenzvariante im BRCA2-Gen identifiziert (s. Abb. 3.3C; s. Tab. 3.5). 
A

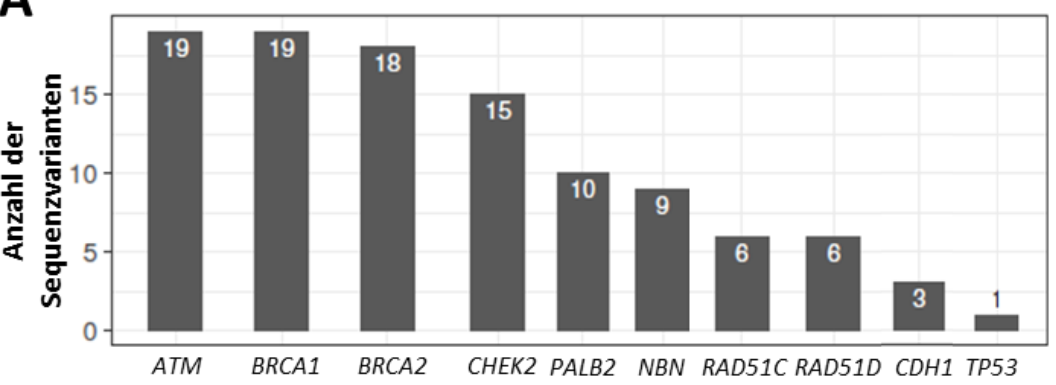

B

Gen

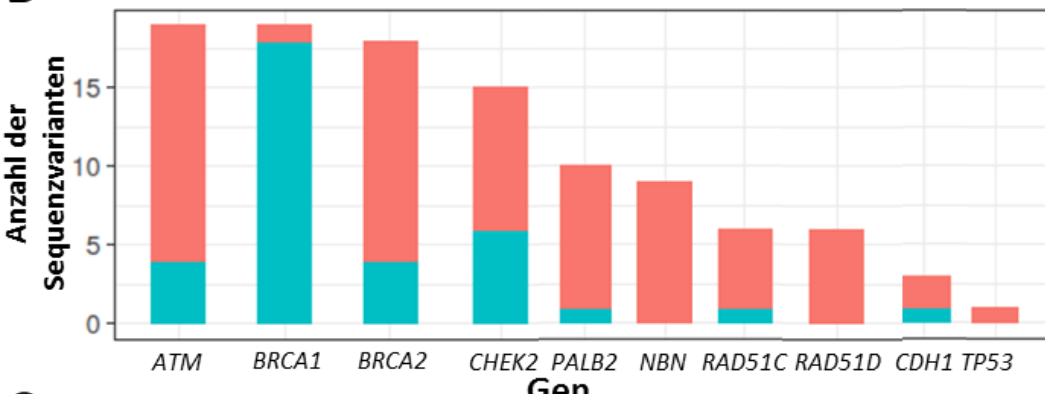

Klasse der

Sequenzvarianten

3

$4 / 5$

C Gen

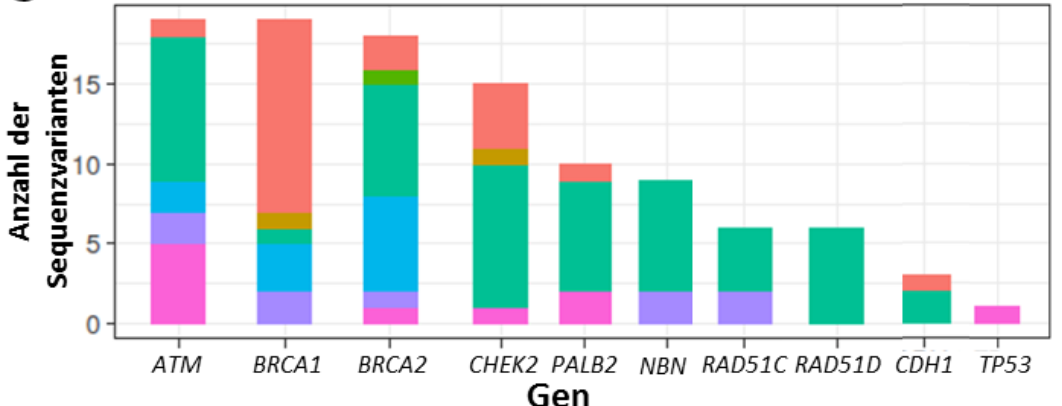

Typ der Sequenzvarianten

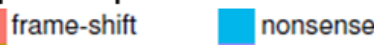
große Deletion splicing in-frame Deletion synonym missense

Abbildung 3.3: Darstellung der 106 identifizierten Sequenzvarianten in den 10 Core-Genen. A) Anzahl der identifizierten Sequenzvarianten der ACMG-Klasse 3, 4 oder 5 in den entsprechenden Core-Genen. B) Anzahl der Sequenzvarianten der ACMG-Klasse $3 \mathrm{im}$ Vergleich zur Anzahl der Mutationen der ACMG-Klasse 4 oder 5 in den Core-Genen. C) Anzahl der Sequenzvarianten der ACMG-Klasse 3, 4 oder 5 unterteilt nach dem Typ der Sequenzvariante in den Core-Genen.

Tabelle 3.5: Verteilung der Sequenzvariantentypen der ACMG-Klasse 3, 4 oder 5 über die 10 Core-Gene

\begin{tabular}{|c|c|c|c|c|c|c|c|c|c|c|c|}
\hline \multirow{2}{*}{$\begin{array}{c}\text { Typ der } \\
\text { Sequenzvariante }\end{array}$} & \multicolumn{11}{|c|}{ Gen } \\
\hline & ATM & BRCA1 & BRCA2 & $\mathrm{CDH} 1$ & CHEK2 & NBN & PALB2 & RAD51C & RAD51D & TP53 & Gesamt \\
\hline Missense & 8 & 1 & 7 & 2 & 9 & 7 & 7 & 4 & 6 & 0 & 51 \\
\hline Frame-shift & 1 & 12 & 2 & 1 & 4 & 0 & 1 & 0 & 0 & 0 & 21 \\
\hline Nonsense & 2 & 3 & 6 & 0 & 0 & 0 & 0 & 0 & 0 & 0 & 11 \\
\hline Synonym & 6 & 0 & 1 & 0 & 1 & 0 & 2 & 0 & 0 & 1 & 11 \\
\hline (Potentielles) Splicing & 2 & 2 & 1 & 0 & 0 & 2 & 0 & 2 & 0 & 0 & 9 \\
\hline Große Deletionen & 0 & 1 & 0 & 0 & 1 & 0 & 0 & 0 & 0 & 0 & 2 \\
\hline In-frame-Deletion & 0 & 0 & 1 & 0 & 0 & 0 & 0 & 0 & 0 & 0 & 1 \\
\hline
\end{tabular}

Wenn die Sequenzvarianten nach dem Typ und der Klasse der Sequenzvariante unterteilt wurden, waren die Sequenzvarianten der ACMG-Klasse 3 mit 48 missense- $(67,6 \%)$ und mit 11 synonymen-Sequenzvarianten $(15,5 \%)$ überrepräsentiert. Potentielle splicing- und nonsenseSequenzvarianten folgten mit sechs bzw. fünf Fällen. Bei den Mutationen der ACMG-Klasse 4 oder 
5 waren 21 frame-shift-Mutationen (60,0\%) der weitverbreitetste Mutationstyp, gefolgt von sechs nonsens- $(17,1 \%)$ und drei missense-(8,6 \%)-Mutationen sowie zwei großen Deletionen $(5,7$ \%) (s. Tab. 3.6).

Tabelle 3.6: Typen der Sequenzvarianten der ACMG-Klasse 3, 4 oder 5 unterteilt in die ACMG-Klasse 3 sowie in die ACMG-Klasse 4 oder 5

\begin{tabular}{|c|c|c|c|}
\hline \multirow{2}{*}{ Typ der Sequenzvariante } & \multicolumn{3}{|c|}{ Anzahl der Sequenzvarianten } \\
\cline { 2 - 4 } & Gesamtzahl (\%) & ACMG-Klasse 3 & ACMG-Klasse 4 oder 5 \\
\hline Missense & $51(48,1)$ & 48 & 3 \\
\hline Frame-shift & $21(19,8)$ & 0 & 21 \\
\hline Nonsense & $11(10,4)$ & 5 & 6 \\
\hline Synonym & $11(10,4)$ & 11 & 0 \\
\hline (Potentielles) Splicing & $9(8,5)$ & 6 & 3 \\
\hline Große Deletionen & $2(1,9)$ & 0 & 2 \\
\hline In-frame-Deletion & $1(0,9)$ & 1 & 35 \\
\hline Gesamtzahl & 106 & 71 & \\
\hline
\end{tabular}

Bei der Unterteilung der molekulargenetischen Typen der Sequenzvarianten in zwei unterschiedliche Gen-Gruppen, d. h. in eine Gruppe mit den Sequenzvarianten in den BRCA1- und BRCA2-Genen (BRCA1/2) und in eine zweite Gruppe mit den Sequenzvarianten in den anderen acht Core-Genen (nicht BRCA1/2), waren deutliche Unterschiede in der Verteilung der molekulargenetischen Typen zwischen den BRCA1/2-Genen und den übrigen Core-Genen zu beobachten. So wurden in den anderen acht Core-Genen 43 missense-Sequenzvarianten im Vergleich zu acht missense-Sequenzvarianten in den BRCA1/2-Genen identifiziert. Weiterhin wurden 14 frame-shift-Sequenzvarianten in den Genen BRCA1 und BRCA2 nachgewiesen, in den anderen Core-Genen dahingegen nur sieben. In den Genen BRCA1 und BRCA2 wurden neun nonsense Sequenzvarianten identifiziert, im Vergleich dazu wurden nur zwei Sequenzvarianten dieser Art in den anderen acht Core-Genen detektiert. Ebenso wurden mehr synonyme-(10 Sequenzvarianten) und splicing- bzw. potentielle splicing-Sequenzvarianten (sechs Sequenzvarianten) in den anderen Core-Genen im Vergleich zu den BRCA1- und BRCA2-Genen (eine synonyme-Sequenzvariante und drei splicing-Sequenzvarianten) identifiziert. Weiterhin wurde eine große Deletion der Exons 13, 14 und $15 \mathrm{im}$ BRCA1-Gen und von den Exons 9 und $10 \mathrm{im}$ CHEK2-Gen identifiziert. Zusätzlich wurde eine in-frame-Deletion c.8181_8189delTGTTAAGGC im BRCA2-Gen identifiziert (s. Abb. 3.4). 


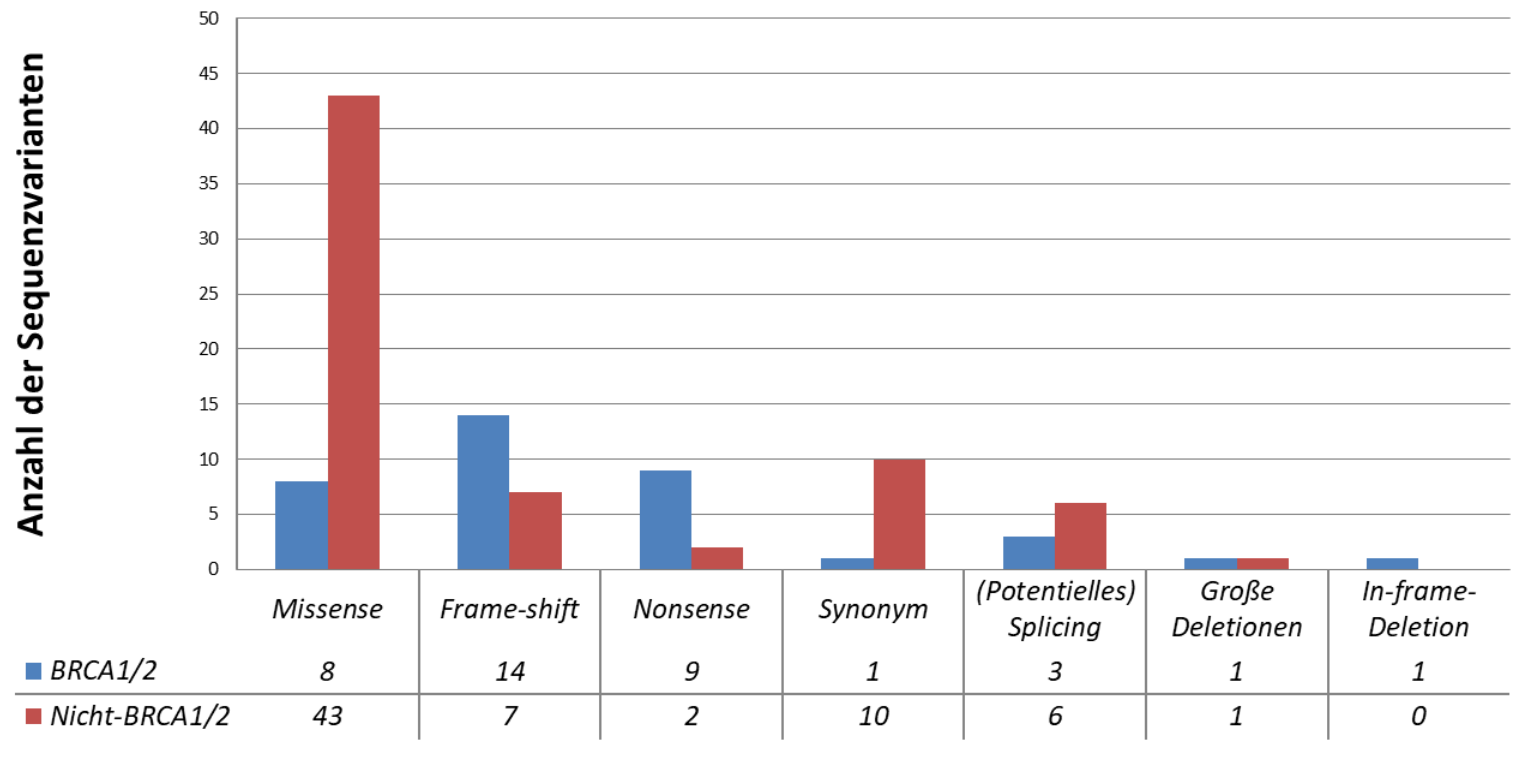

Typ der Sequenzvariante

Abbildung 3.4: Verteilung der molekulargenetischen Typen der Sequenzvarianten in den BRCA1- und BRCA2-Genen (BRCA1/2) im Vergleich zu den anderen acht Core-Genen (nicht BRCA1/2). Als nicht BRCA1/2-Gene sind hier die Gene ATM, CDH1, CHEK2, NBN, PALB2, RAD51C, RAD51D und TP53 definiert.

\subsubsection{Vergleich der identifizierten Sequenzvarianten der ACMG-Klasse 3, 4 oder 5 in Korrelation zu den erfüllten Kriterien}

Es sollte eine Korrelation zwischen der absoluten Zahl der identifizierten Sequenzvarianten (ACMG-Klasse 3, 4 oder 5) in jedem Core-Gen zu dem erfüllten Kriterium, definiert vom Deutschen Konsortium Familiärer Brust- und Eierstockkrebs, aufgezeigt werden (s. Abb. 3.5). Diese Assoziation kann mit den empirischen Risiken des Deutschen Konsortiums Familiärer Brust- und Eierstockkrebs korreliert werden.

Es wurden insgesamt 38 Sequenzvarianten bei 31 Patienten mit dem erfüllten Kriterium A identifiziert. Sieben dieser Sequenzvarianten wurden im ATM-Gen, drei Sequenzvarianten im BRCA1-Gen, sechs Sequenzvarianten im BRCA2-Gen, zwei Sequenzvarianten im CDH1-Gen, jeweils fünf Sequenzvarianten im CHEK2-, NBN- und PALB2-Gen, eine Sequenzvariante im RAD51C-Gen, drei Sequenzvarianten im RAD51D-Gen und eine Sequenzvariante im TP53-Gen festgestellt (s. Abb. 3.5).

Bei 44 Patienten mit dem erfüllten Kriterium G wurden insgesamt 23 Sequenzvarianten bei 21 Patienten gefunden. Drei dieser Sequenzvarianten wurden im ATM-Gen, sechs Sequenzvarianten im BRCA1-Gen, jeweils eine Sequenzvariante im BRCA2- und CDH1-Gen, jeweils drei Sequenzvarianten in den Genen CHEK2, NBN und PALB2, zwei Sequenzvarianten im RAD51C-Gen und eine Sequenzvariante im RAD51D-Gen identifiziert. Im TP53-Gen wurde dagegen keine Sequenzvariante detektiert (s. Abb. 3.5).

Insgesamt wurden 14 Sequenzvarianten in den 10 Core-Genen bei 13 Patienten identifiziert, die das Kriterium J erfüllten. Davon wurden vier Sequenzvarianten im ATM-Gen, eine Sequenzvariante im BRCA1-Gen, jeweils zwei Sequenzvarianten im BRCA2- und CHEK2-Gen, eine Sequenzvariante im NBN-Gen, zwei Sequenzvarianten im PALB2-Gen und jeweils eine Sequenzvariante in den Genen RAD51C und RAD51D identifiziert. In den Genen CDH1 und TP53 wurde bei diesen Patienten keine Sequenzvariante der $A C M G$-Klasse 3, 4 oder 5 nachgewiesen (s. Abb. 3.5).

Bei zwei Patienten, die das Kriterium $\mathrm{N}$ erfüllten, wurden insgesamt drei Sequenzvarianten in den 10 Core-Genen identifiziert. Bei einem Patienten wurde jeweils eine Sequenzvariante in den 
Genen ATM und BRCA1 detektiert und bei dem zweiten Patienten eine BRCA1-Sequenzvariante (s. Abb. 3.5).

Bei vier Patienten, die das Kriterium Q erfüllten, wurden fünf Sequenzvarianten der ACMG-Klasse 3, 4 oder 5 nachgewiesen. Es wurden zwei Sequenzvarianten der ACMG-Klasse 3 identifiziert und jeweils eine Variante im CHEK2-Gen sowie im RAD51C-Gen. Weiterhin wurden drei Mutationen der ACMG-Klasse 5 im BRCA1-Gen in dieser Patientengruppe identifiziert (s. Abb. 3.5).

Bei dem erfüllten Kriterium $R$ wurden insgesamt 12 Sequenzvarianten der ACMG-Klasse 3, 4 oder 5 identifiziert. Zwei dieser Sequenzvarianten wurden im ATM-Gen nachgewiesen, eine Sequenzvariante im BRCA1-Gen, sieben Varianten im BRCA2-Gen und jeweils eine Sequenzvariante im CHEK2- und RAD51C-Gen. In den Genen CDH1, NBN, PALB2, RAD51D und TP53 wurden keine Sequenzvarianten der ACMG-Klasse 3, 4 oder 5 bei den Patienten mit dem erfüllten Kriterium R identifiziert (s. Abb. 3.5).

Wenn das Kriterium $U$ erfüllt war, wurden insgesamt vier Sequenzvarianten der ACMG-Klasse 3, 4 oder 5 bei zwei Patienten detektiert. Bei einem Patienten wurden gleichzeitig zwei Sequenzvarianten im BRCA2-Gen nachgewiesen, eine Mutation der ACMG-Klasse 5 sowie eine Sequenzvariante der $A C M G$-Klasse 3. Bei dem zweiten Patienten wurde jeweils eine Sequenzvariante der ACMG-Klasse 3 in den Genen BRCA1 und RAD51D identifiziert (s. Abb. 3.5).

Es wurden fünf Sequenzvarianten der ACMG-Klasse 3, 4 oder 5 bei insgesamt vier Patienten identifiziert, die das Kriterium $Y$ erfüllten. Bei einem Patienten wurden jeweils eine Sequenzvariante der ACMG-Klasse 3 in den Genen ATM und CHEK2 nachgewiesen. Es wurden noch jeweils eine Sequenzvariante der ACMG-Klasse 3 in den Genen ATM und CHEK2 und eine Mutation der ACMG-Klasse 5 im BRCA1-Gen detektiert (s. Abb. 3.5).

Bei zwei Patienten, die das Kriterium Z erfüllten, wurden eine Mutation der ACMG-Klasse $5 \mathrm{im}$ BRCA1-Gen und eine Sequenzvariante der ACMG-Klasse $3 \mathrm{im} \mathrm{CHEK2-Gen} \mathrm{nachgewiesen} \mathrm{(s.} \mathrm{Abb.}$ 3.5). 

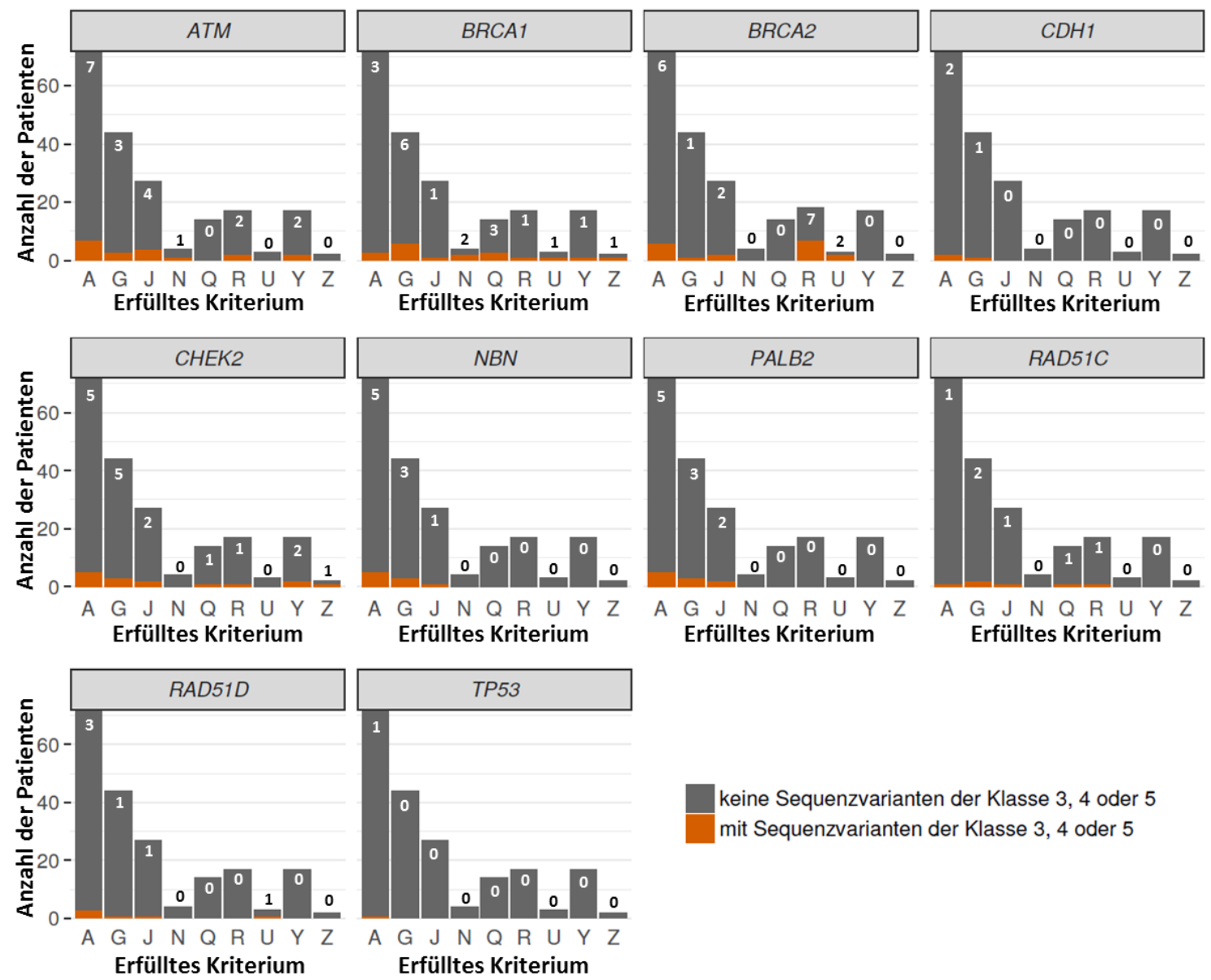

keine Sequenzvarianten der Klasse 3, 4 oder 5

mit Sequenzvarianten der Klasse 3, 4 oder 5

Abbildung 3.5: Einteilung der Sequenzvarianten der ACMG-Klasse 3, 4 oder 5 zum Core-Gen in Assoziation mit dem erfüllten Kriterium. Die dunkelgrau und orange angefärbten Balken zusammengefasst repräsentieren Patienten mit einem entsprechend erfüllten Kriterium. Die orange angefärbten Balkenanteile zeigen die Patienten mit einer identifizierten Sequenzvariante der ACMG-Klasse 3, 4 oder 5 an. Die dunkelgrau gefärbten Balkenabschnitte weisen auf die Patienten hin, bei denen keine Sequenzvariante der ACMG-Klasse 3, 4 oder 5 identifiziert wurde. Die Zahlen in den dunkelgrauen Balken bzw. oberhalb der dunkelgrauen Balken repräsentieren die Anzahl der identifizierten Sequenzvarianten der ACMG-Klasse 3, 4 oder 5 bei Patienten mit dem entsprechend erfüllten Kriterium. Das jeweilige Core-Gen ist oberhalb des Balkendiagramms aufgeführt.

Die Mehrzahl der Sequenzvarianten der ACMG-Klasse 3, 4 oder 5 wurde bei den Patienten mit den erfüllten Kriterien $A$ und $G$ identifiziert, $d$. h. hier wurden 41 Sequenzvarianten der ACMGKlasse 3 (57,7 \%) und 20 Mutationen der ACMG-Klasse 4 oder 5 (57,2 \%) nachgewiesen. Diese Patientengruppen wurden von den Patienten mit den erfüllten Kriterien J und R gefolgt. Hier wurden insgesamt acht Sequenzvarianten der ACMG-Klasse 3 (11,3\%) und sechs Mutationen der ACMG-Klasse 4 oder 5 (17,1\%) bei den Patienten mit dem erfüllten Kriterium J identifiziert. Bei den Patienten mit dem erfüllten Kriterium R wurden 11 Sequenzvarianten der ACMG-Klasse 3 $(15,5 \%)$, dagegen aber nur eine Mutation der ACMG-Klasse 5 (2,9\%) detektiert. Bei den Patienten mit den erfüllten Kriterien $Q, Y, N, U$ und $Z$ wurden einzelne pathogene Mutationen sowie eine kleine Anzahl von Varianten unklarer Signifikanz identifiziert (s. Tab. 3.7). 
Tabelle 3.7: Verteilung der Sequenzvarianten der ACMG-Klasse 3, 4 oder 5 in den Core-Genen nach dem erfüllten Kriterium

\begin{tabular}{|c|c|c|c|}
\hline \multirow{2}{*}{$\begin{array}{l}\text { Erfülltes } \\
\text { Kriterium }\end{array}$} & \multirow{2}{*}{$\begin{array}{c}\text { Anzahl der Patienten } \\
\text { mit Sequenzvarianten der } \\
\text { ACMG-Klasse } 3,4 \text { oder } 5\end{array}$} & \multicolumn{2}{|c|}{ Anzahl der Sequenzvarianten } \\
\hline & & $\begin{array}{c}\text { Sequenzvarianten der } \\
\text { ACMG-Klasse } 3(\%)\end{array}$ & $\begin{array}{c}\text { Mutationen der } \\
\text { ACMG-Klasse } 4 \text { oder } 5(\%)\end{array}$ \\
\hline A & 31 & $28(39,4)$ & $10(28,6)$ \\
\hline G & 21 & $13(18,3)$ & $10(28,6)$ \\
\hline $\mathrm{J}$ & 13 & $8(11,3)$ & $6(17,1)$ \\
\hline $\mathrm{R}$ & 9 & $11(15,5)$ & $1(2,9)$ \\
\hline $\mathrm{Q}$ & 4 & $2(2,8)$ & $3(8,6)$ \\
\hline Y & 4 & $4(5,6)$ & $1(2,9)$ \\
\hline $\mathrm{N}$ & 2 & $1(1,4)$ & $2(5,7)$ \\
\hline $\mathrm{U}$ & 2 & $3(4,2)$ & $1(2,9)$ \\
\hline Z & 2 & $1(1,4)$ & $1(2,9)$ \\
\hline Gesamt & 88 & 71 & 35 \\
\hline
\end{tabular}

Wenn die identifizierten Mutationen der ACMG-Klasse 4 oder 5 in den 10 Core-Genen zwischen den Genen BRCA1/2 und den anderen acht Core-Genen unterschieden wurden, zeigte die Analyse, dass die Mutationen der ACMG-Klasse 4 oder 5 in den BRCA1- und BRCA2-Genen innerhalb aller vom Deutschem Konsortium Familiärer Brust- und Eierstockkrebs definierten Kriterien verbreitet sind. Anderseits wurden die Mutationen der ACMG-Klasse 4 oder 5 in den anderen acht Core-Genen (nicht BRCA1- und BRCA2-Gene) nur bei Patienten mit jeweils einem der drei erfüllten Kriterien A, G oder J nachgewiesen (s. Abb. 3.6).

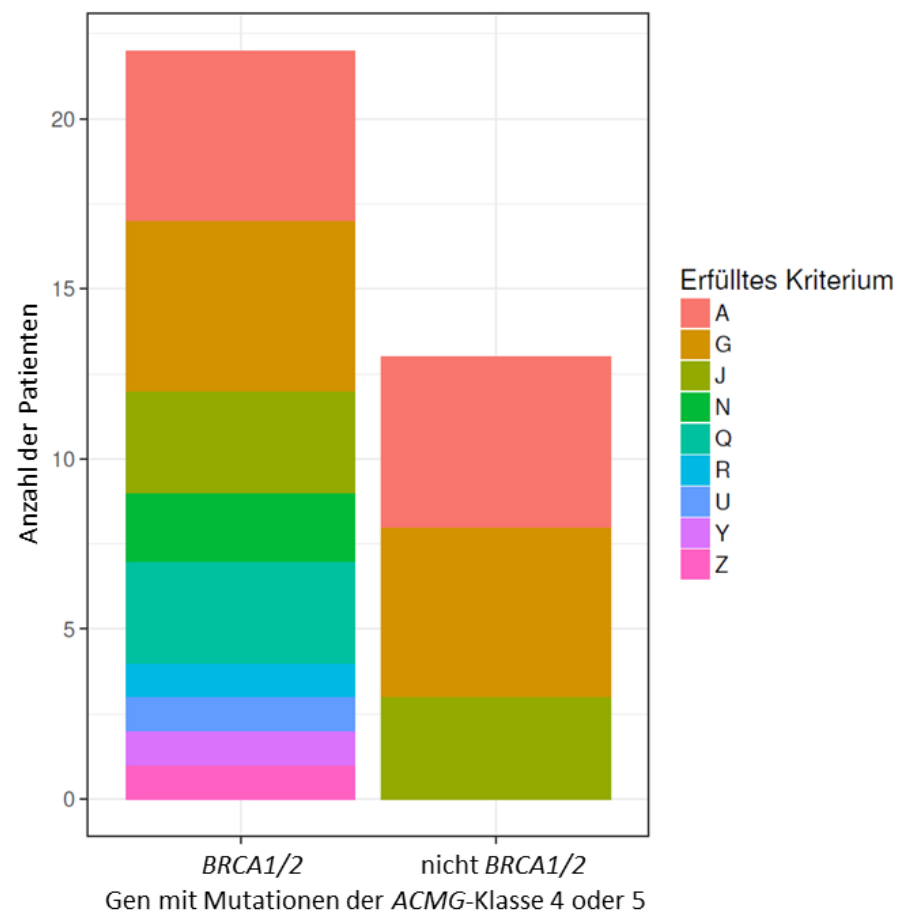

Abbildung 3.6: Verteilung der Patienten mit den Mutationen der ACMG-Klasse 4 oder 5 über die CoreGene in Assoziation mit den definierten Kriterien. Verteilung der Patienten mit nachgewiesenen Mutationen der ACMG-Klasse 4 oder 5 in den Genen BRCA1 und BRCA2 (BRCA1/2) und in den anderen acht Core-Genen (nicht $B R C A 1 / 2$ ) in Abhängigkeit zu den vom Deutschen Konsortium Familiärer Brust- und Eierstockkrebs definierten Kriterien. 


\subsubsection{Patientenalter bei Erstdiagnose des Mammakarzinoms in Abhängigkeit zur Detektionsrate der Sequenzvarianten der ACMG-Klasse 3, 4 oder 5 in den 10 Core-Genen}

Um zu überprüfen ob das Patientenalter bei der Erstdiagnose des Mammakarzinoms mit den identifizierten Sequenzvarianten der ACMG-Klasse 3, 4 oder 5 in den 10 Core-Genen korreliert, wurden diese Werte miteinander verglichen.

Das mittlere Erkrankungsalter der untersuchten Patienten mit einem nachgewiesenen Mammakarzinom betrug $48 \pm 12$ Jahre.

Bei Patienten mit Mutationen der ACMG-Klasse 4 oder 5 betrug das niedrigste Erkrankungsalter 39,0 Jahre im CDH1-Gen. Als Nächstes folgten Patienten mit einem mittleren Erkrankungsalter von 40,5 Jahren und detektierten Mutationen der Klasse 4 oder 5 im BRCA1-Gen. Das höchste Erkrankungsalter von 62,0 Jahren wiesen Patienten mit den Mutationen der Klasse 4 oder 5 im RAD51C-Gen auf. Das mittlere Erkrankungsalter für Patienten mit Mutationen der ACMG-Klasse 4 oder 5 in den Genen NBN, RAD51D und TP53 konnte nicht ermittelt werden, da bei keinem der Patienten eine dieser Mutationen detektiert wurde (s. Tab. 3.8).

Bei den Patienten mit Sequenzvarianten der ACMG-Klasse 3 im RAD51D-Gen betrug das niedrigste Erkrankungsalter 42,5 Jahre, gefolgt von einem Erkrankungsalter von 45,2 Jahren bei Patienten mit den Sequenzvarianten der ACMG-Klasse 3 im RAD51C-Gen. Das höchste Erkrankungsalter von 60,5 Jahren zeigten Patienten mit den Sequenzvarianten der ACMG-Klasse $3 \mathrm{im} C D H 1$-Gen, gefolgt von einem Erkrankungsalter von 51,3 Jahren bei Patienten mit den Sequenzvarianten der ACMG-

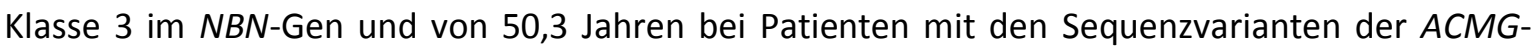
Klasse $3 \mathrm{im}$ PALB2-Gen (s. Tab. 3.8).

Tabelle 3.8: Mittleres Erkrankungsalter bei der Erstdiagnose des Mammakarzinoms bei Patienten mit den Sequenzvarianten der ACMG-Klasse 3 sowie Mutationen der ACMG-Klasse 4 oder 5 in den 10 Core-Genen

\begin{tabular}{|c|c|c|}
\hline \multirow{2}{*}{ Gen } & \multicolumn{2}{|c|}{ Mittleres Erkrankungsalter (in Jahren) bei der Erstdiagnose des MCa } \\
\cline { 2 - 3 } & Mutationen der ACMG-Klasse 4 oder 5 & Sequenzvarianten der ACMG-Klasse 3 \\
\hline CDH1 & 39,0 & 60,5 \\
\hline BRCA1 & 40,5 & 46,0 \\
\hline ATM & 52,3 & 47,3 \\
\hline BRCA2 & 53,2 & 47,1 \\
\hline PALB2 & 45,0 & 50,3 \\
\hline CHEK2 & 46,5 & 48,5 \\
\hline RAD51C & 62,0 & 45,2 \\
\hline NBN & 1 & 51,3 \\
\hline RAD51D & 1 & 42,5 \\
\hline TP53 & 1 & 48,0 \\
\hline
\end{tabular}

MCa = Mammakarzinom; $\backslash=$ keine identifizierte Mutation .

Wurden die Patienten nach den Altersgruppen bei der Ersterkrankung eines Mamma- oder Ovarialkarzinoms unterteilt, war die Mehrzahl der Sequenzvarianten der ACMG-Klasse 3 (28 Sequenzvarianten) in der Altersgruppe zwischen dem 40. und 49. Lebensjahr zu beobachten. Dieses Ergebnis galt ebenso für die Mutationen der ACMG-Klasse 4 oder 5 mit insgesamt 14 Mutationen in dieser Altersgruppe. Die relativen Zahlen zeigten einen großen Anteil der Sequenzvarianten der ACMG-Klasse 3 in der Altersgruppe zwischen dem 70. und 79. Lebensjahr. Die anderen Patienten mit den Sequenzvarianten der $A C M G$-Klasse 3 waren relativ gleichmäßig über die restlichen Altersgruppen verteilt. Bei den Mutationen der ACMG-Klasse 4 oder 5 zeigte sich der größte Anteil für die Altersgruppe der Patienten zwischen dem 30. und 39. Lebensjahr. In 
der Altersgruppe der Patienten zwischen dem 70. und 89. Lebensjahr wurde keine Mutation der ACMG-Klasse 4 oder 5 identifiziert (s. Tab. 3.9).

Tabelle 3.9: Frequenz der detektierten Sequenzvarianten der ACMG-Klasse 3 und Mutationen der ACMGKlasse 4 oder 5 in Korrelation zum Erkrankungsalter bei der Erstdiagnose eines Mamma- oder Ovarialkarzinoms

\begin{tabular}{|c|c|c|c|}
\hline \multirow{2}{*}{ Altersgruppe } & \multicolumn{3}{|c|}{ Anzahl der Patienten } \\
\cline { 2 - 4 } & $\begin{array}{c}\text { Anzahl aller } \\
\text { Patienten } \\
(\%)\end{array}$ & $\begin{array}{c}\text { Anzahl der Patienten mit } \\
\text { Sequenzvarianten der ACMG-Klasse 3 } \\
\text { (\% innerhalb der Altersgruppe) }\end{array}$ & $\begin{array}{c}\text { Anzal der Patienten mit } \\
\text { Mutationen } \\
\text { der ACMG-Klasse 4 oder 5 } \\
\text { (\% innerhalb der Altersgruppe) }\end{array}$ \\
\hline 0-29 Jahre & $10(5,0)$ & $3(30,0)$ & $2(20,0)$ \\
\hline 30-39 Jahre & $32(16,0)$ & $9(28,1)$ & $7(21,9)$ \\
\hline 40-49 Jahre & $68(34,0)$ & $28(44,4)$ & $14(20,6)$ \\
\hline 50-59 Jahre & $43(21,5)$ & $8(19,6)$ & $7(16,3)$ \\
\hline 60-69 Jahre & $19(9,5)$ & $5(26,3)$ & $4(21,1)$ \\
\hline 70-79 Jahre & $7(3,5)$ & $5(71,4)$ & 0 \\
\hline 80-89 Jahre & $4(2,0)$ & $1(25,0)$ & 0 \\
\hline Kein MCa/OvCa & $17(8,5)$ & $3(17,6)$ & $1(5,9)$ \\
\hline
\end{tabular}

$\mathrm{MCa}=$ Mammakarzinom; OvCa $=$ Ovarialkarzinom.

Weiterhin wurde das Erkrankungsalter der Patienten bei der Erstdiagnose eines Mammakarzinoms mit den Sequenzvarianten der ACMG-Klasse 3, 4 oder 5 in den BRCA1- und BRCA2-Genen zu dem Erkrankungsalter der Patienten mit diesen Sequenzvarianten in den anderen (nicht $B R C A 1 / 2$ ) acht Core-Genen verglichen. Diese Analysen ergaben eine Tendenz eines niedrigeren Erkrankungsalters der Patienten mit den Sequenzvarianten in den BRCA1- und BRCA2Genen im Vergleich zu den anderen Core-Genen. Allerdings waren diese Ergebnisse statistisch nicht signifikant $(p=0,14)$. Das mittlere Erkrankungsalter bei den Patienten mit den Sequenzvarianten der ACMG-Klasse 3, 4 oder 5 in den BRCA1- und BRCA2-Genen betrug $45 \pm 11$ Jahre im Vergleich zum mittleren Erkrankungsalter von $48 \pm 10$ Jahren in den anderen acht CoreGenen mit Sequenzvarianten der ACMG-Klasse 3, 4 oder 5 (für medianes Erkrankungsalter s. Abb. 3.7A).

Auch die Ergebnisse für die Patienten mit den Mutationen der ACMG-Klasse 4 oder 5 in den Genen BRCA1 und BRCA2 wiesen eine Tendenz zu einem niedrigeren Erkrankungsalter bei der Erstdiagnose des Mammakarzinoms auf als Patienten mit einer Mutation der ACMG-Klasse 4 oder 5 in einem der anderen Core-Gene. Diese Unterschiede waren ebenfalls statistisch nicht signifikant $(p=0,14)$. Das mittlere Erkrankungsalter bei Patienten mit Mutationen der ACMGKlasse 4 oder 5 in den BRCA1- und BRCA2-Genen lag bei $43 \pm 11$ Jahren im Vergleich zum mittleren Erkrankungsalter von 49 \pm 11 Jahren in den anderen Core-Genen mit den Mutationen der ACMG-Klasse 4 oder 5 (für medianes Erkrankungsalter s. Abb. 3.7B). 

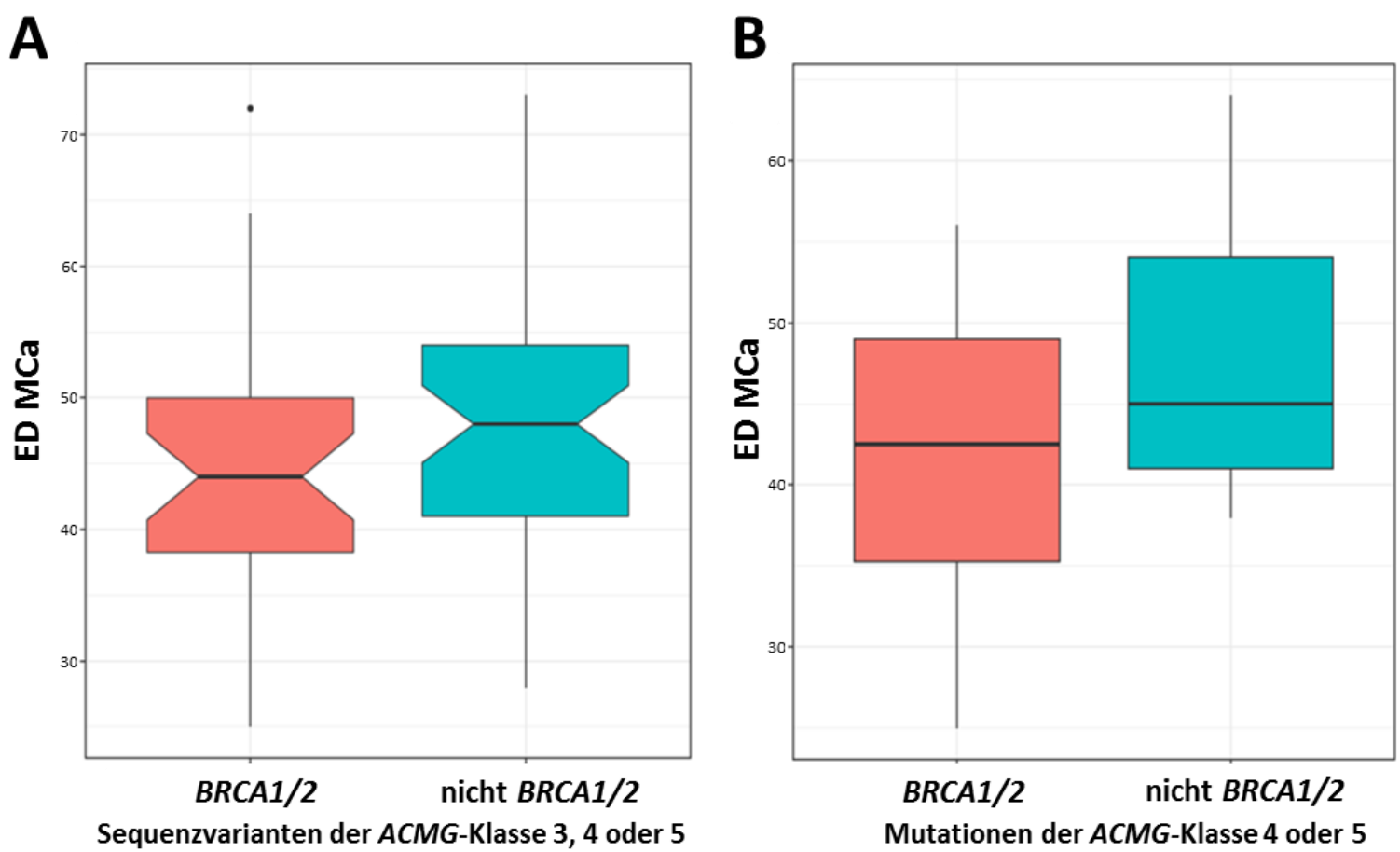

Abbildung 3.7: Medianes Erkrankungsalter bei der Erstdiagnose des Mammakarzinoms bei Patienten mit Sequenzvarianten bzw. Mutationen in den BRCA1- und BRCA2-Genen im Vergleich zu den anderen acht Core-Genen. A) Erkrankungsalter bei der Erstdiagnose des Mammakarzinoms bei den Patienten mit Nachweis einer Sequenzvariante der ACMG-Klasse 3, 4 oder 5 in den BRCA1/2-Genen (rot; BRCA1/2) im Vergleich zu den anderen acht Core-Genen (blau; nicht BRCA1/2). Bei Patienten mit Sequenzvarianten der ACMG-Klasse 3, 4 oder 5 in den Genen BRCA1 und BRCA2 lag das mediane Erkrankungsalter bei 44 Jahren (niedrigstes Erkrankungsalter $=25$ Jahre, höchstes Erkrankungsalter $=72$ Jahre). Bei Patienten ohne Sequenzvarianten der ACMG-Klasse 3, 4 oder 5 in den anderen acht Core-Genen lag das mediane Erkrankungsalter bei 48 Jahren (niedrigstes Erkrankungsalter $=28$ Jahre, höchstes Erkrankungsalter $=73$ Jahre). Die medianen Erkrankungsalter unterscheiden sich statistisch nicht signifikant (logistisches Regressionsmodell; $\mathrm{p}=0,14)$. B) Erkrankungsalter bei der Erstdiagnose des Mammakarzinoms bei den Patienten mit einer Mutation der ACMG-Klasse 4 oder 5 in den Genen BRCA1 und BRCA2 (rot; BRCA1/2) im Vergleich zu den anderen acht Core-Genen (blau; nicht BRCA1/2). Bei Patienten mit Mutationen in den Genen BRCA1 und BRCA2 war das mediane Erkrankungsalter 44 Jahre (niedrigstes Erkrankungsalter $=25$ Jahre, höchstes Erkrankungsalter $=64$ Jahre). Bei Patienten mit Mutationen in den anderen acht CoreGenen lag das mediane Erkrankungsalter bei 45 Jahren (niedrigstes Erkrankungsalter $=38$ Jahre, höchstes Erkrankungsalter $=64$ Jahre). Diese medianen Erkrankungsalter unterscheiden sich statistisch nicht signifikant (logistisches Regressionsmodell; $p=0,14$ ). Statistische Daten wurden mit dem Softwareprogramm R, Version 3.3.1, www.r-project.org, R-Paket Ime4 berechnet. ED MCa = Alter bei Erstdiagnose des Mammakarzinoms.

\subsubsection{Berechnung des Heterozygoten-Risikos in Assoziation mit identifizierten Sequenzvarianten in den 10 Core-Genen}

Für jeden Patienten dieser Kohorte wurde das Heterozygoten-Risiko für die Anlageträgerschaft einer autosomal-dominant vererbten Mutation mit Hilfe des Computerprogramms Cyrillic 2.13 berechnet. Diese rechnerischen Risiken wurden anschließend mit der eigentlichen Detektionsrate der Sequenzvarianten der ACMG-Klasse 3, 4 oder 5 in den 10 Core-Genen in Korrelation gesetzt. Einerseits ergab sich für Patienten mit einer Sequenzvariante der ACMG-Klasse 3, 4 oder 5 in einem der 10 Core-Gene ein mittleres Heterozygoten-Risiko von $41 \pm 32 \%$. Andererseits wurde für Patienten ohne eine identifizierte Sequenzvariante der ACMG-Klasse 3, 4 oder 5 in den 10 Core-Genen ein Heterozygoten-Risiko von $35 \pm 29 \%$ berechnet. Diese Risiken unterscheiden sich statistisch nicht signifikant $(p=0,14)$. 
Bei den Patienten mit einer Sequenzvariante der ACMG-Klasse 3, 4 oder 5 in den Genen BRCA1 oder BRCA2 betrug das mittlere Heterozygoten-Risiko $54 \pm 33 \%$, dahingegen $33 \pm 29 \%$ bei den Patienten mit einer Sequenzvariante der Klasse 3, 4 oder 5 in den anderen acht Core-Genen. Die Werte dieser Risiken unterscheiden sich statistisch signifikant $(p<0,01)$ (für mediane Werte $s$. Abb. 3.8A).

Weiterhin wurde für die Patienten mit einer Mutation der ACMG-Klasse 4 oder 5 in den BRCA1und BRCA2-Genen ein mittleres Heterozygoten-Risiko von $55 \pm 33 \%$ und für die Patienten mit einer Mutation der Klasse 4 oder 5 in den anderen acht Core-Genen von $34 \pm 36 \%$ berechnet. Die Werte dieser Risiken unterscheiden sich statistisch nicht signifikant $(p=0,10)$ (für mediane Werte s. Abb. 3.8B).
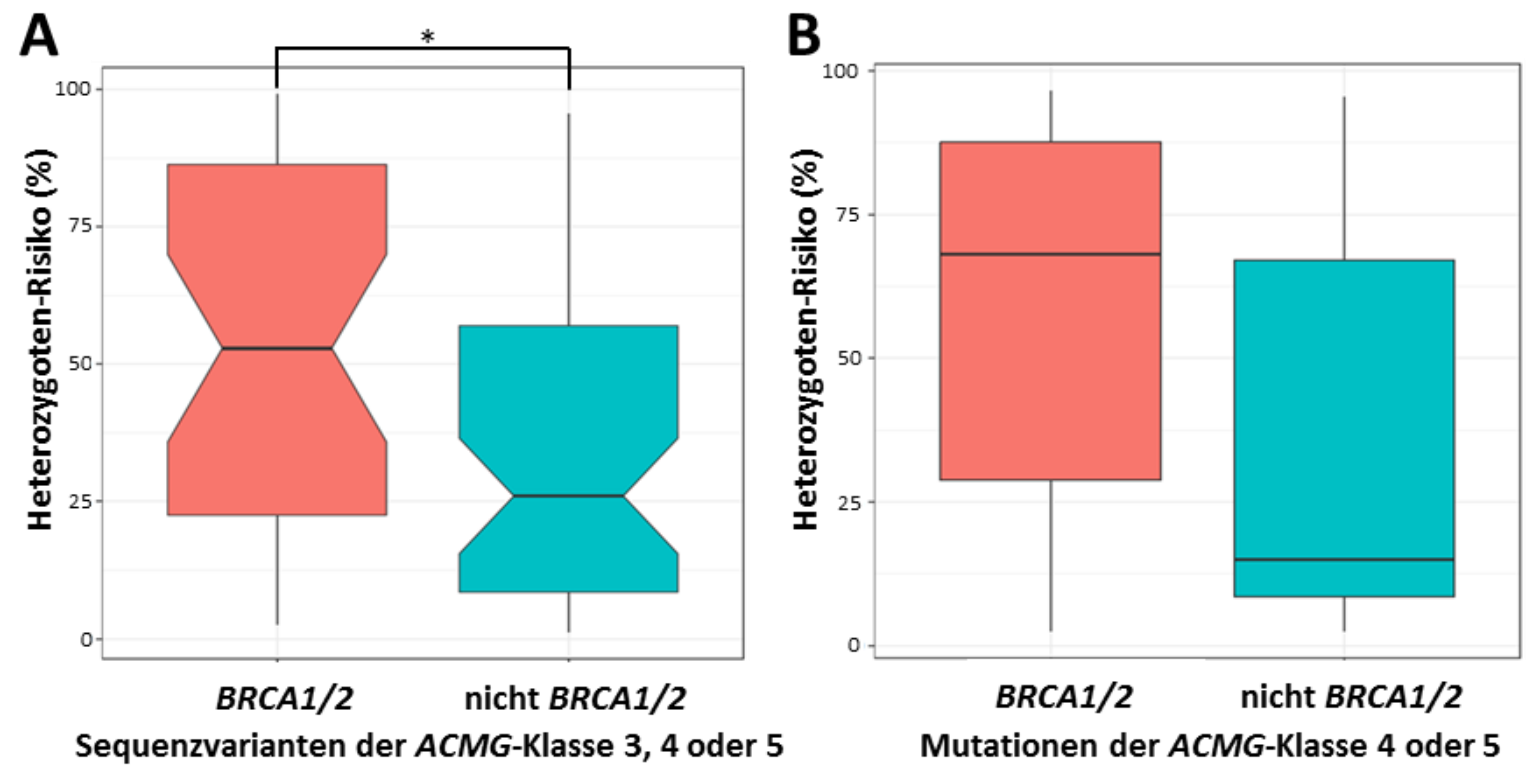

Abbildung 3.8: Berechnung des medianen Heterozygoten-Risikos in Korrelation zu identifizierten Sequenzvarianten in den $\mathbf{1 0}$ Core-Genen. A) Berechnung des medianen Heterozygoten-Risikos (Programm Cyrillic 2.13) bei den Patienten mit einer Sequenzvariante der ACMG-Klasse 3, 4 oder 5 in den BRCA1/2Genen (rot; BRCA1/2) im Vergleich zu den anderen acht Core-Genen (blau; nicht BRCA1/2). Bei Patienten mit Sequenzvarianten der ACMG-Klasse 3, 4 oder 5 in den Genen BRCA1 und BRCA2 lag das mediane berechnete Heterozygoten-Risiko bei 53,0 \% (niedrigstes Heterozygoten-Risiko $=2,6 \%$, höchstes Heterozygoten-Risiko $=99,0 \%$ ). Bei Patienten ohne Sequenzvarianten der ACMG-Klasse 3, 4 oder 5 in den anderen Genen acht Core-Genen lag das mediane berechnete Heterozygoten-Risiko bei 26,0 \% (niedrigstes Heterozygoten-Risiko $=1,2 \%$, höchstes Heterozygoten-Risiko = $96 \%$ ). Die medianen Heterozygoten-Risiken unterscheiden sich statistisch signifikant (logistisches Regressionsmodell; $p<0,01^{*}$ ). B) Medianes Heterozygoten-Risiko der Patienten mit einer Mutation der Klasse 4 oder 5 in den BRCA1/2-Genen (rot; $B R C A 1 / 2) \mathrm{im}$ Vergleich zu den anderen acht Core-Genen (blau; nicht BRCA1/2). Bei Patienten mit Mutationen der ACMG-Klasse 4 oder 5 in den Genen BRCA1 und BRCA2 lag das mediane berechnete Heterozygoten-Risiko bei $60 \%$ (niedrigstes Heterozygoten-Risiko $=2,6 \%$, höchstes Heterozygoten-Risiko = 96,0\%). Bei Patienten ohne Mutationen der ACMG-Klasse 4 oder 5 in den anderen acht Core-Genen lag das mediane berechnete Heterozygoten-Risiko bei 15,0 \% (niedrigstes Heterozygoten-Risiko = 2,5\%, höchstes Heterozygoten-Risiko $=96,0 \%$ ). Die medianen Heterozygoten-Risiken unterscheiden sich statistisch nicht signifikant (logistisches Regressionsmodell; $p=0,10$ ). Statistische Daten wurden mit dem Softwareprogramm R, Version 3.3.1, www.r-project.org, R-Paket Ime4 berechnet.

Das mittlere Heterozygoten-Risiko war bei den Patienten mit einer nachgewiesenen Sequenzvariante der ACMG-Klasse 3, 4 oder 5 in den einzelnen Core-Genen unterschiedlich hoch. Dieses Risiko war bei Patienten mit einer Sequenzvariante der ACMG-Klasse 3, 4 oder 5 in den 
Genen ATM, BRCA1, BRCA2, CDH1, NBN, RAD51C, RAD51D und TP53 höher im Vergleich zu den untersuchten Patienten ohne eine Sequenzvariante in einem dieser Core-Gene. Das mittlere Heterozygoten-Risiko lag mit einem Wert von 56,7 \% am höchsten bei Patienten mit den Sequenzvarianten der ACMG-Klasse 3, 4 oder 5 im BRCA1-Gen, gefolgt von einem mittleren Heterozygoten-Risiko von 54,7 \% im CDH1-Gen. Das dritthöchste mittlere Heterozygoten-Risiko von 51,9 \% zeigten Patienten mit einer Sequenzvariante der ACMG-Klasse 3, 4 oder 5 im NBNGen. Danach folgten die mittleren Heterozygoten-Risiken von 49,1 \% im BRCA2-Gen, von 48,0 \% im RAD51D-Gen und von 41,6 \% im ATM-Gen (s. Abb. 3.9 für mediane Heterozygoten-Risiken).
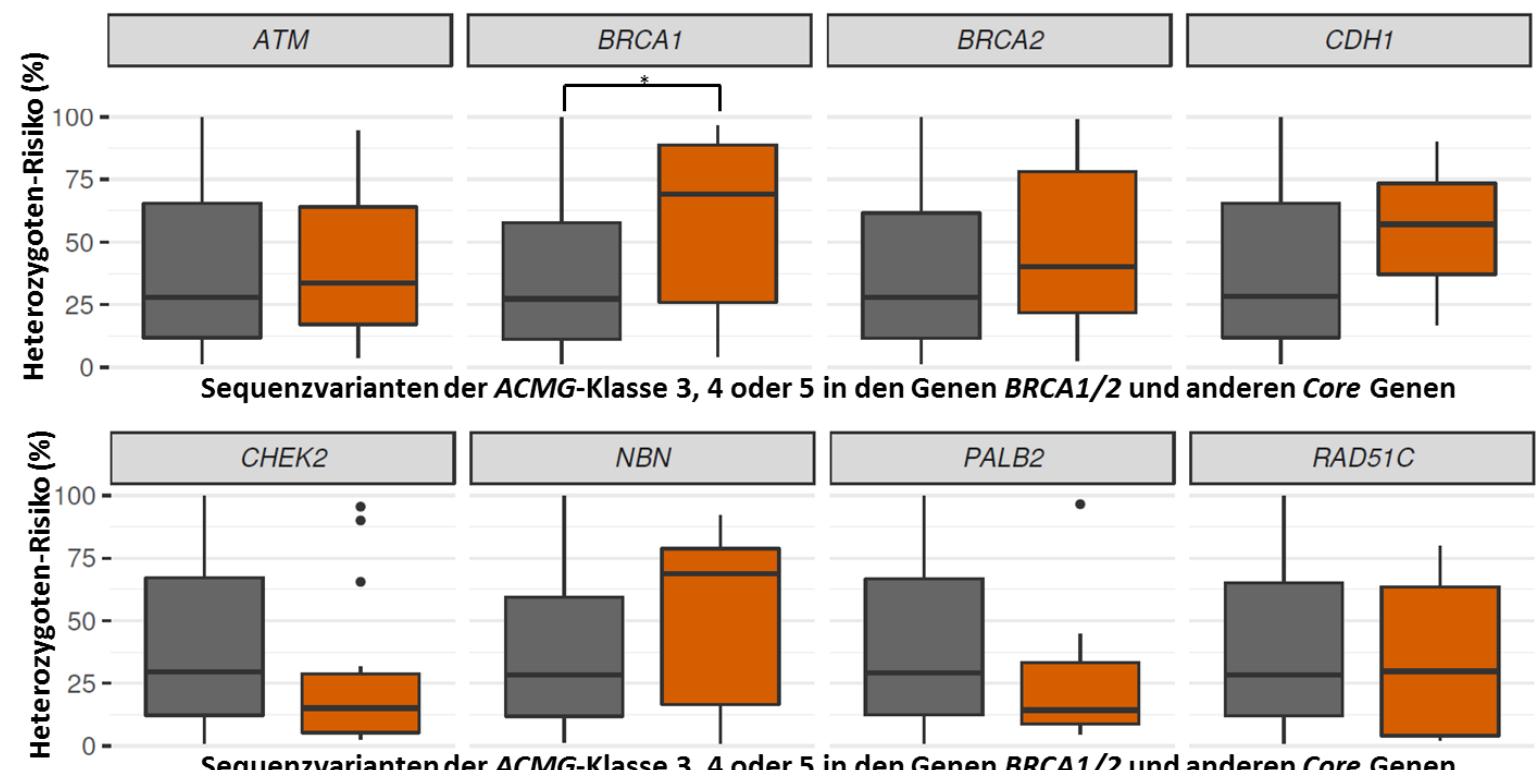

Sequenzvarianten der ACMG-Klasse 3, 4 oder 5 in den Genen BRCA1/2 und anderen Core Genen
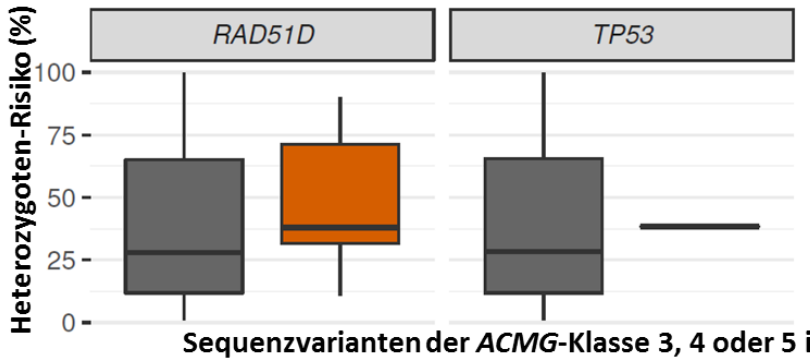

keine Sequenzvarianten der ACMG-Klasse 3, 4 oder 5

官 mit Sequenzvarianten der ACMG-Klasse 3, 4 oder 5

Abbildung 3.9: Berechnung des medianen Heterozygoten-Risikos in Korrelation zu identifizierten Sequenzvarianten in den einzelnen Core-Genen. Für jedes der zehn Core-Gene sind die medianen Heterozygoten-Risiken für Patienten mit einer Sequenzvariante der ACMG-Klasse 3, 4 oder 5 (orange Balken) und bei Patienten ohne Nachweis dieser Sequenzvarianten (dunkelgraue Balken) gezeigt. Die Heterozygoten-Risiken bei Patienten mit den Sequenzvarianten in einem der Core-Gene und ohne Nachweis dieser Sequenzvarianten unterscheiden sich statistisch signifikant nur für das BRCA1-Gen (logistisches Regressionsmodell; $\left.p=0,01^{*}\right)$. Statistische Daten wurden mit dem Softwareprogramm R, Version 3.3.1, www.r-project.org, R-Paket Ime4 berechnet. Das jeweilige Core-Gen ist oberhalb der entsprechenden Abbildung aufgeführt.

Bei 32 Patienten (91,4 \%) mit einer Mutation der ACMG-Klasse 4 oder 5 in den Genen ATM, $B R C A 1, B R C A 2$ und CHEK2 war es möglich das mittlere Heterozygoten-Risiko zu berechnen. In den Genen $C D H 1, P A L B 2$ und RAD51C wurde jeweils nur eine Mutation bei insgesamt drei Patienten $(8,6 \%)$ identifiziert. Für die Gene NBN, RAD51D und TP53 war diese Berechnung nicht möglich, da in diesen Genen keine Mutation der ACMG-Klasse 4 oder 5 identifiziert wurde.

Das mittlere Heterozygoten-Risiko war mit 89,9 \% bei Patienten mit einer Mutation der ACMGKlasse 5 im CDH1-Gen am höchsten. Das mittlere Heterozygoten-Risiko in den Genen ATM, BRCA2 
und CHEK2 war bei Patienten mit einer Mutation der ACMG-Klasse 4 oder 5 in einem dieser Gene niedriger als bei den Patienten ohne diese Mutation im entsprechenden Gen. Dahingegen war bei Patienten mit Mutationen in den Genen BRCA1, CDH1, PALB2 und RAD51C das HeterozygotenRisiko entsprechend höher als ohne identifizierte Mutation.

\subsubsection{Berechnung des Lebenszeitrisikos in Assoziation mit identifizierten Sequenzvarianten in den 10 Core-Genen}

Für jeden Patienten dieser Kohorte wurde das Lebenszeitrisiko bis zum 85. Lebensjahr an einem Mammakarzinom zu erkranken mit Hilfe des Computerprogramms Cyrillic 2.13 berechnet. Diese rechnerischen Risiken wurden anschließend mit der eigentlichen Detektionsrate der Sequenzvarianten der ACMG-Klasse 3, 4 oder 5 in den 10 Core-Genen in Korrelation gesetzt.

Das Lebenszeitrisiko lag bei Patienten mit einer Sequenzvariante der ACMG-Klasse 3, 4 oder 5 in den 10 Core-Genen mit dem Risikokalkulationsprogramm Cyrillic 2.13 bei $31 \pm 23 \%$ und bei den Patienten ohne diese Sequenzvarianten bei $24 \pm 19 \%$. Diese Risiken unterscheiden sich statistisch signifikant $(p=0,03)$.

Bei den Patienten mit einer Sequenzvariante der ACMG-Klasse 3, 4 oder 5 in den Genen BRCA1 oder BRCA2 (BRCA1/2) lag das mittlere Lebenszeitrisiko bei $41 \pm 26 \%$. Bei Patienten mit einer nachgewiesenen Sequenzvariante der ACMG-Klasse 3, 4 oder 5 in den anderen acht Core-Genen (nicht BRCA1/2) betrug das mittlere Lebenszeitrisiko $25 \pm 19 \%$. Diese Risiken unterscheiden sich statistisch signifikant $(p<0,01)$ (für mediane Werte s. Abb. 3.10A).

Für die Patienten mit einer Mutation der ACMG-Klasse 4 oder 5 in den BRCA1- und BRCA2-Genen (BRCA1/2) wurde ein mittleres Lebenszeitrisiko von $42 \pm 27 \%$ berechnet. Für die Patienten mit einer Mutation der ACMG-Klasse 4 oder 5 in den anderen acht Core-Genen (nicht BRCA1/2) wurde ein mittleres Lebenszeitrisiko von $27 \pm 24 \%$ ermittelt. Diese Risiken unterscheiden sich statistisch nicht signifikant $(p=0,12)$ (für mediane Werte s. Abb. 3.10B).
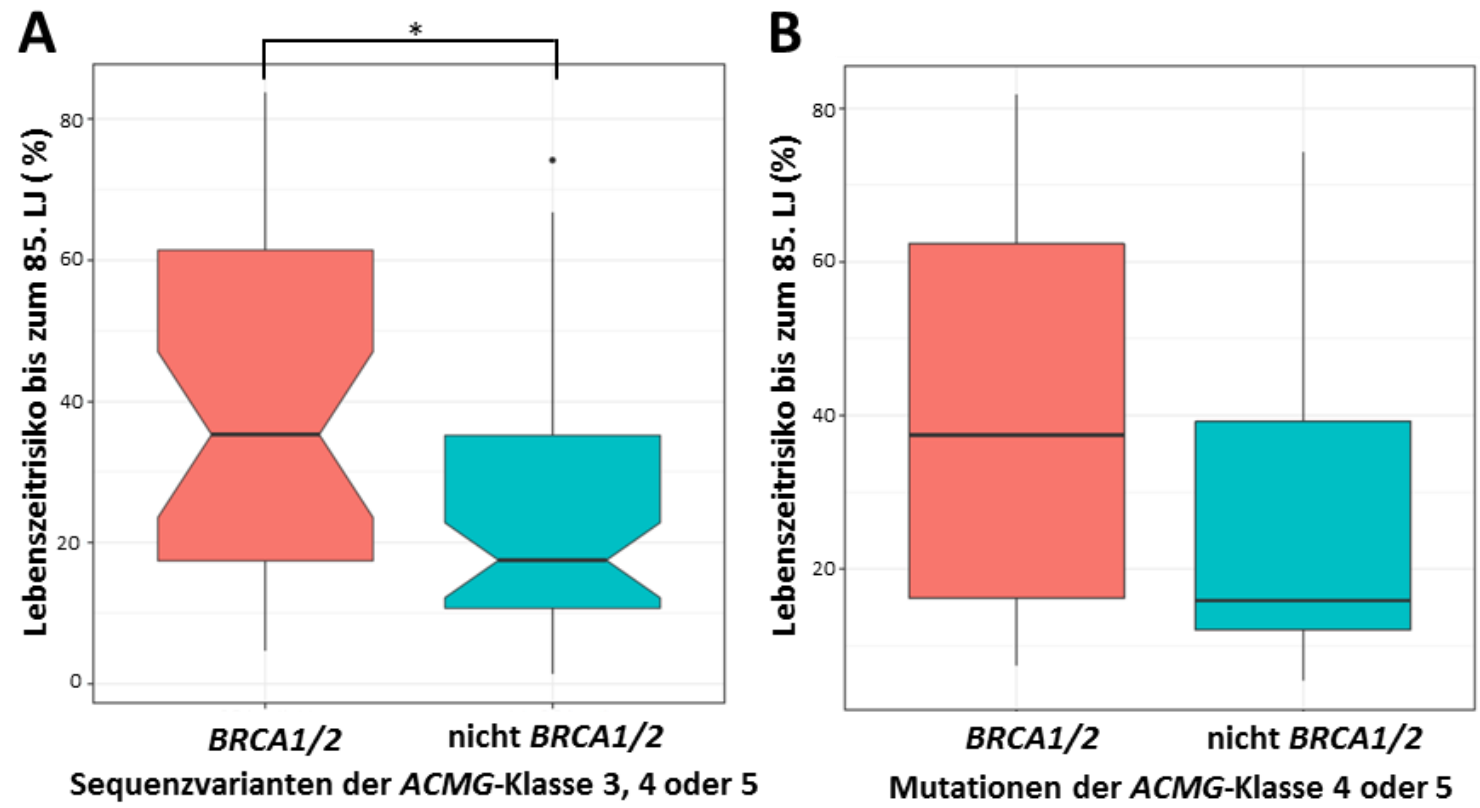

Abbildung 3.10: Berechnung des medianen Lebenszeitrisikos in Korrelation zu identifizierten Sequenzvarianten in den 10 Core-Genen. A) Berechnung des medianen Lebenszeitrisikos bis zum 85. Lebensjahr (LJ) an einem Mammakarzinom zu erkranken (Programm Cyrillic 2.13) bei Patienten mit einer Sequenzvariante der ACMG-Klasse 3, 4 oder 5 in den BRCA1/2-Genen (rot; BRCA1/2) im Vergleich zu den anderen acht Core-Genen (blau; nicht BRCA1/2). Bei Patienten mit Sequenzvarianten der ACMG-Klasse 3, 4 oder 5 in den Genen BRCA1 und BRCA2 lag das berechnete mediane Lebenszeitrisiko bei 35,0 \% (niedrigstes Lebenszeitrisiko $=4,7 \%$, höchstes Lebenszeitrisiko $=84,0 \%$ ). Bei Patienten ohne Sequenzvarianten der 
ACMG-Klasse 3, 4 oder 5 in den anderen acht Core-Genen lag das berechnete mediane Lebenszeitrisiko bei $18,0 \%$ (niedrigstes Lebenszeitrisiko $=1,4 \%$, höchstes Lebenszeitrisiko $=74,0 \%$ ). Die medianen Heterozygoten-Risiken unterscheiden sich statistisch signifikant (logistisches Regressionsmodell, $p<0,01^{*}$ ). B) Das mediane Lebenszeitrisiko, bis zum 85. Lebensjahr an einem Mammakarzinom zu erkranken, bei Patienten mit einer Mutation der ACMG-Klasse 4 oder 5 in den BRCA1/2-Genen (rot; BRCA1/2) im Vergleich zu den anderen acht Core-Genen (blau; nicht BRCA1/2). Bei Patienten mit Mutationen der ACMG-Klasse 4 oder 5 in den Genen BRCA1 und BRCA2 betrug das berechnete mediane Lebenszeitrisiko $37,0 \%$ (niedrigstes Lebenszeitrisiko $=7,5 \%$, höchstes Lebenszeitrisiko $=82,0 \%$ ). Bei Patienten ohne Mutationen der ACMGKlasse 4 oder 5 in den anderen acht Core-Genen lag das berechnete mediane Lebenszeitrisiko bei 16,0\% (niedrigstes Lebenszeitrisiko $=5,5 \%$, höchstes Lebenszeitrisiko $=74,0 \%$ ). Die medianen HeterozygotenRisiken unterscheiden sich statistisch nicht signifikant (logistisches Regressionsmodell; $p=0,12$ ). Statistische Daten wurden mit dem Softwareprogramm R, Version 3.3.1, www.r-project.org, R-Paket Ime4 berechnet.

Das mittlere Lebenszeitrisiko, bis zum 85. Lebensjahr an einem Mammakarzinom zu erkranken, lag bei Patienten mit Sequenzvarianten der ACMG-Klasse 3, 4 oder 5 in den Genen ATM, BRCA1, $B R C A 2, N B N$ und RAD51D höher als bei den Patienten ohne diesen Sequenzvarianten. Bei Patienten mit Sequenzvarianten im BRCA1-Gen wurde das höchste mittlere Lebenszeitrisiko bis zum 85. Lebensjahr an einem Mammakarzinom zu erkranken von 44,0\% verzeichnet. Dieses Risiko ist für Sequenzvarianten der ACMG-Klasse 3, 4 oder 5 im BRCA1-Gen statistisch signifikant höher als bei den Patienten ohne eine Sequenzvariante der Klasse 3, 4 oder 5 im BRCA1-Gen ( $p=$ 0,01 ). Die Lebenszeitrisiken in den anderen neun Core-Genen lagen niedriger als bei Patienten mit Mutationen im BRCA1-Gen und unterscheiden sich statistisch nicht signifikant zu den Lebenszeitrisiken bei Patienten ohne identifizierte Mutation in dem entsprechenden Gen. Das mittlere Lebenszeitrisiko, bis zum 85. Lebensjahr an einem Mammakarzinom zu erkranken, lag bei Patienten mit den Sequenzvarianten der Klasse 3, 4 oder 5 in den Genen CDH1, CHEK2, RAD51C und TP53 niedriger als bei den Patienten ohne diese Sequenzvariante in dem jeweiligen Gen. Die medianen Werte für die Lebenszeitrisiken bei Patienten mit und ohne Sequenzvarianten der ACMG-Klasse 3, 4 oder 5 in einem der 10 Core-Gene sind in der Abbildung 3.11 gezeigt. 


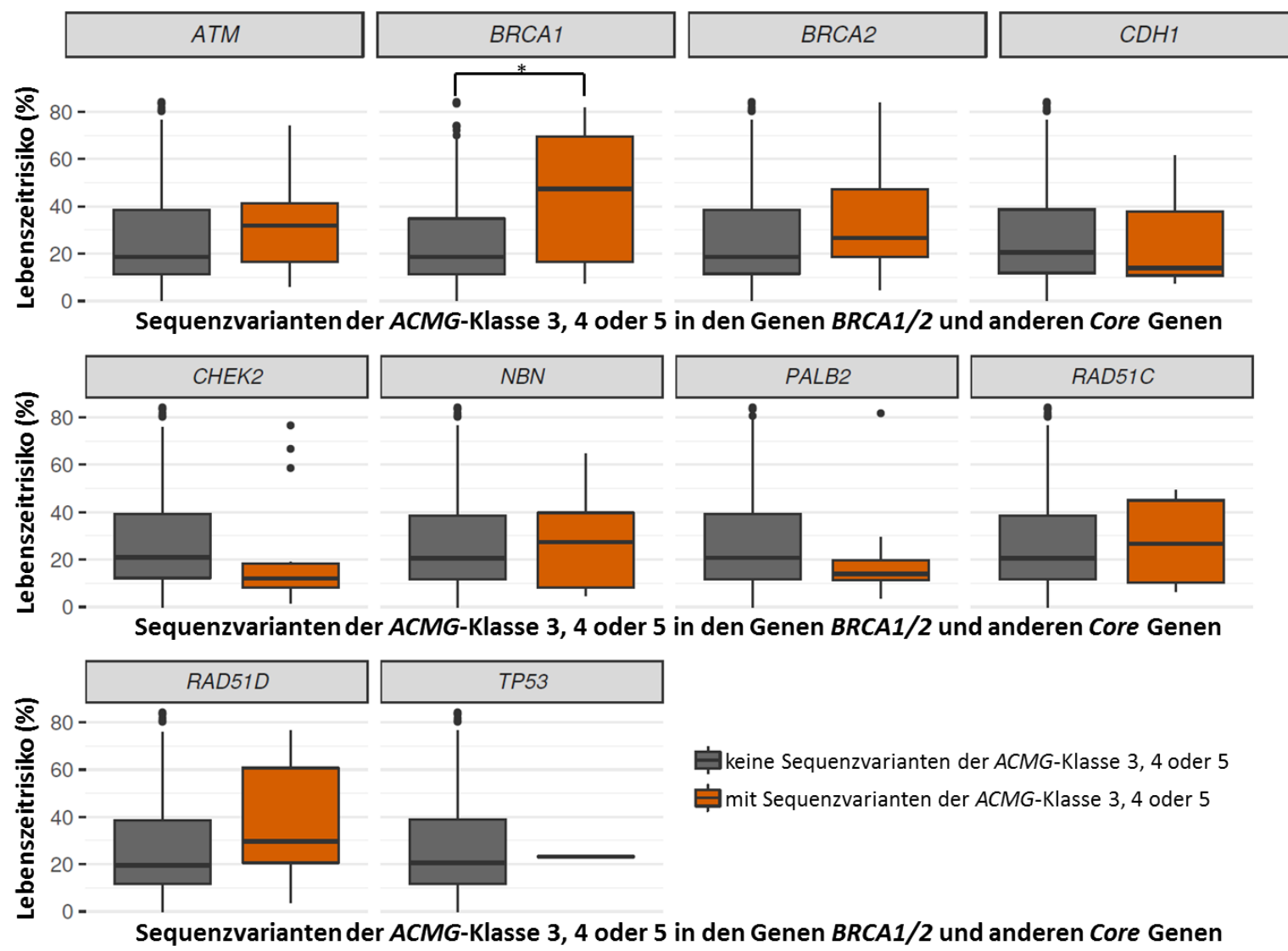

Abbildung 3.11: Berechnung des medianen Lebenszeitrisikos in Korrelation zu identifizierten Sequenzvarianten in den einzelnen Core-Genen. Für jedes der zehn Core-Gene ist das mediane Lebenszeitrisiko für Patienten mit einer Sequenzvariante der ACMG-Klasse 3, 4 oder 5 (orange Balken) und bei Patienten ohne diese Sequenzvariante (dunkelgraue Balken) angezeigt. Dieses Risiko konnte programmbedingt mit Cyrillic 2.13 nur für weibliche Patienten berechnet werden. Für die vier männlichen Patienten in der Kohorte konnte das Lebenszeitrisiko somit nicht ermittelt werden. Ausschließlich die Lebenszeitrisiken bei Patienten mit und ohne Nachweis dieser Sequenzvarianten im BRCA1-Gen unterscheiden sich statistisch signifikant (logistisches Regressionsmodell; $p=0,01^{*}$ ). Statistische Daten wurden mit dem Softwareprogramm R, Version 3.3.1, www.r-project.org, R-Paket Ime4 berechnet. Das jeweilige Core-Gen ist oberhalb der entsprechenden Abbildung aufgeführt.

Das mittlere Lebenszeitrisiko, bis zum 85. Lebensjahr an einem Mammakarzinom zu erkranken, war bei 32 Patienten (91,4\%) mit einer Mutation der ACMG-Klasse 4 oder 5 in den Genen ATM, BRCA1, BRCA2 und CHEK2 möglich zu berechnen. In den Genen CDH1, PALB2 und RAD51C wurde bei insgesamt drei Patienten (8,6 \%) jeweils nur eine Mutation identifiziert. Für die Gene NBN, RAD51D und TP53 war diese Berechnung nicht möglich, da in diesen Genen keine Mutation der ACMG-Klasse 4 oder 5 identifiziert wurde.

Das Lebenszeitrisiko bis zum 85. Lebensjahr an einem Mammakarzinom zu erkranken lag mit 61,5 $\%$ am höchsten bei dem einzelnen Patienten mit einer Mutation der ACMG-Klasse 4 im CDH1-Gen. Das mittlere Risiko war bei den Patienten mit Mutationen der ACMG-Klasse 4 oder 5 in den Genen ATM, BRCA1, CDH1 und RAD51C höher als bei den Patienten ohne Mutationen in diesen Genen. Bei Patienten mit Mutationen der ACMG-Klasse 4 oder 5 in den Genen BRCA2, CHEK2 und PALB2 war dieses Risiko niedriger als bei Patienten ohne Mutationen in einem dieser Gene. 


\subsubsection{Histologische Subtypen der Mammakarzinome in Abhängigkeit von der identifizierten Sequenzvariante in den 10 Core-Genen}

Unter 3.2.5 wurde die Einteilung der histologischen Subtypen der Mammakarzinome bei der untersuchten Patientenkohorte aufgeführt. Um festzustellen, ob und wie die identifizierten Sequenzvarianten der ACMG-Klasse 3, 4 oder 5 in den Core-Genen mit den Tumortypen der Mammakarzinome korrelieren, wurden diese Werte miteinander verglichen.

Bei insgesamt 32 Patienten der Kohorte wurde histopathologisch ein DCIS (duktales Carcinoma in situ), bei 105 Patienten ein invasiv duktales Mammakarzinom, bei 16 Patienten ein invasiv lobuläres Mammakarzinom und bei zwei Patienten ein medulläres Mammakarzinom diagnostiziert.

Beim Vergleich der detektierten Sequenzvarianten der ACMG-Klasse 3, 4 oder 5 bei diesen Patienten wurde eine statistische Signifikanz nur bei Patienten mit und ohne detektierten Sequenzvarianten der ACMG-Klasse 3, 4 oder 5 in einem der 10 Core-Gene und einem invasiv duktalen Mammakarzinom detektiert $(p=0,02)$. Alle anderen Werte unterscheiden sich statistisch nicht signifikant (s. Tab. 3.10).

Tabelle 3.10: Histologischer Subtyp des Mammakarzinoms in Abhängigkeit von identifizierten Sequenzvarianten der ACMG-Klasse 3, 4 oder 5 in den 10 Core-Genen. Statistische Daten wurden mit dem Softwareprogramm R, Version 3.3.1, www.r-project.org, R-Paket Ime4 berechnet.

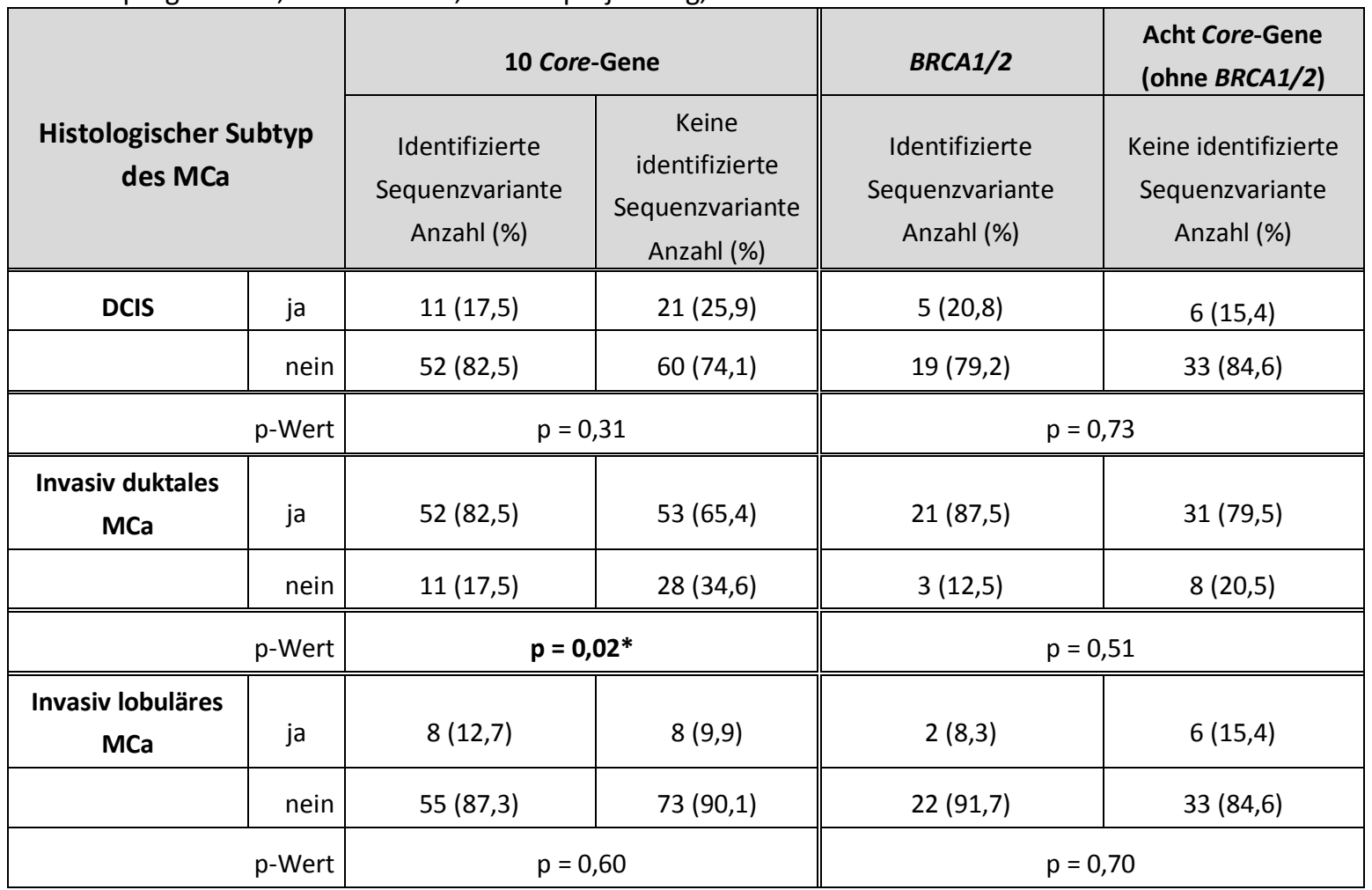

DCIS = duktales Carcinoma in situ; $\mathrm{MCa}=$ Mammakarzinom.

Weiterhin konnte keine statistische Signifikanz zwischen den detektierten Mutationen der ACMGKlasse 4 oder 5 in den Core-Genen und dem histologischen Subtyp des Mammakarzinoms detektiert werden $(p=1,00)$.

Bei drei von insgesamt $31(9,7 \%)$ an einem DCIS erkrankten Patienten konnten Mutationen der ACMG-Klasse 4 oder 5 in den Core-Genen nachgewiesen werden. In den Genen BRCA1 und BRCA2 wurden hierbei insgesamt zwei Mutationen der ACMG-Klasse 4 oder 5 (6,5\%) identifiziert, in den anderen Core-Genen (im ATM-Gen) wurde insgesamt eine Mutation der ACMG-Klasse 5 detektiert $(3,2 \%)$ (s. Abb. 3.12A). 
Bei insgesamt 21 Patienten (20,0 \%) mit einem invasiv duktalen Mammakarzinom konnten 13 Mutationen der ACMG-Klasse 4 oder $5(12,4 \%)$ in den Genen BRCA1 und BRCA2 identifiziert werden und acht $(7,6 \%)$ Mutationen der $A C M G$-Klasse 4 oder 5 in den anderen Core-Genen (s. Abb. 3.12B).

Bei insgesamt vier Patienten $(25,0 \%)$ mit einem invasiv lobulären Mammakarzinom wurden zwei Mutationen der ACMG-Klasse 4 oder $5(12,5 \%)$ in den Genen BRCA1 und BRCA2 und zwei Mutationen (12,5\%) in den anderen acht Core-Genen detektiert (s. Abb. 3.12C). Bei Patienten mit einem medullären Mammakarzinom wurde keine Mutation der ACMG-Klasse 4 oder 5 in einem der Core-Gene detektiert.

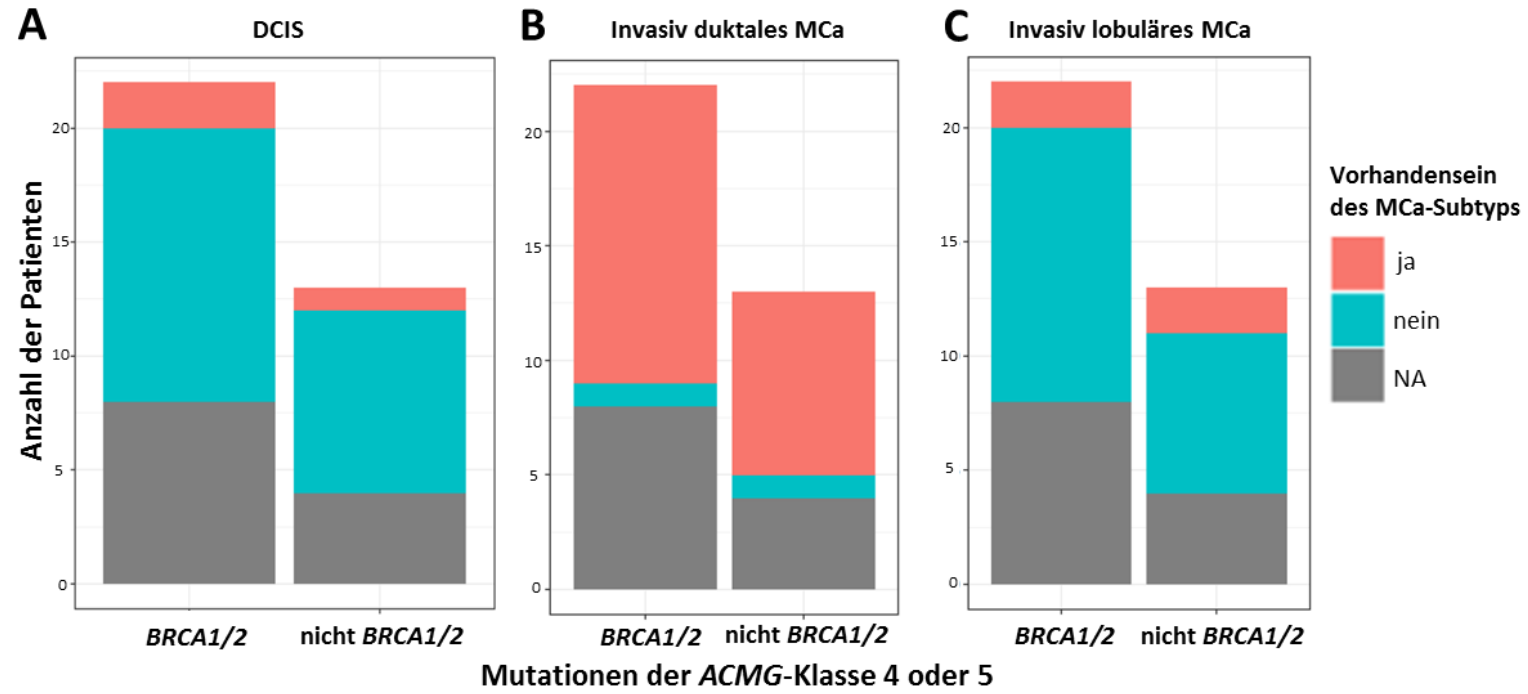

Abbildung 3.12: Histologischer Subtyp des Mammakarzinoms in Abhängigkeit von einer Mutation der ACMG-Klasse 4 oder 5 in den 10 Core-Genen. Die Patienten wurden nach dem Subtyp des Mammakarzinoms (MCa) in die Gruppe DCIS (duktales Carcinoma in situ) (A), invasiv duktales Mammakarzinom (B) und invasiv lobuläres Mammakarzinom (C) unterteilt. Jede Patientengruppe mit einem spezifischen Subtyp des Mammakarzinoms wurde zusätzlich in zwei Gruppen unterteilt, eine Gruppe stellten die Patienten mit Mutation (rot) und ohne Mutation (blau) der ACMG-Klasse 4 oder 5 in den Genen BRCA1 oder BRCA2 (BRCA1/2) dar. Die zweite Gruppe waren Patienten mit Mutation (rot) und ohne Mutation (blau) der ACMG-Klasse 4 oder 5 in einem der anderen acht Core-Gene. Es konnte keine statistische Signifikanz zwischen den detektierten Mutationen der ACMG-Klasse 4 oder 5 in den 10 Core Genen und dem histologischen Subtyp des Mammakarzinoms detektiert werden (logistisches Regressionsmodell; $p=1,00$ ). Statistische Daten wurden mit dem Softwareprogramm R, Version 3.3.1, www.r-project.org, R-Paket Ime4 berechnet. NA = keine Angaben zum Tumortyp vorhanden.

\subsubsection{Rezeptorstatus der Mammakarzinome in Korrelation zu identifizierten Sequenzvarianten in den Core-Genen}

Aus der Literatur ist bekannt, dass die Expression des ER $\alpha$ und des PR sowie die Überexpression des ERBB2-Rezeptors im Gewebe des Mammakarzinoms in Assoziation mit dem Familienstammbaum einen Hinweis auf einen hereditären Ursprung des Mammakarzinoms geben könnte (Honrado et al. 2005).

Daher sollte in der hier vorliegenden Patientenkohorte ein möglicher Zusammenhang zwischen der Expression der o. g. Rezeptoren in den Tumoren und dem Mutationsstatus in den 10 CoreGenen in der genomischen DNA aus Lymphozyten detailliert untersucht werden (s. Anhang Tab. 7.4).

Bei insgesamt 104 Patienten mit exprimierten ER $\alpha$ im Tumorgewebe konnten bei 11 Patienten $(10,6 \%)$ eine Sequenzvariante der ACMG-Klasse 3, 4 oder 5 in den BRCA1- und BRCA2-Genen und bei 37 Patienten $(35,6 \%)$ in den anderen acht Core-Genen identifiziert werden. Bei 15 von 
insgesamt 44 Patienten (34,1\%) ohne nachgewiesene ER $\alpha$-Expression im Mammakarzinom wurde eine Sequenzvariante der ACMG-Klasse 3, 4 oder 5 in den BRCA1- oder BRCA2-Genen und bei sieben Patienten (15,6\%) in den anderen acht Core-Genen detektiert. Diese Werte sind statistisch signifikant $(p<0,01)$ (s. Tab. 7.4 im Anhang und Abb. 3.13A).

Bei 11 von insgesamt 95 Patienten $(11,6 \%)$ mit nachgewiesener PR-Expression im Tumorgewebe konnte eine Sequenzvariante der ACMG-Klasse 3, 4 oder 5 in den BRCA1- oder BRCA2-Genen und bei 33 Patienten $(34,7 \%)$ in den restlichen acht Core-Genen identifiziert werden. Bei 15 von insgesamt 52 Patienten (28,8 \%) ohne PR-Expression im Tumorgewebe konnte eine BRCA1- oder BRCA2-Sequenzvariante der ACMG-Klasse 3, 4 oder 5 und bei 10 Patienten (19,2\%) in den anderen acht Core-Genen identifiziert werden. Diese Werte unterscheiden sich statistisch signifikant $(p=0,01)$ (s. Tab. 7.4 im Anhang und Abb. 3.13B). Alle anderen Unterschiede bezüglich der Expression der Rezeptoren in den Tumoren und der Detektion von Sequenzvarianten in der genomischen DNA aus Lymphozyten waren statistisch nicht signifikant (s. Anhang Tab. 6.4).

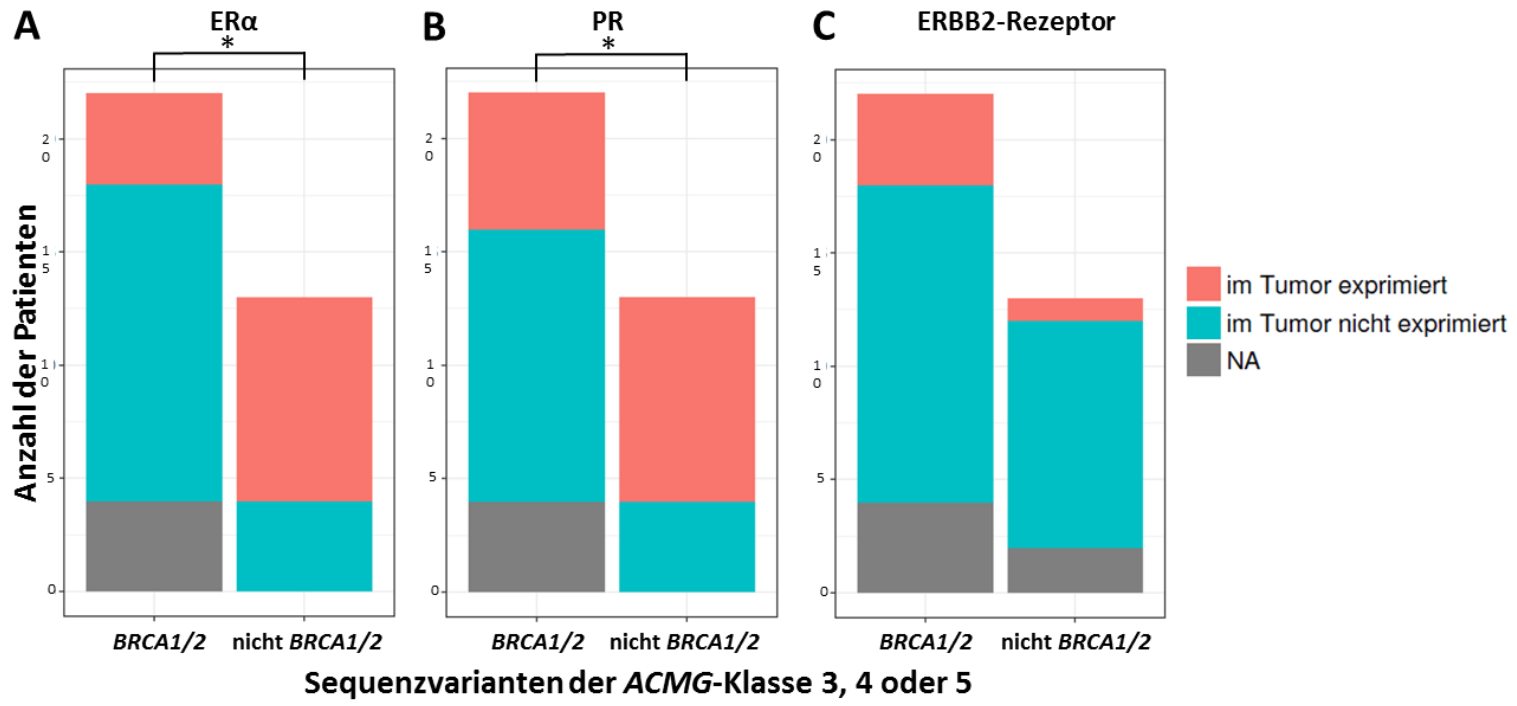

Abbildung 3.13: Rezeptorstatus der untersuchten Mammakarzinome in Korrelation zu den identifizierten Sequenzvarianten in den Genen BRCA1 und BRCA2 (BRCA1/2) und in den anderen Core-Genen (nicht BRCA1/2). Die Patienten wurden nach der Expression des ER $\alpha$ (A), PR (B) und der Überexpression des ERBB2-Rezeptors (C) in den Mammakarzinomen gruppiert. Die jeweilige Patientengruppe mit der Expression bzw. Überexpression des jeweiligen Rezeptors wurde wiederum in zwei Gruppen unterteilt, eine Gruppe stellten Patienten mit Sequenzvarianten (rot) und ohne Sequenzvarianten (blau) der ACMG-Klasse 3, 4 oder 5 in den Genen BRCA1 oder BRCA2 (BRCA1/2) dar. Die zweite Gruppe waren Patienten mit Sequenzvarianten (rot) und ohne Sequenzvarianten (blau) der ACMG-Klasse 3, 4 oder 5 in einem der anderen acht Core-Gene. Die Korrelation der Expression des ER $\alpha$ und PR zur identifizierten Sequenzvariante der ACMG-Klasse 3, 4 oder 5 in den Genen BRCA1 und BRCA2 und den anderen acht Core-Genen ist statistisch signifikant (für ER $\alpha$ : $p<0,01^{*}$ und für PR: $p=0,01^{*}$, logistisches Regressionsmodell). Statistische Daten wurden mit dem Softwareprogramm R, Version 3.3.1, www.r-project.org, R-Paket Ime4 berechnet. $\mathrm{NA}=$ keine Angaben zur Expression des Rezeptors vorhanden.

32 Patienten (18,5\%) der an einem Mammakarzinom erkrankten Patienten wiesen ein triplenegatives Mammakarzinom (keine Expression des ER $\alpha$, des PR und keine Überexpression des ERBB2-Rezeptors im Tumorgewebe) auf. Bei insgesamt 16 dieser Patienten (50,0\%) wurden Sequenzvarianten der ACMG-Klasse 3, 4 oder 5 identifiziert. Diese Detektionsrate unterscheidet sich statistisch nicht signifikant im Vergleich zu der Detektionsrate der Sequenzvarianten der ACMG-Klasse 3, 4 oder 5 der gesamten Kohorte $(p=0,56)$ (s. Tab. 3.11). Zwei dieser Patienten wiesen jeweils zwei Sequenzvarianten der ACMG-Klasse 3, 4 oder 5 auf. Bei einem dieser 
Patienten wurde eine Mutation der ACMG-Klasse 5 im BRCA1-Gen und eine Sequenzvariante der $A C M G$-Klasse $3 \mathrm{im}$ RAD51C-Gen identifiziert. Bei dem anderen Patienten wurde jeweils eine Sequenzvariante der ACMG-Klasse 3 in den Genen BRCA2 und RAD51D detektiert. In der Patientenkohorte mit triple-negativen Mammakarzinomen wurden insgesamt 13 Mutationen (40,6 \%) der ACMG-Klasse 5 detektiert. Wahrscheinlich pathogene Mutationen der ACMG-Klasse 4 wurden nicht identifiziert. Diese Detektionsrate unterscheidet sich statistisch signifikant im Vergleich zu der Detektionsrate bei den Patienten ohne triple-negative Mammakarzinome ( $p=$ 0,001) (s. Tab. 3.11). Patienten mit triple-negativen Mammakarzinomen erkrankten in einem mittleren Alter von 41,8 Jahren (Erkrankungspanne von 25 bis 87 Jahren). Dahingegen erkrankten Patienten ohne triple-negative Mammakarzinome mit einem mittleren Alter von 47,8 Jahren (Erkrankungspanne von 24 bis 88 Jahren). Zehn der Mutationen (75,0 \%) der ACMG-Klasse 5 wurden im BRCA1-Gen identifiziert sowie jeweils eine Mutation in den Genen ATM, BRCA2 und PALB2. Die Detektionsrate der Mutationen im BRCA1-Gen war statistisch signifikant höher $(\mathrm{p}=$ $0,0004)$ im Vergleich zu den Detektionsraten der Mutationen der ACMG-Klasse 4 oder 5 bei Patienten mit triple-negativen Mammakarzinomen in den anderen neun Core-Genen (s. Tab. 3.11). Patienten mit einem triple-negativen Mammakarzinom und einer identifizierten Mutation der ACMG-Klasse 5 erkrankten mit einem mittleren Alter von 42,7 Jahren (Erkrankungspanne von 25 bis 63 Jahren). Auf der anderen Seite erkrankten Patienten mit einem triple-negativen Mammakarzinom ohne eine Mutation der ACMG-Klasse 4 oder 5 mit einem mittleren Alter von 48,8 Jahren (Erkrankungspanne von 27 bis 87 Jahren).

Tabelle 3.11: Triple-negative Mammakarzinome in Abhängigkeit von identifizierten Sequenzvarianten der ACMG-Klasse 3, 4 oder 5 in den 10 Core-Genen. Statistische Daten wurden mit dem Softwareprogramm R, Version 3.3.1, www.r-project.org, R-Paket Ime4, Exakter Fischer-Test, berechnet.

\begin{tabular}{|c|c|c|c|c|c|c|}
\hline \multirow{3}{*}{$\begin{array}{c}\text { Triple-negative } \\
\text { Mammakarzinome }\end{array}$} & \multicolumn{6}{|c|}{ Anzahl der Patienten } \\
\hline & \multicolumn{2}{|c|}{$\begin{array}{l}\text { Sequenzvarianten der } \\
\text { ACMG-Klasse } 3,4 \text { oder } 5\end{array}$} & \multicolumn{2}{|c|}{$\begin{array}{c}\text { Mutationen der ACMG- } \\
\text { Klasse } 4 \text { oder } 5\end{array}$} & \multicolumn{2}{|c|}{$\begin{array}{c}\text { Mutationen der } \\
\text { ACMG-Klasse } 4 \text { oder } 5 \\
\text { im BRCA1-Gen }\end{array}$} \\
\hline & ja & nein & ja & nein & ja & nein \\
\hline ja & 16 & 16 & 13 & 19 & 10 & 22 \\
\hline nein & 72 & 96 & 22 & 146 & 8 & 160 \\
\hline p-Wert & \multicolumn{2}{|c|}{0,56} & \multicolumn{2}{|c|}{$0,001 *$} & \multicolumn{2}{|c|}{$0,0004^{*}$} \\
\hline
\end{tabular}

\subsubsection{Detektionsraten der Sequenzvarianten in den BRCA1- und BRCA2-Genen im Vergleich zu allen $\mathbf{1 0}$ analysierten Core-Genen}

Es sollte überprüft werden, ob die molekulargenetische Analyse aller 10 Core-Gene eine größere Anzahl von Patienten mit einer molekulargenetisch gesicherten hereditären Form des Mammaund Ovarialkarzinoms identifiziert als nur die alleinige Analyse der Gene BRCA1 und BRCA2. Dazu wurden die Detektionsraten der Sequenzvarianten der ACMG-Klasse 3, 4 oder 5 in den BRCA1und BRCA2-Genen mit den entsprechenden Detektionsraten in allen 10 Core-Genen verglichen.

Die Detektionsrate für Sequenzvarianten der ACMG-Klasse 3, 4 oder 5 in allen 10 Core-Genen lag bei insgesamt $44,0 \%$. Wenn nur die BRCA1- und BRCA2-Gene betrachtet wurden, lag die Detektionsrate bei 18,0 \%. Die Detektionsrate der Sequenzvarianten der ACMG-Klasse 3, 4 oder 5 in den 10 Core-Genen war damit statistisch signifikant höher als die Detektionsrate in den Genen $B R C A 1$ und $B R C A 2$ alleine $(p<0,0001)$.

Die Detektionsrate der Mutationen der ACMG-Klassen 4 oder 5 in den BRCA1- und BRCA2-Genen betrug $11,0 \%$, in allen 10 analysierten Core-Genen lag diese Detektionsrate bei 18,0\%. Die Detektionsrate der Mutationen der ACMG-Klasse 4 oder 5 in allen 10 Core-Genen ist somit statistisch signifikant höher als die Detektionsrate in den Genen BRCA1 und BRCA2 alleine $(\mathrm{p}=$ 
0,0009). In den Genen NBN, RAD51D und TP53 wurden keine Mutationen der ACMG-Klasse 4 oder 5 in dieser Patientenkohorte nachgewiesen.

\subsection{Ausgewählte Fälle mit identifizierten Sequenzvarianten}

Aus den insgesamt 200 analysierten Fällen dieser Kohorte wurden insgesamt vier Patienten ausgewählt und weiterführend im Detail molekulargenetisch untersucht. Ebenso wurde ein zusätzlicher Patient (39202) für detaillierte molekulargenetische Analysen ausgewählt, der zwar selbst die Kriterien für die hereditäre Form des Mamma- und Ovarialkarzinoms nicht erfüllt hatte, sondern seine an einem beidseitigen Mammakarzinom verstorbene Tante mütterlicherseits. Diese fünf Patienten wurden einer intensivierten molekulargenetischen Diagnostik unterzogen, da entweder die detektierte Sequenzvariante in der Literatur und in den Datenbanken nicht beschrieben war, die Pathogenität der identifizierten Sequenzvariante mit den funktionellen Analysen weiter klassifiziert werden sollte, oder die Segregationsanalyse der identifizierten Sequenzvariante bzw. der Mutation in der Familie unerwartete Ergebnisse erbrachte.

\subsubsection{Patientin 39784}

\subsubsection{Klinische Daten und Familienanamnese zur Indexpatientin $\mathbf{3 9 7 8 4}$}

Die Indexpatientin 39784 (s. Abb. 3.14, III.11) war im Alter von 29 Jahren an einem linksseitigen Mammakarzinom erkrankt. Es handelte sich um ein invasiv duktales Mammakarzinom im Stadium pT1b. Im Tumorgewebe konnte eine Expression des ER $\alpha$ nachgewiesen werden, wohingegen eine Überexpression des ERBB2-Rezeptors nicht detektiert werden konnte. Die Information bzgl. der Expression des PR im Tumor war nicht vorhanden. Der Bruder (s. Abb. 3.14, III.12) und die Eltern (s. Abb. 3.14, II.4 und II.5) der Indexpatientin waren bezüglich Tumorerkrankungen unauffällig. In der Familie väterlicherseits war der Großvater (s. Abb. 3.14, I.4) im Alter von ca. 80 Jahren an einem Prostatakarzinom erkrankt und an den Folgen verstorben. In der Familie mütterlicherseits war die Tante (s. Abb. 3.14, II.3) mit ca. 40 Jahren an einem Ovarialkarzinom erkrankt und mit 50 Jahren an den Folgen verstorben. Ferner wurde bei der Großmutter mütterlicherseits (s. Abb. 3.14, I.1) mit etwa 72 Jahren ein Lymphom diagnostiziert. Sie war mit 74 Jahren verstorben.

Die Kriterien für eine hereditäre Form des Mamma- und Ovarialkarzinoms, definiert vom Deutschen Konsortium Familiärer Brust- und Eierstockkrebs, für eine molekulargenetische Untersuchung der 10 Core-Gene waren in der Familie der Indexpatientin 39784 gegeben. Im Fall der Indexpatientin 39784 war das Kriterium J erfüllt, d. h. dass mindestens eine Frau in der Familie an einem Mammakarzinom und mindestens eine Frau an einem Ovarialkarzinom erkrankt waren. 


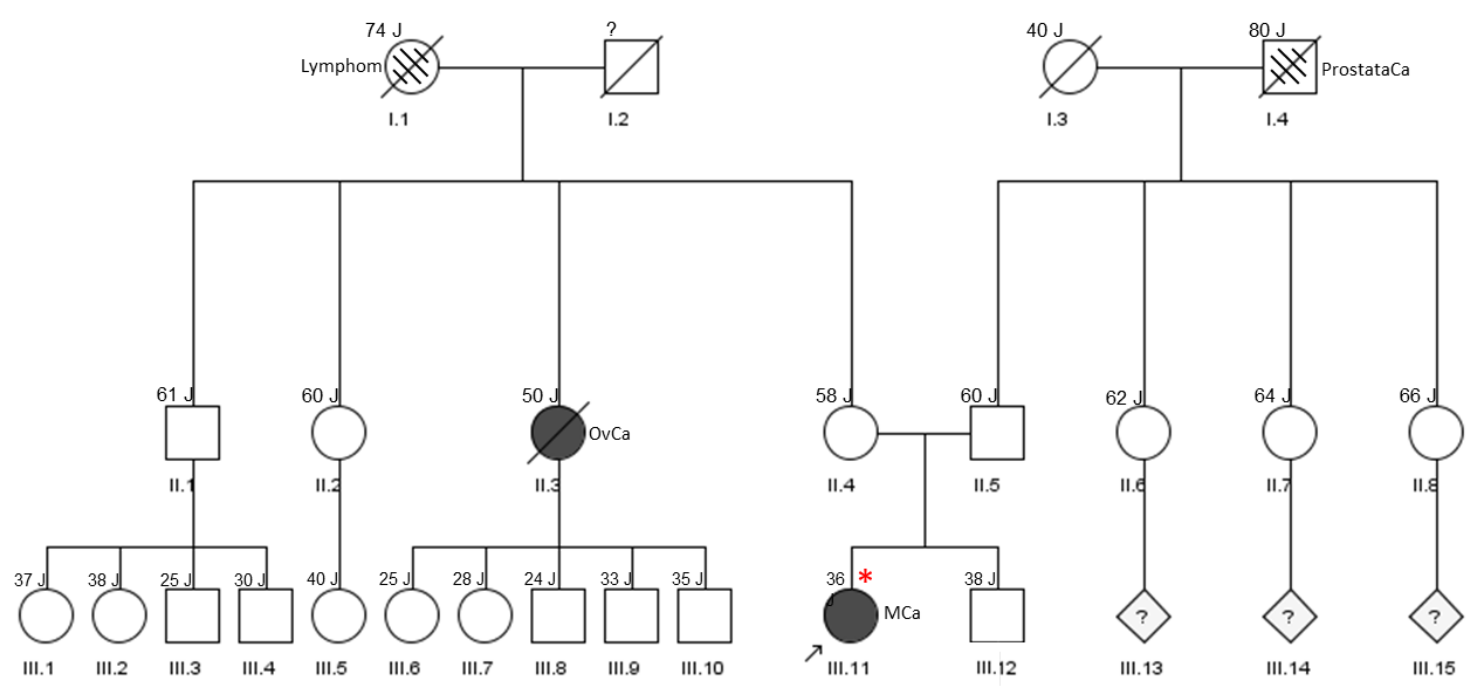

Abbildung 3.14: Stammbaum der Indexpatientin 39784 (III.11) über drei Generationen. Weibliche Personen sind mit einem Kreissymbol, männliche Personen mit einem Quadratsymbol dargestellt. Patientensymbole mit einem diagnostizierten Mamma-(MCa)- oder Ovarialkarzinom (OvCa) sind schwarz gekennzeichnet. Patientensymbole mit anderen Tumorerkrankungen, außer Mamma- und Ovarialkarzinom, sind schraffiert dargestellt. Die Altersangaben im Stammbaum beziehen sich auf das aktuelle Alter der Personen wie bei der genetischen Beratung vom Indexpatienten angegeben. Der Pfeil weist auf die Indexpatientin hin (III.11). Bei der Indexpatientin 39784 konnte die heterozygote Sequenzvariante c.346G>A im RAD51D-Gen nachgewiesen werden (*). Eine Tante mütterlicherseits (II.3) war mit 50 Jahren an den Folgen eines Ovarialkarzinoms verstorben. Bei der Großmutter mütterlicherseits (I.1) war mit ca. 72 Jahren ein Lymphom diagnostiziert worden. In der väterlichen Linie der Familie erkrankte der Großvater (I.4) der Indexpatientin mit ca. 80 Jahren an einem Prostatakarzinom (ProstataCa).

\subsubsection{Ergebnisse der molekulargenetischen Analyse der Indexpatientin 39784}

An der genomischen DNA aus Lymphozyten der Indexpatientin 39784 erfolgte eine Multi-GenPanel-Untersuchung (TruRisk ${ }^{\mathrm{TM}}$ ) mit der Auswertung aller 10 Core-Gene (ATM, BRCA1, BRCA2, CDH1, CHEK2, NBN, PALB2, RAD51C, RAD51D und TP53) sowie eine MLPA-Analyse der Gene BRCA1, BRCA2, CHEK2, PALB2, RAD51C und RAD51D.

Bei der Sequenzanalyse mittels NGS wurde im Exon 5 des RAD51D-Gens die Sequenzvariante c.346G >A (p.(Val116lle)) heterozygot nachgewiesen (s. Abb. 3.15B). Die Sequenzvariante c.346G>A wurde in ca. $46 \%$ der Sequenz-Reads identifiziert, was nahezu einem heterozygoten Zustand entspricht. Die o. g. Sequenzvariante im RAD51D-Gen konnte nach einer unabhängigen PCR und Sanger-Sequenzierung an der genomischen DNA der Indexpatientin 39784 mit einem Primerpaar im Intron 4 und Intron 5 des RAD51D-Gens verifiziert werden (s. Abb. 3.15A und 3.16C). Es wurden keine weiteren Sequenzvarianten der ACMG-Klasse 3, 4 oder 5 in den anderen Core-Genen nachgewiesen. Auch konnte keine Deletion/Duplikation mittels MLPA-Analyse in den o. g. Genen identifiziert werden. 
A RAD51D-Gen

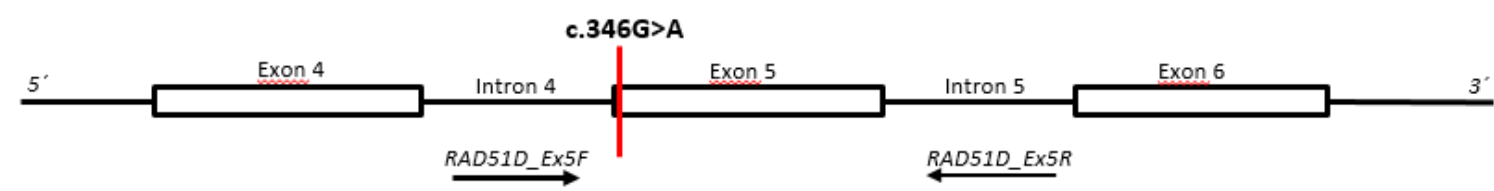

B

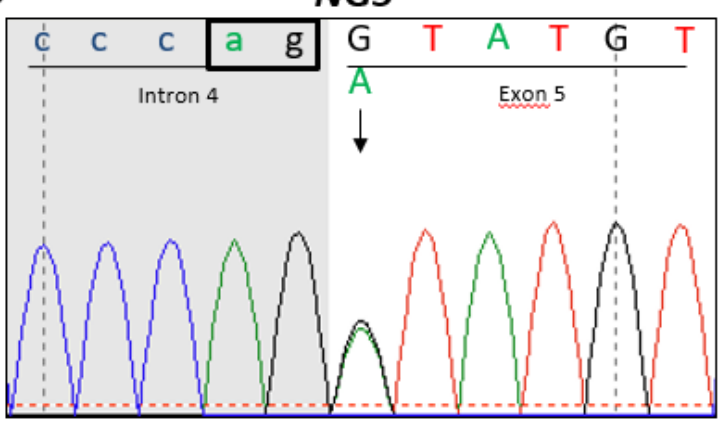

RAD51D, c.346G>A (p.(Val116lle))
C

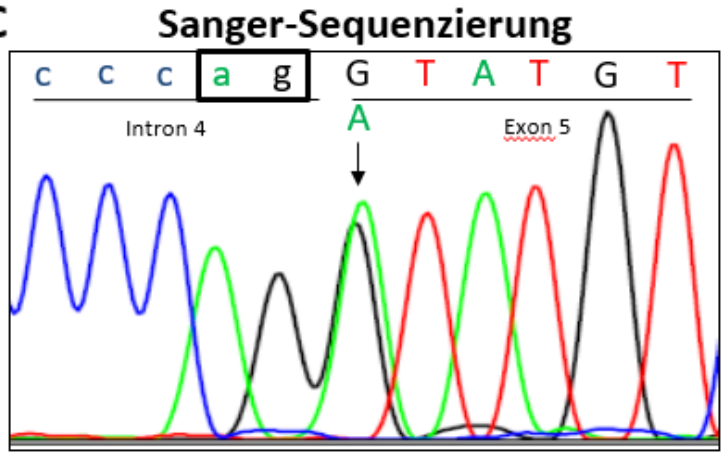

RAD51D, c.346G>A (p.(Val116Ile))

Abbildung 3.15: Nachweis der heterozygoten Sequenzvariante c.346G>A im RAD51D-Gen bei der Indexpatientin 39784. A) Schematische Darstellung der Lokalisation der RAD51D-Gen-spezifischen Primer zur Amplifikation der genomischen DNA der Indexpatientin. Ein Ausschnitt des RAD51D-Gens ist aufgeführt. Drei unterschiedliche Exons und zwei Introns des RAD51D-Gens und deren Nummerierungen sind angegeben. Die Lokalisation des forward (RAD51D_Ex5F) Primers in Intron 4 und des reverse (RAD51D_Ex5R) Primers in Intron 5 sind jeweils mit einem Pfeil markiert. Die rote vertikale Linie zeigt die Lokalisation der Sequenzvariante c.346G>A im RAD51D-Gen. Unter B) und C) ist jeweils ein Ausschnitt aus dem Auswerteprogramm SequencePilot, Modul SeqNext (B) und aus dem Programm Chromas Lite 2.1.1 (C) dargestellt. B) Darstellung der kombinierten Sequenz (forward- und reverse-Richtung) der Sequnezvariante c.346G >A im RAD51D-Gen in heterozygoter Form als Elektropherogramm. C) Elektropherogramm der Sequenzvariante c.346G>A im RAD51D-Gen nach Sanger Sequenzierung. Diese Sequenzvariante wurde sowohl in der forward als auch in der reverse Sequenz heterozygot detektiert. Die Pfeile in B) und C) weisen auf die Nukleotidposition c.346 im RAD51D-Gen hin. Die hochkonservierten Dinukleotide ag der 3'Akzeptor-Spleißstelle im Intron 4 des RAD51D-Gens sind in B) und C) umrahmt. Intronsequenzen sind in Kleinbuchstaben angegeben, Exonsequenzen in Großbuchstaben.

Die Sequenzvariante c.346G>A im Exon 5 des RAD51D-Gens liegt unmittelbar stromabwärts des hochkonservierten Dinukleotids ag der 3'-Akzeptor-Spleißstelle im Intron 4 und wurde in der Datenbank des Deutschen Konsortiums Familiärer Brust- und Eierstockkrebs als Variante unklarer Signifikanz (VUS; ACMG-Klasse 3) gelistet. Die Sequenzvariante ist in der erweiterten Konsensussequenz der 3'-Akzeptor-Spleißstelle lokalisiert (Cartegni et al. 2002). Die klinische Bedeutung dieser Sequenzvariante wurde bisher weder in anderen Datenbanken (HGMD, LOVD und ClinVar) noch in der Literatur beschrieben. Diese VUS wurde zweifach als heterozygote Variante im ExAC-Browser (Exome Aggregation Consortium) gelistet. Die computergestützten Vorhersageprogramme MutationTaster und PolyPhen-2 bewerteten die o. g. Sequenzvariante im RAD51D-Gen als krankheitsverursachend, dagegen stufte das Vorhersageprogramm SIFT diese Sequenzvariante als nicht krankheitsverursachend ein. Die Analyse mit dem Vorhersageprogramm Human Splicing Finder ergab, dass durch den Basenaustausch eine potentielle neue Spleißstelle im RAD51D-Gen generiert wird.

Um eine Beeinträchtigung des Spleißvorgangs durch die o. g. Sequenzvariante im RAD51D-Gen zu ermitteln, wurden funktionelle Analysen an der Lymphozyten-RNA der Indexpatientin 39784 
durchgeführt. Mit Hilfe dieser Untersuchungen sollte gezeigt werden, ob die Sequenzvariante c.346G>A im RAD51D-Gen möglicherweise zu aberranten RAD51D-Transkripten führt.

Dazu wurde aus den Lymphozyten der Indexpatientin 39784 sowie aus einer Wildtypkontrolle zunächst die Gesamt-RNA isoliert und nachfolgend mittels Oligo-dT-Primern und reverser Transkriptase in die entsprechende cDNAs umgeschrieben. Anschließend wurde die cDNA der Indexpatientin mit Hilfe von RAD51D-Gen-spezifischen Primern (forward Primer lokalisiert in Exon 4; reverse Primer lokalisiert in Exon 7) und konventioneller PCR amplifiziert (s. Abb. 3.16). Als Kontrolle wurde die Wildtyp-cDNA unter identischen Bedingungen amplifiziert.

\section{RAD51D-Gen}

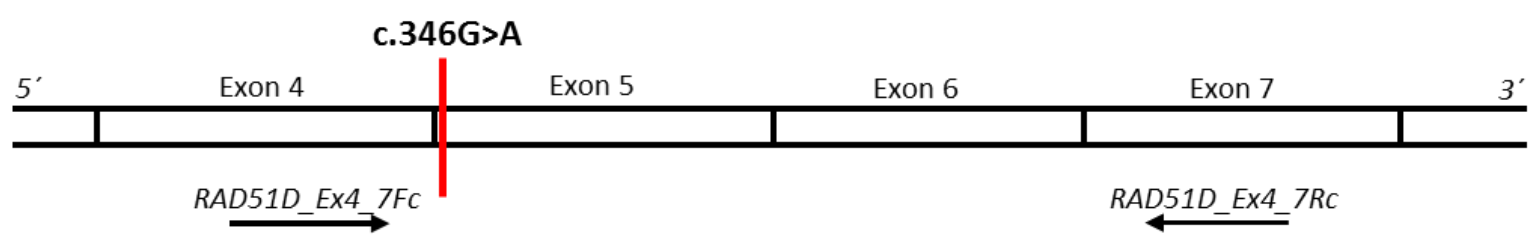

Abbildung 3.16: Schematische Darstellung der Lokalisation der RAD51D-Gen-spezifischen Primer zur Amplifikation der Patienten-cDNA. Ein schematischer Ausschnitt der RAD51D-cDNA ist aufgeführt. Vier unterschiedliche Exons der RAD51D-cDNA und deren Nummerierungen sind angegeben. Die Lokalisation des forward (RAD51D_Ex4_7FC) Primers in Exon 4 und des reverse (RAD51D_Ex4_7RC) Primers in Exon 7 sind jeweils mit einem Pfeil markiert. Die rote vertikale Linie zeigt die Lokalisation der Sequenzvariante c.346G >A auf cDNA-Ebene an.

Nach der Amplifikation der RAD51D-cDNA der Indexpatientin 39784 und der RAD51D-cDNA des Wildtyps wurden die jeweiligen PCR-Produkte mittels Agarosegelelektrophorese aufgetrennt. In der gelelektrophoretischen Auftrennung zeigte sich ein 295 bp großes PCR-Produkt für RAD51D sowohl an der cDNA der Indexpatientin als auch an der mitgeführten cDNA der Wildtyp-Kontrolle. Diese generierten PCR-Produkte entsprachen exakt den berechneten Größen der PCR-Produkte, d. h. aberrante RAD51D-Transkripte konnten mit Hilfe dieses Versuchsansatzes in der CDNA der Indexpatientin nicht beobachtet werden. Die Bande vom 39784 zeigte dagegen eine schwächere Intensität als die vom Wildtyp (WT), was auf ein mögliches nonsense-mediated mRNA decay hindeuten könnte (s. Abb. 3.17A). Um die Intaktheit der eingesetzten RNA-Proben der Indexpatientin 39784 sowie der Wildtyp-Kontrolle zu überprüfen, wurde ebenfalls eine PCR mit spezifischen Primern für das Housekeeping-Gen LDAH durchgeführt (s. Abb. 3.17B).

Da in der oben aufgeführten PCR-Analyse keine aberranten RAD51D-Transkripte nachgewiesen werden konnten und um zu zeigen, ob die genomische Sequenzvariante c.346G>A im RAD51DGen auch auf cDNA-Ebene identifiziert werden kann, wurde eine direkte Sanger-Sequenzanalyse des RAD51D-PCR-Produkts (295 bp) durchgeführt. Die Sequenzanalyse des RAD51D-PCR-Produkts der Indexpatientin 39784 ergab nahezu eine Wildtypsequenz, d. h. die genomische Sequenzvariante c.346G>A im RAD51D-Gen war auf cDNA-Ebene nicht mehr eindeutig zu detektieren (s. Abb. 3.17C). 

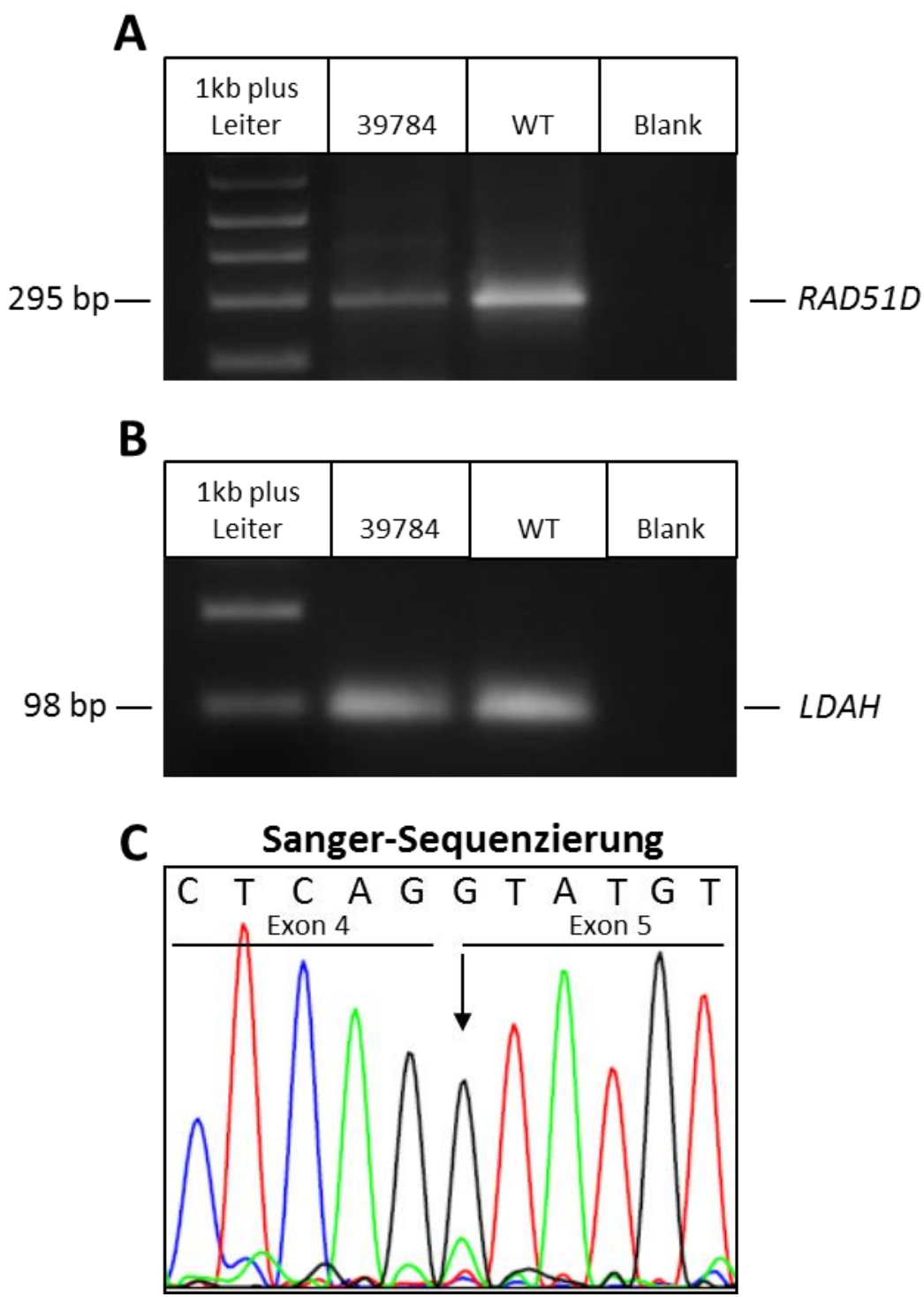

Abbildung 3.17: Gelelektrophoretische Auftrennung der PCR-Produkte nach Amplifikation der RAD51DCDNA und Ergebnisse der Sequenzanalyse des RAD51D-PCR-Produkts der Indexpatientin 39784. A) Exemplarisches Foto einer Agarosegelelektrophorese nach Auftrennung der amplifizierten PCR-Produkte der RAD51D-cDNA der Indexpatientin 39784 und der Wildtypkontrolle (WT). Die mit den o. g. Primern in Exon 4 und Exon 7 der RAD51D-CDNA durchgeführte PCR ergab in beiden Fällen PCR-Produkte mit einer Größe von 295 bp, die exakt den berechneten Größen entsprachen. Als Negativkontrolle wurde eine PCR ohne zugegebene cDNA durchgeführt (Blank). B) Um die Intakheit der eingesetzten RNA-Proben zu überprüfen, wurde eine PCR an der CDNA der Indexpatientin 39784 sowie an der CDNA der Wildtypkontrolle mit spezifischen Primern für das Housekeeping-Gen LDAH (lipid droplet associated hydrolase) vorgenommen. Auch hier ergaben sich PCR-Produkte mit den erwarteten Größen von jeweils 98bp. Als Negativkontrolle wurde wiederum eine PCR ohne zugegebene cDNA durchgeführt (Blank). Durch die parallel als Längenstandard mitgeführte $1 \mathrm{~kb}$-plus-Leiter der Firma Invitrogen war eine vergleichende Größenbestimmung der PCR-Produkte möglich. Zum Nachweis der PCR-Produkte wurde das Agarosegel nach der Elektrophorese auf einen UV-Transilluminator (230-360 nm) überführt und mit einem VideoDokumentationssystem fotografiert. C) Ergebnisse der Sequenzanalyse des RAD51D-PCR-Produkts der Indexpatientin 39784. Ausschnitt der Exon 4-/Exon 5-Sequenz der RAD51D-cDNA aus dem Programm Chromas Lite 2.1.1 als Elektropherogramm. Mittels Sanger-Sequenzierung wurde das RAD51D-PCR-Produkt (Größe von 295 bp) aus der cDNA der Indexpatientin 39784 analysiert. Die Sequenzauswertung mit Hilfe des Computerprogramms Chromas Lite 2.1.1 ergab eine nahezu reine Wildtypsequenz auf cDNA-Ebene bei der Indexpatientin 39784. Die bei der Indexpatientin auf genomischer Ebene detektierte Sequenzvariante 
c.346G>A im RAD51D-Gen konnte somit auf cDNA-Ebene nicht mehr klar nachgewiesen werden. Der Pfeil weist auf die Nukleotidposition c.346 in der RAD51D-cDNA hin.

Aus den vorhergehenden Experimenten ergab sich der deutliche Hinweis auf ein mögliches nonsense-mediated mRNA decay bei der Indexpatientin 39784, $\mathrm{d}$. h. das mutierte bzw. aberrant gespleißte RAD51D-Transkript der Indexpatientin wurde einem enzymatischen Abbau unterworfen. Um diese Hypothese näher zu überprüfen, wurde eine quantitative Real-Time PCRAnalyse an der cDNA der Indexpatientin 39784 sowie an der cDNA der Wildtyp-Kontrolle mit den RAD51D-spezifischen Primern durchgeführt (forward Primer lokalisiert in Exon 4, reverse Primer lokalisiert in Exon 6). Anhand dieser Untersuchungen konnte gezeigt werden, dass die RAD51DTranskriptmenge der Indexpatientin im Vergleich zur Wildtypkontrolle um ca. 50,0 \% verringert vorliegt (s. Abb. 3.18). Dies erklärt auch die schwächere Intensität der Bande vom $39784 \mathrm{im}$ Vergleich zum Wildtyp in der Abbildung 3.17A.

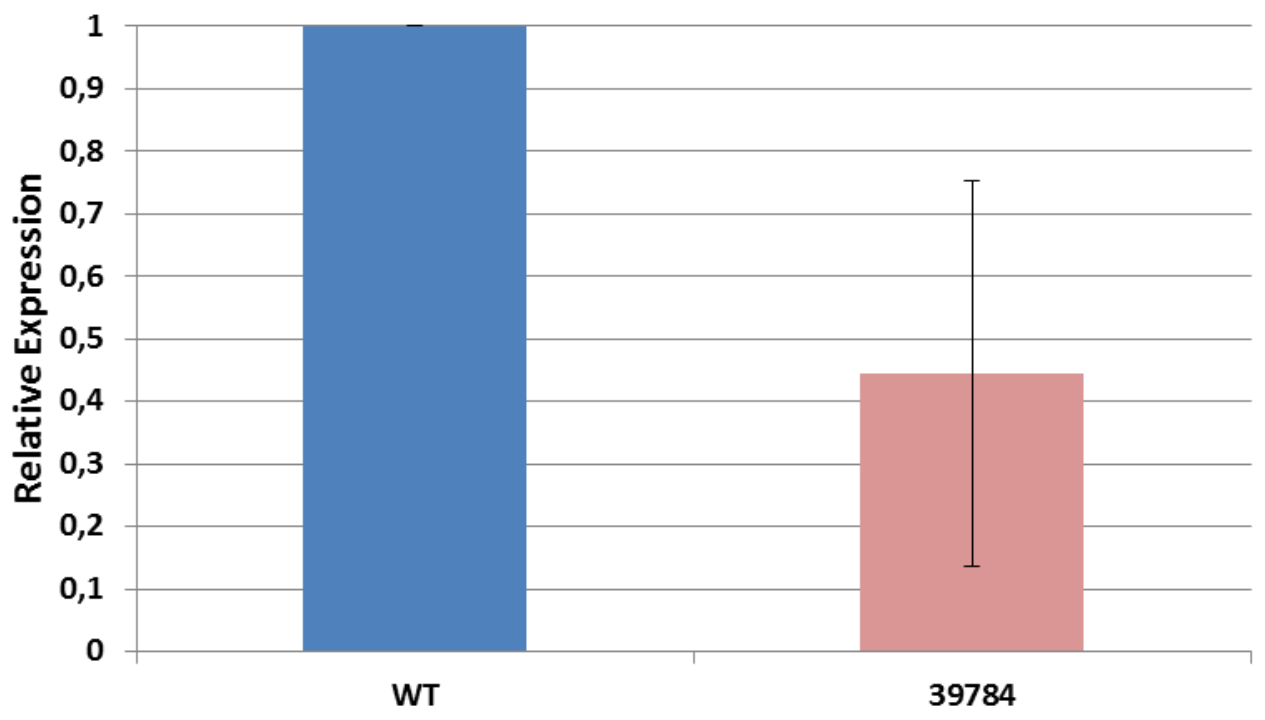

Abbildung 3.18: Ergebnisse der quantitativen Real-Time PCR (qRT PCR)-Analyse der RAD51D-Transkripte der Indexpatientin 39784 und einer Wildtyp-Kontrolle. Die quantitative Real-Time PCR (qRT PCR) Analyse wurde an der cDNA der Indexpatientin 39784 sowie an der CDNA einer Wildtyp-Kontrolle (WT) mit den RAD51D-spezifischen Primern als Triplikat durchgeführt. Dabei konnte eine um ca. $50 \%$ reduzierte RAD51DTranskriptmenge bei der Indexpatientin $39784 \mathrm{im}$ Vergleich zur Wildtyp-Kontrolle aufgezeigt werden.

Mit Hilfe der funktionellen Abklärung der heterozygoten Sequenzvariante c.346G>A im RAD51DGen konnte somit das Ergebnis der computergestüzten Vorhersageprogramme MutationTaster und Human Splicing Finder bestätigt werden. Zusammengefasst deuten die durchgeführten funktionellen Analysen auf ein nonsense-mediated mRNA decay der mutierten bzw. aberrant gespleißten RAD51D-Transkripte hin. Anhand dieser Ergebnise konnte die Sequenzvariante c.346G>A im RAD51D-Gen als Variante unklarer Signifikanz (ACMG-Klasse 3) mit der klinischen Einschätzung einer wahrscheinlich pathogenen Mutation reklassifiziert werden. 


\subsubsection{Patientin 39037}

\subsubsection{Klinische Daten und Familienanamnese zur Indexpatientin 39037}

Die Indexpatientin 39037 (s. Abb. 3.19, III.12) war im Alter von 50 Jahren an einem rechtsseitigen Mammakarzinom erkrankt. Es handelte sich um ein invasiv duktales Mammakarzinom im Stadium pT(2)1a, pNX, M0 mit starker Expression des ER $\alpha$ und des PR, jedoch keiner Überexpression des ERBB2-Rezeptors im Tumorgewebe. Eine Schwester (s. Abb. 3.19, III.11) der Indexpatientin 39039 erkrankte mit 54 Jahren an einem multizentrischen invasiv duktalen Mammakarzinom im Stadium pT1c, pN1, MO mit einer nachgewiesenen Expression des ER $\alpha$ und des PR und ohne Überexpression des ERBB2-Rezeptors im Tumorgewebe. Eine weitere Schwester (s. Abb. 3.19, III.10) der Indexpatientin war mit etwa 63 Jahren an einem rechtsseitigen invasiv lobulären Mammakarzinom erkrankt mit nachgewiesener Expression des ER $\alpha$ und des PR im Tumorgewebe und ohne Überexpression des ERBB2-Rezeptors. Ebenso erkrankte eine Tochter des Onkels mütterlicherseits (s. Abb. 3.19, III.4) mit ca. 50 Jahren an einem einseitigen Mammakarzinom. Weiterhin war bei einer Tante mütterlicherseits (s. Abb. 3.19, II.1) mit ca. 79 Jahren ein Mantelzell-Lymphom diagnostiziert worden und die Großmutter mütterlicherseits (s. Abb. 3.19, I.1) war mit 86 Jahren an einem Hautkrebs erkrankt. Beim Vater (s. Abb. 3.19, II.4) der Indexpatientin 39039 wurde ein Plasmozytom diagnostiziert. Er war mit 80 Jahren verstorben.

Bei der Indexpatientin 39037 waren die Kriterien für eine molekulargenetische Untersuchung bei V. a. ein hereditäres Mamma- und Ovarialkarzinom gegeben. Es war hierbei das Kriterium A erfüllt, d. h. mindestens drei Frauen aus der gleichen Linie einer Familie waren unabhängig vom Alter bei der Erstdiagnose an einem Mammakarzinom erkrankt. 


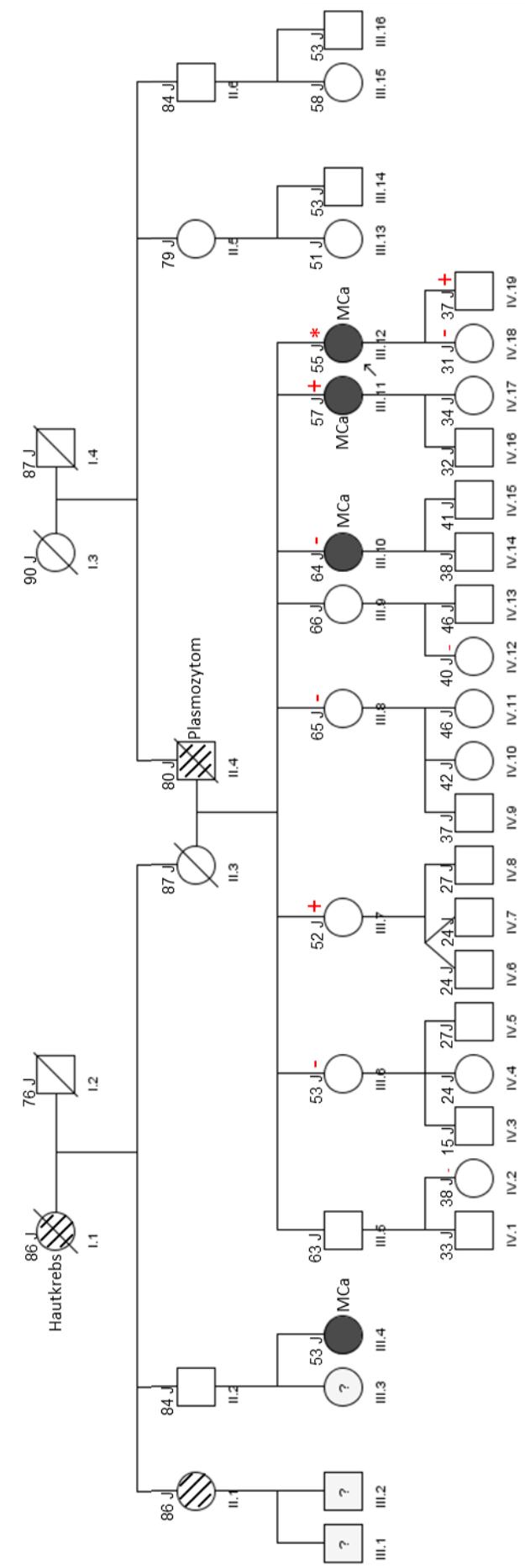

Abbildung 3.19: Stammbaum der Indexpatientin 39037 (III.12) über vier Generationen. Weibliche Personen sind mit einem Kreissymbol, männliche Personen mit einem Quadratsymbol dargestellt. Personensymbole mit einem Mammakarzinom (MCa) sind schwarz gekennzeichnet. Personensymbole mit anderen Tumorerkrankungen, außer einem Mammakarzinom, sind schraffiert dargestellt. Die Altersangaben im Stammbaum beziehen sich auf das aktuelle Alter der Personen wie bei der genetischen Beratung von der Indexpatientin angegeben. Der Pfeil weist auf die Indexpatientin 39037 hin (III.12). Die Indexpatientin 39037 ist Trägerin der heterozygoten Mutation c.6336C>A im ATM-Gen $(*)$. Ein Mammakarzinom wurde ebenfalls bei zwei Schwestern der Ratsuchenden (III.10 und III.11) sowie bei der Tochter des Onkels mütterlicherseits (III.4) diagnostiziert (alle schwarz gekennzeichnet). Eine Tante mütterlicherseits (II.1) war mit ca. 79 Jahren an einem Mantelzell-Lymphom erkrankt. Bei der Großmutter mütterlicherseits (I.1) wurde mit 86 Jahren ein Hautkrebs diagnostiziert. Der Vater (II.4) der Indexpatientin 
39039 war an einem Plasmozytom erkrankt und im Alter von 80 Jahren verstorben. $+=$ Nachweis der Mutation c.6336C >A im ATM-Gen; - = Kein Nachweis der Mutation c.6336C>A im ATM-Gen.

\subsubsection{Ergebnisse der molekulargenetischen Analyse der 10 Core-Gene der Indexpatientin 39037}

Bei der Indexpatientin 39037 wurde eine NGS-Multi-Gen-Untersuchung (TruRisk ${ }^{\mathrm{TM}}$ ) mit der Auswertung der 10 Core-Gene sowie eine MLPA-Untersuchung der Gene BRCA1, BRCA2, CHEK2, $P A L B 2, R A D 51 C$ und RAD51D an der genomischen DNA aus Lymphozyten durchgeführt. Bei der Indexpatientin 39037 wurde die Mutation c.6336C >A (p.(Cys2112*)) im Exon 43 des ATM-Gens detektiert (s. Abb. 3.20A). Die Mutation 6336C $>$ A wurde in ca. $44 \%$ der Sequenz-Reads identifiziert, was nahezu einem heterozygoten Zustand entspricht. Die o. g. Mutation im ATM-Gen wurde nach unabhängiger PCR und Sanger-Sequenzierung an derselben DNA identifiziert sowie an der DNA aus einer zweiten unabhängigen Blutprobe der Indexpatientin 39037 bestätigt (s. Abb. 3.20B). Es wurden weder weitere Sequenzvarianten der ACMG-Klasse 3, 4 oder 5 in den anderen Core-Genen nachgewiesen noch Deletionen/Duplikationen nach der MLPA-Analyse der o.g. Gene identifiziert.

A

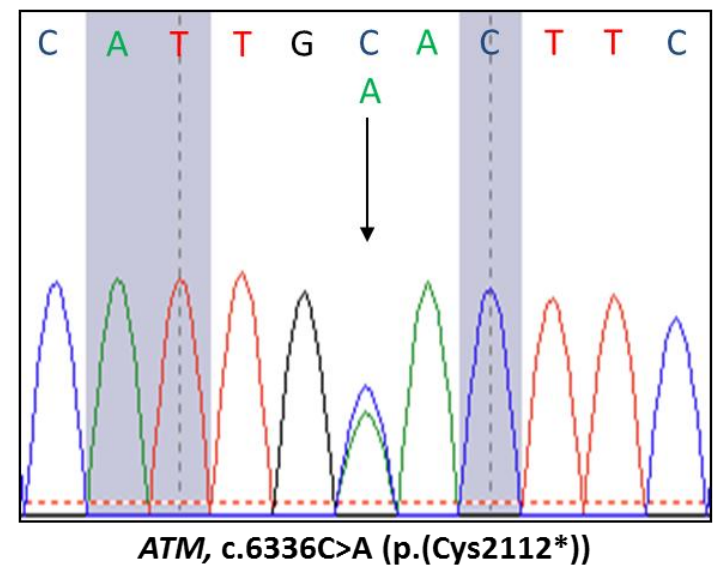

B

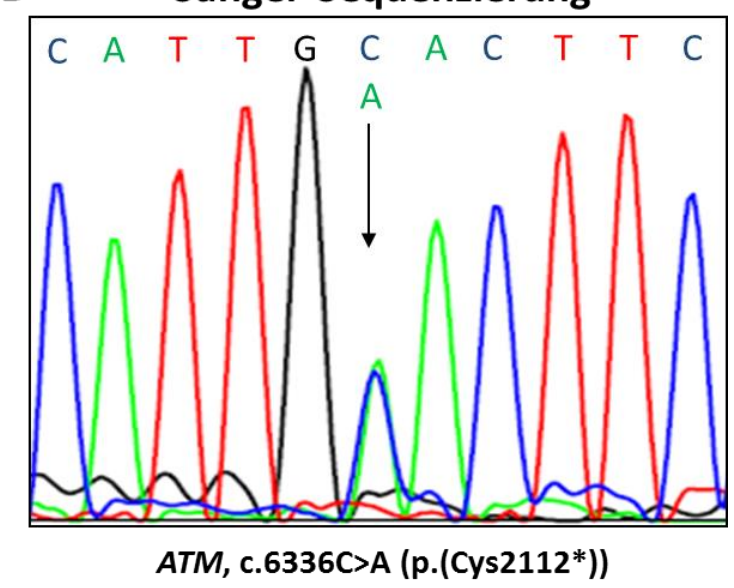

Abbildung 3.20: Nachweis der heterozygoten Mutation c.6336C >A im ATM-Gen an genomischer DNA der Indexpatientin 39037. Ausschnitte von Exon 43 der ATM-Gensequenz als Elektropherogramme aus den Auswerteprogrammen SequencePilot, Modul SeqNext (A) und aus dem Programm Chromas Lite 2.1.1 (B). A) Darstellung der kombinierten Sequenz (forward- und reverse-Richtung) der Mutation c.6336C >A im ATMGen (s. Pfeil) in heterozygoter Form. Diese Mutation wurde nach dem NGS-Verfahren bei der Indexpatientin 39784 detektiert. B) Nachsequenzierung der Mutation c.6336C >A im ATM-Gen (s. Pfeil) mittels SangerTechnologie. Die o. g. Mutation konnte somit durch eine zweite unabhängige Methode bei der Indexpatientin 39037 heterozygot bestätigt werden.

Die heterozygote Mutation c.6336C>A im ATM-Gen führt auf Proteinebene zum Austausch der Aminosäure Cystein an Position 2112 zu einem Stopp-Codon (p.(Cys2112*)) und damit zu einem vorzeitigen Abbruch der Proteinsynthese. Die Mutation c.6336C>A wurde bisher weder in der HGMD-Datenbank oder in der Datenbank des Deutschen Konsortiums Familiärer Brust- und Eierstockkrebs noch in der LOVD-Datenbank gelistet. Sie wurde ebenfalls nicht in der Literatur beschrieben. Die o. g. Mutation war nicht im ExAC-Browser gelistet.

Die o. g. Mutation im ATM-Gen segregiert in der Familie der Indexpatientin 39037 nicht mit dem Auftreten von allen Mammakarzinomen. Die Indexpatientin 39037 III.12 selbst sowie die Schwestern der Indexpatientin (Patientin III.10 und Patientin III.11), waren alle an einem Mammakarzinom erkrankt. Die Mutation c.6336C >A im ATM-Gen wurde bei der Indexpatientin 39037 und bei der mit 54 Jahren (III.11) an einem Mammakarzinom erkrankten Schwester 
identifiziert. Bei der Schwester III.10, die mit 63 Jahren an einem Mammakarzinom erkrankt war, wurde diese Mutation jedoch nicht nachgewiesen (s. Abb. 3.19). Diese Mutation wurde als wahrscheinlich pathogene Mutation der ACMG-Klasse 4 eingestuft.

Bei den nicht an einem Mammakarzinom erkrankten Familienmitgliedern wurde die Mutation c.6336C >A im ATM-Gen bei dem Sohn (IV.19) der Indexpatientin 39037 und bei einer Schwester (III.7) der Indexpatientin 39039 identifiziert. Die o. g. Mutation im ATM-Gen wurde jedoch nicht bei zwei Schwestern (III.6 und III.8) der Indexpatientin 39039 detektiert. Weiterhin wurde die Mutation c.6336C>A im ATM-Gen weder bei der Tochter (IV.18) der Indexpatientin 39037 noch bei zwei Nichten (IV.2 und IV.12) identifiziert (s. Abb. 3.19).

\subsubsection{Patientin 39769}

\subsubsection{Klinische Daten und Familienanamnese zur Patientin 39769}

Die untersuchte Patientin 39769 (s. Abb. 3.21; III.5) war zum Zeitpunkt der genetischen Beratung 36 Jahre alt und bezüglich Tumorerkrankungen unauffällig. Die Mutter der Patientin 39769 (s. Abb. 3.21; II.4) war hingegen mit 44 Jahren an einem Mammakarzinom (ER $\alpha$ und PR im Tumor nicht exprimiert, Informationen zur Überexpression des ERBB2-Rezeptors waren nicht vorhanden) und mit 60 Jahren an einem kolorektalen Karzinom erkrankt. Der Tumortyp des Mammakarzinoms war aus den Krankenunterlagen nicht zu entnehmen. Die Zwillingsschwester der Mutter (s. Abb. 3.21; II.5) war mit 62 Jahren an einem einseitigen Mammakarzinom erkrankt. Eine weitere Tante mütterlicherseits (s. Abb. 3.21; II.8) war mit ca. 42 Jahren an einem Melanom und mit 55 Jahren an einem kolorektalen Karzinom sowie an einem Mammakarzinom erkrankt. Die Großmutter mütterlicherseits (s. Abb. 3.21; I.3) war mit ca. 76 Jahren an einem Mammakarzinom erkrankt. Sie war mit 79 Jahren an den Folgen der Tumorerkrankung verstorben.

Die Patientin 39769 hatte initial keinen Kontakt zu den erkrankten Familienmitgliedern. Für die Patientin 39769 wurde daher das Heterozygoten-Risiko für eine Anlageträgerschaft einer autosomal-dominant vererbten Mutation in einem der Core-Gene mit dem Risikokalkulationsprogramm Cyrillic 2.13 berechnet. Dieses Risiko lag anhand der Familienanamnese für die Patientin 39769 bei $34,8 \%$.

Bei der Patientin 39769 war das Kriterium Y erfüllt, d. h. in diesem Fall war keine erkrankte Indexpatientin verfügbar. Jedoch lag das berechnete Heterozygoten-Risiko für die Anlageträgerschaft einer autosomal-dominant vererbten Mutation bei $\geq 20 \%$. Anhand des hohen berechneten Heterozygoten-Risikos konnte der Patientin 39769 eine molekulargenetische Untersuchung der 10 Core-Gene angeboten werden. 


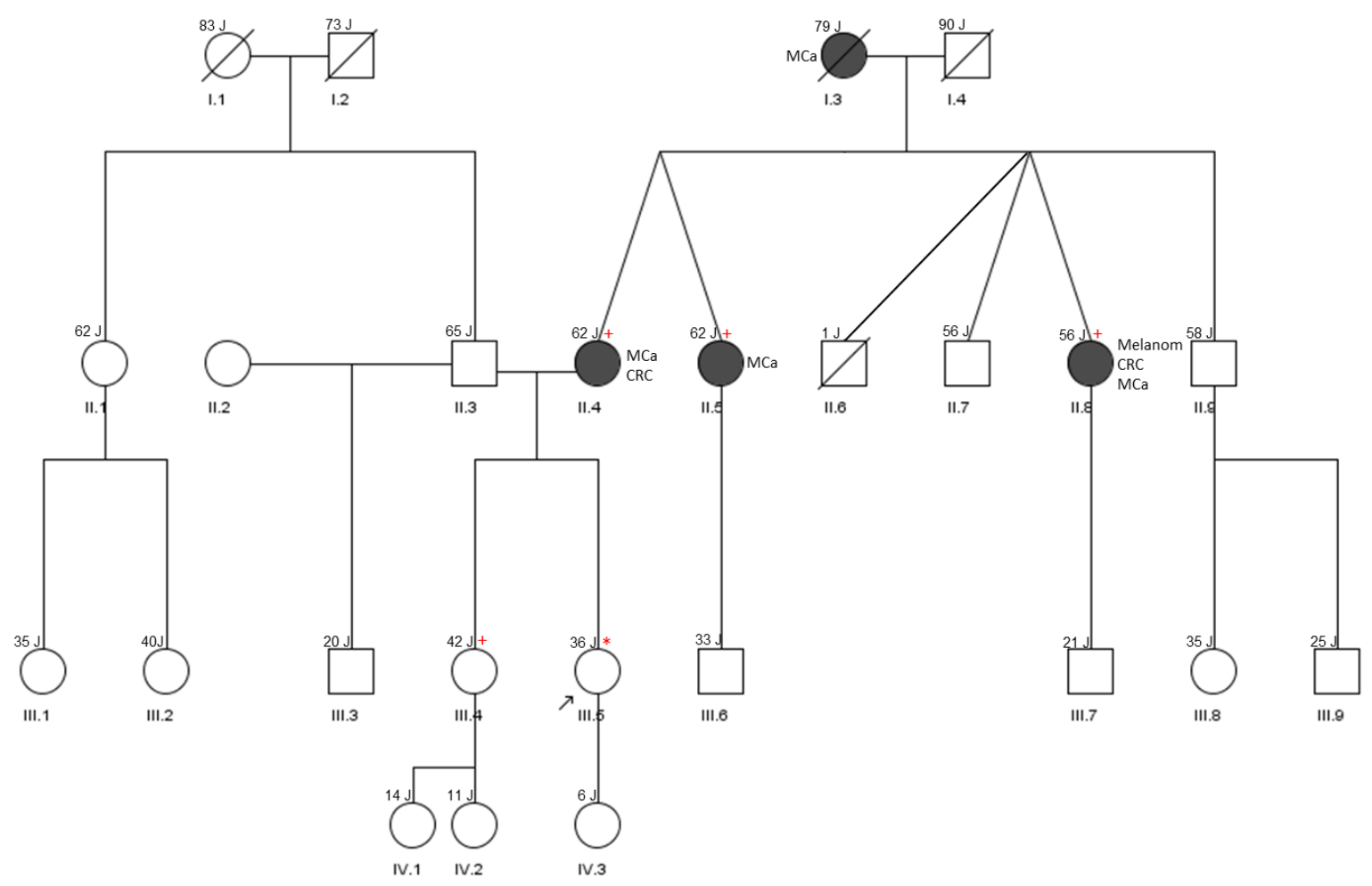

Abbildung 3.21: Stammbaum der Patientin 39769 (III.5) über vier Generationen. Weibliche Personen sind mit einem Kreissymbol, männliche mit einem Quadratsymbol dargestellt. Personensymbole mit einem Mammakarzinom (MCa) sind schwarz gekennzeichnet. Die Altersangaben im Stammbaum beziehen sich auf das aktuelle Alter der Personen wie bei der genetischen Beratung von der Patientin angegeben. Der Pfeil weist auf die Patientin 39769 hin (III.5). Die Patientin 39769 ist Trägerin der heterozygoten Mutation c.7061G>A im RAD51C-Gen (*). Ein Mammakarzinom wurde ebenfalls bei der Mutter der Patientin 39769 (II.4) mit 44 Jahren, bei zwei Tanten mütterlicherseits (II.5 und II.8) mit 62 und 55 Jahren sowie bei der Großmutter mütterlicherseits (I.3) mit ca. 76 Jahren diagnostiziert (alle schwarz gekennzeichnet). Die Mutter der Patientin II.4 war mit ca. 60 Jahren zusätzlich zum Mammakarzinom noch an einem kolorektalen Karzinom (CRC) erkrankt. Die Tante mütterlicherseits (II.8) der Patientin war zusätzlich zum Mammakarzinom an einem Melanom mit 42 Jahren und an einem ein kolorektalen Karzinom (CRC) mit 55 Jahren erkrankt. + = Nachweis der Mutation c.706-1G>A im RAD51C-Gen.

\subsubsection{Ergebnisse der molekulargenetischen Analyse der 10 Core-Gene der Patientin 39769}

Bei der Patientin 39769 wurde eine molekulargenetische Untersuchung der 10 Core-Gene mittels einer Multi-Gen-Untersuchung (TruRisk ${ }^{\mathrm{TM}}$ ) sowie die MLPA-Analyse der Gene BRCA1, BRCA2, CHEK2, PALB2, RAD51C und RAD51D an der genomischen DNA aus Lymphozyten durchgeführt. Im Intron 4 des RAD51C-Gens wurde die heterozygote Mutation c.706-1G>A mittels NGS identifiziert (s. Abb. 3.22A). Die Mutation c.706-1G>A wurde in ca. $45 \%$ der Sequenz-Reads nachgewiesen, welches einem heterozygoten Zustand entspricht. Die o. g. Mutation im RAD51C-Gen wurde mit Hilfe der Sanger-Sequenzierung an derselben Blutprobe (s. Abb. 3.22B) und an einer zweiten unabhängigen Blutprobe der Patientin 39769 bestätigt. Es wurden keine weiteren Sequenzvarianten der ACMG-Klasse 3, 4 oder 5 in den anderen Core-Genen nachgewiesen oder Deletionen/Duplikationen nach der MLPA-Analyse der o. g. Gene identifiziert.

Die Mutation c.706-1G>A liegt in der hochkonservierten Basensequenz ag der 3'-Akzeptor Spleißstelle im Intron 4 des RAD51C-Gens und führt durch das Wegfallen der entsprechenden Spleißstelle möglicherweise zur Synthese von aberranten RAD51C-Transkripten. Die Mutation c.706-1G>A im RAD51C-Gen wird in der Datenbank des Deutschen Konsortiums Familiärer Brustund Eierstockkrebs als pathogene Mutation der ACMG-Klasse 5 geführt. Diese Mutation ist weder 
in den HGMD-, ClinVar- oder LOVD-Datenbanken noch im ExAC-Browser gelistet. Das Vorhersageprogramm Human Splicing Finder zeigte eine Alterierung des hochkonservierten Dinukleotids ag der 3'-Akzeptor-Spleißstelle im Intron 4 des RAD51C-Gens und eine Aktivierung einer neuen intronischen Akzeptor-Spleißstelle.

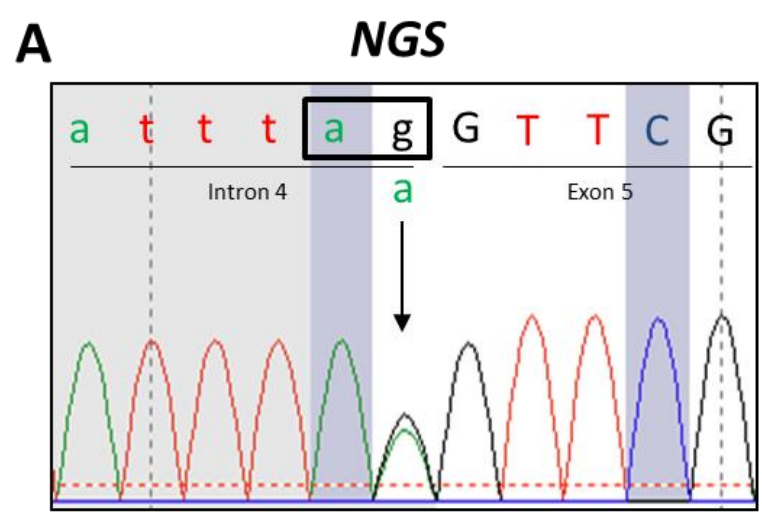

RAD51C, c.706-1G>A
B Sanger-Sequenzierung

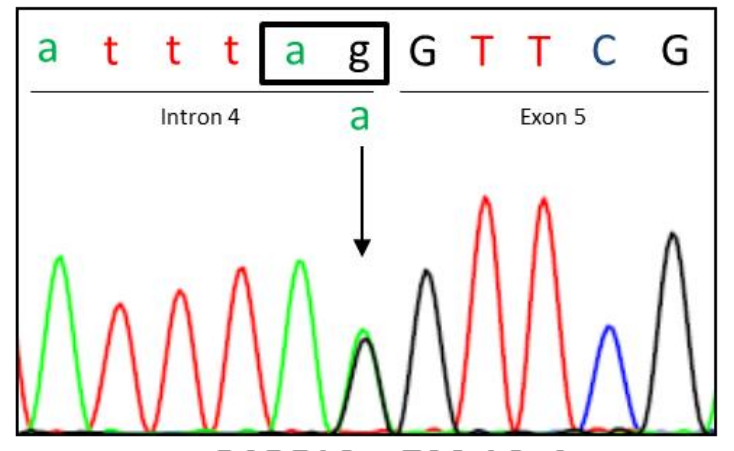

RAD51C, c.706-1G>A

Abbildung 3.22: Nachweis der heterozygoten Mutation c.706-1G>A im RAD51C-Gen an genomischer DNA der Patientin 39769. Dargestellt sind Auschnitte von Elektropherogrammen der Intron 4/Exon 5-Sequenzen des RAD51C-Gens aus dem Auswerteprogramm SequencePilot, Modul SeqNext (A) und aus dem Programm Chromas Lite 2.1.1 (B). A) Darstellung der kombinierten Sequenz (forward- und reverse-Richtung) der Mutation c.706-1G>A im RAD51C-Gen in heterozygoter Form bei Patientin 39769. B) Nachsequenzierung der heteroyzgoten Mutation c.706-1G>A im RAD51C-Gen mittels Sanger-Technologie. Die o. g. Mutation wurde ebenfalls mit einer zweiten unabhängigen Methode bei der Indexpatientin 39769 heterozygot bestätigt. Die Pfeile in A) und B) weisen auf die Mutation c.706-1G>A im RAD51C-Gen hin. Die hochkonservierten Dinukleotide ag der 3'-Akzeptor-Spleißstelle im Intron 4 des RAD51C-Gens sind in A) und B) umrahmt. Intronsequenzen sind in Kleinbuchstaben angegeben, Exonsequenzen in Großbuchstaben.

Die Mutation im RAD51C-Gen wurde danach ebenso bei der noch gesunden Schwester der Patientin 39769 (III.4), der gemeinsamen Mutter (II.4), ihrer Zwillingsschwester (II.5) sowie einer weiteren bereits an einem Mammakarzinom erkrankten Tante (II.8) detektiert (s. Abb. 3.21).

\subsubsection{Patientin 39917}

\subsubsection{Klinische Daten und Familienanamnese zur Indexpatientin 39917}

Die Indexpatientin 39917 (s. Abb. 3.23; III.5) erkrankte mit 39 Jahren an einem duktal teils lobulär invasiven Mammakarzinom der linken Seite (Tumorstadium pT2, pN1, M0, G2). Der ER $\alpha$ war im Tumor mäßig exprimiert, der PR war im Tumor nicht exprimiert, eine Überexpression des ERBB2Rezeptors war im Tumor nicht detektierbar. Der Sohn einer Schwester der Indexpatientin (s. Abb. 3.23; IV.3) erkrankte an einer Leukämie. Die Mutter (s. Abb. 3.23; II.2) der Indexpatientin war im Alter von 65 Jahren an einem rechtsseitigen und mit 67 Jahren an einem linksseitigen Mammakarzinom erkrankt. Die Schwester der Mutter (s. Abb. 3.23; II.4) erkrankte ebenso an einem Mammakarzinom. Das Erkrankungsalter der Tante war nicht bekannt. Der Subtyp des Mammakarzinoms sowie der Rezeptorstatus waren nur bei der Indexpatientin 39917 bekannt.

Die Kriterien für eine molekulargenetische Untersuchung der 10 Core-Gene, definiert vom Deutschen Konsortium Familiärer Brust- und Eierstockkrebs, waren bei der Indexpatientin 39917 erfüllt. In diesem Fall war das Kriterium A erfüllt, d. h. mindestens drei Frauen aus der gleichen Linie einer Familie waren unabhängig vom Alter bei der Erstdiagnose an einem Mammakarzinom erkrankt. 


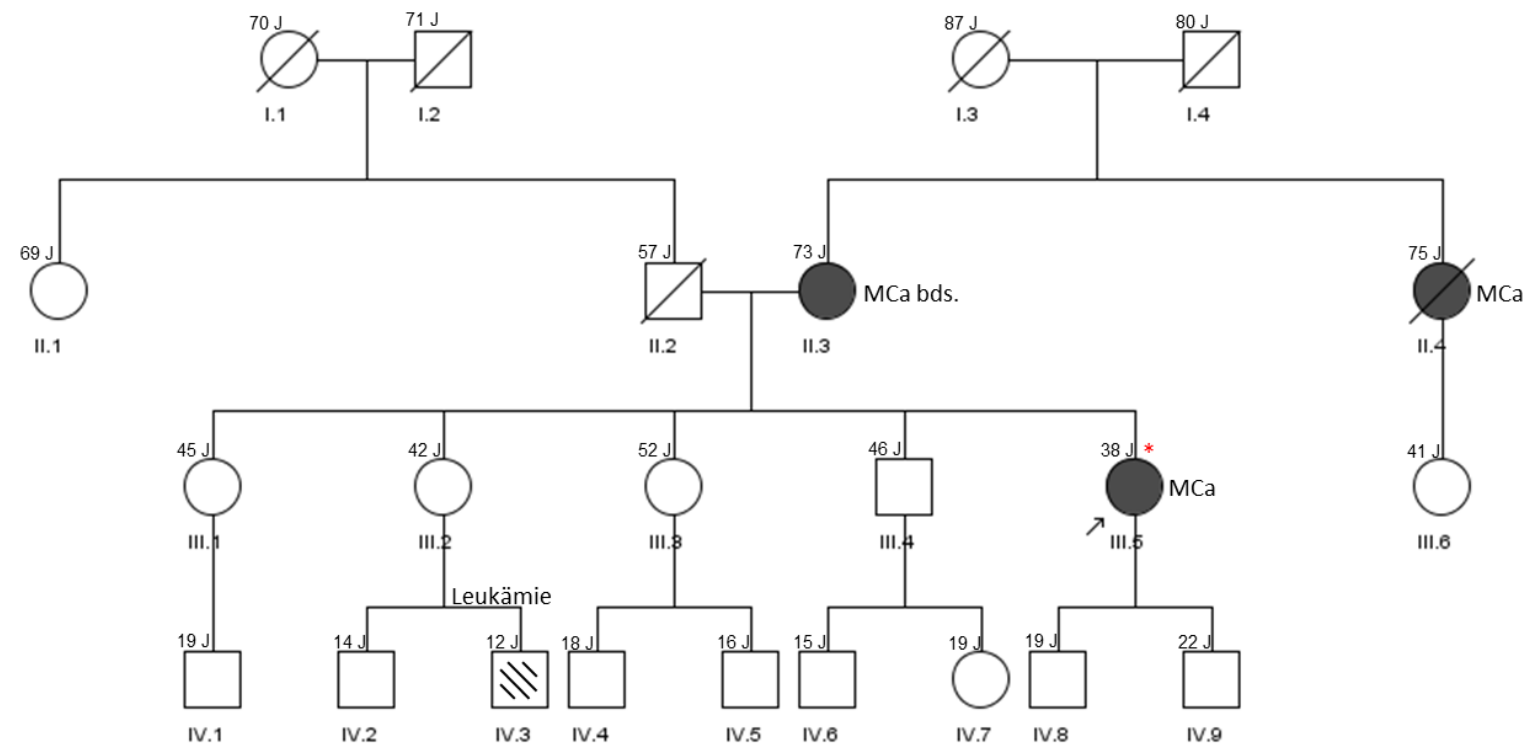

Abbildung 3.23: Stammbaum der Indexpatientin 39917 (III.5) über vier Generationen. Weibliche Personen sind mit einem Kreissymbol, männliche Personen mit einem Quadratsymbol dargestellt. Personensymbole mit einem Mammakarzinom (MCa) sind schwarz gekennzeichnet. Die Altersangaben im Stammbaum beziehen sich auf das aktuelle Alter der Personen wie bei der genetischen Beratung von der Indexpatientin angegeben. Der Pfeil weist auf die Indexpatientin 39917 hin (III.5). Die Indexpatientin 39917 ist Trägerin der heterozygoten Mutation c.1587delT im CDH1-Gen $\left({ }^{*}\right)$. Das gestreifte Quadratsymbol kennzeichnet den Neffen der Indexpatientin mit einer diagnostizierten Leukämie (IV.3). Ein Mammakarzinom wurde bei der Mutter der Indexpatientin (II.3) rechtsseitig mit 65 Jahren und linksseitig mit 67 Jahren (MCa bds.) diagnostiziert. Ebenso wurde bei der Tante mütterlicherseits (II.4) der Indexpatientin 39917 ein Mammakarzinom diagnostiziert. Das Erkrankungsalter der Tante war der Indexpatientin nicht bekannt.

\subsubsection{Ergebnisse der molekulargenetischen Analyse der 10 Core-Gene der Patientin 39917}

Bei der Indexpatientin 39917 wurde eine Sequenzanalyse der 10 Core-Gene mittels einer MultiGen-Untersuchung (TruRisk ${ }^{\mathrm{TM}}$ ) an der genomischen DNA aus Lymphozyten durchgeführt. Zusätzlich erfolgte die MLPA-Analyse der Gene BRCA1, BRCA2, CHEK2, PALB2, RAD51C und RAD51D. Es wurde die heterozygote Mutation c.1587delT (p.(Ala530Profs*27)) im Exon 11 des CDH1-Gens mittels NGS identifiziert (s. Abb. 3.24A). Die Mutation c.1587delT wurde in ca. $48 \%$ der Sequenz-Reads identifiziert, welches einem heterozygoten Zustand entspricht. Die o. g. Mutation wurde per Sanger-Sequenzierung an derselben und an einer zweiten unabhängigen Blutprobe der Indexpatientin 39917 bestätigt (s. Abb. 3.24B). Es wurden keine weiteren Sequenzvarianten der ACMG-Klasse 3, 4 oder 5 in den anderen Core-Genen nachgewiesen oder Deletionen /Duplikationen nach der MLPA-Analyse der o. g. Gene identifiziert.

Die Mutation c.1587delT im Exon 11 des CDH1-Gens führt zu einer Verschiebung des Leserahmens und damit zu einem vorzeitigen Abbruch der Proteinsynthese nach der 556. Aminosäure (p.(Ala530Profs*27)). Diese bekannte Mutation wird in der Datenbank des Deutschen Konsortiums Familiärer Brust- und Eierstockkrebs als pathogene Mutation ohne Angabe der ACMG-Klasse geführt. In den HGMD-, LOVD- oder ClinVar-Datenbanken wird die o. g. Mutation nicht gelistet. Im ExAC-Browser wird die Mutation ebenfalls nicht aufgeführt. Eine Segregationsanalyse dieser Mutation in der Familie wurde der Indexpatientin 39917 zwar angeboten, aber nicht wahrgenommen. Die Mutation c.1587delT im Exon $11 \mathrm{im} \mathrm{CDH1-Gen} \mathrm{wurde}$ daher als wahrscheinlich pathogene Mutation der ACMG-Klasse 4 eingestuft. 
A

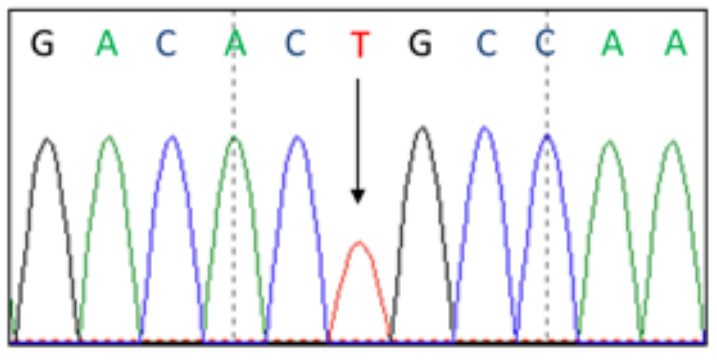

CDH1, c.1587delT (p.(Ala530Profs*27))
B Sanger-Sequenzierung

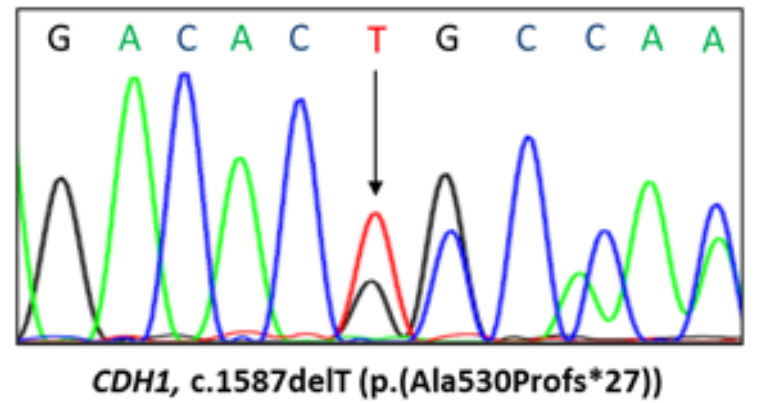

Abbildung 3.24: Nachweis der heterozygoten Mutation c.1587delT im CDH1-Gen an genomischer DNA der Indexpatientin 39917. Dargestellt sind Ausschnitte der Elektropherogramme der Exon 11-Sequenz des CDH1-Gens aus dem Auswerteprogramm SequencePilot, Modul SeqNext (A) und aus dem Programm Chromas Lite 2.1.1 (B). A) Darstellung der kombinierten Sequenz (forward- und reverse-Richtung) der Mutation c.1587delT im CDH1-Gen in heterozygoter Form mit Hilfe des NGS-Verfahrens. B) Nachsequenzierung der Mutation c.1587delT im CDH1-Gen mittels Sanger-Technologie. Die o. g. Mutation konnte ebenfalls mit dieser zweiten unabhängigen Methode bei der Indexpatientin 39917 heterozygot bestätigt werden. Die Pfeile in A) und B) weisen auf die Mutation c.1587delT im CDH1-Gen hin.

\subsubsection{Patient 39202}

\subsubsection{Klinische Daten und Familienanamnese zum Indexpatienten $\mathbf{3 9 2 0 2}$}

Der Indexpatient 39202 ist nicht in der Tabelle 3.3 gelistet, da bei dem Patienten selbst die Kriterien für eine molekulargenetische Untersuchung bezüglich eines hereditären Mamma- und Ovarialkarzinoms, definiert vom Deutschen Konsortium Familiärer Brust- und Eierstockkrebs, nicht erfüllt waren. Jedoch aufgrund der erfüllten Kriterien in der Familie (bei der Tante des Ratsuchenden) und synchron auftretenden Tumoren beim Ratsuchenden selbst wird dieser Fall in der Dissertation im Detail vorgestellt.

Der Indexpatient 39202 ist männlich (s. Abb. 3.25; IV.3) und war im Alter von 50 Jahren an einem synchronen kolorektalen Karzinom und Nierenzellkarzinom erkrankt. Einerseits handelte es sich um ein schlecht differenziertes synchron hepatisch metastasiertes Adenokarzinom des Zökums (pT3b, pN1b (2/20), pM1 (hep), L1, V1, G3, R0), während andererseits ein mäßig differenziertes klarzelliges Nierenzellkarzinom rechts ( $\mathrm{pT} 1 \mathrm{~b}, \mathrm{pNX}, \mathrm{pMX}, \mathrm{L} 0, \mathrm{~V} 0, \mathrm{G} 2, \mathrm{R} 0$ ) diagnostiziert wurde. Ferner war eine Zwillingsschwester (s. Abb. 3.25; III.3) seiner Mutter mit 46 Jahren an einem beidseitigen Mammakarzinom erkrankt und mit 48 Jahren verstorben. Der Urgroßvater mütterlicherseits großmütterlicherseits (s. Abb. 3.25; I.2) war mit ca. 50 Jahren an einem dem Indexpatienten unbekannten Karzinom verstorben. 


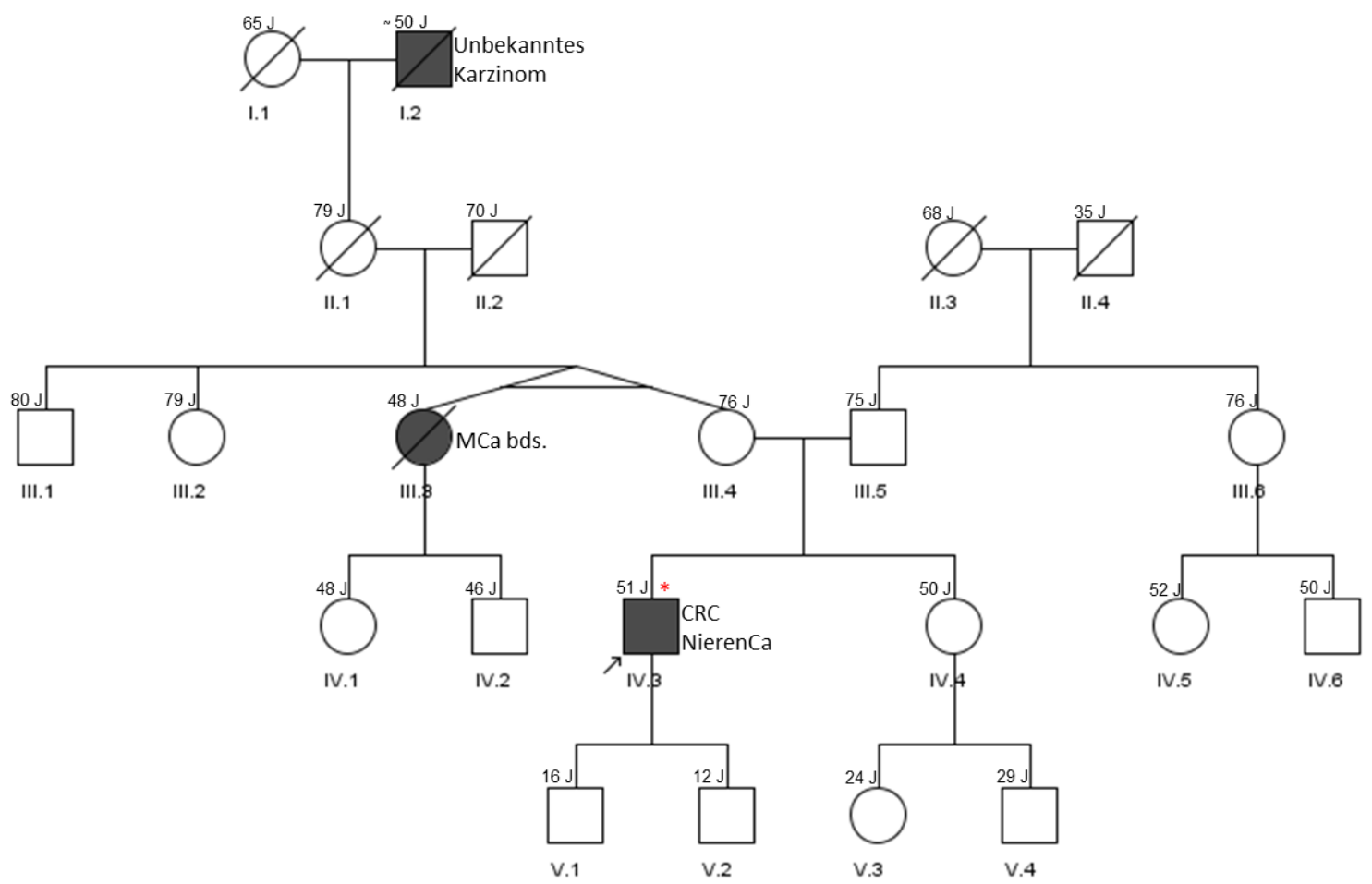

Abbildung 3.25: Stammbaum mit Tumorerkrankungen in der Familie des Indexpatienten 39202. Weibliche Familienmitglieder sind mit einem Kreissymbol, männliche Familienmitglieder sind mit einem Quadratsymbol dargestellt. Die Symbole der Familienmitglieder mit einer Karzinomerkrankung sind schwarz dargestellt. Die Altersangaben im Stammbaum beziehen sich auf das aktuelle Alter der Personen wie bei der genetischen Beratung vom Indexpatienten angegeben. Der Pfeil weist auf den Indexpatienten 39202 (IV.3) hin. Der Indexpatient (IV.3) ist Träger einer 46,1 kB großen heterozygoten Deletion im MSH6-Gen (*). Bei dem Indexpatienten (IV.3) wurden im Alter von 50 Jahren ein metastasiertes synchrones kolorektales Karzinom (CRC)- und ein Nierenzellkarzinom (NierenCa) diagnostiziert. Die eineiige Zwillingsschwester (III.3) der Mutter des Indexpatienten 39202 war mit 48 Jahren an den Folgen eines beidseitigen Mammakarzinoms (MCa bds.) verstorben. Der Urgroßvater mütterlicherseits großmütterlicherseits (I.2) war an einer der Familie unbekannten Tumorerkrankung mit ca. 50 Jahren verstorben.

Wegen der Eigen- und Familienanamnese wurde bei dem Indexpatienten 39202 der Verdacht auf das Vorliegen eines HNPCC (Hereditäres Nicht Polypöses Colon Carcinom; Lynch-Syndrom) geäußert. Es wurden entsprechende immunhistochemische Untersuchungen der DNA-MismatchReparatur-(MMR)-Proteine (MLH1, MSH2, MSH6 und PMS2), eine Mikrosatellitenuntersuchung und eine Analyse der BRAF-Mutation im Tumorgewebe im Institut für Pathologie der UMG durchgeführt. Die an dem Adenokarzinom des Zökums durchgeführte immunhistochemische Untersuchung der Mismatch-Reparatur-Proteine (MLH1, MSH2, MSH6 und PMS2) zeigte einen nuklearen Expressionserhalt sämtlicher untersuchter Proteine. Die an der Lebermetastase vorgenommene immunhistochemische Untersuchung ergab ein inhomogenes und fokal abgeschwächtes Expressionsmuster von MLH1. Die Mutation V600E im BRAF-Gen konnte somatisch nicht nachgewiesen werden. Das kolorektale Karzinom und die Lebermetastase zeigten eine Mikrosatellitenstabilität. Aus den im Institut für Pathologie der UMG durchgeführten Untersuchungen ließ sich kein Hinweis auf ein HNPCC ableiten.

Wegen der inhomogenen Expression des MLH1-Gens im Tumorgewebe der Lebermetastase des Indexpatienten 39202 wurde zusätzlich eine Methylierungsanalyse des distalen und proximalen Promotorbereichs des $\mathrm{MLH1}$-Gens im Tumorgewebe des kolorektalen Karzinoms im Institut für Humangenetik der UMG durchgeführt. Mit Hilfe dieser Analyse kann ebenfalls ein sporadisches Karzinom von einem hereditären Karzinom differenziert werden. Diese Untersuchungen zeigten 
keine Methylierung des proximalen und distalen Promotorbereichs des MLH1-Gens im Tumorgewebe des kolorektalen Karzinoms. Die Ergebnisse der Analyse zur Promotormethylierung des MLH1-Gens wiesen daher eher auf das Vorliegen eines hereditären Karzinoms hin (s. Abb. 3.26).

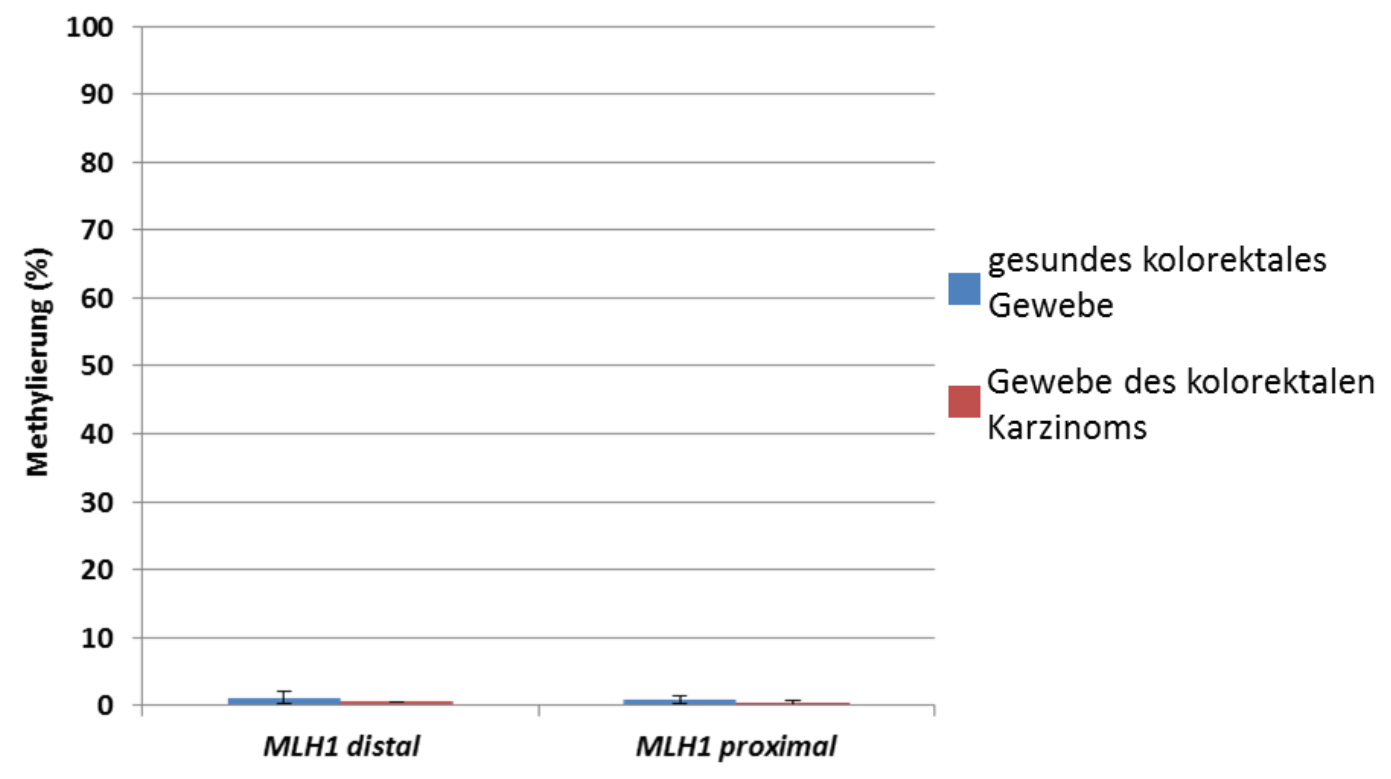

Abbildung 3.26: Methylierungsanalyse des distalen und proximalen MLH1-Promotorbereichs im gesunden kolorektalen Gewebe sowie im Tumorgewebe des kolorektalen Karzinoms. Eine Methylierung des distalen und proximalen Promotorbereichs des MLH1-Gens konnte weder im Tumorgewebe des kolorektalen Karzinoms noch im gesunden kolorektalen Gewebe des Indexpatienten 39202 nachgewiesen werden. Somit konnte ein sporadisches Geschehen aufgrund einer Methylierung des distalen und proximalen Promotorbereichs des MLH1-Gens weitestgehend ausgeschlossen werden.

Da der Ratsuchende selbst an einem synchronen Tumor in jungem Alter und dessen Tante an einem beidseitigen Mammakarzinom erkrankten, wurde an der genomischen DNA aus Lymphozyten des Indexpatienten 39202 eine Multi-Gen-Panel-(NGS)-Analyse im Institut für Humangenetik der UMG durchgeführt.

\subsubsection{Ergebnisse der molekulargenetischen Analyse des Indexpatienten $\mathbf{3 9 2 0 2}$}

In den bereits erwähnten 10 Core-Genen für ein hereditäres Mamma- und Ovarialkarzinom sowie in den zusätzlich analysierten Genen des HNPCC-Spektrums (MLH1, MSH2, MSH6) und im MUTYHGen konnten mit Hilfe der Multi-Gen-Panel-Analyse (TruRisk ${ }^{\text {TM}}$-Panel) keine krankheitsverursachenden Sequenzvarianten beim o. g. Indexpatienten nachgewiesen werden. Allerdings ergab sich nach Auswertung der Kopienzahlvarianten (CNV; copy number variations) der o. g. Gene mit Hilfe des SeqNext-Moduls des Auswerteprogramms Sequence Pilot der Hinweis auf eine heterozygote Deletion von Exon 1 des MSH6-Gens (s. Abb. 3.28A).

Da die CNV-Analyse mit dem Modul SeqNext des Programms Sequence Pilot im Institut für Humangenetik der UMG in Göttingen keine etablierte und validierte Methode darstellt, sollte dieses Ergebnis mit einer zweiten, unabhängig validierten Methode bestätigt werden. Hierzu wurde eine MLPA-Analyse mit Hilfe des MLPA-Kits P072-C1 der Firma MRC Holland an der genomischen DNA des Patienten 39202 durchgeführt, welcher alle Exone des MSH6-Gens abdeckt (s. Abb. 3.28B). In dem o. g. MLPA-Kit waren ebenfalls zwei Sonden mit einer Lokalisation direkt im Exon 1 (eine Sonde in der nicht-kodierenden Region von Exon 1 und eine zweite Sonde im kodierenden Bereich von Exon 1) des MSH6-Gens sowie eine Sonde flankierend vor dem Exon 1 des MSH6-Gens enthalten (s. Abb. 3.27). 


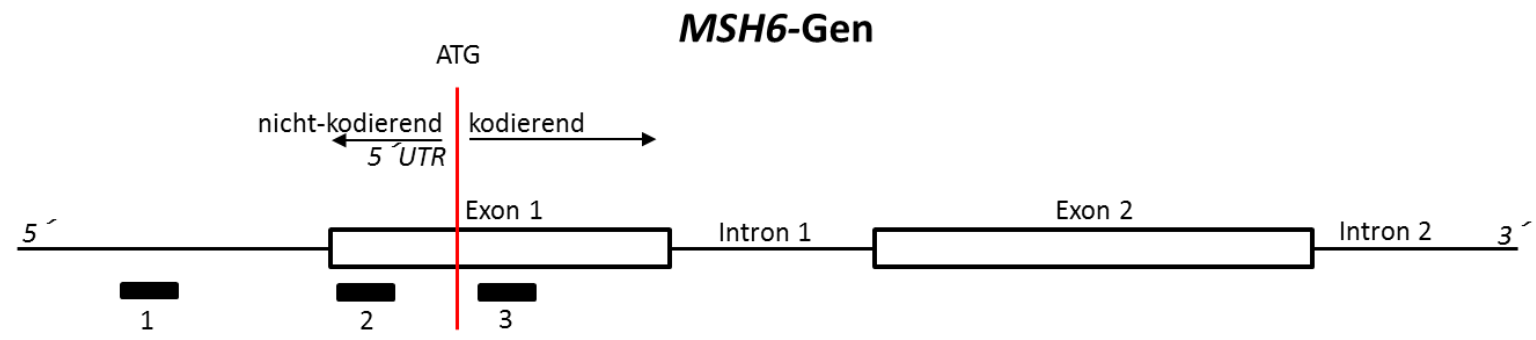

Abbildung 3.27: Schematische Darstellung der Lokalisation der MSH6-Gen-spezifischen Sonden von Exon 1 und flankierender Bereiche des Exons 1 enthalten im MLPA-Kit P072-C1. Schematische Darstellung eines Ausschnitts des MSH6-Gens. Zwei Exons und zwei Introns der genomischen DNA des MSH6-Gens mit deren Nummerierungen sind angegeben. Die Lokalisation von drei Sonden des MLPA-Kits P072-C1 sind jeweils mit einem schwarzen Balken dokumentiert (Sonde 1 stromaufwärts vor dem Exon 1 des MSH6-Gens, Sonde 2 in der 5'-untranslatierten Region (5'-UTR) und Sonde $3 \mathrm{im}$ kodierenden Bereich des Exons 1 des MSH6-Gens). Die rote vertikale Linie zeigt die Lokalisation des Startcodons ATG (Beginn der kodierenden Region) im Exon 1 des MSH6-Gens auf genomischer DNA-Ebene an.

Anschließend wurde eine Multiplex-PCR mit Hilfe des MLPA-Kits P072-C1 an der Patienten-DNA sowie an Kontroll-DNA Proben durchgeführt. Diese PCR-Produkte wurden zur Fragmentanalyse auf das $A B I 3130$ Sequenziergerät gegeben. Die hieraus gewonnenen Daten wurden nachfolgend mit Hilfe des Auswerteprogramms Sequence Pilot, MLPA-Modul, analysiert. Dabei konnte an der genomischen DNA vom Indexpatient 39202 eine heterozygote Deletion von Exon 1 sowie eines stromaufwärts flankierenden Bereichs von Exon 1 des MSH6-Gens im Vergleich zu den KontrollDNA-Proben identifiziert werden (s. Abb. 3.28B). Alle weiteren Sonden (Exon 2 bis Exon 10) im MSH6-Gen ergaben einen unauffälligen Befund in der MLPA-Analyse.

Die o. g. heterozygote Deletion des MSH6-Gens beim Indexpatient 39202 konnte ebenfalls an der genomischen DNA aus einer zweiten, unabhängigen Blutprobe des Indexpatienten wiederholt detektiert werden. 

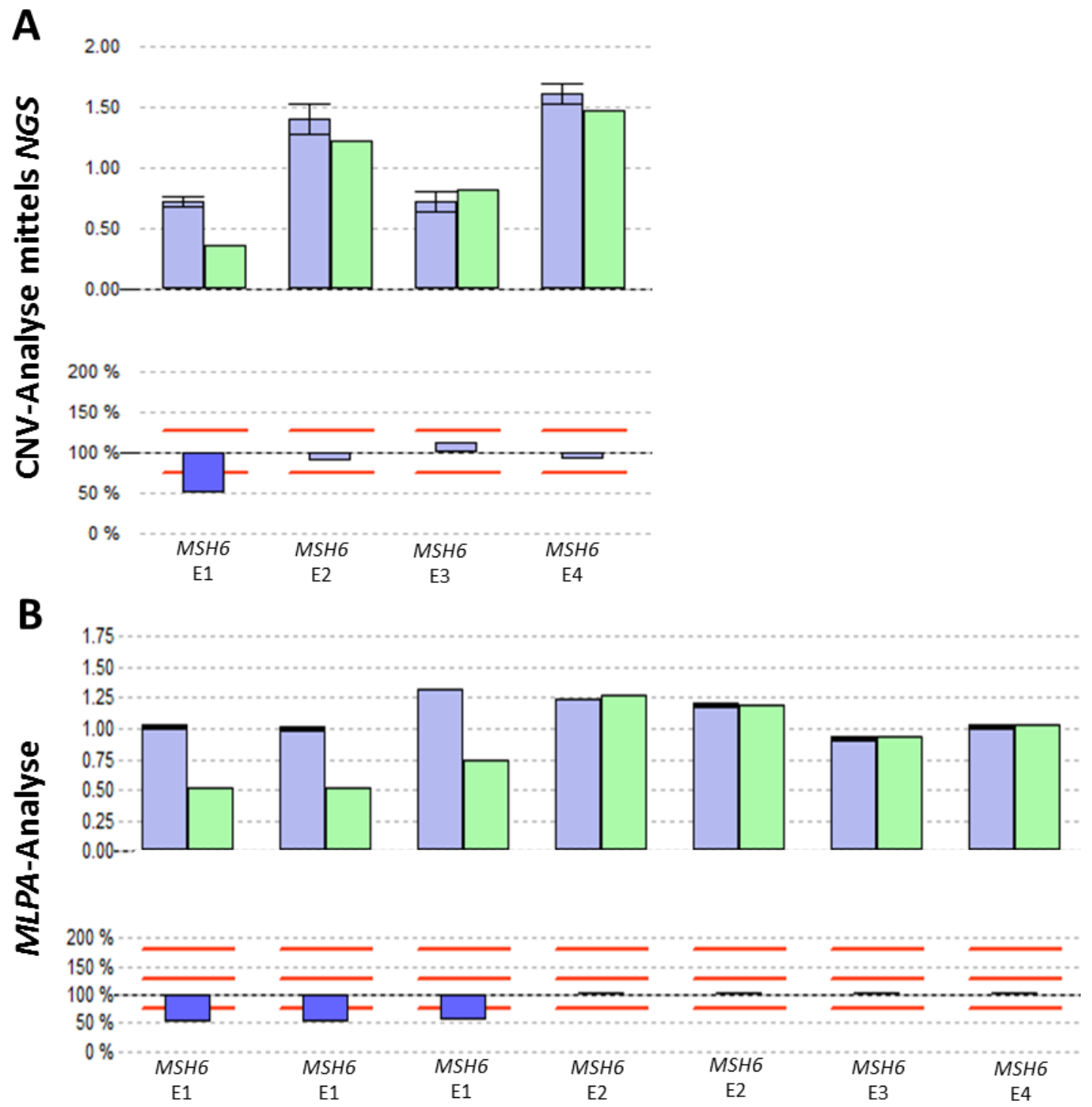

Abbildung 3.28: Nachweis einer heterozygoten Deletion von Exon 1 und flankierender Bereiche des MSH6-Gens beim Indexpatienten 39202 mittels CNV- und MLPA-Analyse. Es ist jeweils ein Ausschnitt des MSH6-Gens aufgeführt. Die roten Linien in A) und B) repräsentieren die Grenze für eine genomische Deletion oder eine Duplikation einzelner Exons. A) Zunächst wurde eine CNV-(Kopienzahlvarianten)-Analyse zur Detektion möglicher Abweichungen der Gendosis (Deletionen und Duplikationen) in den zehn CoreGenen und in den Genen des HNPCC-Spektrums (MLH1, MSH2 und MSH6) und des MUTYH-Gens angewendet. Das Prinzip dieser Methode besteht darin, dass die Abdeckungen einzelner Exone aller ausgewählten Genproben untereinander verglichen werden können. Als Kontrollen dienten DNA-Proben von Patienten ohne Deletionen/Duplikationen in den analysierten Genen. Damit können Deletionen und Duplikationen einzelner bzw. mehrerer Exone bzw. des gesamten Gens detektiert werden. Hellblaue Balken repräsentierten die DNA-Proben der Kontrollen, grüne Balken repräsentieren die DNA des Indexpatienten 39202. Der dunkelblaue Balken zeigt die heterozygote Deletion des Exons 1 im MSH6-Gen (MSH6 E1) an (Software: Sequence Pilot, Modul SeqNext) B) Bestätigung der heterozygoten Deletion von Exon 1 des MSH6-Gens mittels MLPA-Analyse. Es zeigte sich eine Deletion in den Bereichen aller zwei im Kit enthaltenen Sonden des Exons 1 sowie des 5'-flankierenden Bereichs vor dem Exon 1 im MSH6-Gen (dunkelblaue Balken). Hellblaue Balken repräsentieren die DNA-Proben der Kontrollen, grüne Balken entsprechen der DNA des Indexpatienten 39202 (Software: Sequence Pilot, Modul MLPA).

Mit Hilfe der MLPA-Analyse konnte gezeigt werden, dass beim Indexpatienten 39202 die Deletion nicht nur das Exon 1 des MSH6-Gens beinhaltet, sondern bereits flankierend vor dem Exon 1 des 
MSH6-Gens nachzuweisen war. Um die Ausdehnung dieser Deletion im MSH6-Gen weiter einzugrenzen, wurde zusätzlich eine quantitative Real-Time PCR ( $q P C R)$-Analyse mit speziell für diese Untersuchung definierten Primerpaaren an der genomischen DNA von Indexpatient 39202 durchgeführt. Mittels der qPCR-Untersuchung konnte eine genomische Deletion der 5'-UTRRegion des MSH6-Gens, des gesamten Exons 1 des MSH6-Gens sowie des 5'-Bereichs von Intron 1 des MSH6-Gens mit einer Größe von 46,1 kb nachgewiesen werden. Diese Deletion liegt im heterozygoten Zustand in der genomischen DNA von Indexpatient 39202 vor (s. Abb. 3.29B).

A

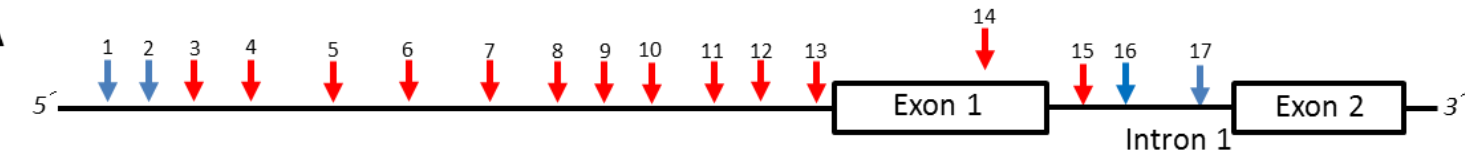

B $_{1,60}$

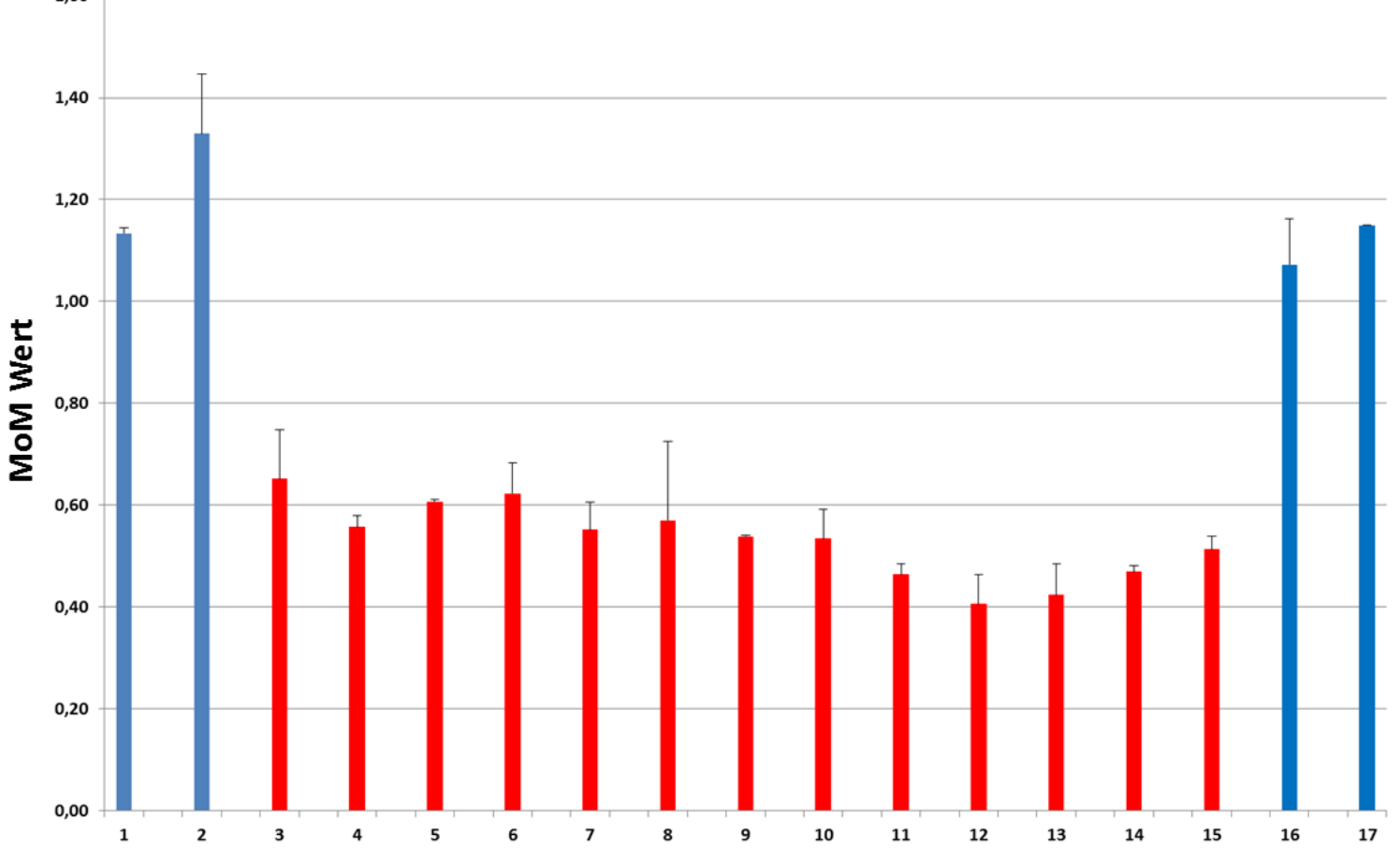

Abbildung 3.29: Nachweis der Deletion im MSH6-Gen mittels qPCR-Analyse an genomischer DNA des Indexpatienten 39202. A) Schematische Darstellung eines Ausschnitts des MSH6-Gens. Zwei Exons und ein Intron der genomischen DNA des MSH6-Gens mit deren Nummerierungen sind angegeben. Die jeweiligen Positionen der siebzehn verwendeten Primerpaare für die $q P C R$-Analyse sind mit Pfeilen markiert. Blaue Pfeile weisen auf ein diploides Genom und rote Pfeile auf eine heterozygote genomische Deletion hin. B) Ergebnisse der QPCR-Analyse. Die errechneten MoM-(multiple of the median)-Werte um 1 weisen auf ein diploides Genom in dieser Region hin (blaue Balken). Die nach der $q P C R$-Analyse erhaltenen MoM-Werte $\leq 0,6$ (rote Balken) bestätigen das Vorliegen einer auf Chromosom 2 befindlichen heterozygoten Deletion an der genomischen DNA von Indexpatient 39202. Diese heterozygote Deletion umfasst die flankierende Region vor dem MSH6-Gen (Primer 3 bis 13), den kodierenden Bereich vom Exon 1 des MSH6-Gens (Primer 14) sowie den Anfangsbereich von Intron 1 des MSH6-Gens (Primer 15) mit einer Gesamtgröße der Deletion von $46,1 \mathrm{~kb}$.

Diese Deletion im MSH6-Gen auf genomischer Ebene war bisher nicht in den Datenbanken (HGMD, Insight, ExAC) und in der Literatur beschrieben. Da die Deletion sowohl den Promotorbereich als auch die 5'-UTR des MSH6-Gens beinhaltete, sollte der Einfluss dieser Deletion auf die Expression des MSH6-Gens daher näher charakterisiert werden. Somit könnte möglicherweise eine nähere Aussage zur Pathogenitätseinschätzung dieser Deletion definiert werden. Hierzu wurde eine quantitative Expressionsanalyse des MSH6-Gens in Lymphozyten 
durchgeführt. Aus den Lymphozyten des Indexpatienten 39202 wurde die Gesamt-RNA isoliert und einerseits mit Hilfe von Random Hexamer Primern oder andererseits mit Oligo-dT-Primern sowie Zugabe von reverser Transkriptase in die jeweilige cDNA umgeschrieben. Anschließend wurde eine quantitative Real-Time PCR (qRT PCR) zur Analyse der MSH6-Transkriptmengen mit vier verschiedenen MSH6-spezifischen Primerpaaren (P1-Primerpaare lokalisiert in Exon 3 und 5, P2- und P3-Primerpaare jeweils lokalisert in Exon 1 und 2 sowie P4-Primerpaar lokalisiert in Exon 6 und 8) an beiden cDNA-Ansätzen getrennt durchgeführt. Als Kontrolle wurde jeweils das Housekeeping-Gen LDAH (LDAH-39202_H und LDAH-39202_O; s. Abb. 3.30A und 3.30B) verwendet.

Mit Hilfe der qRT-PCR-Analysen an beiden getrennten cDNA-Ansätzen konnte gezeigt werden, dass die MSH6-Expression in den Lymphozyten des Indexpatienten $39202 \mathrm{im}$ Vergleich zur Kontrolle um ca. 50 \% herunterreguliert wurde (s. Abb. 3.30A und B). Dieses Ergebnis lässt darauf schließen, dass die heterozygote genomische Deletion von Exon 1 sowie flankierender Bereiche des MSH6-Gens zu einer stark verringerten Expression bzw. zum Verlust der Expression des mutierten MSH6-Allels in Lymphozyten führt. Ein direkter Nachweis, ob es sich beim exprimierten Transkript des MSH6-Gens um das Wildtyp-Transkript oder das mutierte Allel handelte, war aufgrund fehlender Polymorphismen in der kodierenden Sequenz des MSH6-Gens leider nicht möglich.
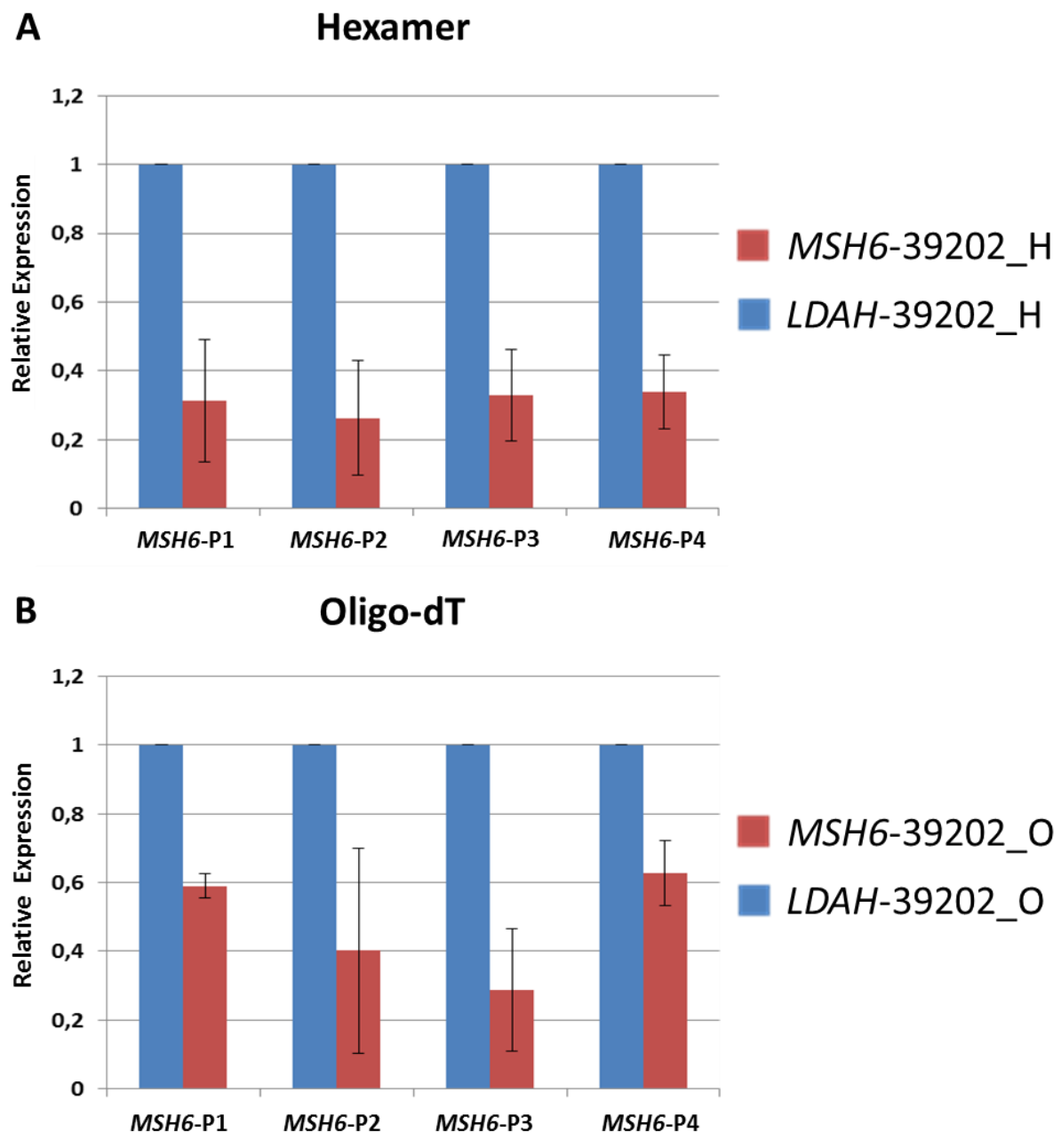

Abbildung 3.30: Nachweis der verringerten Expression des MSH6-Gens in den Lymphozyten des Indexpatienten 39202. Mit Hilfe der qRT PCR-Untersuchungen an zwei getrennten cDNA-Ansätzen konnte eine um etwa $50 \%$ verringerte Expression des MSH6-Gens in den Lymphozyten des Indexpatienten 39202 im Vergleich zu den Kontrollen des LDAH-Gens festgestellt werden. A) Die cDNA 39202B_H des Indexpatienten wurde in diesem ersten Versuchsansatz durch Zugabe von Hexamer-Primern sowie reverser 
Transkriptase aus der Lymphozyten-RNA synthetisiert. Anschließend wurden die MSH6-spezifischen Primerpaare MSH6-P1 bis MSH6-P4 für die quantitative Amplifikation der gewünschten Regionen der MSH6-Transkripte eingesetzt (Duplikat). Als Kontrolle wurde das Housekeeping-Gen LDAH (LDAH-39202_H) für diese quantitativen Analysen verwendet. B) Im zweiten Versuchsansatz wurde die cDNA 39202B_O des Indexpatienten durch Zugabe von OligodT-Primern sowie Reverser Transkriptase aus der Lymphozyten-RNA generiert. Nachfolgend wurden die MSH6-spezifischen Primerpaare MSH6-P1 bis MSH6-P4 für die quantitative Amplifikation der gewünschten Regionen der MSH6-Transkripte eingesetzt (Triplikat). Als Kontrolle wurde das Housekeeping-Gen LDAH (LDAH-39202_O) für diese quantitativen Analysen verwendet.

Eine Segregationsanalyse der identifizierten Deletion im MSH6-Gen in der Familie des Indexpatienten 39202 war nicht möglich, da bereits alle an Tumoren erkrankten Patienten verstorben waren. Anhand der durchgeführten Untersuchungen wurde die nachgewiesene heterozygote Deletion des MSH6-Gens in der genomischen DNA des Indexpatienten 39202 nach den ACMG-Richtlinien als wahrscheinlich pathogen (ACMG-Klasse 4) bewertet. 


\section{Diskussion}

\subsection{Zusammenfassung der klinischen Charakteristika der Patienten-Kohorte und der Multi-Gen-Panel-(NGS)-Analyse}

In der vorliegenden Arbeit wurden insgesamt 200 Patienten mit Verdacht auf ein hereditäres Mamma- und Ovarialkarzinom mittels der Multi-Gen-Panel-(NGS)-Methode analysiert.

Bei 173 Patienten $(86,5 \%)$ der untersuchten Kohorte wurden präanalytisch ein unilaterales Mammakarzinom, bei 22 Patienten (11,0 \%) ein beidseitiges Mammakarzinom, bei 10 Patienten $(5,0 \%)$ ein Ovarialkarzinom, bei vier Patienten (2,0 \%) ein Mamma- und Ovarialkarzinom und bei einem Patienten (0,5\%) ein Mamma- und ein kolorektales Karzinom diagnostiziert. Bei 17 der analysierten Patienten (8,5 \%) war klinisch kein Mamma- oder Ovarialkarzinom bekannt. Weitere Tumorerkrankungen lagen in $102(51,0 \%)$ der Familien der untersuchten Patienten vor. Am häufigsten wurde bei 52,3 \% der Familien das Auftreten eines kolorektalen Karzinoms beobachtet. Bei allen untersuchten Patienten waren die vom Deutschen Konsortium Familiärer Brust- und Eierstockkrebs definierten Kriterien für eine molekulargenetische Untersuchung erfüllt. Das durchschnittliche Alter der Patienten bei der Erstdiagnose eines Mamma- oder Ovarialkarzinoms im untersuchten Kollektiv betrug 41,9 Jahre. Bei $58 \%$ der untersuchten Patienten lag das Kriterium A oder G vor. 72 der untersuchten Patienten (36,0 \%) erfüllten das Kriterium A, d. h. dass mindestens drei Frauen aus der gleichen Linie einer Familie an einem Mammakarzinom erkrankt sind, gefolgt von 44 Patienten $(22,0 \%)$, die das Kriterium $G$ erfüllten, d. h. dass mindestens zwei Frauen aus der gleichen Linie einer Familie an einem Mammakarzinom erkrankt sind, davon eine vor dem 51. Lebensjahr.

Im Rahmen dieser Arbeit wurde bei allen o. g. Patienten 10 Core-Gene mittels der HaloPlex- oder der TruRisk 1.2 $2^{\mathrm{TM}}$-Technologie (Multi-Gen-Panel-(NGS)-Analyse) analysiert. Bei allen 200 Patienten wurden die BRCA1-, BRCA2- und CHEK2-Gene mittels der MLPA-Analyse und bei 181 Patienten (90,5 \%) zusätzlich die PALB2-, RAD51C- und RAD51D-Gene analysiert. Insgesamt wurden 106 Sequenzvarianten der $A C M G$-Klasse 3,4 oder 5 in 88 Proben der untersuchten Patienten detektiert. Dies entspricht einer Detektionsrate dieser Sequenzvarianten von 44,0\%. Wenn nur die Mutationen der ACMG-Klasse 4 oder 5 betrachtet werden, wurde jeweils eine dieser Mutationen bei insgesamt 35 Patienten identifiziert. Dieses Ergebnis entspricht einer Detektionsrate der Mutationen der ACMG-Klasse 4 oder 5 von 18,0\%. Davon wurden 18 Mutationen im BRCA1-Gen, sechs Mutationen im CHEK2-Gen, jeweils vier Mutationen in den Genen ATM und BRCA2 sowie jeweils eine Mutation in den Genen CDH1, PALB2 und RAD51C identifiziert. Die Detektionsrate der Mutationen der ACMG-Klasse 4 oder 5 in den BRCA1- und $B R C A 2-G e n e n$ lag bei $11,0 \%$. Diese Detektionsraten unterscheiden sich statistisch signifikant $(\mathrm{p}=$ 0,0009). Jede der Sequenzvarianten der $A C M G$-Klasse 3, 4 oder 5 war mit einer zweiten molekulargenetischen Methode, wie zum Beispiel der Sanger-Sequenzierung oder einer wiederholten MLPA-Analyse, reproduzierbar.

Die Detektionsrate der Sequenzvarianten der ACMG-Klasse 3, 4 oder 5 der 10 Core-Gene lag im Vergleich zur Detektionsrate in den Genen BRCA1 und BRCA2 statistisch signifikant höher, $\mathrm{d}$. $\mathrm{h}$. $44,0 \%$ vs. $18,0 \%(p<0,0001)$.

Die häufigsten Typen der Sequenzvarianten der ACMG-Klasse 3, 4 oder 5 waren missenseSequenzvarianten mit 52 Sequenzvarianten (49,1\%), gefolgt von 21 frame-shift-Sequenzvarianten (19,8 \%), 11 nonsense-Sequenzvarianten (10,4 \%), 11 synonymen-Sequenzvarianten (9,4 \%), neun splicing- bzw. potentiellen splicing-Sequenzvarianten ( $8,5 \%)$, zwei großen Deletionen $(1,9 \%)$ und einer in-frame-Sequenzvariante (0,9\%).

Für alle Patienten der Kohorte wurden mittels des Risikokalkulationsprogramms Cyrillic 2.13 das Heterozygotenrisiko einer Anlageträgerschaft einer autosomal-dominant vererbten Mutation in einem der 10 Core-Gene sowie das Lebenszeitrisiko, an einem Mammakarzinom bis zum 85 . Lebensjahr zu erkranken, berechnet. 
Für Patienten mit bilateralen Mammakarzinomen mit der Ersterkrankung vor dem 51. Lebensjahr wurde mit 61,6 \% der höchste Mittelwert des Risikos für eine Anlageträgerschaft einer autosomaldominant vererbten Mutation mit dem Risikokalkulationsprogramm Cyrillic 2.13 berechnet, gefolgt von $56,5 \%$ bei Patienten mit mindestens einer gleichzeitig an einem Mamma- und Ovarialkarzinom erkrankten Frau.

Das mittlere berechnete Heterozygoten-Risiko der gesamten Patienten-Kohorte lag bei $38 \pm 30 \%$. Das Lebenszeitrisiko, bis zum 85. Lebensjahr an einem Mammakarzinom zu erkranken, betrug in der gesamten untersuchten Patienten-Kohorte $27 \pm 21 \%$. Für die Patienten mit einer Sequenzvariante der ACMG-Klasse 3, 4 oder 5 in einem der 10 Core-Gene wurde ein mittleres Heterozygoten-Risiko für eine autosomal-dominant vererbte Mutation von $41 \pm 32 \%$ berechnet. Für die Patienten ohne eine Sequenzvariante der ACMG-Klasse 3, 4 oder 5 in einem der 10 CoreGene wurde ein mittleres Heterozygoten-Risiko von $35 \pm 29 \%$ berechnet. Diese Risiken unterscheiden sich statistisch nicht signifikant $(p=0,14)$. Die Heterozygoten-Risiken wiesen nur bei Patienten mit einer Sequenzvariante der ACMG-Klasse 3, 4 oder 5 in den Genen BRCA1 und BRCA2 (54 $\pm 33 \%)$ im Vergleich zu den anderen acht Core-Genen (33 $\pm 29 \%$ ) eine statistisch signifikante Erhöhung auf $(p<0,01)$.

Insgesamt waren 105 der analysierten Patienten an einem invasiv duktalen Mammakarzinom, 32 Patienten an einem DCIS (duktales Carcinoma in situ), 16 Patienten an einem invasiv lobulären Mammakarzinom und zwei Patienten an einem medullären Mammakarzinom erkrankt. Bei Patienten, die an einem invasiv duktalen Mammakarzinom erkrankten, wurden statistisch signifikant häufiger Sequenzvarianten der ACMG-Klasse 3, 4 oder 5 identifiziert $(p=0,02)$ als bei den Patienten mit einem anderen histologischen Typ des Mammakarzinoms.

Bei 46,2 \% der Patienten mit einem exprimierten Östrogen-Rezeptor $\alpha(E R \alpha)$, bei 46,3\% der Patienten mit dem exprimierten Progesteron-Rezeptor (PR) und bei 58,8 \% der Patienten mit einem überexprimierten ERBB2-Rezeptor im Tumorgewebe wurde eine Sequenzvariante der ACMG-Klasse 3, 4 oder 5 in den 10 Core-Genen identifiziert. Patienten mit triple-negativen Mammakarzinomen wiesen statistisch signifikant höhere Detektionsraten an Mutationen der ACMG-Klasse 4 oder 5 in den 10 Core-Genen auf als Patienten mit einem anderen Rezeptorstatus ( $p=0,001)$.

\subsection{Auswertungen der Daten der Multi-Gen-Panel-Analyse (NGS)}

In dieser Studie wurden mit einem Anteil von 95,0 \% (196 von 200) deutlich mehr weibliche als männliche Patienten eingeschlossen. Diese Tendenz spiegelt die Geschlechtsverteilung der Diagnose eines Mammakarzinoms in der Gesamtbevölkerung wider. Insgesamt sind deutlich mehr weibliche als männliche Patienten betroffen. Die Ursache dafür ist vor allem der anatomische Aufbau der Mammae bei Frauen mit deutlich mehr Drüsengewebe als bei der männlichen Mamma. Die Geschlechtsverteilung ist kongruent mit der Verteilung der Krebserkrankungen im deutschen Krebsregister. Im Jahr 2013 waren etwa 69.220 (99,0 \%) Frauen und 682 Männer (1 \%) in Deutschland an einem Mammakarzinom erkrankt (Krebsgeschehen in Deutschland 2016).

Weibliche Patienten in der Algemeinbevölkerung erkrankten mit einem mittleren Erkrankungsalter von 64,3 Jahren an einem Mammakarzinom und männliche Patienten mit einem mittleren Erkrankungsalter von 69,9 Jahren (Krebsgeschehen in Deutschland 2016, Stand 2013). Die Zahlen aus dem Krebsregister enthalten sowohl sporadische als auch hereditäre Formen des Mammakarzinoms. Das in dieser Arbeit ermittelte mittlere Erkrankungsalter bei der Erstdiagnose des Mammakarzinoms lag bei den weiblichen Patienten bei 47,4 Jahren und bei den männlichen Patienten bei 54,0 Jahren. Das hier ermittelte Erkrankungsalter erweist sich daher als deutlich niedriger im Vergleich zu den im deutschen Krebsregister registrierten Betroffenen, was bei einer 
hereditären Form des Mammakarzinoms auch zu erwarten ist (Tung et al. 2015; Mannan et al. 2016; Thompson et al. 2016).

Die in den Arbeiten zu dieser Dissertation ermittelten mittleren Erkrankungsalter sind mit denen aus vorangegangenen Studien vergleichbar. Die Studie von Tung et al. (2015) zeigte ein mittleres Erkrankungsalter bei der Erstdiagnose des Mammakarzinoms von 47,2 Jahren bei Patienten mit Verdacht auf ein hereditäres Mamma- und Ovarialkarzinom. Die in der Studie von Thompson et al. (2016) analysierten Patientinnen mit Verdacht auf ein hereditäres Mammakarzinom wurden nach dem Erkrankungsalter in sechs Altersgruppen eingeteilt: 1) < 40 Jahre (22,9\%), 2) 40 - 44 Jahre $(14,3 \%), 3) 45$ - 49 Jahre $(15,8 \%), 4) 50$ - 54 Jahre $(13,1 \%), 5) 55$ - 59 Jahre $(12,2 \%)$ und 6) > 60 Jahre (21,7 \%). Die Mehrzahl der pathogenen Mutationen wurden bei Patientinnen mit einem Erkrankungsalter von $<40$ Jahren identifiziert $(21,5 \%)$. Es folgten Patientinnen mit einem Erkrankungsalter von $>60$ Jahren (20,3\%), zwischen 50 - 54 Jahren (18,9\%), zwischen 45 - 49 Jahren $(17,7 \%)$, zwischen 40 - 44 Jahren (13,9\%) und zwischen 55 - 59 Jahren (7,6\%). Mannan et al. (2016) detektierten bei Patienten mit Verdacht auf ein hereditäres Mamma- und Ovarialkarzinom bei den Erkrankten < 40. Lebensjahr in 44,0 \% der Fälle eine pathogene Mutation in den untersuchten Genen, bei den Erkrankten zwischen dem 40. und 50. Lebensjahr in 53,0 \% der Fälle und bei den Erkrankten $>50$. Lebensjahr in 27,0 \% der Fälle. Die Tendenz der Altersverteilung aus den oben genannten Studien bei der Erstdiagnose eines Mamma- bzw. Ovarialkarzinoms wurde auch in dieser Dissertation beobachtet. Die größte Altersgruppe entsprach der Gruppe von Patienten, die zwischen dem 40. und 49. Lebensjahr erkrankten. In dieser Gruppe wurden 40,0 \% aller pathogenen Mutationen in den 10 Core-Genen identifiziert. Dieser Altersgruppe folgen die Altersgruppen zwischen dem 30. und 39. Lebensjahr sowie zwischen dem 50. und 59. Lebensjahr mit jeweils 20,0 \% aller identifizierten Mutationen. In der Altersgruppe $>70$. Lebensjahr (insgesamt 11 Patienten) wurden keine Mutationen identifiziert. Bei sehr jung erkrankten Patienten ( $<30$. Lebensjahr) wurden nur 5,7\% aller Mutationen in den 10 Core-Genen identifiziert. Eine Abweichung der Detektionsraten in dieser Kohorte im Vergleich zu den publizierten Daten liegt vermutlich einerseits an der Größe der gesamten Kohorte und der daraus resultierenden Größenordnung der unterschiedlichen Altersgruppen und andererseits an den jeweiligen Einschlusskriterien für eine molekulargenetische Untersuchung.

Vom Deutschen Konsortium Familiärer Brust- und Eierstockkrebs wurden unterschiedliche Kriterien für eine molekulargenetische Untersuchung bei Verdacht auf ein hereditäres Mammaund Ovarialkarzinom anhand der familiären Konstellationen der Tumorerkrankungen definiert. Für diese Kriterien wurden empirische Wahrscheinlichkeiten für pathogene Mutationen in den BRCA1- und BRCA2-Genen mit Abweichungen +/-2 definiert (Meindl et al. 2011) (s. Tab. 4.1). Die empirischen Wahrscheinlichkeiten für pathogene Mutationen in den BRCA1- und BRCA2-Genen sind am niedrigsten bei Patienten mit dem erfüllten Kriterium $G$ und bei den Patienten mit dem erfüllten Kriterium $Q$ (s. Tab. 4.1). Diese Tendenzen wurden in der vorliegenden Arbeit widergespiegelt, mit der Ausnahme, dass die Risiken generell höher berechnet wurden. Die empirischen Daten zeigen die höchste Wahrscheinlichkeit für eine pathogene Mutation von 48,4 $\%$ bei dem erfüllten Kriterium J. Die berechnete Wahrscheinlichkeit für eine pathogene Mutation bei Patienten in der vorliegenden Arbeit, die dieses Kriterium erfüllten, liegt bei 40,2 \% und ist nicht die höchste berechnete Wahrscheinlichkeit. In der vorliegenden Arbeit ist die höchste Wahrscheinlichkeit von 61,6 \% für eine pathogene Mutation bei Patienten mit dem erfüllten Kriterium $R$ berechnet worden. Für die Kriterien $A, G$ und $R$ sind in dieser Arbeit statistisch signifikant höhere Risiken in Vergleich zu den empirischen Risiken berechent worden (s. Tab. 4.1). Die entstehenden Differenzen sind stark von dem untersuchten Kollektiv abhängig. Weiterhin sind die empirischen Daten in Abhängigkeit von den beobachteten Mutationsraten entstanden und hängen nicht von einem Risikokalkulationsprogramm ab. Es wird bereits längere Zeit diskutiert, 
dass die Risiken, welche mit dem Risikokalkulationsprogramm Cyrillic 2.13 ermittelt werden, nicht den realen Risiken entsprechen, sondern insgesamt zu hoch berechnet werden.

Tabelle 4.1: Empirische und berechnete Wahrscheinlichkeiten für Mutationen in den Genen BRCA1 und BRCA2. Statistische Daten wurden mit dem Softwareprogramm R, Version 3.3.1, www.r-project.org, RPaket Ime4, Einstichproben-t-Test, berechnet.

\begin{tabular}{|c|c|c|c|}
\hline Kriterium & $\begin{array}{c}\text { Empirische } \\
\text { Wahrscheinlichkeiten }^{\mathbf{1}}\end{array}$ & $\begin{array}{c}\text { Berechnete } \\
\text { Wahrscheinlichkeiten } \\
\text { (diese Arbeit) in \% }\end{array}$ & p-Wert \\
\hline A & 22,4 & 44,1 & $<0,001^{*}$ \\
\hline G & 9,2 & 23,7 & $0,002^{*}$ \\
\hline J & 48,4 & 40,2 & 0,52 \\
\hline Q & 10,1 & 17,5 & 0,74 \\
\hline R & 24,8 & 61,6 & $\mathbf{0 , 0 0 1 *}$ \\
\hline U & 42,1 & 46,2 & 1,0 \\
\hline Z & 45,0 & 37,2 & 1,0 \\
\hline
\end{tabular}

Kriterium A: mindestens drei Frauen aus der gleichen Linie einer Familie sind an einem MCa erkrankt (unabhängig vom Alter bei ED); Kriterium G: mindestens 2 Frauen aus der gleichen Linie einer Familie sind an einem MCa erkrankt, davon eine vor dem 51. Lebensjahr; Kriterium J: Mindestens eine Frau ist an einem MCa und mindestens eine Frau an einem OvCa erkrankt; Kriterium Q: Mindestens eine Frau ist vor dem 36. Lebensjahr an einem MCa erkrankt; Kriterium R: Mindestens eine Frau ist an einem bilateralen MCa erkrankt, wobei das erste MCa vor dem 51. Lebensjahr aufgetreten ist; Kriterium U: Mindestens ein Mann ist an einem MCa und mindestens eine Frau an einem MCa oder OvCa erkrankt; Kriterium Z: Mindestens zwei Frauen sind an einem OvCa erkrankt. ${ }^{1}$ Meindl et al. 2011; $\mathrm{MCa}=$ Mammakarzinom; OvCa = Ovarialkarzinom; ED = Erstdiagnose.

Bei Patienten mit bilateralem Mammakarzinom und dem höchsten berechneten HeterozygotenRisiko wurde nur eine pathogene Mutation in den 10 Core-Genen identifiziert (Mutation im BRCA1-Gen). Die Mehrzahl der Sequenzvarianten der ACMG-Klasse 3, 4 oder 5 wurden bei Patienten mit den erfüllten Kriterien $A$ und $G$ identifiziert, d. h. 41 Sequenzvarianten der ACMGKlasse $3(57,7 \%)$ und 20 Mutationen der ACMG-Klasse 4 oder 5 (57,2\%) konnten in diesen beiden Patientengruppen nachgewiesen werden. Diese Detektionsraten entsprechen den größten zwei Kollektiven in der untersuchten Kohorte. Das hohe berechnete Heterozygoten-Risiko bei der Konstellation des Kriteriums $U$ korreliert ebenso nicht mit der Detektionsrate der identifizierten Sequenzvarianten in den Core-Genen. Bei diesem erfüllten Kriterium wurden insgesamt nur eine pathogene Mutation und drei Varianten unklarer Signifikanz detektiert.

Die Daten dieser Dissertation deuten darauf hin, dass die berechneten Heterozygoten-Risiken für eine autosomal-dominant vererbte Mutation in einem der 10 Core-Gene nicht mit der eigentlichen Detektionsrate übereinstimmen. Die berechneten Heterozygoten-Risiken weisen auf deutlich höhere Werte hin und entsprechen daher nicht den realen Detektionsraten.

Ab dem 01.10.2016 sind neben den bereits oben erwähnten Kriterien zwei neue Kriterien in Kraft getreten. Diese zwei neuen Kriterien wurden wie folgt definiert: Kriterium 1) mindestens eine Frau ist an einem triple-negativen Mammakarzinom bis zum vollendeten 49. Lebensjahr erkrankt; Kriterium 2) mindestens eine Frau ist an einem Ovarialkarzinom bis zum vollendeten 79. Lebensjahr erkrankt. Da diese zwei neuen Kriterien erst am 01.10.2016 in Kraft getreten sind und die Patienten, die potentiell diese zwei Kriterien vor dem Inkrafttreten erfüllt hätten, für eine humangenetische Beratung in der Interdisziplinären Sprechstunde der Frauenklinik der UMG durch die study nurse nicht erfasst wurden, sind diese Patienten entsprechend nicht in dieser Dissertation enthalten. 


\subsubsection{Vergleich der Daten aus NGS-Analysen bei Verdacht auf ein hereditäres Mamma- und Ovarialkarzinom}

Es wurden bereits eine Vielzahl von Studien mit umfangreichen Patientenkollektiven bei Verdacht auf ein hereditäres Mamma- und Ovarialkarzinom, die mittels Multi-Gen-Panel-Untersuchung (NGS) analysiert wurden, veröffentlicht. In der Mehrzahl der Studien wurde jedoch eine größere Anzahl von Genen analysiert als in dieser Dissertation. In der Tabelle 4.2 wurden daher nur jeweils die vom Deutschen Konsortium definierten 10 Core-Gene betrachtet.

Die Detektionsrate der wahrscheinlich pathogenen und pathogenen Mutationen von $11,0 \%$ in den BRCA1- und BRCA2-Genen in dieser Arbeit ist vergleichbar mit den publizierten Detektionsraten. Nichtsdestotrotz variieren die Detektionsraten deutlich in verschiedenen Studien, wie z. B. die Detektionsrate der Studie von Kurian et al. (2014) und von Mannan et al. (2016) mit einer sehr hohen Detektionsrate der pathogenen Mutationen in den BRCA1- und BRCA2-Genen von 26,2 \% oder einer sehr niedrigen Detektionsrate von Susswein et al. (2016) von $3,9 \%$.

In dieser Arbeit konnte eine Detektionsrate von 6,5\% der wahrscheinlich pathogenen und pathogenen Mutationen in den nicht BRCA1/BRCA2-Core-Genen ermittelt werden. Die Detektionsraten in den nicht BRCA1- und BRCA2-Genen variieren in den unterschiedlichen Studien stark und sind vor allem von der Auswahl der analysierten Gene und den Einschlusskriterien für die molekulargenetische Untersuchung abhängig. Schroeder et al. (2015) analysierten dieselben acht Core-Gene (nicht BRCA1/BRCA2) wie in dieser Arbeit und konnten eine Detektionsrate der pathogenen und wahrscheinlich pathogenen Mutationen von 2,9\% nachweisen. Hauke et al. (2018) ermittelten dagegen in ihrer Studie eine Detektionsrate von 7,4 \%.

Wenn aus allen publizierten NGS-Studien nur die vom Deutschen Konsortium Familiärer Brustund Eierstockkrebs definierten acht nicht BRCA-Core-Gene betrachtet werden, zeigten sich sehr variable Detektionsraten der Mutationen der ACMG-Klasse 4 oder 5. Chong et al. (2014) wiesen eine Detektionsrate der pathogenen Mutationen in den nicht BRCA1- und BRCA2-Genen von 15,1 $\%$ auf, Castéra et al. (2014) von 8,1 \%, Cybulski et al. (2015a) von 4,9\%, Tung et al. (2015) von 3,3 $\%$, Yablonski-Perez et al. (2015) von 2,1\%, Mannan et al. (2016) von 9,1 \%, Thompson et al. (2016) von 3,8 \%, Eliade et al. (2017) von 5,8 \% und Crawford et al. (2017) von 7,9 \% (s. Tab. 4.2). Die angegebenen Detektionsraten sind jedoch nicht direkt miteinander vergleichbar, da nicht in allen Studien alle vom Deutschen Konsortium Familiärer Brust- und Eierstockkrebs definierten acht nicht BRCA1/2-Core-Gene analysiert wurden.

Eine kurze Zusammenfassung von einigen größeren Studien und die Detektionsraten der identifizierten Sequenzvarianten der ACMG-Klasse 3, 4 und 5 ist nachfolgend aufgelistet. Die 10 Core-Gene sind in den folgenden Genlisten fett markiert (s. auch Tab. 4.2):

Tung et al. (2015) untersuchten insgesamt 2.158 Patienten mittels eines Multi-Gen-Panels (NGS). Es wurde hierzu ein Multi-Gen-Panel mit 25 Tumor-assoziierten Genen analysiert und ausgewertet: APC, ATM, BARD1, BMPR1A, BRCA1, BRCA2, BRIP1, CDH1, CDK4, CDKN2A, CHEK2, EPCAM, MLH1, MSH2, MSH6, MUTYH, NBN, PALB2, PMS2, PTEN, RAD51C, RAD51D, SMAD4, STK11 und TP53. Die Patienten wurden dazu in zwei Kohorten unterteilt. In der ersten Kohorte befanden sich 1.781 Patienten mit Verdacht auf ein hereditäres Mamma- und Ovarialkarzinom ohne vorherige molekulargenetische Analyse der BRCA1- und BRCA2-Gene. In dieser Kohorte wurden pathogene Mutationen bei 241 Patienten (13,5\%) detektiert, davon bei 162 Patienten $(9,1 \%)$ in den Genen BRCA1 und BRCA2. Bei 79 Patienten $(4,4 \%)$ wurde mindestens eine Mutation in den restlichen 23 Genen identifiziert, davon 3,3\% in den acht Core-Genen (nicht BRCA1/BRCA2) (s. Tab. 4.2). Varianten unklarer Signifikanz (VUS) wurden bei 742 Patienten $(41,7$ \%) identifiziert. In der zweiten Kohorte mit 377 Hochrisiko-Patienten mit vorheriger negativer Testung auf Mutationen in den Genen BRCA1 und BRCA2 wurden insgesamt 15 pathogene Mutationen bei 14 Patienten (3,7 \%) und 231 VUS bei 157 Patienten $(41,6 \%)$ identifiziert. Die 
allgemeine Detektionsrate der Mutationen in den BRCA1- und BRCA2-Genen lag bei 9,3\%. Die Detektionsrate der Mutationen in allen analysierten Genen lag bei 13,5\%. Wenn nur mit einem Mamma- und Ovarialkarzinom assoziierte Gene betrachtet wurden, lag die Detektionsrate der Mutationen der ACMG-Klasse 4 oder 5 bei 13,2 \% (s. Tab. 4.2).

Schroeder et al. (2015) veröffentlichen Daten von insgesamt 620 Patienten mit Verdacht auf ein hereditäres Mamma- und Ovarialkarzinom, die mit Hilfe eines Multi-Gen-Panels (NGS) analysiert wurden. Bei diesen Patienten wurden die vom Deutschen Konsortium Familiärer Brust- und Eierstockkrebs definierten 10 Core-Gene ausgewertet. Pathogene Mutationen wurden bei 75 Patienten (12,1\%) identifiziert. In den Genen RAD51C und RAD51D konnte dabei keine pathogene Mutation detektiert werden (s. Tab. 4.2).

Desmond et al. (2015) wiesen in einer Kohorte von 1.069 Patienten mit Verdacht auf ein hereditäres Mamma- und Ovarialkarzinom ohne identifizierte Mutation in den Genen BRCA1 und $B R C A 2$ bei $5,9 \%$ der Patienten eine pathogene Mutation in den analysierten Genen nach. Hierzu wurde ein 29-Multi-Gen-Panel (NGS) bzw. ein 25-Multi-Gen-Panel (NGS) durchgeführt und folgende Gene analysiert: APC, ATM, BARD1, BMPR1A, BRIP1, CDH1, CDK4, CDKN2A, CHEK2, EPCAM, MEN1, MET, MLH1, MSH2, MSH6, MUTYH, NBN, PALB2, PALLD, PMS2, PTCH1, PTEN, RAD51C, RAD51D, RET, SMAD4, STK11, VHL und TP53. In den acht analysierten Core-Genen wurden 36 Mutationen (3,4 \%) identifiziert (s. Tab. 4.2). Es wurden zusätzlich 44 Mutationen (4,1 $\%)$ in den Genen APC, BMPR1A, BRIP1, CDKN2A, MSH2, MSH6, MLH1, MUTYH, PMS2 und PTEN detektiert.

Lincoln et al. (2015) untersuchten insgesamt 1.062 Patienten mit Verdacht auf ein hereditäres Mamma- und Ovarialkarzinom mit einem 29-Multi-Gen-Panel (NGS) mit folgenden Genen: APC, ATM, BRCA1, BRCA2, BMPR1A, BRIP1, CDH1, CDK4, CDKN2A, CHEK2, EPCAM, MEN1, MET, MLH1, MSH2, MSH6, MUTYH, NBN, PALB2, PALLD, PMS2, PTCH1, PTEN, RAD51C, RET, SMAD4, STK11, VHL und TP53. Eine Kohorte mit 735 Patienten wurde als die repräsentative Gruppe selektiert. Bei 66 dieser Patienten $(9,0 \%)$ wurde eine pathogene Mutation in den BRCA1- und BRCA2-Genen identifiziert. In den restlichen Genen wurden 26 pathogene Mutationen (3,5\%) nachgewiesen. Es wurden 13 Mutationen (1,8 \%) in den nicht BRCA1/BRCA2-Core-Genen (s. Tab. 4.2) sowie insgesamt neun Mutationen (1,2 \%) in den Genen CDKN2A, MLH1, MSH2, MSH6 und PMS2 detektiert. 2,7 \% der Patienten waren Träger einer heterozygoten pathogenen bzw. wahrscheinlich pathogenen Mutation im MUTYH-Gen. Bei 41,0 \% aller untersuchten PatientenProben wurde mindestens eine VUS identifiziert (s. Tab. 4.2).

Eine umfassende Studie von Susswein et al. (2016) mit insgesamt 10.030 Patienten mit Verdacht auf ein hereditäres Tumorsyndrom verwendete ein Multi-Gen-Tumor-Panel (NGS) mit 29 Genen. Bei 3.315 Frauen mit Verdacht auf ein hereditäres Mamma- und Ovarialkarzinom wurden 21 Gene ausgewertet: ATM, BARD1, BRCA1, BRCA2, BRIP1, CDH1, CHEK2, EPCAM, FANCC, MLH1, MSH2, MSH6, NBN, PALB2, PMS2, PTEN, RAD51C, RAD51D, STK11, XRCC2 und TP53. Bei 320 Frauen $(9,7$ \%) wurden wahrscheinlich pathogene bzw. pathogene Mutationen in einem der o. g. Gene identifiziert. Zusätzlich zu den Mutationen (8,5 \%) in den 10 Core-Genen (s. Tab. 4.2) wurden Mutationen im MSH6-Gen, im PMS2-Gen und im MLH1-Gen detektiert. Pathogene Mutationen wurden bei sechs von 51 Männern (11,8 \%) mit einem diagnostizierten Mammakarzinom identifiziert.

Buys et al. (2017) untersuchten retrospektiv 35.409 Frauen, die vor dem 45. Lebensjahr an einem einseitigen Mammakarzinom erkrankten, sowie Frauen, die nach dem 45. Lebensjahr erkrankten und eine positive Familienanamnese mit einem Mamma- und/oder Pankreaskarzinom aufwiesen. 
Bei allen Frauen wurde ein 25-Gen-Panel (NGS) mit folgenden Genen durchgeführt: $A P C, A T M$, BARD1, BMPR1A, BRCA1, BRCA2, BRIP1, CDH1, CDK4, CDKN2A, CHEK2, EPCAM, MLH1, MSH2, MSH6, MUTYH, NBN, PALB2, PMS2, PTEN, RAD51C, RAD51D, SMAD4, STK11 und TP53. Insgesamt wurde bei 3.305 Patientinnen mindestens eine pathogene Mutation identifiziert (9,3\%). Etwa die Hälfte aller Mutationen wurde in den Genen BRCA1 $(24,0 \%)$ und BRCA2 $(24,4 \%)$ detektiert. In den anderen acht Core-Genen wurden 3,6 \% wahrscheinlich pathogene oder pathogene Mutationen identifiziert (s. Tab. 4.2). In den restlichen Genen wurden 1,4\% pathogene Mutationen detektiert. Nur in den Genen BMPR1A und CDK4 konnte keine Mutation nachgewiesen werden. Die höchste Detektionsrate der pathogenen Mutationen von 13,0 \% bis $18,0 \%$ zeigten Frauen mit einem diagnostizierten Mammakarzinom vor dem 40. Lebensjahr und die niedrigste Detektionsrate wiesen Frauen mit einem diagnostizierten Mammakarzinom zwischen dem 85. und 89. Lebensjahr auf (s. Tab. 4.2).

In der Studie von Couch et al. (2017) wurden 65.057 Patienten mit Verdacht auf ein hereditäres Mammakarzinom mit einem 21-Multi-Gen-Panel (NGS) (ATM, BARD1, BRCA1, BRCA2, BRIP1, CDH1, CDKN2A, CHEK2, MLH1, MRE11A, MSH2, MSH6, NBN, NF1, PALB2, PMS2, PTEN, RAD50, RAD51C, RAD51D, TP53) analysiert. Bei 10,2 \% der Patienten wurde eine pathogene Mutation identifiziert. Die Mutationsfrequenzen in den Core-Genen sind in der Tabelle 4.2 gelistet.

Hauke et al. (2018) veröffentlichten die Ergebnisse einer Multi-Gen-Panel-Analyse (NGS) von 5.589 BRCA1/BRCA2-negativen Patientinnen, bei denen ausschließlich die vom Deutschen Konsoritum für Familiären Brust- und Eierstockkrebs definierten acht Core-Gene analysiert wurden. Die DNA-Proben dieser Patienten wurden in allen konsortialen Zentren des Deutschen Konsortiums Familiärer Brust- und Eierstockkrebs analysiert. Die Gesamt-Detektionsrate in allen nicht BRCA1/2-Core-Genen betrug dabei 7,4 \%. Die identifizierten Detektionsraten der Mutationen der ACMG-Klasse 4 oder 5 in den einzelnen Genen sind in der Tabelle 4.2 gelistet.

Der Vollständigkeit halber sind in der Tabelle 4.2 noch weitere NGS-Studien mit den jeweiligen Detektiosraten der Sequenzvarianten in den 10 Core-Genen aufgeführt: Castéra et al. (2014), LaDuca et al. (2014), Maxwell et al. (2015), Yablonski-Peretz et al. (2015), Li et al. (2016), Mannan et al. (2016), Eliade et al. (2017), Crawford et al. (2017). 
Tabelle 4.2 Übersicht der Detektionsraten der Mutationen und Varianten unklarer Signifikanz in den 10 Core-Genen

\begin{tabular}{|c|c|c|c|c|c|c|c|c|c|c|c|c|c|c|c|c|c|c|}
\hline \multirow[b]{2}{*}{ Gen } & \multicolumn{18}{|c|}{ Detektionsraten der Mutationen der ACMG-Klasse 4 oder 5 und der Varianten unklarer Signifiknaz (ACMG-Klasse 3) in \% } \\
\hline & $\begin{array}{l}\text { Diese } \\
\text { Arbeit }\end{array}$ & $\begin{array}{l}\text { Castéra } \\
\text { et al. } \\
(2014)\end{array}$ & $\begin{array}{l}\text { LaDuca } \\
\text { et al. } \\
(2014) \\
\mathrm{MCa}\end{array}$ & $\begin{array}{l}\text { LaDuca } \\
\text { et al. } \\
\text { (2014) } \\
\text { OvCa }\end{array}$ & $\begin{array}{l}\text { Tung } \\
\text { et al. } \\
\text { (2015) }\end{array}$ & $\begin{array}{c}\text { Schroeder } \\
\text { et al. } \\
\text { (2015) }\end{array}$ & $\begin{array}{l}\text { Maxwell } \\
\text { et al. } \\
\text { (2015) }\end{array}$ & $\begin{array}{c}\text { Desmond } \\
\text { et al. } \\
\text { (2015) }\end{array}$ & $\begin{array}{l}\text { Lincoln } \\
\text { et al. } \\
\text { (2015) }\end{array}$ & $\begin{array}{l}\text { Yablonski } \\
\text {-Peretz } \\
\text { et al. } \\
\text { (2016) }\end{array}$ & $\begin{array}{c}\text { Susswein } \\
\text { et al. } \\
\text { (2016) }\end{array}$ & $\begin{array}{c}\text { Li } \\
\text { et al. } \\
\text { (2016) }\end{array}$ & $\begin{array}{l}\text { Mannan } \\
\text { et al. } \\
(2016)\end{array}$ & $\begin{array}{l}\text { Buys } \\
\text { et al. } \\
\text { (2017) }\end{array}$ & $\begin{array}{l}\text { Eliade } \\
\text { et al. } \\
\text { (2017) }\end{array}$ & $\begin{array}{c}\text { Crawford } \\
\text { et al. } \\
\text { (2017) }\end{array}$ & $\begin{array}{l}\text { Couch } \\
\text { et al. } \\
\text { (2017) }\end{array}$ & $\begin{array}{c}\text { Hauke } \\
\text { et al. } \\
\text { (2018) } \\
\text { DK }^{\#}\end{array}$ \\
\hline ATM & 2,0 & 2,1 & 2,1 & 0,9 & 0,7 & 0,7 & 2,9 & 0,1 & 0,7 & 1,1 & 1,0 & 1,2 & 0,7 & 0,9 & 1,5 & 1,7 & 0,9 & 1,4 \\
\hline BRCA1 & 9,0 & 4,8 & / & / & \multirow{2}{*}{9,1} & 4,8 & / & / & \multirow{2}{*}{9,0} & 3,9 & 1,8 & / & \multirow{2}{*}{26,2} & 23 & \multirow{2}{*}{9,0} & / & \multirow{2}{*}{4,0} & / \\
\hline BRCA2 & 2,0 & 5,6 & / & / & & 4,4 & / & I & & 3,2 & 2,1 & / & & 2,3 & & / & & / \\
\hline $\mathrm{CDH} 1$ & 0,5 & 0,1 & 0 & 0,4 & 0 & 0,5 & 0 & 0,4 & 0,1 & 0 & 0 & 0,2 & 0 & 0,1 & 0 & 0,3 & 0,04 & 0,1 \\
\hline CHEK2 & 3,0 & 2,1 & 2,2 & 0,4 & 1,6 & 0,9 & 4,3 & 1,4 & 0,4 & 0,5 & 2,0 & 2,1 & 0,7 & 1,1 & 3,1 & 3,3 & 5,1 & 3,9 \\
\hline$N B N$ & 0 & 1,1 & 0,1 & 1,3 & 0,2 & 0,3 & 0,4 & 0,2 & 0 & 0 & 0,2 & 0,2 & 0 & 0,2 & - & 0,3 & 0,2 & 0,2 \\
\hline PALB2 & 0,5 & 1,4 & 1,7 & 0,4 & 0,7 & 0,3 & 0,4 & 0,7 & 0,7 & 0 & 0,8 & 2,1 & 2,1 & 0,9 & 0,7 & 1,7 & 0,8 & 1,2 \\
\hline RAD51C & 0,5 & 0,4 & 0,2 & 0,4 & 0 & 0 & 0 & 0,3 & 0,3 & 0,5 & 0,1 & 0,2 & 0,7 & 0,2 & 0 & 0,3 & 0,09 & 0,2 \\
\hline RAD51D & 0 & 0 & - & - & 0 & 0 & - & 0 & 0 & 0 & 0,1 & 0,5 & 0 & 0,1 & - & 0,3 & 0,07 & 0,1 \\
\hline TP53 & 0 & 0,9 & 0,5 & 0,4 & 0,1 & 0,2 & 1,4 & 0,3 & 0 & 0 & 0,4 & 0,9 & 4,9 & 0,2 & 0,5 & 0 & k. A. & 0,3 \\
\hline VUS & 26,0 & - & 19,3 & 25,6 & 41,7 & - & 19,0 & - & 41,0 & 47,0 & - & - & - & - & - & - & - & 14,9 \\
\hline $\begin{array}{c}\text { Weitere } \\
\text { analysierte } \\
\text { Gene }\end{array}$ & nein & ja & ja & ja & ja & nein & ja & ja & ja & ja & ja & ja & ja & ja & ja & ja & ja & nein \\
\hline
\end{tabular}

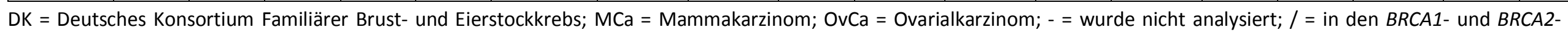

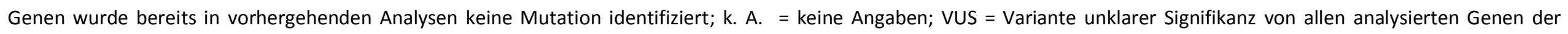
jeweiligen Studie. "In dieser Publikation sind 120 Patienten aus dieser Dissertation miteingeschlossen. 
Die in dieser Arbeit ermittelten Detektionsrate der VUS in den Genen BRCA1 und BRCA2 lag bei $7,0 \%$ und in den anderen acht Core-Genen bei 19,0\%. Die Detektionsraten sind folgendermaßen über die 10 Core-Gene verteilt: 7,5 \% im ATM-Gen, 0,5\% im BRCA1-Gen, 6,0 \% im BRCA2-Gen, 1,0 \% im CDH1-Gen, jeweils 4,5 \% in den Genen CHEK2, NBN und PALB2, 2,5 \% im RAD51C-Gen, 3,0\% im RAD51D-Gen und 0,5\% im TP53-Gen. Im Vergleich dazu identifizierten LaDuca et al. (2014) bei 19,3 \% der Patienten mit Verdacht auf ein hereditäres Mammakarzinom und bei 25,6 \% der Patienten mit Verdacht auf ein hereditäres Ovarialkarzinom mindestens eine VUS. Tung et al. (2015) zeigten eine Detektionsrate der VUS von 41,7 \%, Maxwell et al. (2015) von 19,0 \%, Lincoln et al. (2015) von 41,0 \%, Yablonski-Peretz et al. (2016) von $47 \%$ und Hauke et al. (2018) von 14,9 $\%$. In der Kohorte zu dieser Dissertation wurden insgesamt 71 Varianten unklarer Signifikanz in den nicht BRCA1- und BRCA2-Core-Genen bei 59 Patienten identifiziert, d. h. 1,2 Sequenzvarianten unklarer Signifikanz pro Patient mit der identifizierten Sequenzvariante der ACMGKlasse 3 bzw. 0,3 Sequenzvarianten der ACMG-Klasse 3 über die gesamte untersuchte Kohorte von 200 Patienten. Kurian et al. (2014) identifizierten 428 Varianten unklarerer Signifikanz in 39 Genen bei 175 Patienten, d. h. 2,1 VUS pro Patient der untersuchten Kohorte. In den Arbeiten zu dieser Dissertation wurde dagegen eine deutlich geringere Anzahl von VUS identifiziert als in der Studie von Kurian et al. Die Prozentzahl der detektierten VUS in dieser Dissertation liegt dennoch höher als die Detektionsrate der wahrscheinlich pathogenen und pathogenen Mutationen in den analysierten Genen. In den Studien zu dieser Dissertation spiegelten sich bereits publizierte Daten über eine hohe Detektionsrate von VUS in den nicht BRCA1- und BRCA2-Genen wider und die Detektionsraten der wahrscheinlich pathogenen und pathogenen Mutationen in diesen Genen lag somit deutlich niedriger. Daher sind weitere Segregationsanalysen in den Familien sowie funktionelle Analysen notwendig, um diese VUS in Zukunft optimaler zu charakterisieren bzw. auch evtl. reklassifizieren zu können.

Insgesamt konnten im Rahmen dieser Doktorarbeit bei 17,5 \% der Familien mit Verdacht auf ein hereditäres Mamma- und Ovarialkarzinom der molekulargenetische Ursprung dieser Erkrankung aufgeklärt werden. Allerdings konnte bei der Mehrzahl der Patienten die familiäre Häufung von Tumoren nicht einem hereditären Ursprung zugeordnet werden. Somit muss von weiteren genetischen als auch zusätzlichen nicht genetischen Faktoren bei diesen Patienten/Familien ausgegangen werden. Wie bereits oben erwähnt, wurden in anderen Studien teilweise andere bzw. zusätzliche Gene bei den Patienten analysiert und so konnten zu einem geringen Anteil weitere pathogene Mutationen identifziert werden (s. Tab. 4.2).

Ein weiterer wichtiger Aspekt für weitere Aufklärung der hereditären Genese des Mamma- und Ovarialkarzinoms stellt der Polygenic Risk Score (PRS) dar. Der PRS wird anhand der in GWAS(Genome-Wide Association Study)-Studien definierten Einzelnukleotid-Polymorphismen (SNP; Single Nucleotide Polymorphism) berechnet (Li et al. 2017). Einzelne SNPs sind mit einem relativen Risiko von etwa 1,05 bis 1,3 ein Mammamakarzinom zu entwickeln assoziiert (Michailidou et al. 2013; Michailidou et al. 2015). Die Studie von Li et al. 2017 zeigte eine hoch signifikante Differenz zwischen dem PRS bei Frauen mit einem diagnostizierten Mammakarzinom und gesunden Frauen in der Kontrollkohorte. Somit könnte in Zukunft der PRS eventuell eine wichtige Rolle in der weiteren Aufklärung der Erblichkeit von Mamma- und Ovarialkarzinomen spielen.

\subsubsection{Detektionsraten der Mutationen der ACMG-Klasse 4 oder 5 in einzelnen Core-Genen}

Vorangegangene Studien bei Patienten mit Verdacht auf ein hereditäres Mamma- und Ovarialkarzinom hatten gezeigt, dass die Mehrzahl der Mutationen bei diesen Patienten in den Genen BRCA1 und BRCA2 identifiziert werden konnte (s. Tab. 4.2). In den Arbeiten zu dieser Dissertation wurde eine Detektionsrate von 11,0 \% der Mutationen der ACMG-Klasse 4 oder 5 in 
den Genen BRCA1 und BRCA2 detektiert. 9,0 \% der Mutationen wurden im BRCA1-Gen nachgewiesen und nur 2,0\% der Mutationen im BRCA2-Gen identifiziert.

In der untersuchten Kohorte zu dieser Doktorarbeit wurden 3,0 \% der Mutationen der ACMGKlasse 4 oder 5 im CHEK2-Gen detektiert. Die Detektionsraten der Mutationen im CHEK2-Gen sind in den verschiedenen früheren Studien in unterschiedlichen Größenordnungen vertreten, $d . h$. dort konnten Detektionsraten von $0,4 \%$ bis zu 5,1 \% ermittelt werden (s. Tab. 4.2).

Mutationen im ATM-Gen werden in der Literatur mit einer Häufigkeit von 0,1 \% bis 2,9 \% angegeben (s. Tab. 4.2). Die Detektionsrate von $2 \%$ der Mutationen im ATM-Gen in der Studie zu dieser Dissertation stimmen daher mit den publizierten Detektionsraten überein.

In den Genen CDH1, PALB2 und RAD51C konnten in dieser Doktorarbeit nur vereinzelt Mutationen der ACMG-Klasse 4 oder 5 identifiziert werden und zwar jeweils in 0,5\% der Fälle. Die Detektionsraten der Mutationen in den Genen CDH1 und RAD51C aus dieser Doktorarbeit stimmen mit den publizierten Daten überein. So werden die publizierten Detektionsraten der Mutationen im CDH1-Gen mit bis zu 0,5\% angegeben (s. Tab. 4.2) und die publizierten Detektionsraten der Mutationen der ACMG-Klasse 4 oder 5 im RAD51C-Gen mit bis zu 0,7 \% (s. Tab. 4.2). Die in der Literatur angegebenen Detektionsraten für Mutationen der ACMG-Klasse 4 oder 5 im PALB2-Gen liegen jedoch etwas höher (bis zu 2,1 \%) im Vergleich zu den ermittelten Daten aus der Kohorte dieser Dissertation (s. Tab. 4.2).

In den Genen NBN, RAD51D und TP53 wurde in der Kohorte dieser Dissertation keine Mutation $\operatorname{der} A C M G$-Klasse 4 oder 5 detektiert. Mutationen der ACMG-Klasse 4 oder 5 im NBN-Gen wurden in den vorangegangenen Studien zu einem niedrigen Prozentsatz detektiert und zwar bis 0,4 \% (s. Tab. 4.2). In den Studien von LaDuca et al., Castéra et al. 2014 und Kurian et al. 2014 konnten dagegen Mutationen im NBN-Gen zu einem höheren Prozentsatz von bis zu 1,3\% identifiziert werden (s. Tab. 4.2). Mutationen der ACMG-Klasse 4 oder $5 \mathrm{im}$ TP53-Gen wurden in drei Studien zu einem höheren Prozentsatz detektiert, nämlich in der Studie von Castéra et al. (2014) mit einer Detektionsrate von 0,9 \%, in der Studie von Maxwell et al. (2015) mit einer Detektionsrate von 1,4 \% sowie in der Studie von Mannan et al. (2016) mit einer Detektionsrate von 4,9\%. In der Mehrzahl der früheren Studien wurden Mutationen der ACMG-Klasse 4 oder 5 im TP53-Gen bei Verdacht auf ein hereditäres Mamma- und Ovarialkarzinom in bis zu 0,9\% der Fälle identifiziert (s. Tab. 4.2). Interessanterweise wurde das RAD51D-Gen in vielen Studien mit Verdacht auf ein hereditäres Mamma- und Ovarialkarzinom nicht mitanalysiert. In den Studien, in denen das RAD51D-Gen analysiert wurde, konnten Mutationen in diesem Gen zu einem niedrigen Prozentsatz von $0 \%$ bis maximal $0,5 \%$ nachgewiesen werden (s. Tab. 4.2).

Die in der Kohorte zu dieser Dissertation identifizierten Detektionsraten der Mutationen der ACMG-Klasse 4 oder 5 bei Patienten mit Verdacht auf ein hereditäres Mamma- und Ovarialkarzinom sind größtenteils mit den bereits publizierten Daten vergleichbar. Da jedoch in den vorangegangenen Studien unterschiedliche Einschlusskriterien für eine hereditäre Form des Mamma- und Ovarialkarzinoms berücksichtigt wurden, sind die Detektionsraten nicht direkt miteinander vergleichbar, jedoch stimmen die Größenordnungen überein.

\subsubsection{Typen der identifizierten Sequenzvarianten}

Zum jetzigen Zeitpunkt sind nur wenige Studien bekannt, die systematisch die Verteilung der identifizierten Typen der Sequenzvarianten der ACMG-Klasse 3, 4 oder 5 in allen untersuchten Genen analysierten. Diese Daten sind vor allem für die BRCA1- und BRCA2-Gene bekannt. Manche Studien fokussierten sich nur auf spezifische Typen der Sequenzvarianten oder nur auf einzelne Gene. 
In zu dieser Doktorarbeit konnte die Mehrzahl der identifizierten Sequenzvarianten der ACMGKlasse 3, 4 oder 5 den missense-Sequenzvarianten zugeordnet werden (48,1\%), gefolgt von frame-shift-Sequenzvarianten (19,8\%) und von jeweils $10,4 \%$ nonsense- und synonymenSequenzvarianten. Es wurden weiterhin splicing- bzw. potentielle splicing-Sequenzvarianten $(8,5$ \%) nachgewiesen, große Deletionen (1,9\%) detektiert und in-frame-Deletionen (0,9\%) identifiziert. Die Mehrzahl der missense-Sequenzvarianten entsprach der ACMG-Klasse 3 (94,1\%) und nur 5,9\% der $A C M G$-Klasse 4 oder 5 . Alle synonymen-Sequenzvarianten und die Mehrzahl der potentiellen splicing-Sequenzvarianten (66,7 \%) wurden als $A C M G$-Klasse 3 eingestuft. Alle frame-shift und großen Deletionen sowie mehr als die Hälfte der nonsense-Mutationen (54,5\%) wurden als Mutationen der ACMG-Klasse 4 oder 5 eingestuft. Castéra et al. (2014) und Cybulski et al. (2015a) berichteten nur über trunkierende- und splicing-Mutationen als Mutationen der ACMG-Klasse 4 oder 5 in den jeweiligen untersuchten Kohorten. Lincoln et al. (2015) identifizierten in der untersuchten Kohorte mit den wahrscheinlich pathogenen und pathogenen Mutationen folgende Typen von Mutationen: 52,3 \% kleine Indels (kleine Insertionen und Deletionen), 34,2 \% Punktmutationen, 8,4 \% Kopienzahlvarianten, 3,5 \% große Indels (große Insertionen und Deletionen) und 1,5\% komplexe Veränderungen. Mannan et al. (2016) konnten in den BRCA1- und BRCA2-Genen frame-shift-Mutationen, eine große Deletion, nonsense- und splicing- Mutationen identifizieren, jedoch keine missense-Mutation nachweisen. In den restlichen analysierten Genen wurden jeweils zwei missense- und splicing-Mutationen sowie jeweils fünf nonsense- und frame-shift-Mutationen identifiziert.

Die Verteilung der Typen der Sequenzvarianten in dieser Dissertation spiegelt die Ergebnisse der bereits publizierten Daten von Cybulski et al. (2015a), Castéra et al (2014), Lincoln et al. (2015) und Mannan et al. (2016) wider.

Von insgesamt 51 der identifizierten missense-Sequenzvarianten in der untersuchten Kohorte dieser Dissertation wurden nur acht in den BRCA1 und BRCA2 Genen detektiert. Insgesamt wurden nur drei der identifizierten missense-equenzvarianten als wahrscheinlich pathogene bzw. pathogene Mutationen bewertet. Jeweils eine Mutation der ACMG-Klasse 5 wurde in den Genen BRCA1 und BRCA2 identifiziert sowie eine Mutation der ACMG-Klasse 4 im CHEK2-Gen. Von 21 nachgewiesenen pathogenen frame-shift-Mutationen wurden 14 Mutationen $(66,7 \%)$ in den Genen BRCA1 und BRCA2 identifiziert und die restlichen sieben Mutationen $(33,3 \%)$ in den anderen acht Core-Genen detektiert.

Sowohl an den Daten aus dieser Doktorarbeit als auch an den Daten aus anderen Studien ist erkennbar, dass sich die Sequenzvarianten mit wahrscheinlich pathogenem oder pathogenem Charakter eher als trunkierende Mutationen darstellen. Jedoch muss dieser Trend kritisch betrachtet werden, da die identifizierten missense-Mutationen in den nicht BRCA1/2-Core-Genen oftmals weniger zuverlässig beurteilt und dementsprechend klassifiziert werden können. Aufgrund der fehlenden Datenlage zum genauen Einfluss dieser Gene und deren missenseVarianten auf die Entstehung des Mamma- und Ovarialkarzinoms auf der einen Seite und fehlender strukturierter Untersuchungen größerer Patienten-Kohorten auf der anderen Seite werden diese Sequenzvarianten daher häufig als VUS eingestuft.

\subsubsection{Tumortypen und Rezeptorstatus der Mammakarzinome}

In den bereits publizierten Studien wurden nur vereinzelt Ergebnisse zur Assoziation der histologischen Tumortypen der Mamakarzinome und des Rezeptorstatus im Gewebe des Mammakarzinoms mit den identifizierten Sequenzvarianten der ACMG-Klasse 3, 4 oder 5 berichtet.

In der in dieser Dissertation analysierten Kohorte wurde bei 21 Patienten $(20,0 \%)$ mit einem invasiv duktalen Mammakarzinom, bei vier Patienten (25,0 \%) mit einem invasiv lobulären Mammakarzinom, bei drei Patienten $(9,7 \%)$ mit einem DCIS und bei keinem der Patienten mit 
einem medullären Mammakarzinom eine wahrscheinlich pathogene oder pathogene Mutation in einem der 10 Core-Genen identifiziert. Bei Patienten mit der Diagnose eines invasiven Mammakarzinoms, insbesondere eines invasiv duktalen Mammakarzinoms, lag die Detektionsrate der Sequenzvarianten der ACMG-Klasse 3, 4 oder 5 in den 10 Core-Genen am höchsten (42,9\%) und war statistisch signifikant.

In dieser Arbeit konnte eine Assoziation der identifizierten Sequenzvariante der ACMG-Klasse 3, 4 oder 5 in einem der 10 Core-Gene mit der Expression des ER $\alpha$ und des PR im Tumorgewebe aufgezeigt werden. Bei einem exprimierten ER oder einem exprimierten PR im Mammakarzinom wurde eine signifikant höhere Detektionsrate $(p<0,01$ bzw. $p=0,01)$ der Sequenzvarianten der ACMG-Klasse 3, 4 oder 5 in den nicht BRCA1/2-Core-Genen verzeichnet als in den Genen BRCA1 und $B R C A 2$ sowie in Mammakarzinomen ohne nachgewiesene Expression des ER oder des PR. In der genomischen DNA aus Lymphozyten von Patienten mit Mammakarzinomen ohne Expression des ER $\alpha$ und des PR wurden im BRCA1-Gen signifikant höhere Detektionsraten der Mutationen der ACMG-Klasse 4 oder 5 identifiziert als in den anderen neun Core-Genen. Wenn der ER $\alpha$ oder der PR im Mammakarzinom exprimiert vorlag, war die Wahrscheinlichkeit erhöht eine Sequenzvariante der ACMG-Klasse 3, 4 oder 5 in den anderen neun nicht BRCA1-Core-Genen zu detektieren. In der Studie von Maxwell et al. (2015) wiesen 147 von 214 Patienten (69,0 \%) ein invasives Mammakarzinom mit einer Expression des ER $\alpha$ im Tumor auf. Bei 19 dieser Patienten $(12,9 \%)$ wurde eine pathogene Mutation identifiziert. Insgesamt waren in der Studie von Maxwell et al. (2015) 49 Patienten (22,9\%) mit einem invasiven Mammakarzinom und einem im Tumor überexprimiertem ERBB2-Rezeptor eingeschlossen. Bei sieben dieser Patienten (14,3\%) konnte eine pathogene Mutation nachgewiesen werden. In der Studie des Deutschen Konsortiums Familiärer Brust- und Eierstockkrebs von Hauke et al. (2018) zeigten 2.355 der untersuchten Mammakarzinome eine Expression des ER $(75,7$ \%), 2.188 der Mammakarzinome eine Expression des PR (70,5\%) und 657 der Mammakarzinome eine Überexpression des ERBB2Rezeptors (21,7 \%). Bei 7,3 \% der Patienten mit exprimiertem ER $\alpha$ im Mammakarzinom, bei 7,1 \% der Patienten mit exprimiertem PR und bei 7,9\% der Patienten mit überexprimiertem ERBB2Rezeptor wurde eine Mutation der ACMG-Klasse 4 oder 5 in einem der acht nicht BRCA1/BRCA2Core-Gene detektiert.

Bei 50 \% der Patienten mit triple-negativen Mammakarzinomen (kein Nachweis der Expression des ER $\alpha$, des PR und ohne Überexpression des ERBB2-Rezeptors im Tumorgewebe) wurde in dieser Dissertation eine Sequenzvariante der ACMG-Klasse 3, 4 oder 5 identifiziert. Weiterhin wurden insgesamt 13 Mutationen (40,6 \%) der ACMG-Klasse 5 und keine Mutation der ACMGKlasse 4 detektiert. Die nachgewiesene Mutationsrate in triple-negativen Mammakarzinomen entspricht einer statistisch signifikanten Detektionsrate im Vergleich zu Patienten ohne ein diagnostiziertes triple-negatives Mammakarzinom $(p=0,001)$. Zehn dieser pathogenen Mutationen $(75,0 \%)$ wurden im BRCA1-Gen identifiziert und jeweils eine Mutation wurde in den Genen BRCA2, ATM und PALB2 detektiert. Somit konnte eine Detektionsrate von 34,4\% aller identifizierten pathogenen Mutationen in den Genen BRCA1 und BRCA2 bei Patienten mit triplenegativen Mammakarzinomen verzeichnet werden. Die triple-negativen Mammakarzinome werden allgemein in etwa $11 \%$ - $24 \%$ aller diagnostizierten Mammamakarzinome nachgewiesen (Dent et al. 2007; Foulkes et al. 2010; Stevens et al. 2013; Hahnen et al. 2017a). In dieser Doktorarbeit wurde bei $18,5 \%$ der an einem Mammakarzinom erkrankten Patienten ein triplenegatives Mammakarzinom diagnostiziert, was somit den publizierten Daten entspricht. Die vom Deutschen Konsortium Familiärer Brust- und Eierstockkrebs generierten Daten mit 16.979 an einem Mammakarzinom erkrankten Indexpatienten zeigten ein triple-negatives Mammakarzinom in 21,6 \% der Fälle (Hahnen et al. 2017a, s. Tab. 4.3). Couch et al. (2015) zeigten in 12,2 \% der Patienten mit einem triple-negativen Mammakarzinom und positiver Familienamanese eine 
pathogene Mutation (s. Tab. 4.3). Die Detektionsraten in dieser Dissertation geben die Detektionsraten der bereits publizierten Studien wieder. Somit konnte gezeigt werden, dass bei triple-negativen Mammakarzinomen vor allem Mutationen im BRCA1-Gen zu erwarten sind. Bei Patienten mit triple-negativen Mammakarzinomen wurde in der Studie von Hauke et al. (2018) eine Detektionsrate von Mutationen der ACMG-Klasse 4 oder 5 in einem der acht nicht BRCA1/2Core-Gene von $4,2 \%$ verzeichnet (s. Tab. 4.3).

Tabelle 4.3: Detektionsraten der Mutationen der ACMG-Klasse 4 oder 5 bei Patienten mit triple-negativen Mammakarzinomen

\begin{tabular}{|c|c|c|c|c|}
\hline \multicolumn{5}{|c|}{ Triple-negative Mammakarzinome } \\
\hline $\begin{array}{l}\text { Detektionsrate der Mutationen der } \\
\text { ACMG-Klasse } 4 \text { oder } 5\end{array}$ & Diese Arbeit & $\begin{array}{l}\text { Couch et al. } \\
\qquad(2015)\end{array}$ & $\begin{array}{l}\text { Hahnen et al. } \\
\qquad(2017 a)\end{array}$ & $\begin{array}{l}\text { Hauke et al. } \\
\qquad(2018)\end{array}$ \\
\hline Allgemeine Detektionsrate in \% & 40,6 & 12,2 & 39,0 & 4,2 \\
\hline \multirow{3}{*}{ Einzelne Gene in \% } & BRCA1: 31,3 & \multirow{3}{*}{$\begin{array}{c}B R C A 1 / 2: \\
12,2\end{array}$} & $B R C A 1: 34,2$ & \multirow{3}{*}{$\begin{array}{c}\text { Acht nicht } \\
\text { BRCA1/2- } \\
\text { Core-Gene: } \\
4,2\end{array}$} \\
\hline & BRCA2: 3,1 & & & \\
\hline & ATM, PALB2: 6,3 & & & \\
\hline
\end{tabular}

Die Detektionsrate von 7,1\% der Mutationen der ACMG-Klasse 4 oder 5 war höher bei Patienten mit mindestens einem exprimierten Rezeptor im Tumorgewebe des Mammakarzinoms. Wenn andere (nicht BRCA1- und BRCA2-Gene) mit dem Mammakarzinom assoziierte Gene betrachtet werden, wurde für Mutationen in den Genen PALB2 und FANCM eine Assoziation mit einem triple-negativen Mammakarzinom aufgezeigt (Kiiski et al. 2014; Cybulski et al. 2015b). Die Patientenkohorte mit triple-negativen Mammakarzinomen in der vorliegenden Dissertation ist jedoch nicht umfassend genug um repräsentative Detektionsraten für andere Core-Gene generieren zu können. Im Rahmen dieser Doktorarbeit konnte jedoch nur eine Mutation der ACMG-Klasse 5 im PALB2-Gen bei einem Pateinten mit triple-negativen Mammakarzinom identifiziert werden.

Die bereits publizierten Daten wiesen auf eine Assoziation der diagnostizierten triple-negativen Mammakarzinome zu einem erniedrigten Erkrankungalter der Patienten hin im Vergleich zu Patienten mit einem anderen Rezeptorstatus des Mammakarzinoms (Sharma et al. 2014; Couch et al. 2015). Ebenso zeigen die Daten aus dieser Dissertation, dass Patienten mit einem vorliegenden triple-negativen Mammakarzinom mit einem niedrigeren mittleren Erkrankungsalter von 41,8 Jahren diagnostiziert wurden. Im Vergleich dazu waren die Patienten mit einem anderen Rezeptorstatus des Mammakrzinoms mit einem mittleren Alter von 47,8 Jahren erkrankt. Das niedrigste Erkrankungsalter wiesen Patienen mit einem triple-negativen Mammakarzinom und einer identifizierten pathogenen Mutation der ACMG-Klasse 5 in einem der 10 Core-Gene auf.

Bei etwa $9 \%$ - $18 \%$ der nicht selektieren Patienten mit triple-negativen Mammakarzinomen und bei bis zu $40 \%$ der Patienten mit früh aufgetretendem Mammakarzinom bzw. einer familiären Form des Mammakarzinoms werden Keimbahnmutationen in den Genen BRCA1 und BRCA2 identifiziert. Es wurde gezeigt, dass Träger einer BRCA1- oder BRCA2-Mutation besser auf die Therapie mit Medikamenten, die die DNA-Reparaturmechanisem beeinflussen, ansprechen, inklusive PARP-Inhibitoren. Somit kann der Mutationsstatus bei Patienten mit den triplenegativen Mammakarzinomen als ein Biomarker für die Antwort auf die Therapie angesehen werden (Hahnen et al. 2017b). In einer Studie mit neoadjuvanter Therapie mittels Cisplatin wurde bei $61 \%$ der Patienten mit einem triple-negativen Mammakarzinom und einer BRCA1Keimbahnmutation eine pathologische Komplettremission (keine Tumorresiduen im Mammagewebe sowie in den Lymphknoten) gezeigt (Byrski et al. 2014). Eine weitere Studie von Hahnen et al. (2017b) zeigte, dass Frauen mit triple-negativen Mammakarzinomen und einer 
Mutation im BRCA1-Gen oder im BRCA2-Gen eine bessere pathologische Komplettremission (урTO/is und ypNO) nach einer neoadjuvanten Chemotherapie mit Anthracyclinen, Taxanen und Bevacizumab aufweisen als Frauen ohne eine Mutation in einem dieser zwei Gene (66,7 \% vs. 36,4 $\%)$.

Die hier erhobenen Assoziationen sollten jedoch mit Vorsicht betrachtet werden. Die PatientenKohorte der Studie dieser Dissertation ist wegen ihrer Größe nicht als repräsentativ genügend zu betrachten, um die identifizierten Assoziationen auf die allgemeine Bevölkerung übertragen zu können. Aufgrund fehlender systematischer Daten bei anderen großen Studien zu den Assoziationen der nicht BRCA1/2-Gene mit dem histologischen Subtyp sowie dem Rezeptorstatus der Mammakarzinome ist ein direkter Vergleich daher nur begrenzt möglich.

\subsubsection{Weitere Tumorerkrankungen in den Familien}

Bei vielen Familien der untersuchten Indexpatienten und bei den Indexpatienten selbst mit Verdacht auf ein hereditäres Mamma- und Ovarialkarzinom zeigte die Anamnese neben dem Mamma- und Ovarialkarzinom ein breites Spektrum an zusätzlichen Tumorerkrankungen.

In dieser Arbeit waren 183 Patienten (91,5\%) an einem Mamma- oder Ovarialkarzinom erkrankt. $11,0 \%$ der untersuchten Patienten erkrankten an einem beidseitigen Mammakarzinom. Eine Patientin (0,5 \%) war an einem Mamma- und einem kolorektalen Karzinom erkrankt (s. Tab. 4.4). In den Studien von LaDuca et al. (2014), Desmond et al. (2015) und Lincoln et al. (2015) wurden ebenfalls weitere Tumorerkrankungen, außer dem Mamma- und Ovarialkarzinom, bei den Indexpatienten ermittelt (s. Tab. 4.4).

Tabelle 4.4: Weitere Tumorerkrankungen bei Indexpatienten (außer Mammakarzinomen und Ovarialkarzinomen)

\begin{tabular}{|c|c|c|c|c|}
\hline $\begin{array}{c}\text { Weitere Tumorerkrankungen } \\
\text { bei Indexpatienten } \\
\text { (außer MCa und OvCa) }\end{array}$ & $\begin{array}{c}\text { Diese Arbeit } \\
\text { in \% }\end{array}$ & $\begin{array}{c}\text { LaDuca et al. } \\
(2014) \\
\text { in \% }\end{array}$ & $\begin{array}{c}\text { Desmond et al. } \\
\text { (2015) } \\
\text { in \% }\end{array}$ & $\begin{array}{c}\text { Lincoln et al. } \\
(2015) \\
\text { in \% }\end{array}$ \\
\hline Endometriumkarzinom & $\mathbf{0}$ & 8,5 & 1,8 & 1,6 \\
\hline Kolorektales Karzinom & $\mathbf{0 , 5}$ & 1,7 & 6,0 & 1,2 \\
\hline Pankreaskarzinom & $\mathbf{0}$ & 0,7 & 0,3 & 1,3 \\
\hline
\end{tabular}

$\mathrm{MCa}=$ Mammakarzinom; OvCa $=$ Ovarialkarzinom .

Neben den Mamma- und Ovarialkarzinomen konnten in 102 Familien (51,0 \%) dieser Dissertation noch weitere Tumorerkrankungen diagnostiziert werden, am häufigsten wurde ein kolorektales Karzinom (52,3 \%) beobachtet, gefolgt vom Prostatakarzinom in 24,5 \% der Fälle und an dritter Stelle wurde in jeweils 15,7 \% der Fälle ein Magen- und Pankreaskarzinom nachgewiesen. Kwong et al. (2016) berichteten in den Familien mit Verdacht auf ein hereditäres Mamma- und Ovarialkarzinom bei 691 von 948 Patienten (73,0 \%) von weiteren (außer Mamma- und Ovarialkarzinomen) Tumorerkrankungen. Diese Daten zeigen, dass das Tumorspektrum bei Verdacht auf ein hereditäres Mamma- und Ovarialkarzinomsyndrom nicht nur die klassischen bereits bekannten Tumorerkrankungen enthält, sondern eventuell auf weitere Tumorerkrankungen ausgeweitet werden sollte. Eine Assoziation von Mutationen in den BRCAGenen mit dem Auftreten eines Prostata- und Pankreaskarzinoms war bereits aus einer früheren Studie bekannt (Meindl et al. 2015). Ebenso war bei dem Nachweis von Mutationen in den Genen CDH1, CHEK2, PALB2 und TP53 eine Assoziation mit weiteren Tumorerkrankungen beschrieben worden (Oliveira et al. 2013; Jones et al. 2009; Slater et al. 2010; Tischkowitz et al. 2009; Valdez et al. 2017).

Um genaue Tumorspektren definieren zu können, sind weitere Analysen, wie z. B. Segregationsanalysen der identifizierten Mutationen bei Familienmitgliedern mit anderen (nicht 
Mamma- und Ovarialkarzinom) Tumorerkrankungen notwendig. Somit könnte spezifiziert werden, ob die in den Familien diagnostizierten weiteren Tumorerkrankungen mit der für ein hereditäres Mamma- und Ovarialkarzinom ursächlichen Mutation assoziiert sind. Es muss ebenfalls in Betracht gezogen werden, dass die zusätzlichen identifizierten Tumorerkrankungen in den Familien dieser Kohorte einen anderen Ursprung haben könnten. Eine systematische Segregationsanalyse wurde hier nicht vorgenommen. Dies war aus geographischen Gründen, nicht greifbaren Patienten, ärztlicher Schweigepflicht und bereits vieler verstorbener Patienten systematisch nicht realisierbar.

\subsection{Vergleich der Detektionsraten der Sequenzvarianten der ACMG-Klasse}

\section{3, 4 oder 5 der NGS-Technologie mit der Sanger- Sequenzierungstechnologie}

Bevor die NGS-Technologie im Institut für Humangenetik der UMG im Jahre 2015 eingeführt wurde, wurde den Patienten mit den erfüllten Kriterien für eine molekulargenetische Analyse (definiert vom Deutschen Konsortium Familiärer Brust- und Eierstockkrebs) bei Verdacht auf ein hereditäres Mamma- und Ovarialkarzinom eine Sequenzierungsanalyse der Gene BRCA1 und BRCA2 mittels Sanger-Technologie angeboten.

Um zu vergleichen, ob sich die Detektionsraten der Sequenzvarianten der ACMG-Klasse 3, 4 oder 5 der NGS- und der Sanger-Sequenzierungstechnologie für die Gene BRCA1 und BRCA2 unterscheiden und ob sich die Detektionsraten der Core-Gene im Vergleich zu den Detektionsraten in den Genen BRCA1 und BRCA2 verbessert haben, wurden die Detektionsraten aller 200 Patienten dieser Dissertation mit den Detektionsraten der retrospektiven Patienten, die mittels Sanger-Sequenzierungstechnologie analysiert wurden, verglichen. Es wurden 124 retrospektive Patienten ausgewählt, bei denen die Gene BRCA1 und BRCA2 mittels SangerSequenzierung von Januar bis Dezember 2014 im Institut für Humangenetik der UMG (Auswertung der Gene BRCA1 und BRCA2 mittels Sanger-Sequenzierung durch Prof. Dr. I. Adham) analysiert wurden.

Die Detektionsrate der Sequenzvarianten der ACMG-Klasse 3, 4 oder 5 der Sanger-Sequenzierung der analysierten Gene BRCA1 und BRCA2 wurde mit der Detektionsrate dieser zwei Gene mittels NGS-Technologie verglichen.

Es konnte keine statistisch signifikante Differenz zwischen den Detektionsraten der Sequenzvarianten der ACMG-Klasse 3, 4 oder 5 ( $p=0,12 ;$ s. Tab. 4.5) oder den Mutationen der ACMG-Klasse 4 oder 5 ( $p=0,49$; s. Tab. 4.6) der Sanger- bzw. der NGS-Technologie für die BRCA1und $B R C A 2-G e n e$ festgestellt werden. Die Detektionsrate der Sequenzvarianten der ACMG-Klasse 3, 4 oder 5 in den Genen BRCA1 und BRCA2 mittels Sanger-Sequenzierung betrug 25,0\% (s. Tab. 4.5) und die Detektionsrate der Mutationen der ACMG-Klasse 4 oder 5 in den o. g. zwei Genen lag bei 14,0 \% (s. Tab. 4.6). Die Detektionsrate der Sequenzvarianten der ACMG-Klasse 3, 4 oder 5 in den Genen BRCA1 und BRCA2 mittels der NGS-Technologie betrug $17,5 \%$ (s. Tab. 4.5) und die Detektionsrate der Mutationen der ACMG-Klasse 4 oder 5 in den o. g. zwei Genen lag bei $11,0 \%$ (s. Tab. 4.6).

Tabelle 4.5: Detektionsraten der identifizierten Sequenzvarianten der ACMG-Klasse 3, 4 oder 5 in den Genen BRCA1 und BRCA2 mittels Sanger-Sequenzierung und NGS-Technologie

\begin{tabular}{|c|c|c|}
\hline $\begin{array}{c}\text { Sequenzvarianten der } \boldsymbol{A C M G - K l a s s e ~} 3,4 \text { oder } 5 \\
\text { in den Genen BRCA1 oder BRCA2 }\end{array}$ & $\begin{array}{c}\text { Sanger-Sequenzierung } \\
\text { Anzahl (\%) } \\
\end{array}$ & $\begin{array}{c}\text { NGS } \\
\text { Anzahl (\%) }\end{array}$ \\
\hline vorhanden & $31(25,0)$ & $35(17,5)$ \\
\hline nicht vorhanden & $93(75,0)$ & $165(82,5)$ \\
\hline p-Wert (Exakter Fisher-Test) & \multicolumn{2}{|c|}{$p=0,12$} \\
\hline
\end{tabular}


Tabelle 4.6: Detektionsraten der Mutationen der ACMG-Klasse 4 oder 5 in den Genen BRCA1 und BRCA2 mittels Sanger-Sequenzierung und NGS-Technologie

\begin{tabular}{|c|c|c|}
\hline $\begin{array}{c}\text { Mutationen der ACMG-Klasse 4 oder 5 } \\
\text { in den Genen BRCA1 oder BRCA2 }\end{array}$ & $\begin{array}{c}\text { Sanger-Sequenzierung } \\
\text { Anzahl (\%) }\end{array}$ & $\begin{array}{c}\text { NGS } \\
\text { Anzahl (\%) }\end{array}$ \\
\hline vorhanden & $17(14,0)$ & $22(11,0)$ \\
\hline nicht vorhanden & $107(86,0)$ & $178(89,0)$ \\
\hline$p$-Wert (Exakter Fisher-Test) & \multicolumn{2}{|c|}{$p=0,49$} \\
\hline
\end{tabular}

Weiterhin wurden die Detektionsraten der Sequenzvarianten der ACMG-Klasse 3, 4 oder 5 aller untersuchten 10 Core-Gene der NGS-Technologie mit den Detektionsraten der untersuchten Gene $B R C A 1$ und $B R C A 2$ mittels Sanger-Sequenzierung miteinander verglichen.

Mittels Sanger-Sequenzierung wurden insgesamt 31 Sequenzvarianten der ACMG-Klasse 3, 4 oder 5 bei 31 Patienten $(25,0 \%)$ in den Genen BRCA1 und BRCA2 identifiziert (d. h. eine Sequenzvariante pro Patient). Mit Hilfe der NGS-Technologie wurden bei insgesamt 88 Patienten $(44,0 \%)$ Sequenzvarianten der ACMG-Klasse 3, 4 oder 5 in den 10 Core-Genen identifiziert. Diese Detektionsraten unterscheiden sich statistisch signifikant $(p<0,01)$ (s. Tab. 4.7).

Tabelle 4.7: Detektionsraten der identifizierten Sequenzvarianten der ACMG-Klasse 3, 4 oder 5 pro Patient mittels Sanger-Sequenzierung und NGS-Technologie

\begin{tabular}{|c|c|c|}
\hline $\begin{array}{c}\text { Sequenzvarianten der ACMG-Klasse 3, 4 oder 5 } \\
\text { in den untersuchten Genen }\end{array}$ & $\begin{array}{c}\text { Sanger-Sequenzierung } \\
\text { BRCA1 und BRCA2 } \\
\text { Anzahl (\%) }\end{array}$ & $\begin{array}{c}\text { NGS } \\
\text { 10 Core-Gene } \\
\text { Anzahl (\%) }\end{array}$ \\
\hline vorhanden & $31(25,0)$ & $88(44,0)$ \\
\hline nicht vorhanden & $93(75,0)$ & $112(56,0)$ \\
\hline$p$-Wert (Exakter Fisher-Test) & \multicolumn{2}{|c|}{$\mathbf{p < 0 , 0 1}$} \\
\hline
\end{tabular}

Es wurden insgesamt 17 Mutationen der ACMG-Klasse 4 oder 5 mittels Sanger-Sequenzierung bei 17 Patienten $(14,0 \%)$ in den Genen BRCA1 und BRCA2 nachgewiesen (d. h. eine Mutation pro Patient). Mittels NGS-Technologie wurden in allen 10 Core-Genen 35 Mutationen der ACMGKlasse 4 oder 5 bei insgesamt 35 Patienten (18,0\%) (d. h. eine Mutation pro Patient) identifiziert. Diese Detektionsraten unterscheiden sich statistisch nicht signifikant $(p=0,44)$ (s. Tab. 4.8).

Tabelle 4.8: Vergleich der Detektionsraten der identifizierten Mutationen der ACMG-Klasse 4 oder 5 pro Patient mittels Sanger-Sequenzierung und NGS-Technologie

\begin{tabular}{|c|c|c|}
\hline $\begin{array}{c}\text { Mutationen der ACMG-Klasse 4 oder 5 } \\
\text { in den untersuchten Genen }\end{array}$ & $\begin{array}{c}\text { Sanger-Sequenzierung } \\
\text { BRCA1 und BRCA2 } \\
\text { Anzahl (\%) }\end{array}$ & $\begin{array}{c}\text { NGS } \\
\text { 10 Core-Gene } \\
\text { Anzahl (\%) }\end{array}$ \\
\hline vorhanden & $17(14,0)$ & $35(18,0)$ \\
\hline nicht vorhanden & $107(86,0)$ & $165(82,0)$ \\
\hline$p$-Wert (Exakter Fisher-Test) & \multicolumn{2}{|c|}{$\mathrm{p}=0,44$} \\
\hline
\end{tabular}

Aus den vorliegenden Ergebnissen wird einerseits deutlich, dass die Detektionsrate der Sequenzvarianten der ACMG-Klasse 3, 4 oder 5, falls 10 Core-Gene parallel analysiert wurden, statistisch signifikant erhöht ist im Vergleich zur alleinigen Analyse der Gene BRCA1 und BRCA2 mittels der Sanger-Sequenzierungsmethode. Andererseits wird ebenfalls deutlich, dass mit der Untersuchung einer erhöhten Genanzahl die Detektionsrate der Sequenzvarianten der ACMGKlasse 3 (VUS) statistisch signifikant ansteigt. Die Methode der gewählten Analyse selbst (SangerSequenztechnologie vs. NGS) spielte in diesem Fall eine weniger signifikante Rolle, da alle Sequenzvarianten der ACMG-Klasse 3, 4 oder 5, die mittels NGS identifiziert wurden, ebenfalls mit Hilfe der Sanger-Sequenzierung nachgewiesen werden konnten. 
Weiterhin unterscheiden sich die beiden o. g. Sequenzierungstechnologien im laboratorischen Handling, dem Zeitaufwand der Sequenzierung sowie der Kostenintensivität. Die SangerSequenzierung der BRCA1- und BRCA2-Gene (vom Vorliegen der DNA bis zum Einladen der Sequenzen in das Auswerteprogramm SeqPilot) nahm für fünf Patienten etwa zwei Wochen in Anpruch. Im Gegensatz dazu lag die Zeitspanne der NGS-Methode (TruRisk ${ }^{\mathrm{TM}}$ ) für 16 Patienten bei nur einer Woche (vom Vorliegen der DNA bis zum Einladen der Sequenzen in das Auswerteprogramm SeqNext). Die Sequenzierung der 10 Core-Gene per Sanger-Sequenzierung stellt sich somit wesentlich zeitaufwändiger und kostenintensiver dar als die Sequenzierung mit Hilfe der NGS-Methode. Anderseits waren auch alle mittels NGS-Technologie identifizierten Sequenzvarianten der ACMG-Klasse 3, 4 oder 5 auch mittels Sanger-Technologie reproduzierbar. Es stellt sich die Frage, ob der Aufwand der Nachsequenzierung mittels NGS-Methode identifizierter Sequenzvarianten gerechtfertigt ist. Wir postulieren daher, dass die SangerSequenzierung nicht mehr als Goldstandard der Sequenzierung angesehen werden sollte.

\subsection{Beurteilungen der Sanger-Technologie und der Next-Generation- Sequencing (NGS)}

Mit der Sanger-Technologie konnte nur eine begrenzte Anzahl der Gene mit einem großen Zeitund Kostenaufwand analysiert werden, sodass eine möglichst genaue Verdachtdiagnose nötig war. Die Analyse der Gene erfolgte stufenweise entweder nach den bekannten Frequenzen der identifizierten Sequenzvarianten für ein bestimmtes Krankheitsbild oder wenn möglich nach der genauen klinischen Differenzierung der Symptome.

Mit Anwendung der Next-Generation-Sequencing (NGS) ist es möglich multiple Gene bei verschiedenen Indikationen und mehrere Patientenproben parallel zu analysieren. Somit können neben den Hauptgenen für eine bestimmte Erkrankung noch weitere mit der Erkrankung assoziierte Gene analysiert werden. Es können Multi-Gen-Panels mit einer Vielzahl von Genen, meistens bezogen auf ein Krankheitsbild, sowie die entsprechenden Differentialdiagnosen (MultiGen-Panel; kodierende Bereiche sowie Exon-Intron Grenzen der auf dem Panel liegenden Gene), ganze Exome (Whole-Exome-Sequencing; WES; alle kodierende Bereiche sowie Exon-Intron Grenzen des menschlichen Genoms) bzw. das gesamte menschliche Genom (Whole-GenomeSequencing; WGS) analysiert werden. Mit der WGS-Methode ist die Entdeckung neuer Gene bzw. neuer Sequenzvarianten in den tiefen intronischen Regionen oder in Promotor- sowie regulatorischen Bereichen der Gene möglich (Tucker et al. 2009).

Mit den o. g. NGS-Methoden kann somit bei einem Patienten eine Vielzahl von Sequenzvarianten in verschiedenen Genen identifiziert werden. Viele dieser Sequenzvarianten können jedoch nach dem heutigen Wissensstand nicht eindeutig klassifiziert werden, da die entsprechenden Informationen zu den Genotyp-Phänotyp-Assoziationen fehlen. Weiterhin werden vermutlich pathogene Mutationen in Genen identifiziert, die bis dato nicht einem bestimmten Krankheitsbild zugeordnet waren (Johansen Taber et al. 2014). Es steht zweifellos ausser Frage, dass die NGSTechnologie die Diagnosestellung und das Management der Patienten verbessern kann. Dennoch bestehen heutzutage noch viele Herausforderungen bei der Interpretation und der Speicherung der immensen NGS-Daten sowie der Standardisierung für die Anwendung einzelner Technologien und der Kommunikation der Ergebnisse mit den Patienten (Johansen Taber et al. 2014).

\subsection{Multi-Gen-Panel-Analysen (NGS) bei Patienten mit Verdacht auf ein hereditäres Mamma- und Ovarialkarzinom}

Vor der Einführung der NGS-Technologie wurden den Patienten mit Verdacht auf ein hereditäres Mamma- und Ovarialkarzinom und den erfüllten Kriterien vom Deutschen Konsortium Familiärer Brust- und Eierstockkrebs eine molekulargenetische Analyse der BRCA1- und BRCA2-Gene mittels 
der Sanger-Technologie angeboten. Bei Frauen mit einem diagnostizierten Ovarialkarzinom bzw. wenn in der Familie zusätzlich ein Ovarialkarzinom nachgewiesen werden konnte, wurde zusätzlich das RAD51C-Gen per Sanger-Technologie sequenziert. Nach der Einführung der MultiGen-Panel-Diagnostik (NGS) wurde das diagnostische Angebot auf die 10 Core-Gene erweitert. Mit dieser Untersuchung konnte bei weiteren 2,2 \% (Lincoln et al. 2015) bis 18,0 \% (Castéra et al. 2014) der Patienten der hereditäre Ursprung des Mamma- und/oder Ovarialkarzinoms bestätigt/identifiziert werden.

In multiplen publizierten Studien bei Verdacht auf ein hereditäres Mamma- und Ovarialkarzinom wurde mit dem Multi-Gen-Panel (NGS) eine zusätzliche Detektionsrate von etwa 3,9\% bis etwa $38,1 \%$ der wahrscheinlich pathogenen und pathogenen Mutationen in den nicht BRCA1- und BRCA2-Genen beobachtet (s. Tab. 4.2; Chong et al. 2014; Kurian et al. 2014; Cybulski et al. 2015a; Thompson et al. 2016; Kwong et al. 2016). Es besteht daher die begründete Hoffnung, dass mit Hilfe der NGS-Technologie neue krankheitsverursachende Gene bzw. neue Assoziationen zwischen bekannten Genen und neuen Tumorsyndromen entdeckt werden.

Neben den krankheitsverursachenden Mutationen wurde in den nicht BRCA1- und BRCA2-Genen hauptsächlich ein hoher Prozentsatz der VUS identifiziert. In dieser Doktorarbeit wurden $26,0 \%$ der VUS in den acht nicht BRCA1- und BRCA2-Genen detektiert. Solch hohe Detektionsraten der VUS wurden ebenfalls in den Studien von LaDuca et al. (2014); Kurian et al. (2014); Tung et al. (2015); Maxwell et al. (2015); Lincoln et al. (2015); Yablonski-Perez et al. (2016) und Hauke et al. (2018) nachgewiesen. Diese Ergebnisse zeigen deutlich, dass die vorhandenen Datenbanken, die Segregationsanalysen und die funktionellen Studien für die Klassifizierung der Sequenzvarianten nicht im genügenden Umfang etabliert sind. Die Interpretation dieser Sequenzvarianten und die Erläuterung dieser Informationen für den Patienten/Ratsuchenden stellen die jetzigen Problemfelder der modernen humangenetischen Beratung dar (Johansen Taber et al. 2014).

Bei der Mehrzahl der Patienten (in dieser Dissertation bei 82,0\% der Patienten) mit Verdacht auf ein hereditäres Mamma- und Ovarialkarzinom wurde mit der Analyse der 10 Core-Gene keine wahrscheinlich pathogene bzw. pathogene Mutation identifiziert. In mehreren veröffentlichten Studien mit Multi-Gen-Panel-(NGS)-Analysen wurden bei solchen Patienten jedoch in einigen weiteren Genen krankheitsverursachende Mutationen nachgewiesen (Castéra et al. 2014, LaDuca et al. 2014, Tung et al. 2015, Maxwell et al. 2015, Li et al. 2016, Buys et al. 2017, Crawford et al. 2017, Couch et al. 2017). Daraus ergibt sich die Überlegung, ob das diagnostische Spektrum bzgl. der Anzahl der Gene auf einem Multi-Gen-Panel nicht ausgeweitet werden sollte. In 51,0 \% der Familien mit Verdacht auf ein hereditäres Mamma- und Ovarialkarzinomen wurden in dieser Dissertation zusätzlich zu den Mamma- und Ovarialkarzinomen weitere Tumorerkrankungen beobachtet, und am häufigsten wurde dabei ein kolorektales Karzinom diagnostiziert. Zumindest in solchen Familien mit zusätzlichen Tumorerkrankungen, z. B. bei der Diagnose eines kolorektalen Karzinoms, sollte das diagnostische Angebot auf die sog. HNPCC-Gene (MLH1, MSH2, MSH6 und PMS2) ausgeweitet werden, ohne dass die spezifischen Bethesda-Kriterien (Umar et al. 2004) für eine HNPCC-Erkrankung erfüllt sind. Auch in den Familien mit anderen Tumorsprektren z. B. Leukämien, Lymphome, Leber-, Blasen-, Nieren-, Hoden- und Endometriumkarzinome sowie Hauttumore sollte das diagnostische Angebot entsprechend ausgeweitet werden.

Mit der Identifizierung weiterer krankheitsverursachender Mutationen in bestimmten Genen und somit der Klärung der Ursache des Tumorleidens können möglicherweise weitere therapeutische, vorsorgliche bzw. nachsorgliche Konsequenzen für den Patienten resultieren und somit die allgemeine Patientenversorgung verbessert werden.

\subsection{Falldiskussionen}

Die im Rahmen dieser Arbeit durchgeführten Multi-Gen-Panel-Analysen der 10 Core-Gene führten bei 35 Patienten zur Bestätigung der hereditären Form des Tumorleidens. Bei weiteren 53 
Patienten wurden VUS (ACMG-Klasse 3) identifiziert. Vier dieser Mutationen bzw. Sequenzvarianten und ein weiterer aus molekulargenetischer Sicht interessanter Fall werden im Folgenden diskutiert.

\subsubsection{Heterozygote Sequenzvariante c.346G>A im RAD51D-Gen (Indexpatientin 39784)}

Bei der an einem Mammakarzinom erkrankten Indexpatientin 39784 wurde eine Sequenzvariante im Exon 5 (c.346G>A, heterozygot; p.(Val116lle)) des RAD51D-Gens identifiziert. Diese Sequenzvariante wird in der Datenbank des Deutschen Konsortiums Familiärer Brust- und Eierstockkrebs als Sequenzvariante der ACMG-Klasse 3 gelistet. Diese Sequenzvariante wurde noch nicht von der VUS-TaskForce des Deutschen Konsoritums beurteilt. In der Literatur wurde sie bisher nicht beschrieben. Diese Variante liegt in der erweiterten Konsensussequenz der 3'Akzeptor-Spleißstelle im Exon 5 des RAD51D-Gens (Cartegni et al. 2002), was auf eine mögliche Beeinträchtigung des Spleißvorgangs hindeutet. Die Vorhersageprogramme (MutationTaster und PolyPhen-2) deuteten zusätzlich darauf hin, dass durch den stattgefundenen Aminosäureaustausch zur funktionellen Beeinträchtigung des resultierenden Proteins kommen könnte. Bei der funktionellen Abklärung der Sequenzvariante c.346G>A im RAD51D-Gen konnte auf cDNA-Ebene eine Reduktion der RAD51D-Transkriptmenge durch diese Sequenzvariante gezeigt werden. Diese Sequenzvariante im RAD51D-Gen führt höchstwahrschlich zu einem nonsense-mediated mRNA decay (Cartegni et al. 2002), welches auf einen wahrscheinlich pathogenen Charakter hindeutet. Loveday et al. (2012) beschrieben eine weitere exonische splicing-Mutation c.345G>C im RAD51D-Gen (betrifft die letzte Base im Exon 4 des Gens), die die kanonische 5'-Donor-Spleißstelle im Intron 4 beeinflusst und somit zu einem Exon-Skipping führt. Weiterhin haben Wappenschmidt et al. (2012) mittels in-silico-Prädiktionen bzgl. des Einflusses von exonischen missense-Sequenzvarianten innerhalb einer Grenze von $\leq 3$ Nukleotide der der direkten Intron/Exon-Grenze entfernt im BRCA1-Gen mit funktionellen in-vitro-mRNA-Analysen verglichen. Diese Studie zeigte, dass allein drei von sechs untersuchten exonischen Sequenzvarianten durch in-silico-Analysen fälschlicherweise als funktionell nicht relevant erkannt wurden. Daher sollten die Ergebnisse aus in-silico-Prädiktionsprogrammen mit Vorsicht behandelt werden. So wurde die in dieser Dissertation identifizierte Sequenzvariante im RAD51D-Gen zwar in-silico von drei Vorhersageprogrammen als krankheitsrelevant erkannt, jedoch von einem Prädiktionsprogramm als nicht krankheitsverursachend eingestuft.

In dieser Dissertation wurden keine wahrscheinlich pathogenen bzw. pathogenen Mutationen im RAD51D-Gen identifiziert, es wurden aber insgesamt sechs Varianten unklarer Signifikanz nachgewiesen. Die von anderen Arbeitsgruppen durchgeführten Multi-Gen-Panel-Analysen (NGS) zeigten eine sehr niedrige Detektionsrate von $0,1 \%$ bis $0,5 \%$ von Mutationen im RAD51D-Gen (s. Tab. 4.2). In den Studien von Castéra et al. (2014), Lincoln et al. (2015), Tung et al. (2015), Desmond et al. (2015), Schroeder et al. (2015) und Mannan et al. (2016) wurden keine Mutationen im RAD51D-Gen bei Patienten mit Verdacht auf ein hereditäres Mamma- und Ovarialkarzinom beschrieben. In den publizierten Studien war bei einigen der verwendeten MultiGen-Panels (NGS) bei Patienten mit Verdacht auf ein hereditäres Mamma- und Ovarialkarzinom das RAD51D-Gen jedoch nicht inkludiert (LaDuca et al. 2014; Kurian et al. 2014; Cybulski et al. 2015a; Maxwell et al. 2015; Thompson et al. 2016; Kwong et al. 2016; Eliade et al. 2017).

Mutationen im RAD51D-Gen sind mit einem moderaten Risiko von unter 5,0 \% bis zum 50. Lebensjahr an einem Mammakarzinom zu erkranken, assoziiert. Das Risiko, bis zum 70. Lebensjahr an einem Ovarialkarzinom zu erkranken, wurde auf etwa $12 \%$ geschätzt (Deutsches Konsortium Familiärer Brust- und Eierstockkrebs 2017). Loveday et al. (2011) zeigten ein relatives Risiko von 3,6-fach für ein Ovarialkarzinom bei Patienten mit einer pathogenen RAD51D-Mutation und ein relatives Risiko von 1,32-fach für ein Mammakarzinom. Weitere Studien von Osher et al. (2012), Thompson et al. (2013) und Janatova et al. (2015) bestätigten niedrige Detektionsraten 
(0,57 \% bzw. 0,82 \% bzw. 1,8 \%) der Mutationen im RAD51D-Gen bei Patienten mit einem diagnostizierten Ovarialkarzinom bzw. bei Patienten mit einem Ovarialkarzinom in der Familie. Bei Patienten mit einem Mammakarzinom ohne Ovarialkarzinom bzw. ohne Ovarialkarzinom in der Familienanamnese konnte in der Studie von Thompson et al. (2013) keine pathogene Mutation im RAD51D-Gen detektiert werden.

Die Indexpatientin 39784 erkrankte mit 29 Jahren an einem Mammakarzinom. Ihre Tante mütterlicherseits erkrankte mit etwa 50 Jahren an einem Ovarialkarzinom. Anhand der Familienanamnese und der Datenlage könnte die identifizierte Sequenzvariante im RAD51D-Gen mit dem Karzinom der Patientin assoziiert sein. Diese Sequenzvariante wurde als eine Sequenzvariante der ACMG-Klasse 3 mit der klinischen Bewertung einer wahrscheinlich pathogenen Mutation eingestuft.

Da eine falsche Einstufung dieser Sequenzvariante im RAD51D-Gen als pathogene Mutation schwerwiegende Folgen für die Indexpatientin haben könnte und wir einen Einzelfall mit dieser Sequenzvariante auf cDNA-Ebene abgeklärt hatten, bleibt diese Sequenzvariante weiterhin als Variante unklarer Signifikanz mit der Tendenz zu einer wahrscheinlich pathogenen Mutation eingestuft.

Für die Indexpatientin 39784 wurden mit dem Risikokalkulationsprogramm Cyrillic 2.13 das Heterozygoten- und das Lebenszeitrisiko berechnet. Diese betragen 39,3 \% bzw. 38,3\%. Somit steht der Indexpatientin das intensivierte Früherkennungs- und Nachsorgeprogramm (IFNP) bis zum 50. Lebensjahr unabhängig vom Ergebnis der molekulargenetischen Analyse zur Verfügung. Falls die identifizierte Sequenzvariante im RAD51D-Gen in Zukunft in eine wahrscheinlich pathogene Mutation reklassifiziert wird, können der Indexpatientin zusätzlich eine prophylaktische Ovariektomie ab dem 40. Lebensjahr und das IFNP bis zum 70. Lebensjahr angeboten werden. Somit ergeben sich zurzeit keine Nachteile für die Indexpatientin 39784, selbst wenn die identifizierte Sequenzvariante momentan nicht in eine Mutation der ACMGKlasse 4 eingestuft werden konnte. Der Indexpatientin wurde empfohlen sich erneut in etwa zwei bis drei Jahren an das Brustkrebszentrum der UMG zu wenden, um sich über neue Erkenntnisse zu dieser Sequenzvariante im RAD51D-Gen zu erkundigen. Eine Segregationsanalyse der identifizierten Variante in RAD51D-Gen war nicht möglich, da alle an Tumoren erkrankten Personen aus dieser Familie bereits verstorben waren. Eine prädiktive Untersuchung weiterer Familienmitglieder auf die familiär bekannte Sequenzvariante im RAD51D-Gen eignet sich nach der jetzigen Datenlage jedoch nicht.

\subsubsection{Heterozygote wahrscheinlich pathogene Mutation c.6336C $>$ A im ATM-Gen (Indexpatientin 39037)}

Bei der Indexpatientin 39037 wurde mit 50 Jahren ein Mammakarzinom diagnostiziert. Die Patientin ist Trägerin einer wahrscheinlich pathogenen Keimbahnmutation der ACMG-Klasse 4 (c.6336C >A, heterozygot; p.(Cys2112*) im ATM-Gen. Diese Mutation wurde bisher weder in den bekannten Datenbanken noch in der Literatur gelistet. Aufgrund des Typs dieser Mutation (nonsense-Mutation), des nicht Vorhandenseins bei gesunden Kontrollen (ExAC-Datenbank) und der teilweisen Segregation dieser Mutation mit dem Mammakarzinom in der Familie der Indexpatientin 39037 wurde sie als eine wahrscheinlich pathogene Mutation der ACMG-Klasse 4 eingestuft.

Zwei Schwestern der Indexpatientin erkrankten ebenso an einem Mammakarzinom, d. h. eine Schwester mit 54 Jahren und die andere Schwester mit 63 Jahren. Die mit 54 Jahren erkrankte Schwester wies ebenso wie die Indexpatientin ein invasiv duktales Mammakarzinom auf. Bei der mit 64 Jahren erkrankten Schwester wurde ein invasiv lobuläres Mammakarzinom diagnostiziert. Bei der Segregationsanalyse der familiär bekannten Mutation im ATM-Gen konnte diese Mutation ebenfalls bei der mit 54 Jahren erkrankten Schwester identifiziert werden. Allerdings konnte die familiär bekannte Mutation im ATM-Gen bei der später erkrankten Schwester (mit invasiv 
lobulärem Mammakarzinom) nicht nachgewiesen werden. Zur weiteren Absicherung wurden diese Ergebnisse an einer zweiten unabhängigen Blutprobe der jeweiligen Patientin bestätigt. Die Mutation im ATM-Gen konnte bei einer weiteren nicht an einem Mammakarzinom erkrankten Schwester identifiziert werden.

Die Prävalenz von ATM-Mutationen in der westlichen Allgemeinbevölkerung wurde auf 0,5 \% - 1,0 $\%$ geschätzt (Renwick et al. 2006). Die Multi-Gen-Panel-Analysen (NGS) zeigten bei den Patienten mit Verdacht auf ein hereditäres Mamma- und Ovarialkarzinom eine Detektionsrate der pathogenen Mutationen im ATM-Gen von 0,1 \% bis 15,2 \% (s. Tab. 4.2; LaDuca et al. 2014; Kurian et al. 2014; Cybulski et al. 2015a; Thompson et al. 2016).

Über 80,0 \% der identifizierten Mutationen im ATM-Gen führen zu einem vorzeitigen StoppCodon bzw. beeinflussen den Spleißvorgang (Ahmed und Rahman 2006). Biallelische Mutationen im ATM-Gen verursachen die autosomal-rezessiv vererbte Ataxia-telangiectasia. Bei dieser Erkrankung können eine zerebelläre Ataxie mit einer Kleinhirnatrophie, eine Athetose, Störungen der Augenbewegungen, ein Entwicklungsrückstand, ein Immundefekt, Teleangiektasien, eine Hypersensibilität auf ionisierende Bestrahlung, eine Krebsprädisposition und eine Demenz auftreten (Sandoval et al. 1999). Es wurde gezeigt, dass heterozygote Anlageträgerinnen für ATMMutationen ein etwas erhöhtes relatives Risiko aufweisen, an einem Mammakarzinom zu erkranken. Dies wurde auf 2,23 geschätzt (Thompson et al. 2005). Mutationen im ATM-Gen sind mit einem zweifach erhöhten Risiko für ein Mammakarzinom und einem Lebenszeitrisiko von 20,0 \% - 40,0 \% für ein Mammakarzinom assoziiert. Es sind nur begrenzte Daten zum altersabhängigen Risiko unter dem 40. Lebensjahr vorhanden. Dieses wird auf $<10,0 \%$ geschätzt. Es ist nicht bekannt, ob Patienten mit einer Mutation im ATM-Gen ein erhöhtes Risiko haben an einem Ovarialkarzinom zu erkranken. Ob Männer mit einer Mutation im ATM-Gen ein erhöhtes Risiko haben, an einem Mammakarzinom zu erkranken, ist ebenfalls nicht bekannt (Deutsches Konsortium Familiärer Brust- und Eierstockkrebs 2017).

In der Familie der Indexpatientin 39037 wurde gezeigt, dass auch innerhalb einer Familie sowohl Patienten mit hereditären als auch Patienten mit vermutlich sporadischen Mammakarzinomen koexistieren können. Bei der älteren Schwester der Patientin 39037 kann von einem sporadischen Mammakarzinom ausgegangen werden, da sie einen histologisch anderen Tumortyp entwickelt hat und sie auch im höheren Alter erkrankt ist. Andererseits gehört das ATM-Gen zu den moderat penetranten Genen, d. h. dass mit einem multifaktoriellen Geschehen das Auftreten von Mammakarzinomen erklärt werden kann. In solch einem Fall kann auch eine oligogene bzw. polygene Vererbung vermutet werden.

Bei den molekulargenetisch prädiktiv untersuchten Familienmitgliedern der Indexpatientin 39037, die im reproduktiven Alter sind, wurde jedem mit einer nachgewiesenen familiär bekannten Mutation im ATM-Gen eine vollständige Analyse des ATM-Gens aus Lymphozyten aus genomischer DNA bei dem Partner angeboten. Nur somit kann das Risiko für gemeinsame Kinder präzisiert werden, an einer Ataxia-telangiectasia zu erkranken. Wenn beide Partner heterozygote Anlageträger einer wahrscheinlich pathogenen bzw. pathogenen Mutation im ATM-Gen sind, kann dem Paar eine Präimplantationsdiagnostik vor einer bestehenden Schwangerschaft bzw. eine pränatale Diagnostik in einer bestehenden Schwangerschaft angeboten werden.

Den Anlageträgerinnen einer heterozygoten ATM-Mutation steht ein intensiviertes Früherkennungs- und Nachsorgeprogramm (IFNP) ab dem Erkrankungsalter bzw. bei gesunden Anlageträgerinnen ab dem 30. und bis zum 70. Lebensjahr zur Verfügung. Eine prophylaktische Mastektomie oder eine prophylaktische Salpingo-Oophorektomie sind dagegen nicht indiziert (Deutsches Konsortium Familiärer Brust- und Eierstockkrebs 2017).

Bei einer negativen prädiktiven Testung auf eine familiär bekannte Mutation in einem moderat penetranten Risikogen, wie z. B. dem ATM-Gen, ist eine Entlastung der Patientin nicht möglich. Es wird vermutet, dass mindestens ein weiteres Gen für die Tumorerkrankung mitverantwortlich sein kann (polygener bzw. oligogener Erbgang). Bei den weiblichen Familienmitgliedern ohne die 
identifizierte familiär bekannte Mutation im ATM-Gen können anhand der Familienanamnese das Heterozygoten- und Lebenszeitrisiko mittels des Risikokalkulationsprogramms Cyrillic 2.13 berechnet werden. Wenn ein Heterozygotenrisiko von $\geq 20 \%$ bzw. ein Lebenszeitrisiko von $\geq 30$ $\%$ berechnet wird, kann der Person ohne identifizierte familiär bekannte Mutation ein intensiviertes Früherkennungs- und Nachsorgeprogramm (IFNP) vom 30. bis zum 50. Lebensjahr angeboten werden.

\subsubsection{Heterozygote pathogene Mutation c.706-1G>A im RAD51C-Gen (Patientin 39769)}

In der Familie der gesunden Patientin 39769 war kein Indexpatient für eine molekulargenetische Analyse verfügbar. Aufgrund des berechneten hohen Heterozygoten-Risikos von $34,8 \%$ (Risikokalkulationsprogramm Cyrillic 2.13) konnte der Patientin eine molekulargenetische Untersuchung der 10 Core-Gene angeboten werden. Bei der Patientin 39769 wurde eine pathogene Keimbahnmutation der ACMG-Klasse 5 (c.706-1G>A, heterozygot) im RAD51C-Gen identifiziert. Diese Mutation wurde nur in der Datenbank des Deutschen Konsortiums Familiärer Brust- und Eierstock als pathogen gelistet. In den Datenbanken HGMD und ClinVar ist nur an der Position c.706-2A>G eine pathogene Mutation aufgeführt. Diese Mutation betrifft die identische hochkonservierte 3'-Akzeptor-Spleißstelle im Intron 4 des RAD51C-Gens wie die bei der Patientin 39769 identifizierte Mutation c.706-1G>A. Die Keimbahnmutation c.706-2A>G im RAD51C-Gen wurde sowohl bei Patienten mit einer peritonealen Karzinose (Walsh et al. 2011), einem Ovarialkarzinom sowie einer Patientin mit einem Mamma- und Ovarialkarzinom (Loveday et al. 2012; Breast Cancer Susceptibility Collaboration et al. 2012) als auch bei Patienten mit einem Mammakarzinom, einem Tubenkarzinom und einem Melanom nachgewiesen (Susswein et al. 2016). Zusätzlich wurde die Mutation c.706-2A>G ebenfalls bei Patienten mit einem sporadischen oropharingealen Karzinom (Scheckenbach et al. 2014) detektiert. Die funktionelle Analyse dieser Sequenzvariante von Davy et al. (2017) mittles RNA-Seq-Analyse und qRT-PCR zeigte eine Überexpression von Exon 5 des RAD51C-Gens. In der Studie von Scheckenbach et al. (2014) wurden bei 5,8 \% der Patienten mit einem sporadischen Plattenepithelkarzinom des Kopf-HalsBereichs Keimbahnmutationen im RAD51C-Gen detektiert. Ob die in dieser Dissertation identifizierte Mutation c.706-1G>A im RAD51C-Gen ebenfalls zu einem erhöhten Risiko für ein Plattenepithelkarzinom des Kopf-Hals-Bereichs bzw. zu einem erhöhten Risiko für ein Melanom führt, ist aufgrund der geringen Datenlage zum jetzigen Zeitpunkt nicht beurteilbar.

Die Mutation c.706-1G>A im RAD51C-Gen segregiert in der Familie der Indexpatientin mit den diagnostizierten Mammakarzinomen. Nach dem gegenwärtigen Stand der Wissenschaft ist davon auszugehen, dass die Mutation c.706-1G>A zu einer erhöhten Neigung für Tumorerkrankungen bei der Patientin 39769 und allen weiteren Trägerinnen dieser Mutation in der Familie führen kann.

Beim Screening auf Mutationen im RAD51C-Gen wurden diese in 1,3\% der BRCA1- und BRCA2negativen Familien mit einem Mamma- und/oder Ovarialkarzinom identifiziert (Meindl et al. 2010). In der Studie von Lu et al. (2012) von Familien mit Verdacht auf ein hereditäres Mammakarzinom wurde keine Mutation im RAD51C-Gen nachgewiesen. In der Studie von Janatova et al. (2015) wurden Mutationen im RAD51C-Gen bei 1,2 \% der Patienten mit einem Ovarialkarzinom identifiziert. Jønson et al. (2016) zeigten in den Familien mit Verdacht auf ein hereditäres Mamma- und Ovarialkarzinom bei 0,5 \% Patienten eine Mutation im RAD51C-Gen. Viele Multi-Gen-Panel-Untersuchungen (NGS) identifizierten in den Hochrisiko-Familien keine Mutation im RAD51C-Gen (s. Tab. 4.2; Kurian et al. 2014). In anderen publizierten Studien wurden zumindest niedrige Detektionsraten von $0,1 \%$ bis 0,7 \% für Mutationen im RAD51C-Gen aufgezeigt (s. Tab 4.2; LaDuca et al. 2014). In den Arbeiten zu dieser Dissertation wurde nur die eine o. g. pathogene Mutation (Detektionsrate 0,5\%) im RAD51C-Gen identifiziert. 
Mutationen im RAD51C-Gen gehen mit einem moderaten Risiko von $<5,0 \%$ einher bis zum 50. Lebensjahr an einem Mammakarzinom zu erkranken. Für das Ovarialkarzinom besteht ein lebenslanges Risiko von etwa 12 \% bis zum 70. Lebensjahr zu erkranken (Deutsches Konsortium Familiärer Brust- und Eierstockkrebs 2017).

Der Patientin 39769 kann anhand dieses molekulargenetischen Ergebnisses vom 30. bis zum 70. Lebensjahr ein intensiviertes Früherkennungs- und Nachsorgeprogramm (IFNP) angeboten werden. Patienten mit Mutationen im RAD51C-Gen kann ebenfalls eine prophylaktische SalpingoOophorektomie ab dem 40. Lebensjahr bzw. 5 Jahre vor dem frühesten Erkrankungsalter in der Familie angeboten werden.

Bei einer identifizierten pathogenen Mutation im RAD51C-Gen in der Familie wurde für weitere volljährige Familienmitglieder eine prädiktive molekulargenetische Untersuchung auf die familiär bekannte Mutation im Rahmen einer humangenetischen Beratung empfohlen.

Bei Patienten mit Mutationen im RAD51C-Gen im reproduktiven Alter und einem bestehenden Kinderwunsch sollte dem Partner eine vollständige molekulargenetische Analyse des RAD51CGens empfohlen werden. Somit kann das Risiko für gemeinsame Kinder mit einer autosomalrezessiven Fanconi-Anämie Typ O (Vaz et al. 2010) bestimmt werden. Wenn beide Partner heterozygote Anlageträger einer wahrscheinlich pathogenen bzw. pathogenen Mutation im RAD51C-Gen sind, kann dem Paar eine Präimplantationsdiagnostik vor einer bestehenden Schwangerschaft bzw. eine pränatale Diagnostik in einer bestehenden Schwangerschaft angeboten werden.

\subsubsection{Heterozygote wahrscheinlich pathogene Mutation c.1587delT im CDH1-Gen (Indexpatientin 39917)}

Bei der Indexpatientin 39917 wurde histologisch ein teilweise duktales und ein partiell lobulär invasives Mammakarzinom diagnostiziert. Die molekulargenetische Diagnostik ergab bei ihr das Vorliegen einer wahrscheinlich pathogenen Keimbahnmutation der ACMG-Klasse 4 (c.1587delT, heterozygot; p.(Ala530Profs*27) im CDH1-Gen. Eine Segregationsanalyse wurde der Familie zwar angeboten, aber nicht in Anspruch genommen. Nach dem gegenwärtigen Stand der Wissenschaft ist davon auszugehen, dass die Mutation c.1587delT zu einer erhöhten Neigung für Krebserkrankungen bei der Indexpatientin führt.

Mutationen im CDH1-Gen sind mit einem hohen Risiko für ein diffuses Magenkarzinom und besonders für ein lobuläres Mammakarzinom (Lei et al. 2002) assoziiert. Das Lebenszeitrisiko für das Auftreten eines Mammakarzinoms in Familien mit einem Mamma- und Magenkarzinom wird für Frauen mit ca. 40 \% (Pharoah et al. 2001) bzw. 42,0 \% (Hansford et al. 2015) angegeben. Das kumulative Risiko an einem Magenkarzinom bis zum 80. Lebensjahr zu erkranken wird für Frauen mit 83,0 \% (Pharoah et al. 2001) bzw. mit 56 \% (Hansford et al. 2015) und für Männer mit 67,0 \% (Pharoah et al. 2001) bzw. 70 \% (Hansford et al. 2015) beziffert. In Familien mit einem Auftreten von Mammakarzinomen ist das Risiko für die Entwicklung eines Magenkarzinoms jedoch unbekannt. Die Arbeitsgruppe von Benusiglio et al. (2013a) schlug sogar eine Umbennenung des hereditären diffusen Magenkarzinoms in das hereditäre diffuse Magen- und lobuläre Mammakarzinom vor. Petridis et al. (2014) analysierten 50 Patientinnen mit einem diagnostizierten bilateralen lobulären Mammakarzinom auf Keimbahnmutationen im CDH1-Gen hin. Bei $8 \%$ der Patientinnen wurde eine heterozygote pathogene Loss-of-functionKeimbahnmutation im CDH1-Gen identifiziert. Die Studie zeigte eindeutig, dass Keimbahnmutationen im CDH1-Gen für ein bilaterales lobuläres Mammakarzinom vor dem 50. Lebensjahr prädisponieren. In Familien mit Magenkarzinomen wurden bisher folgende Altersabhängigkeiten für ein Mammakarzinom aufgezeichnet: 10,0 \% bis zum 50. Lebensjahr, 20,0 $\%$ bis zum 60. Lebensjahr, 30,0 \% bis zum 70. Lebensjahr und 40,0 \% - 50,0 \% bis zum 80 . Lebensjahr. Über Erkrankungsrisiken für das Ovarialkarzinom liegen derzeit keine Daten vor (Deutsches Konsortium Familiärer Brust- und Eierstockkrebs 2017). 
In den Multi-Gen-Panel-Analysen (NGS) bei Verdacht auf ein hereditäres Mamma- und Ovarialkarzinom wurden pathogene Mutationen im CDH1-Gen bei $0 \%$ bis 0,5\% der Patienten identifiziert (s. Tab. 4.2 und LaDuca et al. 2014; Kurian et al. 2014; Thompson et al. 2016).

Bei einem Neffen der Indexpatientin wurde eine Leukämie im Kindesalter diagnostiziert. Genaue Angaben zu der Erkrankung waren nicht bekannt. In den Studien von Ewerth et al. (2016) und von Zhang et al. (2017) konnten zwar eine verminderte somatische Expression von CDH1 bei Patienten mit einer sporadischen akuten myeloischen Leukämie gezeigt werden. Ob jedoch eine Assoziation zwischen Keimbahnmutationen im CDH1-Gen und dem Auftreten von Leukämien existiert, ist bis dato nicht analysiert worden.

In den Studien von Frebourg et al. 2006, Kluijt et al. 2012 und Benusiglio et al. 2013b zeigte sich eine Segregation einer Lippen- bzw. Lippengaumenspalte mit dem hereditären Magenkarzinom in einigen Familien mit pathogenen CDH1-Mutationen. Die Studie von Vogelaar et al. (2013) an 81 Patienten mit nicht-syndromalen orofazialen Spalten zeigte bei $5 \%$ dieser Patienten eine wahrscheinlich pathogene Keimbahnmutation im CDH1-Gen. Die Studie von Brito et al. (2015) analysierte 211 Patienten mit nicht-syndromalen orofazialen Spalten und stellte bei $2 \%$ der Betroffenen eine CDH1-Keimbahnmutation fest. Brito et al. (2015) detektierten insgesamt 10 verschiedene $C D H 1$-Keimbahnmutationen in Patienten, die mit einer nicht-syndromalen orofazialen Spalte beschrieben worden sind, wobei sechs dieser Mutationen mit einem hereditären Magenkarzinom in der Familie segregierten. Die bei der Indexpatientin 39917 identifizierte Mutation zählt jedoch nicht zu den bekannten Mutationen welche mit orofazialen Spalten assoziiert wurden. Weiterhin wurden CDH1-Keimbahnmutationen bei Patienten mit einem Blepharo-cheilo-dontic-(BCD)-Syndrom Typ 1 (OMIM 119580) beschrieben. Dabei handelt es sich um ein seltenes autosomal-dominant vererbtes Syndrom mit Malformationen der Augenlider, Lippen-/Gaumenspalten und einer ektodermalen Dysplasie. Ghoumid et al. (2017) analysierten 11 Patienten aus acht Familien mit der klinischen Diagnose des BCD-Syndroms und identifizierten fünf pathogene Keimbahnmutationen im CDH1-Gen. Eine weitere Keimbahnmutation im CDH1-Gen wurde bei Patienten mit BCD-Syndrom von Nishi et al. (2016) detektiert. Es wurde von den Autoren postuliert, dass eine beschleunigte Degradation von ECadherin in den Zellen die molekulare Basis für die Entstehung des BCD-Syndroms darstellt (Ghoumid et al. 2017). Dieses Phänomen wurde ebenso als die molekulare Grundlage für die Entwicklung eines hereditären Magenkarzinoms diskutiert. In der Familie der Indexpatientin 39917 waren Lippen-/Gaumenspalten über drei Generationen nicht bekannt. Auch die bei der Indexpatientin 39917 identifizierte Mutation stimmt nicht mit den bisher beschriebenen Mutationen überein, die bis dato bei den Betroffenen mit BCD-Syndrom beschrieben wurden.

Patienten mit Mutationen im CDH1-Gen kann vom 30. bis zum 70. Lebensjahr ein intensiviertes Früherkennungs- und Nachsorgeprogramm (IFNP) angeboten werden.

Bezüglich der Empfehlungen zu operativen Maßnahmen sollte die spezifische familiäre Situation berücksichtigt werden. In jedem Fall sind Früherkennungsmaßnahmen wie regelmäßige Gastroskopien ab dem 20. Lebensjahr und ggf. eine prophylaktische Gastrektomie in Betracht zu ziehen. Es stellt sich jedoch als extrem schwierig dar, die Risiken für ein Mammakarzinom zu ermitteln, wenn in der Familie hauptsächlich ein Magenkarzinom aufgetreten war. Umgekehrt gilt dies für eine Risikoermittlung des Magenkarzinoms, wenn in der Familie hauptsächlich ein Mammakarzinom aufgetreten war (Deutsches Konsortium Familiärer Brust- und Eierstockkrebs 2017).

Da die identifizierte Mutation im CDH1-Gen einem autosomal-dominanten Erbgang folgt, kann allen volljährigen Verwandten der Indexpatientin 39917 im Rahmen einer humangenetischen Beratung eine prädiktive molekulargenetische Untersuchung auf die familiär bekannte Mutation im CDH1-Gen angeboten werden. 
Der Indexpatientin 39917 mit der identifizierten Mutation im CDH1-Gen wurde das intensivierte Früherkennungs- und Nachsorgeprogramm (IFNP) angeboten und regelmäßige Gastroskopien empfohlen. Eine Gastrektomie kann ebenso erwogen werden.

\subsubsection{Große genomische Deletion des MSH6-Gens (Indexpatient 39202)}

Bei dem Indexpatienten 39022 wurde eine wahrscheinlich pathogene Keimbahnmutation der ACMG-Klasse 4 (genomische Deletion mit einer Ausdehnung von 46,1 kb, heterozygot) im MSH6Gen identifiziert. Die exakte Mutation wurde bisher noch nicht in den Datenbanken (z. B. Datenbank des Deutschen Konsortiums, HGMD ${ }^{\circledR}$ Professional 2016.4, Insight, ExAC) sowie in der Literatur beschrieben.

Der Indexpatient 39202 wurde in der humangenetischen Sprechstunde mit Verdacht auf ein Hereditäres Nicht-polypöses kolorektales Karzinom-(HNPCC)-Syndrom vorgestellt.

Das kolorektale Karzinom (CRC) zählt zu den häufigsten Tumorerkrankungen des Menschen. Bei etwa 5,0 \% - 10,0 \% der Fälle ist eine familiäre Häufung zu beobachten. Das HNPCC-Syndrom (auch als Lynch-Syndrom bezeichnet) ist eine primär genetisch bedingte kolorektale Erkrankung, die in etwa 2,0 \% - 3,0 \% aller CRC vorkommt (Hampel et al. 2008, Lynch et al. 2009). Das HNPCC wird durch Mutationen in den DNA-Reparaturgenen (Mismatch-Reparaturgene; MMR) MLH1, MSH2, MSH6 und PMS2 verursacht und wird autosomal-dominant vererbt (Hegde et al. 2014). Träger einer krankheitsverursachenden Mutation in einem der vier DNA-Reparaturgene weisen zusätzlich ein erhöhtes Lebenszeitrisiko für die Entwicklung weiterer Tumore auf. Das Lebenszeitrisiko bezieht sich v. a. auf Karzinome des Endometriums, der Ovarien, des Magens, des Urothels, der Gallengänge und des Dünndarms (Aarnio et al. 1999). Bei Patienten mit einem HNPCC werden pathogene Mutationen in den Genen MLH1 und MSH2 in etwa $90 \%$, im MSH6Gen in etwa $7 \%-10 \%$ und im PMS2-Gen in < 5,0 \% der Fälle nachgewiesen (NCBI Bookshelf, Lynch Syndrome, Letzte Aktualisierung am 22. Mai 2014). Um HNPCC-Patienten zu identifizieren, wurden die Amsterdam- und die revidierten Bethesda-Kriterien (Umar et al. 2004) formuliert. Wie bei allen hereditären Tumorerkrankungen sollte zunächst eine erkrankte Person (Indexpatient) untersucht werden. Wenn mindestens eines der revidierten Bethesda-Kriterien erfüllt ist, erfolgt zunächst die Untersuchung des Tumorgewebes des CRCs mittels immunhistochemischer (IHC)Analyse bzw. mit Hilfe der Mikrosatelliteninstabilität (MSI)-Untersuchung (Umar et al. 2004). Zeigt sich hierbei immunhistochemisch ein Ausfall der Proteinexpression eines der MMR-Gene bzw. eine hohe Mikrosatelliteninstabilität, kann aus einer Blutprobe des Patienten gezielt auf eine Keimbahnmutation des MMR-Gens/der MMR-Gene hin untersucht werden (Hegde et al. 2014).

Der oben genannten Vorgehensweise wurde bei dem Indexpatienten 39202 gefolgt. Im Institut für Pathologie der UMG wurden am Tumorgewebe des kolorektalen Karzinoms eine IHC-Analyse der MMR-Proteine und eine MSI-Analyse durchgeführt. Beide Untersuchungen ergaben unauffällige Ergebnisse. Diese zwei Untersuchungen wurden ebenfalls am Gewebe einer Lebermetastase durchgeführt. Die MSI-Untersuchung ergab ein unauffälliges Ergebnis und die IHC-Untersuchung zeigte eine partielle inhomogene und abgeschwächte Expression des MLH1Proteins. Somit bestanden nach den Bethesda-Leitlinien keine Indizien für einen hereditären Ursprung des Tumorleidens.

Bei der Tante mütterlicherseits des Indexpatienten 39202 waren die Kriterien für eine molekulargenetische Untersuchung bei Verdacht auf ein hereditäres Mamma- und Ovarialkarzinom erfüllt. Diese Patientin war jedoch bereits verstorben, sodass für den Indexpatienten 39202 mit dem Risikokalkulationsprogramm Cyrillic 2.13 das Heterozygoten-Risiko berechnet wurde. Dieses Risiko betrug 2,5\%.

Anhand der Leitlinien konnte dem Indexpatienten 39202 keine molekulargenetische Untersuchung bezüglich des hereditären kolorektalen Karzinoms oder des Mammakarzinoms angeboten werden. Aufgrund der sehr auffälligen und für ein hereditäres Geschehen verdächtigen Eigen- und Familienanamnese wurde bei diesem Indexpatienten trotz der nicht 
erfüllten Kriterien eine molekulargenetische Untersuchung der 10 Core-Gene sowie der HNPCCGene mittels Multi-Gen-Panel-Analyse (NGS, TruRisk ${ }^{\mathrm{TM}}$ ) veranlasst.

Mittels der CNV-(engl. çopy number variations, Kopienzahlvarianten)-Analyse mit dem Programm SequencePilot, Modul SeqNext, und einer nachfolgenden qPCR-Untersuchung wurde eine 46,1 kb große heterozygote genomische Deletion identifiziert, die das Exon 1 des MSH6-Gens beinhaltet. Die identische Mutation wurde in den Datenbanken und in der Literatur bisher nicht beschrieben. Jedoch wurden ähnliche Deletionen in der entsprechenden Region des MSH6-Gens bereits bei Patienten mit einem diagnostizierten HNPCC von Moir-Meyer at al. (2015), van der Klift et al. (2005), Plaschke et al. (2003), Buchanan et al. (2014), Nilbert et al. (2009), Hampel et al. (2006), Kets et al. (2006), Talseth-Pamler et al. (2010), Lotsari et al. (2012) und Baglietto et al. (2010) beschrieben (s. Abb. 4.1).

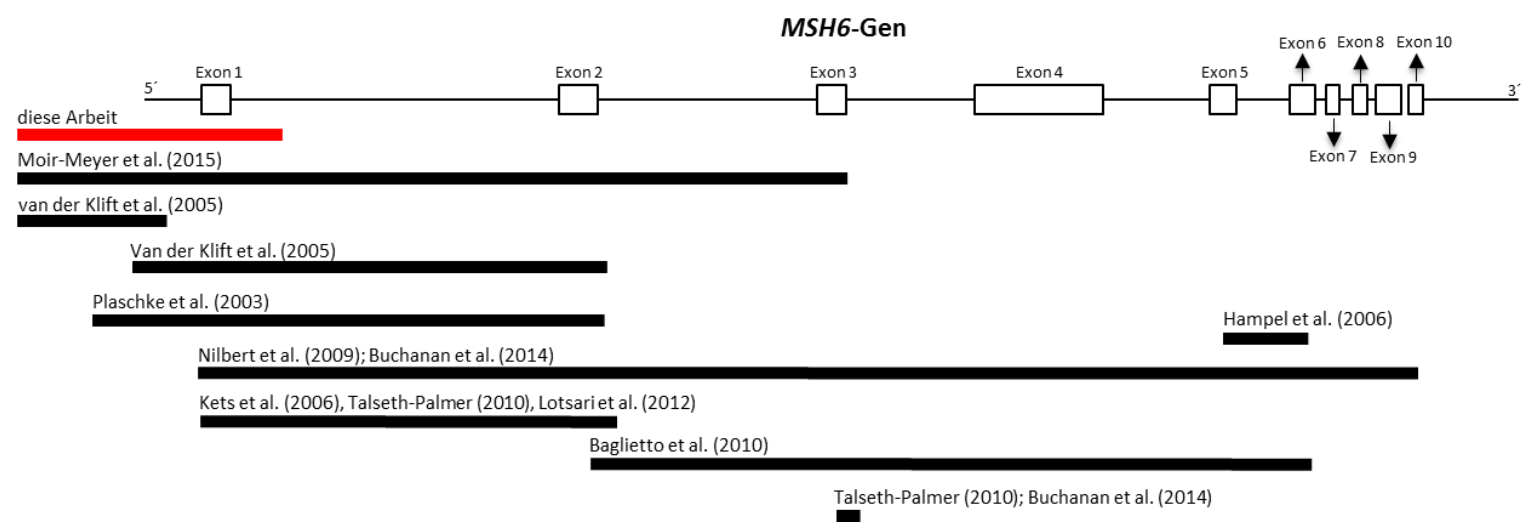

Abbildung 4.1: Schematischer Vergleich der bei dem Indexpatienten 39202 identifizierten genomischen Deletion im MSH6-Gen mit den publizierten Fällen. Im oberen Teil der Abbildung ist die genomische Struktur des MSH6-Gens mit seinen 10 Exons schematisch abgebildet. Der rote Balken zeigt die bei dem Indexpatienten 39202 identifizierte Deletion im MSH6-Gen. Die schwarzen Balken zeigen die bereits in der Literatur beschriebenen heterozygoten Deletionen im MSH6-Gen an.

Eine Assoziation zwischen einem erhöhten Risiko für ein Mammakarzinom und einem HNPCCSyndrom ist bisher bei Patienten mit einer Deletion im MSH6-Gen unklar (Scott und Ashton 2004; Win et al. 2013). In der Studie von Goldberg et al. (2017) konnte eine Assoziation zwischen Mutationen im MSH2-Gen und dem Risiko für die Entwicklung eines Mammakarzinoms aufgezeigt (kumulative lebenslange Inzidenz für die Entwicklung eines Mammakarzinoms bei Frauen mit MSH2-Mutation lag hier bei $22 \%)$ werden. Eine eindeutige Assoziation der MSH6Keimbahnmutationen wurde jedoch bisher nicht bewiesen (Wasielewski et al. 2010; Ford 2012). Anderseits wurden bei Patienten mit Verdacht auf ein hereditäres Mamma- und Ovarialkarzinomsyndrom selten Mutationen im MSH6-Gen detektiert und zwar bei etwa 1,3\% der Fälle (Maxwell et al. 2015; Lincoln et al. 2015; Tung et al. 2015; Desmond et al. 2015; Susswein et al. 2016; Buys et al. 2017; Eliade et al. 2017).

Eine Segregationsanalyse der in dieser Arbeit identifizierten Deletion im MSH6-Gen war in der Familie des Indexpatienten 39202 nicht möglich, da alle an Tumoren erkrankten Personen bereits verstorben waren. Somit bleibt unklar, ob die am beidseitigen Mammakarzinom erkrankte Tante mütterlicherseits ebenso Trägerin der genomischen Deletion im MSH6-Gen war.

Die funktionelle Analyse der MSH6-Expression zeigte im Vergleich zu den Kontrollen eine stark verminderte Expression bzw. einen Verlust der Expression vom vermutlich mutierten Allel bei dem Indexpatienten 39202. In Assoziation mit den bereits veröffentlichen Deletionen im MSH6Gen bei HNPCC-Patienten, der zwei synchron auftretenden unabhängigen Karzinome beim Indexpatienten 39202 und der Familienanamnese wurde die genomische Deletion im MSH6 als eine wahrscheinlich pathogene Mutation (ACMG-Klasse 4) bewertet. 
Mutationen im MSH6-Gen folgen einem autosomal-dominanten Erbgang. Allen Verwandten des Indexpatienten 39202 kann im Rahmen einer humangenetischen Beratung volljährigen eine prädiktive molekulargenetische Untersuchung auf die familiär bekannte Mutation im MSH6-Gen hin angeboten werden.

Patienten mit einem genetisch gesicherten HNPCC sollen in der Regel ab dem 25. Lebensjahr bzw. $a b$ der Feststellung der hereditären Form des kolorektalen Karzinoms bzw. 5 Jahren vor dem frühesten Erkrankungsalter in der Familie jährlich koloskopiert werden. Ferner sollte ab dem 35. Lebensjahr zusätzlich jährlich eine Ösophago-Gastro-Duodenoskopie (ÖGD) durchgeführt werden. Bei weiblichen HNPCC-Patienten sollte ab dem 25. Lebensjahr zusätzlich zur jährlichen gynäkologischen Untersuchung ein transvaginaler Ultraschall im Hinblick auf Endometrium- und Ovarialkarzinome durchgeführt werden. Ab dem 35. Lebensjahr sollte zusätzlich jährlich eine Endometriumbiopsie durchgeführt werden (Stufe-3-Leitlinie 2014 zum kolorektalen Karzinom).

\subsection{Perspektiven}

Die Multi-Gen-Panel-Untersuchungen mittels der NGS-Technologie werden derzeit zunehmend in der klinischen Diagnostik eingesetzt und ersetzen einen Großteil der stufenweise durchgeführten Sanger-Sequenzierungen einzelner Gene. Das Erfassen der Ergebnisse und die Analysen der Sequenzvarianten anhand der vorhandenen und mit der Zeit verbesserten Datenbanken, der Segregationsanalysen und funktionellen Studien werden somit zur Optimierung der Beurteilung ermittelter Sequenzvarianten hinsichtlich ihrer Pathogenität führen.

Um bei einem höheren Anteil der Patienen mit Verdacht auf ein hereditäres Mamma- und Ovarialkarzinom in der analysierten Kohorte die genetische Ursache der Tumorerkrankung zu ermitteln, könnten weiterhin alle identifizierten Varianten unklarer Signifikanz (VUS) ausführlich genetisch abgeklärt werden, d. h. es könnten Segregationsanalysen der VUS in den Familien erfolgen. In diesem Fall würden vor allem weitere betroffene Familienmitglieder auf die VUS hin untersucht werden. Alle VUS könnten ebenso funktionell auf cDNA-Ebene abgeklärt werden, z. B. einerseits mittels qRT-PCR-Analysen und andererseits mit Hilfe von RNA-Seq-Untersuchungen zur Detektion von alternativen bzw. abnormalen Transkripten (Mercer et al. 2014).

Bei denjenigen Patienten ohne eine nachgewiesene Sequenzvariante der ACMG-Klasse 3, 4 oder 5 könnten im ersten Schritt alle Gene auf dem Multi-Gen-Panel, die bereits mit dem NGS-Verfahren angereichert und sequenziert waren, ausgewertet werden. Weiterhin sollte bei allen Patienten eine CNV-Analyse aller im Panel beinhalteten Gene erfolgen. Somit könnten eventuell weitere große Deletionen bzw. Duplikationen identifiziert werden. Warum dies ein wichtiger weiterer Schritt wäre, zeigt die aktuelle Diskussion von Mitgliedern im Deutschen Konsortium Familiärer Brust- und Eierstockkrebs. Das Konsortium wird eine Reorganisation der 10 Core-Gene vornehmen. Eine neue Studie vom BRIDGES-(B Breast Cancer Risk after Diagnostic Gene Sequencing)-Projekt zeigte (nicht publizierte Daten), dass heterozygote Mutationen im NBN-Gen nicht mit einem statistisch signifikant erhöhten Risiko für die Entwicklung eines Mammakarzinoms assoziiert sind. Daher wurde vom Deutschen Konsortium Familiärer Brust- und Eierstockkrebs beschlossen, dass anstatt des NBN-Gens das BRIP1-Gen zu den 10 Core-Genen zugeordnet wird. Vorhergehende Studien hatten nämlich gezeigt, dass heterozgote loss-of-functionKeimbahnmutationen im BRIP1-Gen mit einem OR (Odds Ratio) von 20,97\% mit dem Ovarialkarzinom assoziiert waren (Weber-Lassalle et al. 2018).

Wenn die o. g. Maßnahmen nicht zur Klärung des genetischen Hintergrundes führen würden, könnten im nächsten Schritt die Whole-Exome-Sequenzierung (WES) oder sogar eine WholeGenome-Sequenzierung (WGS) erfolgen. Bei einer identifizierten vermutlich pathogenen Mutation in einem neuen Gen bzw. einem Gen, das nicht bekanntermassen mit einem hereditären Mamma- und Ovarialkarzinom assoziiert ist, könnte dieses Gen spezifisch bei weiteren Patienten analysiert werden. 
Weiterhin könnten Mamma- bzw. Ovarialkarzinome der betroffenen Patienten auf somatische Mutationen hin analysiert werden. Bei identifizierten somatischen Mutationen könnten diese auf der Keimbahnebene an DNA aus Lymphozyten des Patienten überprüft werden.

Ferner könnten Segregationsanalysen der bereits in dieser Kohorte detektierten pathogenen Keimbahnmutationen in den Familien durchgeführt werden. Somit könnte definiert werden, ob weitere in den Familien vorkommende Tumorerkrankungen auf dem Boden der familiär bekannten Keimbahnmutation entstanden sind.

Auch die variable Expressivität in den Familien mit identischer heterozygoter Keimbahnmutation könnte genauer betrachtet werden. Hierfür sollten sowohl weitere genetische Faktoren (u. a. Polygenic Risk Score, polygene Vererbung) als auch nicht genetische Faktoren (u. a. Alter bei der Menarche, Eintreten der Menopause, Einnahme von Kontrazeptiva, Lebensstil) betrachtet werden.

Alle weiteren Analysen könnten zu einem besseren Verständnis der multifaktoriellen und polygenen Genese des hereditären Mamma- und Ovarialkarzinoms beitragen. 


\section{Zusammenfassung}

Das Mammakarzinom repräsentiert die häufigste weibliche Karzinomerkrankung. Weiterhin ist das Ovarialkarzinom nach dem Mammakarzinom der dritthäufigste gynäkologische maligne Tumor in Deutschland. Neben den sporadischen Mamma- und Ovarialkarzinomen weisen etwa 5 $\%-10 \%$ aller erkrankten Patienten eine hereditäre Form des Mamma- und Ovarialkarzinoms auf. In dieser Arbeit wurden 200 Patienten mit Verdacht auf eine hereditäre Form des Mamma- und Ovarialkarzinoms, welche die vom Deutschen Konsortium Familiärer Brust- und Eierstockkrebs definierten Kriterien erfüllten, molekulargenetisch auf das Vorhandensein von Keimbahnmutationen mittels der NGS-Methode hin analysiert.

Es wurden genomische DNA-Proben aus EDTA-Blut von insgesamt 196 weiblichen (98,0 \%) und vier männlichen $(2,0 \%)$ Patienten analysiert. Das durchschnittliche Alter der Patienten bei der Erstdiagnose des Mamma- oder Ovarialkarzinoms im untersuchten Kollektiv betrug 41,9 Jahre. Jeder der 200 in dieser Arbeit untersuchten Patienten erfüllte eines der vom Deutschen Konsortium Familiärer Brust- und Eierstockkrebs definierten Kriterien für die Durchführung einer molekulargenetischen Analyse bei Verdacht auf ein hereditäres Mamma- und Ovarialkarzinom. Die Kriterien wurden in dieser Dissertation mit den Buchstaben $A, G, J, N, Q, R, Y, U$ und $Z$ bezeichnet (s. Einleitung Tab. 1.3). Für alle 200 Patienten der Kohorte wurden mittels des Risikokalkulationsprogramms Cyrillic 2.13 das Heterozygoten- und Lebenszeitrisiko berechnet. Das mittlere berechnete Heterozygoten-Risiko der gesamten Patienten-Kohorte lag bei $38 \pm 30 \%$. Das Lebenszeitrisiko, an einem Mammakarzinom bis zum 85. Lebensjahr zu erkranken, betrug in der gesamten untersuchten Patienten-Kohorte $27 \pm 21 \%$. Für die Patienten mit dem erfüllten Kriterium R wurde der höchste Mittelwert des Risikos für die Anlageträgerschaft einer Mutation in einem der 10 Core-Gene (61,6 \%) berechnet, gefolgt von den Patienten mit dem erfüllten Kriterium N (56,5\%). Es wurden ebenso die histologischen Typen sowie der Rezeptorstatus der Mammakarzinome erfasst. Bei 105 der untersuchten Patienten (52,5 \%) konnte ein invasiv duktales Mammakarzinom, bei 32 Patienten (16,0\%) ein DCIS (duktales Carcinoma in situ), bei 16 Patienten (8,0 \%) ein invasiv lobuläres Mammakarzinom und bei zwei Patienten ein Mammakarzinom (1,0 \%) mit einer medullären Histologie nachgewiesen werden. Die Angaben zum histologischen Subtyp des Mammakarzinoms fehlten bei insgesamt 33 Patienten (16,5\%). Bei den untersuchten Patienten wurden unterschiedliche Expressionsmuster des Östrogenrezeptors $\alpha$ $(E R \alpha)$, des Progesteron-Rezeptors (PR) und der Überexpression des ERBB2-Rezeptors im Gewebe des Mammakarzinoms beobachtet. Das weitverbreitetste Expressionsmuster konnte für eine Expression des ER $\alpha$ und des PR und ohne eine Überexpression des ERBB2-Rezeptors bei 63 der untersuchten Mammakarzinome (45,7 \%) ermittelt werden. Das zweithäufigste nachgewiesene Expressionsmuster waren die sog. triple negativen Mammakarzinome (keine Expression des ER $\alpha$ und des PR und keine Überexpression des ERBB2-Rezeptors) mit 32 Mammakarzinomen (23,2 \%). Die dritthäufigste Gruppe bestand aus Mammakarzinomen mit Expression des ER $\alpha$ und des PR und einer Überexpression des ERRB2-Rezeptors mit 21 Tumoren (15,2 \%). Neben den Mammaund Ovarialkarzinomen wurden in den Stammbäumen der untersuchten Patienten über mindestens drei Generationen in etwa mehr als der Hälfte der Familien (51,0 \%) weitere Tumorerkrankungen beobachtet, u. a. kolorektale Karzinome (52,9\%), Prostata-(24,5 \%)-, Magen$(15,7 \%)-$, Pankreas-(15,7 \%)- und Lungenkarzinome $(13,7 \%)$. Weiterhin wurden Leukämien sowie Lymphome in jeweils 10 Fällen (9,8 \%) beobachtet. Seltener wurden andere Tumoren (z. B. Leber, Blasen-, Nieren-, Hoden- und Endometriumkarzinome sowie Sarkome und Hauttumoren) in den analysierten Familien beobachtet.

Bei allen Patienten wurden die vom Deutschen Konsortium Familiärer Brust- und Eierstockkrebs definierten 10 Core-Gene (ATM, BRCA1, BRCA2, CDH1, CHEK2, NBN, PALB2, RAD51C, RAD51D und TP53) als Bestandteil eines Multi-Gen-Panels auf Keimbahnmutationen hin analysiert. Es wurden zwei verschiedene Technologien der Anreicherung und Amplifizierung angewendet und zwar die 
HaloPlex-Technologie bei den ersten 28 Patienten und bei den restlichen 172 Patienten das SureSelect ${ }^{\mathrm{QXT}}$-(TruRisk ${ }^{\mathrm{TM}}$ )-Verfahren. Mit der Next-Generation-Sequencing-(NGS)-Technologie wurden die Core-Gene auf dem Illumina MiSeq-System sequenziert. Zur Erfassung von größeren genomischen Rearrangements (Deletionen oder Duplikationen) wurde bei allen 200 Patienten eine Multiplex Ligation-dependent Probe Amplification (MLPA)-Analyse der Gene BRCA1, BRCA2 und CHEK2 durchgeführt. Bei 181 Patienten (90,5 \%) wurde zusätzlich die MLPA-Analyse der Gene $P A L B 2, R A D 51 C$ und RAD51D durchgeführt.

In dieser Dissertation wurden die identifizierten Sequenzveränderungen der ACMG-Klasse 3 (Varianten unklarer Signifikanz; VUS), ACMG-Klasse 4 (wahrscheinlich pathogene Mutationen) und der ACMG-Klasse 5 (pathogene Mutationen) in den 10 Core-Genen im Zusammenhang mit den klinischen Angaben analysiert.

Insgesamt wurden 106 Sequenzvarianten (44,0\%) der ACMG-Klasse 3, 4 oder 5 bei 88 der untersuchten Patienten nachgewiesen. Die Nachweisrate von Mutationen der ACMG-Klasse 4 oder 5 in den 10 Core-Genen lag dagegen bei 18,0\%. In den Genen NBN, RAD51D und TP53 wurde keine Mutation der ACMG-Klasse 4 oder 5 detektiert. Die Detektionsrate von Mutationen der ACMG-Klasse 4 oder 5 in den zwei Hochrisikogenen BRCA1 und BRCA2 betrug dagegen nur $11,0 \%$. Somit lag die Detektionsrate der Mutationen der ACMG-Klasse 4 oder 5 in allen 10 CoreGenen statistisch signifikant höher im Vergleich zur Detektionsrate in den Genen BRCA1 und BRCA2 alleine.

Der häufigste molekulargenetische Typ der identifizierten Sequenzvarianten der ACMG-Klasse 3, 4 oder 5 waren missense-Sequenzvarianten (49,1\%), gefolgt von frame-shift- (19,8\%), nonsense$(10,4 \%)$, synonymen- $(9,4 \%)$, splicing- bzw. potentiellen splicing-(8,5\%)-Sequenzvarianten, großen genomischen Deletionen (1,9\%) und einer in-frame-Sequenzvariante. Es wurde eine deutlich größere Anzahl von missense-Sequenzvarianten in den nicht BRCA1- und BRCA2-CoreGenen (43 Sequenzvarianten bzw. 84,3\%) identifiziert als in den Genen BRCA1 und BRCA2 (8 Sequenzvarianten bzw. 15,7\%).

Bei Patienten mit Mutationen der ACMG-Klasse 4 oder 5 betrug das niedrigste Erkrankungsalter 39,0 Jahre. Wenn die Patienten nach den Altersgruppen bei der Ersterkrankung eines Mammaoder Ovarialkarzinoms unterteilt wurden, war die Mehrzahl der Sequenzvarianten der ACMGKlasse 3, 4 und $5(34,0 \%)$ in der Altersgruppe zwischen dem 40. und 49. Lebensjahr zu beobachten. Diese Analyse ergab auch eine Tendenz eines niedrigeren Erkrankungsalters der Patienten mit den Sequenzvarianten der ACMG-Klasse 3, 4 und 5 in den BRCA1- und BRCA2Genen im Vergleich zu den anderen acht Core-Genen.

Das berechnete mittlere Heterozygoten-Risiko lag bei den Patienten mit einer Sequenzvariante der ACMG-Klasse 3, 4 oder 5 in den Genen BRCA1 und BRCA2 (54 $\pm 33 \%$ ) signifikant höher im Vergleich zu den Patienten mit einer Sequenzvariante der ACMG-Klasse 3, 4 oder 5 in den anderen acht Core-Genen ( $33 \pm 29 \%$ ). Die Heterozygoten-Risiken bei Patienten mit oder ohne Sequenzvariante der ACMG-Klasse 3, 4 oder 5 in einem bestimmten Core-Gen unterschieden sich statistisch signifikant nur für das BRCA1-Gen.

Das berechnete Lebenszeitrisiko bei Patienten mit einer Sequenzvariante der ACMG-Klasse 3, 4 oder 5 in den 10 Core-Genen (31 $\pm 23 \%)$ war statistisch signifikant höher im Vergleich zu Patienten ohne diese Sequenzvarianten (24 $\pm 19 \%)$. Ebenso waren die berechneten Lebenszeitrisiken der Patienten mit einer Sequenzvariante der ACMG-Klasse 3, 4 oder 5 in den Genen BRCA1 oder BRCA2 (41 $\pm 26 \%$ ) signifikant höher im Vergleich zu Patienten mit einer Sequenzvariante der ACMG-Klasse 3, 4 oder 5 in den anderen acht Core-Genen ( $25 \pm 19 \%$ ).

Die Nachweisrate der Sequenzvarianten der ACMG-Klasse 3, 4 oder 5 war nur bei Patienten mit Sequenzvarianten der ACMG-Klasse 3, 4 oder 5 in einem der 10 Core-Gene und Vorliegen eines invasiv duktalen Mammakarzinoms statistisch signifikant. Für die anderen histologischen Subtypen der Mammakarzinome zeigte sich keine statistische Signifikanz in Relation zu den detektierten Sequenzvarianten der ACMG-Klasse 3, 4 oder 5. 
Weiterhin wurde ein Zusammenhang zwischen der Expression der Hormonrezeptoren (ER $\alpha, P R$ ) und der Überexpression des ERBB2-Rezeptors in den Tumoren und dem Status der Sequenzvarianten der ACMG-Klasse 3, 4 oder 5 in den 10 Core-Genen in der genomischen DNA aus Lymphozyten detailliert untersucht. Bei Patienten mit nachweislicher Expression der Hormonrezeptoren ER $\alpha$ oder PR im Tumorgewebe konnten statistisch signifikant niedrigere Detektionsraten der Sequenzvarianten der ACMG-Klasse 3, 4 oder 5 in den BRCA1- und BRCA2Genen im Vergleich zu den anderen acht Core-Genen identifiziert werden (ER $\alpha: 10,6 \%$ vs. 35,6\% bzw. PR: 11,6 \% vs. 34,7 \%). Eine solche Assoziation konnte zwischen der Überexpression der RTK ERBB2 im Tumorgewebe und der Detektion der Sequenzvarianten der ACMG-Klasse 3, 4 oder 5 nicht festgestellt werden. In der Patientenkohorte mit triple-negativen Mammakarzinomen (keine Expression des ER $\alpha$, des PR und keine Überexpression von ERBB2 im Tumorgewebe) wurden statistisch signifikant höhere Detektionsraten von Mutationen der ACMG-Klasse 4 oder 5 beobachtet als bei den Patienten mit nicht triple-negativen Mammakarzinomen (40,6 \% vs. 13,1 \%). Innerhalb der Gruppe mit triple-negativen Mammakarzinomen war die Detektionsrate der Mutationen im BRCA1-Gen statistisch signifikant erhöht im Vergleich zu den Detektionsraten der Mutationen der ACMG-Klasse 4 oder 5 bei Patienten mit triple-negativen Mammakarzinomen in den anderen neun Core-Genen (75\% vs. $25 \%$ ).

Aus den insgesamt 200 analysierten Fällen dieser Kohorte wurden vier Patienten ausgewählt und weiterführend näher molekulargenetisch analysiert. Ebenso wurde ein zusätzlicher Patient, der nicht in der Kohorte mit 200 Patienten gelistet war, für detaillierte molekulargenetische Analysen ausgewählt. Bei diesem Patienten waren die Kriterien für die hereditäre Form des Mamma- und Ovarialkarzinoms durch seine an einem beidseitigen Mammakarzinom verstorbene Tante mütterlicherseits erfüllt.

Die Indexpatientin 39784 war an einem Mammakarzinom erkrankt. An der genomischen DNA aus

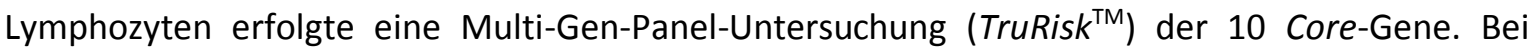
dieser Indexpatientin wurde eine Variante unklarer Signifikanz der ACMG-Klasse 3 (c.346G>A, heterozygot; p.(Val116lle)) im Exon 5 des RAD51D-Gens nachgewiesen. Nach der funktionellen Abklärung dieser Variante auf RNA-Ebene konnte sie als Variante unklarer Signifikanz (ACMGKlasse 3) mit der klinischen Einschätzung einer wahrscheinlich pathogenen Mutation eingestuft werden.

Die Indexpatientin 39037 war ebenso an einem Mammakarzinom erkrankt. Mittels der Multi-GenPanel-Untersuchung und der molekulargenetischen Analyse der 10 Core-Gene (TruRisk $^{\mathrm{TM}}{ }^{\text {) }}$ ) wurde bei ihr die wahrscheinlich pathogene Keimbahnmutation der ACMG-Klasse 4 (c.6336C >A, heterozygot; p.(Cys2112*)) im Exon 43 des ATM-Gens detektiert. Diese Mutation war bisher nicht in den Datenbanken eingetragen und in der Literatur nicht beschrieben. Die o. g. Mutation im ATM-Gen segregierte zwar nicht mit dem Auftreten von allen Mammakarzinomen in der Familie, jedoch ist dieser Mutationstyp bei der in Frage stehenden Erkrankung bekanntermaßen pathogen.

Die Patientin 39769 war selbst nicht an einem Mamma- oder Ovarialkarzinom erkrankt. Ihre Familienanamnese ergab jedoch Hinweise auf eine hereditäre Form des Mamma- und Ovarialkarzinoms. Die Patientin hatte initial keinen Kontakt zu den anderen erkrankten Familienmitgliedern. Daher wurde der Patientin 39769 anhand des berechneten HeterozygotenRisikos von 34,8 \% eine molekulargenetische Untersuchung der 10 Core-Gene angeboten. Bei der Patientin 39769 konnte eine pathogene splice site Keimbahnmutation der ACMG-Klasse 5 (c.706$1 \mathrm{G}>\mathrm{A}$, heterozygot) im RAD51C-Gen detektiert werden. Diese Mutation im RAD51C-Gen wird in der Datenbank des Deutschen Konsortiums Familiärer Brust- und Eierstockkrebs als pathogene Mutation der ACMG-Klasse 5 geführt. Die Segregationsanalyse in der Familie zeigte eine vollständige Segregation dieser Mutation bei allen molekulargenetisch untersuchten Familienmitgliedern mit der Diagnose eines Mammakarzinoms. 
Die Indexpatientin 39917 war an einem duktal teils lobulär invasiven Mammakarzinom erkrankt. Bei der Indexpatientin wurde bei der molekulargenetischen Untersuchung der 10 Core-Gene mittels einer Multi-Gen-Panel-Untersuchung die wahrscheinlich pathogene Mutation der ACMGKlasse 4 (c.1587delT, heterozygot; p.(Ala530Profs*27)) im Exon 11 des CDH1-Gens detektiert. Diese Mutation wird in der Datenbank des Deutschen Konsortiums Familiärer Brust- und Eierstockkrebs als pathogene Mutation geführt und wurde daher als Mutation der ACMG-Klasse 4 eingestuft. Weitere betroffene Familienmitglieder nahmen eine molekulargenetische Analyse nicht in Anspruch.

Der Indexpatient 39202 zählte nicht zu den 200 analysierten Fällen dieser Dissertation. Die Kriterien für eine molekulargenetische Untersuchung der 10 Core-Gene waren ausschließlich in der Familie des Patienten erfüllt (d. h. bei der Tante des Ratsuchenden). Der Indexpatient 39202 war im Alter von 50 Jahren an einem synchronen kolorektalen Karzinom und Nierenzellkarzinom erkrankt. Dieser Fall zeigte sich unter wissenschaftlichen und familienberaterischen Aspekten dennoch molekulargenetisch interessant. Bei dem Patienten wurden alle 10 Core-Gene sowie zusätzlich wegen des Vorliegens eines kolorektalen Karzinoms die Gene MLH1, MSH2, MSH6 und MUTYH analysiert. Nach Auswertung der Kopienzahlvarianten (CNV; copy number variations) der genannten Gene mit Hilfe des SeqNext-Moduls des Auswerteprogramms Sequence Pilot ergab sich der Hinweis auf eine heterozygote Deletion des Exons 1 des MSH6-Gens, die mit Hilfe der MLPA-Analyse bestätigt werden konnte. Die nachfolgende qPCR-Analyse ergab, dass diese heterozygote Deletion eine Gesamtgröße von 46,1 kb aufweist. Da die detektierte Deletion im MSH6-Gen nicht in den Datenbanken und in der Literatur beschrieben war, wurde sie als wahrscheinlich pathogene Mutation der ACMG-Klasse 4 eingestuft. Eine Segregationsanalyse der identifizierten Deletion im MSH6-Gen in der Familie des Indexpatienten 39202 war leider nicht möglich, da bereits alle an Tumoren erkrankten Patienten verstorben waren.

Die klinischen Konsequenzen einer identifizierten Mutation in einem der Core-Gene resultieren in einem Angebot für ein intensiviertes Früherkennnung- bzw. Nachsorgeprogramm (IFNP) und ggf. einem Angebot für eine prophylaktische Mastektomie bzw. eine Salpingo-Oopherektomie. Auch Patienten ohne eine nachgewiesene Mutation in einem der 10 Core-Gene kann anhand des berechneten Heterozygoten- bzw. Lebenszeitrisikos von $\geq 20 \%$ bzw. von $\geq 30 \%$ ein IFNP angeboten werden.

Ebenso wurden die mittels NGS erhaltenen Detektionsraten von allen 200 Patienten mit den Detektionsraten von 124 retrospektiven Patienten verglichen, die noch mittels der SangerSequenzierungstechnologie analysiert wurden. Dazu konnte gezeigt werden, dass die Detektionsrate der Sequenzvarianten der ACMG-Klasse 3, 4 oder 5 nach paralleler Analyse der 10 Core-Gene statistisch signifikant höher lag im Vergleich zur alleinigen Analyse der Gene BRCA1 und BRCA2 mittels der Sanger-Sequenziermethode (44,0\% vs. $25 \%)$. Andererseits konnte auch demonstriert werden, dass mit der Untersuchung einer größeren Anzahl von Genen die Detektionsrate der Sequenzvarianten der ACMG-Klasse 3 statistisch signifikant höher lag. Die Methode der Analyse (NGS vs. Sanger-Sequenziertechnologie) spielte in der Studie dieser Dissertation eine weniger signifikante Rolle, da alle Sequenzvarianten der ACMG-Klasse 3, 4 oder 5 sowohl per NGS als auch mittels der Sanger-Sequenziermethode reproduzierbar waren. Die Validität der NGS-Methode wurde mittels der Sanger-Sequenziermethode bestätigt.

Die Daten dieser Dissertation zeigen einen großen Vorteil der molekulargenetischen Untersuchung mittels der Multi-Gen-Panel-Analyse (NGS) auf, da eine parallele Untersuchung mehrerer Gene eines Patienten sowie eine gleichzeitige molekulargenetische Analyse der DNA mehrerer Patienten möglich ist. Somit ist diese Methode im Vergleich zur SangerSequenziermethode zeit- und kostensparend. Ein Nachteil der parallelen Analyse einer Großzahl 
der Gene ist jedoch die Detektion einer Vielzahl von Varianten unklarer Signifikanz (VUS), die nach dem heutigen Wissensstand nicht eindeutig eingestuft werden können. Weiterhin konnte mit der molekulargenetischen Analyse der 10 Core-Gene nur bei einem Bruchteil (18,0 \%) der Patienten mit Verdacht auf ein hereditäres Mamma- und Ovarialkarzinom die hereditäre Genese aufgeklärt werden. Neben der polygenen Vererbung und multifaktoriellen Genese des Mamma- und Ovarialkarzinoms werden noch weitere Risikofaktoren wie verschiedene Polymorphismen diskutiert. Nichtsdestoweniger ist bei einer gestellten Indikation eine molekulargenetische Analyse der 10 Core-Gene mittels NGS gerechtfertigt, da mit dieser Untersuchung eine statistisch signifikant größere Anzahl von Mutationen bei Patienten identifiziert und bestätigt werden können im Vergleich zur alleinigen molekulargenetischen Analyse der Hochrisikogene BRCA1 und BRCA2. 


\section{Anhang}

\subsection{Gene beinhaltet im HaloPlex- und TruRisk ${ }^{\mathrm{TM}}$-Design}

Tabelle 6.1: Gene im HaloPlex-Panel-Design

\begin{tabular}{|c|c|}
\hline Genliste & ENST-Nummer \\
\hline$A_{T} M^{\$}$ & ENST00000278616 \\
\hline$B A P 1$ & ENST00000460680 \\
\hline$B A R D 1$ & ENST00000260947 \\
\hline$B R C A 1^{\$}$ & ENST00000357654 \\
\hline$B R C A 2^{\$}$ & ENST00000544455 \\
\hline$B R I P 1$ & ENST00000259008 \\
\hline CASP8 & ENST00000264275 \\
\hline$C D H 1^{\$}$ & ENST00000261769 \\
\hline CHEK $2^{\$}$ & ENST00000328354 \\
\hline $\operatorname{cox} 11$ & ENST00000299335 \\
\hline FANCA & ENST00000389301 \\
\hline FANCC & ENST00000289081 \\
\hline FANCD2 & ENST00000287647 \\
\hline FANCE & ENST00000229769 \\
\hline FANCF & ENST00000327470 \\
\hline FANCG & ENST00000378643 \\
\hline FGFR2 & ENST00000358487 \\
\hline$H M M R$ & ENST00000393915 \\
\hline LSP1 & ENST00000381775 \\
\hline МАР $3 K 1$ & ENST00000399503 \\
\hline MEN1 & ENST00000312049 \\
\hline MLH1 & ENST00000231790 \\
\hline MRE11A & ENST00000323929 \\
\hline $\mathrm{MSH} 2$ & ENST00000233146 \\
\hline MSH6 & ENST00000234420 \\
\hline$N B N^{\$}$ & ENST00000265433 \\
\hline NEIL1 & ENST00000564784 \\
\hline NQO2 & ENST00000338130 \\
\hline PALB2 & ENST00000337432 \\
\hline PHB & ENST00000300408 \\
\hline PPM1D & ENST00000305921 \\
\hline PTEN & ENST00000371953 \\
\hline RAD50 & ENST00000378823 \\
\hline RAD51B & ENST00000487861 \\
\hline RAD51C ${ }^{S}$ & ENST00000345365 \\
\hline RAD51D & ENST00000269305 \\
\hline RAD1L1 & ENST00000487270 \\
\hline RAD54L & ENST00000371975 \\
\hline SLC4A7 & ENST00000295736 \\
\hline STK11 & ENST00000326873 \\
\hline TOX3 & ENST00000219746 \\
\hline
\end{tabular}




\begin{tabular}{|c|c|}
\hline Genliste & ENST-Nummer \\
\hline TP53 $^{\text {S }}$ & ENST00000261584 \\
\hline XRCC2 & ENST00000359321 \\
\hline XRCC3 & ENST00000553264 \\
\hline
\end{tabular}

\$vom Deutschen Konsortium Familiärer Brust- und Eierstockes definierte 10 Core-Gene; ENST_Nummer übernommen aus Ensembl genome browser 88 (www.ensembl.org), fett markiert sind die 10 Core-Gene.

Tabelle 6.2: Gene im TruRisk ${ }^{\mathrm{TM}}$-Panel-Design

\begin{tabular}{|c|c|}
\hline Genliste & ENST-Nummer \\
\hline ATM $^{\$}$ & ENST00000278616 \\
\hline$B A P 1$ & ENST00000460680 \\
\hline BARD1 & ENST00000260947 \\
\hline$B R C A 1^{\$}$ & ENST00000357654 \\
\hline$B R C A 2^{S}$ & ENST00000544455 \\
\hline$B R I P 1$ & ENST00000259008 \\
\hline CASP8 & ENST00000264275 \\
\hline $\mathrm{CDH} 1^{S}$ & ENST00000261769 \\
\hline CHEK2 $2^{S}$ & ENST00000328354 \\
\hline $\operatorname{cox} 11$ & ENST00000299335 \\
\hline FANCA & ENST00000389301 \\
\hline FANCC & ENST00000289081 \\
\hline FANCD2 & ENST00000287647 \\
\hline FANCE & ENST00000229769 \\
\hline FANCF & ENST00000327470 \\
\hline FANCG & ENST00000378643 \\
\hline FGFR2 & ENST00000358487 \\
\hline$H M M R$ & ENST00000393915 \\
\hline LSP1 & ENST00000381775 \\
\hline MAP3К1 & ENST00000399503 \\
\hline MEN1 & ENST00000312049 \\
\hline MLH1 & ENST00000231790 \\
\hline MRE11A & ENST00000323929 \\
\hline $\mathrm{MSH} 2$ & ENST00000233146 \\
\hline MSH6 & ENST00000234420 \\
\hline$N_{B N}{ }^{\$}$ & ENST00000265433 \\
\hline NEIL1 & ENST00000564784 \\
\hline NQO2 & ENST00000338130 \\
\hline PALB2 ${ }^{\text {S }}$ & ENST00000337432 \\
\hline PHB & ENST00000300408 \\
\hline PPM1D & ENST00000305921 \\
\hline PTEN & ENST00000371953 \\
\hline RAD50 & ENST00000378823 \\
\hline RAD51B & ENST00000487270 \\
\hline RAD51C & ENST00000345365 \\
\hline RAD51D & ENST00000269305 \\
\hline
\end{tabular}




\begin{tabular}{|c|c|}
\hline Genliste & ENST-Nummer \\
\hline RAD54L & ENST00000371975 \\
\hline SLC4A7 & ENST00000295736 \\
\hline STK11 & ENST00000326873 \\
\hline TOX3 & ENST00000219746 \\
\hline TP53 & ENST00000261584 \\
\hline XRCC2 & ENST00000359321 \\
\hline XRCC3 & ENST00000553264 \\
\hline
\end{tabular}

\$vom Deutschen Konsortium Familiärer Brust- und Eierstockes definierten 10 Core-Gene; ENST_Nummer übernommen aus Ensembl genome browser 88 (www.ensembl.org), fett markiert sind die 10 Core-Gene.

\subsection{Liste der Patienten ohne eine detektierte Sequenzvariante der ACMG- Klasse 3, 4 oder 5 in einem der 10 Core-Gene}

Tabelle 6.3 Analysierte Patienten ohne eine identifizierte Sequenzvariante der ACMG-Klasse 3, 4 oder 5. In der Tabelle sind 112 Patienten ohne nachgewiesene Sequenzvarianten der ACMG-Klasse 3, 4 oder 5 in den 10 analysierten Core-Genen aufgeführt. In diesen Patienten konnten keine Sequenzvarianten mittels der NGS-Technologie nachgewiesen werden. Ebenfalls konnten mit Hilfe der MLPA-Untersuchung keine Deletionen/Duplikationen identifiziert werden. Bei diesen Patienten lagen nur Sequenzvarianten der ACMG-Klasse 1 und 2 vor.

\begin{tabular}{|c|c|c|c|c|c|}
\hline Anzahl & Patienten-Nummer & $\mathrm{MCa}$ & OvCa & Geschlecht & $\begin{array}{l}\text { Vorhandensein der Sequenzvarianten der } \\
\text { ACMG-Klasse } 3,4 \text { oder } 5 \text { in } 10 \text { Core-Genen }\end{array}$ \\
\hline 1 & 38550 & ja & nein & $\mathrm{m}$ & keine \\
\hline 2 & 38556 & ja & nein & w & keine \\
\hline 3 & 38557 & ja & nein & $w$ & keine \\
\hline 4 & 38562 & ja & nein & $w$ & keine \\
\hline 5 & 38563 & ja & nein & $w$ & keine \\
\hline 6 & 38570 & ja & nein & $w$ & keine \\
\hline 7 & 38588 & ja & nein & $w$ & keine \\
\hline 8 & 38551 & nein & ja & $w$ & keine \\
\hline 9 & 38578 & ja & nein & $w$ & keine \\
\hline 10 & 38580 & ja & nein & w & keine \\
\hline 11 & 38583 & ja & nein & $w$ & keine \\
\hline 12 & 38584 & ja & nein & $w$ & keine \\
\hline 13 & 38582 & ja & nein & $w$ & keine \\
\hline 14 & 38587 & ja & nein & $w$ & keine \\
\hline 15 & 39001 & nein & nein & $w$ & keine \\
\hline 16 & 38595 & ja & nein & w & keine \\
\hline 17 & 35789 & ja & nein & w & keine \\
\hline 18 & 39002 & ja & nein & $w$ & keine \\
\hline 19 & 39013 & ja & nein & $w$ & keine \\
\hline 20 & 39014 & ja & nein & $w$ & keine \\
\hline 21 & 39019 & ja & nein & w & keine \\
\hline 22 & 39022 & ja & nein & $w$ & keine \\
\hline 23 & 38958 & nein & nein & $w$ & keine \\
\hline 24 & 39011 & nein & nein & $\mathrm{m}$ & keine \\
\hline 25 & 39023 & ja & nein & $w$ & keine \\
\hline
\end{tabular}




\begin{tabular}{|c|c|c|c|c|c|}
\hline Anzahl & Patienten-Nummer & $\mathrm{MCa}$ & OvCa & Geschlecht & $\begin{array}{l}\text { Vorhandensein der Sequenzvarianten der } \\
\text { ACMG-Klasse 3, } 4 \text { oder } 5 \text { in } 10 \text { Core-Genen }\end{array}$ \\
\hline 26 & 39026 & ja & ja & $w$ & keine \\
\hline 27 & 39034 & ja & nein & $w$ & keine \\
\hline 28 & 39041 & ja & nein & w & keine \\
\hline 29 & 39044 & ja & nein & $w$ & keine \\
\hline 30 & 39062 & nein & nein & $w$ & keine \\
\hline 31 & 39047 & ja & nein & $w$ & keine \\
\hline 32 & 39049 & ja & nein & $w$ & keine \\
\hline 33 & 39052 & ja & nein & w & keine \\
\hline 34 & 39058 & ja & nein & $w$ & keine \\
\hline 35 & 39059 & ja & nein & w & keine \\
\hline 36 & 39063 & ja & nein & $w$ & keine \\
\hline 37 & 39068 & ja & nein & $w$ & keine \\
\hline 38 & 39027 & ja & nein & $w$ & keine \\
\hline 39 & 39020 & ja & nein & $w$ & keine \\
\hline 40 & 38975 & ja & nein & $w$ & keine \\
\hline 41 & 39073 & ja & nein & $w$ & keine \\
\hline 42 & 39075 & ja & nein & $w$ & keine \\
\hline 43 & 39078 & ja & nein & $w$ & keine \\
\hline 44 & 39079 & ja & nein & $w$ & keine \\
\hline 45 & 39080 & nein & nein & $w$ & keine \\
\hline 46 & 39087 & ja & nein & $w$ & keine \\
\hline 47 & 39088 & ja & nein & $w$ & keine \\
\hline 48 & 39091 & nein & nein & $w$ & keine \\
\hline 49 & 39098 & ja & nein & $w$ & keine \\
\hline 50 & 39099 & ja & nein & w & keine \\
\hline 51 & 39700 & ja & nein & $w$ & keine \\
\hline 52 & 39701 & ja & nein & $w$ & keine \\
\hline 53 & 39706 & ja & nein & w & keine \\
\hline 54 & 39708 & ja & nein & $w$ & keine \\
\hline 55 & 39709 & ja & nein & $w$ & keine \\
\hline 56 & 39710 & ja & nein & $w$ & keine \\
\hline 57 & 39713 & ja & nein & $w$ & keine \\
\hline 58 & 39714 & ja & nein & $w$ & keine \\
\hline 59 & 39721 & ja & nein & $w$ & keine \\
\hline 60 & 37874 & ja & nein & $w$ & keine \\
\hline 61 & 38718 & ja & nein & $w$ & keine \\
\hline 62 & 39724 & nein & nein & $w$ & keine \\
\hline 63 & 39727 & nein & nein & $w$ & keine \\
\hline 64 & 39733 & nein & ja & $w$ & keine \\
\hline 65 & $34444 B$ & ja & nein & $w$ & keine \\
\hline 66 & 39735 & ja & nein & $w$ & keine \\
\hline 67 & 39739 & ja & nein & $w$ & keine \\
\hline 68 & 39740 & ja & nein & $w$ & keine \\
\hline 69 & $36779 B$ & ja & nein & $w$ & keine \\
\hline
\end{tabular}




\begin{tabular}{|c|c|c|c|c|c|}
\hline Anzahl & Patienten-Nummer & $\mathrm{MCa}$ & OvCa & Geschlecht & $\begin{array}{l}\text { Vorhandensein der Sequenzvarianten der } \\
\text { ACMG-Klasse 3, } 4 \text { oder } 5 \text { in } 10 \text { Core-Genen }\end{array}$ \\
\hline 70 & 39742 & nein & nein & $w$ & keine \\
\hline 71 & 39747 & ja & nein & $w$ & keine \\
\hline 72 & $34450 B$ & ja & nein & w & keine \\
\hline 73 & 39738 & ja & nein & $w$ & keine \\
\hline 74 & 39749 & ja & nein & w & keine \\
\hline 75 & 39757 & ja & nein & w & keine \\
\hline 76 & 39758 & ja & nein & $w$ & keine \\
\hline 77 & 39759 & ja & nein & w & keine \\
\hline 78 & 39762 & ja & nein & $w$ & keine \\
\hline 79 & 39768 & ja & nein & w & keine \\
\hline 80 & 39785 & ja & nein & $w$ & keine \\
\hline 81 & 39786 & nein & nein & $w$ & keine \\
\hline 82 & 39787 & ja & nein & $w$ & keine \\
\hline 83 & 39790 & ja & nein & $w$ & keine \\
\hline 84 & $26959 C$ & ja & nein & $w$ & keine \\
\hline 85 & 39767 & ja & nein & $w$ & keine \\
\hline 86 & 39774 & nein & ja & $w$ & keine \\
\hline 87 & 39781 & ja & nein & w & keine \\
\hline 88 & 39796 & ja & nein & $w$ & keine \\
\hline 89 & 39910 & ja & nein & $w$ & keine \\
\hline 90 & 39901 & ja & nein & $w$ & keine \\
\hline 91 & 39908 & ja & nein & $\mathrm{m}$ & keine \\
\hline 92 & 39913 & nein & nein & $w$ & keine \\
\hline 93 & 39914 & nein & nein & $w$ & keine \\
\hline 94 & 39923 & ja & nein & w & keine \\
\hline 95 & 39925 & nein & nein & w & keine \\
\hline 96 & 39928 & ja & nein & $w$ & keine \\
\hline 97 & 39931 & ja & nein & w & keine \\
\hline 98 & 39929 & ja & nein & $w$ & keine \\
\hline 99 & 39932 & ja & nein & $\mathrm{m}$ & keine \\
\hline 100 & 39933 & ja & nein & $w$ & keine \\
\hline 101 & 39935 & ja & nein & $w$ & keine \\
\hline 102 & 39936 & ja & nein & $w$ & keine \\
\hline 103 & 39937 & ja & nein & $w$ & keine \\
\hline 104 & 39949 & ja & nein & w & keine \\
\hline 105 & 39953 & ja & ja & $w$ & keine \\
\hline 106 & 39939 & nein & nein & $w$ & keine \\
\hline 107 & 39941 & ja & nein & $w$ & keine \\
\hline 108 & 39942 & nein & nein & $w$ & keine \\
\hline 109 & 39947 & ja & nein & $w$ & keine \\
\hline 110 & 39948 & ja & nein & $w$ & keine \\
\hline 111 & 39955 & ja & nein & $w$ & keine \\
\hline 112 & 39962 & ja & nein & $w$ & keine \\
\hline
\end{tabular}




\subsection{Rezeptorstatus der Mammkarzinome in Assoziation mit identifizierten Sequenzvarianten in den 10 Core-Genen}

Tabelle 6.4: Rezeptorstatus der Mammakarzinome in Abhängigkeit von identifizierten Sequenzvarianten in den 10 Core-Genen

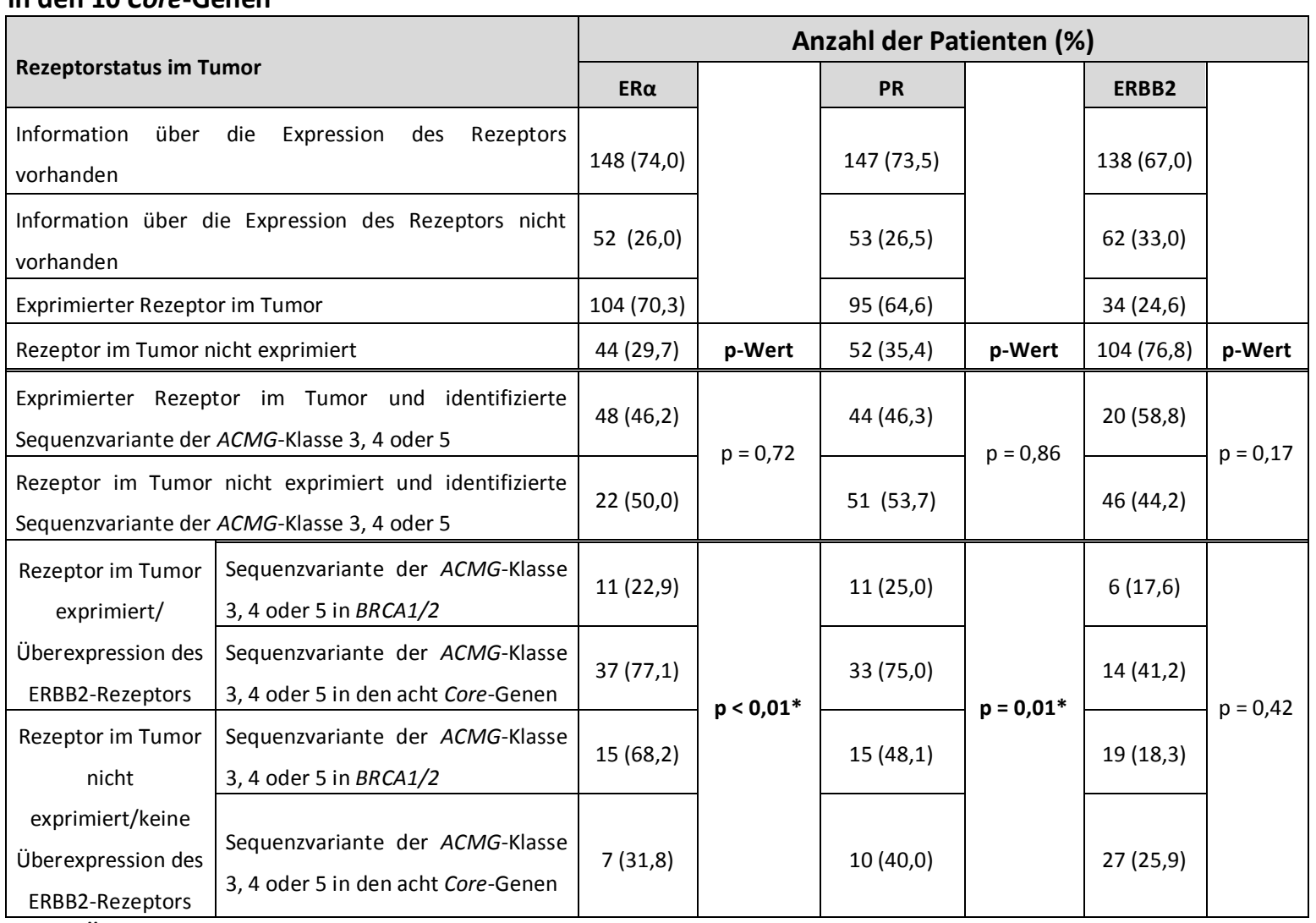

$\mathrm{ER} \alpha=$ Östrogenrezeptor $\alpha, \mathrm{PR}=$ Progesteron-Rezeptor. 


\section{Literaturverzeichnis}

Aarnio M, Sankila R, Pukkala E, Salovaara R, Aaltonen LA, de la Chapelle A, Peltomäki P, Mecklin JP, Järvinen HJ (1999): Cancer risk in mutation carriers of DNA-mismatch-repair genes. Int J Cancer 81, 214-218

Ahmed M, Rahman N (2006): ATM and breast cancer susceptibility. Oncogene 25, 5906-5911

Allen G. (1952): The meaning of concordance and discordance in estimation of penetrance and gene frequency. Am J Hum Genet 4, 155-172

Alter BP, Rosenberg PS, Brody LC (2007): Clinical and molecular features associated with biallelic mutations in FANCD1/BRCA2. J Med Genet 44, 1-9

Anderson E (2002): The role of oestrogen and progesterone receptors in human mammary development and tumorigenesis. Breast Cancer Res 4 , 197-201

Antoniou AC, Casadei S, Heikkinen T, Barrowdale D, Pylkäs K, Roberts J (2014): Breast-cancer risk in families with mutations in PALB2. N Engl J Med 371, 497-506

Aretz S. Erbliche Tumorsyndrome. In: Moog U, Rieß O (Hrsg.): Medizinische Genetik für die Praxis. 1. Auflage; Thieme, Stuttgart 2014, 160-165

Asten KV, Neven P, Lintermans A, Wildiers H, Paridaens R (2014): Aromatase inhibitors in the breast cancer clinic: focus on exemestane. Endocr Relat Cancer 21, R31-R49

Auber B, Heinecke K, Morlot S, Schlegelberger B, Steinemann D (2014): Massive parallele Sequenzierung in der Diagnostik hereditärer BRCA1-/-2-Mutationen. Medgen 26, 255-263

Badowska-Kozakiewicz AM, Patera J, Sobol M, Przybylski J (2015): The role of oestrogen and progesterone receptors in breast cancer - immunohistochemical evaluation of oestrogen and progesterone receptor expression in invasive breast cancer in women. Contemp Oncol (Pozn) $\underline{19}$, 220-225

Baglietto L, Lindor NM, Dowty JG, White DM, Wagner A, Gomez Garcia EB, Vriends AHJT, Dutch Lynch Syndrome Study Group, Cartwright NR, Barnetson RA et al (2010): Risks of Lynch syndrome cancers for MSH6 mutation carriers. J Natl Cancer Inst 102, 193-201

Bartek J, Falck J, Lukas J (2001): CHK2 kinase--a busy messenger. Nat Rev Mol Cell Biol 2, 877-886

Baselga J, Swain SM (2009): Novel anticancer targets: revisiting ERBB2 and discovering ERBB3. Nat Rev Cancer $\underline{9}, 463-475$

Benusiglio PR, Caron O, Consolino E, Duvillard P, Coulet F, Blayau M, Malka D (2013a): Cleft lip, cleft palate, hereditary diffuse gastric cancer and germline mutations in $\mathrm{CDH1}$. Int J Cancer $\underline{132}$, 2470

Benusiglio PR, Malka D, Rouleau E, De Pauw A, Buecher B, Noguès C, Fourme E, Colas C, Coulet F, Warcoin $\mathrm{M}$ et al. (2013b): $C D H 1$ germline mutations and the hereditary diffuse gastric and lobular breast cancer syndrome: a multicentre study. J Med Gen $\underline{50}$, 486-489 
Beral V, Million Women Study Collaborators (2003): Breast cancer and hormone-replacement therapy in the Million Women Study. Lancet 362, 419-427

Berchuck A, Heron KA, Carney ME, Lancaster JM, Fraser EG, Vinson VL, Deffenbaugh AM, Miron A, Marks JR, Futreal PA et al. (1998): Frequency of germline and somatic BRCA1 mutations in ovarian cancer. Clin Cancer Res 4 , 2433-2437

Bericht zum Krebsgeschehen in Deutschland, Epidemiologie von Krebserkrankungen 2016, Robert Koch-Institut, Berlin 2016

Bettegowda C, Sausen M, Leary RJ, Kinde I, Wang Y, Agrawal N, Bartlett BR, Wang H, Luber B, Alani RM et al. (2014): Detection of Circulating Tumor DNA in Early- and Late-Stage Human Malignancies. Sci Transl Med $\underline{6}$, 224ra24-224ra24

Bettstetter M, Dechant S, Ruemmele P, Vogel C, Kurz K, Morak M, Keller G, Holinski-Feder E, Hofstaedter F, Dietmaier W (2008): MethyQESD, a robust and fast method for quantitative methylation analyses in HNPCC diagnostics using formalin-fixed and paraffin-embedded tissue samples. Lab Invest $\underline{88}$ 1367-1375

Bilous M, Morey AL, Armes JE, Bell R, Button PH, Cummings MC, Fox SB, Francis GD, Waite B, McCue $G$ et al. (2012): Assessing HER2 amplification in breast cancer: findings from the Australian In Situ Hybridization Program. Breast Cancer Res Treat 134, 617-624

Bochar DA, Wang L, Beniya H, Kinev A, Xue Y, Lane WS, Wang W, Kashanchi F, Shiekhattar R (2000): BRCA1 Is Associated with a Human SWI/SNF-Related Complex: Linking Chromatin Remodeling to Breast Cancer. Cell 102, 257-265

Boonyaratanakornkit V, Scott MP, Ribon V, Sherman L, Anderson SM, Maller JL, Miller WT, Edwards DP (2001): Progesterone receptor contains a proline-rich motif that directly interacts with SH3 domains and activates c-Src family tyrosine kinases. Mol Cell $\underline{8}, 269-280$.

Boonyaratanakornkit V, McGowan E, Sherman L, Mancini MA, Cheskis BJ, Edwards DP (2007): The role of extranuclear signaling actions of progesterone receptor in mediating progesterone regulation of gene expression and the cell cycle. Mol Endocrinol 21, 359-375

Breast Cancer Susceptibility Collaboration (BCSC) (UK), Loveday C, Turnbull C, Ruark E, Xicola, RMM, Ramsay E, Hughes D, Warren-Perry M, Snape K, Eccles D et al. (2012): Germline RAD51C mutations confer susceptibility to ovarian cancer. Nat Genet $\underline{44}$, 475-476

Brito LA, Yamamoto GL, Melo S, Malcher C, Ferreira SG, Figueiredo J, Alvizi L, Kobayashi GS, Naslavsky MS, Alonso N et al. (2015): Rare Variants in the Epithelial Cadherin Gene Underlying the Genetic Etiology of Nonsyndromic Cleft Lip with or without Cleft Palate. Hum Mutat $\underline{36}$, 10291033

Buchanan DD, Tan YY, Walsh MD, Clendenning M, Metcalf AM, Ferguson K, Arnold ST, Thompson BA, Lose FA, Parsons MT et al. (2014): Tumor mismatch repair immunohistochemistry and DNA MLH1 methylation testing of patients with endometrial cancer diagnosed at age younger than 60 years optimizes triage for population-level germline mismatch repair gene mutation testing. J Clin Oncol $\underline{32}, 90-100$ 
Burris HA (2004): Dual kinase inhibition in the treatment of breast cancer: initial experience with the EGFR/ErbB-2 inhibitor lapatinib. Oncologist 9 Supp/ 3, 10-15

Buslov KG, Iyevleva AG, Chekmariova EV, Suspitsin EN, Togo AV, Kuligina ES, Sokolenko AP, Matsko DE, Turkevich EA, Lazareva YR et al. (2005): NBS1 657del5 mutation may contribute only to a limited fraction of breast cancer cases in Russia. Int J Cancer 114, 585-589

Buys SS, Sandbach JF, Gammon A, Patel G, Kidd J, Brown KL, Sharma L, Saam J, Lancaster J, Daly MB (2017): A study of over 35,000 women with breast cancer tested with a 25-gene panel of hereditary cancer genes. Cancer $\underline{123}, 1721-1730$

Byrski T, Huzarski T, Dent R, Marczyk E, Jasiowka M, Gronwald J, Jakubowicz J, Cybulski C, Wisniowski R, Godlewski D et al. (2014): Pathologic complete response to neoadjuvant cisplatin in BRCA1- positive breast cancer patients. Breast Cancer Res Treat 147, 401-405

Carney JP, Maser RS, Olivares H, Davis EM, Le Beau M, Yates JR, Hays L, Morgan WF, Petrini JH (1998): The hMre11/hRad50 protein complex and Nijmegen breakage syndrome: linkage of double-strand break repair to the cellular DNA damage response. Cell 93 , 477-486

Carnevale RP, Proietti CJ, Salatino M, Urtreger A, Peluffo G, Edwards DP, Boonyaratanakornkit V, Charreau EH, Bal de Kier Joffé E, Schillaci R et al. (2007): Progestin effects on breast cancer cell proliferation, proteases activation, and in vivo development of metastatic phenotype all depend on progesterone receptor capacity to activate cytoplasmic signaling pathways. Mol Endocrinol 21 , 1335-1358

Cartegni L, Chew SL, Krainer AR (2002): Listening to silence and understanding nonsense: exonic mutations that affect splicing. Nat Rev Genet $\underline{3}, 285-298$

Casadei S, Norquist BM, Walsh T, Stray S, Mandell JB, Lee MK (2011): Contribution to familial breast cancer of inherited mutations in the BRCA2-interacting protein PALB2. Cancer Res $\underline{71}$, 2222-2229

Castéra L, Krieger S, Rousselin A, Legros A, Baumann J-J, Bruet O, Brault B, Fouillet R, Goardon N, Letac $O$ et al. (2014): Next-generation sequencing for the diagnosis of hereditary breast and ovarian cancer using genomic capture targeting multiple candidate genes. Eur J Hum Genet $\underline{22}$, 1305-1313

Cavalieri E, Chakravarti D, Guttenplan J, Hart E, Ingle J, Jankowiak R, Muti P, Rogan E, Russo J, Santen R et al. (2006): Catechol estrogen quinones as initiators of breast and other human cancers: implications for biomarkers of susceptibility and cancer prevention. Acta Biochim Biophys $1766,63-78$

Chao A, Chang T-C, Lapke N, Jung S-M, Chi P, Chen C-H, Yang L-Y, Lin C-T, Huang H-J, Chou H-H et al. (2016): Prevalence and clinical significance of BRCA1/2 germline and somatic mutations in Taiwanese patients with ovarian cancer. Oncotarget $\underline{7}, 85529-85541$

Chen WY, Manson JE, Hankinson SE, Rosner B, Holmes MD, Willett WC, Colditz GA (2006): Unopposed estrogen therapy and the risk of invasive breast cancer. Arch Intern Med 166, 10271032 
Chie W-C, Hsieh C, Newcomb PA, Longnecker MP, Mittendorf, R., Greenberg ER, Clapp RW, Burke KP, Titus-Ernstoff L, Trentham-Dietz A et al. (2000): Age at Any Full-term Pregnancy and Breast Cancer Risk. Am J Epidemiol 151, 715-722

Chlebowski RT, Kuller LH, Prentice RL, Stefanick ML, Manson JE, Gass M, Aragaki AK, Ockene JK, Lane DS, Sarto GE et al. (2009): Breast Cancer after Use of Estrogen plus Progestin in Postmenopausal Women. N Engl J Med $\underline{360}$,573-587

Chong HK, Wang T, Lu H-M, Seidler S, Lu H, Keiles S, Chao EC, Stuenkel AJ, Li X, Elliott AM (2014): The Validation and Clinical Implementation of BRCAplus: A Comprehensive High-Risk Breast Cancer Diagnostic Assay. PLoS One $\underline{9}$, e97408

Chrzanowska KH, Gregorek H, Dembowska-Bagińska B, Kalina MA, Digweed M (2012): Nijmegen breakage syndrome (NBS). Orphanet J Rare Dis $\underline{7}, 13$

Chun J, Buechelmaier ES, Powell SN (2013): Rad51 paralog complexes BCDX2 and CX3 act at different stages in the BRCA1-BRCA2-dependent homologous recombination pathway. Mol Cell Biol $\underline{33}, 387-395$

Clarke CL, Sutherland RL (1990): Progestin regulation of cellular proliferation. Endocr Rev $\underline{11}$, 266301

Clemons M, Goss P (2001): Estrogen and the Risk of Breast Cancer. N Engl J Med 344, 276-285

Cloud AJ, Thai A, Liao Y, Terry MB (2015): The impact of cancer prevention guideline adherence on overall mortality in a high-risk cohort of women from the New York site of the Breast Cancer Family Registry. Breast Cancer Res Treat. 149, 537-546

Collaborative Group on Hormonal Factors in Breast Cancer (2002): Breast cancer and breastfeeding: collaborative reanalysis of individual data from 47 epidemiological studies in 30 countries, including 50302 women with breast cancer and 96973 women without the disease. Lancet $\underline{360}, 187-195$

Collins N, McManus R, Wooster R, Mangion J, Seal S, Lakhani SR, Ormiston W, Daly PA, Ford D, Easton DF (1995): Consistent loss of the wild type allele in breast cancers from a family linked to the BRCA2 gene on chromosome 13q12-13. Oncogene $\underline{10}, 1673-1675$

Couch FJ, Hart SN, Sharma P, Toland AE, Wang X, Miron P, Olson JE, Godwin AK, Pankratz VS, Olswold $C$ et al. (2015): Inherited mutations in 17 breast cancer susceptibility genes among a large triple-negative breast cancer cohort unselected for family history of breast cancer. J Clin Oncol $\underline{33}$, 304-311

Couch FJ, Shimelis H, Hu C, Hart SN, Polley EC, Na J, Hallberg E, Moore R, Thomas A, Lilyquist J et al. (2017): Associations Between Cancer Predisposition Testing Panel Genes and Breast Cancer. JAMA Oncol $\underline{3}, 1190-1196$

Coulet F, Fajac A, Colas C, Eyries M, Dion-Minière A, Rouzier R, Uzan S, Lefranc J-P, Carbonnel M, Cornelis F et al. (2013): Germline RAD51C mutations in ovarian cancer susceptibility. Clin Genet 83, 332-336 
Crawford B, Adams SB, Sittler T, van den Akker J, Chan S, Leitner O, Ryan L, Gil E, van 't Veer L (2017): Multi-gene panel testing for hereditary cancer predisposition in unsolved high-risk breast and ovarian cancer patients. Breast Cancer Res Treat 63 , 383-390

Cybulski C, Huzarski T, Górski B, Masojć B, Mierzejewski M, Debniak T, Gliniewicz B, Matyjasik J, Złowocka E, Kurzawski $G$ et al. (2004): A novel founder CHEK2 mutation is associated with increased prostate cancer risk. Cancer Res 64, 2677-2679

Cybulski C, Wokołorczyk D, Jakubowska A, Huzarski T, Byrski T, Gronwald J, Masojć B, Dębniak T, Górski B, Blecharz P et al. (201a): Risk of Breast Cancer in Women With a CHEK2 Mutation With and Without a Family History of Breast Cancer. J Clin Oncol 29, 3747-52

Cybulski C, Lubiński J, Wokołorczyk D, Kuźniak W, Kashyap A, Sopik V, Huzarski T, Gronwald J, Byrski T, Szwiec M et al. (2015a): Mutations predisposing to breast cancer in 12 candidate genes in breast cancer patients from Poland. Clin Genet $\underline{88}, 366-370$

Cybulski C, Kluźniak W, Huzarski T, Wokołorczyk D, Kashyap A, Jakubowska A, Szwiec M, Byrski T, Dębniak T, Górski B et al. (2015b): Clinical outcomes in women with breast cancer and a PALB2 mutation: a prospective cohort analysis. Lancet Oncol $\underline{16}$, 638-644

Davy G, Rousselin A, Goardon N, Castéra L, Harter V, Legros A, Muller E, Fouillet R, Brault B, Smirnova AS et al. (2017): Detecting splicing patterns in genes involved in hereditary breast and ovarian cancer. Eur J Hum Genet 25, 1147-1154

den Dunnen JT, Dalgleish R, Maglott DR, Hart RK, Greenblatt MS, McGowan-Jordan J, Roux A-F, Smith T, Antonarakis SE, Taschner PEM et al. (2016): HGVS Recommendations for the Description of Sequence Variants: 2016 Update. Hum Mutat 37, 564-569

Dent R, Trudeau M, Pritchard KI, Hanna WM, Kahn HK, Sawka CA, Lickley LA, Rawlinson E, Sun P, Narod SA (2007): Triple-Negative Breast Cancer: Clinical Features and Patterns of Recurrence. Clin Cancer Res $\underline{13}$, 4429-4434

Desmond A, Kurian AW, Gabree M, Mills MA, Anderson MJ, Kobayashi Y, Horick N, Yang S, Shannon KM, Tung N et al. (2015): Clinical Actionability of Multigene Panel Testing for Hereditary Breast and Ovarian Cancer Risk Assessment. JAMA Oncol 1, 943-951

Deutsches Konsortium Familiärer Brust- und Eierstockkrebs (2017): Verinbarung zur Einhaltung der im Deutschen Konsortium Familiärer Brust- und Eierstockkrebs konsertierten SOP, o.O, o. Verl., o. 0.

Early Breast Cancer Trialists' Collaborative Group (EBCTCG) (2015): Aromatase inhibitors versus tamoxifen in early breast cancer: patient-level meta-analysis of the randomised trials. Lancet $\underline{386}$, 1341-1352

Eliade M, Skrzypski J, Baurand A, Jacquot C, Bertolone G, Loustalot C, Coutant C, Guy F, Fumoleau $P$, Duffourd $Y$ et al. (2017): The transfer of multigene panel testing for hereditary breast and ovarian cancer to healthcare: What are the implications for the management of patients and families? Oncotarget $\underline{8}, 1957-1971$ 
Engel C, Zachariae S, Fischer C (2015): Familiärer Brustkrebs - empirische Erkrankungsrisiken und Risikoberechnungsmodelle. Medgen 27, 217-222

Ewerth D, Schmidts A, Hein M, Schnerch D, Kvainickas A, Greil C, Duyster J, Engelhardt M, Wäsch $R$ (2016): Suppression of $A P C / C^{C d h 1}$ has subtype specific biological effects in acute myeloid leukemia. Oncotarget $\underline{7}, 48220-48230$

Ferrarini A, Auteri-Kaczmarek A, Pica A, Boesch N, Heinimann K, Schäfer SC, Vesnaver-Megalo S, Cina V, Beckmann JS, Monnerat C (2011): Early occurrence of lung adenocarcinoma and breast cancer after radiotherapy of a chest wall sarcoma in a patient with a de novo germline mutation in TP53. Fam Cancer 10, 187-192

Fischer DC, Bickeböller H (2007): Risikokalkulationen bei erblichen Krebserkrankungen. Medgen 19, 245-249

Foo TK, Tischkowitz M, Simhadri S, Boshari T, Zayed N, Burke KA, Berman SH, Blecua P, Riaz N, Huo $Y$ et al. (2017): Compromised BRCA1-PALB2 interaction is associated with breast cancer risk. Oncogene $\underline{36}, 4161-4170$

Ford JM (2012): Is breast cancer a part of Lynch syndrome? Breast Cancer Res 14,110

Fostira F, Konstantopoulou I, Mavroudis D, Tryfonopoulos D, Yannoukakos D, Voutsinas Ge (2015): Genetic evaluation based on family history and Her2 status correctly identifies TP53 mutations in very early onset breast cancer cases. Clin Genet 87, 383-387

Foulkes WD, Smith IE, Reis-Filho JS (2010): Triple-Negative Breast Cancer. N Engl J Med $\underline{363}$, 1938-1948

Francis GD, Jones MA, Beadle GF, Stein SR (2009): Bright-field in situ hybridization for HER2 gene amplification in breast cancer using tissue microarrays: correlation between chromogenic (CISH) and automated silver-enhanced (SISH) methods with patient outcome. Diagn Mol Pathol $\underline{18}, 88-$ 95

Frebourg T, Oliveira C, Hochain P, Karam R, Manouvrier S, Graziadio C, Vekemans M, Hartmann A, Baert-Desurmont S, Alexandre $C$ et al. (2006): Cleft lip/palate and $C D H 1 / E$-cadherin mutations in families with hereditary diffuse gastric cancer. J Med Genet $\underline{43}, 138-142$

Furey TS (2012): ChIP-seq and beyond: new and improved methodologies to detect and characterize protein-DNA interactions. Nat Rev Genet $\underline{13}, 840-852$

Gage M, Wattendorf D, Henry LR (2012): Translational advances regarding hereditary breast cancer syndromes. J Surg Oncol $\underline{105}, 444-451$

Gao P, Ma N, Li M, Tian Q-B, Liu D-W (2013): Functional variants in NBS1 and cancer risk: evidence from a meta-analysis of 60 publications with 111 individual studies. Mutagenesis $\underline{28}, 683-697$

Ghoumid J, Stichelbout M, Jourdain A-S, Frenois F, Lejeune-Dumoulin S, Alex-Cordier M-P, Lebrun $M$, Guerreschi P, Duquennoy-Martinot V, Vinchon M et al. (2017): Blepharocheilodontic syndrome is a $C D H 1$ pathway-related disorder due to mutations in $C D H 1$ and CTNND1. Genet Med $\underline{19}, 1013$ 
Gil MM, Quezada MS, Revello R, Akolekar R, Nicolaides KH (2015): Analysis of cell-free DNA in maternal blood in screening for fetal aneuploidies: updated meta-analysis. Ultrasound Obstet Gynecol 45, 249-266

Goldberg, M., Bell, K., Aronson, M., Semotiuk, K., Pond, G., Gallinger, S., and Zbuk, K. (2017): Association between the Lynch syndrome gene MSH2 and breast cancer susceptibility in a Canadian familial cancer registry. J Med Gen $\underline{4}$, 742-746

Graeser MK, Engel C, Rhiem K, Gadzicki D, Bick U, Kast K, Froster UG, Schlehe B, Bechtold A, Arnold N et al. (2009): Contralateral Breast Cancer Risk in BRCA1 and BRCA2 Mutation Carriers. J Clin Ocol 27, 5887-5892

Grimm T: Risikoberechnung in BC/OC-Familien mit Hilfe von Cyrillic. Kurs Risikoberechnung der Akademie Humangenetik der GfH. Würzburg, 2014

Gruber CJ, Tschugguel W, Schneeberger C, Huber JC (2009): Production and Actions of Estrogens. N Engl J Med 346, 340-352

Hahnen E, Hauke J, Engel C, Neidhardt G, Rhiem K, Schmutzler RK (2017a): Germline Mutations in Triple-Negative Breast Cancer. Breast Care 12, 15-19

Hahnen E, Lederer B, Hauke J, Loibl S, Kröber S, Schneeweiss A, Denkert C, Fasching PA, Blohmer JU, Jackisch C et al. (2017b): Germline Mutation Status, Pathological Complete Response, and Disease-Free Survival in Triple-Negative Breast Cancer: Secondary Analysis of the GeparSixto Randomized Clinical Trial. JAMA Oncol $\underline{3}, 1378$

Hampel H, Frankel WL, Martin E, Arnold M, Khanduja K, Kuebler P, Clendenning M, Sotamaa K, Prior T, Westman JA et al. (2008): Feasibility of Screening for Lynch Syndrome Among Patients With Colorectal Cancer. J Clin Oncol 26, 5783-5788

Hansford S, Kaurah P, Li-Chang H, Woo M, Senz J, Pinheiro H, Schrader KA, Schaeffer DF, Shumansky K, Zogopoulos G et al. (2015): Hereditary Diffuse Gastric Cancer Syndrome: CDH1 Mutations and Beyond. JAMA Oncol $1,23-32$.

Hauke J, Horvath J, Groß E, Gehrig A, Honisch E, Hackmann K, Schmidt G, Arnold N, Faust U, Sutter $C$ et al. (2018): Gene panel testing of 5,589 BRCA1/2-negative index patients with breast cancer in a routine diagnostic setting: Results of the German Consortium for Hereditary Breast and Ovarian Cancer. Cancer Med ㄱ, 1349-1358.

Heemskerk-Gerritsen BA, Hooning MJ, Collee M, Tilanus-Linthorst MM, Bartels CC, Ouweland A van den, Ansink A, Seynaeve C (2009): Prevention of primary and contralateral breast cancer by risk reducing salpingo-oophorectomy in high risk women with a BRCA1/2 mutation or familial predisposition. Cancer Res $\underline{69}, 504$

Hegde M, Ferber M, Mao R, Samowitz W, Ganguly A, Working Group of the American College of Medical Genetics and Genomics (ACMG) Laboratory Quality Assurance Committee (2014): ACMG technical standards and guidelines for genetic testing for inherited colorectal cancer (Lynch syndrome, familial adenomatous polyposis, and MYH-associated polyposis). Genet Med $\underline{16}, 101-$ 116 
Heitzer E, Ulz P, GeigI JB (2015): Circulating tumor DNA as a liquid biopsy for cancer. Clin Chem $\underline{61}$, $112-123$.

Hennessy BTJ, Timms KM, Carey MS, Gutin A, Meyer LA, Flake DD, Abkevich V, Potter J, Pruss D, Glenn P et al. (2010): Somatic mutations in BRCA1 and BRCA2 could expand the number of patients that benefit from poly (ADP ribose) polymerase inhibitors in ovarian cancer. J Clin Oncol $\underline{28}, 3570-3576$

Honrado E, Benítez J, Palacios J (2005): The molecular pathology of hereditary breast cancer: genetic testing and therapeutic implications. Mod Pathol $\underline{18}, 1305-1320$

Hudis CA (2007): Trastuzumab - Mechanism of Action and Use in Clinical Practice. N Engl J Med 357, 39-51

Huijts PE, Hollestelle A, Balliu B, Houwing-Duistermaat JJ, Meijers CM, Blom JC, Ozturk B, KrolWarmerdam EM, Wijnen J, Berns EM et al. (2014): CHEK2*1100delC homozygosity in the Netherlands - prevalence and risk of breast and lung cancer. Eur J Hum Genet 22, 46-51

Hynes NE, Stern, DF (1994): The biology of erbB-2/neu/HER-2 and its role in cancer. Biochim Biophys Acta 1198, 165-184

Ismail PM, Li J, DeMayo FJ, O'Malley BW, Lydon JP (2002): A novel LacZ reporter mouse reveals complex regulation of the progesterone receptor promoter during mammary gland development. Mol Endocrinol 16, 2475-2489

Janatova M, Soukupova J, Stribrna J, Kleiblova P, Vocka M, Boudova P, Kleibl Z, Pohlreich P (2015): Mutation Analysis of the RAD51C and RAD51D Genes in High-Risk Ovarian Cancer Patients and Families from the Czech Republic. PLoS One 10, e0127711

Johansen Taber KA, Dickinson BD, Wilson M (2014): The promise and challenges of nextgeneration genome sequencing for clinical care. JAMA Intern Med 174, 275-280

Jones S, Hruban RH, Kamiyama M, Borges M, Zhang X, Parsons DW, Cheng J, Lin H, Palmisano E, Brune $K$ et al. (2009): Exomic Sequencing Identifies PALB2 as a Pancreatic Cancer Susceptibility Gene. Science $\underline{324}, 217$

Jønson L, Ahlborn LB, Steffensen AY, Djursby M, Ejlertsen B, Timshel S, Nielsen FC, Gerdes A-M, Hansen TVO (2016): Identification of six pathogenic RAD51C mutations via mutational screening of 1228 Danish individuals with increased risk of hereditary breast and/or ovarian cancer. Breast Cancer Res Treat. 155, 215-222

Kaaks R, Rinaldi S, Key TJ, Berrino F, Peeters PHM, Biessy C, Dossus L, Lukanova A, Bingham S, Khaw K-T et al. (2005). Postmenopausal serum androgens, oestrogens and breast cancer risk: the European prospective investigation into cancer and nutrition. Endocr Relat Cancer 12, 1071-1082

Kauff ND, Satagopan JM, Robson ME, Scheuer L, Hensley M, Hudis CA, Ellis NA, Boyd J, Borgen PI, Barakat RR et al. (2002): Risk-reducing salpingo-oophorectomy in women with a BRCA1 or BRCA2 mutation. N Engl J Med 346, 1609-1615 
Kaufman B, Shapira-Frommer R, Schmutzler RK, Audeh MW, Friedlander M, Balmaña J, Mitchell G, Fried G, Stemmer SM, Hubert A et al. (2015): Olaparib monotherapy in patients with advanced cancer and a germline BRCA1/2 mutation. J Clin Oncol 33, 244-250

Kaurah P, MacMillan A, Boyd N, Senz J, De Luca A, Chun N, Suriano G, Zaor S, Van Manen L, Gilpin $C$ et al. (2007): Founder and recurrent $C D H 1$ mutations in families with hereditary diffuse gastric cancer. JAMA 297, 2360-2372

Kets CM, van Krieken JHJM, Hebeda KM, Wezenberg SJ, Goossens M, Brunner HG, Ligtenberg MJL, Hoogerbrugge N (2006): Very low prevalence of germline MSH6 mutations in hereditary nonpolyposis colorectal cancer suspected patients with colorectal cancer without microsatellite instability. Br J Cancer 95, 1678-1682

Key TJ, Appleby PN, Reeves GK, Roddam A, Dorgan JF, Longcope C, Stanczyk FZ, Stephenson HE, Falk RT, Miller R et al. (2003): Body mass index, serum sex hormones, and breast cancer risk in postmenopausal women. J Natl Cancer Inst $\underline{95}$, 1218-1226

Khan SA, Rogers MA, Obando JA, Tamsen A (1994): Estrogen receptor expression of benign breast epithelium and its association with breast cancer. Cancer Res $\underline{54}$ 993-997

Kiechle M, Paepke S. Schmalfeldt B, Harbeck N, Heywang-Körbrunner S, Neises M: Tumorartige Veränderungen und Tumoren. In: Kiechle M (Hrsg.): Gynakologie und Geburtshilfe, 2. Auflage; Urban \& Fischer in Elsevier München 2010, 431-508

Kiiski Jl, Pelttari LM, Khan S, Freysteinsdottir ES, Reynisdottir I, Hart SN, Shimelis H, Vilske S, Kallioniemi A, Schleutker J et al. (2014): Exome sequencing identifies FANCM as a susceptibility gene for triple-negative breast cancer. Proc Natl Acad Sci 111, 15172-15177

Kim JJ, Kurita T, Bulun SE (2013): Progesterone Action in Endometrial Cancer, Endometriosis, Uterine Fibroids, and Breast Cancer. Endocr Rev 34 , 130-162

King M-C, Marks JH, Mandell JB, New York Breast Cancer Study Group (2003): Breast and ovarian cancer risks due to inherited mutations in BRCA1 and BRCA2. Science $\underline{302}, 643-646$

Kluijt I, Siemerink EJM, Ausems MGEM, van Os TAM, de Jong D, Simões-Correia J, van Krieken JH, Ligtenberg MJ, Figueiredo J, van Riel E et al. (2012): CDH1-related hereditary diffuse gastric cancer syndrome: clinical variations and implications for counseling. Int J Cancer $\underline{131}, 367-376$

Knudson AG (1971): Mutation and cancer: statistical study of retinoblastoma. Proc Natl Acad Sci USA $\underline{68}, 820-823$

Kobayashi J (2004): Molecular mechanism of the recruitment of NBS1/hMRE11/hRAD50 complex to DNA double-strand breaks: NBS1 binds to gamma-H2AX through FHA/BRCT domain. J Radiat Res $\underline{45}, 473-478$

Kote-Jarai Z, Leongamornlert D, Saunders E, Tymrakiewicz M, Castro E, Mahmud N, Guy M, Edwards S, O'Brien L, Sawyer E et al. (2011): BRCA2 is a moderate penetrance gene contributing to young-onset prostate cancer: implications for genetic testing in prostate cancer patients. $\mathrm{Br} J$ Cancer $105,1230-1234$ 
Krebsgeschehen in Deutschland 2016 s. Bericht zum Krebsgeschehen in Deutschland. 2009

Kruk J (2007): Lifetime physical activity and the risk of breast cancer: a case-control study. Cancer Detect Prev $\underline{31}, 18-28$

Kumar V, Green S, Stack G, Berry M, Jin JR, Chambon P (1987): Functional domains of the human estrogen receptor. Cell $\underline{51}, 941-951$

Kurian AW, Hare EE, Mills MA, Kingham KE, McPherson L, Whittemore AS, McGuire V, Ladabaum U, Kobayashi Y, Lincoln SE et al. (2014): Clinical evaluation of a multiple-gene sequencing panel for hereditary cancer risk assessment. J Clin Oncol 32, 2001-2009

Kwong A, Shin VY, Au CH, Law FBF, Ho DN, Ip BK, Wong ATC, Lau SS, To RMY, Choy G et al. (2016): Detection of Germline Mutation in Hereditary Breast and/or Ovarian Cancers by Next-Generation Sequencing on a Four-Gene Panel. J Mol Diagn 18, 580-594

LaDuca H, Stuenkel AJ, Dolinsky JS, Keiles S, Tandy S, Pesaran T, Chen E, Gau C-L, Palmaer E, Shoaepour K et al. (2014): Utilization of multigene panels in hereditary cancer predisposition testing: analysis of more than 2,000 patients. Genet Med 16, 830-837

Lakhani SR, Gusterson BA, Jacquemier J, Sloane JP, Anderson TJ, van de Vijver MJ, Venter D, Freeman A, Antoniou A, McGuffog L et al. (2000): The pathology of familial breast cancer: histological features of cancers in families not attributable to mutations in BRCA1 or BRCA2. Clin Cancer Res $\underline{6}$, 782-789

Lakhani SR, Van De Vijver MJ, Jacquemier J, Anderson TJ, Osin PP, McGuffog L, Easton DF (2002): The pathology of familial breast cancer: predictive value of immunohistochemical markers estrogen receptor, progesterone receptor, HER-2, and p53 in patients with mutations in BRCA1 and BRCA2. J Clin Oncol 20, 2310-2318

Lalloo F, Evans DG (2012): Familial breast cancer. Clin Genet 82, 105-114

Lee E, McKean-Cowdin R, Ma H, Spicer DV, Van Den Berg D, Bernstein L, Ursin G (2011): Characteristics of Triple-Negative Breast Cancer in Patients With a BRCA1 Mutation: Results From a Population-Based Study of Young Women. J Clin Oncol 29, 4373-4380

Lei H, Sjöberg-Margolin S, Salahshor S, Werelius B, Jandáková E, Hemminki K, Lindblom A, Vorechovský I (2002): CDH1 mutations are present in both ductal and lobular breast cancer, but promoter allelic variants show no detectable breast cancer risk. Int J Cancer 98, 199-204

Leongamornlert D, Mahmud N, Tymrakiewicz M, Saunders E, Dadaev T, Castro E, Goh C, Govindasami K, Guy M, O'Brien L et al. (2012): Germline BRCA1 mutations increase prostate cancer risk. Br J Cancer 106, 1697-1701

Li H, Feng B, Miron A, Chen X, Beesley J, Bimeh E, Barrowdale D, John EM, Daly MB, Andrulis IL et al. (2017): Breast cancer risk prediction using a polygenic risk score in the familial setting: a prospective study from the Breast Cancer Family Registry and kConFab. Genet Med 19, 30-35

Li J, Meeks H, Feng B-J, Healey S, Thorne H, Makunin I, Ellis J, kConFab Investigators, Campbell I, Southey $\mathrm{M}$ et al. (2016): Targeted massively parallel sequencing of a panel of putative breast 
cancer susceptibility genes in a large cohort of multiple-case breast and ovarian cancer families. J Med Genet 53, 34-42

Lincoln SE, Kobayashi Y, Anderson MJ, Yang S, Desmond AJ, Mills MA, Nilsen GB, Jacobs KB, Monzon, FA, Kurian AW et al. (2015): A Systematic Comparison of Traditional and Multigene Panel Testing for Hereditary Breast and Ovarian Cancer Genes in More Than 1000 Patients. J Mol Diagn 17, 533-544

Lindberg MK, Movérare S, Skrtic S, Gao H, Dahlman-Wright K, Gustafsson J-A, Ohlsson C (2003): Estrogen receptor (ER)-beta reduces ERalpha-regulated gene transcription, supporting a "ying yang" relationship between ERalpha and ERbeta in mice. Mol Endocrinol 17, 203-208

Liu X, Chu K-M (2014): E-Cadherin and Gastric Cancer: Cause, Consequence, and Applications. BioMed Res Int 2014, 1-9

Lotsari JE, Gylling A, Abdel-Rahman WM, Nieminen TT, Aittomäki K, Friman M, Pitkänen R, Aarnio M, Järvinen HJ, Mecklin J-P et al. (2012): Breast carcinoma and Lynch syndrome: molecular analysis of tumors arising in mutation carriers, non-carriers, and sporadic cases. Breast Cancer Res 14, R90

Loveday C, Turnbull C, Ramsay E, Hughes D, Ruark E, Frankum JR, Bowden G, Kalmyrzaev B, Warren-Perry M, Snape K et al. (2011): Germline mutations in RAD51D confer susceptibility to ovarian cancer. Nat Genet $\underline{43}, 879-882$

Loveday C, Turnbull C, Ruark E, Xicola RMM, Ramsay E, Hughes D, Warren-Perry M, Snape K, Eccles D, Evans DG et al. (2012): Germline RAD51C mutations confer susceptibility to ovarian cancer. Nature Genetics 44 , 475-476

Lu W, Wang X, Lin H, Lindor NM, Couch FJ (2012): Mutation screening of RAD51C in high-risk breast and ovarian cancer families. Fam Cancer $\underline{11}$, 381-385

Lynch H, Lynch P, Lanspa S, Snyder C, Lynch J, Boland, C (2009): Review of the Lynch syndrome: history, molecular genetics, screening, differential diagnosis, and medicolegal ramifications. Clin Genet $\underline{76}, 1-18$

Manders P, Pijpe A, Hooning MJ, Kluijt I, Vasen HFA, Hoogerbrugge N, van Asperen CJ, MeijersHeijboer H, Ausems MGEM, van Os TA et al. (2011): Body weight and risk of breast cancer in BRCA1/2 mutation carriers. Breast Cancer Res Treat $\underline{126}$, 193-202

Mannan AU, Singh J, Lakshmikeshava R, Thota N, Singh S, Sowmya TS, Mishra A, Sinha A, Deshwal $S$, Soni MR et al. (2016): Detection of high frequency of mutations in a breast and/or ovarian cancer cohort: implications of embracing a multi-gene panel in molecular diagnosis in India. J Hum Genet $\underline{61}, 515-522$

Masson JY, Tarsounas MC, Stasiak AZ, Stasiak A, Shah R, Mcllwraith MJ, Benson FE, West SC (2001): Identification and purification of two distinct complexes containing the five RAD51 paralogs. Genes Dev 15, 3296-3307 
Maxwell KN, Wubbenhorst B, D'Andrea K, Garman B, Long JM, Powers J, Rathbun K, Stopfer JE, Zhu J, Bradbury AR et al. (2015): Prevalence of mutations in a panel of breast cancer susceptibility genes in BRCA1/2-negative patients with early-onset breast cancer. Genet Med 17, 630-638

Maxwell KN, Wubbenhorst B, Wenz BM, Sloover DD, Pluta J, Emery L, Barrett A, Kraya AA, Anastopoulos IN, Yu S et al. (2017): BRCA locus-specific loss of heterozygosity in germline BRCA1 and BRCA2 carriers. Nat Commun $\underline{8}, 319$

Maxwell S, Dickinson JE, Murch A, O'Leary P (2015): The potential impact of NIPT as a second-tier screen on the outcomes of high-risk pregnancies with rare chromosomal abnormalities. Aust $\mathrm{N} Z \mathrm{~J}$ Obstet Gynaecol $\underline{55}$, 420-426

McCuaig JM, Armel SR, Novokmet A, Ginsburg OM, Demsky R, Narod SA, Malkin D (2012): Routine TP53 testing for breast cancer under age 30: ready for prime time? Fam Cancer 11, 607-613.

McDonald ES, Clark AS, Tchou J, Zhang P, Freedman GM (2016): Clinical Diagnosis and Management of Breast Cancer. J Nucl Med 57 Suppl 1, 9S-16S

Meindl A, Hellebrand H, Wiek C, Erven V, Wappenschmidt B, Niederacher D, Freund M, Lichtner P, Hartmann L, Schaal H et al. (2010): Germline mutations in breast and ovarian cancer pedigrees establish RAD51C as a human cancer susceptibility gene. Nat Genet $\underline{42}, 410-414$

Meindl A, Ditsch N, Kast K, Rhiem K, Schmutzler RK (2011): Hereditary breast and ovarian cancer-new genes, new treatments, new concepts. Dtsch Arztebl Int 108: 323-330

Meindl A, Ramser J, Hauke J, Hahnen E (2015): Genetik des familiären Brust- und Eierstockkrebses: Paneldiagnostik - Möglichkeiten und Grenzen. Medgen 27, 202-210

Menigatti M, Di Gregorio C, Borghi F, Sala E, Scarselli A, Pedroni M, Foroni M, Benatti P, Roncucci L, Ponz de Leon $M$ et al. (2001): Methylation pattern of different regions of the MLH1 promoter and silencing of gene expression in hereditary and sporadic colorectal cancer. Genes Chromosom Cancer $\underline{31}, 357-361$

Merajver SD, Pham TM, Caduff RF, Chen M, Poy EL, Cooney KA, Weber BL, Collins FS, Johnston C, Frank TS (1995): Somatic mutations in the BRCA1 gene in sporadic ovarian tumours. Nat Genet $\underline{9}$, 439-443

Mercer TR, Clark MB, Crawford J, Brunck ME, Gerhardt DJ, Taft RJ, Nielsen LK, Dinger ME, Mattick JS (2014): Targeted sequencing for gene discovery and quantification using RNA CaptureSeq. Nature Protoc 9 , 989-1009

Metzker ML (2010): Sequencing technologies - the next generation. Nat Rev Genet $\underline{11}, 31-46$

Michailidou K, Hall P, Gonzalez-Neira A, Ghoussaini M, Dennis J, Milne RL, Schmidt MK, ChangClaude J, Bojesen SE, Bolla MK et al. (2013): Large-scale genotyping identifies 41 new loci associated with breast cancer risk. Nat Genet $\underline{45}$, 353-361, 361e1-2

Michailidou K, Beesley J, Lindstrom S, Canisius S, Dennis J, Lush MJ, Maranian MJ, Bolla MK, Wang Q, Shah M et al. (2015): Genome-wide association analysis of more than 120,000 individuals identifies 15 new susceptibility loci for breast cancer. Nat Genet $\underline{47}, 373-380$ 
Miki Y, Swensen J, Shattuck-Eidens D, Futreal PA, Harshman K, Tavtigian S, Liu Q, Cochran C, Bennett LM, Ding W (1994): A strong candidate for the breast and ovarian cancer susceptibility gene BRCA1. Science $\underline{266}, 66-71$

Moir-Meyer GL, Pearson JF, Lose F, Australian National Endometrial Cancer Study Group, Scott RJ, McEvoy M, Attia J, Holliday EG, Hunter Community Study, Studies of Epidemiology and Risk Factors in Cancer Heredity et al. (2015): Rare germline copy number deletions of likely functional importance are implicated in endometrial cancer predisposition. Hum Genet 134, 269-278

Mulac-Jericevic B, Mullinax RA, DeMayo FJ, Lydon JP, Conneely OM (2000): Subgroup of reproductive functions of progesterone mediated by progesterone receptor-B isoform. Science 289, 1751-1754

Mulac-Jericevic B, Lydon JP, DeMayo FJ, Conneely OM (2003): Defective mammary gland morphogenesis in mice lacking the progesterone receptor B isoform. Proc Natl Acad Sci USA $\underline{100}$, 9744-9749

Murai J, Huang S-yN, Das BB, Renaud A, Zhang Y, Doroshow JH, Ji J, Takeda S, Pommier Y (2012): Trapping of PARP1 and PARP2 by Clinical PARP Inhibitors. Cancer Res $\underline{72}, 5588-5599$

Nadji M, Gomez-Fernandez C, Ganjei-Azar P, Morales AR (2005): Immunohistochemistry of estrogen and progesterone receptors reconsidered: experience with 5,993 breast cancers. Am J Clin Pathol $\underline{123}, 21-27$

Narod SA, Foulkes WD (2004): BRCA1 and BRCA2: 1994 and beyond. Nat Rev Cancer 4, 665-676

Nelson MH, Dolder CR (2006): Lapatinib: a novel dual tyrosine kinase inhibitor with activity in solid tumors. Ann Pharmacother 40, 261-269

Netter FH: NETTERs Gynäkologie. Thieme, Stuttgart 2006

Neuhausen SL, Marshall CJ (1994): Loss of heterozygosity in familial tumors from three BRCA1linked kindreds. Cancer Res 54, 6069-6072

Nevanlinna H, Bartek J (2006): The CHEK2 gene and inherited breast cancer susceptibility. Oncogene $\underline{25}, 5912-5919$

Nilbert M, Wikman FP, Hansen TVO, Krarup HB, Orntoft TF, Nielsen FC, Sunde L, Gerdes A-M, Cruger D, Timshel S et al. (2009): Major contribution from recurrent alterations and MSH6 mutations in the Danish Lynch syndrome population. Fam Cancer $\underline{8}, 75-83$

Nishi E, Masuda K, Arakawa M, Kawame H, Kosho T, Kitahara M, Kubota N, Hidaka E, Katoh Y, Shirahige $K$ et al. (2016): Exome sequencing-based identification of mutations in non-syndromic genes among individuals with apparently syndromic features. Am J Med Genet 170, 2889-2894

O'Donovan PJ, Livingston DM (2010): BRCA1 and BRCA2: breast/ovarian cancer susceptibility gene products and participants in DNA double-strand break repair. Carcinogenesis $\underline{31}, 961-967$

Obr AE, Edwards DP (2012): The biology of progesterone receptor in the normal mammary gland and in breast cancer. Mol Cell Endocrinol 357, 4-17 
Oh H, Eliassen AH, Wang M, Smith-Warner SA, Beck AH, Schnitt SJ, Collins LC, Connolly JL, Montaser-Kouhsari L, Polyak K et al. (2016): Expression of estrogen receptor, progesterone receptor, and Ki67 in normal breast tissue in relation to subsequent risk of breast cancer. NPJ Breast Cancer $\underline{2}, 16032$.

Oliveira C, Pinheiro H, Figueiredo J, Seruca R, Carneiro F. Chapter Fifteen (2013): E-Cadherin Alterations in Hereditary Disorders with Emphasis on Hereditary Diffuse Gastric Cancer. In: Roy F van (2013): Prog Mol Biol Trans Sci 116, 337-359

Ono M, Tsuda H, Yoshida M, Shimizu C, Kinoshita T, Tamura K (2017): Prognostic Significance of Progesterone Receptor Expression in Estrogen-Receptor Positive, HER2-Negative, Node-Negative Invasive Breast Cancer With a Low Ki-67 Labeling Index. Clin Breast Cancer 17, 41-47

Osborne CK (2009): Tamoxifen in the Treatment of Breast Cancer. N Engl J Med 339,1609-1618

Osher DJ, De Leeneer K, Michils G, Hamel N, Tomiak E, Poppe B, Leunen K, Legius E, Shuen A, Smith E et al. (2012): Mutation analysis of RAD51D in non-BRCA1/2 ovarian and breast cancer families. Br J Cancer 106, 1460-1463

Osorio A, Endt D, Fernández F, Eirich K, de la Hoya M, Schmutzler R, Caldés T, Meindl A, Schindler $D$, Benitez J (2012): Predominance of pathogenic missense variants in the RAD51C gene occurring in breast and ovarian cancer families. Hum Mol Genet 21, 2889-2898

Palacios J, Honrado E, Osorio A, Cazorla A, Sarrió D, Barroso A, Rodríguez S, Cigudosa JC, Diez O, Alonso $C$ et al. (2003): Immunohistochemical characteristics defined by tissue microarray of hereditary breast cancer not attributable to BRCA1 or BRCA2 mutations: differences from breast carcinomas arising in BRCA1 and BRCA2 mutation carriers. Clin Cancer Res $\underline{9}, 3606-3614$

Pareek CS, Smoczynski R, Tretyn A (2011): Sequencing technologies and genome sequencing. J Appl Genet $\underline{52}$, 413-435

Park J-Y, Zhang F, Andreassen PR (2014): PALB2: the hub of a network of tumor suppressors involved in DNA damage responses. Biochim Biophys Acta 1846, 263-275

Pauty J, Rodrigue A, Couturier A, Buisson R, Masson J-Y (2014): Exploring the roles of PALB2 at the crossroads of DNA repair and cancer. Biochem J $\underline{460}, 331-342$

Pećina-Slaus N (2003): Tumor suppressor gene E-cadherin and its role in normal and malignant cells. Cancer Cell Int $\underline{3}, 17$

Petridis C, Shinomiya I, Kohut K, Gorman P, Caneppele M, Shah V, Troy M, Pinder SE, Hanby A, Tomlinson I et al. (2014): Germline CDH1 mutations in bilateral lobular carcinoma in situ. $\mathrm{Br} J$ Cancer 110 , 1053-1057

Pharoah PD, Guilford P, Caldas C, International Gastric Cancer Linkage Consortium (2001): Incidence of gastric cancer and breast cancer in $\mathrm{CDH1}$ (E-cadherin) mutation carriers from hereditary diffuse gastric cancer families. Gastroenterology $\underline{121}, 1348-1353$ 
Plaschke J, Rüschoff J, Schackert HK (2003): Genomic rearrangements of hMSH6 contribute to the genetic predisposition in suspected hereditary non-polyposis colorectal cancer syndrome. J Med Genet $\underline{40}$, 597-600

Plon SE, Eccles DM, Easton D, Foulkes WD, Genuardi M, Greenblatt MS, Hogervorst FBL, Hoogerbrugge N, Spurdle AB, Tavtigian SV et al. (2008): Sequence variant classification and reporting: recommendations for improving the interpretation of cancer susceptibility genetic test results. Hum Mutat $\underline{29}, 1282-1291$

Poole AJ, Li Y, Kim Y, Lin S-CJ, Lee W-H, Lee EY-HP (2006): Prevention of Brca1-mediated mammary tumorigenesis in mice by a progesterone antagonist. Science $\underline{314}, 1467-1470$

Pox C, Aretz S, Bischoff S, Graeven U, Hass M, Heußner P, Hohenberger W, Holstege A, Hübner J, Kolligs F et al. (2014): Stufe-3-Leitlinie Kolorektales Karzinom. Kurzversion 1.1. o. Verl., o. O. 2014

Prat J, Ribé A, Gallardo A (2005): Hereditary ovarian cancer. Hum Pathol 36, $861-870$

Preston-Martin S, Pike MC, Ross RK, Jones PA, Henderson BE (1990): Increased cell division as a cause of human cancer. Cancer Res $\underline{50}$ 7415-7421

Preston-Martin S, Pike MC, Ross RK, Henderson BE (1993): Epidemiologic evidence for the increased cell proliferation model of carcinogenesis. Environ Health Perspect 101 Supp/ 5, 137138

Quail MA, Kozarewa I, Smith F, Scally A, Stephens PJ, Durbin R, Swerdlow H, Turner DJ (2008): A large genome center's improvements to the Illumina sequencing system. Nat Methods $\underline{5}, 1005-$ 1010

Quenneville LA, Phillips K-A, Ozcelik H, Parkes RK, Knight JA, Goodwin, PJ, Andrulis IL, O'Malley FP (2002): HER-2/neu status and tumor morphology of invasive breast carcinomas in Ashkenazi women with known BRCA1 mutation status in the Ontario Familial Breast Cancer Registry. Cancer 95, 2068-2075

Rahman N, Seal S, Thompson D, Kelly P, Renwick A, Elliott A, Reid S, Spanova K, Barfoot R, Chagtai T et al. (2007): PALB2, which encodes a BRCA2-interacting protein, is a breast cancer susceptibility gene. Nat Genet $\underline{39}, 165-167$

Rebbeck TR, Lynch HT, Neuhausen SL, Narod SA, Van't Veer L, Garber JE, Evans G, Isaacs C, Daly MB, Matloff E et al. (2002): Prophylactic oophorectomy in carriers of BRCA1 or BRCA2 mutations. N Engl J Med $\underline{346}, 1616-1622$

Rebbeck TR, Friebel T, Lynch HT, Neuhausen SL, van 't Veer L, Garber JE, Evans GR, Narod SA, Isaacs C, Matloff E et al. (2004): Bilateral Prophylactic Mastectomy Reduces Breast Cancer Risk in BRCA1 and BRCA2 Mutation Carriers: The PROSE Study Group. J Clin Oncol 22, 1055-1062

Rebbeck TR, Friebel T, Wagner T, Lynch HT, Garber JE, Daly MB, Isaacs C, Olopade OI, Neuhausen $S L$, van 't Veer L et al. (2005): Effect of short-term hormone replacement therapy on breast cancer risk reduction after bilateral prophylactic oophorectomy in BRCA1 and BRCA2 mutation carriers: the PROSE Study Group. J Clin Oncol 23, 7804-7810 
Renwick A, Thompson D, Seal S, Kelly P, Chagtai T, Ahmed M, North B, Jayatilake H, Barfoot R, Spanova $\mathrm{K}$ et al. (2006): ATM mutations that cause ataxia-telangiectasia are breast cancer susceptibility alleles. Nat Genet $\underline{38}, 873-875$

Riede U-N, Werner M, Freudenberg, N: Basiswissen Allgemeine und Spezielle Pathologie. Springer-Verlag, Heidelberg 2009

Richards S, Aziz N, Bale S, Bick D, Das S, Gastier-Foster J, Grody WW, Hegde M, Lyon E, Spector E et al. (2015): Standards and Guidelines for the Interpretation of Sequence Variants: A Joint Consensus Recommendation of the American College of Medical Genetics and Genomics and the Association for Molecular Pathology. Genet Med 17, 405-424

Riggs BL, Hartmann LC (2003): Selective Estrogen-Receptor Modulators - Mechanisms of Action and Application to Clinical Practice. N Engl J Med $\underline{348}, 618-629$

Risch HA, McLaughlin JR, Cole DEC, Rosen B, Bradley L, Fan I, Tang J, Li S, Zhang S, Shaw PA et al. (2006): Population BRCA1 and BRCA2 mutation frequencies and cancer penetrances: a kin-cohort study in Ontario, Canada. J Natl Cancer Inst $\underline{98}, 1694-1706$

Rosner B, Eliassen AH, Toriola AT, Chen WY, Hankinson SE, Willett WC, Berkey CS, Colditz GA (2017): Weight and weight changes in early adulthood and later breast cancer risk. Int J Cancer $\underline{140}, 2003-2014$

Saiki RK, Gelfand DH, Stoffel S, Scharf SJ, Higuchi R, Horn GT, Mullis KB, Erlich HA (1988): Primerdirected enzymatic amplification of DNA with a thermostable DNA polymerase. Science $\underline{239}$, 487491

Salmon A, Amikam D, Sodha N, Davidson S, Basel-Vanagaite L, Eeles RA, Abeliovich D, Peretz T (2007): Rapid Development of Post-radiotherapy Sarcoma and Breast Cancer in a Patient with a Novel Germline ‘De-Novo' TP53 Mutation. Clin Oncol 19, 490-493

Sandoval N, Platzer M, Rosenthal A, Dörk T, Bendix R, Skawran B, Stuhrmann M, Wegner RD, Sperling K, Banin S et al. (1999). Characterization of ATM gene mutations in 66 ataxia telangiectasia families. Hum Mol Genet $\underline{8}, 69-79$

Sanger F, Nicklen S, Coulson AR (1977): DNA sequencing with chain-terminating inhibitors. Proc Natl Acad Sci USA 프, 5463-5467

Schaaf CP, Zschocke J: Basiswissen Humangenetik. 2. Auflage; Springer-Verlag, Berlin 2013

Scheckenbach K, Baldus SE, Balz V, Freund M, Pakropa P, Sproll C, Schäfer K-L, Wagenmann M, Schipper J, Hanenberg H (2014): RAD51C - A new human cancer susceptibility gene for sporadic squamous cell carcinoma of the head and neck (HNSCC). Oral Oncology 50, 196-199

Schmutzler R, Schlegelberger B, Meindl A, Schreer I, Heywang- Köbrunner S, Engel C, Kreipe H: Hereditäre Brustkrebserkrankung. In: Albert U-S (Hrsg.): Stufe-3-Leitlinie BrustkrebsFrüherkennung in Deutschland. 1. Aktualisierung 2008. Zuckschwerdt Verlag, München 2008, 5661 
Schouten JP, McElgunn CJ, Waaijer R, Zwijnenburg D, Diepvens F, Pals G (2002): Relative quantification of 40 nucleic acid sequences by multiplex ligation-dependent probe amplification. Nucleic Acids Res $\underline{30}$, e57

Schrader KA, Masciari S, Boyd N, Salamanca C, Senz J, Saunders DN, Yorida E, Maines-Bandiera S, Kaurah $\mathrm{P}$, Tung $\mathrm{N}$ et al. (2011): Germline mutations in CDH1 are infrequent in women with earlyonset or familial lobular breast cancers. J Med Genet $\underline{48}, 64-68$

Schroeder C, Faust U, Sturm M, Hackmann K, Grundmann K, Harmuth F, Bosse K, Kehrer M, Benkert T, Klink B et al. (2015): HBOC multi-gene panel testing: comparison of two sequencing centers. Breast Cancer Res Treat 152, 129-136

Scott RJ, Ashton KA (2004): Familial Breast and Bowel Cancer: Does It Exist? Hered Cancer Clin Pract 2, 25-29

Shaag A, Walsh T, Renbaum P, Kirchhoff T, Nafa K, Shiovitz S, Mandell JB, Welcsh P, Lee MK, Ellis N et al. (2005): Functional and genomic approaches reveal an ancient CHEK2 allele associated with breast cancer in the Ashkenazi Jewish population. Hum Mol Genet 14, 555-563

Sharma P, Klemp JR, Kimler BF, Mahnken JD, Geier L, Khan QJ, Elia M, Connor CS, McGinness MK, Mammen JMW et al. (2014): Germline BRCA mutation evaluation in a prospective triple-negative breast cancer registry: implications for hereditary breast and/or ovarian cancer syndrome testing. Breast Cancer Res Treat 145, 707-714

Shawky RM (2014): Reduced penetrance in human inherited disease. Egypt J Med Hum Gen $\underline{15}$, 103-111

Shyamala G, Chou Y-C, Louie SG, Guzman RC, Smith GH, Nandi S (2002): Cellular expression of estrogen and progesterone receptors in mammary glands: regulation by hormones, development and aging. J Steroid Biochem Mol Biol $\underline{80}$, 137-148

Silberstein GB, Van Horn K, Shyamala G, Daniel CW (1996): Progesterone receptors in the mouse mammary duct: distribution and developmental regulation. Cell Growth Differ $\underline{7}, 945-952$

Silwal-Pandit L, Vollan HKM, Chin S-F, Rueda OM, McKinney S, Osako T, Quigley DA, Kristensen VN, Aparicio S, Borresen-Dale A-L et al. (2014): TP53 Mutation Spectrum in Breast Cancer Is Subtype Specific and Has Distinct Prognostic Relevance. Clin Cancer Res 20, 3569-3580

Slater E, Langer P, Niemczyk E, Strauch K, Butler J, Habbe N, Neoptolemos J, Greenhalf W, Bartsch D (2010): PALB2 mutations in European familial pancreatic cancer families. Clin Genet $\underline{78}, 490$ 494

Sliwkowski MX, Yarden Y (2001): Untangling the ErbB signalling network. Nat Rev Mol Cell Bio $\underline{2}$, 127

Sodha N, Williams R, Mangion J, Bullock SL, Yuille MR, Eeles RA (2000): Screening hCHK2 for mutations. Science 289, 359-359 
Sodha N, Bullock S, Taylor R, Mitchell G, Guertl-Lackner B, Williams RD, Bevan S, Bishop K, McGuire S, Houlston RS et al. (2002): CHEK2 variants in susceptibility to breast cancer and evidence of retention of the wild type allele in tumours. Br J Cancer 87, 1445-1448

Speiser P, Gharehbaghi-Schnell E, Eder S, Haid A, Kovarík J, Nenutil R, Sauter G, Schneeberger CH, Vojtesek B, Wiltschke $\mathrm{CH}$ et al. (1996): A constitutional de novo mutation in exon 8 of the p53 gene in a patient with multiple primary malignancies. Br J Cancer $\underline{74}, 269-273$

Stevens KN, Vachon CM, Couch FJ (2013): Genetic Susceptibility to Triple Negative Breast Cancer. Cancer Res 73, 2025-2030

Stratton MR (1997): Pathology of familial breast cancer: differences between breast cancers in carriers of BRCA1 or BRCA2 mutations and sporadic cases. Lancet $\underline{349}, 1505-1510$

Suspitsin EN, Yanus GA, Sokolenko AP, Yatsuk OS, Zaitseva OA, Bessonov AA, Ivantsov AO, Heinstein VA, Klimashevskiy VF, Togo AV et al. (2014): Development of breast tumors in CHEK2, NBN/NBS1 and BLM mutation carriers does not commonly involve somatic inactivation of the wild-type allele. Med Oncol $\underline{31}, 828$

Susswein LR, Marshall ML, Nusbaum R, Vogel Postula KJ, Weissman SM, Yackowski L, Vaccari EM, Bissonnette J, Booker JK, Cremona ML et al. (2016): Pathogenic and likely pathogenic variant prevalence among the first 10,000 patients referred for next-generation cancer panel testing. Genet Med 18, 823-832

Ta HQ, Ivey ML, Frierson HF, Conaway MR, Dziegielewski J, Larner JM, Gioeli D (2015): Checkpoint Kinase 2 Negatively Regulates Androgen Sensitivity and Prostate Cancer Cell Growth. Cancer Res 75, 5093-5105

Talseth-Palmer BA, McPhillips M, Groombridge C, Spigelman A, Scott RJ (2010): MSH6 and PMS2 mutation positive Australian Lynch syndrome families: novel mutations, cancer risk and age of diagnosis of colorectal cancer. Hered Cancer Clin Pract $\underline{8}, 5$

Thompson D, Easton DF, Breast Cancer Linkage Consortium (2002): Cancer Incidence in BRCA1 mutation carriers. J Natl Cancer Inst 94, 1358-1365

Thompson D, Duedal S, Kirner J, McGuffog L, Last J, Reiman A, Byrd P, Taylor M, Easton DF (2005): Cancer risks and mortality in heterozygous ATM mutation carriers. J Natl Cancer Inst $\underline{97}, 813-822$

Thompson ER, Rowley SM, Sawyer S, kConfab null, Eccles DM, Trainer AH, Mitchell G, James PA, Campbell IG (2013): Analysis of RAD51D in ovarian cancer patients and families with a history of ovarian or breast cancer. PLoS One $\underline{8}$, e54772.

Thompson ER, Rowley SM, Li N, Mclnerny S, Devereux L, Wong-Brown MW, Trainer AH, Mitchell G, Scott RJ, James PA et al. (2016): Panel Testing for Familial Breast Cancer: Calibrating the Tension Between Research and Clinical Care. J Clin Oncol 34, 1455-1459

Tichý A, Vávrová J, Pejchal J, Rezácová M (2010): Ataxia-telangiectasia mutated kinase (ATM) as a central regulator of radiation-induced DNA damage response. Acta Medica (Hradec Kralove) $\underline{53}$, $13-17$ 
Tinat J, Bougeard G, Baert-Desurmont S, Vasseur S, Martin C, Bouvignies E, Caron O, Bressac-de Paillerets B, Berthet P, Dugast C et al. (2009): 2009 version of the Chompret criteria for Li Fraumeni syndrome. J Clin Oncol 27, e108-109; author reply e110

Tischkowitz M, Xia B, Sabbaghian N, Reis-Filho JS, Hamel N, Li G, van Beers EH, Li L, Khalil T, Quenneville LA et al. (2007): Analysis of PALB2/FANCN-associated breast cancer families. Proc Natl Acad Sci USA 104, 6788-6793

Tischkowitz, MD, Sabbaghian N, Hamel N, Borgida A, Rosner C, Taherian N, Srivastava A, Holter S, Rothenmund H, Ghadirian P et al. (2009): Analysis of the Gene Coding for the BRCA2-Interacting Protein PALB2 in Familial and Sporadic Pancreatic Cancer. Gastroenterology 137, 1183-1186

Truin W, Roumen RMH, Siesling S, van de Vijver KK, Tjan-Heijnen VCG, Voogd AC (2017): Estrogen and progesterone receptor expression levels do not differ between lobular and ductal carcinoma in patients with hormone receptor-positive tumors. Breast Cancer Res Treat 164, 133-138

Tucker T, Marra M, Friedman JM (2009): Massively parallel sequencing: the next big thing in genetic medicine. Am J Hum Genet $\underline{85}$, 142-154

Tung N, Battelli C, Allen B, Kaldate R, Bhatnagar S, Bowles K, Timms K, Garber JE, Herold C, Ellisen $L$ et al. (2015): Frequency of mutations in individuals with breast cancer referred for BRCA1 and BRCA2 testing using next-generation sequencing with a 25-gene panel. Cancer $\underline{121}, 25-33$

Umar A, Boland CR, Terdiman JP, Syngal S, de la Chapelle A, Rüschoff J, Fishel R, Lindor NM, Burgart L, Hamelin R et al. (2004): Revised Bethesda Guidelines for Hereditary Nonpolyposis Colorectal Cancer (Lynch Syndrome) and Microsatellite Instability. J Natl Cancer Inst 96, 261-268

Valdez JM, Nichols KE, Kesserwan C (2017): Li-Fraumeni syndrome: a paradigm for the understanding of hereditary cancer predisposition. $\mathrm{Br} \mathrm{J}$ Haematol $\underline{176}, 539-552$

van der Klift H, Wijnen J, Wagner A, Verkuilen P, Tops C, Otway R, Kohonen-Corish M, Vasen $\mathrm{H}$, Oliani C, Barana D et al. (2005): Molecular characterization of the spectrum of genomic deletions in the mismatch repair genes MSH2, MLH1, MSH6, and PMS2 responsible for hereditary nonpolyposis colorectal cancer (HNPCC). Genes Chromosom Cancer 44, 123-138

van Roy F, Berx G (2008): The cell-cell adhesion molecule E-cadherin. Cell Mol Life Sci $\underline{65}$, 37563788

Vaz F, Hanenberg H, Schuster B, Barker K, Wiek C, Erven V, Neveling K, Endt D, Kesterton I, Autore $F$ et al. (2010): Mutation of the RAD51C gene in a Fanconi anemia-like disorder. Nat Genet 42 , 406-409

Voelkerding KV, Dames SA, Durtschi JD (2009): Next-Generation Sequencing: From Basic Research to Diagnostics. Clin Chem $\underline{55}, 641-658$

Vogelaar IP, Figueiredo J, van Rooij IALM, Simoes-Correia J, van der Post RS, Melo S, Seruca R, Carels CEL, Ligtenberg MJL, Hoogerbrugge N (2013): Identification of germline mutations in the cancer predisposing gene $\mathrm{CDH} 1$ in patients with orofacial clefts. Hum Mol Genet 22, 919-926 
Walsh T, Casadei S, Lee MK, Pennil CC, Nord AS, Thornton AM, Roeb W, Agnew KJ, Stray SM, Wickramanayake A et al. (2011): Mutations in 12 genes for inherited ovarian, fallopian tube, and peritoneal carcinoma identified by massively parallel sequencing. Proc Natl Acad Sci USA 108 , 18032-18037

Wang Z, Gerstein M, Snyder M (2009): RNA-Seq: a revolutionary tool for transcriptomics. Nat Rev Genet $\underline{10}$, nrg2484

Wappenschmidt B, Becker AA, Hauke J, Weber U, Engert S, Köhler J, Kast K, Arnold N, Rhiem K, Hahnen E et al. (2012): Analysis of 30 Putative BRCA1 Splicing Mutations in Hereditary Breast and Ovarian Cancer Families Identifies Exonic Splice Site Mutations That Escape In Silico Prediction. PLoS One $\underline{7}$, e50800

Wasielewski M, Riaz M, Vermeulen J, van den Ouweland A, Labrijn-Marks I, Olmer R, van der Spaa L, Klijn JGM, Meijers-Heijboer H, Dooijes D et al. (2010): Association of rare MSH6 variants with familial breast cancer. Breast Cancer Res Treat 123, 315-320

Weber-Lassalle N, Hauke J, Ramser J, Richters L, Groß E, Blümcke B, Gehrig A, Kahlert A-K, Müller $\mathrm{CR}$, Hackmann $\mathrm{K}$ et al. (2018): BRIP1 loss-of-function mutations confer high risk for familial ovarian cancer, but not familial breast cancer. Breast Cancer Res 20:7

Win AK, Lindor NM, Jenkins MA (2013): Risk of breast cancer in Lynch syndrome: a systematic review. Breast Cancer Res $\underline{15}$, R27

Winter C, Nilsson MP, Olsson E, George AM, Chen Y, Kvist A, Törngren T, Vallon-Christersson J, Hegardt C, Häkkinen J et al. (2016): Targeted sequencing of BRCA1 and BRCA2 across a large unselected breast cancer cohort suggests that one-third of mutations are somatic. Ann Oncol 27 , 1532-1538

Woolcott CG, SenGupta SK, Hanna WM, Aronson KJ (2008): Estrogen and progesterone receptor levels in nonneoplastic breast epithelium of breast cancer cases versus benign breast biopsy controls. BMC Cancer $\underline{8}, 130$

Wooster R, Bignell G, Lancaster J, Swift S, Seal S, Mangion J, Collins N, Gregory S, Gumbs C, Micklem $G$ et al. (1995): Identification of the breast cancer susceptibility gene BRCA2. Nature $\underline{378}$, 789-792

Yablonski-Peretz T, Paluch-Shimon S, Gutman LS, Kaplan Y, Dvir A, Barnes-Kedar I, Kadouri L, Semenisty V, Efrat N, Neiman V et al. (2016): Screening for germline mutations in breast/ovarian cancer susceptibility genes in high-risk families in Israel. Breast Cancer Res Treat 155, 133-138

Yager JD, Davidson NE (2006): Estrogen carcinogenesis in breast cancer. N Engl J Med $\underline{354}$, 270282

Yue W, Wang J-P, Li Y, Fan P, Liu G, Zhang N, Conaway M, Wang H, Korach KS, Bocchinfuso W et al. (2010): Effects of estrogen on breast cancer development: Role of estrogen receptor independent mechanisms. Int J Cancer $\underline{127}, 1748-1757$

Zhang T, Zhou J, Ma J, Deng Z, Qian Z, Yao D, Yang J, Li X, Lin J, Qian J (2017): CDH1 (E-cadherin) expression independently affects clinical outcome in acute myeloid leukemia with normal 
cytogenetics. Clin Chem Lab Med $\underline{55}, 123-131$

Internetquellen:

BOADICEA Risikokalkulationsprogramm

http://ccge.medschl.cam.ac.uk/boadicea; Zugriff am 20.09.2017

BIC-(Breast Cancer Information Core)-Datenbank

https://research.nhgri.nih.gov/bic; Zugriff am 18.09.2017

Cancer Research UK

http://www.cancerresearchuk.org/health-professional/cancer-statistics; Zugriff am 24.11.2017

ClinVar-Datenbank von NCBI

http://www.ncbi.nlm.nih.gov/clinvar; Zugriff am 18.09.2017

Deutsches Konsortium Familiärer Brust- und Eierstockkrebs

http://www.konsortium-familiaerer-brustkrebs.de; Zugriff am 24.11.2017

Ensembl genome browser 88

www.ensembl.org; Zugriff am 18.09.2017

ExAC-Exome Aggregation Consortium

http://www.exac.broadinstitute.org; Zugriff am 18.09.2017

HGMD (Human Gene Mutation Database)-Professional

https://portal.biobase-international.com/hgmd; Zugriff am 18.09.2017

Homepage des Deutschen Konsortiums Familiärer Brust- und Eierstockkrebs

http://www.konsortium-familiaerer-brustkrebs.de; Zugriff am 17.08.2017

Human Splicing Finder Version 3.0

http://www.umd.be/HSF3; Zugriff am 18.09.2017

LOVD v.3.0-(Leiden Open Variation Database)-Datenbank

http://www.lovd.nl/3.0/home; Zugriff am 18.09.2017

$N C B I$

https://www.ncbi.nlm.nih.gov/guide/howto/find-transcript-gene; Zugriff am 29.09.2017

MutationTaster

http://www.mutationtaster.org; Zugriff am 18.09.2017

NCBI Bookshelf, BRCA1- and BRCA2-Associated Hereditary Breast and Ovarian Cancer https://www.ncbi.nlm.nih.gov/books/NBK1247; Zugriff am 27.03.2017

NCBI Bookshelf, Lynch Syndrome

https://www.ncbi.nlm.nih.gov/books/NBK1211; Zugriff am 10.04.2017

PolyPhen-2

http://genetics.bwh.harvard.edu/pph2; Zugriff am 18.09.2017 
Robert Koch-Institut - Krebsregister https://www.krebsdaten.de; Zugriff am 10.09.2017

SIFT

http://sift.jcvi.org; Zugriff am 18.09.2017

USA National Cancer Insitute

http://www.breastcancer.org/symptoms/understand_bc/statistics; Zugriff am 24.11.2017

World Cancer Research Fund International

http://www.wcrf.org/int/cancer-facts-figures/worldwide-data; Zugriff am 25.10.2017 


\section{Danksagung}

An dieser Stelle möchte ich mich bei allen herzlich bedanken, die mich bei der Erstellung meiner Doktorarbeit unterstützt haben.

Mein besonderer Dank gilt hierbei Herrn Prof. Dr. rer. nat. Peter Burfeind für die außergewöhnlich gute Betreuung, seine Geduld und unermüdliche Unterstützung.

Bedanken möchte ich mich auch bei allen Mitarbeitern des Instituts für Humangenetik der Universitätsmedizin Göttingen, insbesondere bei Frau PD Dr. med. Silke Pauli für die Anregungen bei der Anfertigung meiner Doktorarbeit und bei Frau Dr. med. U. Engel für die Akquirierung der meisten Patienten.

Vielen Dank an Herrn Dr. Andreas Leha für die statistische Bearbeitung meiner Daten. 